

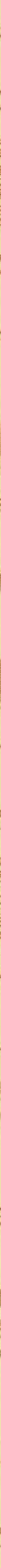




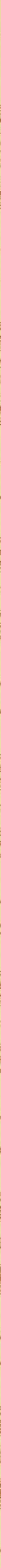





V. 2

Birds

OF

\section{B R I T I S H B I R D S,}

WITH COLOURED ILLUSTRATIONS

OF THEIR

EGGS.

BY

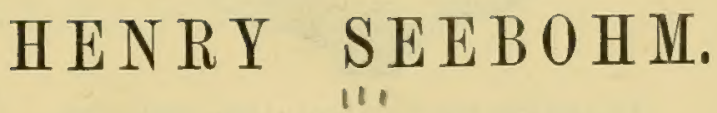

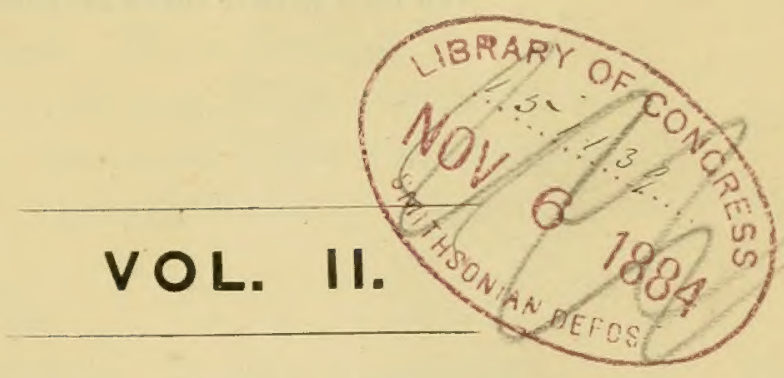

SMITHSONIAN

LONDON: MAY 271987

PUBLISHED FOR THE AUTHOR YY GIUKARIES

R. H. PORTER, 6 TENTERDEN STREET, W.,

$$
\text { AND }
$$

DULAU \& CO., SOHO SQUARE, W.

1884 . 


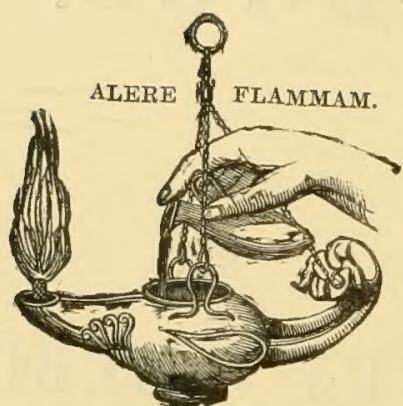

PRINTED BY TAYLOR AND FRANCIS, RED LION COURT, FLEET GTREET. 


\section{CONTENTS OF VOL. II.}

INTRODUCTION (On the Protective Colour of Eggs)

Plate Page

ix

Subfamily $A M P E L I N A \ldots \ldots \ldots \ldots \ldots \ldots \ldots \ldots \ldots$

Genus AMPELIS $\ldots \ldots \ldots \ldots \ldots \ldots \ldots \ldots \ldots \ldots \ldots \ldots \ldots$

Ampelis garmlus. Waxwing ........... 11.

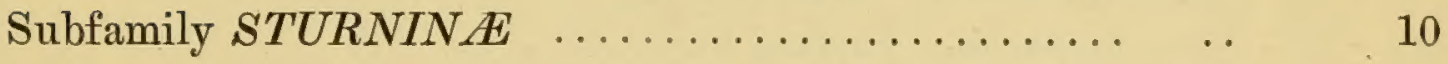

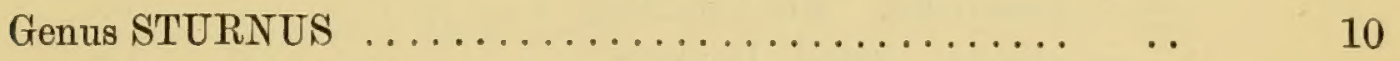

Sturnus vulgaris. Starling .............. 11. 12

Genus PASTOR .......................... 19

Pastor roseus. Rose-coloured Starling ........... $11 . \quad 20$

Subfamily FRINGILLIN $\mathbb{E} \ldots \ldots \ldots \ldots \ldots \ldots \ldots \ldots \ldots \ldots$

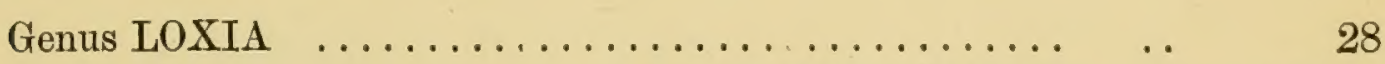

Loxia curvirostra. Common Crossbill $\} \ldots \ldots \ldots \quad 13 . \quad 30$

$\left.\begin{array}{lll}\text { - pityopsittacus. Parrot Crossbill } \\ \text { bifasciata. European White-winged Crossbill } \\ \text { Zeucoptera. American White-winged Crossbill }\end{array}\right\} \quad \begin{array}{ll}19 . & 37\end{array}$

$\begin{array}{lll}\text { - leucoptera. American White-winged Crossbill J } & \\ \text { enucleator. Pine-Grosbeak ............. 12. } & 41\end{array}$

Genus CARPODACUS .................... .. 45

Carpodacus erythrinus. Scarlet Rose-Finch ..... 12.

Genus PYRRHULA . ................. . 50

Pyrrhula vulgaris. Bullfinch $\ldots \ldots \ldots \ldots \ldots \ldots, 12 . \quad 51$

Genus COCCOTHRAUSTES ................ .. 56

Coccothraustes vulgaris. Hawfinch .... . . . . 13.

Genus PASSER ....................... . 62

Passer domesticus. House-Sparrow . . . . . . . $13 . \quad 63$ montanus. Tree-Sparrow $\ldots \ldots \ldots \ldots \ldots$. $13 . \quad 69$ 
Fringilla chloris. Greenfinch ........... 12. 74

- canaria. Canary ................. $12 . \quad 79$

— serinus. Serin Finch . . . . . . . . . 12.

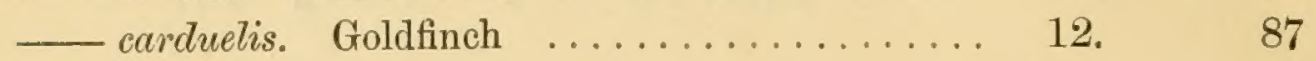

— spinus. Siskin ................ $12 . \quad 92$

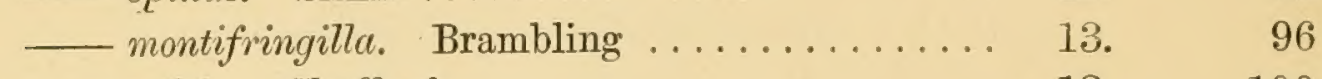

— celebs. Chaffinch ................. 13. 100

_ cannabina. Linnet .............. 13. 106

— flavirostris. Twite ............... 13. 111

_ rufescens. Lesser Redpole ...

- hornemanni. Greenland Redpole

Genus EMBERIZA .................... . 123

Emberiza nivalis. Snow-Bunting ............ 15. 125

_lapponica. Lapland Bunting ........... 15. 131

— schoeniclus. Reed-Bunting ............ 15. 135

— rustica. Rustic Bunting . . . . . . . . . . 15. 140

- pusilla. Little Bunting ............. 15. 144

— miliaria. Corn-Bunting .............. 13. 148

- hortulana. Ortolan Bunting .......... 15. 153

_irlus. Cirl Bunting ............. $13 . \quad 156$

_ citrinella. Yellow Hammer............ 13. 160

_ melanocephala. Black-headed Bunting ..... $15 . \quad 165$

Subfamily HIRUNDININ $A \quad \ldots \ldots \ldots \ldots \ldots \ldots \ldots \ldots \ldots$

Genus HIRUNDO . . . . . . . . . . . . . . . . . . 169

Hirundo rustica. Swallow . . . . . . . . . . $17 . \quad 171$

_urbica. House-Martin............... 17. 178

- riparia. Sand-Martin ............ 17. 184

Genus PROGNE........................ 188

Progne purpurea. Purple Martin............ 18. 189

Subfamily MOTACILLINA $\ldots \ldots \ldots \ldots \ldots \ldots \ldots \ldots \ldots$

Genus MOTACILLA ........................ . 192

Motacilla yarrellii. Pied Wagtail............. 14. 194

— alba. White Wagtail ............... 14. 199

_ sulphurea. Grey Wagtail ............ 14. 203

flava. Blue-headed Wagtail ........... 14. 208

- raii. Yellow Wagtail ............... 14. 212 


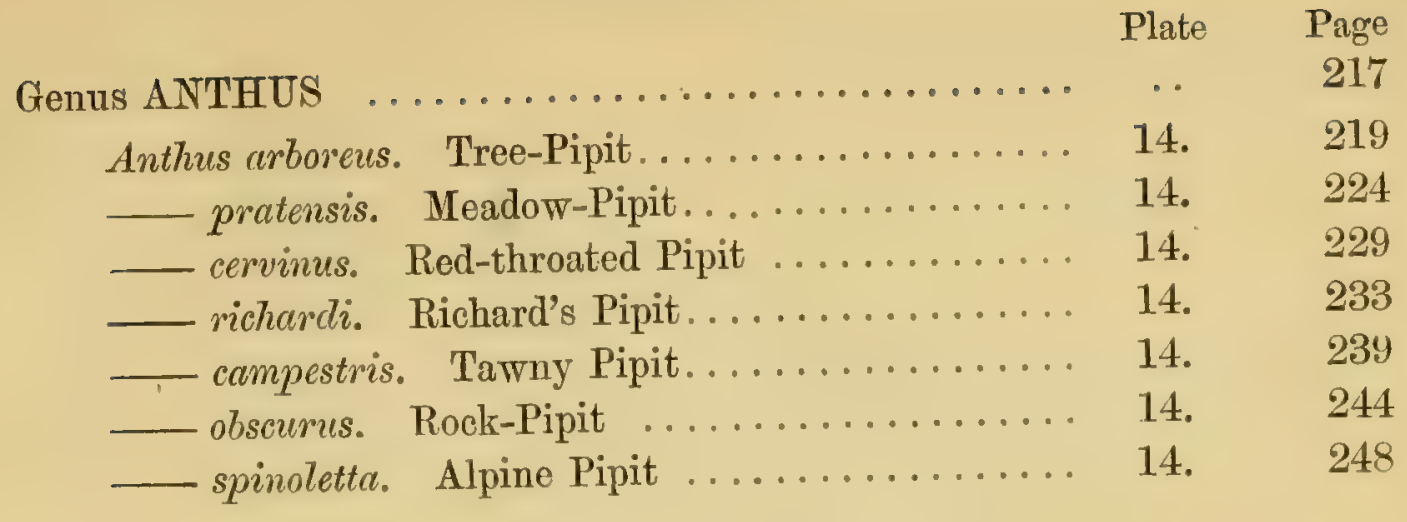

Subfamily $A L A U D I N \mathbb{E} \ldots \ldots \ldots \ldots \ldots \ldots \ldots \ldots$

Genus ALADDA ....................., 253

Alauda arborea. Wood-Lark ............ 15. 256

_ cristata. Crested Lark................ 15. 261

— arvensis. Sky-Lark ............... 15. 266

_ brachydactyla. Short-toed Lark .......... $15 . \quad 274$

—_ sibirica. White-winged Lark .......... 15. . 279

—alpestris. Shore-Lark ............. 15. 284

Family CYPSELID正 ................... . 289

Genus CYPSELUS........................ . 290

Cypselus apus. Common Swift............. 18. 292

melba. Alpine Swift ............ 18. 297

Genus CHETURA ...................... . 302

Chcetura caudacuta. Necdle-tailed Swift ...... .. 303

Family CAPRIMIULGIDÆ............... 307

Genus CAPRTMULGUS .................. . 308

Caprimulgus europaus. Common Nightjar ....... $17 . \quad 309$

- regyptius. Isabelline Nightjar ........ .. 315

Family MEROPID出 ................... 319

Gonus MEROPS ....................... . 319

Merops apiaster. Common Bee-eater ......... 18. 321

Genus CORACTAS .................... .. 326

Coracias garrula. Common Roller ........... 18. 327 
Family UPUPID卌

Genus UPUPA

Upupa epops. Hoopoe

Family ALCEDINID

Genus ALCEDO

Alcedo ispida. Common Kingfisher

.

341

Genus CERYLE

347

Ceryle alcyon. Belted Kingfisher.

$\cdots$

348

\section{Family PICID丑}

Genus PICUS

\section{2}

Picus major. Great Spotted Woodpecker ....... 18. 354

— minor. Lesser Spotted Woodpecker ...... 18. 359

Genus GECINUS ...................... . 363

Gecinus viridis. Green Woodpecker ......... 18. 364

Genus IYNX. . . . . . . . . . . . . . 371

Iyne torquilla. Wryneck............... 18. 372

\section{Family CUCULID出}

Genus CUCULUS ...................... 376

Creculus canorus. Cuckoo............... 20. 378 glandarius. Great Spotted Cuckoo........ $68 . \quad 386$

Genus COCCYZUS ..................... . 389

Coccyzus americanus. Yellow-billed Cuckoo ..... 68. 390

\section{Family COLUIMBID स}

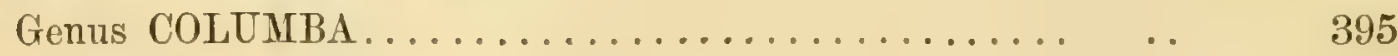

Columba palumbus. Ring-Dove ............ 17. 396

— conas. Stock-Dove ............... 17. 401

- livia. Rock-Dove ................ 17. 405

Genus TURTUR ...................... 410

Turtur auritus. Turtle-Dove ........... 17. 411 
Genus SYRRHAPTES ....................

Sym.haptes paradoxus. Pallas's Sand-Grouse ..... 20.

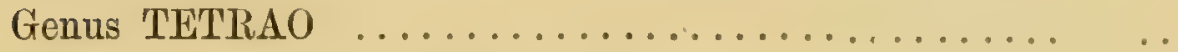

Tetrao mutus. Common Ptarmigan............ 20

- scoticus. Red Grouso ...................

20.

- tetrix. Black Grouse ...............

20.

- urogallus. Capercaillie

Genus PHASIANUS..................... 444

Phasianus colchicus. Pheasant............. 21. 445

Genus PERDIX ........................ 451

Perclix cinerea. Common Partridge........... $21 . \quad 452$

- rufa. Red-legged Partridge ........... 20. 457

Genus COTURNIX ....................... . 461

Coturnix communis. Common Quail ......... 20. 462

\section{Family PELARGID尼}

Genus ARDEA....................... 467

Ardea cinerea. Common Heron ............ 38. 468

— purpurea. Purple Heron ............ 38. 473

- alba. Great White Egret ............ 38. 477

— garzetta. Little Egret................ 38. 481

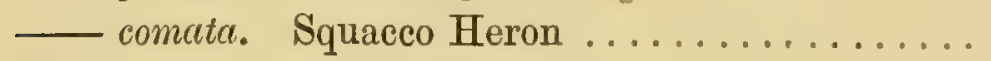

$38 . \quad 486$

38. $\quad 492$

Genus NYCTICORAX ..................... . 495

Nycticoraw mycticorax. Night-Horon .......... 38.496

Genus BOTAURUs ........................ . 502

Botaunus stellaris. Bittorn ............. 39. 503

— Tentiginosus. American Bittern ......... 39. 506

— minutus. Little Bittern ............ 38. 510

Genus PLATALEA ..................... . 513

Platalea Teucorodia. Spoonbill............. 37. 514

Genus IBI $\ldots \ldots \ldots \ldots \ldots \ldots \ldots \ldots \ldots \ldots \ldots \ldots \ldots \ldots \ldots . . .619$

Ibis falcinellus. Glossy Ibis. . . . . . . . . . 38. 520 


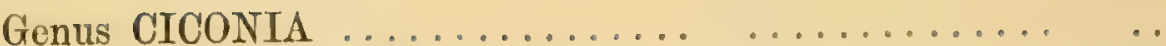

Plate Page

Ciconia alba. White Stork ............ $37 . \quad 525$

— nigra. Black Stork ............... 37. 529

Family RALLID无 $\ldots \ldots \ldots \ldots \ldots \ldots \ldots \ldots \ldots \ldots \ldots$

Genus CREX........................... 533

Crex pratensis. Corn-Crake.............. $23 . \quad 535$

- porzana. Spotted Crake ............. 23. 540

_ bailloni. Baillon's Crake............. 23. 543

- parva. Little Crake ............. 23. 547

Genus RALLUS ....................... 551

Rallus aquaticus. Water-Rail ............ $23 \quad 552$

Genus GALLINULA...................... 556

Gallinula chloropus. Waterhen ........... $23 . \quad 557$

Genus FULICA....................... 563

Fulice atra. Common Coot ............... $23 . \quad 564$

Family GRUID正 $\ldots \ldots \ldots \ldots \ldots \ldots \ldots \ldots \ldots \ldots \ldots$

Genus GRUS ......................... 568

Grus cinerea. Common Crane............. 36. 570

— virgo. Demoiselle Crane.............. 36. 575

Family OTIDID画.................... . 579

Genus $\operatorname{OTIS} \ldots \ldots \ldots \ldots \ldots \ldots \ldots \ldots \ldots \ldots \ldots \ldots \ldots$

Otis turda. Great Bustard ............... 22. 581

- tetrax. Little Bustard ............ 22. 587

— macqueeni. Macqueen's Bustard ......... 21. 591

Genus (EDICNEMUS ..................... . 595

Edicnemus crepitans. Stone-Curlew ........ 21. 596 


\section{INTRODUCTION.}

\section{ON THE PROTECTIVE COLOUR OF EGGS.}

[THIs chapter has been written for me by Mr. Charles Dixon, and is sufficiently elaborated to post my readers up in the questions which have arisen on this subject since it has been regarded from the evolutionist point of view. It is, of course, partly based upon Darwin ('Descent of MIm,' ii. p. 166) and Wallace ('Natural Selection,' pp. 211, 231), who have endeavoured to explain, by the laws of Natural Selection, the facts (long ago remarked by Gloger* and others) respecting the colour of eggs.

The results of the investigation are not quite so satisfactory as might have been expected. There are so many cases which cannot be explained by protective selection, that the student, not being able in this instance to fall back upon sexual selection, is obliged to assume that many effects are the results of extinct causes. To my mind they are suggestive rather of other powerful factors in addition to protective and sexual selection.H. S.]

OoLogy has until lately been a much neglected science. Looked upon as an occupation which has for its object the mere collecting, labelling, and arranging in a cabinet the eggs of birds, or threading them on strings like beads, or, wor'se still, sticking them on cards in all kinds of fantastic patterns, egg-collecting has long been regarded as a schoolboy's hobby, and quite beneath the dignity of the man of science. But since the great discoveries of those illustrious naturalists Charles Darwin and Alfred Russel Wallace have placed the study of natural history on a different basis, and completely revolutionized scientific research, oology may be said to have slowly risen from a schoolboy's pastime or a collector's craze to a science so fascinating and so instructive as to claim the careful attention of many of our ablest naturalists. Such hitherto despised objects as birds' eggs have a tale to tell quite as interesting as that of any other object in the organic world; they have a history to reveal which assists in pointing out the line of march which organic life has taken from its earliest dawn to its present endless and varied ramifications. But a study of eggs camuot be made satisfactorily without including the birds; the two subjects are inseparably linked together, and it is necessary to have the bird and its life-listory before us when studying the egg with its

* In the 'Edinburgh Journal of Natural and Geographical Science' (i. p. 303), published in 1830, a short résumé of Gloger's paper of the previous year is given, translated from the 'Verhandlungen der Gesellschaft naturforschender Freunde in Berlin.'

VOL. II. 
varied markings, and the nest which contains it with its infinite diversity of structure and position.

Until very recently the great variety of colour in the plumage of birds was looked upon as so much ornament of no particular use to the species, but for the sole purpose of gratifying the eye and adding to the general harmony of animated nature. Within the last thirty years scientific research has shown that many of the beautiful colours on the plumage of birds materially affect not only their welfare, but, as will shortly be seen, that of their young, and consequently the very existence of their species. This beauty is not given aimlessly, it has a fixed and definite object-the benefit of the species acquiring and possessing it. The student of birds must therefore view each varied tint on their plumage not as so much mere ornament, but as a factor which is or has becn essential to the safety or well-being of the species possessing it, which has had its origin in the struggle for existence to which each bird is subject, either through natural or sexual selection. In like manner the infinite variation of colour, and to some extent of form, in the eggs of birds and the endless diversity of their nests have had their origin in the subtle laws of variation and inheritance, aided by natural selection and the survival of the fittest.

No writer has investigated this interesting subject so closely as $\mathrm{Mr}$. Wallace; and the views he has taken, together with the conclusions at which he has arrived, are probably well known to most of our readers. $\mathrm{Mr}$. Wallace's theory of birds' nests is said to be far too swceping and arbitrary; and certainly it does not explain all the facts. He divides birds into two great classes-one in which the sexes are alike and of conspicuous or showy colours, and which nidificate in a covered site; and the other in which there is a marked difference between the colour of the sexes, the male being showy and the female sombre, and which nidificate in an open site. Nearly all known birds are supposed to come into one or the other of these two groups. In each of these great divisions, however, there are almost as many exceptions as there are cases that conform to the rule; and this has been taken advantage of by Mr. J. A. Allen, the well-known American ornithologist, who endleavours, by a critical study of the nidification of North-American birds, to overthrow the whole theory (Bull. Nutt. Orn. Club, 18\%8, p. 23). In treating the subject so far as birds and their nests are concerned, I propose to divide birds into the same two great groups as Mr. Wallace; but I shall subrlivide them into several minor groups, which will include all the "exceptions" to either great rule. I purpose specially to take examples of each, as far as possible, from birds inhabiting our own islands, as being most interesting to the student of British oology. In the birds belonging to the class which build open nests we will notice as the first group

Birds in which the plumage of the male is bright and conspicuous 
in colour, and that of the female dull and sombre, and which nidificate in open sites. - The merest tyro in ornithology is aware that the plumage of the female bird is in a great many cases far more sombre than that of the male. Until comparatively recently the cause of this phenomenon was never dreamed of. It is an ascertained fact that the colour of many female birds is connected in no small degree with their mode of nidification, and that the sitting bird is protected by the harmony which exists between its own sober plumage and the colour of the surroundings of its nesting-site. Let us glance over the nesting-habits of some of our best-known birds, and learn the working of this law. The males of many of our common birds possess extreme brilliancy of plumnge, whilst their females are of such dull and inconspicuous colours that an inexperienced person would suppose them to belong to different species. The gorgeous Pheasant (Phasianus colchicus), for instance, has a mate whose garb is dingy and subdued in the extreme. Her sober plumage, however, is of the greatest importance; for on this circumstance in part depends the very existence of her species. She builds her slight nest on the ground, and her plumage harmonizes with the dead bracken and dry herbage around, and most effectually conceals her from her enemies. A still more striking instance is to be found in the Black Grouse (Tetrao tetrix). The male bird is dressed in a rich garb of purplish black, but his mate does not resemble him in the least degrce; indeed, so widely does she differ in the colour of her plumage as to defy even the most expert ornithologist unacquainted with the matter, so far as outward appearances go, to class her as the same species as her mate, her plumage being mottled brown of various shades. But this diversity of plumage between the sexes serves the great purpose of shielding the female during the season of nidification on the brown heathery wastes where she rears her young. Take another instance. The Mallard, or Wild Duck (Anas boschas), exhibits such brilliant tints as to render him one of the showiest of our native birds; but his mate is of dull and inconspicuous colours, which harmonize closely with the tints of her nesting-site, which is an open and exposcd one. Again, the male Teal (Anas crecca) is richly adorned, but his mate is so dull in plumage as to suggest the idea of their being distinct species. By this great difference in the sexes the same end is served; for the female Teal builds an open nest, and the safety of that nest and its eggs depends on her dull and sober plumage. Amongst our smaller birds we have many instances: the Blackbird (Merula merula) mated to a dull brown spouse, who sits in an opeu nest, and the Ring-Ouzel (M.torquata) may be cited. The male of the latter species is showy, rich black and grey, with a snow-white band across the breast; the female is brown, and the band across the breast is dull-a plumage in harmony with the brown tints of the moorland, where she sits upon her open nest comparatively safe. The male Chaffinch 
(Fringilla celebs) and the Bullfinch (Pyrrhula vulgaris) are showy birds; their mates are more sombre in appearance, and they build open nests, where conspicuous or showy plumes would only lead to their destruction. The charming Stonechat (Pratincola rubicola), in his garb of chestnut, black, and white, is mated to a dull unassuming spouse, who derives her chief safety during the trying period of nidification from the dull and sombre hues with which she is arrayed. Our second group consists of

Birds in which the plumage of both sexes is showy or brilliant in colour, and which nidificate in open nests. - This group forms one of those exceptions which, at first sight, appears seriously to affect the validity of the whole theory; but I think it can be shown that the birds included in it may possibly secure their safety in other ways. It is unfair to suppose that erery species is equally liable to the attacks of enemies. Some gaily attired female birds may have no special enemies against which to guardtheir brilliant or showy dress is no disadvantage to them, as is the case with many conspicuous insects; and this fact may in itself explain why it is that they have assumed such tints. Again, as some female birds became more brilliant through natural selection, it is very possible that they gradually altered the form of their nests (from an open one to a covered one), or if the acquisition of a showy dress did not render them more liable to the attacks of any special enemy (and we know that many animals are singularly free from persecution), no change in the manner of nesting would be required; and this would explain many of the apparent exceptions to the gencral rule that gaily dressed female birds sit in covered nests. We must also take into consideration what colour's are showy in certain haunts. Bright colours that would be very conspicuous in some places may be specially protective in others. Take the case of the 'Tiger's stripes, conspicuons enough in the open or the green forest, but blending beautifully with the jungle; the light sand-coloured plumage of many desertbirds would be conspicuous enough in fertile districts, but on the burning sauds it is invisible; many other brightly plumaged birds are safe enough in the localities where they build their nests or deposit their eggs; but these facts are too often overlookel for want of careful investigation. Again, and most important of all, the colour of the eggs in many cases plays a prominent part ; for the moment dauger threatens, the ever-watchful and conspicuonsly coloured female quits her charge and seeks her own safety in flight, leaving her eggs or young to the safety which their tints insure. In this group may be instanced the Orioles, represented in this country by the Golden Oriole (Oriolus galbula). All these birds build open nests, the sexes are almost alike in colour and of brilliant tints; but they conceal their nests amongst the thickest foliage, and, as Mr. Wallace states, protect their offspring by incessant anxious watching.

To this group also belong the Jays, the Crows, the Birds of Prey, the 
Gulls, the Herons, and many other large birds, all of which are more or less conspicuous and make open nests. In most of these cases, however, the birds are well able to defend themselves and their nests from enemies; but the more helpless species (as, for instance, the Sandpipers) seek safety for themselves in flight, relying upon the protective tints of their eggs or young. I shall, however, return more specially to this group of birds when I treat on that part of the subject which concerns cggs and young birds. We now notice a small group of

Birds in which the male is less brilliant than the female, and which nidificate in open nests. - The birds in this group are exceedingly few in number, but are nevertheless very interesting. Let us take, for instance, the Dotterel (Eudromias morinellus); although the differences between the seres of this species are not very striking, they exist, and the female is more showy than her mate: or, better still, take as examples several of the Phalaropes (Phalaropus), where the females are more brilliant in their uuptial dress than the males, the Common Cassowary (Casuarins bennettii) or the Emu (Dromceus irroratus), a Carrion-Hawk (Milvago leucurus) from the Falkland Islands, an Australian Creeper (Climacteris erythrops), and an Australian Goatsucker (Eurostopodus albogularis), in all of which the females are of more decidedly conspicuous colours than the males, and the nests are open and exposed. Curiously enough we find in all these cases that the male bird performs the duties of incubation, and in several instances is known to show much more solicitude than the female for the young! We have, however, an exception to this in the African Ostrich, where the male is more showy than the female; nevertheless he performs the duties of incubation (Sclater, Proc. Zool. Soc. 1863, p. 233). The Ostrich has few enemies; and this fact, together with that of its peculiar manner of nidification, is probably the reason that its plumes have had no check to their present dcvelopment. It is also worthy of remark that the young of probably all these birds, instead of resembling the females, as is the case with most species, more closely resemble the males, a circumstance which seems to prove absolutely that sexual selection has been exclusively confined to the female in these cases.

Having now treated of those birds which rear their young in open nests we pass on to the second great group, in which the nests are concealed, first on our list being

Birds in which both sexes are brightly coloured and which rear their young in holes or covered nests.-One of the most striking instances in our, for the most part, dull-plumaged northern birds is that of the Kingfisher (Alcedo ispida). The male and female are exactly alike in colour, and both are adorned with the same refulgent dress. But how does Nature shield the sitting bird during the nesting-period? Why has 
she allowed such brilliant tints to be developed in the female? By sending the Kingfisher to a hole in a bank to lay her eggs and rear her young in darkness, Nature provides most admirably a means of safety for this bird, one of the brightest of her gems. The gaily dressed Woodpeckers (Picida) liave the sexes nearly alike, and the females nest shielded from view in holes of trees. The Tits (Parinx) are another instance. Both sexes in this group of birds are alike, and generally gaily attired; they lay their eggs and rear their young in holes of trees, stumps, and walls, where the beantiful but conspicuous plumage of the female does not affect the safety of her brood. In the delicate and somewhat showy Goldcrests (Regulus) the seses are but slightly different in colour, and the female hides her showy crest in a well-concealed nest. The homely Starling (Sturmus vulgaris) is another instance where the sexes are similarly adorned with bright and showy tints, and, as is well linown, it nests in holes well concealed from view. The showy Swallows and Martins also have the sexes alike, and build corcred nests in which the brightly adorned females are protected. The gaudy Rollers and brilliant Bee-eaters (Meropida) have both sexes similarly bright and conspicuous, and they nest in holes. The showy Hoopoe $\left(U_{p u p a t}\right)$ and charming Wall-Crecper (Tichodroma) and Nuthatch (Sitta) have the sexes almost alike in colour, and rear their young in holes. The Common Sheldrake is another instance, from a widely different group of birds *

It las been urged by Mr. Allen (in his article already mentioned) that many domed nests, in which the showy parent bird is concealed from view whilst incubating, are in reality not so safe as many open, but better concealed, nests. But this I think cannot be regarded as an objection. Among North-American birds that build purse-shaped or pensile nests may be cited the American Orioles (Icteridæ), which construct a nest, Mr. Allen says, "most illy adapted for protection from the most dangerous foes of the species, the predatory Crows, Jays, and Cuckoos, being often a conspicuous object, with, so far as the United States species are concerned, no compensating feature of security." But I venture to assert that these pendent purse-shaped structures, which are built by so many birds in the tropics, are very secure from such enemies, and even more so from snakes, weasels, monkeys, wild cats, and other animals. They are often hung at the extremity of long slender branches, in many cases over water, or the nest itself is suspended by a long neatly-woven cord, or, in some cases, a narrow

* It is worthy of remark that the brilliantly dressed males of so many of the Ducks assume a dull inconspicuous garb during the period when the young are being reared. These birds have probably acquired this peculiarity through the fact of their young being reared in the open. Showily dressed polygamous males desort the female during this anxious period; others, which are not polygamous, in the majority of cases, rear their young in corered nests. 
tube. In Australia there is a very conspicuous black-and-white Pigeon (C'arpophaga luctuosa) which always, it is said, prefers to build its slight nest on a branch over water. How is it possible for even winged enemies to take such a citadel by storm, or harm the parent safely swinging in her wonderful cradle? This is undoubtedly the true reason that these nests are hung so conspicuously; the eggs, the young, and the brooding (often brightly coloured) parent are all equally safe in such a structure, where concealment could serve no special end in shielding them from their natural encmies. It seems also a most interesting fact that these domed peusile nests are not always so conspicuous as might be imagined. As an example, I will take the by no means brilliantly arrayed little Sericornis citreogularis of Australia, whose nest is built in the dense and humid forests, where the trees are covered with moss, often accumulated in large masses at the extremities of the drooping branches. In these masses of moss, or suspended to them, the little bird places its nest with so much skill that it is impossible to say which are really nests, and which are mere festoons of moss, until each is minutely examined. Our next group consists of

Birds in which both sexes are dull in colour, and which build covered nests from motives of safety other than concealment.-I do not think that the fact of dull-coloured females sitting in covered nests can be taken as a serious objection to the law of bright-coloured females sitting in covered nests ; for, as Darwin remarks ('Descent of Man,' ii. p. 168), other advantages may be gained irrespective of concealment, such as shelter, greater warmth, or in hot countries protection from the sun, or sudden changes of temperature, or, in the case of many domed pensile nests built on slender branches, protection from certain enemies, as is the case with the Indian Ploceus baya, which makes the entrance to its bottleshaped pendulous nest inverted, so as to baffle the approaches of treesnakes and other enemies. Another explanation may be that these plaincoloured birds of both sexes are the descendants of some showy ancestor that built in a covered nest; and this peculiarity has been transmitted to an entire genus, and retained, even in cases where the plumage of the bird has assumed a more sombre tint, through the laws of Inheritance. It is easy to believe that if no direct and special cause for a change arises, the nesting-economy will remain unchanged even if the plumage of the bird or of any of its descendants changes to less showy tints.

'The Swift (Cypselus apus) and the Sand-Martin (Hirundo riparia) are both dull-coloured birds, the sexes are alike, and they build nests concealed in holes. But in these cases the colour of the plumage does not influence the conditions of nidification. The Swift makes its rude nest in a hole, it has, so far as we can determine, no means of protecting itself or its eggs from enemies, and consequently retires to such a site where it can rear its 
young in comparative safety. So in like manner the sombre Sand-Martin, for a similar reason, seeks the sand-banks. Sparrows (Passer domesticus) do not nest in holes because the plumage of the female demands concealment during the nesting-season, but from other motives, perhaps the result of a deeply rooted habit acquired during different conditions of life or inherited from a common ancestor of far more brilliant tints requiring concealment during the nesting-season. Again, we have the case of the Wren (Troglodytes parvulus), which builds a domed nest, and is yet one of the most soberly arrayed of our native birds. But this is undoubtedly from other motives of safety than concealment; for from the peculiar structure of her nest few encmies indeed are able to storm her little citadel. Weak and defenceless as this little creature is, she attains by subtlety what she would fail to procure by prowess. The Dipper (Cinclus aquaticus) builds a domed nest, possibly for the purpose of shielding her eggs and young from the spray which so often surrounds them in her rock-bound watery haunts, as is also the case with a little dull-coloured Australian bird (Origma rubricata) which also frequents rocky streams and gullies. The Willow-Warblers (Phylloscopus) build domed or partially domed nests, perhaps because a remote ancestor built a domed nest, but more probably to shield their tender offspring from the moisture which surrounds their usual nesting-places amongst herbage or tall vegetation. The WillowWarblers are an Arctic group of birds breeding in a climate subject to sudden changes of temperature; and this, I think, may explain their domed nests. As another instance we have the Owls (Strigidæ), which, as a rule, rear their young in holes in buildings, rocks, or trees, from no motive of safety, but simply because they dislike the light of day, and naturally breed in situations which are their daily haunts. Our next group consists of

Birds in which the female is duller in colour than the male, and which nidificate in covered nests.-This group is one of the most interesting, and furnishes convincing proofs of the truth of the theory of scxual selection. We will take as our first example the gay little Redstart (Ruticilla phonicurus). The female of this bird is dull indeed in comparison with the male, yet the young are reared in all cases in a concealed nest in a wall, treee, or the crevice of a rock; but I can assert from personal observation that the bright-plumaged male assists in no small degree in the duties of incubation. The Pied Flycatcher (Muscicapa atricapilla) is a similar instance. Others may be found in the Rock-Thrushes (Monticola), the Chats (Saxicola), and the Robin Chats (Thamnobia), in most of the species of which genera the female is far less brilliant than the male; nevertheless she sits in a covered nest, although we cannot see any valid reason why she should require concealment during the period of incubation; in all cases her colours are dull and well adapted for 
safety in an open nest. One of the most striking instances is to be found in the birds forming the genus Malurus. The males are often of the most gorgeous tints, which are assumed exclusively in the nuptial season; and in many cases, at least, it is known that they do not assist in incubation. There are several possible explanations of these interesting facts. The domed nests may be for the purpose of shielding the sitting bird and its charge from cold, or rain, or from some special enemies. It must also be borne in mind that throughont this group the eggs are conspicuous, and this may to some extent influence the morle of nidification. If we grant that these domed nests are built for other purposes than the concealment of the sitting female, it is easy to explain the great difference of colour between the sexes. The more brilliant colours of the males have been obtained by sexual selection; for in genera nearly allied to Malurus, such as Stipiturus, Dasyornis, Sphenceacus, the sexes are alike and dull in colour, but the nests are always domed and the eggs more or less conspicuous-a convincing proof, I think, that the nests are not so built to conceal any showy colours in the parent birds. As previously stated, in many cases the showy male bird of many of the species belonging to this group assists in incubation, the domed nest allowing him to do so with safety. It is necessary now briefly to notice those

Birds which do not hatch their own eggs.-The birds that come into this division may be divided into two groups : of one our Common Cuckoo (Cuculus canorus) is a good example, and the other contains the Megapodes (Megapodidre) or Mound-birds of the Australian Region. The former group will be more fully discussed in the article on the Cuckoo ; and of the latter so little is known that to Gould's and Hume's interesting descriptions little more can be added. It is a wonderful instinct for a bird to bury its eggs in the sand or amongst decaying vegetable matter, and leave them to be hatched by the heat of the sun or the warmth generated by putrefaction. The young, when hatched, are said to break out of their prison and to be able to take care of themselves almost directly afterwards. May not this singular habit, which so closely resembles the mode of propagation of the Turtles and Snakes, be an unchanged inheritance from some semi-reptilian ancestor?* Let us now glance briefly at

Birds' Nests.-These structures have long been regarded as one of the most convincing proofs of an instinctive power, a power which is popularly supposed to be almost supernatural, of spontaneous origin, and nearly infallible. Such a belief, as Mr. Wallace very justly remarks, one would naturally expect to find supported by incontestable facts; but little or nothing can be brought forward in its favour, and the evidence in support

* Lizards' eggs have been taken from these mounds by Uavison ('Stray Feathers,' ii. p. 278). 
of blind Instinct* being solely employed in the fabrication of birds' nests is not supported by one particle of proof. I do not for one moment deny the existence of true instinct in some cases; but so far as birds' nests are concerned, no powers are revealed in their fabrication beyond those which we ourselves possess in a higher or lower degree. A young Duck taking to the water or a nestling Plover crouching to the earth and remaining motionless are good examples of true instinct, or action performed without instruction, experience, or previously acquired knowledge. In the same manner a bird's impulse to build a nest is instinctive; but the means it adopts to carry out such an impulse are controlled by similar mental facultics to those possessed by man. Mr. Wallace's theory that birds do not make their nests instinctively, but by imitating the nests in which they were reared - that if they never saw or were not brought up in a nest peculiar to their species they would be unable to construct one for themselves similar in position, form, and materials-is probably the true solution of this interesting problem.

The question arises, How do birds build their nest, and especially their first nest? is it by blind Instinct or by other mental faculties? To credit the bird with such instinct, which because it seems so self-evident is taken to be matter of fact, is to admit that it possesses intellectual powers infinitely superior to those of man; whilst the evidence that can be gathered on the subject all goes to show that its intellectual powers are of precisely the same kind as man's, but some of them, of course, are infinitely inferior in degree, whilst others are unquestionably superior. Reason in birds can only be regarded as rudimentary, though there is undoubted evidence of its existence. The faculties a bird brings into play in nest-building are probably these: the one that plays the greatest part is imitation, and the next important faculty of the mind is memory, both of which are distinct from what is popularly called reason, which together with hereditary habit play the minor parts. All these powers are found in man, but, with the exception of reason, in a much less pronounced degree, especially in civilized man, in whom it has to a large extent replaced the lower faculties; for the

[* I am not able to understand what Mr. Dixon means by Instinct, and therefore do not agree with his remarlis on this faculty in various parts of the chapter. I regard the word Instinct as the popular term for the mysterious impulses which scientific men call Hereditary Habit; and I think that it plays a great part, an overwhelmingly great part, not only in Bird-nest building, but in every other action of every animal, man included. Whether the explanation of Hereditary Habit be that it is transmitted unconscious memory (see Butler's 'Life and Habit,' p. 198) is another question. All one can say is, that this is a plausible hypothesis which, in the entire absence of any other, may provisionally be accepted. If Hereditary Habit have the lion's share in the production of a bird's nest, we must also allow that Memory, Imitation, and a rudimentary form of Reason also play their subordinate parts.-H. S.] 
more reason is developed the less are the other powers employed ; consequently, so far as man is concerned, they have lost much of their force through disuse. To credit birds with such a marvellous power as blind and infallible instinct in building their nests would be to place them far beyond man himself in intelligence, and allot to them a faculty which is superhuman. The evidence that we are able to collect all tends to disprove such a mysterious power. Birds brought up in confinement do not make a nest typical of their species, and in most cases content themselves with forming the merest rudiments of a nest, merely heaping a lot of material together on which they lay their eggs ; and in some cases they do not make even this slight provision. This may be Instinct (or, more properly speaking, Hereditary Habit) - the blind impulse to make a nest; but without tuition, or some standard to work by, it is a failure. The same remarks apply to man; for with all his boasted reason he is equally as incapable of building a habitation peculiar to his race, if he has not seen one or been initiated in the secrets of its construction. Savage man neither alters nor improves any more than the birds; and each of his great races has a peculiar style of architecture. The Arab and the American Indian dwell in tents, the negro builds a hut, and the bushman lives in caves, whilst the Malay erects his house on posts. Transfer an infant of any one of these races of men, say to civilized Europe, and is it conceivable that when grown up to manhood he would set to work to build a tent, a hut, or a house on posts, according to the particular race to which he belongs, instinctively, and with no instruction? If man is so helpless in such a case, why should not the bird be the same? Why should a creature infinitely below man in so many of its intellectual attributes be so far in advance of him in this particular respect? The same remarks equally apply to a bird's song and to the language of mankind-each have to be learnt. A bird's intellectual powers advance towards maturity much more quickly than in the human species. A young bird three or four days old is capable of considerable powers of memory and observation, and during the time that elapses in which it is in the nest it has ample opportunity of gaining an insight into the architecture peculiar to its species. It sees the position of the nest, it notes the materials, and when it requires one for itself, is it so very extraordinary that, profiting by such experience, it builds one on the same plan? Again, birds often return to the place of their birth the following season, and possibly see the old home many times ere they want one for themselves. This, aided by the strong hereditary impulse to build a nest similar to the one in which they were born, inherited from their parents, aids them in their task. Further, we know that some birds do not breed for several seasons after they are hatched, and consequently see the older birds at work and profit by the experience. The nests they build may, and do often, vary from the original type in many slight particulars; and 
it is by these slight variations, which, when beneficial, are preserved by natural selection, that birds adapt themselves to any changed conditions of life.

With birds, as with man, "when once a particular mode of building has been adopted and has been confirmed by habit and by hereditary custom it will be long retained, even when its utility has been lost through changed conditions" (Wallace). Although many habits have long since ceased to be of any service, they are retained. Witness the fact of the hole-building Ducks covering their eggs like their congeners nesting in the open; the Jackdaws often elaborate a nest in a position where one even of the slightest description is of small necessity; and our domestic Swan adds to its nest (undoubtedly a habit originally acquired for its protection from floods) when that nest is far removed from the waters. Neither birds nor men can change old habits suddenly. Witness how we still retain the side-straps and the arms in our first-class railway carriages (a custom handed down from the old coaching days), or the buttons on the backs of our coats (which were formerly used to fasten up the long tails), and many other cases which are now quite as useless as the instances noticed among birds. Another instance, the Apteryx of New Zealand (Apteryx australis) when it sleeps goes through the formality of placing as much of its head as possible under its rudimentary wings*. With regard to birds, however, these superfluous actions are in no way injurious to the species performing them-were they so, natural selection would assert its influence and would eliminate those individuals who did not conform to their changed conditions of life.

It is thought a remarkable fact by some naturalists that species of very wide range should build typical nests throughout their distribution. But surely there is nothing extraordinary in this if the area of distribution is continuous! Cetti's Warbler (Cettia cetti) is a good instance. This bird breeds from Spain and Algeria to Turkestan, and examples of its nest almost from these two extremes do not differ in the least in their construction; but I do not see any thing remarkable in this, even though this bird is not migratory, for it breeds "along the whole line," and there is nothing to prevent one style of arehitecture being common to the species $\dagger$. The Woodchat Shrike (Lanius rufus) is another good instance.

One of the great points brought forward in favour of instinct is the uniformity of the nests of the birds of each species, even though they be

* Trans. New Zealand Institute, ii. p. 75 (1869).

+ It would be very interesting to know if those non-migratory species that are separated by discontinuous areas of geographical distribution build typical nests throughout. This is a subject of which we possess no information, and is well worthy the attention of those observers suitably situated for studying this interesting question. 
widely spread, in localities where they are subjected to various conditions. If this was strictly true, I think it would go far to prove the existence of instinct; but it is not; for birds, even within the memory of living men, have been known to change and improve their nests under the influence of altered conditions. If a bird built by instinct, it is fair to assume that that instinct is unchangeable, and only allows the bird to build on a certain plan. Instinct practically remains stationary; reason, however, advances. What proof have we of this? Swallows are a most interesting instance, they having partially ceased to build on rocks or in caves, choosing houses and sheds instead. Starlings and many other birds will readily take advantage of a box placed on the house-side for them, and abandon their hole in the trees for the new quarters. The House-Sparrow is another instance of a recently changed mode of nest-building; so is the Waterhen, which often builds in trees in districts liable to sudden floods. Another instance: the Penguins on the Tristan d'Acunha group of islands have changed their mode of nesting from an open to a corered site, in consequence of the incessant persecution of the recently introduced wild pigs with which these islands now abound *. Many other instances might be cited all tending to prove that birds take advantage of any favourable circumstances to alter and improve their nests-a fact which can only be accounted for by the direct influence of their reasoning faculties. What may be regarded as direct evidence of a reasoning power employed by birds in making their nests may be seen in the wonderful way that many species assimilate their nests so closely to surrounding objects as to render their discovery very difficult, and the admirable plan on which some nests, especially of tropical species, are constructed. A good example is to be seen in the nest of the Common Tailor-bird of India (Orthotomus longicauda). This bird selects a broad leaf and draws the edges together with fibres, lining the cone, thus formed, with fine grass and vegetable down, and the ends of the fibres with which it is sewn are knotted as a tailor knots his thread!

I do not think, however, that Mr. Wallace is currect in all his details respecting the manner in which nests are built. I think we should be very careful in imputing the various apparent imperfections (and the perfection, too) in the architectural qualities of birds' nests to the appliances or tools with which they are constructed. To far more important causes I believe the many differences in these structures may be safely attributed; and instead, therefore, of viewing the Swift's rude nest, or the Ring-Dove's wickcr cradle as the inevitable results of imperfect natural appliances, they should be viewed as structures made perfect for the purpose they serve, and completely in harmony with the requirements of their builders. Instead of viewing the nests of the Chaffiuch and the Wren as mere structures the

\footnotetext{
* Notes by a Naturalist on the 'Challenger,' p. 125.
} 
paragon of perfection and architectural skill, the results of perfect natural tools, they should be regarded as nests, the only object their beauty and perfection serves beinga useful and protective one.

A bird's beak and its legs and feet are the tools with which its nest is made; yet neither on the form, the length, or any other peculiarity of these parts does the comparative beauty and perfection of the nest depend. The Wren has a fincly pointed bill and long legs: with these tools she builds a well-made nest which seems to owe its perfect form and well-wove walls to the little creature's natural nest-building tools. But the Chaffinch, with her comparatively clumsy bill and short legs, also makes a nest equally well woven, and even rivalling in its external appearance the W'ren's abode. The Tits, with their short bills and clumsy legs, build nests in holes in trees and walls-structures so poorly made that it is impossible to remove them entire. But the Long-tailed Tit (Acredula caudata and its allies), we know, with similar tools builds a nest in the branches the paragon of beauty and well-wove perfection! The Dipper is another instance. The Swift, with its weak bill and short legs, seems unable to make an elaborate nest; but we know it sceks a hole for its purpose from other motives than its sceming inability to make one, and, as is the case with nearly all hole-building birds, irrespective of their natural tools, it is poorly made. The Swallows and the Martins possess similar tools to those of the Swift, yet they build well-made structures, either fastened to the eaves of buildings or on the beams and ledges in sheds and chimneys. The delicate Warblers (as, for iustauce, the Blackcap, the Whitethroat, and the Garden-Warbler), all with appliances similar to those of the Wren, make slight net-like nests; whilst the Finches (as, for iustance, the Goldfinch, the Bullfinch, the Redpole, and the Chaffinch), with clumsy beaks and somewhat short legs, weave nests well made and beautifully adapted to the purposes they serve.

The Jay and most birds of the Crow tribe, particularly the Magpie (whose well-made and intricately woven nest is a masterpiece of nest-building art), have powerful and somewhat clumsy bills and feet; yet we know their nests can compare favourably with those of any other class of birds. Many of the clumsy-billed Gulls with webbed feet make well-made nests; as also do certain Raptores, Herons, the Coot, the Moorhen, the Grebes, the Ducks, and the Swans-nests that exhibit the same principles as those of the smaller birds, but of course carried out on a much larger scale. Again, what difference is there between the nest-building tools of the Sparrow-Hawk and the Kestrel? None whaterer; yet the one builds a fairly made nest, and the other never makes a nest at all, and rears its young either in the deserted nests of other birds or on the leclges of the beetling cliffs, on no other resting-place than the bare rocks or the refuse of its food. The Woodpeckers, the King fisher, the Starling, and sometimes the 
Jackdaw, well provided with the requisite appliances for building an elaborate nest, rear their young in structures poorly fabricated in the holes of trees, rocks, banks, or buildings, or do not make a nest at all. From the above-mentioned facts I think that we are perfectly justified in drawing the inference that birds are in no way influenced by the appliances they possess in building their nests. We have seen that birds are capable, quite irrespective of the form of their bills and feet, of making elaborate nests of matchless beauty, or poorly fabricated and very plain in appearance, respectively, and according to circumstances; and we may therefore rest assured that the nest-building capabilities of birds are not in any way subordinate to their natural appliances or tools for making their nests, but are regulated by, and subordinate to, the various conditions under which their young are produced, and especially by the colour of the eggs. Why does each species build a different kind of nest? I am at present quite unable to say what influences birds in the choice of their materials. Mr. Wallace says that birds select those materials which are nearest to hand and easiest to obtain. He may be right ; but when we find very differently constructed nests in the same localities, almost side by side, this explanation does not seem reasonable or sufficient. The above remarks on the nests of birds naturally draw our attention to

Birds' eggs studied in relation to their colour.-In these objects the chief peculiarity which claims our notice is their beautiful groundcolours and varied markings. Why, we naturally ask, do these eggs exhibit such diversity of colour? Why are some eggs white, whilst others are painted in tints rich and beantiful? or why are some spotless and others thickly marked? Some persons may urge that these colours are developed for no object beyond that of adding to the beauty and harmony of Nature's works, as they similarly urge the colours of the plumage of the birds themselves; but let us see what an important part the colouringmatter of birds' eggs plays in the economy of the birds-let us see how their complex and ever varying colours conform to the subtle influence of Law. 'The colouring-matter of birds' eggs is influenced by the bird's mode of nidification, and is partly subordinated to the colours of the parents' plumage. For convenience of treatment it is advisable to divide birds' eggs into two great classes, quite irrespective of the affinities of the birds themselves, but solely in accordance with the fact of their being coluured or uncoloured, spotted or unspotted. Each of these great groups may be further subdivided into two subgroups which will include the exceptional cases to each. As regards white eggs, our first division will be

White eggs laid in covered nests. - I think we must star't with the very probable supposition that the eggs of the earliest forms of bird-life were white. Colour is a development for protective purposes, and to that cause alone must be ascribed all the wouderful and beautiful diversity of 
tints with which so many birds' eggs are now adorned. In most birds where the eggs are hid from sight, either in domed nests or in nests in holes, we never find their eggs exhibiting much colouring-matter-it is not required, therefore it is not developed. Eggs brought to maturity in such places are mostly pure white or pale blue, and only in the minority of cases more or less faintly spotted. As instances coming into this particular group we have the eggs of the Woodpeckers, the Kingfishers, the Rollers, Bee-eaters, Tits, Willow-Warblers, Wrens, nearly all the Owls, and the Martins, all of which are pure white or, in some few cases, sparsely spotted, and are laid in covered nests. This law is almost universal, and, curiously enough, white eggs are correlated to a great extent with the brilliant plumage of the bird; for we have already seen how so many of these showy birds breed in covered nests. Indeed it may almost be laid down as an axiom in oology that brilliant birds do not lay handsome eggs, and most of the finest marked eggs are laid by species of dull and sombre plumage. Every rule, however, has its exceptions; and we now have to notice

White eggs laid in open nests.-If these examples are sufficiently numerous to merit the importance of a separate group, the existence of any laws of colour might be doubted by the casual observer. These instances are both striking and numerous; but when we come to study and investigate them, we find that they only tend to prove the existence of such laws in a very marked degree. The Ducks all lay spotless eggs, light in colour, greenish white, cream-colour, and pure white, and as they lay in the nest are very conspicuous and readily seen at long distances. The Pheasant and the Partridge also lay eggs of colours not much aiding in their concealment. The Grebes may also be cited as instances. But all these birds possess the singular habit of covering their eggs with materials similar in colour to surrounding objects when they leave their nests. Take, as an instance, the Little Grebe. The nest of this bird is rarely indeed placed far from the water, to which the sitting bird instantly retires on the approach of danger. The eggs of this bird are very conspicuous; but the moment danger threatens she adroitly covers them over with the materials around ere she glides hurriedly away. So perfect is this deception that the nest is often passed by as a mere mass of reeds and rubbish, yet under it lies the treasure she has so cleverly concealed. This little bird is ever on the alert for enemics; her mate also gives the signal of alarm, and so quickly does she accomplish her purpose that rarely indeed are her eggs seen exposed, except when the full complement is not laid. It has been urged, and several accomplished naturalists are still of the opinion, that birds do not cover their eggs for concealment, but for warmth. The Pheasant covers her eggs when she leaves them; but the Grouse is never known to do so. Now the former bird's eggrs are certainly 
conspicuous in an open nest, and those of the latter are well adapted by their colour to harmonize with surrounding tints. If warmth is required in the one case, certainly it should be in the other also. Again, I have known the Wild Duck cover her eggs so completely as almost to defy detection, and that, too, long before she had commenced to sit, and when no warmth was required. I think, therefore, that there can be little doubt that it is solely from motives of concealment that these conspicuous eggs are covered. Stevenson, in his 'Birds of Norfolk' (ii. p. 417), also confirms this opinion, and says that (in the case of the Moorhen) the precaution of covering the eggs is more particularly adopted when the nest is in an exposed situation.

But we find many conspicuous eggs laid in bare open places that are not concealed in such a cunning manner. We can talse as an instance the Short-eared Owl, who lays her white eggs on the open fens and marshes, or many of the Goatsuckers, who deposit their white eggs in flimsy open nests, or certain Ground-Pigeons (Geophaps) of Australia, who lay their buffish-white eggs on the bare ground. How are such eggs protected? In this manner:--The plumage of all these birds is remarkably protective and assimilates very closely with the surroundings; morcover, they possess the habit of sitting very closely, conscious that they resemble the ground or branches and cannot readily be seen; and so they brood over their conspicuous eggs, shiclding them by their sober plumage until almost trodden upon, ere they rise from them. We might also notice another rather puzzling instance belonging to this group, and that is to be found amongst the Pigeons. The nests of nearly all these birds are remarkably similar-platforms of twigs built in trees, rocks, or on the ground; and the cggs are in all cases, so far as is known, white, or nearly so, and spotless. Pigeons' nests are very slight and inconspicuous, and, as a rule, built in the dense cover; moreover, the birds themselves are excessively wary. Again the very fact that these birds are so abundant and so widely spread over the world, notwithstanding their open nests and white eggs, is, in itself, strong evidence that these birds and their eggs are not much exposed to enemies or are well able to elude them, and also shows us how cautious we should be in looking upon such facts as serious objections opposed to laws of nidification and colour. As an instance of how complex this subject is, we might take the great family of the Goatsuckers. Some of these birds (Afyotheles, or Owlet Nightjars of Australia) lay white eggs in holes of trees; others, as the Frog-mouths (Podargida), build a Pigeon-like nest on a branch and lay white eggrs, depending for safety onl. the protective colours of their own plumage; whilst the true Goatsuckers, of which our Common Nightjar may be taken as an example, lay eggs on the bare ground of protective tints, as well as depending on the sober colour's of their plumage for safety. It remains now but to notice in this group

VOL. II. 
such birds as the Herons, the Cormorants, Pelicans, and Storks, all of which lay conspicuous eggs in an open nest. It is quite evident in these cases that the birds by their own prowess alone shield their eggs from danger; besides, most of these birds are gregarious, and are well able to beat off any enemy that is likely to approach, if not singly, by uniting for the purpose, so that it is of no special advantage for them to conceal their eggs. We must also remember that these birds may have descended from a hole-building ancestor-most probably from an ancestor that laid colourless eggs. The coloration of eggs is characteristic in many groups of birds; and in these instances the eggs of the various species conform to those colours peculiar to their special group, although they depend upon other sources for the requisite amount of protection than those which a remote ancestor practised. We now come to our second great division, in which the eggs are beautifully adorned with various hues; and, as our first group, we will take

Spotted eggs laid in open nests.-As our first instances we notice two birds nesting on sandy shores, the Lesser Tern and the Ringed Plover. Buth these birds lay eggs more or less sand-coloured, which circumstance effectually conceals them from view. A still more detailed account of the nesting of these two birds will serve to show even more closely the importance of this fact. The Ringed Plover's eggs are far more minutely speckled than those of the Lesser 'Tern, and as a consequence we find them laid on the finest sand; but the Lesser Tern's are more richly and elaborately marked, and they are only found amongst the coarser shingle, where their larger markings harmonize with surrounding tints most effectually. Take another instance. The Common Sandpijer's eggs assimilate so closely with the tints around them as to make their discovery a matter of no small difficulty, as every oologist can testify who has searched for them. The Peervit's eggs, dark in ground-colour and boldly marked, are in strict harmony with the sober tints of moor and fallow, and on this circumstance alone their concealment and safety depend. Another instance may be found in the eggs of the Dotterel, far up the hillsides, amongst the incessant mists, where their rich brown markings and stone-coloured groundtints harmonize closely with the colours of their mountain resting-place. The Diver's eggs furnish another example of protective colour; they are generally laid close to the water's edge, amongst drift and shingle, where their dark tints and black spots conceal them by harmonizing closely with surrounding objects. The Snipes and the great army of Sandpipers furnish instances innumerable of protectively coloured eggs. In all the instances given the sitting bird invariably leaves the eggs uncovered when it quits them, and consequently their safety depends solely on the colours which adorn them. A passing word should here be given to the eggs of the Gulis. Sume of these species depend for the safety of their eggs upon 
the colours which adorn them ; but some species do not require such protection, the birds being well able to guard them from any enemies by their own prowess. The law of inheritance explains this:-The Gulls have descended from a common ancestor - a form probably intermediate between a Gull and a Plover, which depended on the colour of its eggs for their safety; and consequently we find a certain type of eggs peculiar to the whole group, of benefit to the majority of species, of little or no scrvice to a few, but still retained by the law of inheritance.

Those birds building open nests amongst the foliage of trees and shrubs, as a rulc, lay eggs more or less of a green colour. The Crows in the topmost branches, the Thrushes in the lower shrubs, and many of the Warblers in the dense undergrowth may be cited as instances. Again, the Bullfinch and the Greenfinch lay bluish-white eggs, spotted with red, in open nests; but these birds build in the darkest thickets and hedgerows and amongst evergreens.

A word as to the marvellous variation and beautiful colours of the eggs of the Guillemot. The extraordinary amount of variation in the colour of these eggs appears to be a grave difficulty, and one which utterly refuses to conform to those laws that govern the tints with which so many birds' eggs are adorned. It is one of those very few instances where Nature has seemingly run riot in her variations, in a similar manner to those which occur in domesticated animals; for once let the checks to variation be removed, and its ramifications are infinite and eudless in a few generations. Why, we are apt to ask, do the Guillemot's eggs vary so considerably? Why are they allowed to present such diversity of colour whilst the eggs of most other birds are strictly confined to certain tints? We may attribute the vast variation in the colouring of their eggs to the comparatively easy conditions under which they are brought to maturity. The birds' haunts are practically inaccessible; they have few enemies of their eggs and young, and the variations which occur in their eggs are consequently of small moment. Each variety, according to the Guillemot's present conditions of life, has no more favour than the other; but should the conditions of their existence change, should their eggs be exposed to some new danger, the variety best suited to those changed conditions would doubtless be most favoured-the others not so suitably coloured would, in the course of time, ultimately be weeded out by a rigorous selection, and the colours would most probably be confined to certain uniform protective tints. The colour of birds' eggs is hereditary. A Guillemot that lays a green egg, always lays a green egg, and it will transmit the faculty of laying a green egg to its offspring. This circumstance is not peculiar to the Guillemot, but is common to all birds; and the variation we see in every species is the produce of certain individuals and is transmitted to their young. Hence it is easy to imagine how the Guillemot's eggs would soon revert to a 
miform and protective tint wcre their conditions of life to demand it; hirds laying eggs unadapted in colour to their changed conditions of life would have small chance of transmitting those injurious colours to postcrity, would soon die out completely; and the birds that laid cggs most suitable to the changed conditions and in harmony with them would increase and multiply, and the colours on their eggs be preserved. This, I believe, is how all eggs have got their beautiful tints, and how they are preserved or changed as circumstances arise.

Again, the young birds of many species absolutely depend for safety on the colour of their down. The Lapwing is arrayed in tints that put us in mind of the tropies; the sexes are alike; yet they build an open nest on the bleak common, moor, or pasture, where sometimes not a shrub or heath-tuft affords a haven of safety. Both birds lack weapons of defence; but note how the safety of their young is insured: their sombre plumage of brown effectually conceals them from view. Upon the least alarm the brightly-coloured parents leave their helpless young, who instantly crouch to the ground and remain motionless; their colour so closely harmonizes with surrounding tints as to hide them effectually from the enemy that menaces them. The young of the Game Birds, all the Sandpipers, and many sea-birds might also be given as instances, all of which (where the parents' plumage is conspicuous and dangerous to the welfare of their eggs or young, and which nest in an open site) have young of protective tints. As our last group we notice

Spotted eggs laid in covered nests.-As we found the anomaly of white eggs in open nests, so we also find that of spotted and highly-coloured eggs in covered nests. We will first notice a few instances amongst British birds. We take as our first example the Jackdaw, whose eggs are spotted and coloured in a remarkable manner, considering they are laid in a corered nest. The Chough is another instance, and the Magpie a third. I am inclined to believe that these three birds have changed the form or position of their nest from an open to a covered one, and the eggs are consequently gradually losing their colours. The eggs of the birds just noticed are generally much paler than the eggs of the Crows laying in open nests, and they scem slowly reverting to a colourless type. When once any particular development ceases to be of any service, its tcndency is gradually to die out; and this, I think, is the reason that so many birds nesting in covered sites lay eggs only slightly spotted, or, as in many cascs, when compared with the eggs of the family of birds to which they beloug, show a marked decrease of coloration. The Robin's eggs, as compared with those of its ally the Bluethroat (Erithacus corulecula), furnish another instance. The Robin's nest is well concealed and often built in holes, and its eggs are often white or only faintly spotted; the Blue- 
throat's nest is open and more or less exposed, and its eggs are dark green and protective in colour.

One of the best examples coming into the present group that I know of is to be found in the Grass-Warbler (Cisticola cursitans). This bird builds a purse-shaped nest amongst the grass, in which the eggs are hidden from view; and these eggs exhibit several very distinct types-white or blue spotted with rufous, and sometimes unspotted blue or white. Another instance may be found in the Australian genus Chthonicola, in which the nest is domed and the eggs are red or chocolate in colour.

What do these facts teach us? I think that their explanation is to be found in the fact that these domed nests have only comparatively recently been adopted by these species, and the eggs have not yet lost their colour. These coloured eggs show a changed mode of nesting. Their colour remains unchanged, or alters very slightly; and we know many other contrivances are retained long after their direct use has passed away, because they are not in any way injurious to the welfare of the species, yet they have always a tendency to die out; in the case of eggs this, I think, is shown in such instances as Cisticola, in which we so often find a colourless or plain type. We may rest assured that these colours have not been acquired since the nest has been covered; they are a previous development, most probably destined in time to pass completely away if the present conditions under which the eggs are brought to maturity remain unchanged for any length of time.

From a study of all these interesting facts we learn that birds' eggs exhibit such great diversity of colour for other and far more important ends than that of mere beauty; and their varied tints must be vicwed (with all other beauty of colour in nature) as an object by means of which great ends are attained. A few words should now be given to

Generic types of eggs, and what they teach.-The true relationship of birds is often demonstrated by a study of their eggs. The family likeness of birds, which extends through an entire natural group, is stamped indelibly on their eggs. Thus the experienced oologist, guided by their peculiar characteristics, is able to separate at a glance the eggs of the Shrikes, the Crows, the Snipes, the Birds of Prey, or those of any other large natural group of birds. This is almost as apparent in shape as in colour. Snipe's and Plover's eggs are extremely pyriform; Kingfisher's and Roller's are round; Pigeon's, Goatsucker's, and Sand-Grouse's are oval; Grebe's are pointed at each end. We find these characters constant in each group respectively. Take, for instance, the great family of the Ducks (Anatidæ), numbering nearly two hundred species distributed throughout the world. All their eggs possess certain characteristics which enable us readily to identify them. The same remarks apply to the Sandpipers (Scolopacidæ) 
and the Plovers (Charadriidre), each of which great natural groups numbers upwards of a hundred species, which are as cosmopolitan as the Ducks; and the eggs of both are so characteristic that a glance is sufficient to recognize them. Take, as another instance, the eggs of the great cosmopolitan family Laridx: those of the Gulls (Larinæ) most nearly resemble those of the Sandpipers in colour, whilst those of the Terns (Sternina) show more affinity to the true Plovers; and this may probably be accounted for by the nidification of each group resembling most closely that to which the eggs are allicd in general appearance. The Game Birds are also another instance. So far as I know, the eggs of these birds never have any underlying markings, all the colour is on the surface; and this is one great reason why the aberrant Hemipodes (Turnix) should be cxcluded from this group of birds, for their eggs possess both characters of markings, and therefore show the birds' affinity to the Rails, the Plovers, or the Bustards*. Canon Tristram is probably right when he says that the style of architecture and coloration and form of the egg cast as much light on the true grouping of species and the arrangement of genera in the great subfamily of the Warblers (Sylviinæ) as in any other class of birds. I think that it is even a better generic character than any the birds themselves are known to possess. This group of birds exhibits in a wonderful manner certain distinct types of eggs, a study of which alone will place the birds in almost the same position as that to which they have been assigned by the best systematists. Details cannot well be given here, but the remarks on this subject by Canon 'Tristram ('Ibis,' 1867, p. 74) are worthy the perusal of all interested in oology : it has been briefly noticed in the present work (vol. $\mathrm{i}$. p. 373). 'The subfamily of the Thrushes (Turdinæ) is another remarkable instance, and might almost be split up into fairly natural genera by the coloration of the eggs alone.

It is also very remarkable how the eggs of some birds resemble those of species belonging to very distantly related groups, where the conditions of nidification are similar; and this I think is one of the strongest proofs of a universal law of colour governing these objects. The Sand-Martin and the Woodpecker, or the Dipper and the Weaver-bird are good examples in which a covered nesting-site is peculiar to each and the eggs are uniformly white. In cases where the eggs differ considerably from those typical to the group, we generally find that the mode of nidification adopted by the species is from some cause different and abcrrant too. Take, for instance, the eggs of the American Quail (Ortyx virginianus), which are white and laid in a domed or covered nest, whilst those of the allied Plumed Quail (Lophortyx yambeli) are normally spotted and blotched, and, it is needles: to say, laid in an open nest.

* Conf. Hume, 'Nests and Eggs of Indian Birds,' p. 554. 
What do we infer from these interesting facts? What do they teach us? I think they show beyond the possibility of doubt the more or less close relationship of one bird to another, and prove the community of origin of birds in each great natural group, in each family, and in many genera. Again, I feel convinced that community of origin and inheritance will account for, if it does not fully explain, much of the difficulty one meets with in a scientific study of oology.

Concluding Remarks. - We have thus seen that birds, aided by a rigorous natural selection, strive to the utmost of their ability, in many different ways, to insure the protection of their eggs and young from danger until they reach maturity-

"Each its well-chosen site selects where Nature

To its best concealment aids and favours it."

Lnemies numerous and deadly continually surround them-the prying Magpies and Jays, the subtle snakes and lizards, the active field-mice, rats, and weasels are all passionately fond of eggs and search incessantly for them. We have seen that all the wiles birds display during the period of nidification, all or nearly all the beauty in their nests, all or nearly all the beauty in the colouring of their eggs and in much of the old and young birds' plumage (in the former through the subtle working of sexual selection) are subservient to the conditions of reproduction, and may safely be attributed to a one great Protective Cause.

The instances adduced in this paper in support of the laws of Inheritance and Bird-nidification have chiefly been selected from the birds of our own land. But were we to seek instances from other climes, where bird-life under favourable conditions exists on a much wider and more comprehensive basis, still more startling would our proofs become. As regards eggs, perhaps, but little more could be said; but as regards the plumage of birds and their nests-say in the Tropics-instances almost innumerable might be found showing how universal are those laws which govern the nidification of birds. Sufficient, however, I think has been said to show what an important part Colour plays in the nidification of birds, and that this part of their economy is governed most closely by law. If I have succeeded in showing, in this meagre paper, that Birds' Eggs and Nests are not the unimportant objects they are so popularly believed to be, and that a careful study of them, in conjunction with the birds themselves, helps to elucidate some of the grandest questions affecting organic life, my end has been amply attained. For no matter how unimportant an object or a series of facts may seem, we must not despise them and pass them by. Nature's system is one mass of intricate complexity, becoming more evident the more we study it; and the only means of gaining an insight as to how that system works is by dealing with each phenomenon, not separately, 
but as a relative part which assists in forming an almost perfect and harmonious whole. In the words of the illustrious Darwin :- "When we no longer look at an organic being as a savage looks at a ship, as something wholly beyond his comprehension, when we regard every production of Nature as one which has had a long history, when we contemplate every complex structure and instinct as the summing-up of many contrivances, each useful to the possessor, in the same way as any great mechanical invention is the summing-up of the labour, the experience, the reason, and even the blunders of numerous workmen; when we thus view each organic being, how far more interesting (I speak from experience) does the study of natural history become!"

Oology, as a science, is almost virgin ground for research, and its importance in elucidating much that is strange in the economy of birds is great. It is when Oology becomes more gencrally and comparatively studied, and an interchange of observations by oologists in various parts of the world effected, that the importance of protective colouring, mimicry, bird architecture, \&c. will become manifest, the present insufficiency of data bearing on the subject being a very great obstacle to its scientific progress. Every little detail, however insignificant it may seem, must be recorded ere we can gain a complete knowledge of this interesting branch of research; and the remote history of a species must not be neglected where it can be traced with reasonable certainty.

I hope to return to this fascinating subject at no distant date, treating it on a wider basis by including. the nests and eggs of birds from all parts of the world. I shall be extremely obliged for any notes from any part of the world bearing on the subject of Birds' Nests, Eggs, and Nidification; for I am convinced that it is only by collecting an immense variety of such facts that the subject can be successfully investigated.

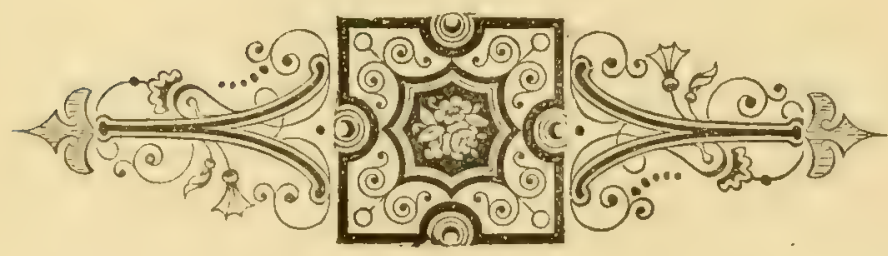




\section{xxxiii}

\section{ADDENDUM.}

Page 142. Since writing the article on the Rustic Bunting, in which I copied the description of the supposed eggs of this species given by Dresser in his "Birds of Lurope,' I [have seen three clutches of eggs, said to be of this species, also collected in the neighbourhood of Archangel. As they agree with each other and differ from eggs of any other North-Russian species, it seems probable that they may be genuine eggs of the Rustic Bunting, though this cannot be regarded as proved until properly authenticated eggs have been taken. The ground-colour varies from greenish white to bluish white, and the overlying spots are greenish brown and the underlying spots greyish brown. The spotting is very profuse and more or less confluent at the large end of the egg; but there are no streaks, the character of the egg being that of a Sparrow rather than that of a Bunting. In this respect they show an affinity with the eggs of Emberiaa melanocephala and E. luteola, and, to some extent, with those of $E$. nivalis, though the latter often have some small streaks. They vary in length from 86 to $\cdot 76 \mathrm{inch}$, and in breadth from $\cdot 6$ to 56 inch. The egg figured on Plate 15 is probably that of E. luteola, and those described by Dresser are probably eggs of E, pusilla. I intend to figure one of these eggrs on Plate 68. 



\section{A HISTORY}

\section{B R I T I S H B I R D S.}

\section{Subfamily AMPELIN E, on W AX WINGS.}

The Waxwings are a very small subfamily, consisting of birds having the wing of a Starling, the foot of a Shrike, and a bill intermediate between that of a Shrike and a Swallow. They are probably most nearly allied to the Shrikes and the Starlings: from the former they may at once be distinguished by the minuteness of their bastard primary, their short tarsus, and their nearly obsolete rictal bristles. Although they agree with the Starlings in having their bastard primary very small and their second primary long, combined with a short even tail and almost obsolete rictal bristles, ornithologists are perhaps justified in placing them in a distinct subfamily, in consequence of the shortness of their tarsus, their shorter, wider, and notched beak, and the presence of small bristles which cover the nostrils. The Waxwings only moult once in the year, in autumn. The young in first plumage differ from their parents in many respects, and are streaked on the underparts; but this plumage is moulted during their first autumn.

The Ampelinæe were in all probability originally an aretic group of birds, of which only eight species are at present known to exist. One of these is circumpolar, one is confined to Japan, whilst a third inhabits the temperate portions of the Nearctic Region. The remaining five species inhabit the Neotropical portion of North America; only one species is European. 


\section{Genus AMPELIS.}

In the tenth edition of the 'Systema Natur'e' of Linnæus, published in 1758, the Waxwings were included in the genus Lamius. In 1760 Brisson, in his 'Ornithologia,' placed them in the genus Turdus; but in 1766, in the twelfth edition of his great work (i. p. 297), Linnæus associated them with half a dozen very distantly allied birds in a new genus, Ampelis. These stranger's were subsequently removed to other gencra by later writers, leaving the Common Waxwing as the type.

In the birds of the genus Ampelis the shafts of the secondaries are either prolonged into wax-like appendages, or each feather has a red terminal spot to the outside web; the tail-feather's are broadly tipped either with yellow or red; and the throat, lores, and the feathers behind the eyes are black. They have also a well-developed crest. 'This genus contains only three species, one of which is confined to North America, one to Japan and the adjoining mainland, whilst the thired is circumpolar; the latter is the only species found in Europe, and is an irregular winter visitor to the British Islands.

In many of their habits the Waxwings resemble very closely the Rosecoloured Starling. 'They are very erratic in their migrations, and appear' irregularly in certain districts often in considerable numbers. They chiefly frequent pine- and larch-woods; but when wandering far from their breeding-grounds in winter, they scem to have no preference for any particular haunt. They are comparatively tame birds, and resemble the Titmice somewhat in their actions. They possess scarcely any song. Their food consists of fruit, berries, and insects. They build open cup-shaped mests placed in the branches of trees, and made of twigs, moss, feathers, lichens, \&c. Their eggs are from five to seven in number, rarying from French white to sea-green in ground-colour, spotted, blotched, and speckled with deep brownish black and pale underlying markings of lilac. 


\section{AMPELIS GARRULUS.}

\section{WAXWING.}

(Plate 11.)

Turdus Bombycilla bohemica, Briss. Om. ii. p. 333 (1760).

Ampelis garrulus, Linn. Syst. Nat. i. p. 297 (1766); et auctorum plurimorumBonaparte, Temminct, (Tieyserling \&. Blasius), Degland, Salvadori, Baird, Ridyway, Dresser, Newton, \&c.

Bombyciphora poliocœlia, Meyer, Vög. Liv-u. Esthl. p. $10 \pm$ (1815).

Bombycivora garrula (Lim.), Temm. Man. d' Om. p. 77 (1815).

Bombycilla garrula (Limn.), Vieill. N. Dict. d'Hist. Nat. xvi. p. 523 (1817).

Parus bombycilla, Pall. Zoogr. Rosso-Asiat, i. p. 548 (1826).

This charming and interesting bird may be regarded as an irregular winter visitor to Great Britain, having been met with in almost every county, in some years in considerable numbers. It was first made known as a British bird by Lister in the 'Philosophical Transactions' (1685, no. 75. p. 1161, fig. 9), from specimens shot at York in January 1681. From this early date down to the present day the Waxining has occurred almost yearly in some parts of Great Britain. Among the years when it appeared in extraordinary numbers may be cited the winters of 1830-31, 1834-35, 1849-50, and 1866-67. This latter will long be remembered by British ornithologists as one of the great Waxwing seasous. The whole of 1866 (the year of the eattle plague) was wet, the mild winter at each end being scarcely distinguishable from the cold summer between. On New-Year's day frost and heavy snow set in. Early in November great numbers of the Bohemian Waxwing made their appearance. The largest flocks were seen in Norfolk; but north of that county many birds were shot at Scarborough, Newcastle, Berwick, up to Aberdeen and Inverness, and to the south they were obtained as far as Dover and Rye.

It is of far more frequent occurrence in the eastern counties than in the midland and western; this is doubtless because the birds are so eagerly sought after and shot upon their arrival on our castern coasts that comparatively few succed in reaching the more distant parts of the kingdom. In Scotland the Waxwing is almost as well lnown as it is in England as an uncertain and irregular winter guest. It has not been obtained in the Outer Hebrides, but has occurred on Sliye and the Orkney, Shetland, and Faroe Islands. In Ireland, as might be expected, it is of much less frequent occurrence, most probably for the reasons above cited.

The Waxwing is almost a circumpolar bird, breeding in the pine-regious of both hemispheres at or near the Aretic circle. It is common, though very local, in Lapland; and most of the eggs of this bird in collections have 
been obtained there. I have seen it in its breeding-season in the valleys of the Petchora and the Ycnesay; and Middendorff met with it during winter on the shores of the Sea of Ochotsk. Mr. Dall states that its eggs have been obtained near Fort Yukon in Alaska; and it has been found during the breeding-scason in the valley of the Anderson River, north of the Great Bear Lake. It possibly may not breed further east in America; but very little is known of the arctic regions of either continent, and the Waxwing is so erratic in its habits, breeding in enormous numbers in a certain district for some scasons and then almost deserting it for several years, that it may easily have been overlooked.

The Waxwing is as erratic in its choice of winter-quarters. It is a very irregular migrant, wandering southwards on the approach of cold weather, and revisiting the north whenever a thaw of sufficient length occurs. Throughout Central Europe it is a tolerably regular winter visitor. It occurs accidentally on Heligoland, and occasionally strays as far west as France and as far south as Lombardy and Turkey, but has not yet been recorded from Spain or Grece. It winters in South Siberia, occasionally straying as far as Turkestan, Mongolia, North China, and the north island of Japan. In America its winter range extends as far south as Lakes Michigan and Eric ; but it appears to be only an accidental straggler further east, and it is doubtful if it has ever occurred west of the Rocky Mountains.

One of the nearest allies of the Waxwing is the Japanese Waxwing (A. phonicopter $a$ ), which breeds in Japan and wanders in winter to the valley of the Lower Amoor and North China, and occasionally to Formosa. This species may be easily distinguished from its arctic ally by having the ycllow at the tip of the tail replaced by red, and by having no "wax" tips to the secondaries, the white tips on their outside webs being replaced by red. A still nearer ally is the American Waxwing or Cedar-bird, A. cedrorum, which is said to inhabit the whole of North America as far north as lat. $52^{\circ}$, extending southwards to Guatemala, Jamaica, and Cuba in winter. This bird is somewhat less than the northern specics, and like it has the "wax" tips to the secondaries and the yellow tips to the tail, but is without the white on the wing. The Cedar-bird has been erroneously included in the British list, in several cases skins of this species having been substituted by dishonest bird-stuffers for specimens of the Waxwing shot in this country.

I was fortunate enough to meet with a small party of Waxwings as I was walling down the Glossop Road to business into Sheffield on the morning of the 29th of December, 1866. My attention was arrested by three or four birds which flew across the road and alighted in a laburnum tree in Miss Ray's garden. I imagined from their flight that they must be Starlings; but fancying that they showed white marks on the 
wing, I had the curiosity to step across the road to get a nearer view of them. The tree on which they alighted was only a few yards from the road, and I watched them over the wall for some time. I recognized them at once by their crests. The yellow markings on the wings and tail were very conspicuous, and I fancied I could distinguish the red wax-like appendages. They were very active, putting themselves in all sorts of positions, and did not seem at all disturbed by my scrutiny; and when at las they flew away, and I turned round to continue my walk, I found that quite a small crowd had collected behind me, one of whom (probably a Sheffield grinder, and consequently well up in pigeons, dogs, and other branches of sporting zoology) volunteered the information that they were French Starlings. I sent a short notice of the appearance of these illustrious strangers in our town to one of the local papers; and the following day more than one gentleman assured me that birds agreeing with my description had been seen in Broomhall Park, and on the 31st two specimens were shot there by the gardener of Mr. Willis Dixon; so that it is probable that the flock continued in the neighbourhood for some days. A few months afterwards I bought a pair of these birds and kept them in a cage for some time. They were most voracious eaters, and the cage required cleaning several times a day. They were very active and restless, and even when perched at rest seemed to be continually moving their heads. If alarmed they would stretch out their necks to almost double the usual length. They were remarkably silent birds; the only note I heard was a cir-ir-ir-ir-re, very similar to a well-known note of the Blue Tit. Occasionally this succession of notes was repeated so rapidly as to form a trill like the song of the Redpole. The Waxwing is almost omnivorous. Mr. Gunn, of Norwich, through whose hands more than a hundred birds passed in the winter of 1866-67, found their food to consist of the berries of the guelder-rose, dog-rose, whitethorn, and privet; those of the dog-rose, being too large for one mouthful, were picked to pieces. Collett, who dissected birds shot at their breeding-grounds in Finmark in July, found the stomachs filled almost exchisively with entire or dismembered bodics of a species of crane-fly allied to our "Tommy long-legs." One of the males had some juniper-berries in his gullet. Other ornithologists have found various berries and insects in the stomachs of these birds; and in confinement they feed greedily on bread and carrots.

The Waxwing is generally very fat in winter, and is highly esteemed as an article of food. Hundreds are sold in the frozen market of St. Petersburg at three-halfpence each.

Although this bird has been well known to ornithologists for some centuries, its breeding-grounds were only discovered as recently as 1856 . Before that date various legendary stories of its breeding in holes of trees and amongst rocks were recorded; and, incredible as it may seem, were 
repeated as late as 1870 in what professed to be a scientific work on the History of British Birds. The merit of the discovery belongs to John Wolley. This indcfatigable ornithologist spent five consecutive summers, and two out of the four intervening winters, in Lapland in searching for the eggs of this and other rare birds; but, owing to the erratic habits of this species, he did not succeed in his object until the fourth summer. Like the Rose-coloured Starling, the Warwing continually changes its breeding-grounds. These two birds breed in cnormous colonies in localities which they probably choose from year to year, in places where an abundant supply of food can be obtaincd. Wolley's headquarters were at Muoniovara, a Swedish village on the river Muonio, opposite the Russian village of Mronioniska, about halfway between the Gulf of Bothnia and the southern extremity of the Porsanger fjord. During the first three summers, although he was very successful in obtaining eggs of many birds of which authenticated specimens were then unknown, it was not until the summer of 1856 (his fourth season) that the nests of the Warming were obtained by his faithful servant Ludwig Matthias Kuoblock. Six nests were brought in to him, but he himself did not sẹe one in situ. In 1857 he succeeded in finding a nest, which had been deserted a day or two before, and beneath which the broken egges were lying on the ground; but during that season eight nests were brought to him. The following summer this district was apparently chosen by the Waxwings as their lieadquarters; and Wolley's collectors obtained nearly a hundred and fifty nests containing nearly seven luundred eggs, most of which were sent to him in England, he having visited Iceland that year in search of the Great Auk. On his return from this expedition his health began to fail, and in November 1859 British Ornithology lost its most promising student at the early age of thirty-five.

The first discovery of the nest of the Waxwing was made in the valley of the Kemi in Russian Lapland. Ludwig made an expedition to the Kittila river early in June, having in some places to wade up to his middle in snow. Arrived at Sardio, where he had apparently commissioned the natives to search for him, he found, as would naturally be the case whilst the snow was in process of melting, every one at home "deep in dirt and laziness." He soon ascertained from them that a pair of Waxwings had been seen in the neighbourhood; and accordingly he started off at once into the forest, and there he saw a bird which he took to be a Warwing, but he ras not quite sure, for in the sunshine the end of its tail looked white, instead of yellow as in the picture with which Wolley had provided him. On the following day it was cloudy, and Ludwig saw the yellow on the tail, and had no longer any doubt. He engaged the Russian boys by the day, telling them that they must scarch, even if it were for a week, till they had found the nest. They sought all that night and the next day till 
about noon, when a lad called out that he had found the nest; and there it was, about nine fect high on the branch of a spruce. Ludwig succeeded in snaring the old bird, a beautiful cock, at the end of five days, and packed up the nest, eggs, and bird in a strong box until Wolley's arrival. Wolley writes:- "You can fancy how eagerly I waited for Ludwig to produce the eggs. With a trembling hand he brought them out-but first the nest beautifully prescrved ; it is made principally of black 'tree-hair' (lichen), with dried spruce-twigs outside, partially lined with a little shecp's grass and one or two feathers-a large deep nest. The eggs-beautiful! magnificent!!-just the character of the American bird. An indescribable glow of colour about them!..... Almost every day (and it is now the sixth since that of my arrival here) Ludwig has told me the whole story of the Sidensvan's nest, and I am never tired of hearing it:-how the season was very backward; how in their expedition he and Piko Heiki were getting very much out of spirits at the little success they met with; how he saw the bird in the sunshine; how, when at last the nest was found, he could scarcely believe his eyes; how he went to it again and again, each time convinced when at the spot, but believing it all a dream as soon as he was at a distance; the rising and falling of the crest of the bird; its curious song or voice. All he is eager to tell over and over again; and I have the fullest version, with all the 'I said,' 'Heiki said,' 'Michel said,' 'Ole said,' " \&c. Since Wolley's great discovery many other nests of the Waxwing have been obtained by various ornithologists. In 1857 Dr. Nylander obtained a nest with five eggs from the island of Ajos at the head of the Gulf of Bothnia, off the coast of Finland. In 1858 Dresser obtained a nest with unfledged young from the island of Sanden, twenty-seven miles from Uleiborg, a little to the south of the previous locality. In 1862 Wheelwright obtained a nest with two eggs near Quickiock; in 1868 Nordvi procured its eggs in north-east Norway; and in 1872 Mr. Berlin discovered two nests containing eggs in the same district.

A nest of the Waxwing, which Mr. Nordvi procured for me from Muonioniska, is a large and very compact structure. The outside diameter is seven inches, and the inside four inches. It is about four inches high outside, and nearly two inches deep. The foundation is made of twigs of the spruce-fir and reindeer-moss. The nest itself is composed of feathers and black hair-lichen, interwoven together with very slender twigs and a little moss and inuer bark, the feathers being most numerous in the lining. Five or six, and occasionally seven, is the number of eggs laid. Newton (in whose collection the greater part of the enormous series obtained by Wolley still remains) describes them as measuring from $1 \cdot 11$ to 82 in length by $\cdot 73$ to 64 inch in breadth. He writes:- "The ground is most generally of a delicate sea-green, sometimes fading to French white, but very often of a more or less pale olive, and occasionally of a dull 
purplish grey. On this are almost always bold blotches, spots, and specks of deep brownish black, though sometimes the edges are blurred. Beneath these stronger markings there is nearly always a series of blotches or streaks of greyish lilac, and among them well-defined spots or specks of yellowish brown are interspersed. In some eggs the darkest markings are quite wanting, in others the ground is of a deep olive-colour."

The adult male Waxwing is an exquisitely beautiful bird. The upper parts are a delicate vinaceous brown, gradually shading into chestnut on the forehead, and into pale slate-grey or dove-colour on the rump and upper tail-coverts. A narrow frontal band, the lores, and the feathers behind the eyes are black. The quills and tail-feathers are dark brown, nearly black, varied with a broad yellow band across the tips of the tailfeathers, and a narrow band of the same colour on the outside webs of the primaries at the tip, and a white band across the tips of the primaries on the inside webs, and on the outside webs of the secondaries at the tips. The primary-coverts are tipped with white, and the shafts of the secondaries are prolonged and flattened into scarlet tips. A similar development of the shafts of the tail-feathers frequently occurs. The underparts are vinaceous brown on the breast and flanks, shading into greyish white on the centre of the belly and into chestnut on the cheeks. At the base of the lower mandible on each side is a white streak. The chin and upper throat are black, and the under tail-coverts chestnut. Bill nearly black, paler at the base; legs, feet, and claws black; irides hazel.

The difference in plumage between the sexes of the Waxwing is still a disputed question amongst ornithologists. A great proportion of males have large wax-like appendages to the tips of the secondaries, broad bright yellow tips to the tail-feathers, and have the bright yellow tips of the outside web of the primaries connected with a white tip at the end of the inside web, making the marking on the primaries $\mathrm{V}$-shaped. Most of the females have the wax-like appendages smaller, the tips of the tail-feathers narrower and paler, and the tips of the outside webs of the primaries pale and entirely wanting at the ond of the inside webs, thus causing the markings on the primaries to be I-shaped. Males of the year generally are indistinguishable from females, but frequently are slightly intermediate between the two sexes when adult in one or all of the points alluded to. The presence of wax on the tail-feathers and on the eighth secondary, which is without the white stripe on the outside web, is apparently a question of vigour or age, and not of sex. The richness of the chestnut of the under tail-coverts and of the black of the throat appears to be a question of age. The Waxwing is most brilliant in plumage immediately after the autumn moult, which takes place late in October. I have an example in my collection in full moult obtained at Krasnoyarsk on the 3rd of November; examples from the same locality in May are already considerably faded. 
The alleged females in collections with $\mathrm{V}$-shaped markings on the primaries are so rare that we may suppose them to be old and barren females which have assumed the male plumage, or it is possible that a mistake in the sexing or labelling may have occurred. Young in first plumage resemble females, but are paler in colour, and are without the black on the throat; the underparts are streaked, and the wax-like appendages to the secondaries are few and small.

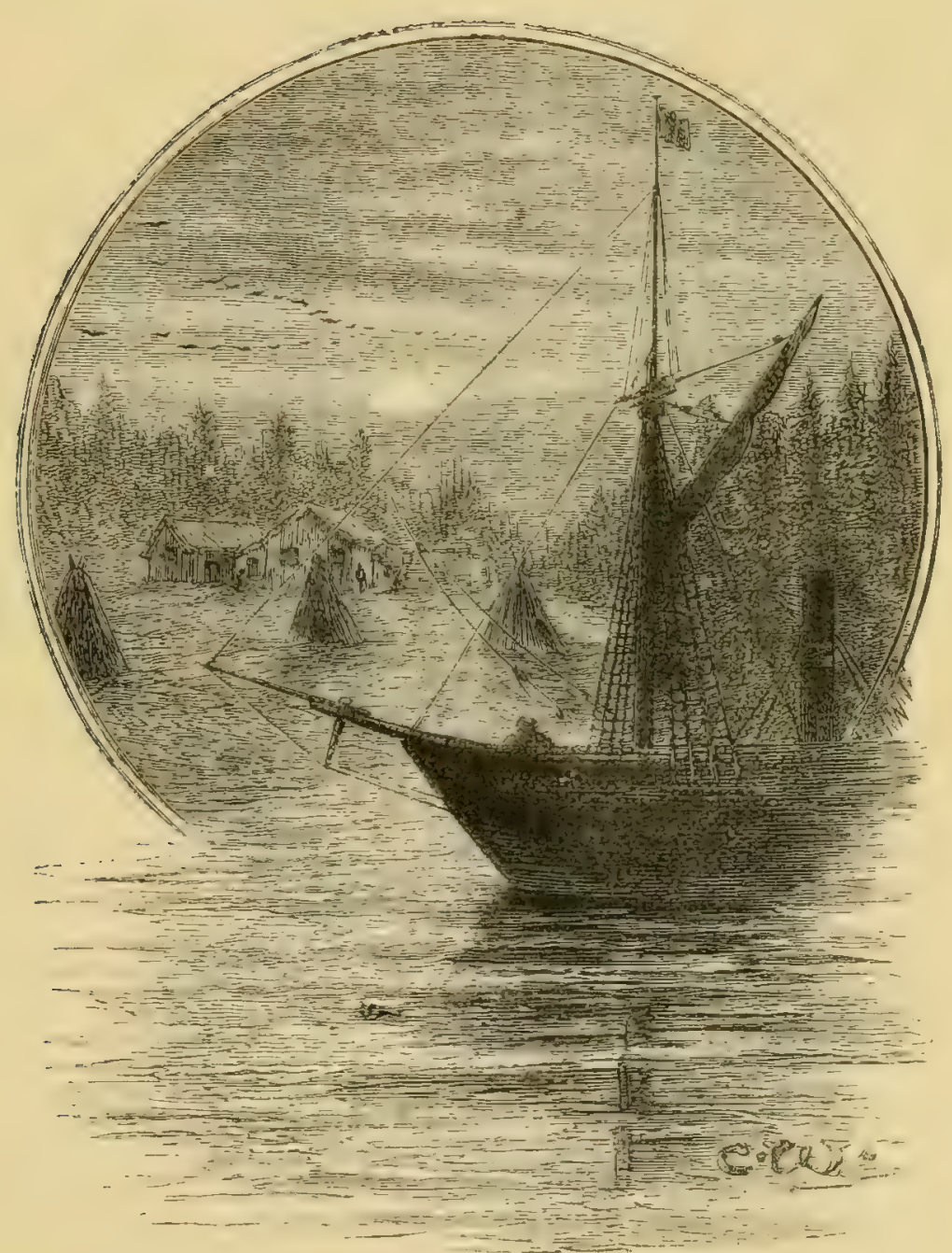




\section{Subfamily STURNIN无, oR STARLINGS.}

The minute hastard primary and the great length of the second primary, which is the longest in the wing, together with the absence of the nasal bristles and of scutellations at the back of the tarsus, are characters which diagnose the Starlings from the other subfamilies of the Passeridx. The tarsus is moderately long and scutellated in front, and the bill is straight, slender, aud unfumisherl with rictal bristles. The Starlings moult once a ycar in autumn, the spring plumage being attained by casting the ends of the feathers. The young in first plumage differ consiclerably from their parcuts, being a nearly uniform brown more or less streaked on the underparts; but this plumage is lost by the first autumn moult.

The Sturnine are an Old-World group of birds, found in every part of the eastern hemisphere, except in the arctic and antarctic regions and on the continent of Australia. Wallace includes 124 species in this group of birds. Four only are found in Europe, of which one is a resident in the British Islands and a second is a rare straggler to our shores.

\section{Genus STURNUS.}

Linnæus included the genus Sturnus in the 12th edition of his 'Systema Nature,' published in 1766 (vol. i. p. 290). The Common Starling, because it is the Sturnus sturnus of Brisson, has indisputable claims to be considered the type.

The most striking peculiarity in the Starlings is the metallic tint of their plumage-purple, green, and bronze. This character is sufficient, in conjunction with their size, to distinguish them from all other European birds. The rictal bristles are obsolete, and the nostrils are bare of feathers, but half-covered with a soft horny operculum. The forehead is very depressed; and the feathers on the head, throat, and breast are elongated something like the hackles of a Cock.

The genus Sturnus contains about eight or nine species and subspecies, confined to the central and southern portions of the Paliearctic Region and the extreme north of the Oriental Region.

In their habits the Starlings are gregarious. They frequent pastures, 
where they are very fond of closely attending cattle while feeding, and almost every other kind of haunt, both inland and on the coast, notably near houses and ruins. Their food consists of insects, worms, grubs, fruit, berries, and various kinds of seeds. Their call-notes are harsh; but they have considerable powers of song, and in confinement readily learn to imitate different tunes and even words. Their flight is very strong and powerful, and on the ground they walk or run. They build bulky slovenly nests of grass, straws, roots, feathers, and almost every kind of material to hand, placing them in holes of walls, rocks, trees, or buildings. Their eggs are from four to six in number, greenish blue in ground-colour, without any markings.

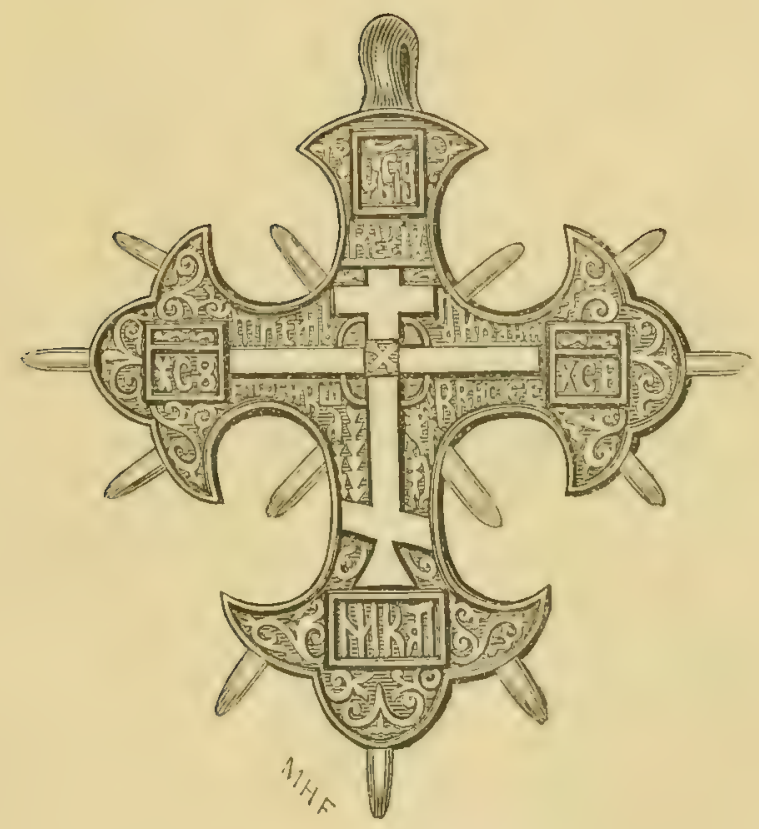




\title{
STURNUS VULGARIS.
}

STARLING.

\author{
(Plate 11.)
}

Sturnus sturnus, Briss. Orn. ii. p. 489 (1760).

Sturnus vulgaris, Linn. Syst. Nat. i. p. 290 (1766); et auctorum plurimorumGmelin, Latham, Scopoli, Bonaparte, Salvadori, Degland \& Gerbe, Newton, Dresser, \&c.

Sturnus varius, Wolf, Taschenb. i. p. 208 (1810).

Turdus solitarus, Lath. apud Montagu, Orn. Dict. Suppl. (1813).

Sturnus solitarius (Lath.), apud Leach, Syst. Cat. Mamm. \&c. Brit. Mus. p. 18 (1816).

Sturnus guttatus, Macgill. Brit. B. i. p. 595 (1837).

Sturnus europæus, Linn., fide Blasins, Journ. Orn. 1863, Bericht, p. 60.

Sturnus faroensis, Feilden, Zoologist, 1872, p. 3257.

The Starling is one of the commonest and most widely distributed of our indigenous birds. It is of less frequent occurrence in the breedingseason in Wales and in Cornwall; but otherwise nests commonly in almost every county of England. In Scotland it has considerably increased in numbers within the last half-century. According to Mr. Gray, thirty years ago it was comparatively a scarce bird throughout the Scottish mainland, although in the Western Isles, Orkney, and Shetland it appears to have always been a common resident. At the present time, however, it is a resident bird near all the large Scotch towns, generally distributed over the cultivated districts, and breeds in almost every county. In Ireland the Starling is not so widely distributed, and is best known as a winter visitor, its breeding-places being somewhat local. On the Faroes it is a common and resident bird; and a specimen was sent from Greenland by Holböll to Copenhagen in 1851 ; but it does not appear to have ever been noticed in Iccland. The Starling has been introduced into New Zealand; and being such a hardy and favourite cage-bird, its colonization in other parts of the world is probably only a question of time.

The Starling breeds throughout Europe north of lat. $44^{\circ}$, and is a resident in the Azores. In Scandinavia it is found as far north as lat. $69^{\circ}$, in Sweden and Finland up to lat. $65^{\circ}$, and in the Urals only up to lat. $57^{\circ}$, which also appears to be its northern limit in Asia. The European birds that are migratory winter in the south of France, the Spanish peninsula, Italy, Greece, North Africa, and Palestine. In Asia it breeds in South Siberia, Persia, and Turkestan, ranging as far east as the sources of the Amoor, passing through Mongolia on migration, and wintering in India.

The Starliug has two very near allies. In eastem Asia Minor, where it is probably a resident, and in Turliestan and Afghanistan, whence it 
migrates in autumn to the Punjaub and North-west India, Sturnus purpurascens occurs, distinguished by its bronze-coloured wings and flanks, and, on an average, longer beak. In Sindh, Cashmere, and Nepal S. indicus is a resident, distinguished by its small size, the wing measuring from 4.25 to 4.75 inch (the wing of $S$. vulyaris measures from $4 \cdot 85$ to $5 \cdot 3$ ). In all these species the colour occasionally changes from green to purple, according to the position in which the bird is held as regards the light; they are also probably subject to some slight local variations in colour.

The Starling is almost as closely associated with man as the Sparrow; but, unlike that bird, it seems to have a peculiar way of accommodating itself to its surroundings with the greatest ease. Thus we see it almost everywhere and in every varicty of scenery. It will sharc the eaves and the dovecot with the Sparrows and Pigeons; it will nestle in the hollow trees far away from houses, or make its home just as easily in the sides of the stupendous occan-cliffs in company with the noisy crowd of sea-birds, or on the limestone rocks further inland. After the breeding-season the Starling becomes even more widely distributed, and from August until the following spring haunts fields and marshes, commons, gardens, and the low-lying shores, as its food-supply may be the most abundant. The Starling is a gregarious bird at all seasons of the year; but this habit is most marked after the nesting-season, for in spring the scarcity of suitable breeding-places usually disperses them.

Early in the year, sometimes as soon as the middle of January, the Starling returns almost daily to its old nesting-place, and in a week or so the male begins his unpretentious song. He usually sings when perched on a chimmey or on the caves near his nesting-hole, or on the tree-tops near at hand; and his song is warbled forth as he ruffles the feathers of his head and throat and shakes and droops his wings, as though full of nervous excitement. Although many of the Starling's notes are harsh, still some of them are very full and plcasing, and heard as they are, at a season when every sign of returning spring is eagerly looked for and welcomed, are certainly one of the most cheerful sounds that greet the ear. Each note is uttered in seeming caprice; the harsh ones are mingled with the sweet ones with no approach to order. It is indeed a strange song, and cannot be mistaken for that of any other British bird, the Rosecoloured Starling excepted. The Starling's alarm-notes are very harsh and rapidly repeated, resembling somewhat those of the Missel-Thrush. Its call-note is a clear long-drawn piping cry.

Early in April, sometimes not until the beginning of May, the Starlings have mostly mated and gone to their breeding-holes. Previous to this, however, much quarrelling goes on for the choice of suitable sites; the strong gain the best located holes, whilst the weak seek quarters elsewhere. The Starling will build its nest almost everywhere, and it needs but slight 
encouragement to take up its quarters in any suitable hole or box placed for its reception. It will even dislodge large tiles and burrow considerable distances under the eaves; and its bulky nest often stops up some spout, to the dismay of the householder. A hole in the gable or inside the dovecot are also favourite places, whilst its partiality for holes in trees is none the less. It also commonly breeds in ruins, churches, and old masonry of every description. In the wilder portions of the country the Starling selects a hole cither in a trec or rock for its purpose; and it will often breed in great numbers in caves or in the crevices of the oceancliffs. The nest is sometimes but a few inches from the cutrance to the hole, at others it is several feet, and in many cases, especially in trees and rocks, is absolutely inaccessible. In the Outer Hebrides, where trees are absent, the Starling breeds, according to Mr. Gray, under the stones on the beach, in disused rat-holes, in turf-dykes, and in holes in walls. Saxby states that in Shetland it breeds in peat-stacks and rabbit-holes. It has also been known in one or two instances to build an open and exposed nest in trees, to rear its young in a hole in the ground, and to share the same nest with a Magpie.

The Starling's nest is a somewhat slovenly structure, made of straw, dead grass, and rootlets, sometimes a twig or two, and is lined with a few feathers, a little wool, or even a scrap or two of moss, paper, rag, or twine. In many cases the birds do not trouble about a lining at all; and the cup of the nest is entirely composed of straws, arranged very evenly and smoothly, but with a lot of straggling bents around it. The nest is in some cases much more elaborately made than in other's; and in some holes the dry and powdered wood at the bottom almost does sole duty for a bed. With great perseverance the Starling will continue to build in the same hole, although its nest is repeatedly removed, and each year the birds will return to their old quarters.

The eggs of the Starling are from four to seven in number, six being an average clutch. They are slightly elongated and rough in grain, but very highly polished, and are a delicate greenish blue, sometimes very pale bluish white. They vary in length from $1 \cdot 25$ to $1 \cdot 1$ inch, and in breadth from ' 88 to 80 inch. From the eggs of the Rose-coloured Starling, those of the present species may always be distinguished by their greenish or bluish tints; those of the former are shining white, almost like a Woodpecker's. The Starling, in most cases, rears two broods in the year, sometimes three, though this has been denied. As soon as the young of the first broods can shift for themselves they are abandoned and roam about in flocks, and their parents go off to their nesting-holes again. As is usual with life-paired birds, the Starling will continue to lay in its old nest, although its eggs are repeatedly taken. Dixon, in a single season, has taken from a nest of this bird as many as forty eggs; and he has every 
reason to believe that they were laid by one pair of birds. In the Starling's laying-season, as most egg-collectors are probably aware, the bird often drops an egg upon the fields. During the hatching-period the female, who sits very closely, is fed assiduously by the male. Dixon has known this bird remove its eggs from a hole from which they were constantly being taken. Few birds are more noisy than young Starlings; and throughout the rearing-period their nest-hole is betrayed to any passerby by the clamouring young within, who greet their parents' arrival with a chorus of cries. But far different is the case with the old birds, who are usually very wary, and always silent at the nest.

As previously stated, the Starling is gregarious. It looks a remarkably handsome bird as it wander's about the grass-plot or the meadows, progressing with slow and regular pace, every now and then stopping to pull up a worm or dislodge a beetle from the little heaps of manurc. It is also very fond of searching the ground where cattle are feeding, and may repeatedly be seen perched on the backs of sheep, which it rids of various vermin. If alarmed, the whole of the flock generally take wing simultaneously, and alight in the nearest tree-tops, where they licep up an incessant chorus of mixed harsh and musical notes. The flight of the Starling is very rapid and well-sustained, performed by a series of rapid beating's, occasionally varied by smooth gliding motions with the wings expanded. As a proof of the Starling's great power's of wing may be mentioned the fact that it may very often be seen high in the air coursing about in search of insects, like the Swallows and Swifts. It will sometimes mount to a great height and perform evolutions which we are apt to think astonishing from any bird save those just mentioned. When in the air thus, the bird seldom utters a note, and it will often keep flying about for an hour or more.

'The food of the Starling is for the most part of the year' composed of worms, slugs, and beetles; but in winter these birds are often seen to feed on grain and sceds. In autumn they are very fond of fruit and berrics. Elderberries are part of their favourite food, and soon the trees, which had previously bent under the weight of their clustering branches of black fruit, will be totally denuded. In severe weather they will sometimes feed on hips and haws; and are often seen on the lowlying coasts searching for sand-worms and various small mollusks. The Starling, like most other birds, has not escaped a certain amount of persecution, and is charged with several offences. The gardener says it robs his fruit-trees; the farmer, that it destroys his Pigeons' eggs; whilst very recently the poor bird was accused of cating Larks' egg's to such an extent as to cause a perceptible decrease of those fime chorister's in certain districts ! To the former of these charges the bird must perhaps plead guilty, but its depredations are small and amply repaid by 
its good offices for the rest of the year; whilst of that of egg-stealing, there can be little doubt that it is most wrongfully accused. Gray and Saxby bring forward very conclusive evidence of this bird's evil propensities, but such instances are only exceptional. Waterton's defence of the Starling leaves no room for further remark.

In autumn, when the young are all reared and family cares are over for the year, the habits of the Starling are the most interesting and easiest to observe. The birds are now at liberty to follow their gregarious instincts to the full, and the size of the flocks is sometimes almost beyond belief. The smaller flocks, chiefly composed of young birds, join together; the old birds unite with them, until each district possesses its flock. In the daytime they may be seen on the fields and marshy lands in search of food, or on the tree-tops, which they almost blacken with their numbers, keeping up an incessant babel of sounds. Their evolutions in the air at this period are also highly interesting, especially at nightfall, ere they finally settle down to roost. It is astonishing how regular the flock will wheel and gyrate in the air, as though moved by one common impulse. They appear like a huge net as it hovers for a moment above the reed-bed where they roost-now the horizon seems clouded with their numbers as they turn full towards the observer; the next moment they will turn rapidly, seeming to disappear; then appear again in a clustering mass, to turn and poise, spread, close up, rise, and descend ere alighting. Regularly each night the birds repair to certain roosting-places. Sometimes the flock will divide into several portions, each to seek a different roosting-place, uniting agaiu at dawn. These clouds of Starlings often assume various shapes as they pass through the air, sometimes like huge balloons, then changing to a spiral, or spread ont like a net, and sometimes like a thin indistinct wreath of smoke. Sometimes a flock will roost in a large wood, a plantation, or more frequently in a low shrubbery. These places are a common rendezvous for all the birds in the district; flock joins flock; and their aerial movements and babel of cries make the place, ornithologically, a most interesting one. At this season of the year Starlings often congregate with Rooks and Jackdaws on the pastures, and later in the year with Redwings. When alarmed, the Starlings, as if to a bird obeying a commander's voice, fly off in a compact mass, and if the danger soon passes they will wheel and return again in the greatest order. The Rooks and Daws will scurry off in all directions, and the Redwings will seek the nearest trees in a long straggling train, but the Starlings seem to act under one common impulse. During the whole winter Starlings are very erratic in their movements; they lead a nomad kind of life, wandering about the country in search of food, or even extending their journeys across the sea if the winter be severe. A few individuals, who prefer to lead a hermit-life instead of joining the bustle of "Society," may almost 
always be seen, no matter how hard the frost; but the great majority of birds retreat before it.

In this country the Starling may be fairly considered a resident bird; but there is no doubt that it receives large additions to its numbers from Northern Europe every season. It is also a well-known bird at Heligoland, and passes that isolated rock yearly on its migrations. Flocks of Starlings are also believed to cross over from the south-west of Scotland to Ireland, where, as previously stated, the bird is best known as a winter visitor. On our coasts during the period of migration the Starling is often seen at the lighthouses, and numbers perish by dashing against the lantern, dazzled by its glare.

The adult male Starling in full breeding-plumage is a very handsome bird. Almost all the small feathers are dark metallic purple or green, those on the upper parts below the nape having arrow-shaped buff tips, most conspicuous on the sides of the rump, but almost obsolete on the centre of the back. The underparts are unspotted, but the uncler tailcoverts have broad buff edges. The wings and tail-feather's are brown, with broad glossy black margins. The distribution of the purple and green on the small feathers is subject to some variation; but gencrally the entire head except the ear-coverts, the nape, upper breast and upper back, and the flanks are purple-the ear-coverts, scenpular's, lower back, rump and upper tail-coverts, the lower breast, aud belly being green; but by altering the position in which the bird is held, green reflections to a limited extent may often be seen on the purple feathers and purple reflections on the green ones. Examples, however, occur, even in the British Islands, in which this distribution of colour is exactly reversed, except that the greater and median wing-coverts always show some green reflections. The wing-coverts occasionally show bluish-purple reflections, but are never iridescent bronze like those of $S$. purpurascens. There seems to be no reason to suppose that any of these variations in the colour of the plumage are produced by interbreeding with the latter species, as they appear to occur irrespective of geographical distribution. The Starling's bill is lemonyellow; legs and feet reddish brown; irides hazel. After the autumn moult, the bird presents quite a different appearance. All the metallic colour's of the plumage are half concealed, in consequence of each feather of the upper parts having a buff tip and those of the underparts a white tip, whilst the wing and tail-feathers have buff margins; the bill has changed to dark brown. As the spring approaches, these margins are almost entirely cast from the head of the male, and usually completely so from the underparts. The female somewhat closely rescmbles the male; but the tints are usually not so purple, the spots are much larger and do not abrade so much, and the long hackle-like feather's on the throat are less developed. In the female the bill is yellow, tipped with blackish brown.

VOL. II. 
The young differ still more in appearance from their parents--so much so that they have becu crromeously described as a distinct species under the name of Turdus solitarius. 'They have the general colour greyish brown, much paler on the margins of the feathers of the throat and belly; the quill- and tail-feather's have light brown margins. This brown plumage is changed during the first antumm for the showy dress of the parents; and in the moult, when the feathers are in process of being changed, these young birds present a very singular piebald appearance.

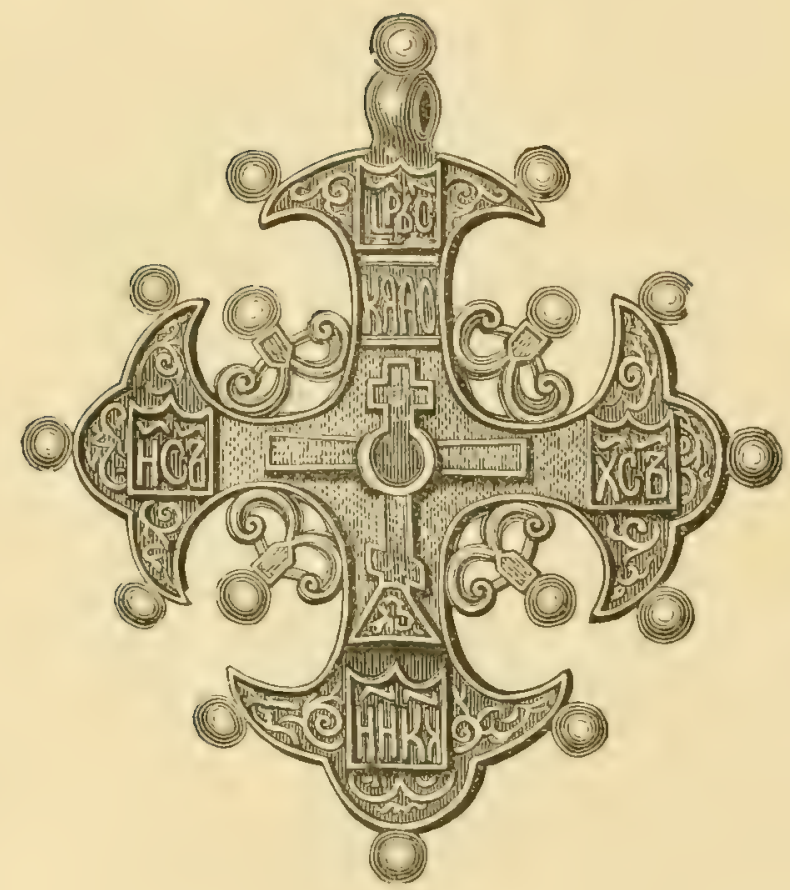




\section{Genus PASTOR.}

The Rose-coloured Starling was included by Linnæus and Brisson in the genus Turdus. Scopoli removed it into the genus Sturnas; but in 1815 Temminck somerwat unnecessarily placed it in a separate genus. In the first edition of his 'Manuel d'Ornithologie,' p. 83, he invented the genus Pastor, where the Rose-coloured Starling reigns supreme as the typical and only species. The characters which distinguish this genus from Sturnus are of the most frivolous kind: the upper mandible is not quite as straight, the nostrils are rather more concealed by feathers, and the head is furnished with a crest. In its habits, food, and nidification the Rose-coloured Starling differs very little from the so-called true Starlings.

The Rose-coloured Starling is confined to the southern portions of the South Palæarctic Region during the breeding-season ; but in winter wanders into the Oriental Region. 


\title{
PASTOR ROSEUS.
}

\section{ROSE-COLOURED STARLING.}

\author{
(Plate 11.)
}

Turdus merula rosen, Briss. Orn. ii. p. 250 (1760).

Turdus roseus, Linn. Syst. Nat. i. p. 294 (1766); et auctorum plurimorum(Scopoli), Latham, Gmelin, (Bonaparte), (Temminck), (Degland \& Gerbe) (Salvadori), (Newton), (Dresser), \&c.

Sturnus roseus (Limn.), Scop. Ann. I. Hist. Nat. p. 130 (1769).

Turdus seleucis, Forskial, Descr. Animal. p. vi. no. 16 (1775).

Sturnus asiaticus, Wirsing fide Lath. Ind. Om. i. p. 344 (1790).

Pastor roseus (Linn.), Temm. Man. d' Orn. p. 83 (1815).

Psaroides roseus (Limn.), Vieill. Analyse, p. 42 (1816).

Merula rosea (Lim.), Koch, Syst. baier. Zool. p. 242 (1816).

Acridotheres roseus (Linn.), Rañ. Elementi di Zoolog. iii. pt. v. p. 177 (1823).

Gracula rosea (Limn.), Cuv. Règne Anim. i. p. 378 (1829).

Pastor peguanus, Less. Bélanger's Voy. Ind. Orient., Zool. p. 268 (1834).

Pecuarius roseus (Limn.), Temm. Man。 d'Om。 iii. p. 76 (1835).

Thremmaphilus roseus (Limo), Macrill. Brit. B. i. p. 613 (1837).

Nomadites roseus (Lim.), Peteniv fide Bonap. Cat. Met. Uc. Eur. p. 44 (1842).

Although this handsome bird has been often shot in our islands, it can only be looked upon as an accidental visitor of frequent occurrence. The Rose-coloured Starlings which reach our shores are principally birds of the year on their first autumn migration, who have lost their way, and have wandered into Western Lurope instead of migrating eastwards into India. Willughby and Ray were apparently unacquainted with the occasional visits of this bird to our islands, and copy the account given of it by Aldrovaudus. The first British-killed example of which we have auy record was the one described by Edwards in 1743, which was killed at Norwood, near' London, and was fig'ured in his 'Natural History' (i. 1) '20, pl. $\left.x x_{\circ}\right)$. He quaintly tells us that "we may see this bird very perfect, curiously stufied and set on a perch at Salter's coffec-house in Chelsea." It is muecessary to enumerate the many examples that have since wandered to our shores. It has occurred in almost every county of England, principally in those bordering the east coast; but cxamples have repeatedly been obtained in the extreme west, in IVales, in Cormwall, and the Scilly Isles. In Scotland, although it has not yet been noticed in the outer islands, it appear's to have occurred in almost every county from Wigtownshire to Sutherland in the west, and from the Orkneys and Shetland to Berwichshire in the east. In Ireland the bird, although quite as uncertain in its appearance as in England, has nevertheless been met with in most parts of the country, even in the extreme wester'n districts. Müller 
states that it has twice been killed on the Faroes; but its occurrence in Iceland has not yet been noticed.

Like the Waxwing, the Rose-coloured Starling is preeminently gregarions in the brecding-season; and, like that bird, it seems to vary its nesting-locality according to the abundance of food, generally selecting some district where locusts and grasshopper's abound. It breeds more or less regularly in Asia Minor and on the western shores of the Black Sea. The most westerly recorded instance of its breeding in large numbers is in Lombardy. At Villafranca, near Verona, in 1875 great numbers bred in the castle, having followed in the wake of a flight of locusts. They have not been known to breed in Palestine; but Tristram describes enormous numbers passing through on their spring migration. Eastwards they breed in South Russia and the Caucasus, Turkestan, and South Siberia, as far east as Lake Saisan. They have also been observed in North-west Persia and Afghanistan in spring. They winter in India in cnormous numbers, and are occasionally found as far south as Ceylon. The most easterly locality recorded of this bird is the Andaman Islands, where flocks were seen by Col. Tytlcr in January ('Ibis,' 1867, p. 331). At this season of the year, and on the spring and autumn migrations, they have occurred in almost every country of Europe, from Spain in the west to Sweden in the north, and have been known to stray as far south as North Africa, one or two cxamples having been recorded from Egypt and Algeria.

The Rose-coloured Starling, like the Black-headed Bunting, is one of the few birds which migrate east in autmmm. The natural inference to be drawn from this fact is that when its habits of migration were formed it was exclusircly an Asiatic species, which has gradually extended its breeding-range westward in comparatively modern, that is in post-glacial, times. Amongst Aretic birds, the Petchora Pipit (Anthus gustavi) and theAretic Willow-Wren (Phylloscopus boreulis) migrate in the same direction, probably from similar causes. The Rose-coloured Starlings are very late breeders. They scldom arrive at their breeding-quarter's before the end of May, and do not begin to breed until the middle of June. They migrate in enormous flocks. During his last visit to Palestine Canon Tristram had the good fortune to cross the line of migration of these interesting birds. His party were travelling in a north-easterly direction across the plains of Syria, in the valley of the Orontes; and for three days, during the last week in May, flock after flock of Rose-coloured Starings passed them, flying due west. They chattered incessantly as they flew; and sometimes the noise of the myriads of voices, as the flock passed over, was quite deafening. Whey fly in dense clouds like Starlings, and Canon Tristram describes them as forming into a balloon before alighting. The party had just crossed some acres of young locusts, which "lose at every 
step of their horses, like sand-lice on the sea-shore from a piece of seaweed left by the tide." After they had passed they saw "a great globe in the air, which suddenly turned, expanded, and, like a vast fan, descended to the ground," which was in a few seconds covered with a moving black mass, dappled with pink. After watching them for some minutes, the party turned back and rode up to them. They rose quietly, but not till they were close on them. So eager had the birds been in search of their prey that not a locust was to be seen. At another place the party came suddenly, after mounting a gentle ascent, on the crater of an extinct volcano, full of water, and surrounded with basalt boulders. As they approached, their attention was attracted by one of these flights of Rosecoloured Starlings, which had alighted to drink, and which rose in alarm and darkened the air overhead. At another place a solitary tree over a well was so covered with them that the colour of the tree changed from black to green as they approached and frightened the birds away. The natives all declared the visits of these birds to be most uncertain and occasional, and said that they had not met with them for three years. They only sce them on the spring migration, when their flight is always from east to west. Canon Tristram adds that they were all apparently in full breeding-plumage.

The mystery which for some time shrouded the breeding of the Rosecoloured Starling has been at length completely dispelled. The old stories of their breeding in hollow trees, and the modern Greek or Bulgar fables of their boring holes in banks like Sand-Martins, are entirely unsupported by evidence. The Rose-coloured Starling is essentially a Rock-Starling in its breeding-habits. When I was in the Dobrudscha in the spring of 1883, I visited a village about three miles north of Kustendji, where these birds had bred in great numbers the preceding year. They had occupied a pile of rough building-stone, most of which was, unfortunately, removed during the following winter. A small heap near a cottage still remained, and I was informed by the peasant who lived there that it had been full of nests. After removing a few stones from the top I soon came upon the old nests. They were more carefully made than those of the Starling, and might easily have been mistaken for nests of the RingOuzel; they were chiefly composed of dry grass, but in several of them a few feathers were interwoven. Mr. Barkley, in his 'Bulgaria before the War,' describes two similar breeding-places between Rustchuk and Tarna, where thousands took possession of a mound of broken stone and rock thrown out of a cutting on the railway. In several parts of the Dobrudscha I met German emigrants from Bessarabia who told me that the Rose-colomed Starling not unfrequently bred in thousands in the peasants' gardens, which are surrounded by rough stone walls, in the holes of which the nests are made. These birds also often breed between 
Tchermavoda and Kiustendji ; but I had the misfortune to drop upon a blank year. The railway from Tchernavoda to Medjidi is across a series of swamps full of reeds some twelve fect high. Ducks and Geese come down here to feed, and the Great Reed-Warbler and the Bearded Tit make the reeds their home. Now and then a Purple IIcron, a Stork, or a Demoiselle Crane gets up, and Marsh-Harriers range over the swamp. On the out skirts of the reed-hed luxurious grass grows, leading up to perpendicular cliffs from 50 to 100 feet high. Some of these are white chalk, and some consist of a buff calcurcous conglomerate; but most of the cliffs are sandy earth, full of Bee-eaters' holes. The valley is about a mile wide, and has evidently within a comparatively recent date, geologically speaking, been the main mouth of the Danube. The lakes north and south of Kustendji are as evidently the silted-up mouths of the various arms of the river which formed the ancient delta of the Danube, which was probably destroyed by the drifting sand driven by the east winds from the shores of the Black Sea. Where the cliffs are rock the action of the water, and possibly of the ice, has hollowed them into caverns and ledges and holes, usually tenanted by Jackdaws, Starlings, Tree-Sparrows, and Rollers, and every two or three years by Rose-coloured Starlings. In driving across the steppes between the Dauube and the Black Sea we now and then came upon small flocks of these birds. At a distance they are indistinguishable from Common Starlings; they run along the ground in the same way, they have the same rapid straight flight, and the same habit of clustering together. On the ground they feed with the same eager anxiety, but frequently perch on the stunted bushes, when their pink colour is very conspicuous. The notes of this bird are almost exactly the same as those of the Starling, they chatter together in the same way; and in confinement the low warble mixed with the chatter is very similar in both species. In most places where this bird breeds it is protected on account of the enormous number of locusts it devours. In autumu it takes its toll on the fruit (mulberries, cherrics, \&c.) ; but its usefulness in spring is so apparent, that the Greeks and Turks do not begrudge it so small a trifle. In Asia Minor, as in the Dobrudscha, I had the misfortune to arrive the day after the fair. Dr. Krüper and I were informed by our friend Guido von Gonzenbach that the Rose-coloured Starlings had bred in the previous spring (18\%1) in enormous numbers in the neighbourhood of Smyrna, and had deroured the grubs and locusts to the admiration of the peasantry. They fixed upon some village unknown as a central breeding-place, and more than 200 of their eggs were brought in to Mr. Gonzenbach; but all his information being Greek, he was unable to find the locality. After many inquiries we succeeded in discovering it amongst the hills. It appeared to be deserted, not a soul could we find; everybody was down in the valley harvesting. At last we met an old man travelling with a mule, 
buying up fleeces of sheep from the peasants. He told us that he had travelled all the country round, and could assure us that there was not a bird to be found of the kind we sought. He told us that last year the birds swarmed in thousands in the valley below, and had built nests like Blackbirds' in the elefts of the rocks and on the stony ground on the steep hill-sides. That year (1872) he said that they had arrived in great numbers, but at the expiration of a week had suddenly disappeared. A very interesting account of the breeding of these birds in the same district sixteen years previously is to be found in the 'Zoologist' for 1857, p. 5668, translated from an article in 'Naumannia' by the Marquis O. Antinori. IIe and Mr. Gonzenbach did not discover the locality until the young had left the nests. The birds arrived during the last week of May, and fresh eggs must have been laid about the 10th of June; but by the end of that month the young had left the nest, and by the middle of July both old and young had left the locality. The breeding-place was a rocky mountain-side, and long before it was reached they noticed that every rock and stone was corered with the white droppings of the birds. The nests were in thousands, some quite open and uncovered, others so concealed amongst the blocks of stone that it was necessary to turn the rocks over to find them. Some were more than a foot below the surface, and others beyond arm's length. The nests were often so close together as to touch one another; they were carelessly made of dry stalks and leaves, oceasionally lined with fine grass. Many eggs were laid on the bare ground. The great number of birds naturally attracted many enemies; and the remains of birds were lying abont in all directions which had fallen a prey to jackals, martens, wild eats, rats, \&c. In these ravines the oleander is rery common; and a small flock of Rose-coloured Starlings often suddenly becomes invisible as it drops on one of these shrubs, the pink backs and breasts of the Starlings being scarcely distinguishable from the pink flower's of the oleander. During the breeding-scason the females of the Rose-coloured Starling sit very close and are assiduonsly fed by the males; and during the short time that the young are in the nest they are most carefully tended by both parents. They are said to take pleasure in killing locusts even when their appetites are satisfied.

In the 'Zoologist' for 1878, p. 16, is a most interesting account of the visit of these birds in $18 \% 5$ to Villafranca, translated from the Italian of Edoardo de Betta. About four o'clock in the afternoon of the 3rd of June about a score Rose-coloured Starlings arrived at the castle, and were followed in about half an hour by a much larger flock of perhaps a luundred birds. Towards evening some thousands arrived, and at dusk dispersed in flocks orer the country. The next day the numbers increased to albout fourteen thousand; and they soon ejected the Common Starlings, Swallows, Sparrows, and Pigeons from the holes in the battlements of the 
castle. The following day these holes were cleaned out, and nest-building began on the 5th. It was not until the 17 th that it was ascertained for certain that eggs had been laid; but by the 1-th of July the young were scen migrating with their parents, and soon afterwards the birds had all disappeared. The nests were described as roughly composed of small sticks, little branches, stratrs, hay, grasses, and other dry herbs disposed in a shapeless mass, with a limited hollow space in the midddle to contain the eggs, and irregularly lined with herbaceous fibres, leaves, mosses, and feathers. The males went out to feed in small parties, returning together.

The Rose-coloured Starliug arrires in India carly in August, and appears in some districts in such mumbers as to be injurious to the crops of white "Jowaree," and before it leaves in spring it fects on the fruit of the mulbcrry. During the cold season it eats insects of various kinds, the seeds of grasses and plants, and any kind of fruit it can obtain.

The eggs of this bird vary from five to seven in number, and are so palc a grey in colour as to be scarcely distinguishable from white; they are very fine-grained, smooth, and glossy, and vary in length from $1 \cdot 15$ to 1.07 inch, and in breadth from .83 to 8 inch.

The male Rose-coloured Starling is a very conspicuous bird, with the head, neck and breast, wings and wing-coverts, axillaries, tail, upper and under tail-coverts, and thighs glossy black, the head, neck, and breast with purple reflections, and the wings and tail with green reflections, the rest of the upper and underparts being a delicate rose or salmon-colour. Beak rose-coloured, dark at the base; legs, feet, and claws dull brown; irides rich brown. The female is ererywhore duller in colour. This bird only moults once in the year, in autumn, when almost every feather is margined with pale brown, so that the whole bird looks brown, with black wings and tail. The breeding-plumage is assumed by casting the brown margins of the feathers. Young in first plumage are very similar to adults in autumn, but have paler wings and tail, and are without the concealed black or rose-coloured bases to the feathers; they are very similar to the young of the Common Starling, but are much paler in colour. The adult plumage is assumed in the first September by a moult.

Three species belonging to the subfamily Icterinæ have been known to visit this country. This subfamily is intermediate between the Sturnine and the Fringilline, and is strictly confined to the American continent. Of the first of these, the Red-rringed Starling or Red-rwinged Oriolc (Ageleus phoniceus), nearly a dozen examples have occurred in the British Islands; but as it is a very common cage-birt, it is probable that most of them had escaped from confinement. This species appears to be found throughout North America as far north as the Great Slave Lake. In the south it is a resident, but in the north it is a migratory bird, and it is 
possible that occasional examples may have gone astray on migration and wandered as far as Europe. In winter they are gregarious, but in spring they pair and separate for breeding-purposes. The nest is usually placed on low bushes, but occasionally in high trees and sometimes on the ground. It is pensile, the framework, usually made of rushes and the strong leaves of the iris, being carefully and strongly interwoven with the adjacent twigs. The inner nest is composed of grass and sedges. The number of eggs is said to be five, varying considerably in size from 1.08 to 9 inch in length, and from 82 to 65 inch in breadth. The ground-colour varies from greyish white to pale greenish blue, sparingly but generally very boldly blotehed and streaked, principally at the large end, with very dark brown; the underlying spots are very indistinct (Plate 11). In summer these birds feed principally on insects, but in autumn they commit great havoc amongst the grain-crops. Wilson describes their notes as " not remarkably various, but very peculiar; the most common one resembles the syllables conknquer-ree, others the shrill sounds produced by filing a saw, some are more guttural, and others remarkably clear. The usual note of both male and female is a single chuch." The male Red-winged Oriole is black, with crimson shoulders and lesser wing-coverts; the female is brown, streaked on the upper parts with buff and on the lower parts with white.

Of the second species, the Rusty Grakle (Scolecophayus ferrugineus), a single example was obtained near Cardiff on the 4th of October 1881 (Proc. Zool. Soc. 1881, p. 968). This species breeds in the arctic regious of America $u p$ to the limit of forest-growth. It passes through the Northern States on spring and autumn migration, where a few remain to breed, and winters in the Southern States. In its habits, food, and mode of constructing its nest it is said to resemble very closely the Redwinged Oriole. The eggs are light bluish green in ground-colour, spotted and blotched with purplish brown of various shades, and very rarely streaked with rich brown (Plate 11); they measure from 1.02 to 98 inch in length, and from 82 to .75 inch in breadth. The notes of this bird are said to be musical and more melodious than those of the allied species. The male Rusty Grakle has the general colour black, with green and purple reflections. After the autumn moult the broad brown margins to the feathers give the bird a very dingy appearance. The female is blackish grey, the wings and tail sometimes having a greenish tinge.

Of the third species, the American Meadow-Starling (Sturnella marma), one was seen in Norfolk in October 1851, and another was shot in Suffolk in March 1860, whilst a third was obtained near Cheltenham. It is common in the Eastern States of North America, being migratory in the north and more or less gregarious in winter. In the west it is represented by a nearly allied form, which is only subspecifically distinct, S. magna, var. 
neglecta. It frequents pasture-lands, being very rarely found in woods. It is celebrated for the sweetness of its song. The nest is domed, and always built on the ground. This bird lays four or five eggs, white in ground-colour, spotted all over, but principally at the large end, with conspicuous reddish-brown blotehes; the underlying spots are generally somewhat indistinct, but occasionally they form an important feature in the egg and are slate-grey (Plate 11 ). They vary in length from 1.2 to 95 inch, and in breadth from 9 to 68 inch. It is said to feed both on insects and seeds. The male Meadow-Starling is pale brown, spotted and barred with dark brown and reddish brown; the lores, the breast, and belly are yellow, with a conspicuous black crescent below the throat. The female is slightly duller in colour.

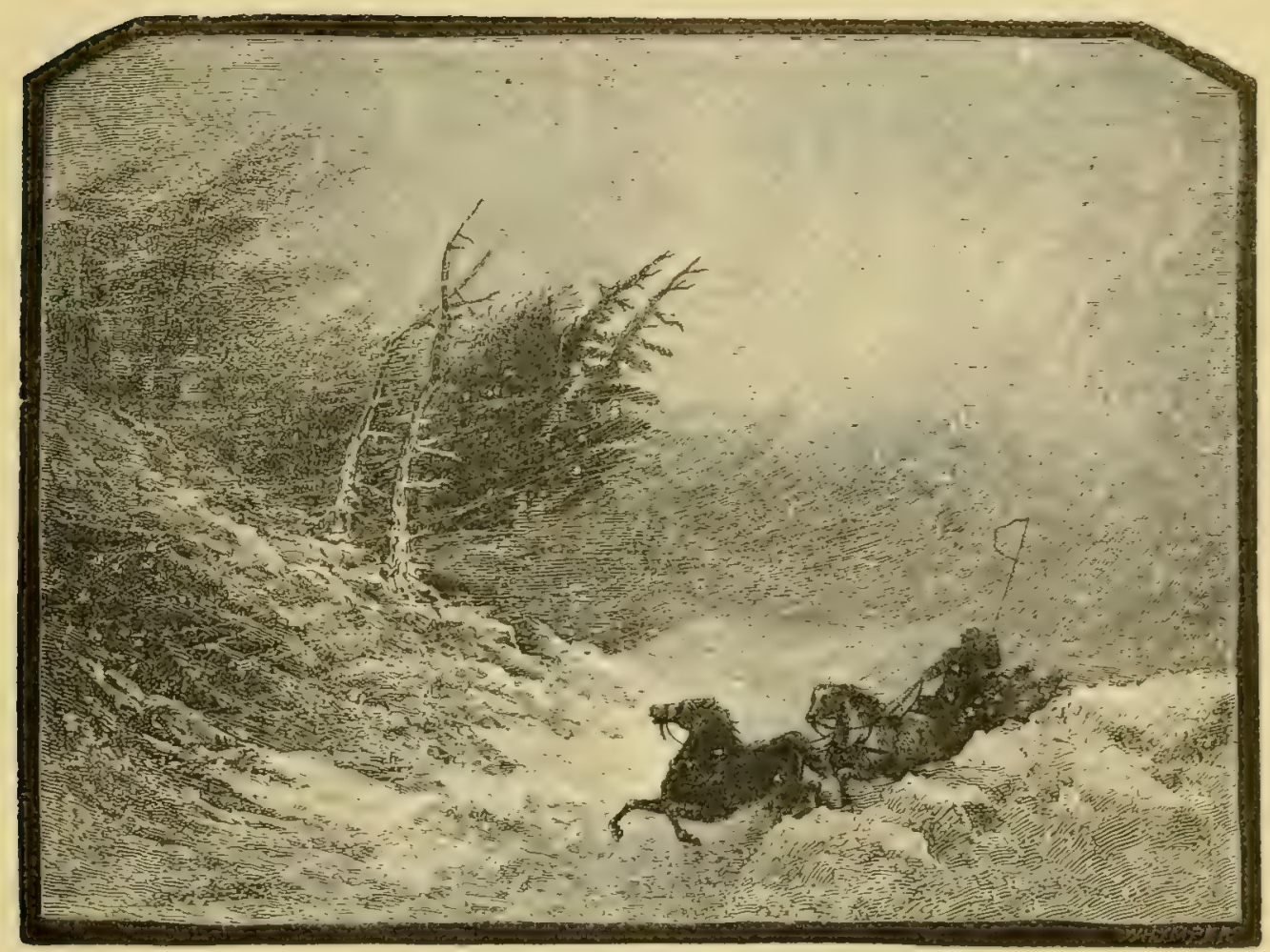




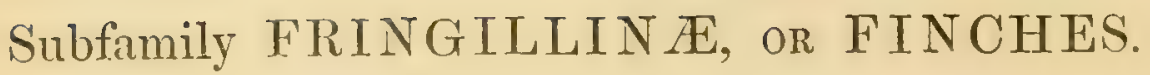

The Finclies form a large group of birds, which may at once be distinguished from all the other subfamilies of the Passerida by their combination of a stont conical bill with the cntire absence of a first primary. The wings are long and pointed, the second, third, and fourth primaries being nearly equal in length. The tarsus is short and scutellated in front, but not at the back.

The Finches only moult once in the year, in autumn. The spring plumage, where it differs from that of autumn, is attained by casting the ends of the feathers and the small, so to speak, pinnules of the leaflets or pinnre, and sometimes by a simultancous increase of brilliancy in the colour of the feather itself. The plumage of the young is more spotted and streaked than that of adults, but is moulted in the first autumn.

The Fringilline are almost cosmopolitan, being found throughont the world except in the Australian Region, where they are represented by the Weaver-birds (Ploceinie), which are also found thronghout the tropical regions of the Old World. There are upwards of 500 species of Finches, which have been divided by ornithologists into upwards of seventy genera. The characters of most of these are, however, of such a trivial nature that to retain many of them, even as a matter of courtesy to their founders, rould only bring the science of ornithology into contempt. In the present neglected state of this group of birds it is impossible to form any key to the genera. Sixty species of Finches are found in Furope, of which half are included in the British list.

\section{Genus LOXIA.}

The genus Loxia is recognized by Linnæus in the trelfth edition of his 'Systema Naturx,' i. p. 299, and consequently dlates from 1766. The Common Crossbill (L.curvirostra) has by common consent been accepted as the type. It is the Loxia loxia of Brisson, and the first species named by Linnieus, though the IIawfinch, the Grosheak, the Bullfinch, and other more distantly allied birds are included in the same genus. 
The chief characteristic in the present group of birds is their parrot-like bill, the upper mandible being curved to such an extent that it overlaps the under mandible at the point, in some species crossing its point. An almost equally important character is the change which takes place in the colour of the plumage from the young to the adult, beginning with green and passing through yellow into red.

This genus probably contains only four well-defined species, several of which are, however, subject to considerable local variation. The range of this genus is principally confined to the Palrearctic and Nearetic Regions, extending in the former to the Himalayas and in the latter to the Mexican plateaux.

The Crossbills frequent fir-, pine-, and lareh-forests during the brecdingseason; but at other times of the year they frequently haunt gardens, orchards, deciduous woods, and small plantations and shrubberies. After the breeding-season they are more or less gregarious and often associate with other birds. Their song is low and somewhat sweet, and their callnotes are harsh, but sometimes more musical. They breed very early, often before the suow is melted. Their nests are open and cup-shaped, made of twigs, moss, rootlets, wool, \&c., and placed at various licights in conifer trees. Their eggs are five or six in number, white or bluish white in ground-colour, spotted and blotched with reddish brown of different shades. Their food consists of seeds, fruits, berries, and insects of different kinds.

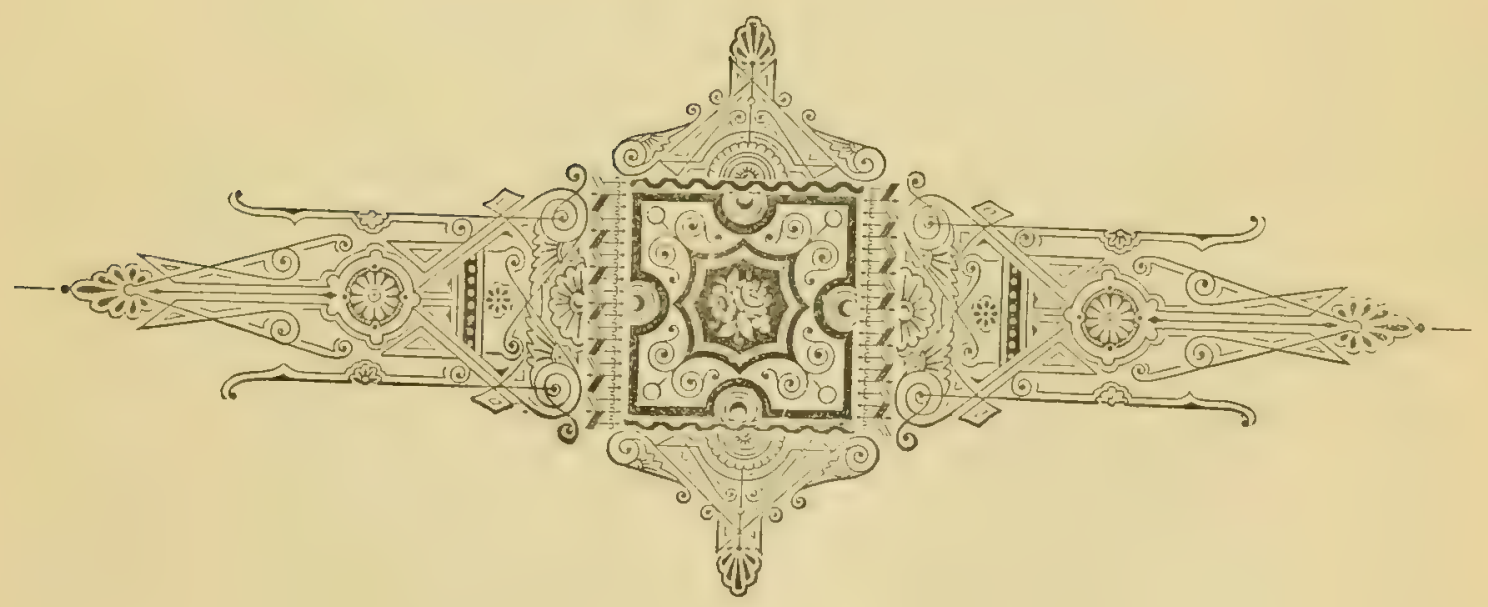




\title{
LOXIA CURVIROSTRA AND LOXIA PITYOPSITTACUS.
}

\section{CONMON CROSSBILL and PARROT CROSSBILL.}

\author{
(Plate 13.)
}

English ornithologists, having voluntarily cramped their ideas by putting on the straight jacket of a binomial nomenclature, have for the most part treated the Common and Parrot Crossbills as distinct species. The facts of nature do not warrant such a conclusion in the least. A large series of examples from Europe, Siberia, China, Canada, and Mexico show some differences in size, especially in the bill, which varies almost as much as that of the Lesser Redpole or the Reed-Bunting. Crossbills from the pine-forests of Europe have the largest bills; those from Mexico have nearly as large bills, but the upper mandible is slightly weaker. Examples from the larch- and spruce-forests of Europe and Asia have both mandibles weaker; whilst those from Canada have still smaller bills, and approach very near to the Himalayan Crossbill in this respect. The length of wing varies much less, being as under :-

\section{Length of wing. $\quad$ Height of bill.}

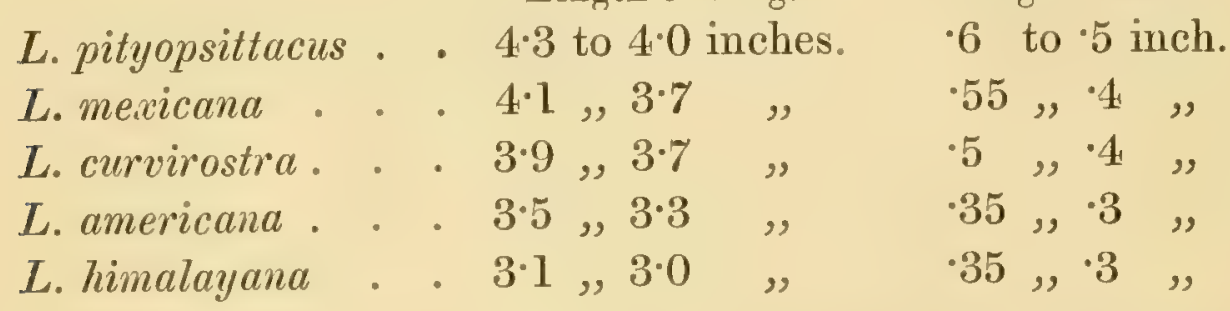

It is probable that in a sufficiently large series the measurements of each of these supposed species would be found to overlap that next to it, and that all these forms are conspecific and nothing but local races. It is not known that they differ in colour or in any other respect except in size, thickness of bill, and choice of food. The two lastnamed peculiarities are probably cause and effect. In 'Naumannia' for 1853, p. 78 , is a plate of twenty bills of Crossbills to illustrate a paper by Brehm, who attempts to discriminate between six species of Parrot Crosshill and eight or more species of Common Crossbill. Scotch examples are intermediate between the Parrot and Common Crossbills of the continent; they probably feed on both kinds of cones. The fact that the tropical form of the Old World is a small weak-billed race, whilst that of the New World is larger and stronger-billed than its northern representative, is probably also merely a question of food. The synonymy of the two forms which are found in our islands is as follows :- 


\section{LOXIA CURVIROSTRA.}

Comion Crossille.

Loxia loxia, Briss. Orn. iii. p. 329 (1760).

Loxia curvirostra, Linn. Syst. Nat. i. p. 299 (1766); et auctorum plurimorumGmelin, Scopoli, Latham, Bonaparte, Schlegel, Degland \& Gerbe,Temminck, Newton, Dresser, S.c.

Crucirostra europæa, Leach, Syst. Cat. Mamm.\&c. Brit. Mus. p. 12 (1816).

Crucirostra abietina, Meyer, Vög. Liv- u. Esthl.p. 72 (1815).

Loxia europæa (Leach), Macgill. Hist. Brit. B. i.p. 417 (1837).

Crucirostra curvirostra (Linn.), var. balearica, Homeyer, Journ. Orn. 1862, p. 256.

Crucirostra balearica (Homeyer), Homeyer, Joum. Orn. 1864, p. 224.

Loxia balearica (Homeyer), Nevoton, Zool. Record, 1864, p. 84.

Loxia albiventris, Swinhoe, Proc. Zool. Soc. 1870, p. 437.

\section{LOXIA CURVIROSTRA, VAR. PITYOPSITTACUS.}

\section{Parrot Crossbili.}

Loxia curvirostra, var. $\gamma$, Gmel. Syst. Nat. i. p. 843 (1788).

Loxia pityopsittacus, Bechst. Oin. Taschenb. p. 106 (1802); et auctorum plurimorum-Temminck, Bonaparte, Salvadori, Deyland \& Gerbe, Dresser, Newton, \&c.

Crucirostra pinetorum, Meyer, Vög. Liv- u. Esthl. p. 71 (1815).

Crucirostra pityopsittncus (Bechst.), Brehm, Tög. Deutschl. p. 241 (1831).

The Common Crossbill is a somewhat rare and local resident in our islands, but is best known as an irregular winter visitor, often appearing in large flocks; and at this season of the year it has either been obtained or seen in every county. In Scotland it is a resident in some districts, and, according to Mr. Gray, breeds most numerously in the central counties. It is also well known as a winter visitor, often appearing in immense flocks, although it is not known to have visited any of the outer islands. In Orkney it is less regular in its appearance; but in the Shetlands, especially of late years, it has been frequently seen in large numbers, and was said by Saxby to have visited the islands every year between May and December during his residence at Unst. Of its breeding in England much has been recorded; and nests have so frequently been discorered in various parts of the country, that it is needless to enter into a detailed account of them. It has been known to breed in Devonshire, Somerset, Ilants, Sussex, Kent, Surrey, Essex, Herts, Bedford, Norfolk, Suffolk, Gloucester, Yorkshire, Durham, Northumberland, and Cumberland. In Ireland, according to Thompson, the bird has long been known as an occasional visitor in late autumn or winter, leaving again early in the spring. He also states that it has bred there.

The Parrot Crossbill was first noticed as a British bird by Pennant in 
1766, in his 'British Zoology' (p. 106). He received a male and female "out of Shropshire." Upwards of a score examples of this bird have since Pemnant's day been taken in our islands. Most of these specimens have been captured in England, a few in Scotland, and one in Wales.

The typical form of the Crossbill brecds in most of the pine-forests of the Palcarctic liesion, in Norway occasionally ranging north of the Aretic circle, but in North Russia not ranging above lat. 61. , and in Asia probably not above lat. $62^{\circ}$. It breeds in the Pyrenees, the Alps, and the Carpathians, and probably also in the Urals; but it has not been recorded from the Caucasus. It is said to be a resident in the Balearic Islands, and in the Atlas Mountains in Algeria. It has not been recorded from Persia or Turkestau, nor did Fiusch or 'Tancrés collector find it in the Altai MLountains. It certainly breeds in Kamtschatlia, and probably also in other pine-regions in Eastern Siberia. In winter it is a very irregular migrant to most parts of Europe, having been obtained in Denmark, Holland, Belgimm, France, Spain, Italy, and Greece; but Sharpe and Dresser's statement, which Newton * appears to have copied, that Dr. Krüper found its nest in the Parnassus, is probably based on a mistranslation. Eastwards it winters in South Siberia, North China, and Japan, in which islands it is said to be very abundant; but ornithologists have omitted to say at what scason of the year.

The large form of the Common Crossbill, generally linown as the Parrot Crossbill, brecds principally in Scandinaria, the Baltic provinces, and North Germany. It does not appear to wander far in winter; but at this season it occasionally visits Denmark, Holland, France, Southern Germany, Switzerland, and Italy.

The Crossbill is one of the few migratory birds which do not wander further from home in winter than the inclemency of the season or the scarcity of food compels them. They have consequently been called gipsy migrants-irregular visitors who may be rery common one year and very rare the next, sometimes coming early, sometimes late, and sometimes not at all. They are preeminently gregarious birds. In winter they wander abont in large flocks; and even in the breeding-season small parties of males may be seen seeking food in company. They are very early breeders; and fresh eggs are usually found in February and March. Egos have becn taken in April and May; but these are probably laid by birds whose first nests have been destroyed by their numerous enemies or by heavy falls of snow, and are not second broods, as some ornithologists have supposed. If these birds are successful in rearing a brood, the family-party appear at once to commence their gipsy life. If

* Professor Newton appears also to havo copied Sharpe and Dresser's assertion that Swinhoe found the Crossbill on the island of Formosa, a statement for which $I$ am unable to find any authority. 
they meet a similar family-party they appear to fraternize at once, and form the nucleus of a flock, which is sometimes seen far from home as early as Jume, wandering in search of food. It is a very pretty sight to see these flocks feeding upon the berries of the mountain-ash, or stripping the larch or spruce trees of their cones. In winter they are exceedingly tame, and will allow the obscrver to approach very near and watch them without showing any signs of alarm. They are very active, and when busily engaged in feeding place themsclves in all sorts of positions, like a Tit or a Willow-Wreu. They pass from tree to tree with strong but undulating flight, continually calling to cach other. In late winter or early spring the males have a low warbling song, which reminds one somewhat of that of the Starling. The female is said al to to sing nearly as well as the male.

The note is short and clear, a loud shrill tsip, tsip, tsip, far louder than the similar notes of the Chaffinches and Limmets by which it is surrounded; it is subject to slight modulations, occasionally sounding almost like tsup, and sometimes like tsop. This note is principally uttered when the birds are on the wing, and is apparently the common call-note by which the flock is kept together. The call-note of the male to the female is quite as loud, but more prolonged; it may be represented by the word tso, occasionally modified almost to tsow on the one hand and to tsoo on the other. I hav : generally heard this note when the bird was sitting alone on or near the top of a pine tree. The valleys of the Upper Engadine are an excellent locality in which to wateh the habits of the Crossbill; they lie about six thousand feet above the level of the sea, and are hemmed in by mountains which rise to twice that height. Whenever the ground is smooth enough it is used as meadow, and where it is rocky it is covered up to the mouth of the glaciers with lareh trees intermixed with a few spruce-firs and Siberian cedars (Pinus cembra). It is impossible to walk through the forest from Puntresina to St. Moritz, even in August and September (a time of the year when birds are most skulking in their habits and almost silent), without seeing many birds specially interesting to the British ornithologist. At first, perhaps, the forest may look empty, not a bird to be seen or heard; for at this season forest-birds are not only gregarious but social, and you may perhaps have to walk a mile before you meet with the flock. Then all at once you hear the call-notes of Titmice and distinguish the Crested Tit and the continental variety of the MarshTit. Amongst them may be a few Chaffinches and Mealy Redpoles, and almost certainly a pair of Nuthatches and Creepers. 'The main flock will consist of Thrushes, principally Missel-Thrushes, feeding on the bilberries and other ground-fruit, and rising one by one from the ground as you disturb them. Then you may come across a small party of Nuteracker's, which are not nearly so shy as the Thrushes, and may be seen both in the 
trees, on the rocks, and on the ground. At last the loud tsip of the Crossbills is heard, and a small compact party of perhaps a dozen birds, conspicuous amongst the Thrushes by their smaller size and shorter tails, pass by, and you may remark the brick-red of the rumps of many of them, which glisten in the sum as they fly away. However tame the Crossbills may be in our country in winter (and I have approached them within a few feet and watched them feching undisturbed), in the Engadine in their summer-quarters they are wild enough. They associate with the Thrushes as Starlings do with Rooks, in a flock within a flock, and like them cover square yards of ground, whilst their companions spread over acres. Sometimes I saw an isolated wale or two flying orer the trees with rapid steady flight, but broken by continual short pauses, giving it an undulatory character. I found them extremely shy; and although I could slowly follow a flock of Thurushes for a mile, I never came again upon a flock of Crossbills when I had once put them up. I only once observed them on the ground; and this was in an open space in the forest abounding with ripe bilberries, upon which they probably had been feeding.

The bill of the Crossbill has become specially adapted for extracting the seeds from the cones of the lareh and various species of pine. The strongestbilled birds, to which the name of Parrot Crossbill has been applied, form a local race which live in the pine-forests and feed principally on the cones of the Scotch fir (Pimus sylvestris). The more slender-billed birds choose localities where spruce-fir and lareh cones are obtainable; they range further north during the breeding-season than their thicker-billed cousins-not because they are able to withstand a greater degree of cold but because the trees whose fruit form their favourite food are found further north. In the valley of the Ienesay the larch and spruce range to lat. $69^{\circ}$, whilst the Scotch fir only grows as far north as lat. $62 \frac{1}{2}^{\circ}$. The Crossbill breaks off the cone wich his beak and flies with it to a thick bough. The cone is held firmly againsi the bough with one claw, exactly as a Ripptorial bird holds its prey, and the cone is torn to pieces and the seed extracted with the bill, the outside covering or shell being removed and the kemel only eaten. The Crossbill also feeds on many other seeds, and is very foud of apples. Meves found them feeding in South Sweden on the caterpillar and chrysalis of a small green moth (Tortrix viridana) which is very destructive to oak trees, and it is said that the Crossbill generally feeds its young upon insects.

The nest is generally placed in a pine tree of some kind, occasionally not more than five fect from the ground, but more often at a much greater elevation. The favourite position seems to be almost at the top of the tree in the cup formed by the forking of the branches; but it is not unfrequently built on a horizontal branch at some distance from the trunk. It is formed on the same model as the nest of the Bullfinch, an outside 
nest of sticks, and an inside nest of soft material, the latter rising somewhat higher than the former. The outside nest is made of twigs of Scotch fir, about $\frac{3}{16}$ of an inch thick, somewhat loosely interlaced together, and has an inside diameter of four inches, and an outside diameter of six inches or more. The inside nest is composed of dry grass and hair-lichen, with occasionally a little moss or wool or a few feathers in the lining; the cup has a diameter of $2 \frac{3}{4}$ inches, and is about $1 \frac{1}{4}$ inch deep. The usual number of eggs is four, but five are sometimes found; they vary in length from $\cdot 95$ to $\cdot 85$ inch, and in breadth from $\cdot 7$ to $\cdot 65 \%$. Eggs of the Parrot Crossbill do not differ in size from those of the Common Crossbill. The ground-colour of the eggs varies from pale grecnish blue to almost white. The overlying spots are dark brown, principally at the large end, most of them very small, but some as large as No. 10 shot, and many elongated into streaks; the underlying spots are pale reddish brown, but do not differ in size, shape, or distribution from the overlying spots.

The female sits very close, and is fed on the nest by the male. In confinement these birds are very amusing, climbing about their cages, both with claws and bill, like Parrots.

The general colour of the adult male Crossbill is intermediate between scarlet and crimson, somewhat shaded with brown on the back, and most brilliant on the rump. The wings, tail, longest tail-coverts, and hindmost ear-coverts are brown. The centre of the belly and the under tail-coverts are pale grey, the latter with dark centres. Bill, legs, feet, and claws brown; irides dark hazel. The adult female differs from the male in having the red replaced by greenish yellow. Males of the year are intermediate in plumage between adult males and females; in some examples the red feathers predominate, and in others the yellow feathers. Females of the year only differ from adult females in having much less yellow on the plumage. Young in first plumage of both sexes are plain brown, each of the sunall feathers having a dark centre; they moult in the first autumn into their respective plumage of males and females of the year.

The variation in the plumage of the Crossbill is a question upon which great difference of opinion has existed, and, strange to say, still exists amongst ornithologists who have had the best opportunities of forming a judgment on the matter. Bechstein and Hancock describe the males of the year as red, which gradually changes to yellowish green as in the adult and immature fomale. Wheelwright thinks that the red plumage of the male is only assumed after the second moult, but he looks upon it as an intermediate stage, though lasting through several scasons, between the mixed plumage of birds of the year and the yellow plumage of what he considers to be fully adult males. Naumann, Brehm, Wolley, Meves,

* Abnormally small egrgs may measure · 73 by 5.5 (fide Newton), but the egg's measuriug: 1 inch by $\cdot 75$ (see Dresser) are larger than any I have ever seen. 
and others hold an intermediate view, which appears to me to be the correct one. It cannot, however, be denied that, in confinement, red males change to yellow after their first moult, and only differ from females in not being quite so green; they never reassume the red plumage. Yellow males occasionally occus in a wild state, and are possibly old and barren birds.

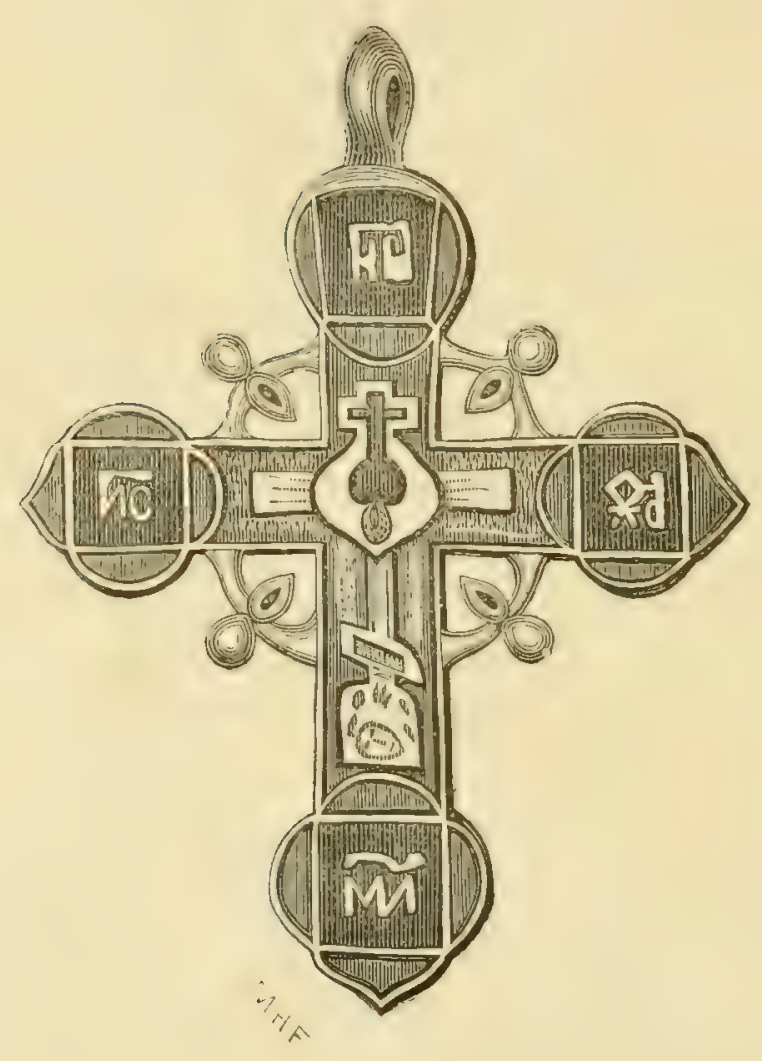




\title{
LOXIA BIFASCIATA AND LOXIA LEUCOPTERA.
}

\section{EUROPEAN WHITE-WINGED CROSSBILL and AIIERICAN WHITE-WINGED CROSSBILL.}

\author{
(Plate 19.)
}

The two White-winged Crossbills are so nearly allied that many ornithologists have considered them to be specifically identical. The points relied upon to distinguish them are as follows:-The birds of the Old World are said to be larger and to have a stouter bill. This is, on an average, undoubtedly the case. European examples vary in length of wing from $3 \cdot 8$ to $3 \cdot 4$, whilst those from America only measure 3.5 to 3.2 inches. The average height of the bill in European examples is 4 and that of Americau examples 3 inch. The scapulars and the middle of the back of European examples are dark red with brown centres in the adult male, whilst the same feathers are nearly uniform very dark brown in American examples. European examples are said to have the tail less forked than in American birds; but I cannot find the slightest difference in this respect. Our birds are also said to have more distinct white edges to the tail-feathers; but, so far as my observations go, I find that newly moulted birds from both localities have equally white edges, which disappear in both forms before the next autumn. It is also stated that the red of the adult male inclines to scarlet in the European bird and to crimson in the American; but this appears to be an unreliable character, the former being probably younger or less vigorous birds. It is not known that there is any difference whatever in the notes or habits of the two forms, and it will perhaps be best to treat them as local races of a common species. The synonymy of the two races is as follows:-

\section{LOXIA BIFASCIATA.}

European White-Winged Crossbill.

Crucirostra bifasciata $B r e h m, I s i s, 1827$, p. 714 ; et auctorum plurimorumBonaparte, Degland \&. Gerbe, Taczanowsky, Newton, Dresser, \&c.

Crucirostra tænioptera (Gloger), Brehm, Isis, 1827, p. 716.

Loxia tænioptera, Gloger, Isis, 1827, p. 419.

Loxia bifasciata (Brehm), Selys-Longch. Faun. Belge, p. 76 (1842).

Loxia leucoptera, Gmel. apud Middendorff, Schrenck, Radde, \&c.

\section{LOXIA LEUCOPTERA.}

American White-winged Crossbill.

Loxia leucoptera, Gmel. Syst. Nat. i. p. 844 (1788); et auctorum plurimorumTemminck, Audubon, Bonaparte \&. Schlegel, (Wilson), (Baird), Gould, Newton, \&c, 
Loxia falcirostra, Lath. Ind. Orn. i. p. 371 (1790).

Curvirostra leucoptera (Gmel.), Wils. Am. Oin. iv. p. 48, pl. xxxi. fig. 3 (1811).

Crucirostra leucoptera (Gmel.), Brehm, Isis, 1827, p. 720.

The first recold of the occurrence of the European White-winged Crossbill in the British Islands is that of Templeton, who, in a communication to the Linmean Society, stated that a specimen had been shot at Grenville, near Belfast, on the 11th of May, 1802. Although the specimen has apparently been lost, a coloured drawing of it is still in existence, and assisted Thompson in his identification of the species. In 1843 Mr. Rold records, in the 'Zoologist' for that year' (p. 142), a second specimen killed a few years previously at Larrigan, in Cornwall.

In the autumn of 1845 there appears to have been a remarkable migration of European White-winged Crossbills to this country; for a female was shot out of a flock of about fifteen near Brampton, Cumberland, in November, and two or three others were killed about the same time and place (Hancock, Cat. Birds Northumb. and Durh. p. 50). They appear to have remained in this country during the winter; for in May 1846 a flock was seen at Thetford, in Norfolk, and one specimen was killed, whilst a second was obtained in the neighbourhood of Bury St. Edmunds *.

Another specimen, a young bird, is recorded by Yarrell as having been shot about this time by Doubleday in his garden at Epping. A second example occurred in Ireland in 1868, and was mentioned in the 'Zoologist' for that yenr (p. 13\%6) by Mr. Blake Knox. It was obtained in county Dublin in July or August. The oceurrence of this species in Scotland is very doubtful, as the " Whitc-winged Crossbills" which have at various times been obtained there have not been sufficiently well identified.

Owing to the imperfect identification of the species, it is difficult to determine the exact number of specimens of the American form of the White-winged Crossbill which have found their way to our shores. As this species is said to be common throughout the year in Newfoundland, and is occasionally found in Greenland, it may reasonably be expected to visit our northern coasts. The earliest known instance of its occurrence in the British Islands is that of a female now in the Strickland collection, Cambridge, and which was obtained near Woreester in 1838 (Salvin, Cat. B. Strickl. Coll. p. 203). In 1815 Mr. E. B. Fitton cxhibited, at a meeting of the Zoological Society, a second example, an adult male found by him on the shore at Exmouth on the 1\%th of September of that year. A third specimen, a female, was caught in the rigging of a ship which came into

* The occurrence of several examples of this species at Drinkston, in Suffolk, in 1849 (Bree, 'Zoulogist,' 1849, p. 2419), quoted by Harting in his 'IIandbook of British Birds,' p. 116, is a myth, the record probably referring to the birds mentioned above as liilled in that district in 1846 . 
the port of Yarmouth, and was bought alive by Mr. G. H. Gurney in October 1872. Gray, in his ' Birds of the West of Scotland,' mentions a specimen shot, in February 1841, near Jedburgh, and also the occurrence of a great number, "twelve or fiftcen years ago," at sea, seen by Dr. Dewar "crossing the Atlantic before a stiff westerly brecze." Many alighted on the steamer when about 600 miles cast of Newfoundland, and several were captured and brought to this country. In addition to these occurrences, Saxby, in his 'Birds of Shetland,' states that he shot two Crossbills at Halligarth on the 4th of September 1859, which he refers to the American species.

The European White-win ged Crossbill appears to have a somewhat more northerly breeding-range than the Common Crossbill. Henke records it as a common resident near Archangel, and it probably breeds in the Urals. Middendorff says that it is especially common in the valley of the Yenesay, and was the only Crossbill observed between lat. $63^{\circ}$ and the Arctic circle. Dybowsky is satisfied that it breeds in the mountains near Lake Baikal; Middendorff met with it on the Pacific const in lat. $55^{\circ}$, in June. In winter it wanders into South Sweden, Denmark, Poland, Germany, and has been recorded from Holland, Normandy, Switzerland, the Tyrol, Lombardy, and Hungary.

The A merican White-ringed Crossbill breeds across that continent from Alaska to Labrador. It has becn obtained in Greenland, and occasionally winters in the northern States. It has never been found in Europe, except in the British Islands, and possibly in Heligoland.

The history of the White-winged Crossbill, so far as it is known, is a repetition of that of the Common Crossbill. Like its near ally, it is a very early breeder, and collects into flocks in summer, which wander south in winter. It fecds principally on the cones of larch and spruce, but in confinement is very fond of apples. In a cage thcy are described as clinging to the sides and top with their feet, and as apparently enjoying to walk with their heads downwards. Both male and female sing well; their note is said to be very plaintive, and to resemble the call of the Bullfinch.

Very little appears to be known respecting the nidification of this bird. A nest of the American form, obtained by Dr. A. Adams at Fredericton, New Brunswick, in 1868, is described by Messrs. Baird, Brewer, and Ridgway as "deeply saucer-shaped, and composed of a rather thin wall of fibrous pale-green lichens encased on the outside with spruce-twigs and thinly lined with coarse hairs and shreds of inner bark. Its cxtcrnal riameter is a little less than four inches, the rim being almost perfectly circular; the cavity is an inch and a half deep by two and a half broad. The one egg is pale blue, the large end rather thickly spattcred with black and ashy lilac, is regularly or rather slightly elongate oval, the 
small end rather obtuse. It measures .8 inch in length by 56 in breadth." A nest of the European species, obtaincd through Mr. Craemers at Archangel, is described by Dresser as closely resembling that of the Common Crosshill, hut smaller and somewhat slighter in structure. He also remarks that the eggs are rather darker in ground-colour than those of that species, and are smaller in size, but otherwise closely resemble them.

The White-winged Crosshill is specifically distinet from the Common Crossbill, though its only difference appears to consist in having the greater and median wing-coverts broadly tipped with white. The difference between the seres is alike in both species, and the males of both appear to change colour with age in exactly the same way.

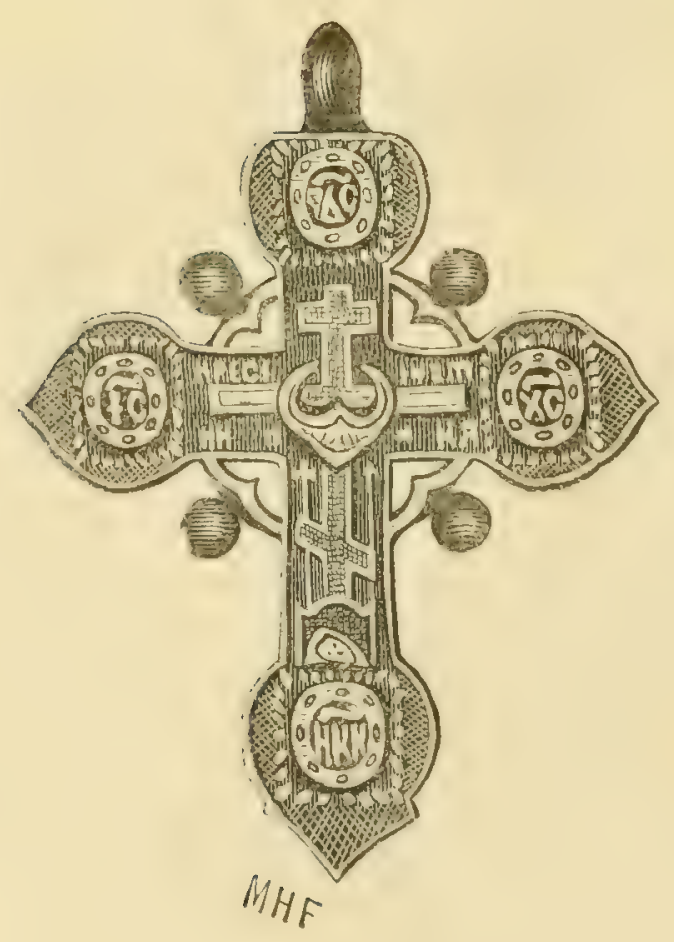




\section{LOXIA ENUCLEATOR。}

\section{PINE-GROSBEAK.}

(Plate 12.)

Coccothraustes canadensis, Briss. Orn. iii. p. 250, pl. xii. fig. 3 (1760).

Loxia enucleator, Limn. Syst. Nat.i. p. 299 (1766); et auctorum plurimorumGmelin, (Bonaparte), (Temminck), (Degland \& Gerbe), (Salvadorr), (Newton), (Dresser), ste.

Loxia flamengo, Sparrm. Mus. Carls. no. 17 (1786).

Pinicola rubra, Vieill. Ois. d'Am. Sept. i. p. iv (1807).

Fringilla enucleator (Linn.), Meyer, Vög. Liv-u. Esthl. p. 74 (1815).

Strobiliphaga enucleator (Lim.), Vicill. N. Dict. d'Hist. Nat. ix. p. 609 (1817).

Corythus enucleator (Linn.), Cuv. Règne An. i. p. 391 (1817).

Pyrrhula enucleator (Linn.), Temm. Man. d'Orn. i. p. 383 (1820).

Loxia psittacea, Pall. Zoogr. Rosso-Asiat. ii. p. 5 (1826).

Corythus enucleator (Linn.), Fleming, Bvit. An. p. 76 (1828).

Corythus angustirostris, Brehm, Vög. Deutscht. p. 247 (1831).

Pinicola enucleator (Linn.), Cab. Ersch.\& Grub. Encycl. 1. p. 279 (1849).

Pinicola americana, Cab. fide Bonap. Consp. i. p. 528 (1850).

Pinicola canadensis (Briss.), Cab. Mus. Hein. i. p. 167 (1851).

The Pine-Grosbeak is a very rare winter visitor to the British Islands, which lie beyond its usual winter range. It is one of those gipsy migrants which flock together in winter and lead a roving life, not going further from their breeding-grounds than the severity of the season compels them to wander in search of food. Their range of migration is consequently very irregular; and in very hard winters they cross the sea into Denmark, and occasionally wauder as far as Heligoland and the shores of Britain. There is no satisfactory evidence of the occurrence of the PineGrosbeak in Scotland or Ireland; and of the five occurrences in England three of them, all females, were on the east coast-one near Neweastle in 1831, one near Yarmouth in 1815, and one near London at a still earlier date. In 1845 a male was shot near Rochdale, and in 1854 a second male near Exeter. Details of these captures, as well as of many other alleged occurrences of this species, may be found in the 'Zoologist' for 1877 , p. 242.

The Pine-Grosbcak is a circumpolar bird, breeding in the forests at or near the Arctic circle. It is common in Norwegian Lapland, Archangel, and the valleys of the Petchora and the Ycnesay; Dybowsky obtained it in Kamtschatka in November, and also says that it breeds in the pine-regions of the mountains near Lake Baikal. On the American continent it is found from Alaska in the west to Labrador in the east, and 
wanders into the northern States in winter. In the Old World it winters in South Scandinavia, Denmark, and South Siberia, and occasionally throughout North Germany. It has also occurred at this season in IIolland, France, Bohemia, and Hungary. In the Himalayas the PineGrosbeak is represented by a much smaller species, Loxia sublimachalus, which differs in being smaller, richer-coloured, and in having 110 white on the wing.

The summer home of the Pine-Grosbeak is a very picturesque country. Almost all the forest districts of Siberia are hilly, and in the north as the trees become smaller they are also more thinly scattered over the ground, and the interminable extent of wood is broken by occasional flat open marshes, which become gay with flowers as soon as the snow melts. The scencry is more park-like than further south, and birds are much more plentiful and more easily seen.

The Pine-Grosbeaks arrive at their breeding-grounds in small flocks in April, and continue to be gregarious until summer comes, when they disperse for the purpose of building their nests. They appear to be somewhat shy and retiring birds, because they do not frequent the roads like the Bullfinches, the Snow-Buntings, and the Mealy Redpoles, who feed largely on the droppings of the horses; but this is by no means the ease ; they confine themselves principally to the woods, where they are not difficult to approach, even when the sportsman is obliged to hunt them in snow-shoes six fect long to support his weight on the untrodden surface. In the large pine-forests they prefer the banks of the rivers or the outskirts of some open place, and may often escape detection from their habit of frequenting the tops of the trees. On the Arctic circle many of the trees are small, and on the hilly ground they are scattered in small clumps, or sometimes in isolated trees, the drooping boughs of the spruce-firs looking very graceful on the white snow. In places like these the Pine-Grosbeak may often be seen perehed conspicuously on the top of a spruce-fir twenty or thirty fect from the ground, but looking so much like the last spike of the tree as frequently to escape notice. The first time that IIarvie-Brown and I met with these birds in the valiey of the Petchora was on the 21th of May, eiglit days after our arrival, in lat. $65 \frac{1}{2}^{\circ}$. They had probably been there some weeks, as in the valley of the Yenesay I found them on the 23rd of April in lat. $66_{3}^{10}$, and was assured by the sailors that they had been in the forests a long time. We had no diffeculty in shooting as many as we requircd, and once as we were lunching under the shade of a spruce-fir one or two of these fine birds came close to us. We generally saw them on or near the tops of the trees; but on one occasion we shot one from a fallen tree stump. They very rarcly visit the ground; but I once saw one hopping along like a Thrush under a fir tree. The call-note is a plaintive single note somewhat like that of our Bullfinch, but incapable of being 
expressed on paper. The song is very melodious, not very loud or long, but flute-like. When I first heard it I took it for the song of some rare Siberian Thrush, and was quite disappointed when I shot the bird to find it only a Pine-Grosbeak. The flight is undulating and powerful. We found several nests which could only have belonged to birds of this species; but our search for eggrs was unsnccessful. The breeding-season is said to be the end of May or begimning of June. The nests are generally placed in a spruce-fir tree ten or twelve feet from the ground on a thick branch close to the main stem. The nest is made on the same model as that of the Hawfinch and Bullfinch, but of coarser matcrials. The outside is a framework of slender fir-twigs; and the inside, which projects above the outside, is composed of roots, fine grass, and a lichen which grows on the branches of the trees, and might easily be mistaken for hair. The first clearly identified eggs of the Pine-Grosbeak which came to this country were those obtained by John Wolley ncar MLuonioniska in 1855, and seven years later Wheelwriglt found five nests near Quickiock. The number of eggs varies from three to four; they measure from 1.07 to .97 inch in length and from $\cdot 7 \cdot$ to $\cdot 7$ in breadth. They may be described as large handsome Bullfinch's eggs. The ground-colour is pale grecnish blue, boldly spotted, principally at the larger end, with surface-spots varying from rich brown to almost black, and with underlying spots of greyer brown. Some eggs are also profusely speckled with very small spots, and occasionally a Chaffinch-like streak is seen on the large end. On some eggs the spots are so large and numerous as to be more or less confluent.

In winter the Pine-Grosbeak is much easicr of approach than it is in summer, and it is said that it may even be caught by a snare fastened to the end of a rod. It feeds upon the buds of various forest trees, the seeds of pine and fir cones, and the berries of various shrubs, especially those of the southernwood.

The adult male Pine-Grosbcak is a rery handsome bird; the general colour of the plumage is dull slate-grey, darker and browner on the wings and tail, and paler on the under tail-coverts. The wing-coverts, innermost secondaries, and upper tail-coverts lave broad white margins, and cvery feather, except those of the belly and under tail-coverts, is fringed with rose-red. Bill dark brown; legs, feet, and claws nearly black; irides hazel. The rose-red is very brilliant after the autumn moult, but fades during winter to some extent. In spring the colour appears to intensify, although there is no change of feather.

The changes of plumage of this species have been the subject of much needless controversy. A series of skins of these birds shot during the breeding-season is easily divided into three groups. Most of the feathers are grey, those of the adult males fringed with rose-red, and those of the adult females with golden yellow. Immature females scarcely differ from 
adults, cxcept that fewer of the feathers have the golden-yellow fringes. The third group, which consists of the immature males, is quite distinct. In these birds the fringes are dull reddish orange, but there is a considerable individual variation. In some the orange is very yellow, in others very red, and occasionally both colours are found on the same bird. The Pine-Grosbeak only moults once a year, in autumn, and consequently the adult plumage is not assumed until the second autumn; but it is said that immature males have been found breeding in their first spring. The confusion on this question has arisen from the fact that in confinement the adult males lose the red plumage after the first moult, and remain ever afterwards in the orange or immature plumage. It is possible that very old males may reassume the immature plumage in a wild state, as cagebirds always do ; and it may also be possible that very vigorous young birds may moult from their first plumage direct into the red adult dress, or they may assume the red adult dress in their first spring by a change of colour of the feather without a moult. These possibilities are, however, by no means proved, and, even if they do occur, are probably very exceptional.

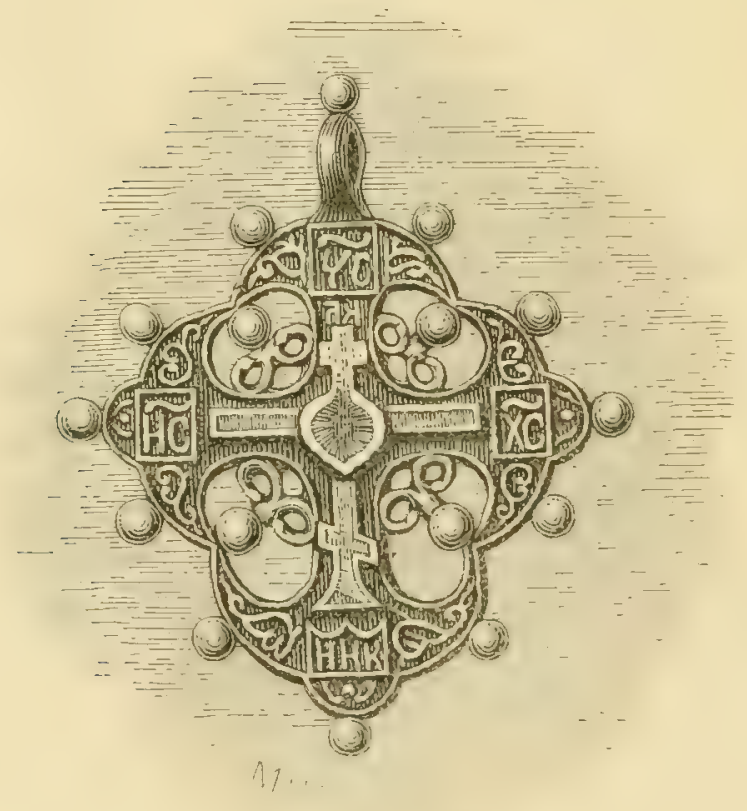




\section{Genus CARPODACUS.}

The Rose-Finches appear to have been unknown to Brissou and Linnæeus, and, after they were discovered, were placed by different writers with the Crossbills, the Hawfinches, the Bullfinches, \&c., until, in 1828, Brehm established the genus Erythrina for their reception (Isis, 1828, p. 1276). This name, however, may be rejected, on the ground that it had already been applied in 1767 by Limmæus, in his 'Systema Naturæ,' ii. p. 4.73 , to a genus of plants. In 1829 Kaup established the genus Carpodacus, in his 'Natürliches System,' p. 161, making C. erythrinus the type.

The Rose-Finches resemble the birds in the preceding genus in the general distribution of their colour, and ought never to have been generically separated from them. The name Carpodacus, however, has been so extensively applied to them that it may be retained, to avoid unnecessary change. They may be distinguished by the shape of the upper mandible, which in its profile shows an even curve meeting the point of the lower mandible, instead of a curve somewhat suddenly bent or hooked over the latter.

The geographical distribution of the birds in this genus is precisely similar to that in the preceding one. They are confined to the Palaenretic and Nearctic Regions, extending in the former into the Himalayas and in the latter into the tablelands of Mexico. They number about twenty species, only four of which are found in the western portions of the Palæarctic Region. One of these is an accidental visitor to the British Islands.

In their habits the Rose-Finches do not differ much from the allied species. Their haunts are very similar to those of the birds in the preceding genus; but the birds do not appear to be so much confined to the conifer growth, and breed in cultivated districts and amongst deciduous trees. In winter, when they are more or less gregarious, their haunts are much more varied than in summer, their choice being influenced only by the presence of the food-supply. They possess consilerable powers of song. Their nests are open, resembling those of their allies; and their eggs are five or six in number, blue of different shades, spotted with blackish brown. Their food consists of buds, seeds, and inscets of various kinds. 


\title{
CARPODACUS ERYTHRINUS.
}

\section{SCARLET ROSE FINCH.}

\author{
(Plate 12.)
}

Pyrrhula erythrina, Pall. N. Comm. Acad. Sci. Imp. Petrop. xiv. p. 587, tab. 23. fig. 1 (1770) ; et auctorum plurimorum-Naumann, Temminck, (Bonaparte), (Degland \&.Gerbe), (Salvadori), (Dresser), (Newton), sc.

Loxia rosea, Vieill. Ois. Chant. pl. 1xv. (1805).

Loxia errthrea, Endlev \& Scholtz, Schl. Nat. i. p. 17, pl.5; ii. p. 185, pl. 7 7 (1809-10).

Fringilla erythrina (Pall.), Meyer, Vög. Liv- u. Esthl. p. 77 (1815).

Coccothraustes rosea, Vieill. N. Dict. d' Hist. Nat. xiii. p. 539 (1817).

Linaria erythrina (Pall.), Boie, Isis, 1822, p. 554 .

Coccothraustes erythrina (Pallo), Bonn. et Vieill. Enc. Méth. p. 1003 (1823).

Carpodacus erythrinus (Pall.), Kaup, Natiirl. Syst. p. 161 (1829).

Erythrospiza erythrina (Pall.), Bonap. Comp. List B. Eur. \& N. Amer. p. 35 (1838).

Hæmorrhous roseus (Vieill.), Jerd. Madr. Journ. p. 36 (1840).

Erythospiza rosea (Vieill.), Blyth, Joum. As. Soc. Beng. xi. p. 461 (1842).

Propasser sordida, Hodgs. Gray's Zool. Miscel. p. 84 (1844).

Pyrrhulinota rosæcolor, Hodgs. Gray's Zool. MLiscel. p. 85 (1844).

Pyrrhulinota rosea (Vieill.), Hodgs. Gray's Zool. Miscel. p. 85 (1814).

Pyrrhulinota roseata, Hodgs. Proc. Zool. Soc. 1845, p. 36.

The claim of the Scarlet Rose-Finch to be considered a British bird rests upon the occurrence of two examples on our shores. The first specimen was captured near Brighton, on the downs, during the last week of September 18(6), and was recorded by Mr. Wonfor in the 'Zoologist' for that year (p. 1918), under a wrong name, which was afterwards corrected by $2 I r$. Boud in the same periodical for 1870 (p. 1981). It was a female, and was kept alive for some time by Mr. Swaysland, of Brighton; it afterwards came into the possession of Mr. Monk, in whose aviary it lived several years. A second example, also a female, was recorded by Mr. Bond in the 'Zoologist' for' $18 \% 0$ (p. 2383). It was taken near Caen Wood, Hampstear, by a bird-catcher, on the 5th of October of that year, and is now in the above-named gentleman's collection. The Scarlet RoseFinch breeds throughout North Europe and Siberia, from the Baltic to the Pacific. The western limit of its breeding-range appears to be Finland, the Baltic provinees of Russia, and Poland *. It passes through South

* The statement of Sharpe and Dresser, repeated by Nerrton, that Naumann found this bird breeding on the island of Sylt, is not strictly correct. Naunamn saw a cock bird in full song on the 7 th of June, probably just arrived, as this bird does not reach the Baltic Provinces before the second week in Nay, and the egrgs are not laid before the first week in June. An old nest was pointed out to him as the nest of the bird, and the female and young were said to be in the neighbourhood; but it is not clear that he saw them himself. 
Russia on migration, but breeds in Asia Minor, on the Caucasus up to 10,000 feet above the level of the sea, and on the Ural Mountains. To the north it rauges slightly beyond the Aretic circle; and to the south it breeds throughout Turkestan, Gilgit, Cashmere, and Mongolia. Dybowsky found it in Kamtschatka ; but it has not been recorded from Japan. Great numbers pass through North China on migration, a few remaining to breed in the mountains near Pekin. Its principal winter-quarters appear to be Northern and Central India and the Burma peninsula; but it occasionally strays into Lurope as far west as France and Italy. It appears also to be an accidental visitor to Persia and Scinde. There are several allies of this bird in Palestine, the Cancasus, Turkestan, South Sibcria, the Himalayas, and North America. One of the American species (C. purpureus) approaches very near to our bird, and may prove to be only subspecifically distinct from it, but may be distinguishcd by the more carmine (less scarlet) tint of the plumage.

The Scarlet Rose-Finch is not particularly interesting at its breedinggrounds. Such a finc-looking bird, perching so conspicuously as it does, is sure to attract attention; but I did not observe any thing in its habits to distinguish it from other Finches which was worthy of note. North of lat. $68^{\circ}$, when the trees began to diminish in size, it disappeared. The call-note is very similar to that of the Canary. In autumn these birds collect into flocks, and are amongst the first birds to migrate southwards before the approach of winter.

The migrations of the Scarlet liose-Finch are very interesting. It appears probable that all the migrants of this species to Europe, from the Baltic to the Ural Mountaius, winter in India. This fact alone suggests the theory that it is only a recent emigrant to our continent; and even within ornithologically historic times it is said to have become common in Finland and the Baltic Provinces. Another fact which supports this theory may be found in the dates of its migrations. Taczanowsky says that in Warsaw this bird does not arrive before the middle of May; and this is confirmed by Russow, who says that in the Baltic Provinces it is one of the latest summer visitors, arriving from the 8th to the 10th of May. On the other hand, in Siberia, where birds usually arrive much later than in Western Lurope, the Scarlet Rose-Finch is recorded at considerably carlier dates. Eversmann says that they arrive in the Southern Ural carly in April. Radde says he observed them at T'arei-nor, in Dauria, on the rth of April, and near Lake Baikal on the 26th of that month. Middendorff obtained one on the shores of the Pacific, in lat. $55^{\circ}$, about the same date; and I first saw them on the Aretic circle, in the valley of the Yenesay, on the Gth of June, almost at the northern limit of their range, in the first of the three great weels of migration. It is only fair, however, to mention that Dybowsky did not see them at Lake Baikal until after the middle of 
May, and suggests that Middendorff and Radde confounded this species with the Rosy Bullfinch, which arrives earlier.

The song of the Scarlet Rose-Finch is a very striking one, and not to be confused with that of any other bird. It is a loud, clear whistle-

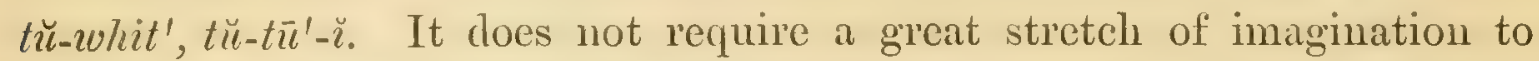
fancy the bird says, "I'm pleased' to see' you ;" the word "see" being strongly acceuted and slightly prolonged. This song is never varied, but is sometimes repeated twice in rapid succession. When it is heard, the bird may usually be seen perehed conspicuously on the top of a bush or low tree. The marshy forest-banks of the great Siberian rivers are a very favourite resort of this bird; and in the Baltic Provinces, where it is common, and in the valley of the Upper Volga, it is described as frequenting willows and other low trees in marshy districts.

The food of this bird consists of secds of various kinds, grain, and the buds of trees. In spring it eats insects, and in autumn berries and other fruit.

The nest of the Scarlet liose-Finch is built in the fork of a small bush, or amongst climbing plants not far from the ground. It bears little resemblance to the nest of a Finch, and might easily be mistaken for that of a Warbler. It is composed of dry grass-stallis and lined with horsehair. It is rather decp, and very neatly and carefully made, although it is so slender as to be semitrausparent when held up to the light. The inside diameter is two inches and a quarter. Five is the usual number of eggs; but sometimes only four are laid, and occasionally as many as six. They vary in length from $\cdot 9$ to $\cdot \% 3$, and in breadth from $\cdot 63$ to 55 . The groundcolour is greenish blue, not so pale as that of the eggs of the Bullfinch; the spots are also fewer, smaller, and blacker than in typical eggs of the latter species. They are smaller than the eggs of the Bullfinch, and are not likely to be mistaken for the eggs of any other bird.

In the winter the Scarlet Rose-Hinch ranges orer the plains of India, sometimes in large flocks, but more generally in small parties, frequenting alike the groves, the gardens, and the jungle. At this season of the year its habits much resemble those of the true linches. In Gilgit they breed at an elevation of 10,000 feet above the level of the sea, and fresh eggs have been obtained there in the second half of July. Early in September they leave the hills and come down into the valley, and soon migrate to their winter-quarters. Captain Butler, describing its habits in Rajpootana, west of Scinde, says that it is very fond of the watery nectar contained in the flower of the Indian coral-tree (Erythrina indica), upon which tree the bird is always found when it is in blossom.

The adult male Scarlet Rose-Finch is a very brilliant bird, but he is almost as much crimson as scarlet. The colour is most brilliant on the head, rump, throat, and breast. The wings and tail are brown, each 
feather obscurely margined with crimson. The underparts below the breast gradually fade into buffish white on the under tail-coverts. Bill, legs, feet, and claws brown; irides hazel. The female is a very plainlooking bird, not unlike a small hen Sparrow. The general colour is a neutral brown, darkest on the wings, tail, and the centres of the feathers of the head, nape, throat, and breast, palest on the tips of the wing-coverts, the margins of the innermost secondaries and of the throat and breastfeathers, and on the rest of the underparts. The back and rump are slightly suffused with olive.

The changes of plumage in this species have never been clearly described. The female in first winter plumage is very brown, and has the dark centres of the feathers much developed. In this stage it bears a striking resemblance to the cross between the Linuet and the Greenfinch (Fringilla cannabina $\times$ chloris) ; but the latter may at once be distinguished by the obscureness of its wing-bar's and by the shape of its bill. Scen from above, the bill of the Carpodacus is a cone with convex sides, whilst that of the Fringilla is a cone with concave sides. The female in first summer plumage is scarcely distinguishable from the adult; the brown centres of the feathers appear to fade or bleach, and the pale margins to abrade, so that the streaks are much less conspicuous. No further change takes place in the plumage of the female beyond the faded and abraded appearance of the feathers just before the autumn moult.

Males in first winter plumage are scarcely distinguishable from adult females, and even in first summer plumage are sometimes indistinguishable from them. I shot one of these males in the plumage of the female in the valley of the Yenesay on June 20, which I sexed myself; and Major Biddulph obtained several near Gilgit in July, which were evidently breeding. Probably no males attain more than an occasional faint rosy tinge until after their second autumn moult. If this be so, the adult plumage is not assumed until after the third autumn moult, and males of the second ycar may be recognized by the almost entire absence of the crimson on the back and underparts below the breast. The fully adult male retains his brilliant livery throughout the year, some allowance being made for wear and tear, which is only very apparent in late summer, just before the autumn moult.

If this explanation of the difference in the plumages of the Scarlet Rose-Finch be the true one, Jerdon's theory that the winter plumage is duller than that of summer, and Dresser's theory that the summer plumage is more brilliant than that of spring, fall to the ground. Newton does not refer to the subject. 


\section{Genus PYRRHULA.}

The Bullfinches were included by Linnæus in his genus Loxia, where it is a great pity that they were not allowed to remain; but Brisson having in 1760, in his 'Ornithologia,' iii. p. 308, already established the genus Pyrrhula for their reception, it has been almost universally accepted by ornithologists. The Common Bullfinch, the Pyrrhula pyrrhule of Brisson, is the type.

The chief character's by which the Bullfinches may be distinguished from the rest of the Finches are the convex profile of the bill, the metallic blue-black wings and tail, and the white rump. The latter character is perhaps the most conspicuous; but unfortunately in one species, $P$. auruntiaca from the Himalayas, the white is suffused with yellow, and in another, $P$. murina from the Azores, it is so much suffused with brown as to be scarcely distinguishable from the back. The black wings and tail are also more or less common to the genus Coccothraustes, though in most of the species in this genus there is a considerable amount of white either on the one or the other. These two genera are so closely connected, that it is impossible to decide to which Pyrohula nipalensis should be assigned. In its general appearauce it is undoubterly a Bulltinch; but the rump is almost concolorous with the back, aud it agrees with Coccothraustes personatus and $C$. melanurus in the eccentric character of its tail.

This genus has a more restricted range than any other in this subfamily, being almost confined to the Palaearetic Region, extending as far north as the Arctic circle, as far south as the southern slopes of the Himalayas, and eastwards across Behring's Straits into Alaska. Abour a dozen species have been described, of which several are only worthy of subspecific rank. Only one species is found in the British Islands, which is represcnted in Eastern Europe by a larger form. No other species occur in the Western Palæarctic Region except the one already alluded to, which inhabits the Azores.

The Bullfinches inhabit well-wooded districts, and frequent shrubberies, gardens, forests, hedges, and groves. In their habits, local distribution, and food they resemble very closely the Rose-Finches, but are not so gregarious in winter and are more retiring, especially in the breedingseason. Their nests are open and do not differ materially from those of the Crossbills and Grosbeaks, nor is it known that there is any characteristic difference in the colour or number of their eggs. 


\title{
PYRRHULA VULGARIS.
}

\section{BULLFINCH.}

\author{
(Plate 12.)
}

Pyrrhula pyrrhula, Briss. Orn. iii. p. 308 (1760).

Loxia pyrrhula, Lim. Syst. Nat. i. p. 300 (1766).

Fringilla pyrrhula (Briss.), Temm. Man. d'Orn. p. 200 (1815).

Pyrrhula europsea, Vieill. N. Dict. d'Hist. Nat. iv. p. 286 (1810).

Pyrrluula rufa, Koch, Syst. baier. Zool. i. p. 227 (1816).

Pyrrhula vulgaris, Temm. Man. d'Om. i. p. $0: 38$ (1820); et auctorum plurimorum -Degland, Gerbe, Savi, Doderlein, Meyer, Bolle, Bädeker, Dubous, Naumann, Bonaparte, Brelem, Blasius, Homeyer, Droste, Goebel, Stevenson, Gray, Fritsch, Thompson, Cabanis, Harting, Russow, Seebohm \& IIarvie-Brown, Severtzow, Cordeaux, Sharpe, Lilford, Schlegel, Sachse, Finsch, Crown Prince Rudolf, Newton, Brandt, Schalow, Blyth, Gould, Giglioli, Godman, \&c.

Pyrrhula pileata, Macgill, Brit. B. i. p. 407 (1837).

The Bullfinch is one of the best known of our smaller birds, and oue that from its tame and confiding nature is easily kept in confinement. From its love of dense thickets and its retiring habits it is apt to be regarded as much rarer than it really is. It is found commonly, although more or less locally, in all the wooded portions of Great Britain, and occasionally breeds in the Channel Islands. It does not appear to visit the Hebrides, these islauds probably being too bare and treeless for such a species. An example was obtained in Orkney in 1809; and in Shetland a female was shot in 1863 at Halligarth. In Irelaud the Bullfinch is said not to be so common as in Eugland, nevertheless it is to be met with throughout the country.

The Bullfinch breeds throughout North Europe and Asia, not extending much beyond the Aretic circle. In South Europe, Turkestan, and South Siberia it is principally known as a winter visitor, occasionally straying as far south as Algeria and Asia Minor; but a few remain to breed in the mountains of North Portugal and Spain, North Italy, the Carpathians, and the Caucasus.

Throughout its extensive range the Bullfinch shows some slight variations both of size and colour. In Europe west of Poland and south of Norway the birds are the smallest, the grey of the back is slightly the darkest, the red of the underparts is least brilliant, and the tips of the greater wing-coverts are grey. The extreme eastern form from Kamtschatka is slightly larger, especially in the bill, the grey of the upper parts is paler and brighter, and the tips of the greater wing-coverts are pure white; there is no red on the outside web of the first innermost secondary, and the outside tail-feather has a white streak on the middle of 
the inner web next the shaft. This form has been named P. kamtschatica by Taczanowsky. In the intervening localities intermediate forms occur; examples from Asia Minor are intermediate in the colour of the back, but are darker than examples from Krasnoyarsk. One example from Kamtschatka has the white on the outside tail-feathers, and an example from the Ussuri river, though it has the white on the outside tail-feathers, has also the red on the innermost secondary. These intermediate forms are known by the name of $P$. major; but there can be no doubt that neither of these two eastern forms are specifically distinct from the Common Bullfinch; and if we accept the western form as the typical one, the Pyrrhule vulyaris of Temminck (the Pyrrhula pyrrhula of Brisson), the eastern form must bear the name of P. vulyaris, var. major. Examples of the latter form occasionally occur in winter in Eastern Germany, and the Bullfinches found in Greece and Asia Minor also belong to this varicty. The Bullfinch has several allies in the Himalayas, East Siberia, China, and Japan, but none of them have the black head combined with the red breast as in the males of our bird.

The Bullfinch is one of our most retiring birds, especially in summer, and seeks at this season the seclusion of the woods and dense shrubberies to rear its young. In autumn and winter its range is considerably wider, and it may then be seen in fields and gardens, in small plantations where the undergrowth is dense, and in matted hedgerows where tall herbaceous plants and brambles struggle through and haug over whitethorn and hazel bushes. In winter, especially just before spring, the Bullfinch is very commonly seen in large gardens and orchards. It very rarely visits the wilder portions of the country, and where there are no trees there will be no Bullfinches.

The habits of the Bullfinch are so quiet and retiring that it is only when the leaves are off the trees that we have much opportunity of studying them. It is not by any means a gregarious bird, nor does it usually evince any partiality for the company of other birds, as is the case with so many Finches, and gencrally it is only accompanied by its mate. In late autumn, however, Bullfinches are sometimes seen in little partics composed of the young of the year and their parents. In winter it is by no means a shy bird, and will allow the observer to approach it quite closely and watch its restless actions as it skips from twig to twig searching for berries and sceds. The Bullfinch is rarely seen on the ground in this comntry; lut in the forrsts of Siberia it is glad enough to make friends with the Snow-Buntings, Mealy Redpoles, and Siberian Jays, and feed on the droppings of the horses on the snow. The call-note of the Bullfinch to lis mate is a full, rich, but low piping whistle, very monotonous and plaintive, and sounds like dy $\breve{u}, d y \breve{u}$; and his song, which is usually uttered in so low a tone as to be scarcely audible at a distance, as if he were 
fearful of being discovered in the act, is very pleasing and mellow. Usually it is warbled as he sits bolt upright, and every now and then jerks his wings and tail and turns his head from side to side, as if about to take wing. The female also sings; but her performance is much inferior to that of the male. The Bullfinch is in great request as a cage-bird, from the readiness with which it will learn to whistle various tunes, and from its docile and confiding disposition.

There can be little doubt that Bullfinches mate for life. At all seasons of the year they may be observed in pairs, and even in midwinter marks of affection may be constantly seen passing between them. In early spring the male retires with his mate to the haunts he loves best, and in which he seems most at home, to the dense shrubberies and thickets, amongst a superabundance of verdure of all descriptions, where the young can be reared in seclusion. So retiring is he, that during the breeding-season he is very rarely seen, and seldom, indeed, betrays the whereabouts of his nest; in fact, at this time of the year the Bullfinch is one of the most silent of birds; for its bridal song is only heard at intervals in early spring. It usually commences to build its nest about the middle of April, and eggs may be found by the latter end of that month. The site for the nest is chosen in a low tree or bush; very often some species of evergreen is selected, as a holly or a yer, and always in a dense situation. Plantations of young firs are very often selected by the Bullfinch, and its nest is frequently placed in the branches of a small spruce. $\Lambda$ whitethorn hedge near a plantation or a thick wood is also a favourite place. The nest of the Bullfinch ean readily be told from that of almost every other British bird. It is a very beautiful structure, the framework almost entirely composed of slender twigs, and is very flat, not unlike a miniature Wood-Pigeon's nest. The sticks are very artfully woren and matted together' and in the middle of this platform of sticks the cup of the nest is formed of fine rootlets projecting above the framework, making the inside as deep as usual. In some nests a little wool or a feather or two are found. The eggs are from four to six in number, greenish blue in ground-colour, spotted and sometimes streaked with dark purplish brown, and with larger and paler blotches of pinkish brown. In some eggs the spots are evenly distributed over the entire surface, but in the majority of specimens they form an irregular zone round the large end. The eggs of the Bullfinch are much bluer than those of any allied common birds, except those of the Lesser Redpole, with which their size effectually prevents any confusion. They are in fact miniature PineGrosbeak's eggs. The only eggs of British birds which they at all closely resemble are those of the Scarlet Bullfinch; but as this bird does not breed in this country, they cannot be confused with them, except in the cabinet. These eggs may be distinguished from those of the common 
species by having the markings smaller, and generally of a much richer brown, almost black; they have also more gloss upon them. The eggs of the Common Bullfinch vary from 85 to $\cdot \gamma$ inch in length, and from $\cdot 6$ to $\cdot 55$ inch in breadth.

During the hatching-season the Bullfinches are very quiet; the female alone appears to sit upon the nest, and is so tame at this period, or rather so unwilling to move, that she will often allow the observer to approach her within a few fect ere she quits her charge. It is not improbable that the Bullfinch rears two broods in the season; for eggs of this bird may be found as late as the end of June and beginning of July. The young are tended for some considerable time after they leave the nest, and, in some instances at least, remain with their parents throughout the autumn and winter.

The food of the Bullfinch is almost exclusively composed of vegetable sulsstances-fruits and berries and various kinds of seeds. It does not, however, live exclusively on these, and in summer will feed on small insects. Dixon has the following note on this subject:- "I have seen a Bullfinch in July, a time of the year when it is umusually shy and retiring, hovering above the tall plants near a sticam in the secluded corner of a shrubbery, catching insects just like a Flycatcher. It was a female bird, and had a nest close at hand in a dense yew tree. It also repeatedly endeavoured to alight on some large fern-leaves, which always bent under its weight, as if sceking for the varions insects that infest such situations. The Greenfinch will also feed in a precisely similar mamner. It is also hard to believe that the young of this bird are reared on any other food but inscets, and doubtless many linds of larvae are captured for this purpose." For the greater part of the year, however, the Bullfinch fecels on the seeds of the most noxions plants and rank grasses. It will eat those of the dock, the nettle, the groundsel, chickweed, thistle, and a liost of others, whilst its love for berries is none the less, and it eagerly feeds on those of the wild rose, the hawthorn, the privet, the elder, and some others. The Bullfinch is also fond of other fare, and its love for the tender buds of fruit-trees too often lures it to destruction. It is seldom respected by the gardencr, who, in shooting it down, makes bad worse, and does more damage in one discharge of his gun than a host of Bullfinches would in a week. Early in the year the bird may often be seen on the branches of cherry-, plum-, apple-, and pear-trees, or on the twigs of the gooseberry and currant-bushes, and the ground is strewed with the cases of the buds, marking out its course. Singularly cnough the bird confines its attentions to the flower-buds, those produeing leaves being passed by. 'This destructive habit of the Bullfinch cannot be defended or excused; but further rescarch may prove that the bird is, after all, a real benefactor to the tree from which it levies such a costly tribute. At this season of the 
year the Bullfinch is very conspicuous on the fruit-trees, his gay colours contrasting strongly with those of the opening blossoms. He is now almost incessantly in motion, like a Tit ol a Goldcrest; and as he passes from tree to tree we have an opportunity of examining his flight, which is undulating and not very rapid. The bird rarely flies far at a time, although well capable of dlomg so, but prefers to progress in short jerky flights from bush to bush, or even by hopping from one branch to another. In winter Bullfinches are very fond of frequenting hedges, where they busily scarch for the seeds of all kinds of weeds; and although half a dozen birds may be met with close together they do not associate; and the mere accident of their being together is caused by the abundance of food.

The Bullfinch belongs to the class of gipsy migrants, and has no settled winter home. A few examples occasionally appear on our coast and are secn near the lighthouses, but the instances are solitary. In this country they wander about considerably in winter, remaining in a district for a short time, then disappearing again; but in the severest winters they do not retire southwards nor ever cross the sea.

The Bullfinch is singularly striking in appearance and is a remarkably haudsome bird. The head above the eyes, the upper tail-coverts and the tail, and the wings (except the tips of the greater coverts, which are ashy grey, and the lesser wing-coverts, which are bluish grey) are glossy bluish black; the outer web of the innermost secondary is almost all red; the nape and back are bluish grey; the rump is pure white; the chin is black; the sides of the head, the throat, breast, and belly are brick-red, and the vent and under tail-coverts are white. Bill black; lcgs, feet, and claws dark brown; iricles brown. The female has the same pattern of colour as the male; the head, wings, and tail are very similar in colour, but not quite so glossy black; the parts that are red in the male are replaced by brown, and the white parts are not so pure. Young in first plumage resemble the female, but have no black on the head. The adult plumage is, however, attained by a moult in their first autumn. Melanistic varieties of the Bullfinch are not uncommon in confinement; and Mr. Gurney records, in the 'Zoologist' for 1854 (p. 4252), an entirely black specimen, which eventually moulted into the normal-coloured plumage.

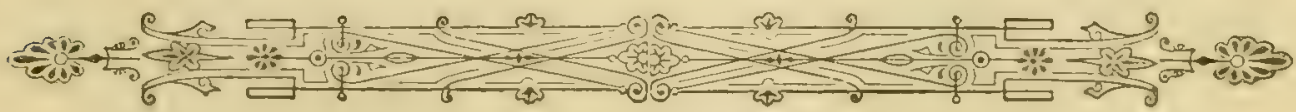




\section{Genus COCCOTHRAUSTES.}

The Grosbeaks were included by Linnæus in his genus Loxic, and are closely allied to the Crossbills. Brisson established the genus Coccothraustes for their reception in 1760 in his 'Omithologia,' iii. p. 218, making the Common Hawfinch, his Coccothraustes coccothraustes, the type.

The Hawfinches may be distinguished by their very large bills, which are nearly as long as the tarsus, and are so thick that the ridge of the upper mandible forms almost a continuous curve with the contour of the head. The wings and tail are black, in some species glossy black, but there are generally white patches on many of the feathers of one or the other. None of the species have white rumps.

The geographical distribution of this genus is almost precisely the same as that of the Crossbills, the Rose-Finches, and the Bullfinches, to which they are so closely allied as to be scarcely generically separable. They inhabit the Palrearctic and Nearctic Regions south of the Arctic circle, beyond the former extending as far south as the southern slopes of the IIimalayas, and in the latter haring a still more southern range, brecding not only in Mexico but also in the mountains of Guatemala. The number of species in the genus probably does not exceed a dozcn. Only one species oceurs in Europe, which is a resident in the British Islands.

Most of the Grosbeaks are inhabitants of pine-forests; but the European species is most partial to beech- and oak-woods. Except during the breeding-season they are gregarious in their habits. They are almost omnivorous in their dict, feeding alike on seeds, fruit, and insects. None of them have any great powers of song. They breed in trees at various heights from the ground, and their nests are formed on a similar model to that of the Bullfinch. Very little eoncerning the eggs of the Grosbeaks is known, beyond those of the European species; but they probably do not differ in character from them. 


\title{
COCCOTHRAUSTES VULGARIS.
}

\section{HAWFINCH.}

\author{
(Plate 13.)
}

Coccothraustes coccothraustes, Briss. Orn. iii. p. 219 (1760).

Loxia cocéothraustes, Linn. Syst. Nat. i. p. 299 (1766).

Fringilla coccothraustes (Briss.), Meyer, Vög. Liv- und Esthl. p.73 (1815).

Coccothraustes deformis, Koch, Syst. baier. Zool. i. p. 226 (1810).

Coccothraustes vulgaris, Pall. Zoogr. Rosso-Asict. ii. p. 12 (1826); et auctorum plurimorum_Vieillot, Degland \&. Gerbe, Savi, Salvadori, Nevoton, Dresser, \&c. Coccothraustes europæus, Selby, fide Swains. Classif. B. ii. p. 277 (1837).

Coccothraustes atrogularis, Macgill. Brit. B. i. p. 356 (1837).

Coccothraustes vulgaris japonicus, Temm. \& Schl. Faun. Japon. p. 90, pl. li. (1847).

The Hawfinch is by no means so rare a bird as has been generally supposed. It is very local, and during the breeding-season, like its relations the Pine-Grosbeak and the Crossbill, it is so shy and skulking that it frequently escapes detection. It probably breeds in suitable localities in almost every county of England and Wales, except perhaps north of Yorkshire. I have seen its nest in my brother's garden near Hitchin, and have received many accounts of its brecding in various localitics near London. I have shot it during the breeding-season near Sheffield; but no reliable accounts of its nesting in the western counties are to be found. It ccrtainly brceds in Ireland; but in Scotland it appears to be an accidental winter straggler to almost every county.

The Hawfinch is found in suitable localities throughout Europe, Siberia, and the north island of Japan south of lat. $60^{\circ}$. Its southern range in the west extends to Algeria, and in the east to Asia Minor and the Caucasus. It appears to be very rare in North Persia and Turkestan, but has been known to stray as far as the north-west frontiers of India. It passes through Manchooria on migration, and winters in North China and the main island of Japan. Where the winters are not too severe it is a resident bird. The Hawfinch has no ally with which it is likely to be confounded, no other species in the genus having the peculiar wing-feathers expanded at the tip and curled. The Hawfinch of Japan has been separated from the European species under the name of C.vulgaris japonicus, on the ground of its being lighter and paler in colour; but the difference is scarcely perceptible, and is not greater than that to be found in eastern as compared with western examples of every species.

The Hawfinch is a resident in this country; but possibly some of the younger birds may cross the Channel in autumn, and it seems probable that some of the flocks seen in winter may be migrants from South Scandinavia, as it has frequently occurred on the island of Heligoland. 
There are several plantations, or small woods, within a mile or two of the outskirts of Sheffield where the Hawfinch may be seen at all times of the year. One, in particular, is principally composed of bech. Every now and then you may hear a sharp click repeated several times, and you may catch sight of a small flock of half a clozen birds flying in a straggling manner through the topmost branches of the trees. You may recognize them at once by their short tails and Hawk- or Cuckoo-like heads, causing them to appear to have scarcely any meck. They are very wild and shy, and this, together with their rapid and powerful flight, inalies them difficult to shoot; but occasionally you may see them on the ground busily engaged in feeding upon the fallen mast uuder the beeches. Besides the sharp click which appears to be generally uttered on the wing, and of which the letters bpt serve to remind me, they liave a fecble song in spring. A gentleman who lives not far from this plantation tells me that before the nesting-season he often hears the notes of these birds, which are by no means unmusical, and are unlike those of any other bird-four simple whistles in an ascending scale, the first two at a slight interval and the last two repeated rapidly one after the other, the final one being somewhat drawn out. The old birds bring the young in their first spotted plumage to his garden to feed upon the peas; and he tells me that they also make havoc amongst his cherries; but unlike the Blackibirds, who eat the fruit and reject the stone, the Hawfinches eat the stone and reject the fruit.

As is usual with most showy birds, the Hawfinch is excessively shy, and only frequents those localities that are well timbered and afford it plenty of shelter. Its chicf haunts are in woods, ficlds in which there are occasional clumps of trees, old orchards, and dense shrubberies, where the cvergreens make it a secluded retreat. Even in the suburbs of London the IIawfiuch is far from being a scarce bird, if a local one; and, according to Mr. Harting, it has nested, amongst other places, in the Horticultural Gardens at Chiswick, in the neighbourhood of Harrow, at Muswell Hill, and Hampstead. A bird that is so shy and retiring as the Hawfinch, leaves but little to be said of its habits; and the observer usually only gains a transicnt glimpse of it as it hastens away into the deepest parts of the cover. Like most of the British Finches, the IIawfinch congregates into flocks in winter, sometimes of only half a dozen individuals, probably the young of the previous scason and their parents, but occasionally in very large numbers. The Hawfinch seems to have a great liking for yew trees, probably because they are so gloomy and dense, and partly because the luscious berries are very palatable to it. The birds also frequent these trees in winter to roost, approaching them in a very hurried manner, and instantly disappearing amongst the foliage.

Dixon, when in Mlgeria, made the following notes on this bird:- "We only found the Hawfinch in the evergreen-oak forests on the hills above 
Lambessa. Here it was by no means common, and we only saw several scattered pairs. The Hawfinch is shy enough in England, as is well known, and one would almost be led to think that the cause of this shyness was the incessant manner in which it is hunted both by gardeners and collectors, if we did not find it just as wild and wary in these forest solitudes of Algeria, where man is so rare an animal as to cause it no alarm. The birds were evidently mated, although incubation had not commenced, for each male was accompanied by a female. We first met with them in a small natural clearing in the forest, where the trees were scattered in clumps far apart. It was, as a rulc, only when they were flying from tree to tree that we could see them; but sometimes we observed them sitting quictly amongst the branches, turning their large heads from side to side, and peering about in all directions, as if in search of the cause of alarm. The flight of this bird is undulating, but sometimes straightforward, and is then very rapid. As they flew from tree to tree, I noticed that they usually dropped down into the branches, far less frequently flying up into them. We did not hear them utter any callnotes; but when at rest the male birds occasionally twittered a little, something like Greenfinches."

The Hawfinch is not much of a songster. It has a few notes, which can scarcely be called more than a low chatter. There is nothing very striking in its performance; but when several are twittering away together the general effect is very pleasant. Its call-note is said to rescmble the wellknown $z h$ of the Greenfinch.

The Hawfinch pairs about the middle of April, and its nest is rarely built before the trees are in full foliage. The site for the nest differs considerably. A favourite place is in the apple- or pear-trecs in an orchard, or in an old whitethorn, often in quite an exposed situation; and when it breeds in woods it often selects a hornbeam, or less frequently a holly. The Hawfinch does not often breed in shrubberics, and its nest is somewhat rarely placed in evergreen trees; but it has been found amongst ivy. It will also build in tall oak trees; and Doubleday says that it occasionally nests in fir trees in plantations. Sometimes the nest is only a few feet from the ground, at others it is as much as forty feet. The nest is usually commenced by the latter end of April or carly in May, and sometimes several will be found in the same plantation. Mr. Thomasson informs me that he once found three nests in one orchard. The nest is a very beautiful piece of handiwork, and is similar to that of the Bullfinch, but on an enlarged scale. The outside is invariably made of twigs, frequently intermixed with lichens and sometimes with dry plants; and the cup of the nest is formed of dry grasses, lined with fine roots and often a little hair. The nest, as a whole, is very flat and somewhat bulky; but the cup is not unusually shallow, and is neatly finished. The eggs of the Hawfinch vary from four 
to six in number, and are usually laid about the second week in May, sometimes carlier. There are two very distinct types. The usual type is pale olive or bluish green in ground-colour, streaked with dark olivebrown, and having a few spots of the same colour on the surface, and with underlying markings of greyish brown. The second type differs only in having the ground-colour buff and the underlying spots more inclined to violet-grey. The eggs of the Hawfinch do not resemble those of any other British Finch, their peculiar streaky markings distinguishing them at a glance. They are usually quite as much streaked as Buntings' eggs, and most nearly resemble in colour those of the Reed-Bunting; but the rich purplish-brown markings and much smaller size prevent any confusion between them. Some eggs of the Hawfinch are not so streaked, and the markings are fer and very distinct; but even on this variety a few hairlike lines occur. Two very remarkable eggs from Pomerania, in my collection, have the ground-colour pale bluish green, and the markings are confined to one clouded mass of pale brown, over which runs a broad and irregular darker streak. They vary in length from 1.0 to 85 inch, and in breadth from $\cdot 8$ to $\cdot 67$ inch.

The Hawfinch throughout the brecding-season is very shy and retiring, and when its nest is approached, should it only contain eggs, the bird will glide rapidly away into the cover; but sometimes when the young are hatched it will fly round the hend of the intruder uttering anxious cries. The Hawfinch probally only rears one brood in the year; but if its first clutch of eggrs be taken others will be laid; and this circumstance probably accounts for the late broorls sometimes met with. The young are fed largely on caterpillars; and in summer insects form no small portion of the bird's diet; but its principal food is sceds of various kinds, as its stout strong bill abundantly proves. It is very fond of the seeds of the hornbeam, beech-nuts, the berries of the hawthorn, and cherrystones, which it cracks with ease. It feeds on various soft fruits, especially on peas and the berries of the yew.

The Hawfinch is not an elegant-looking bird, nevertheless it is a very handsome one. The feathers at the base of the bill, the lores, and the throat are black; the rest of the head is reddish brown, palest on the earcoverts and forehead; the nape is ashy grey; the back and the scapulars are dark chestnut-brown, becoming paler on the rump, and shading into rellowish brown on the upper tail-coverts; the median wing-coverts are white, the rest black; the wings are black, with blue and purple reflections, the outermost primaries having a white spot near the middle of the inner web; the remainder of the quills have most of the inner web greyish white; the sixth and four succeding primaries are truncate, the inner edge of the tips rounded like a billhook; the tail is black, the four outer feathers on each side having a large terminal white spot on the inner web, the four 
centre ones narrowly tipped with white and tinged with rufous. The underparts are pale yellowish brown, shading into white on the under tailcoverts. Bill in summer lead-blue, in winter pinkish brown; legs, feet, and claws pale brown ; irides greyish white. The female is not very different from the male; but the colours are duller, and the white spots are not so pure.

Young in first plumage have the wings and tail of the adult; but the black at the base of the bill and on the throat is absent, as is also the grey collar; the breast and flanks are barred with brown; and the head, throat, and upper parts are more or less suffused with yellow. This plumage is, however, clanged into that of the adult by a moult in the first autumn. The autumn plumage of the adult is much richer than in summer, but does not otherwise differ.

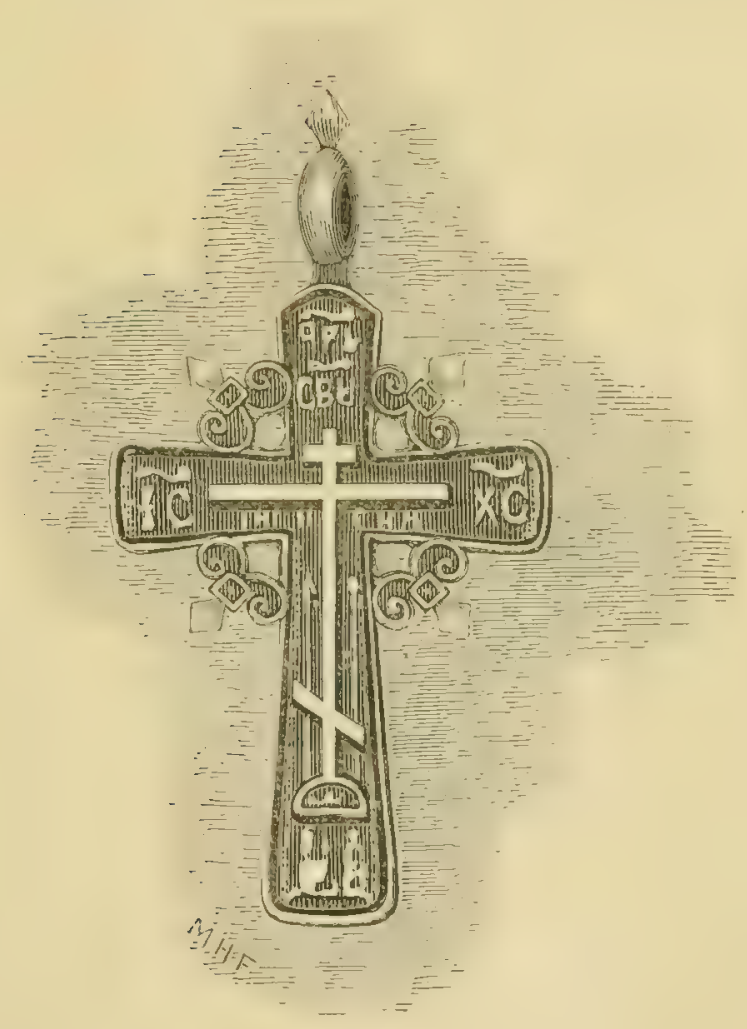




\section{Genus PASSER.}

The genus Passer is another of the genera of Brisson which are additional to those of Limmeus, and have been so universally adopted that an exception to the rules of the Stricklandian Code had to be made in their favour. It was, however, so clumsily done that, according to the letter of the law as it stands, the gencra additional to those of Linmeus of all the other contemporaries of the great Swede are equally admissible. Linneus included the Sparrows in his genus Fringilla; and as Brisson called the Chaffinch Passer fringilla, that bird has been accepted as the type. Brisson's genus Passer, which he established in 1760 ('Ornithologia,' iii. p. 72), is synonymous with the genus Fringilla of Linnæus, exeept that he removed the Goldfinches into a new genus which he called Curduelis. The fact that Brisson placed the Sparrow at the head of his genus Passer, though he did not adopt his usual custom and call it Passer passer only, but gave it the trinomial name of Passer passer domesticus, has caused most writer's to regard the Sparrow as the type of the genus Passer, thus making it legally additional to, instead of symonymous with, the genus Fringilla of Linnæus.

It is not known that there are any structural characters by which the Sparrows may be distinguished from the other genera of Finches. Their principal characteristic is that the general colour of the plumage is brown of different shades, occasionally varied with black and white. The bill rescmbles very much that of the Rose-Finches, but is somewhat more elongated.

The Sparrows inhalit the whole of the Old World south of the Aretic circle, with the exception of the Australian Region. One species has been recently introduced into the latter region, as well as into the New World. Wallace includes thirty-four species in this genus, of which seven oceur in the Western Palæaretic Region, two of these being residents in the British Islands.

The Sparrows are essentially birds of the plains. They are practically omnivorous, and possess very little powers of song. They are more or less gregarious in their habits. They build in holes, or form domed nests in trees and hushes; and their egges are whitish in ground-colour, profusely spotted with brown of various shades, principally at the large end. 


\title{
PASSER DOMESTICUS.
}

\section{HOUSE-SPARROW.}

\author{
(Plate 13.)
}

\begin{abstract}
Passer domesticus, Briss. Om. iii. p. 72 (1.760); et auctorum plurimorum(Gmelin), (Scopoli), (Latham), (Temminck), Degland \& Gerbe, (Naumann), Dresser, Newton, \&c.
\end{abstract}

Fringilla domestica, Linn. Syst. Nat. i. p. 323 (1766).

Pyroita domestica (Briss.), Boie, Isis, 1822, p. 554.

Passer tingitanus, Bonap. Cat. Par*ud. p. 18 (1856).

The House-Sparrow is certainly the best known, the most widely distributed, and the most closely attached to man of all our British birds. Almost without exception it is commonly distributed throughout the British Islands, only being absent from certain isolated places in the Highlands, the bare and rocky islauds of Scotlaud, and one or two similar places in Ireland. As is gencrally known, the House-Sparrow is by far the commonest in the most populous districts, and as the wilder localities are brought under cultivation the Sparrow soon follows-as, for instance, in the Outer Hebrides where, half a century ago, the bird was unknown, but has now firmly established itself.

The House-Sparrow is distributed over the whole of Europe (up to, and occasionally beyond, the Aretic circle), with the exception of Sicily, Sardinia, and Malta (where it is replaced by Pusser hisponiolensis, which is also found in Spain, Asia Minor, Egypt, Nubia, and Algeria, together with our bird, the latter being chiefly confined to the towns), and of Italy, Corsica, and the Southern Tyrol, in which latter countries it is replaced by $P$. italice. Both these species may be casily distinguished by having the crown of the head chestnut instead of ash-grey. In Asia the Sparrow extends as far as the sourecs of the Amoor, but does not appear to be found in the valley of the Lena, further east in Siberia, or in Japan and China, although it is found throughout India and the Burmah peninsula.

Examples from South Persia, Afghanistan, Beluchistan, India, and Burmah are slightly palcr and more brilliant in colour, and have the earcoverts white instead of ashy grey. They have been described as a distinct species under the name of Passer indicus. This form must, howerer, be considered only subspecifically distinct from that of Europe and North Asia, inasmuch as the Sparrows of the Caucasus, North Persia, and T'urkestan are intermediate in colour.

The range of the House-Sparrow has been artificially increased to a very 
large extent. The bird has been introduced into America and several of the islands in the Atlantic and the Pacific, into Australia, and even New Zealand. These emigrants appear to thrive well, and in some instances have multiplied considerably in their new homes. Thus the time is probably not far distant when the Sparrow will be absolutely cosmopolitan.

It might almost appear an unnecessary task to give a full history of such a well-known bird as the House-Sparrow; nevertheless there is much in its cconomy of interest. It is so closely associated with man and his habitations that it may be considered to be semi-domesticated; for almost without exception it may be secn close to his haunts and industries. It is as much at lome in the midst of our grimiest cities as in the quiet country farmyard, and lives and rear's its young on the peer's mansion as well as on the peasant's cottage. Wherever it is introduced it makes itself at home, and is as familiar an object from the wiudows of the Fifth Avenue Hotel as it is from those of the Langham. It appears to have no more love for a country life than a town one, and in both situations is equally as pert and impudent. It is gencrally found close to houses; but in summer it is as frequently in the fields. The House-Sparrow is a thoroughly gregarious bird, and at all seasons of the year lives in close companionship with its fellows. It is one of our tamest birds, and will come with all the boldness of inspired confidence to our doors in search of crumbs and other food. It also frequents railway-stations, hopping about amougst the carriagewheels or chirping on the iron girder's above. It is equally common in the grain-docks, where it breeds under the sheds, and finds a plentiful supply of food scattered from the unloading ships. The House-Sparrow is perhaps nowhere so common as in the gardens of the Zoological Society of London. They liteially swarm there, and evidently have a very easy time of it, obtaining their food by feeding in the pens of the amimals. At dusk the evergreen trees swarm with the birds, who go there to roost, a proceeding which is taken advantage of by the keepers, who net them for the purpose of supplying some of the animals with food.

The House-Sparrow is a life-paired bird; and doubtless, owing to the fact that its conditions of cxistence are so casy, it may be found breeding, more or less, throughout the whole year, especially in towns. Sparrows often fight fiercely in the early months of the year; and when two birds are cugaged in combat, their angry cries seem to be the sigual for all the birds in the neighbourhood to collect and join in the fray. They will pursue each other like lightning through the bushes, all gathering in a confused heap, every moment the din being increased by fresh arrivals; and when the difference is satisfactorily settled each attends to its own concerns again. The breeding-season of the Sparrow usually commences in April, and lasts through May and June. Nany of the birds breed in societies, others singly, according to the accommodation afforded them; and their 
choice of a nesting-site is very various. The usual situation is under the eaves, in the niches of masonry, in walls, amongst thatch, and in holes in trees ; in fact the bird will take possession of any suitable hole in a wall or pipe and there make its nest.

The Sparrow chooses also other sites; and in this particular we have perhaps the most interesting part of its life-history. In addition to the clumsy, ill-made nest which the Sparrow always builds in holes, it frequently constructs a well-made domed nest in a tree. It is probable that the birds which build domed nests always breed in trees, and that the habit is hereditary; but some ornithologists have supposed that the Sparrow builds in trees for the sake of coolness, and only in exceptionally hot weather. Almost every kind of tree is selected, but evergreens are perhaps the most frequently chosen. The nests are also often built amongst ivy, either growing on walls or on tree-trunks. A more unusual breeding-place was noticed by Dixon when in Skye; he writes :- "A fact worthy of note is the breeding-place of this bird at Portree. In some few instances I found their nests in the dense furze bushes by the roadside, within a few inches of the ground. They were domed structures, like those the bird invariably makes when in the branches of trees, and it was no uncommon thing to see two in the same bush." The Sparrow also very often usurps the nest of the House-Martin, or even that of the Barll-Swallow; and it will frequently build amongst the sticks of Rooks' nests; and in the Dobrudscha I saw the nest of an Egyptian Vulture containing two young half-fledged birds, underneath which one or more Sparrows had built their nests, and were hopping about amongst the sticks as unconcernedly as possible. It also sometimes builds in the old nest of a Magpie. A Sparrow's nest in a tree is a very different structure to a Sparrow's nest in a hole. In the latter situation it is very looscly and slovenly put together, very often a portion of the materials hanging out of the hole, attracting the attention of every passer-by; but in a tree it is globular and well woven, and the hole which admits the parent birds is often so effectually concealed as to render it necessary to pull the structure to pieces to get at the eggs within. Dry grass and straws, intermixed with all kinds of rubbish, such as strips of rags, twine, worsted, \&rc., form the outside, and it is always warmly lined with a profusion of feathers, and sometimes masses of wool and hair.

The eggs of the House-Sparrow vary from five to seven in number, and are pale bluish white in ground-colour, more or less thickly blotched, spotted, and speckled with dark brown, lilac, and greyish brown. They vary considerably in size, shape, and colour. In some the ground-colour is almost concealed by the rich brown markings, freckled and blotehed over the entire surface; in others the spots are large and very bold, and chiefly massed on the large end of the egg; whilst many specimens are scarcely distinguishable from those of the Pied Wagtail. They vary in VOL. II. 
length from $\cdot 95$ to $\cdot 8$ inch, and in breadth from $\cdot 65$ to $\cdot 57$ inch. It is often impossible to distinguish small eggs of the present species from those of the Tree-Sparrow. Many eggs of this bird also very closely resemble certain varieties of the eggs of the Meadow-Pipit. The Sparrow often sits upon the first egg as soon as it is laid, and the female bird performs the task of incubating the eggs. After the young leave the nest they are often fed and tended by the old birds, but sometimes are abandoned ere they can well take care of themselves.

In the hot months of the year the House-Sparrow is excessively fond of dusting itself, like the domestic fowl; and sometimes as many as half a dozen may be seen enjoying this luxury in company. In Derbyshire, where the roads are mostly limestone, Sparrows are not unfrequently seen to fly from them with their plumage almost as white as snow. The Sparrow's flight is rapil, and when prolonged for any great distance is undulating, but when only flying a little way it is almost direct. Upon the ground it progresses in a series of hops. It is by no means an inactive bird; and were it not so common, its sprightly form and not unshowy dress would win for it considerable admiration. But the Sparrow - of the country, the clean bird of the farmyard, is a very different-looking bird to the little smoke-begrimed objects that go by the name in towns. Even the country Sparrows in England camnot contrast farourably in purity of plumage with the birds inhabiting North-European and Siberian towns, where the Sparrow's beanty is perhaps seen at its best. The song of the Sparrow searcely deserves the name, and consists of a few twittering notes, resembling somewhat the song of a Greenfinch; and its love-note is a musical twitter, uttered to serenade his mate as she sits, or rather lies, upon the walls or copings. Its call-note is a sharp chirp, at best most unsatisfactorily deseribed on paper; but most probably, even whilst these pages are being read, certainly whilst they are being written, the Sparrow's merry note sounds outside, and renders a bad attempt to describe it unnecessary.

The House-Sparrow is partly granivorous and partly insectivorous. In towns the bird chiefly subsists upon the undigested grain amongst the droppings in the streets and on whatever edible substances may be thrown from the houses; it may also be often seen chasing a butterfly or other large insect, and it feeds upon various larve which it finds in woodwork and crevices of masonry. In the country its diet is rather more varied; it feeds on grain, both the seed-corn and the harvest, the seeds of grasses, caterpillars, and most kinds of fruit and berries. It is also frequently seen on the ground in fields and grass-plots, probably in search of worms and grubs.

Dixon writes:- "Much controversy has taken place respecting the present bird's injurious qualities. The Sparrow eats much that is harmful 
to the crops-the seeds of the charlock and the dock and other noxious wceds; but as a set-off against this it devours an astonishing amount of grain. It feeds on larve and perfect insects, but it also levies at considerable tithe from the fruit-trees. Kept in proper bounds, the Sparrow is undoubtedly a useful bird; but its increase is so rapid, its conditions of life so smooth, and its enemies so few, that, unless artificial means be taken to keep its numbers in check, it soou becomes a perfect pest. I have known farmers in the north of lingland cease from growing corn at all, or only in the smallest quantities, entirely owing to the inroads of the House-Sparrow! and I have seen fields of corn so stripled by these destructive birds that the straw was the only recompense the poor farmer got for his outlay of time and seed. Of course this is only in the meighbourhood of large towns. It is not what the birds absolutely eat, although one Sparrow will take its own bulk of corn in a day, but it is what they waste in the process, by shaking it to the ground or breaking the straws. The Sparrow must be kept under; and this is the opinion of every farmer who has the ill luck to follow his plough near a town. The bird has been introduced into the United States, and its increase there is so rapid that the day will come when our Americau cousins will repent of having introduced such a destructive souvenir of 'home.' After the young are reared the Sparrows unite into flocks and (that is to say the country-bred ones) retire to the fields, where they live chiefly upon grasssecds until the corn is ripe. These flocks are often composed of many hundreds of birds; and a British farmer usually looks upon their visits to his fields with as much dismay as an Lastern firmer docs upon a flock of locusts."

The Housc-Sparrow is not at all migratory in this country; but that it occasionally wanders from home is proved by the fact of its being taken on migration on Heligoland. The immense flocks of this species that frequent our fields in autumn would almost lead us to suppose that the number of Sparrows was increased by migrants from the continent; for the number of birds in the towns is not visibly decreased; but upon closer examination it will probably be found that these hordes of Sparroms are mostly young birds. Although the Sparrow is a very hardy bird, it is undoubtedly a migrant in the coldest portion of its range. In the valley of the Petchora it did not appear to arrive until early in May.

The House-Sparrow has the crown, nape, lower back, rump, and upper tail-coverts bluish grey; over the lores and the eye is a narrow white streak; behind the eye and surrounding the ear-coverts and the sides of the neck is a broad chestnut band; the upper back is very dark brown, each feather edged with reddish brown; the wings and tail are brown, across the former is a broad white bar, caused by the lesser wing-coverts being broadly tipped with white; the lores, throat, and fore neck are 
black, the cheeks are white, shading into pale grey on the ear-coverts, and the rest of the underparts are white, shading into grey on the flanks. Bill lead-blue in summer, black in winter ; legs, feet, and claws brown; irides dark brown. The female differs considerably from the male, and has the whole of the upper parts dull brown, the back streaked with darker brown; the eye-stripe is pale buff, the white wing-bar is not so pure, and the underparts are darker and browner. Young birds resemble the female, but are lighter in colour. After the first moult the young males resemble the old birds of that sex; but it appears not to be until the second year that they assume the richness of colour which stamps the fully adult bird. After the autumu moult the adult male has pale edges to the feathers of the head and throat, but these pale edges are cast in spring.

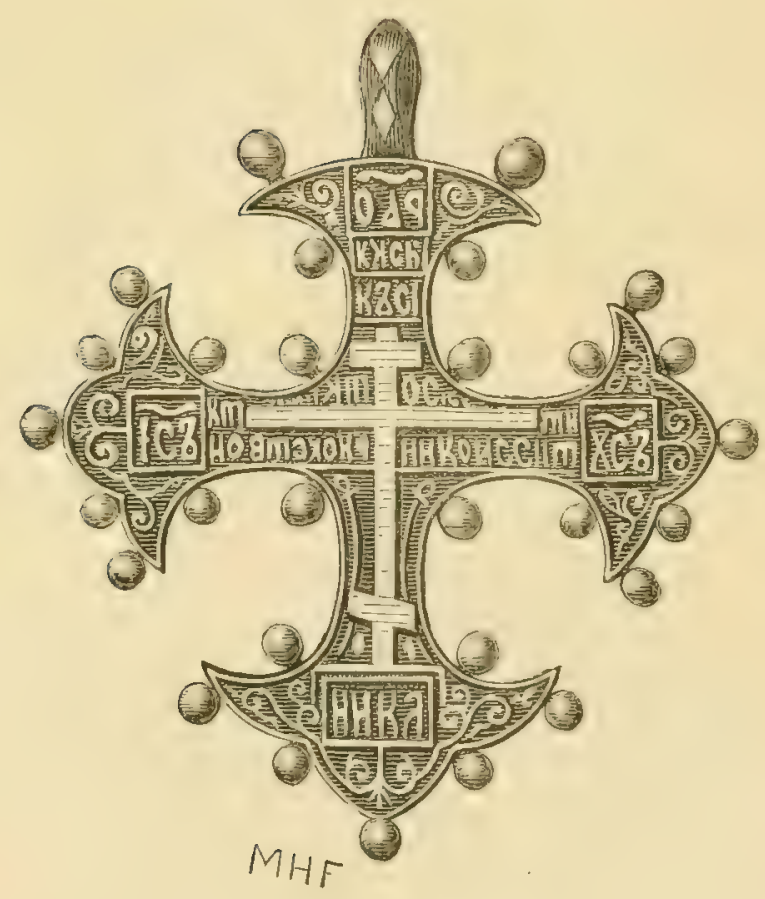




\section{PASSER MONTANUS.}

\section{TREE-SPARROW.}

(Plate 13.)

Passer montanus, Briss. Om. iii. p. 79 (1760); et auctorum plurimorum(Gmelin), (Scopoli), (Latham), (Temminck), Degland \&: Gerbe, (Naumann), Salvadori, Newton, Dresser, \&c.

Passer campestris, Briss. Orn. iii. p. 82 (1760).

Pyrrhula pyrrhula hamburgensis, Briss. Orn. iii. p. 314 (1760).

Friugilla montana, Linn. Syst. Nat. i. p. 324 (1766).

Loxia hamburgia, Gmel. Syst. Nat. i. p. 854 (1788).

Fringilla campestris (Briss.), Schrant, Fauna Boica, i. p. 181 (1798-1803).

Pyrgita montana (Briss.), Cuv. Règne An. i. p. 385 (1817).

Passer montanina, Pall. Zoogr. Rosso-Asiat. ii. p. 30 (1826).

Pyrgita campestris (Briss.), Brehm, Vög. Deutschl. p. 267 (1831).

Passer arboreus, Blyth, Renn. Field Nat. i. p. 467 (1833).

The Tree-Sparrow is a much rarer bird than the House-Sparrow, and its distribution is more local. Even in those districts where it is the most common it appears to keep to certain localities. It is commonest during the breeding-season in the central and eastern counties of England, but is found as far north as Northumberland. It appears not to have been found breeding in Wales; but in Scotland, according to Mr. Gray, it is commoner than is generally supposed. He states that its chief stronghold is in East Lothian. Its breeding-places in Scotland, according to Professor Newton, are in Berwick, Haddington, possibly Clackmannan, Aberdeen, Perth, Elgin, and Sutherland. In the west of Scotland it is very rare; and Mr. Gray states that it cannot with certainty be included in the list of regular migrants. In Ireland this specics was unknown until Mr. II. Blake-Knox recorded, in the 'Zoologist' (1870, p. 2018), the fact that it had been obtained in co. Dublin at Dalkey and Baldoyle, where it is believed to be a resident, but scarce. It does not appear to have ever been obtained in the Orkneys or Shetland. A few pairs visited the Faroes about the year 1869, where, according to Capt. Feilden, they have multiplied so quickly as to become a pest.

The Tree-Sparrow is common, though somewhat local, throughout the Palæarctic Region from the Atlantic to the Pacific up to and, in Europe, slightly beyoud the Aretic circle. It appears to be very rare in North Africa, and to be absent altogether from Grecce, Asia Minor, Palestine, Central and Southern Persia, Baluchistan, and India south of the Himalayas ; it is, however, abundant in Turkestan, Afghanistan, and the Himalayas, and is found in suitable localities throughout the rest of Eastern Asia, including Japan, Formosa, Hainan, and Java. The Tree-Sparrow 
has several near allies, the nearest apparently being $P$. rutilans (which is found in Japan, the island of Askold, South China, and Formosa), $P$. flaveolus and P. assimilis (from the Burmese peninsula), and P. cinnamomeus (from the Himalayas) ; but from all these it may easily be distinguished by the car-coverts, which form a triangular black spot surrounded with white. The Trec-Sparrow is said to have been introduced into North America.

A sturly of the habits of the Tree-Sparrow is very interesting, and tends to prove that it is much more remotely related to the Common Sparrow than is popularly supposed. The haunts of the Tree-Sparrow in our islands are chiefly the fields and wilder districts away from houses. It is nerer scen in the towns, but sometimes approaches the villages, where it associates with the House-Sparrow. On the continent, however, the hird lias so fax overcome its shyness and adapted itself to circumstances as to frequent the towns, and is quite as pert and impudent as its congener, which it otherwise resembles in its habits. The Tree-Sparrow in this country frequents groves of old trees more or less remote from houses, and the banks of sluggish streams that wind along through a lane of pollard willows; it also not unfrequently takes up its residence in the fir-plantations near the moorlands, as, for instance, in the High Peak of Derbyshire, where it nests in the rocks. Sometimes a pair of birds will frequent a large and solitary tree in the open ficlds; and it often takes up its quarters in an old stone-quarry.

In this comntry the Tree-Sparrow is a much shyer bird than the HouseSparrow, otherwise the tro species have much in common. It is a much more lively bird. Long residence in towns and its close companionship with man have probably caused the House-Sparrow to become more or less shusish; hut the Tree-Sparrow is a very active bird, its flight is more rapid, and it seems to have more command over itself in the air. It is, of course, very often observed on the ground, where it hops just like the common species; but when in the branches it is often seen to pass from twig to twig with as much ease and rapidity as a Titmouse. It very often kecps company with the House-Sparrow, especially in winter, and may then be seen upon the dunghills and in the farmyards with that bird. It may casily be recognized by its note, which is much more musical and shriller. Trhen observed it appears to become very wary and restless, and often immediately flies off to the nearest cover. It is quite as pugnacious as the Ilousc-Sparrow, and several of them will gencrally join in a scrimmage, which usually only results in plenty of noise and the loss of a few feathers. The Tree-Sparrow can scarcely lay claim to possess a song; but in the carly months of the year it utters a few notes, which are principally modulations of its call-note; but some of them are not unmusical.

The Tree-Sparrow is rather a late breeder, its nest usually being com- 
menced in April. The bird may pair for life, for in many cases the same site is tenanted yearly. The Tree-Sparrow is particularly fond of breeding in pollard willows. The hole is usually at the top of the stump, but sometimes in the side. Dixon has found the nest of this bird in the branch of an oak tree. It also nests on isolated houses, such as old barns and outhouses, making a hole under the thatch, whilst in rarer instances it will build in crevices of rocks, and even, it is said, in walls. Like its relation the House-Sparrow, it is said occasionally to utilize the old nests of Crows and Magpies; and in such a situation the nest is domed. In the majority of cases the nest is cup-shaped and is rather loosely put together. It is made very similarly to that of the Housc-Sparrow, hut is not, perhaps, so bulky, and does not contain such an assortment of rubbish. It is usually made of dry grass, straws, and rootlets, lined with wool, feathers, and sometimes a little hair. The eggs of the Tree-Sparrow are from four to six in number, and vary considerably in colour. The eggs in each clutch are usually pretty uniform in colour, except one egg, which is generally much lighter than the rest. These light-coloured eggs may be the produce of the bird when its colour-producing powers are getting exhausted. The eggs are bluish white in ground-colour; but generally little of this can be seen, for the surfacc-markings are distributed so finely and evenly over the entire surface as to hide it. The markings vary from rich brown to greyish and grecnish brown. On some eggs, especially those which are more boldly and less evenly spotted, the underlying markings are very large and violet-grey. Some eggs are streaked with very dark brown, something like those of the Mcadow-Pipit. They vary in length from $\cdot 85$ to $\cdot 73 \mathrm{inch}$, and in breadth from 62 to 54 inch. TreeSparrow's eggs very closely resemble those of the House-Sparrow, but are, on an average, smaller and usually darker and redder. The same types are found in each species; but 'Tree-Sparrow's eggs do not seem to vary so much, and the markings are gencrally more thickly and finely dispersed over the entire surface. The Tree-Sparrow is said to rcar as many as three broods in the season; but ccrtainly some pairs of birds never rear more than one. When the nest is disturbed, the old birds, especially if they have young, are very anxious, and uttering their shrill chirping alarm-note, will hop restlessly from branch to branch and approach quite near.

The food of the Tree-Sparrow is very similar to that of the HouseSparrow, but consists more of small seeds than grain, and in summer of insects. The young are fed largely on caterpillars.

In winter the Tree-Sparrow often wanders far from its usual haunts, and may be observed to mingle with flocks of other birds, and is not unfrequently seen in the stackyards with the House-Sparrow. There can be little doubt that our resident birds are increased in numbers in the 
autumn by migrants from the cxtreme north. In confirmation of this may be mentioned that a flock of these birds, in November 1860, according to Mr. Rodd, alighted on a Norwegian vessel when near the English const. It is said that this flock consisted of many hundreds. Mr. Gray also remarks that in some seasons the eastern countics of Scotland are visited by migratory flocks from Scandinavia. Another flock, in October 1833, settled on a ship as it passed the Norfolk and Suffolk coast, and remained on board until it was almost in the Thames. The Tree-Sparrow is regularly observed in October and November on our east coast, sometimes coming in with Greenfinches, and passes Heligoland in some numbers on migration.

The Tree-Sparrow is smaller than the House-Sparrow, and may readily be distinguished from that bird by its clestnut head and nape, buffishbrown rump and upper tail-coverts, black car-coverts surrounded with white, and by the double bar on the wing. Another very interesting distinction between the two birds is that the male and female TreeSparrows are almost precisely alike. The colours of the bill, legs, claws, and irides are similar. In the young in first plumage the black parts are brown.

The TThite-throated Sparrow, Zonotrichia albicollis, has becn recorded as a British bird on the strength of a female specimen shot near the Broadhill, on Aberdeen Linlis, on the 17th of August, 1867. The particulars were communicated in March 1868 to the Natural History Society of Clasgow, who subsequently published in their 'Proceedings' a full description of the bird, with other details. Without wishing to cast any doubt upon the specimen in question, it is, however, extremely probable that the lird had escaped from confinement; and to admit it into the present work scems scarcely advisable. It lias not the remotest elaim to be considered a "British bird," as the term is generally understood. The White-throated Sparrow is found commonly in North America, where it is a migrant, wintering in the southern portions of that country.

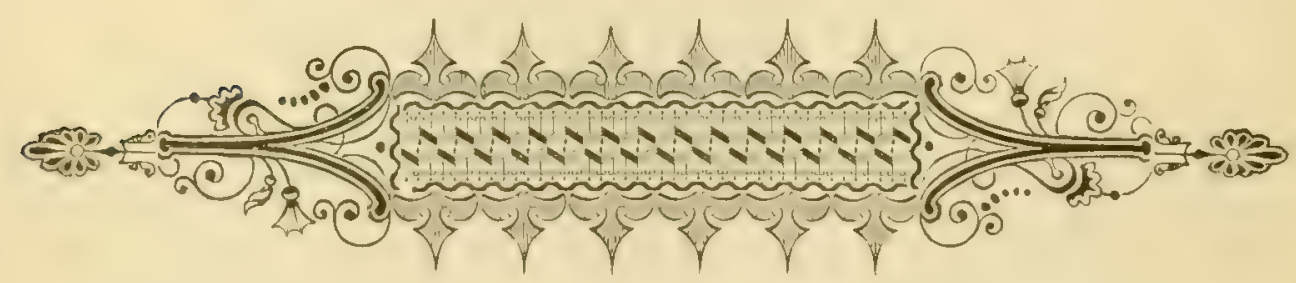




\section{Genus FRINGILLA.}

The genus Fringilla was included by Linnaus in 1766 in his ' Systema Nature,' i. p. 31\%, and the Chaffinch, the Pesser frimgille of Brisson, has been almost universally admitted to be the type. Subsequent writers have subdivided this genus into almost as many genera as it contains species; but there seems to be no reason why the Palicaretic species should not remain in the genus in which Linnaus placed them, with the exception, perhaps, of the Sparrows, to whom we may grant generic rank in deference to custom.

There appear to be no characters by which the Finches can be satisfactorily subdivided. The arbitrary selection of any one of them, whether it be the shape of the bill, the general colour of the plumage, or the pattern of colour on the wings and tail, would separate many species which are obviously very closely allied. In this genus the majority of species have the profile of the upper mandible nearly straight; but those species in which it is curver may be distinguished from the genera hitherto treated of by the prevailing colour of the plumage being green and yellow. About 100 species of this genus are known, which are found throughout the New World, but in the Old World are absent from the Australian and Oriental regions.

These birds are found in almost every locality, from the mountainforests to the open plains. Their food consists largely of seeds; lout in summer insects and fruit are eaten. Many of these birds possess considerable power's of song. They are gregarious in their habits, except in the brecling-season. They build open nests, placing them in trees and bushes at various heights from the ground. Many of the nests belonging to the Finches are elaborately and very beautifully made. Their eggs vary from bluish white to light green in ground-colour, spotted and blotehed with brown of different shades and pale grey, with the exception of the Snow-Finches (Montifringilla et Leucosticte, auct.), all of which lay, so far as is known, pure white eggs. 


\title{
FRINGILLA CHLORIS.
}

GREENFINCH.

\author{
(Plate 12.)
}

Passer chloris, Briss. Orn. iii. p. 190 (1760); et auctorum plurimorum-(Scopoli), (Latham), (Gmelin), (Bonaparte), (Temminck), (Degland \& Gerbe), (Salvador), (Newton), (Dresser), \&c.

Loxia chloris, Linn. Syst. Nat. i. p. $30 \pm$ (1766).

Fringilla chloris (Briss.), Meyer, Vög. Liv- und Esthl. p. 76 (1815).

Ligurinus chloris (Briss.), Koch, Syst. baier. Zool. p. 230 (1816).

Serinus chloris (Briss.), Boie, Isis, 1822, p. 555.

Ligurinus chloroticus, Licht. Nomencl. Av. p. 46 (1823).

Coccothraustes chloris (Briss.), Steph. Shaw's Gen. Zool. xiv. p. 87 (1826).

Chloris flavigaster, Swains. Classif. B. ii. p. 281 (1837).

Chlorospiza chloris (Briss.), Bonap. Comp. List B. Eur. \&. N. Amer. p. 30 (1838).

Chlorospiza chlorotica (Licht.), Bonap. Consp. i. p. 514 (1850).

Ligurinus aurantiiventris, Cab. Mus. Hein. i. p. 158 (1851).

Chloris aurantiiventris $(C a b$.), Salvin, Ibis, 1859, p. 313.

The Greenfinch is a lover of well-cultivated districts, and in such is commonly distributed throughout the British Islands, including the Channel Islands. It is as widely distributed in Scotland as in England, and, according to Mr. Gray, is a permanent resident from north to south. It is found, according to that naturalist, in the Outer Hebrides in such districts as are suited to it; and in many of the inner islands it is equally common. Large flocks of this bird are now often found on the Shetlands, where, within the last few years, it has become a regular winter visitor, though formerly it was very rare there. It is also well known as a winter visitor to the Orkneys, and has occurred on the Faroes several times in winter. In Ircland it is as well distributed and common in suitable districts as in the rest of the United Kingdom.

The Greenfinch breeds throughout Europe, in Norway extending as far north as lat. $65^{\circ}$, and in the Urals as far as lat. $60^{\circ}$. It is also a common resident in North-west Africa, Asia Minor, and the Caucasus, cxtending into North-west Persia and North-west Turkestan. To Palestine it is only known as a winter visitor; and to Madeira it is only a straggler. Examples from the extreme southern portions of its range are said to be more brilliant in colour and to have a larger bill. They have been described as distinct under the name of $F$. chlorotica; but these differences are merely climatic, the colours being most brilliant in examples from districts where the rainfall is small, and dullest in those from moister climates.

The Greenfinch does not appear to have any near ally in Central Asia; 
but on the shores of the Pacific two species belonging to the same subgenus occur, both of which are smaller, and may at once be distinguished by the rich brown colour of the back. The larger of these species, $F$. kavaratiba, ranges from Kamtschatka to Japan; the smaller, $F$. sinica, is found in the valley of the Lower Amoor, the island of Askold, the main and south islands of Japan, and throughout China.

The Greenfiuch, of all the British Finches (excepting the Sparrow), is a bird which is perhaps the best known. This is because its favourite haunts are in our gardens, shrublberies, and pleasure-grounds. It is not a bird of the wilds, and away from the localities just mentioned is local and even scarce. It is, however, very common in fields which are bounded by thick hedges or adjoin plantations of spruce-firs. When found in large woods, it is rarely seen far from the borders. It is a resident bird in this country, and in winter its haunts are perhaps a little less confined to the districts above mentioned; it may then be sometimes seen on the stubbles, near the moorland, in company with Linnets and Trites.

The Greenfinch in summer is to a great extent shy and retiring in its habits, and, like the Bullfinch, it is far more often heard than seen at that season. Its song commences in April, at which time the birds also pair. There is nothing very striking in its music - it is a song which bears some resemblance to that of an inferior Canary; and it is only when several birds are singing in chorus that their notes are at all attractive. In spring half a dozen cock-birds will sometimes be secn in a single tree; and when they are all warbling together, one against the other, the effect is very harmonious and pleasing. It will warble incessantly through the spring, not so frequently in the nesting-season; but in autumn its tremulous and chirping song is heard repeatedly from amongst the richly tinted foliage. Its call-note to its mate is a harsh and long-drawn $z h$; but the common note of a flock as they fly together is a $y i k, y i k, y i k$, rapidly repeated.

Although the Greenfinch caunot be called a gregarious bird in summer, it is a sociable one; and we often find numbers of nests within a small area, sometimes two in the branches of the same tree. I once found two Greenfinches' nests, which were placed side by side on the branch of a tree in my brother's garden at Hitchin. Both nests contained eggs. A similar instance is recorded by Mr. Gurney (Zool. 1852, p. 3577). This bird is a rather late breeder, and eggs are seldom laid before the latter end of April. The great breeding-grounds of the Greenfinch are in shrubberies; by far the greatest number of its nests are built in evergreen trees and shrubs. It also breeds in whitethorn hedges, in gardens, and more rarely in gorse-thickets. Sometimes it will select a nesting-site fifty feet or more from the ground, in a fork of an elm, or eren in a cavity in the trunk. It also builds amongst ivy, both growing on trees and on walls, 
whilst rose-briars are not unfrequently selected as a site. Of evergreens, the yew and the spruce are perhaps most often selected; whilst fruit-trees are very rarely chosen. The nest is built amongst slender twigs, sometimes very loosely, and occasionally it is placed in a fork, or simply built on the flat hongh of a yew. Mr. Maurice C. H. Bird writes to inform me that he knew a nest of this bird at Poxwell, in Dorset, in 1880, built in a hollow at the top of a gatepost. Few nests are pretticer than that of a Greenfinch. It is not so neat as the nest of a Goldfinch or a Chaffinch; but its very slovenliness is the secret of its beauty. The outside is made of moss, dry grass, and wool, through which a few slender twigs are often entwined; the inside is lined first with moss, and then with hair, feathers, and wool. Some nests are much more elaborately constructed than others; and Dixon has known them built entirely of new-mown hay, without any lining whatever. The Greenfinch takes but little trouble to conceal its nest; but the peculiarities of the site selected render it almost invisible except to the closest scrutiny. The eggs of the Greenfinch are from four to six in number, and vary from pale greenish white to white with the faintest tinge of blue in ground-colour. The markings are usually almost confined to the larger end, and are purplish-brown spots, blotches, and more rarely streaks, with underlying spots of pinkish brown. As a rule, there are as many underlying markings as surface oncs; but in some cggss the former predominate. They do not vary much, but some are very boldly streaked, whilst others have the markings in a confluent zone round the end of the egg; and my friend MTr. J. II. Gurney, Jun., writes to me that he harl a nest of this bird in his garden in which the eggs were unspotted-certainly a very exceptional occurrence. They vary in length from 9 to $\cdot 72$ inch, and in breadth from $\cdot 62$ to $\cdot 53$ inch. The eggs of the (irecnfinch very closcly resemble those of the Goldfinch and Limnet; and small specimens are indistinguishable from large eggs of the two latter species. They also resemble those of the Crossbill so closely that it is almost impossible to distinguish them; but, as a rule, they are perhaps smaller in size. The Grecufinch is one of those birds that sometimes sit upon their first egg as soon as it is laid. When the nest is menaced by danger the old birds often become extremely anxions, and glide about from branch to branch above the intruder's licad, uttering their plaintive alarmnote; and should the nest contain young, the female will approach still closer, and by every action and cry show her anxiety. The duties of inculation are performed by the female; but the male is seldom far away from the nest. The young are tended some time after they quit the nest, when they are abandoned, and the old birds mostly rear another, and in some cases perhaps even a third, brood.

In early summer these young Greenfinches congregate into flocks and little parties, which chiefly frequent the grass-ficlds, in company very often 
with Sparrows. They may be seen hovering above the grass, catching the small flies, but chiefly feeding upon the seeds of the grasses. As the year advances, and the grain-fields assume their golden tints, these flocks of Greenfinches are joined by the old birds, together with those of the later broods. In winter Greenfinches flock in company with Buntings, and frequent the newly sown fields. At this season they flock in considerable numbers to the shrubberies to roost, and sometimes, ere they settle, perform various wheeling motions in the air. The flight of the Greenfinch is undulating; and although the bird is somewhat heavy-looking, it has no small power over itself in the air.

The Greenfinch is, like most other Finches, partly granivorous and partly insectivorous. The bird feeds almost as much on grain as the Sparrow, and would be equally as destructive to the crops if its numbers were at all proportionate. But the amount of noxious sceds this bird devours is enormous, and amply repays any trifling loss of grain the farmer may suffer. It does not appear to feed so much on fruit as the Sparrow; but it will eat several kinds of berries, and is fond of the buds of trees. In winter it often makes its appearance in the stackyard, and is frequently flushed in straggling parties from the stubbles, where the objects of its search are small seeds of various kinds.

The Greenfinch is a resident bird in this country; but its numbers are increased in autumn by large flocks from the continent, which make their appearance principally on the castern and southern coasts. It has often been observed that a considerable separation of the sexes takes place in winter; but this is not so marked as that which takes place with the Chaffinch. The birds of the year and the females flock together, with only a sprinkling of old males, whilst other and smaller flocks are composed almost entirely of old males. These flocks do not break up sometimes until very late in the year'; and Mr. Cordeaux remarks that he has seen them feeding on the marshes of the Humber in the first weck of June. The Greenfinch is frequently kept in confinement, and is said to be more hardy than most birds; but its powers of song are never great, and it learns slowly. Greenfinches are often crossed with Canaries; and hybrids of this bird and the Brown or Common Limet are sometimes caught in a wild state. A hylorid of this description will be more fully noticed in the article on the Linnet.

The adult male Greenfinch has the general colour of the plumage bright yellowish green, brightest on the rump, and shading into slate-grey on the flanks and lower belly, and into yellowish white on the under tail-coverts. The crown, the sides of the head and neck, the throat and breast, the margins of the secondaries and greater wing-coverts are more or less slategrey; the wings are brownish black, the basal half of the outer web of the primaries broadly margined with bright yellow. All the two central 
tail-feathers and the terminal half of the rest are blackish brown, bordered with slate-grey; the remaining portion of the latter feathers is bright yellow. Bill fleshy pink; leg's, toes, and claws pale brown; irides hazel. The female is much duller in colour than the male, and browner; but the pattern of colour on the wings and tail is the same, although the yellow is not so brilliant. Young birds in nestling-plumage resemble the female, and have the yellow on the wings and tail. After the first moult the young males gain the adult plumage. After the autumn moult the feather's have pale margins, which conceal much of the bright tints of the plumage.

A specimen of the Nompareil Finch, Cyanospiza ciris, was taken alive in 1802 on Portland Island, and was recorded by Montagu under the name of "White-winged Grosbeak," in the Supplement to his "Ornithological Dictionary' (1813). It had evidently escaped from confinement. It is an inhabitant of Central and North America, and, as a land-bird purely confined to the New World, requires no further mention here.

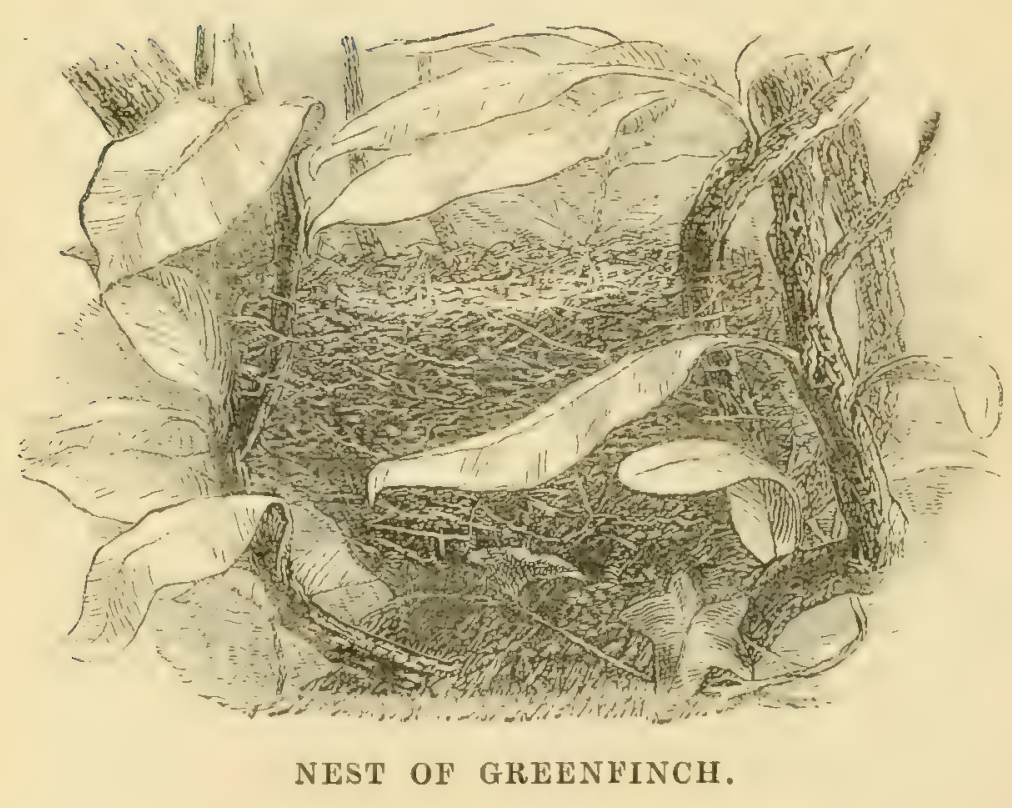




\section{FRINGILLA CANARIA.}

\section{CANARY.}

$($ Plate 12.)*

Passer serinus canarius, Briss. Orn. iii.p. 184 (1760).

Fringilla canaria, Limn. Syst. Nat. i. p. 321 (1766); et auctorum plurimorumGmelin, Latham, (Bonaparte), (Godman), (Dresser), \&c.

Carduelis canaria (Linn.), Less. Traité d'Om. p. 443 (1831).

Crithagra canaria (Limn.), Swains. Classif. B. ii. p. 294 (1837).

Serinus canarius (Linn.), Cab. Mus. Hein. i. p. 163 (1850).

Dryospiza canaria (Linn.), Gray, Hand-l. B. ii. p. 83 (1870).

The first alleged occurrence of the Canary in our islands in a wild state rests on the authority of Mr. Swaysland, who states that at least fifty year's ago he caught one in his father's net early one morning in April near Brighton. It was a bird of remarkably rapid flight, and when it was caught it turned sharp and flew into the net with the rapidity of a Hawk. He further states that the actions of the bird, when it was transferred to a cage, were extremely wild.

There can be little doubt that the Canary is an accidental visitor to the British Islands. Birds indistinguishable from the wild Canary of the Azores, and having no appcarance of ever having been in confinement, are occasionally caught by the bird-catchers in the ncighbourhood of London. Mr. Boud has an example thus obtained in his collection; and Mr. Bartlett informs me that at least four cxamples have passed through his hands. Other specimens have been obtained near Brighton. The number of birds passing along the coast in autumn on migration is almost fabulous; they are caught with clap-nets. A bird-catcher told me that he once caught three thousand Greenfinches in a fortuight near Brighton, and that he was sure that he did not catch more than one in a hundred of the birds that flew over. In October, on the cliffs between Brighton and Shoreham, and between Brighton and Newhaven, a hundred pairs of nets are set every morning; and it is not an uncommon thing for one man to catch a hundred, and on special occasions, with a north-cast wind, five or six hundred Grecnfinches and Limnets in a morning. Amougst the thousands of common birds which are caught in this way, an occasional rare bird occurs, and is offered to Mr. Swaysland for sale. Every two or three years a wild Canary is brought to his shop; and cxamples thus obtained are in the collections of Mr. Monk, Lord Clifton, Major Spicer

* The small eggo of the Greenfinch figured on this Plate is an exact duplicate of an eggr of the Canary. 
of Chippenham, near Bath, the Rev. Hugh A. Macpherson of Carlisle, and others. Mr. G. Dawson Rowley exhibited one at a meeting of the Zoological Society of London (see Proc. Zool. Soc. 1870, p. 53), which was taken on the 20th of November, 1869. Many other's have, no doubt, been overlooked. Some have been passed over as small Greenfinches, other's have been recorded as Seriu Finches, whilst the committee of the ' This' list of British Birds admit that they are often met with in England, but assume that they have in all cases escaped from captivity. The wild Canary is, however, such a very rare bird in cages in England, and escaped birds of the tame Canary are so rarely caught, that we cannot accept this theory of their origin. None of the examples of British-killed Canaries which I have seen show any of those marks of confinement which can usually be detected in the state of the fect and tail of caged birds, and the more probable explanation is that they are birds which have been driven over by south-westerly gales from Maderia or the Azores. Mr. Godman, in speaking of these islands, says that "scarcely a storm occurs in spring or autumn without bringing one or more species foreign to the islands," and enumerates Swallows, Larks, \&c. anong them. There ean therefore be no insuperable difficulty in stragglers from the Azores reaching our shores.

The Canary is abundant on most of the Canary Islands, on Madeira, and throughout the Azores. It breeds not only in the gardens of the large towns, but also in the pine-forest up to an elevation of six thousand fect; and after the breeding-season is over the Canaries collect in large flocks and may be seen flying from one island to another. It is not to be wondered at that they are sometimes carried away by storms to the mainland.

The Camary is the island form of the Serin. In its habits it closely resembles other Finches, and after the breeding-season frequents the fields, where it is said to be very destructive to the flax. Like the Greenfinch and Goldfinch, the Canary appears to have a liking for gardens, even frequenting those in the middle of towns; and it is also common in the vineyards, and in the little swampy places which are left as the sole remmants of the streams that flow in winter. It also inhabits the pineroods on the mountains, and breeds in them, coming down to the plains in winter.

It is a somewhat carly breeder, commencing nest-building in the latter part of March. The nesting-site is usually selected in some evergreen tree or shrub, placed at a considerable height from the ground, and is seldom below eight feet. A nest of this bird found by Dr. Bolle was built in the fork of a box-tree about twelve feet high, growing ont of a myrtle hedge. This nest was described by him as being broad at the base, narrow at the top, and very neatly built of snow-white cotton-plant 
mixed with a few dry grass-stems. The eggs are four or five in number, bluish green in ground-colour, spotted and speckled with reddish brown; they measure about 8 inch in length, and about 55 inch in breadth. According to Dr. Bolle the Canary will rear as many as four broods in the season, but sometimes only three. The female alone performs the duties of incubation, and the male may often be seen perched on a bush or tree near at hand warbling forth his song.

The song of the Canary is too well known to need description; but it seems that domestication has increased the beauty of its uotes, for it is said that birds in confinement possess a better song than those in a wild state. After the breeding-scason the birds unite into flocks, and search for food in company. When alarmed they fly off in a straggling train like Linnets, continually calling to each other as they go. Their flight is very similar to that of the Linnet, and is usually only prolonged from tree to tree; they are, however, capable of taking long flights; and Mr. Godman remarks that on the island of Fayal the birds congregate towards evening near a small hill, and cross in a body to the island of Pico. In their habits at nightfall they very closely resemble Bramblings, and at the selected roosting-place are very noisy.

The food of the Canary consists of seeds of various kinds, and fruits, especially figs, of which it is said to be very fond. There can be little doubt that it also feeds on insects, as all other Finches doubtless do more or less.

From the beginning of the sixteenth century the Canary has been a highly-prized cage-bird, and is still as popular as ever. In Germany it is in even higher repute than in this country; it is the favourite cage-bird; and great numbers are bred there every year, as well as in England. Canary-breeding has almost reached the dignity of a science; its devotees have their socicties and their shows, and the perfection of breeding and the varieties obtained by judicious intercrossing are most remarkable. Many wild birds are still caught on their rocky isolated retreats, and scarcely a person visits the islands without bringing away with him a bird or two under the delusion that they are real souvenirs of the place. But by far the greater number brought from the islands yearly are not native: the demand far exceeds the supply; and tame-bred birds are actually imported from England and Germany and sold there as natives. Wild birds, it is said, do not bear confinement well, and do not breed so freely as those bred in eages. In confinement the female sometimes sings as sweetly as the male.

The wild Canary is quite a different-looking bird from that usually seen in cages. It has the crown yellowish green, narrowly streaked with blackish brown; the feathers of the back and the upper tail-coverts are blackish brown, broadly margined with grey, and marlied with olive-greeu; 
forehead and rump bright yellowish green; wing-coverts blackish brown, tipped and margined with olive-grecn. The whole of the underparts are golden yellow, shating into almost white on the under tail-coverts, and the flanks are striped with blackish brown. Bill light brown; legs, feet, and raws fleshy brown; irides hazel. The female is much duller than the male, and has much less golden yellow in the plumage; the crown is grey, streaked with blackish; and the underparts are buffy white, yellower on the throat and breast. English examples have obscure grey margins to the yellow feathers, and the margins to the feathers of the back are brown instead of grey, which appears to be characteristic of autumn plumage, or that of birds of the year. I have not had an opportunity of comparing them with birds in autumn plumage from the islands.

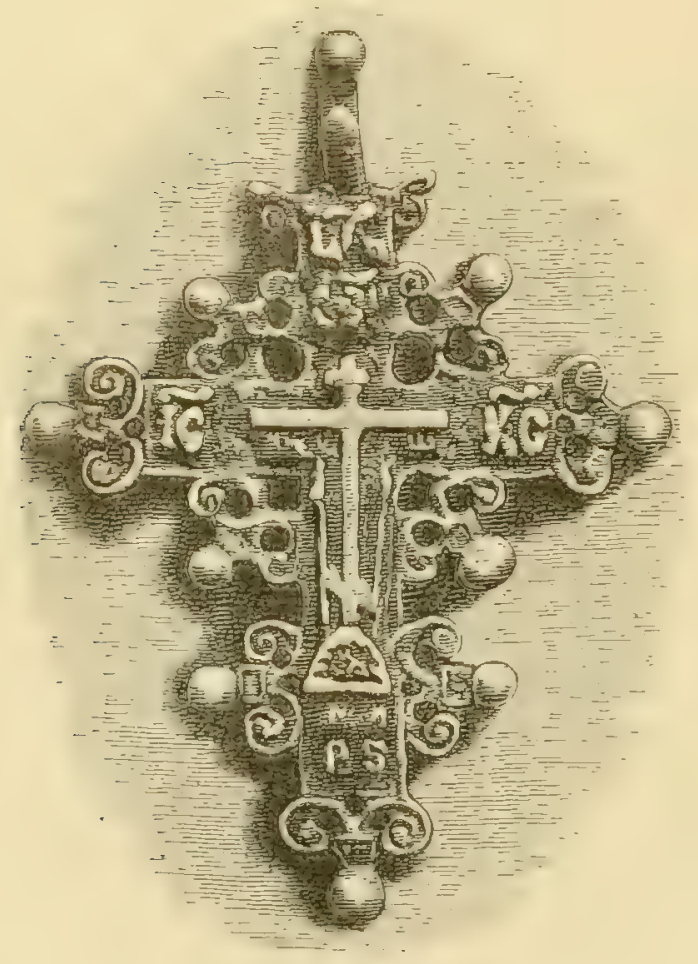




\section{FRINGILLA SERINUS.}

\section{SERIN FINCH.}

(Plate 12.)

Passer serinus, Briss. Orn. iii. p. 179 (1760).

Fringilla serinus, Linn. Syst. Nat. i. p. 320 (1766); et auctorum plurimorum(Gmelin),(Latham), (Temminch), (Gray), (Miiller), (Schlegel), (Degland), (Bree), (Elwes \& Buckley), (Danford \& Harvie-Brown), (Brehm), (Homeyer), (Schalow), (Blasius), (Reichenow), \&c.

Loxia serinus (Briss.), Scop. Ann. I. Hist. Nat. p. 140 (1769).

Serinus hortulanus, Koch, Syst. baier. Zool. i. p. 229 (1816).

Serinus flavescens, Gould, B. Eur. pl. 194 (1837).

Pyrrhula (Dryospiza) serinus (Briss.), Keys. u. Blas. Wirb. Eur. p. xli (1840).

Pyrrhula serinus (Briss.), Degland, Orn. Eur. i. p. 192 (1849).

Crithagra serinus (Briss.), Heugl. Om. N.O.-Afr. i. p. 647 (1871).

Serinus luteolus, Homeyer, Journ. Orn. 1873, p. 223.

The evidence in support of the opinion that the Serin is an accidental visitor to our shores rests on no better foundation than that which can be adduced in support of the claim of the Canary to be so considered. It is said that a Serin was caught near Portsmouth in $\Lambda$ pril 1852, another at Taunton in 1866, and a third at Worthing in 1869; but by far the greater number are those brought by the Brighton bird-catchers to Mr. Swaysland. Rarely a year passes without two or three being thus obtained, although it sometimes happens that none are caught for a couple of years. Some ornithologists have supposed that these birds have escaped from confinement, alleging that these captures have become much commoner since the Serin was appreciated as a cage-bird in this country; whilst others have doubted the good faith of both the captors and the vendors. So many frauds have been attempted on collectors that scepticism has become a virtue in ornithologists. In the present case, however, I see no reason to doubt the veracity of those concerned, or to question the occasional visits of the Serin to our islands. The wonders of Heligoland were at first doubted by distinguished ornithologists: now we ask whether the Serin has occurred on Heligoland, and finding that it has we accept the fact as strong evidence of its having also occurred in this country.

On the continent the range of the Serin is remarkably restricted, being confined to Europe, west of Russia, and to North Africa. To the north of France, Belgium, and the north of Germany the Serin is an accidental visitor, as it is to the south of England. It breeds in Central and Southern France, Luxembourg, Switzerland, South Germany, Austria, and Turkey; and in all these countries a few remain during the winter. In Portugal, Spain, Italy, Greece, and Asia Minor it is a resident, breeding 
principally in the mountains, and having its numbers largely increased during winter by migrants from the north. Great numbers winter in Palestine and Egypt; and in the west of North Africa it not only winters in considerable numbers, but a few remain to breed.

There scems to be no account of the habits of the Serin except that of the great German ornithologist, Naumann; and I translate the following from his 'Birds of Germany:' - "It prefers to live in hilly cultivated districts, and is much rarer in the plains. It takes up its quarters chiefly in the orchards, in plantations, or avenues of fruit- and walnut-trees, in vineyards, . . . and even in gardens in the middle of villages or eluse by houses. ... The male is most restless and joyous in fine spring weather; he calls and sings continually from the tops of the trees, aud delights to bound from one to the other in singular flight, sometimes hovering or rising and falling with trembling wings. His usual flight resembles that of the Siskin and similar birds and is very rapid; it would have nothing extraordinary about it if the birds did not attract attention by their peculiar voice during flight. . . . . Its song is very agreeable, clear as a bell, .... more like that of the Siskin than that of the Canary, with which it has becu compared. When singing it is always perehed ligh on the topmost spray of the tree or on a high branch. .... It not only sings on the wing, as described, but sometimes springs from the top of a tree like a TreePipit, almost perpendicularly, singing, then descends and continues its song on the same or a neighlbouring spray. . . . . It feeds, like its congeners, on small seeds of various plants, especially those cultivated in gardens, or such as grow wild in vineyards and on the roadside, chicfly such as are oleaginous. . . . . It shells all the seeds, and rejects the husks."

When I was in Dresden with Mr. Sclater and Mr. Forbes, we found the Serin very common in the Zoological Gardens outside the town. One of these little birds was singing from almost every clump of trees. It is a charming, delicate, little song, very much like that of the Siskin, but richer and more varied. Compared with the song of a Canary or a Nightingale, it might be called weak and monotonous; but I was charmed with its clearness and richness. The call-note is not unlike that of the Canary, and resembles the word sweet. Heuke reintroduced me to the Serin in the charming little village where he lives in Saxon Switzerland, and took me to an orchard where he showed me a pair of birds busily engaged in building a nest on the branch of a pear-tree. He told me that it was only during the last twenty years that the Serin had become common near Dresden. Other ornithologists have noticed the recent increase in the numbers of this species in various localities. This is probably to be explained by supposing that previously the numbers had been very much lessened by an unusually hard winter or a heavy and sudden fall of snow, and that it has talien years before the natural increase 
has restored them to thcir usual abundance. Small birds, like the Dartford Warbler, which winter north of Central Europe, are sometimes almost exterminated in some localities by bad weather.

Dixon met with this bird in Algeria, and writes as follows :- "We did not meet with this charming little bird until we arrived in the most tropical portion of Algeria-in the palm-oases of El Kantara and Biskra. It is a bird that appears to love the richest districts, and we never met with it in the pine- and cedar-forests on the Aurès. In the oases the birds inhabited the luxuriant gardens, the groves of fig-trees, and were seen amongst the apricot-trees and wealth of shrubs bountifully clothed in the fairest of blooms. But amongst this semitropical verdure the Serin is difficult to see, and you only catch a liasty glimpse of it as it appears on the outermost branches for a moment and then disappears again. Amongst the date-palms, however, it is very conspicuous. There is little or no underwood beneath these trees, and the bird perches exclusively upon them. It was seen sitting on the topmost point of the broad leaves, sixty feet from the ground, whence it occasionally took a little fluttering flight into the air to catch an insect from the swarms flitting round the tree-tops. All the Finches in summer-time are more or less insectivorous, and the little Serin is no cxception; indeed it seems most inclustrious in its search after insects, not only flitting into the air but occasionally clinging to the stems of the palm trees, as if searching for its food amongst the rugged bark. We repeatedly saw it, too, upon the tops of the walls that divide the Arab gardens; but it was always rather shy, and after a moment or two's rest flew off to its usual refuge, the tops of the date-palms. Although it must have been its breeling-season (May), we never heard it utter any song-only its sweet and somewhat plaintive little call-note."

The nest of the Serin, though very loosely made of short slender stalks and roots, held together with thistle-down, spider's web, and bits of wool or cotton, is very carefully and neatly constructed. There is no special lining, except that the proportion of soft material is greater inside than outside. The outside diameter is only about $2 \frac{3}{4}$ inches, and that of the inside only $1 \frac{3}{4}$ inches; the depth is little more than an inch. Naumann says that hair and feathers are used in the lining; but the nests I have seen have never contained either. The nest is generally built in fruit-trees, but frequently in other small trees and shrubs. Five is the usual number of eggs, but sometimes there are only four. They are on an average smaller than those of the Goldfinch or Siskin, but are indistinguishable from them, being subject to the same variations of colour. The length ranges from - 65 to $\cdot 6$ inch, and the breadth from 5 to $\cdot 15$ inch. The ground-colour is very pale bluish green, more or less spotted and blotched and occasionally streaked, chiefly at the large cud, with dark reddish-brown overlying spots and pale reddish-brown underlying ones. 
The Scrin is a miniature Canary, and though much more streaked on the flanks scarcely differs from that species except in size and proportion. The wing of the Canary is about 2.9 inches in length, whilst that of the Serin is about $2 \cdot 8$, and it is probable that large examples of the latter have a wing as long as small examples of the former. The difference in the length of the respective tails of the two birds is, howcver, much more important: that of the Siskin is usder 2 inches, whilst that of the Canary is over $2 \frac{1}{4}$ inches.

The Serin bears some superficial resemblance to the Siskin; but the black crown of the male of the latter and the yellow bases of the tailfeathers in both sexes are sufficient to distinguish them. The shape of the bill is also quite different. In the Serin the profile of the bill shows an arched instead of a nearly straight upper mandible, and secn from above it represents a cone with convex instead of concave sides. Some ornithologists, whose apparent object has been to introduce as much confusion as possible into our nomenclature, have placed these convex-billed birds in a separate genus, which they call Serinus. Besides the Canary and the Serin, it contains 'Tristram's Serin (Fringilla canonicus) and the Red-frouted Finch ( $F$. pusilla). The former is a local race of the Canary which is resident in Palestine, and differs from it in being somewhat yellower and less striated both above and below; the latter is a resident in Asia Minor, the Caucasus, Persia, Turkestan, and Cashmere, and is somewhat distantly related to the Serin, from which it may at once be distinguished by its black throat and the orange-red instead of yellow prevailing tints of the plumage.

In the adult male Serin in breeding-plumage the forehead, a line over each eye, the rump, the throat, breast, and belly are bright yellow; the feathers of the rest of the upper parts and the flanks are dark brown, margined with yellow; the greater and median wing-coverts are dark brown tipped with yellow, and the wings and tail-feathers are brown margined with yellow ; the under tail-coverts are nearly white. Bill dark horn, paler at the base of the lower mandible; legs, feet, and claws pale brown; irides dark brown. The female is slightly duller in colour than the male, and after the autumu moult the yellow feathers, especially of the head, have buff margins.

A specimen of the Yellow-rumped Seed-cater (Crithagra chrysopyga) was recorded as a British bird in the 'Naturalist' for 1853 (p. 20) by $\mathrm{Mr}$. W. Hazel; it is said to have been taken near Portsmouth. There can scarcely be a doubt that the bird had escaped from confinement, having been brought to that port by some vessel from the West-African coast, where it is a native. 


\section{FRINGILLA CARDUELIS.}

\section{GOLDFINCH.}

\section{(Plate 12.)}

Carduelis carduelis, Briss. Orn. iii. p. 53 (1760); et auctorum plurimorum(Gmelin), (Latham), (Pennant), (MLontagu), (Bevick), (Temminck), (Gray), (Naumann), (Danford \& Harvie-Brown), (Finsch), \&c.

Fringilla carduelis, Linn. Syst. Nat. i.p. 318 (1766).

Emberiza carduelis (Briss.), Scop. Ann. I. Hist. Nat. p. 144 (1769).

Acanthis carduelis (Briss.), Bechst. Naturg. Deutschl. p. 199 (1807).

Spinus carduelis (Briss.), Koch, Syst. baier. Zool. i. p. 233 (1816).

Passer carduelis (Briss.), Pall. Zoogr. Rosso-Asiat. ii. p. 15 (1826).

Carduelis elegans, Steph. Shaw's Gen. Zool. xiv. p. 30 (1826).

Carduelis aurata, Eyton, Cat. Brit. B. p. 20 (1836).

The Goldfinch is locally distributed throughout England, breeding in suitable districts in probably every county, with the exception of Northumberland, where Mr. Hancock states that it must only be considered an accidental visitor. It is also not uncommon in the Channel Islands, and, according to Mr. Cecil Smith, brecds in all of them. In Scotland its distribution is more local than in England, but it is nevertheless found in most if not all of the counties; but it does not appear ever to visit the Orkneys and Shetland. In Mr. Gray's opinion this charming little bird is decreasing in numbers in Scotland; and this is also said to be the case in many parts of England. In Ireland it is decidedly local, and though found in most parts of the country, its distribution is confined to certain favoured districts.

The Goldfinch brecls throughout Europe, in Norway as far north as lat. $65^{\circ}$, but in the Ural Mountains only as far north as lat. $60^{\circ}$. North of St. Petersburg it is extremely rarc, and its alleged occurrence at Archangel appears to be supported by insufficient evidence. In the extreme north of its range it is a partial migrant. It is a resident in the Canary Islands, Madeira, and North-west Africa, but to Egypt it is only a winter visitor. It has been found in Palestine, and is a resident in Asia Minor and Persia. In South Siberia it has been found from Omsk to Krasnoyarsk, and as far south as the Altai Mountains. It is only a winter visitor to Turkestan. Examples obtained east of the Ural Mountains are large and nearly white on the rump and flanks, and have been described as specifically distinct under the + name of $F$. major. There can, however, be scarcely any doubt that these two forms interbreed, as at Krasnoyarsk $F$. mrijor is found interbreeding with a more distant ally, $F$. caniceps, which differ's in having no black on the crown and nape, and in having much more white on the wing. This subspecies ranges southwards to the Altai Mountains and westwards to 
Afghanistan, the North-west Himalayas, and Turkestan. A variety of the Goldfinch having the throat white has been obtained at Pesth, and has been described under the name of $C$. albogularis; but further information is necessary to prove that this variation is constant.

Althongh this charming little bird loves to dwell in the richest parts of the country, it is most common on those little pieces of waste land which, in spite of "high farming;" are still left in their primeval state to grow thistles and docks and other rank weeds in abundance. The Goldfinch is an attendant upon the slovenly farmer who dloes not make use of his "odd corncrs" and is not very careful about his hedgerows; but on those farms where scarcely a weed is left to grow the bird is rarely seen. It does not affect the decp woods like some Finches, nor does it frequent the pine- and fir-woods. It may often be seen in country orchards, and appears to have a partiality for the neighbourhood of houses, and near them it most commonly builds its nest. It is a very active little bird, almost as much so as a Titmouse or a Willow-Wren.

Dixon made the following notes on this hird :- "The Goldfinch is one of the commonest and most widely spread birds in Algeria. It haunts the palm-studiled oises, the orange-groves, fig- and prickly-pear gardens, even on the borders of the Great Desert, just as much as the luxuriant forest country of the Aurès. It is not, however, a bird of the wilderness; it inhabits the cultirated districts, especially the $\Lambda \mathrm{rab}$ gardens, building its nest in their fruit-trees and warbling incessantly from the sprays of bloom. I never in any place saw the Goldfinch so common as at Oucd Taga, the mountain home of the Kaid of the Aures, lying at an elevation of probably 1000 feet above the sea. The gardens at this Arab settlement were full of them. I often counted three or four in the same tree, and the air was made resonant with their charming song. They were not at all shy; the Aral never molests them; and they breed in his apple-trees in abundance. I often saw them upon the ground, and searching the twigs and branches of the trees as if looking for insects, which probably form their staple food in the summer months. In the oases the Goldfinch does not appear to affect the palm trees like the Serin Finch, but is especially fond of the luxuriant gardens gay with flowers and literally buricd in an exubcrance of greenest foliage. Here they nest in the apricot- and fig-trees; and at Lil Kantara in May a pair were making their neat little home in a fork of a lemon-trec almost within arm's leugth of the windows of the 'Hôtel d'El Kantara,' as the tiny little I'rench caravensérai is ambitiously named."

The song of the Goldfinch is almost as loud and sweet as that of the Limmet, and is commeneed almost before the winter is over, being sometimes heard as carly as the beginuing of March, and it will continue through the summer (in the latter part less frequently) till the moultingscason in August. The ordinary call-note of this bird is a sharp and 
quickly repeated twit or twit-it. It is incessantly uttering this note, both when flying through the air and as it sits on or clings to the tall stems of thistles and other weeds. The call-note of the male to the female sounds something like the word eaglet.

It is not improbable that the Goldfinch in many cases pairs for life. In the depth of winter the birds are often seen in pairs, and as the spring advances the little parties break up and in pairs search out their nestingsites. The bird at this season often takes up its quarters in a garden or an orchard, sometimes in a grove quite near to a house, where it remains until its young are strong upon the wing. The site usually selected for the nest is in an apple- or a pear-tree, especially the former; and a branch which is covered with moss or lichen is generally preferred. The bird will also build in a clestnut- or a beech tree, sometimes at the extremity of a long drooping branch, and when in such a situation it is often quite inaccessible. It less frequently selects a site in a whitethorn hedge or in the evergreens in a shrubbery. It is one of the commonest birds in the lower valleys of the Parnassus, and breeds in great numbers in the olive-trees between the site of the temple of Apollo at Delphi and the Gulf of Lepanto, especially in the village gardens. The nest is a charming piece of birdarchitecture. It is much smaller than that of the Chaffinch, but is to a certain extent marle on the same model. It usually measures from $1 \frac{1}{2}$ to 2 inches in inside diameter, and is about 1 inch deep. It is often made of moss, lichens, vegetable down, fime roots, and grass-stems, and lined plentifully with feathers and down and a few long hairs. Nests taken in Greece and Asia Minor were almost entirely made of stems of a plant with round flat seed-cases attached, strengthened by rootlets and lined with vegetable down. Some nests are almost entirely made of down and bits of worsted with a few roots, without any feathers. The eggs of the Goldfinch are four or five in number, and are laid by the middle of May. They are greenish white in ground-colour, spotted and streaked with purplish brown and with underlying markings of violetgrey. The spots vary considerably in intensity of colour, and on some eggs are almost black. Some specimens are only scratched and indistinctly marked with reddish brown, others are almost spotless. The larger end of the egg is usually the most spotted, where the markings form an irregular zone. Some eggs are much more boldly streaked than others, and the streaks are longer. The eggs vary in length from $\cdot 7$ to 62 inch, and in breadth from '53 to 48 inch. Goldfinch's eggs can generally be distinguished from Linnet's and Greenfinch's, which they much resemble in colour, by their smaller size; whilst from those of the Lesser Redpole they are easily told by their much lighter ground-colour. From those of the Citril Finch, Serin, and Siskin they are indistinguishable, except in perhaps being blunter and a trifle larger. 
The food of the Goldfinch is composed principally of insects and their larva in summer; but in winter this bird is almost, if not quite, granivorous. At this scason it feeds on seeds of various kinds, especially on those of the dock and the thistle; it also eats those of the dandelion, chickweed, groundsel, and plantain. In winter the birds are often seen in small parties, sometimes in large flocks, which are ever wandering about in search of food. No frost or snow, however severe, seems to inconvenience this charming little bird, for it can always find plenty of food on the tall weeds that tower high above the deepest snow. It is a very pretty sight to see a party of Goldfinches searching for food, especially when the ground is covered deep in snow. You may approach them quite closely and they will take but little heed of your presence. You may watch how deftly they poise on the thistle-heads or cling, sometimes head downwards, to the bushy docks. Bencath the plants the husks are thickly strewed upon the suow, and betray the recent presence of these charming creatures in the locality. They are very restless birds and do not stay long in one place; they are incessantly flitting on and on, from one stem to another, in drooping jerling flight, and the air is filled with their clear twittering notes.

A considerable number of Goldfinches remain with us throughout the winter; but most of them go southwards in autumn, in company with migrants from North Europe that pass our islands. Our Goldfinches appear to fly south until they strike the coast, which they follow, "cuddling the cliffs," until the narrowest part of the Channel is reached near Dover, where they start for the continent.

The wholesale capture of this bird is no doubt one of the causes of its decrease in numbers. Mr. Swaysland states that near Brighton a boy could formerly catch as many as forty dozen of these birds in a single morning; but this wholesale work soon perceptibly thimned the ranks of the Goldfinch, and the bird is now comparatively rare. The Goldfinch is in great request as a cage-bird, and may be taught many tricks; it is also used considerably by Canary-breeders to cross with that bird.

The Goldfinch has a black band from the centre of the crown of the head, which meets on the nape a similar black band reaching halfway round the neck. The feathers at the base of the bill and the lores are black; the forehear and throat are rich scarlet; the rest of the upper parts are reddish brown, shading into white on the upper tail-coverts; a patch on the nape and the sides of the head and the underparts below the throat are dull white, shading into buffy brown on the breast and flanks; the wings are black, broadly barred with yellow and tipped with white; the tail is black, the two outer feathers on each side (occasionally the three outer feathers) have a spot of white on the inner web and the rest are tipped with white. Bill pinkish white, darkest at the tip; legs and feet fleshy 
brown, claws dark brown; irides brown. The female resembles the male, but is duller; the red parts are not so pure and not so much developed. Young in first plumage have no black and red on the head; the wings and tail are similar to the adult, except that the white spots are replaced by buff; the underparts are much browner, and the breast is indistinctly spotted. The red and black plumage on the head is assumed after the first autumn moult. The autumn plumage of the Goldfinch differs but very slightly from that of spring; some of the black feathers have pale edges, and the red on the head is not so intense in colour.

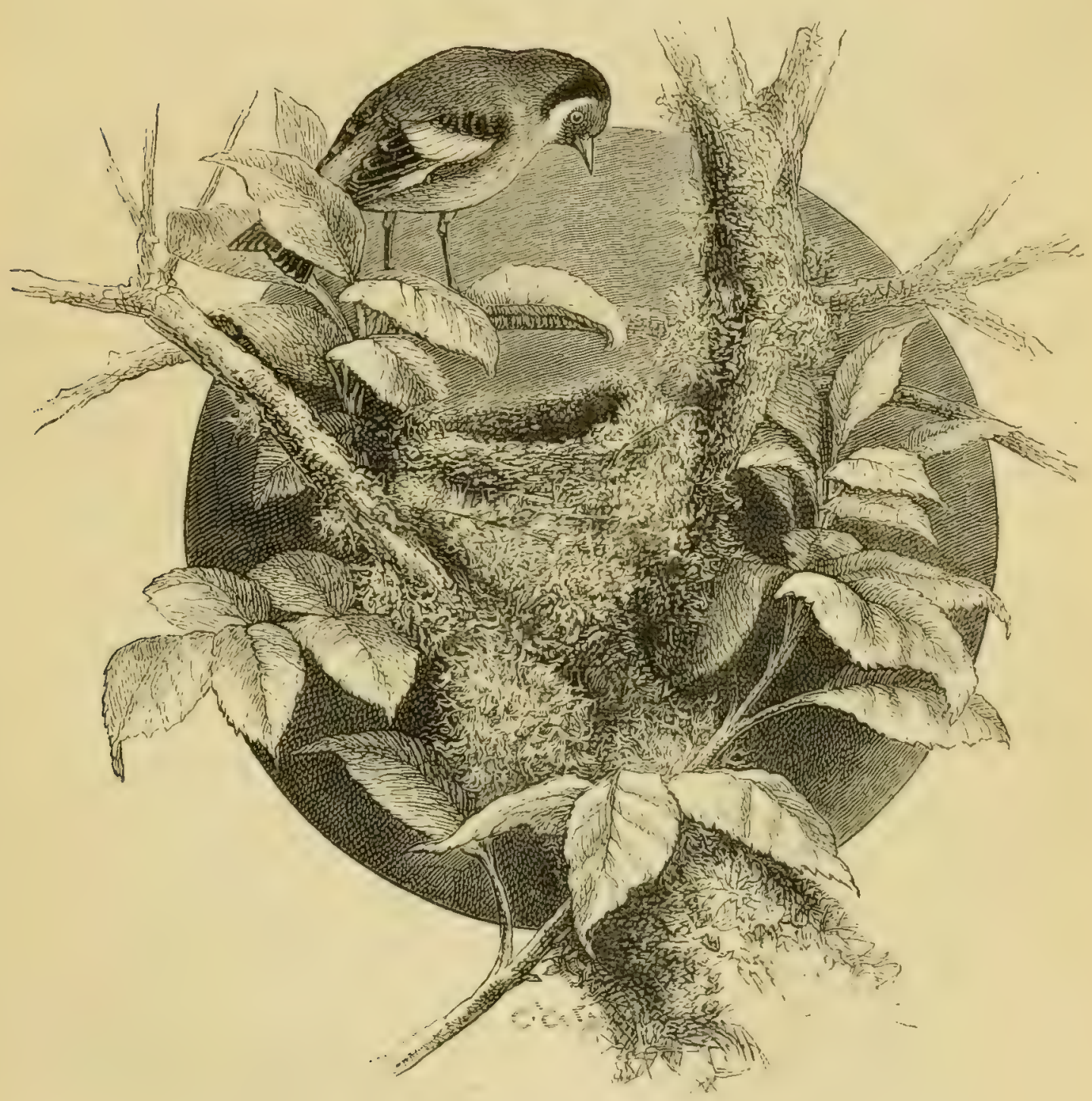

NEST OF GOLDFINCH. 


\section{FRINGILLA SPINUS.}

\section{SISKIN.}

(Plate 12.)

Carduelis ligurinus, Briss. Om. iii. p. 65 (1760).

Fringilla spinus, Linn. Syst. Nat. i. p. 322 (1766); et auctorum plurimorumGmelin, Scopoli, Latham, Temminck, (Bonaparte), (Degland \& Gerbe), (Dresser), (Newton), \&e.

Emberiza spinus (Limn.), Scop. Ann. T. Hist. Nat. p. 145 (1769).

Fringilla fasciata, Mïll. Natursyst. Suppl. p. 165 (1770).

Linaria spinus (Linn.), Leach, Syst. Cat. Mamm. Sc. Brit. Mus. p. 15 (1816).

Spinus viridis, Koch, Syst. baier. Zool. i. p. 235 (1816).

Serinus spinus (Linn.), Boie, Isis, 1822, p. 555.

Passer spinus (Linn.), Pall. Zoogr. Rosso-Asiat. ii. p. 16 (1826).

Carduelis spinus (Limn.), Steph. Shaw's Gen. Zool. xiv. i. p. 33 (1826).

Chrysomitris spinus (Linn.), Boie, Isis, 1828, p. 322.

Fringilla (Acanthis) spinus (Linn.), Keys, u. Blas. Wirb. Eur. p. xli (1840).

Spinus vulgaris, Goebel, Joum. Om. 1873, p. 15.

Chrysomitris dybowskii, Taczanowsky, Joum. Orn. 1876, p. 199.

In England and Wales the Siskin is principally knomn as a winter visitor, and is at that scason more or less commonly distributed throughout the country, becoming rarer in the extreme south-west. To the Channel Islands it is only known as a rare straggler. Its occurrence in summer in England is very cxceptional; and the instances of its remaining in this country to breed are few, although it is quite possible more remain than is generally supposed. From the evidence to be gleaned upon the subject, there can be little doubt that the Siskin has bred in the counties of Kent, Surrey, Dorset, Sussex, Middlesex, Oxford, Gloucester, Denbigh, Bedford, Derby, York, Westmoreland, and Durham. In Scotland the bird is much commoner than in Eugland, and breeds regularly in many localities, according to Mr. Gray chiefly in the castern counties. In the west of Scotlaud, with the exception of Argyleshire and Sutherlandshire (in which latter county it is said to be a resident), it is known as a winter visitor. It has not yet been met with in Orkney, but is a scarce winter visitor to Shetland. In Ireland it is best known as a winter visitor to most suitable districts. Although Thompson suggested that the bird may occasionally breed in Wicklow and other localities in the north, it was not until 1871 that a nest was found in that county. An account of this was contributed to the 'Zoologist' for 1874 (p. 3915) by Mr. Barrington, in whose grounds it was discovered. A second nest was also found by this gentleman in the same county, and particulars concerning it furnished to the same periodical for 1876 (p. 4957). 
The Siskin breeds in the pine-woods of Northern and Central Europe, in Norway ranging as far north as lat. $67^{\circ}$, in Russia as far as Archangel, and in the Urals up to about lat. $58^{\circ}$. It also breeds in some of the mountainous districts of Southern Europe, as, for instance, near Florence and in the Caucasus. Its winter range is much more extensive; and at this season it is also found in the Spanish peninsula, the plains of Austria, Turkey, Greece, Asia Minor, and South Russia. It is also a rare winter visitor to North-west Africa, and occasionally strays as far as the Canaries and Teneriffe. East of the Ural Mountains the Siskin has not been found until we reach the shores of the Pacific, where it breeds in the Lower Amoor and Japan, passes through North China on migration, and winters in South China as far as Foochow. Whether this is a case of discontinuous area of distribution is very difficult to say; for possibly the bird may have been overlooked in the intervening country, although it is searcely probable that Dybowsky during his long residence near Lake Baikal could have missed it. Nor has the Siskin ever been met with in India, being there apparently replaced by $F$. spinoides, a species confined to the Himalayas, and easily distinguished from our bird by its dark greenish-brown back and much stouter bill. Another allied species, the Citril Finch, $F$. citrinella (erroneously included in the British list), inhabits the mountain-ranges of Southern Europe, but is easily distinguished by the absence of the black head and the strealss on the underparts. In North America several allied species are found; but they all differ, either in not having the black head or in not having any streaks on the back and underparts.

Of the numerous Finches which are annually caught in the south of England, in the neighbourhood of London and on the Brighton downs, the Siskin is by no means the least interesting; and most bird-catchers find it worth their while to have one or two decoy-birds of this species. It is very common during migration in Mr. Swaysland's garden near Brighton, which is exceptionally well situated for the observation of birds. My son has frequently eaught a score or more of these birds in Mr. Swaysland's clap-net before breakfast. He has frequently seen them flying up wind in small flocks. Several of the birds were nearly always attracted by the "brace-bird" and the "call-bird ;" some flew up at once into the net, whilst others alighted first in the elder-bushes and dry sticks placed there for the purpose. They were very tame and continually answered to the call-bird, and were generally caught without difficulty. At other times I have seen them in the fir trees to the south of his garden in early spring, their short twittering song attracting attention at once. In many of their actions they much resemble a Tit or a Willow-Wren, seldom being still for a moment, and putting themselves into all kinds of positions.

At their breeding-haunts, which are principally pine-woods, their song 
is described by Naumam as being very peculiar and interesting. In the pairing-season they are in the habit of flying up into the air from the top of a tree, describing a circle, and with fluttering wings and puffedout plumage and outspread tail, the wings sometimes almost meeting, descending to the tree again, singing all the time-a proceeding which is by no means peculiar to this bird, but has also been observed of its near relation the Serin, its more distant cousin the Snow-Bunting, the still more distantly related Tree-Pipit, and even of such widely different birds as the Wood-Sandpiper and T'emminck's Stint. The song of the Siskin is not very powerful, but is very pleasing-a succession of very rapid notes, some possessing considerable melody. It is an extremely industrious singer, and may be heard all the year round except in the moultingseason. The word Zeisig, which is one of the local names for the bird in Germany, is supposed to be an imitation of the call-note of the male to the female, and may best be expressed in English as tsyzing. The ordinary call-note of the Siskin is a weak tit-tit-tit-tit. The food of the Siskin is principally composed of seeds; but it also eats buds and tender leaves, whilst in summer it catches insects, and on these its young are probably exclusively reared.

The Siskin is a somewhat early breeder. Two broods are reared in the year, the first eggs boing laid in April and the sccond in June. Some early English ornithologists have described the nest as being found in furze bushes within a few feet of the ground, in hedges, and even in juniper bushes; but some doubt attaches to these records, as more recent observers in this country have found it in fir trees at a considerable distance from the ground; and Naumann, whose account of this bird forms the basis of Dresser's description of its habits, says that the nest is always in conifer trees at a great height, scldow less than 25 feet from the ground. The next is extremely difficult to find, so much so that it has given rise to the legend that the bird places among the eggs a small stone which lias the porer of rendering the nest invisible. It is usually placed in the fork of a horizontal branch at some distance from the trunk. One in my collection obtained in Ross-shire, Scotland, on the branch of a fir twenty feet from the ground, on the 30th of May, 1861, by Alexander Macdonald, resembles that of the Greenfinch, but is smaller. Upon a scanty foundation of grass-stalks mixed with a few heather-twigs, the nest is built almost entirely of moss and roots, the finest material being selected for the lining, in which is also a little vegetable down. Other nests are described as having a few feathers in the lining. The eggs are five or six in number, pale bluish green in ground-colour, with dark reddish-brown spots and specks and an occasional streak, and with underlying markings of pinkish grey. The markings on some eggs are much more profuse than on others, but on almost all they are most 
conspicuous near the large end. They vary in length from $\cdot 7$ to 62 inch, and in brealth from 53 to 5 inch. They appear to go through the same variations both in size and colour as the eggs of the Goldfinch, from which they are absolutely indistinguishable. The female alone is said to make the nest and hatch the eggs.

In winter the Siskins unite into flocks of greater or less extent, and lead a nomad kind of life, wandering about the country in search of food. They very often join a party of Tits or Goldcrests, and are especially fond of congregating with Lesser Redpoles. These flocks of Siskins usually appear in the south of England about September, and leave again for their breeding-grounds early in the spring. The Siskin in winter is often secn in the alder-plantations, picking out the seeds of those trees as deftly as the Tits, and, in doing so, poising and twisting in every conceivable attitude. They are not at all shy, and will often allow the observer to watch them quite closely as they flit about the branches over his head. These flocks of Siskins are very irregular in their appearance. Sometimes several years will pass by without a single bird being seen in haunts where they formerly occurred in abundance; and this is probably because the secds of the trees on which they feed were not plentiful. In this respect it resembles many of its congeners, the Goldfinch and the Brambling especially. The Siskin is a favourite cage-bird, and few birds are so soon reconciled to their captivity or so soon become tame and intimate with their keepers.

The Siskin is intermediate in the colour of its plumage between the Greenfinch and the Serin, but differs from both in having the crown, nape, and chin black. With these exceptions, the upper parts, including the wings and tail, very nearly resemble those of the Greenfinch, the dark parts being slightly blacker and the feathers of the back having dark central streaks, whilst the underparts are like those of the Serin. Bill brown, paler at the base; legs, feet, and claws pale brown; irides dark brown. In the female the colours are duller; there is very little yellow in the plumage, and there is no black on the head or throat. After the autumn moult the dark feathers of both sexes have pale margins. 


\section{FRINGILLA MONTIFRINGILLA.}

\section{BRAIIBLING.}

\section{(Plate 13.)}

Carduelis suecicn, Briss. Orn. iii. p. 63 (1760).

Passer montifriugilla, Briss. Orn. iii. p. 155 (1760); et auctorum plurimorum(Scopoli), (Gmelin), (Latham), (Bonaparte), (Temminck), (Degland \& Gerbe), (Salvadori), (Newton), (Dresser), \&c.

Fringilla montifringilla, Linn. Syst. Nat, i。 p. 318 (1766).

Fringilla lulensis, Linn. Syst. Nat. i. p. 318 (1766).

Fringilla flammea, Beseke, Vög. Kurl. p. 79 (1821).

Struthus montifringilla (Briss.), Boie, Isis, 1828, p. 323.

Fringilla septentrionalis, Brehm, Vög. Deutschl. p. 274 (1831).

Fringilla media, Jaub. Rev. et Mag. de Zool. v. p. 117 (1853).

The Brambling is only known as a winter migrant to our islands, arriving late in the autumn and remaining until early in the following spring. Its visits are exceedingly irregular and crlatic, and districts frequented by thousands of the birds one year may be entirely deserted the next. Apart from this the bird is generally distributed throughout our islauds in winter; but it appear's to be less numerous in the extreme west of England, and in the Chamnel Islands its appearance is only exceptional. In Scotland it is perhaps more numerous than in England and as widely dispersed, although it only sparingly visits the immer islands of the west coast, and probably never reaches the outer islands at all. The Shetland Islauds are only used by this bird as a resting-place on its annual journeys to and from its northern breeding-grounds. A small flock once visited the Faroes. In Ireland the Brambling is probably as widely distributed as in England and Scotland; but Mr. Watters states that its numbers gradually decline as it reaches the south. The Brambling has been reported to have bred several times in the British Islands; but such a circumstance is very improbable, and until more decisive proofs have been obtained than those already put forward, the statement cannot be accepted.

'The Brambling is confined to the eastern hemisphere, and ranges from the Atlantic to the Pacific. It breeds throughout the northern portions of the Palacarctic Region, frequenting the pine- and especially the birchforests at or mear the limit of forest-growth. In Scandinavia it breeds as far south as lat. $60^{\circ}$; lut in the valley of the Amoor, where the mean temperature is so much lower, it brecds as low as lat. $50^{\circ}$. It wanders southwards in winter, a few birds remaining in the sonthern limits of its breedingrauge, but other's straying as lar south as Southern Europe and even Algeria. It also winters in Asia Minor, Turkestan, the north-west Hima- 
layas, China, and Japan. The Brambling does not appear to have any nearer ally than the Chaffinch, from which it is easily distinguished by its black and white instead of green rump.

The Brambling is an aretic bird. As soon as the south wind begins to drive away the snow which has paved the forests for eight months or more, Bramblings arrive in large flocks and disperse themselves in the birchforests to breed. The glossy black contrasting with the pure white and brilliant buff make the male a very conspicuous bird; and at all hours he may be seen flying about in the sunshine, for he seldom reaches his breeding-quarters before the sun has ceased to set.

They are early breeders and generally have eggs before June, at least a fortnight earlier than the arrival of the later birds of passage which visit these regions. They prefer bireh-forests; and I have generally found them most numcrous in plantations where spruce-firs are mixed with the birch, and where there is an occasional larch, alcler, or juniper. Brilliant as is the plumage of the Brambling, he is not so conspicuous as might be imagined. The bark on the birch trees presents almost as strong contrasts in black and white; and in August I have seen as brilliant yellows on the birch-leaves and as gorgeous chromes and Indian reds on the poplar's as any thing on the plumage of the Brambling. The autumual tiuts of the Siberian forests, if it is allowable to use the term in a country where summer suddenly changes to winter and there is 110 antumn, are as brilliant as the celebrated autumn tints of North America.

The Brambling is a quict bird, in this respect very different from his near ally the Chaffinch. The song of the male is very rarely heard; it is not ummusical, but is a short, low warble. The note most frequently heard, which is probably the call-note, is a $\approx h$ loug drawn out, not unlike the calluote of the Greeufinch. The alarm-note is a hurried ziv, ziv. 'llhe Brambling is almost as omnivorous as the Sparrow, and devour's sceds, fruit, and insects of all sorts. When they first arrive they eagerly frequent the bare patches of cultivated land where the snow has melted; and beyoud the range of cultivation they frequent the open places in the woods, no doubt eating the ground-fruit which has been frozen up all winter. The cnormous flocks which visit Germany in autumn very largely frequent the beech-forests, and thousands of these birds may be seen under the beech trees shelling the fallen mast. They are said to feed their young exclusively with inscets. In August the Bramblings begin again to llock, and by the middle of September many have left their breeding-grounds. Nammanm says that in Central Lurope a few Bramblings appear amongst the Chaffinches towards the end of September. In the first half of Octolser small flocks appear, but in the list half of that month rery large flocks pass through to winter further south. In England the migration of this bird is not so regular. Of its occurrence in Yorkshire Dixon writes as follows:- 
"The Brambling is a very irregular and uncertain visitor to the neighbourhood of Sheffield, and seldom appears two consecutive years in one locality in the same numbers. When once a flock of Bramblings appear in a district they seldom leave it until the following spring. All winter they are found either upon the fields or in the woods, and they are remarkably regular in their movements. Soon after their arrival they frequent the beech-woods to feed upon the nuts; and it is an animating sight to see the trees literally alive with these charming birds, each busy eagerly shelling out the coveted nuts from their hard sheath. The whole flock kecps up a noisy clamour of twittering notes, and may be closely approached. In winter a favourite haunt of the Brambling is in the newly manured fields-for this bird I am certain is far more insectivorous at this season than is generally snpposed. The flock keeps well together; but if alarmed they fly off in a long straggling train, trooping away to some tree-top, which is soon darkened by their numbers, and their notes, heard from a distance, are like a low continuous murmur. As soon as the cause of their alarm subsides the birds fly down once more, a few at a time, until they are all engaged feeding as before. The Brambling is not abroad very late in the evening (in fact all Finches, as a rule, retire to roost early) and about sunset may be seen at their usual resting-place. When we have a "Brambling-year" near Sheffield, great numbers of the birds always roost in the shrubbery in Meersbrook Park, in company with Redwings. The Redwings use this quiet retreat every season; and the Bramblings are equally attracted when they pay their nomad visits to the district. They are remarkably woisy birds, and sit upon the tree-tops twittering to each other until dusk; they sometimes fly up into the air in a compact mass, and after wheeling round several times again alight. They roost in the yew and holly trees, aud a fair proportion of them seek quarters in the ivy. The Brambling and the Chaffinch seem fast friends and may always be found in company."

The Brambling frequently breeds in a spruce-fir, but more often in a birch. The nest is usually fifteen to twenty feet from the ground, and generally built in the fork of a large branch from the main stem. Occasionally they build at a less elevation. The nest is very handsome, not quite so neatly and compactly made as that of the Chaffinch, and rather larger. Its principal beauty is derived from the mixture of green moss, lavender-coloured lichens, and white birch-bark, interworen with cobwebs, thistle-down, and buff inner birch-bark. The nest is lined with fine grass and feathers. Six is the usual number of eggs, sometimes there are only five, and occasionally as many as seven. They vary in size from 85 by 6 inch to .75 by 55 inch. Some eggs of the Brambling camnot be distinguished from those of the Chaffinch ; but, as a rule, the ground-colour is greener and the spots smaller and paler. The pale bluish-green ground- 
colour is generally washed here and there with patches of reddish brown, which look like underlying spots that have rum. The overlying spots vary from the size of No. 10 shot down to a point, and in colour from pale reddish brown to very dark brown: sometimes they are absent altogether.

The male Brambling in full breeding-plumage has the general colour of the upper parts, including the sides of the neck, the car-coverts, and the cheeks, black glossed with blue on the head and dullest on the quills; lesser wing-coverts chestnut-buff; median wing-coverts white; greater wing-coverts tipped with white. The centre of the rump is white, and a spot of white is formed on the wing by the fourth and succecling primaries, which have the outside web white at the base. A narrow white margin is also generally left on most of the quills and tail-feathers. The chin, throat, and breast are chestnut-buff, and the rest of the underparts are white with black spots on the flanks. Bill bluish black; legs, feet, and claws reddish brown; irides hazel.

The Brambling is an excellent example of a bird which only moults in autumn, but completely changes his appearance in spring by casting the ends of the feathers. To such an extent is this the case that it would almost be possible by carefully cutting off with a pair of scissors the chestnut-buff margins of the feathers, which nearly conceal the black of the upper parts, to change a bird in autumu plumage to that of spring. This process would not, however, quite complete the change. In autumn the bill becomes bright yellow tipped with horn-colour; the tips of the greater wing-coverts and the margins of the innermost secondaries are broad and chestnut-buff; the margins of the quills and tail-feather's are also broader and greenish yellow, so that there must also be a change in the colour of the feather.

The young male in first winter plumage differs very slightly from the adult, but the pale margins of the upper tail-coverts and the two central rectrices extend almost over the whole feather as in the female. The female very much resembles the male in autumn plumage, except that all the colours are duller, the black is replaced by brown, and the chestmut-buff and white on the wing-coverts are reduced to an obscure margiu. Females in first winter plumage are very chestnut, and adults in summer plumage are very grey, otherwise in this sex the changes produced by age and season are very slight.

Varietics of the Brambling occasionally occur with more or less black on the chin and throat. 


\title{
FRINGILLA CALEBS.
}

\section{CHAFFINCH.}

\author{
(Platie 13.)
}

Passer fringilla, Briss. Om. iii. p. 148 (1760).

Fringilla colebs, Limn. Syst. Nat. i. p. 318 (1766); et auctorum plurimorumGmelin, Scopoli, Latham, Temminck, Degland \& Gerbe, Dresser, Newton, \&c.

Fringilla nobilis, Schrank, Faun. Boica, p. 176 (1798).

Passer spiza, Pall. Zoogr. Rosso-Asiat. ii. p. 17 (1826).

Struthus cœlebs (Linn.), Boie, Isis, 1826, p. 974.

The Chaffinch is one of the commonest of our native birds, and is found in all suitable localitics throughout the British Islands. Its distribution is somerhat affected by the physical aspects of the country, and bare and treeless districts are little frequented by this gay and lively bird. In Scotland, including several localities on the Outer Hebrides and all the sheltered and wooded portions of the inner islands, it is almost as gencrally distributed as in England. It occasionally visits barren districts, and is a common bird in winter in the Shetlands. In Ireland the Chatfinch is as common as in England and Scotland, and is found throughout all the cultivated and wooded districts. To the Faroes it is only known as an occasional straggler.

The Chaffinch breeds throughout Europe, in Scandinavia as far north as the Arctic circle and occasionally beyond, but in the Ural Mountains only up to lat. $62^{\circ}$. In the northern portion of its breeding-range it is a migratory bird, and in South Europe it breeds on the mountains and winters in the plains. It is a somewhat rare and local resident in Algeria, and also winters in Egypt. In Asia, Finsch found it east of the Ural Mountains, and received an example from Professor Slovzow from the neighbourhood of Omsk. Severtzow records it as wintering in North-west Turkestan. It breeds in the oak-forests of Western Persia and on the mountains of Asia Minor and Palestine. Its occurrence in Beluchistan, recorded by Sharpe and Dresser, and also by Professor Newton, is contradicted bv Blanford in his 'Eastern Persia.'

The Chaffinch has several very near allies. Our Chaffinch is found as far south as the cork-woods on the coast of Algeria; but in the evergreenoak forests of the uplands of that country it is replaced by a very nearly allied species, F. spodiogena, in which the back is suffused with yellowish green instead of dull chestnut, and the underparts are pinkish buff instead of pale dull chestnut. On the island of Madeira the Chaffinch is somewhat intermediate between these two species. It is nearest allied to the 
Algerian birl, but differs from it in having the throat and upper breast buff, instead of pinkish buff. In the Azores, six or seven hundred miles to the north-rwest, not only the throat and upper brenst, but the whole of the underparts are buff. This specics has becu named $F$. moreleti. In the Canary Islands, which lie some three hundred miles south of Madeira, and are obviously an extension of the Atlas Mountains, the 'Chaffinch, which is known by the name $F$. tintillon, has scarcely any trace of grecu on the slate-grey of the upper back, but has the buff underparts of the Azores bird. These forms are probably only subspecifically distinct. It seems probable that these islands occasionally receive emigrants from the other islands and the mainland, which probably remain and interbreed with their congeners, as examples from Tenerifie are occasionally suffused with ycllowish green on the upper back, and the amount of yellowish green on the upper back of birds from the Azores varies and, in very rare instances, is absent altogether. In the alpine regions of Teneriffe a much more distinct species occurs, $F$. teydea, in which the whole of the plumage of both upper and underparts is slate-grey, paler on the tips of the wing-coverts, and shading into white on the under tail-coverts.

Few of our British birds are more gaily attired than the pert and lively Chaffinch, and few are better known; for there is scarcely a hedgerow, wood, garden, or shrubbery that does not, at some season of the year, contain Chaffinches in abundance. The bird may be easily recognized by its oft-repeated and checrily uttered note of pink, pink, pink, whence it has derived its commonest local name "Spink." The hauuts of this gay little bird are shrubberies, woods, and hedgerows, together with orchards, well-wooded parks, and gardens. In autumn and winter it also frequents the open fields and stubbles, the commons, and the waste lands near the sea.

The Chaffinch is a lively bird, and rarely fails to attract the attention of even the most casual obscrver, as it either sits on some exposed twig and rattles off its merry laughing song, or mayhap as it flits along the hedgerows, or as it hops and runs up and down the country-road picking amongst the droppings. Early in March, when the pale primroses are peeping from under the withered leaves, and the hawthorn shows the first signs of verdure, the song of the Chaffinch assists in welcoming the advent of spring. At this season it is the life of the roods and groves, almost the only music the boughs afford. The song of the Chaffinch is short and even monotonous compared with that of many other birds; still there is a freshness and sprightliness about it which well makes up for its lack of melody. The bird also seems so earnest in his performance that his entire vigour seems thrown into his melody, and its loud ringing tones fill the air and the woodlands around with gladness. His song may be heard incessantly from March to June, and occasionally to the middle of July, when it ceases 
in the moulting-scason, and is usually not regained until the following spring. Some of the birds will, however, sing after recovery from the moult, and may be heard at intervals throughout the autumn. In addition to the call- and alarm-note of pink, pink, pink, common to both sexes, there is another note which is peculiar to the male, and which is only uttered in the pairing-and breeding-seasons. It is something like the call-note of the Willow-Wren, only much louder, and not at all plaintive. It may be expressed as a clear whit. The call-note as the bird flies in small partics is a sip, sip, sip. In the Engadine in the autumn I noticed that the Claffinches at rest in the pine trees occasionally uttered a sound like the word kurrt.

In March the Chaffinch secks the hedgerows and the open places; but at nightfall it always retires to the shrubberies and evergreens to roost; and if the weather be cold and cloudy, it remains in the shelter of such places. Although the bird loves the warm shelter of evergreens, it scldom builds its nest in them, but seeks the branches of deciduous trees. The site for the nest is varied. It is often in the forked branches of a hawthorn, only a few feet from the ground, or on the lichen- and moss-covered branches of the birch and ash trees, far up in the towering branches of the oak, the alder, and the poplar, and on the lowly branches of the holly, more rarely in the yew, and frequently in the gorse shrubs. A favourite situation is in the fruit-trees in the garden and orchard. Dixon mentions a curious site for the nest of this bird:"On the banks of the river Derwent, amongst the frowning lills of the High Peak, I once found a Chaffinch's nest built under a tuft of grass growing on the side of a wall bordering the river. The materials of the nest were so closely woven with the grass that it required no other support; indeed other support was wanting, and the nest hung suspended over the roaring stream. It contained five eggs, and the female was sitting quietly upon them." My friend Mr. C. Doncaster also contributes the following note on a remarkable Chaffinch's nest, also in the Peak district:- " On an old thorn tree by the river Derwent, near Baslow, the stem of which was covered with ivy, I saw a long strip of moss, two feet long and four inches wide, attached to the ivy. I did not suspect that it was a nest; but touching it with my stick, a Chaffinch flew off from a nest with four eggs, about ten feet from the ground. On looking closely I was astonished to find that this two feet of moss was attacher to and hanging from the nest, and that it was all manufactured by the bird, containing also lichen and wool, and the whole was attached to the ivy by horsehair. There was no moss on the tree growing naturally, and it was evidently a derice for the concealment of the nest. The amount of material woven together in the part that hung down would be several times more than that used in the nest itself." 
The nest of the Chaffinch, being so claborate and highly finished, naturally takes some little time in its construction; indeed, with the exception of the Long-tailed Titmouse, the female Chaffinch probably takes more time to build her charming little nest than any other British bird. You may visit it day after day for nearly a fortnight erc you find it ready for the eggs. First the outside framework made of rootlets, moss, and grasses, woven beautifully together, and further strengthened with cobwebs and lichens, is completed; then the inside is lined with a thick and soft bed of hair and feathers and the down from various secds. Were you to stay near the place during the whole period the mest is being made you would probably never see the male bird do any of the nest-building. He, however, brings the greater part of the materials to his mate, who receives them, and, unaided, weaves them into the structure which is a matchless piece of handiwork. No bird shows more anxiety for its unfinished nest than the Chaffinch. Approach the nest, even though it be but just commeneed, and the birds will flit around you, and by their actions and incessant cries invariably betray the site. Dixon thus writes:- "Few nests better illustrate the art of 'mimicry' in birds than the nest of the Chaffinch. Wherever the Chaffinch's nest is found there too may be observed an example of her mimicry. Let us glance at a few striking instances of this peculiar protective power. Here on this grassy bank is a gorse bush, dry and withered, killed by the relentless frosts of the preceding winter. Amongst its prickly branches, however, a Chaffinch has made her nest. Found merely by accident, let us examine it closely. The outside of the nest is thickly covered with little pieces of decayed wood, obtained from a log close by, which assimilate her nest most admirably to the brown dead foliage of the gorse bush and its withered blooms. So closely does it resemble surrounding tints that, seen at a short distance, it appears part of the bush itself. Take another instance: on the lichencovered brauch of this hoary birch tree something is seen which appears to be a knotted prominence of the bark; closer inspection reveals the nest of the Chaffinch, its walls being decked with lichens and spider's webs, the whole harmonizing so closely with the tints of the bark as to defy all but the keenest gaze to detect the bird's secret. Another instance: in youder hawthorn tree clothed in fairest bloom is a Chaffinch's nest; the lichens and the decayed wood, however, have been discarded, and in their place are small scraps of paper, so thickly studding the outside of the nest as to appear at a casual glance nothing more than an exceptionally handsome bunch of bloom. The female Chaffinch is also much less showily arrayed than the male, and as their nest is an open one she alone performs the duties of incubation."

The eggs of the Chaffinch are from four to six in number. Typical eggs are pale bluish green in ground-colour, clouded with pale reddish 
brown, sometimes to such an extent as to entirely conceal the green ground, spotted and occasionally streaked with dark reddish-brown overlying markings and pale purplish-brown underlying ones, usually most profuse at the larger end of the egg. A somewhat rare variety, which I have taken both in this country, in Grece, and in Germany, are scarcely distinguishable from exge of the Bullfinch; they are elear greenish blue in groundcolour, with large underlying blotches of faint purple, and surface-spots and streaks of rich purplish brown. They vary in length from $\cdot 8$ to $\cdot 7$ inch, and in breadth from ' 65 to 55 inch. Chaffinch's eggs very closely resemble those of the Brambling, hut as a rule are much more clouded with reddish bromn. The Chaffinch generally rears two broods in the year.

When the young are able to take care of themselves, they appear to be abancioned by their parents; but in late autumn the Chaffinches congregate into large flocks, and continne nnore or less gregarious for the winter. At this scason of the year a considcrable separation of the sexes appears to oceur; but it is probable that this peculiar habit is confined to those birds that come to our shores in autumn; for our resident Chaffinches of both sexes may be seen in company throughout the winter. It may be that the Chaffinches separate into flocks (the females and young in one, the old males in another) to perform their anmual journey; for certainly after they have sojourned here some time these flocks secm to merge into each other, irrespective of sex. These flocks frequent the stubbles and the newly manured ficlds, and later on in the season the lands where sowing-operations are going on. A favourite place is in the becch-woods, where they kecp company with Branıblings. Their roosting-places are almost invariably amongst evergreens.

The food of the Chaffinch in summer is almost exclusively composed of inscets; but during the remainder of the year consists of grain and seeds of various kinds. The bird is often seen hovering in the air catching inscets like a Flycatcher, and the young are fed on larve. In winter the bird consumes the secds of many noxious plants, and often visits the stackyards and manure-heaps, feeding with the Sparrows. It is somew hat troublesome to the gardener in seed-time; but a few scarecrows will usually suffice to keep the little plunderer away; otherwise the Chaffinch is one of the gardener's best friends.

Great numbers of Chaffinches annually come to this country to winter. The east and south-east coasts of England are the places where they usually arrive; and their journeys are performed almost exclusirely in the night, consequently many birds are obtained at our lighthouses, and frequently strike against the lautern in their wanderings.

The Chaffineh is in great request as a cagc-bird, especially on the continent, in France and Germany, where the poor birds are often blinded for the purpose of increasing their power's of song. 
In the adult male Chaffinch in spring plumage the general colour of the upper parts is slate-grey, suffused with chestnut on the mantle, and with yellowish green on the rump; the wings are dark brown, the outside web margined with dull yellow; the median wing-coverts are white, and the greater wing-coverts are black, tipped with yellow; the tail is dark brown, with a considerable amount of white on two and sometimes three of the outer feathers at each side; the forchead is black; the lores, the feathers round the eye, the ear-coverts, checks, and the whole of the underparts are pale chestnut-brown, suffused with pink on the belly, and shading into nearly white on the under tail-coverts. Bill lead-blue in summer, fleshy pink, darkest at the tip, in winter; legs, fect, and claws brown; irides hazel. The female differs from the male in having the slate-grey of the upper parts replaced by brown, and by having the underparts much paler. After the autumn moult the slate-grey feathers of the upper parts have brown edges, the white on the wings is suffused with yellow, and the unclerparts are paler. Young males in first plumage somewhat closely resemble females; but assume an intermediate plumage after their first autumn moult.

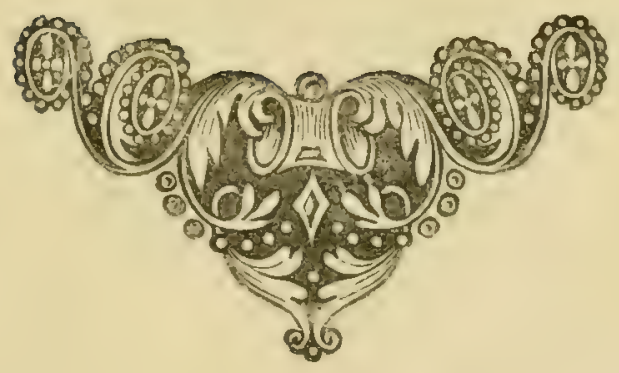




\section{FRINGILLA CANNABINA.}

\section{LINNET.}

\section{(Plate 13.)}

Passer linaria, Briss. Orn. iii. p. 131 (1760).

Passer linaria rubra major, Briss. Orn. iii. p. 135 (1760).

Passer linaria argentoratensis, Briss. Orn. iii. p. 146 (1760).

Fringilla cammabina, Lim. Syst. Nat. i. p. 322 (1766); et auctorum plurimorum -Gmelin, Scopoli, Latham, Temminck, Naumann, (Macgillivray), (Newton̉), (Dresser), \&c.

Fringilla linota, Gmel. Syst. Nat. i. p. 916 (1788).

Linaria linota (Gmel.), Bechst. Naturg. Deutschl. ii. p. 141 (1807).

Linota fringillirostris, Bonap. Consp. i. p. 539 (1850).

Cannabina bella, Hempr. et Ehr. fide Cab. Mus. Hein. i. p. 161 (1850).

Ligurinus cannabinus (Linn.), Koch, Syst. baier. Zool. i. p. 231 (1816).

Linaria cannabina (Linn.), Boie, Isis, 1822, p. 554.

Passer cannabina (Linn.), Pall. Zoogr. Rosso-Asiat. ii. p. 26 (1826).

Passer papaverina, Pall. Zoogr. Rosso-Asiat. ii. p. 27 (1826).

Linota cannabina (Lim.), Bonap. Comp. List B. Eur. \& N. Amer. p. 34 (1838).

Cannabina linota (Gmel.), Gray, List Gen. B. p. 45 (1840).

The Linnet is generally distributed throughout the British Islands, principally on commons and uncultivated lands. Its ristribution is perhaps more restricted in the breeding-scason than at other times of the year; nevertheless there is probably no suitable part of the mainland of the United Kingdom in which the Linuet does not breed. It is found on the Western Isles, even on the treeless islands, where it breeds amongst the heather; but it does not appear to visit Shetland.

The Linnet breeds throughout Europe-in Scandinavia south of lat. $64^{\circ}$, and in East Russia south of lat. 59 . In the most northern portion of its range it is a migrant; but south of the Baltic it is found in greater or less numbers at all seasons of the year. To North-castern Africa it is a winter visitor as far south as Abyssinia; but in Algeria, Taugiers, and Norocco it is a resident. It is a resident in the Canaries and Madeira, but appears to be absent from the Azores. It is a resident in Asia Minor, Palestine, Persia, and Turkestan. It also breeds in the south-west of Siberia as far east as the Altai Mountains. Examples from Central Asia have been described as distinct under the name of $F$. fingillirostris ( $F$. bella of Cabanis). This is a slightly larger and rathe rpaler form; the red on the breast and head is a little more scarlet, it has perhaps more white on the rump, and the dark centres to the feathers on the back are less distinct. Examples from Asia Ninor are intermediate. The difference between the 
two extreme forms is so slight that the Eastern form is scarcely deserving of even subspecific rank.

The Common, Brown, or Red Linnet, or Lintic, as it is variously called, is one of our best-known species, and, from its tame disposition and pleasing song, is also one of our most popular cage-birds. In vinter (in fact throughout the year, the few months of the breeding-season excepted) it may be seen in almost every rural district, and not unfrequently visits the busy metropolis, where it is sometimes seen in the parks. The Linnet appears to be decreasing in numbers in our islands, partly in consequence of the immense numbers netted by the bird-catchers, and partly on account of the reclamation of land, by which its favourite haunts are destroyed. It is most abundant in the less cultivated districts, on commons, especially in gorse-coverts, and on the half-tilled lauds near the moors. In winter it is more widely dispersed, and frequents grass-ficlds and stubbles, often coming into gardens, where a few pairs remain during the summer.

The Common Limnet is a gregarious bird, and even in the breedingseason is more or less sociable. In the boisterous month of March, when winter scems struggling for supremacy with spring, the Linnet pairs, the large flocks break up, and most of the birds retire to the wilder districts to breed. The Linnet's song is heard most frequently at this season; and very often the males of a flock will warble in chorus from some tree-top, filling the air for some distance around with melody. Pcrhaps the song of the Linnet is heard to best advantage when the flocks are clispersed, and each pair is engaged in domestic duties on the breezy uplands. Here, it may be in some dense mass of furze bushes, a low warbling song may be heard, not unlike that of the Swallow, proceeding from a cock Linnet sitting on the topmost spray of a gorse bush screnading his mate. When singing he is very shy, and usually drops into the cover when disturbed. The song is not very loud, part of it is somewhat harsh, but it is varied by those low melodious notes which make this species so popular with the bird-fancier. It is only in the pairing-season that the bird sings frequently, and when the eggs are laid he seems too busy in feeding his mate to devote much of his time to music. The common call-note of the Linnet is a musical twit, twit, rapilly repeated; that of one sex to the other is intermediate between the similar notes of the Canary and the Goldfinch, and might be represented by the word tyew-ee.

The great brecding-grounds of the Linnet are on the rough lands which lie between the moors and the well-cultivated districts. It is almost a mountain-bird, but not so much so as the Twite. In the lowlands it shows a decided preference for gorse-thickets, where its nest is most frequently found. Other favourite situations are in masses of broom or in a rugged sloe-tree, and sometimes in the branches of tall heather or amongst brambles and briars. In more low-lying districts the bird will sometimes 
build in a whitethorn hedge and amongst honeysuckle; but in all kinds of country gorse bushes are preferred. The site is usually a convenient fork, where the nest can obtain support by the surrounding branches. Instances of the Linnet constructing its nest on the ground are oceasionally met with. The nest is formed in the first place of moss and dry grass, strengthened with a few fine twigs, often those of the gorse, dead and withered, and bound together with wool obtained from the branches, where it has been left by the sheep in endeavouring to force their way through the dense thicket. It is lined with hair, wool, and regetable down, and sometimes a few feathers. Although it often looks somewhat loosely put together, it will be found on close inspection to be well made, and the cup containing the eggs to be beautifully smooth and rounded. The inside measurement is about two inches across and one and a half deep. It is usually built a few feet from the ground, but sometimes at a much greater height. The eggs of the Linnet are from four to six in number, the latter being the usual clutch. They are greenish white or French white in ground-colour, blotched, spotted, speckled, and streaked with reddish brown and rich purplish brown. Some eggs are much more richly marked than others, and on some specimens the markings are very small, pale, and indistinct. As is usual, the larger end of the egg is the most spotted, gencrally in the form of an irregular zone. The underlying markings are not very numerous, and on most eggs light and dark orerlying spots oceur. On some specimens there are a few streaks of rich brown. They vary in length from $\cdot 8$ to $\cdot 66$ inch, and in breadth from $\cdot 55$ to 5 inch. Eggs of this species and its allies ought to be very carefully identified, as small examples are indistinguishable from large eggs of the Goldfinch, and large examples from small eggs of the Greenfinch. The female sits very closely on her eggs, sometimes allowing herself to be removed by the hand. The Limnet probably in many cases rears two broods in the season.

In early autumn the gregarious habits of these birds are again assumed, and they keep in flocks throughout the winter. At this season their habits can most readily be observed. They resort to the stubbles and pastures on low-lying lands, or weedy ground near their breeding-places. They are not very shy, but more so than Redpoles, and search for the greater part of their food on the ground. When alarmed they often fly off together to the nearest tree-tops, where they keep up a twittering chorus; but sometimes those nearest to the observer fly ahead and again alight. Occasionally, in feeding, the flock gets more or less dispersed, but the birds soon unite again. Limuets generally roost upon the ground or in low bushes near their feeding-places. They do not come to the shrubberies to roost like Bramblings, nor do they secm at all partial to evergreens. The flocks constantly wander from place to place, and 
there can be no doubt they are highly serviceable to the agriculturist. They usually keep to themselves, but very often a few birds will intermingle with Greenfinches, Twites, Rerlpoles, or Chaffinches. The flight of the Linnet is rapid but undulating. A flock will sometimes wheel and poise in the air, displaying great powers of wing, especially when alarmed from their fecding-places. Upon the ground this bird hops with ease, and also displays considerable dexterity in clinging to the stems of wceds, such as thistles and docks.

The food of the Linnet is largely composed of seeds of rarious kinds. It does not feed much on grain, although it is sometimes seen on the newly sown wheat-ficlds; but it eats the seeds of the smaller plants, especially of those that are troublesome to the farmer, such as docks, nettles, dandelious, thistles, charlocks, \&c. It is also, as is well known, very fond of hemp and kindred seeds. Inseets doubtless form part of its food in summer; but Naumann states that it fecds its young on seeds carefully shelled and partially softened in its crop. In winter it is said to feed on various berries; and Macgillivray states that it has been known to eat oats.

Although the Linnet is a resident in this country it is probable that many, if not most of the birds of the year join the flocks of this species that pass our islands every autumn, and migrate further south with them. On the east coast, flocks of these birds may be seen as early as July frequenting the weedy pastures and the "denes" or "links," as these sand-hills are locally called. In autumu they are joined by other migrants, probably from the continent. Dixon has scen flocks of Linnets arriving: at intervals, day after day, from the sea on the Lincolnshire coast, and passing south-west together with Redwings and other birds; whilst on the south coast great numbers are caught duriug the autumn migration at Brighton and other places.

The adult male Limnet in breeding-plumage has a crimson frontal patch reaching to the centre of the crown; the rest of the head, the nape, and the sides of the neck are brownish grey, shading into chestnut-brown on the back and into pale chestnut-brown on the rump, each feather, including the wing-coverts and imncrmost secondaries, having an obscure dark centre; the upper tail-coverts are blackish brown, broadly edged with buffish white; the quills are dark brown, margined with white on the outer web; the tail-feathers are dark brown, with white margins, which are especially broad on the inner webs; the general colour of the underparts is buft, shading into dull chestnut-brown on the flanks and into buffish white on the belly and under tail-coverts, and richly suflused with carnine-red on the breast; there are a few indistinct dark streaks on the chin, throat, flanks, and under tail-coverts. Bill lead-colour, paler at the base of the lower mandible; legs, fect, and claws brown; irides hazel. The female differs from the male in having no crimson on the crown or breast, in having the 
general colour of the upper parts much duller, with the streaks on the upper and underparts more pronounced. Young males in first plumage resemble the adult female. After the autumn moult, the male has pale margins to all the feathers, which almost conceal the crimson of the head and breast; but these margins drop off as the season advances, and the red on the head and breast and the chestnut on the back seem to intensify. In captivity the males gradually lose the crimson on the crown and breast, which changes without a moult into ochre-yellow; and after the first moult they assume the plumage of the female, which they retain ever afterwards. Birds in which the crimson is replaced by ochre-yellow are occasionally caught wild, and are probably males deficient in vigour.

In addition to the Eastern form of this species already alluded to, the Common Limnet has several near allies; but the only British species with which it is at all likely to be confused are the Twite and Redpole. Both may always be distinguished by their yellowish bills and the absence of the broad white margins to the inner webs of the tail-feathers; and the Redpole, which is less closely allied to the Common Limnet than is the Twite, possesses the additional characters of a dark brown chin-spot and a double wing-bar.

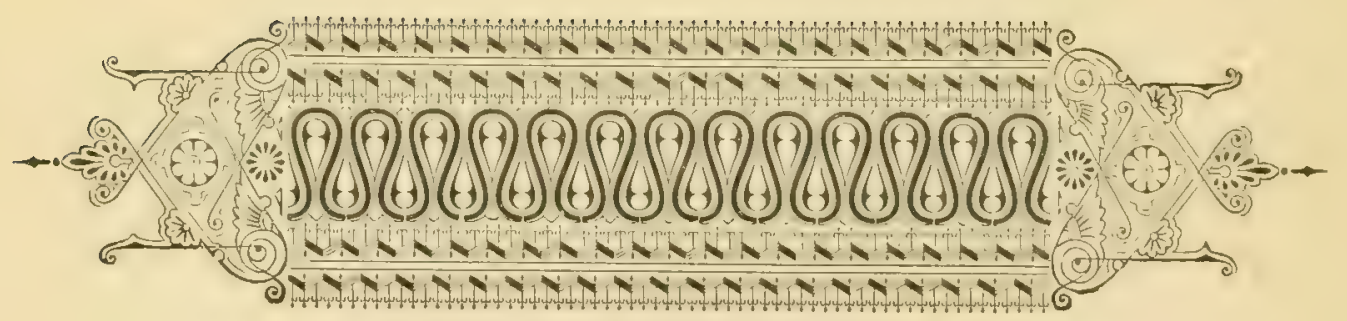




\title{
FRINGILLA FLAVIROSTRIS.
}

\section{TWITE.}

\author{
(Plate 13.)
}

\author{
Passer linaria montana, Briss. Orn. iii. p. 145 (1760). \\ Fringilla flavirostris, Lim. Syst. Nat. i. p. 322 (1766); et auctorum plurimorum- \\ Latham, Pallas, (Bonaparte), (Degland \& Gerbe), (Gray), (Salvadori), (Gould), \\ (Dresser), (Newton), \&c. \\ Fringilla montium, Gmel. Syst. Nat. i. p. 917 (1788). \\ Linaria montium (Gmel.), Leach, Syst. Cat. Mamm.\&c. Brit. Mus. p. 15 (1816). \\ Cannabina montium (Gmel.), Brehm, Vög. Deutschl. p. 278 (1831). \\ Cannabina flavirostris'(Linn.), Brehm, Vög. Deutschl. p. 278 (1831). \\ Linaria flavirostris (Limn.), Macgill. Hist. Brit. B. i. p. 379 (1837). \\ Linota montium (Gmel.), Bonap. Comp. List B. Eur. \& N. Amer. p. 34 (1838). \\ Acanthis montium (Gmel.), Blyth, fide Bonap. Consp. i. p. 540 (1850). \\ Linota flavirostris (Linn.), Saunders, Ibis, 1869, p. 172.
}

So far as is known, the Twite was first described from specimens obtained in the neighbourhood of Sheffield by Francis Jessop, F.R.S., the discoverer also of the Garden-Warbler and the Wood-Wren. Rather more than two centuries ago this ornithologist resided on his ancestral estate of Broom Hall, just outside the dirty village down in the hollow, where a thriving business in the manufacture of knives and other kinds of cutlery had been carried on for three centuries or more. Jessop discovered the Twite in the Peak of Derbyshire, though he need not have gone so far; for even at the present time this bird breeds within three miles of his old hall. He communicated the discovery of this bird to his friend Willughby, who described it under the name of the MountainLinnet, Linaria montana, in his 'Ornithologia,' a work which appeared after his death, in 1676, under the able editorship of John Ray. Since then it has been ascertained to breed in most parts of the British Islands, wherever uncultivated bits of heathy land or Grouse-moors are to be found. It breeds in all suitable localities in Ireland, but in the cultivated districts of that country as well as of Scotland and England it is almost exclusively known as a winter visitor. It is especially common on the islands off the coast of Scotland, the Hebrides, the Orkneys, and the Shetlands, but it has not been recorded from the Faroes.

Fewer British species have a more restricted range than the Twite. Outside the British Islands it is only known to breed in the alpine and subalpine districts of Norway, principally on the islands and near the coast. In winter it has been met with sparingly in most parts of Europe south of the Baltic and west of Russia.' In the East it is replaced by a 
very nearly allied species, $F$. brevirostris, a bird of much more southern distribution, breeding from the Caucasus through Turkestan to Northern Thibet. This species is slightly less than our bird and decidedly paler, and is probably fairly entitled to specific distinction on the ground that, as the areas of distribution of the two birds are discontinuous, they have no opportunity of interbreeding. A single cxample of a female bird allied to the Twite was shot in Massachusetts, and named AEyiothus flavirostris by Ridgray, which may possibly prove to be an American representative of this species, but is more probably the young of some known species.

The Twite is essentially a bird of the moors; he makes his home amongst the heath and the ling in company with the Grouse and the Ring-Ouzel. From his geographical distribution it might be inferred that he is a maritime bird; but this is not the case. He loves wild open rocky country wherever it is, and breeds as freely on the Derbyshire moors inland as on the Hebrides and the Loffodens. The reasou that he does not go inland in Norway is easy to find in the fact that it is only on the islands and near the coast that the bleak nor'-westerly gales and the violent sou'-westers have prevented the pine-forests from seizing upon all the rocky country, leaving none open enough in the interior to suit the taste of the Twite. In its mode of flight and other habits this bird differs very little from the Linnet. In Norway it is a migratory bird, collecting together in flocks in autumn, which wander south in winter, like other gipsy migrants, appearing irregularly in considerable numbers in various parts of Europe, delaying their departure to dally amongst the stubbles of the lowlands to the last possible moment and then hurrying across. Sometimes they choose the route across England, via Heligoland, the favourite "fly-line," as the Americans call it, of so many species; but more often they probably pass direct into Germany, or take the coast-line through Holland and Belgium. In the British Islands the 'Twite is a resident; but even with us a partial migration takes place, the moors are deserted, and in winter this bird is principally seen in small flocks on the stubble-ficlds and in the farmyards. In the former its services in eating the seeds of all sorts of weeds are of great value, and in the latter its food is similar. It can scarcely be doubted that in summer it also eats insects. It is probable that many flocks, principally comsisting of birds of the year, leave our islands in late autumn and join their Norwegian brethren on the continent. The Twite is a rery industrious singer, but its vocal powers are not of a very high order. The song is very much like that of a Linuet, but scarcely so loud and much less varied, and may even be heard on a sunshiny day in winter. The ordinary call-note, which is almost constantly heard whilst the flocks are either flying from place to place, feeding on the ground, or restiug on the heather', is a twitter very similar to that of the Limnet or the Redpole, but scarcely so harsh as that of 
the former nor so soft as that of the latter. In the breeding-season, when the male ealls to the female, the note is supposed to resemble the word twah-it or twite, whence its name. It is rather a late breeder, and seldom has eggs before the middle of May. The nest is often built in the heather, a few inches from the ground; very often it is placed in a depression in the ground itself or on a ledge of rock; but Capt. Elwes, speaking of its breeding-habits in the Hebrides, says that it makes its nest in a bush or in creeper's against a garden wall. Saxby, in his 'Birds of the Shetland Islands,' describes a nest built in a slight hollow under a long strip of turf which had been nearly reversed by the plough. He watched this nest in the process of construction, both parents working at it during eight days. The unobtrusive Twite is often neglected by the oologist for more attractive game. On the 28th of May, 1870, I took a nest with four fresh eggs, betwcen Moscar Bar and Strines, near Sheffield, during an afternoon's ramble on the moors. The nest was in a niche on the edge of the turf which had been cut to make a road, and the top of the nest was level with the surface of the ground. The bird flew off the nest to a small rock close by in the heather, where it remained for a long time, giving me and my companiou ample opportunity of examining it through a binocular. It was a very pretty sight; but not more than a dozen yards further on, in a precisely similar situation, was the nest of a Ring-Ouzcl. In the course of the aftcrnoon we found several more nests of the RingOuzel containing eggs, peeped into three or four nests of the Red Grouse, took a nest of the Merlin containing five eggs, climbed up to a SparrowHawk's nest with six eggs, and examined a nest of the Kestrel, which we took two days afterwards, together with a clutch of Golden Plover's eggs and a forsaken nest of the Black Grouse, so that the poor little Twite, really the most interesting of all, was almost forgotton.

The nest of the Twite is beautifully finished inside, and is almost as neat as that of the Lesser Redpole. When it is placed ou the ground, the outside is of course built in to suit the cavity; but in a tree or amongst lieather the nest is somewhat large and clumsy outside, the foundation being twigs of heather interwoven with grass-stalks, which alone form the upper portion. Inside the cup is very small, not more than an inch and half across and almost as deep. The lining is fine roots, shecp's wool, feather's, hair- or thistle-down, sometimes two or three of these materials at once. The number of eggs is usually five, very often only four, but occasionally six. The eggs measure from $\cdot 72$ to $\cdot 65$ inch in length, by $\cdot 53$ to 4.4 inch in breadth; they are very pale greenish blue, and are indistinguishable in their markings from eggs of the Linnet, except that perhaps they are more often streaked.

The Twite is very similar to the Limnet, but is smaller, with a louger tail, so that it looks almost as large, but slightly more slender. It has no

VOL. II. 
red on the crown or breast like the male Linnet or Redpole; but the male Twite has the red on the rump like the latter bird. The general colour is pale reddish brown, shading into greyish white on the belly and under tailcoverts, each feather of the upper parts, the breast, and the flanks having a dark brown centre. The wings and tail are dark brown as in the Linnet; but the white edging to the middle quills is less marked, and the broad white margins of the inner webs of the tail-feathers are replaced by an illdefined pale brown edge. The legs, feet, and claws are dark brown, as in the Limet, and the irides are also hazel, but the bill is yellow. The female is slightly paler and has no red on the rump. After the autumn moult, the pale reddish-brown margins of the feathers obscure more of the dark brown centres. The yellow bill is assumed with the autumn moult, but fades into pale horn-colour before the next moult takes place.

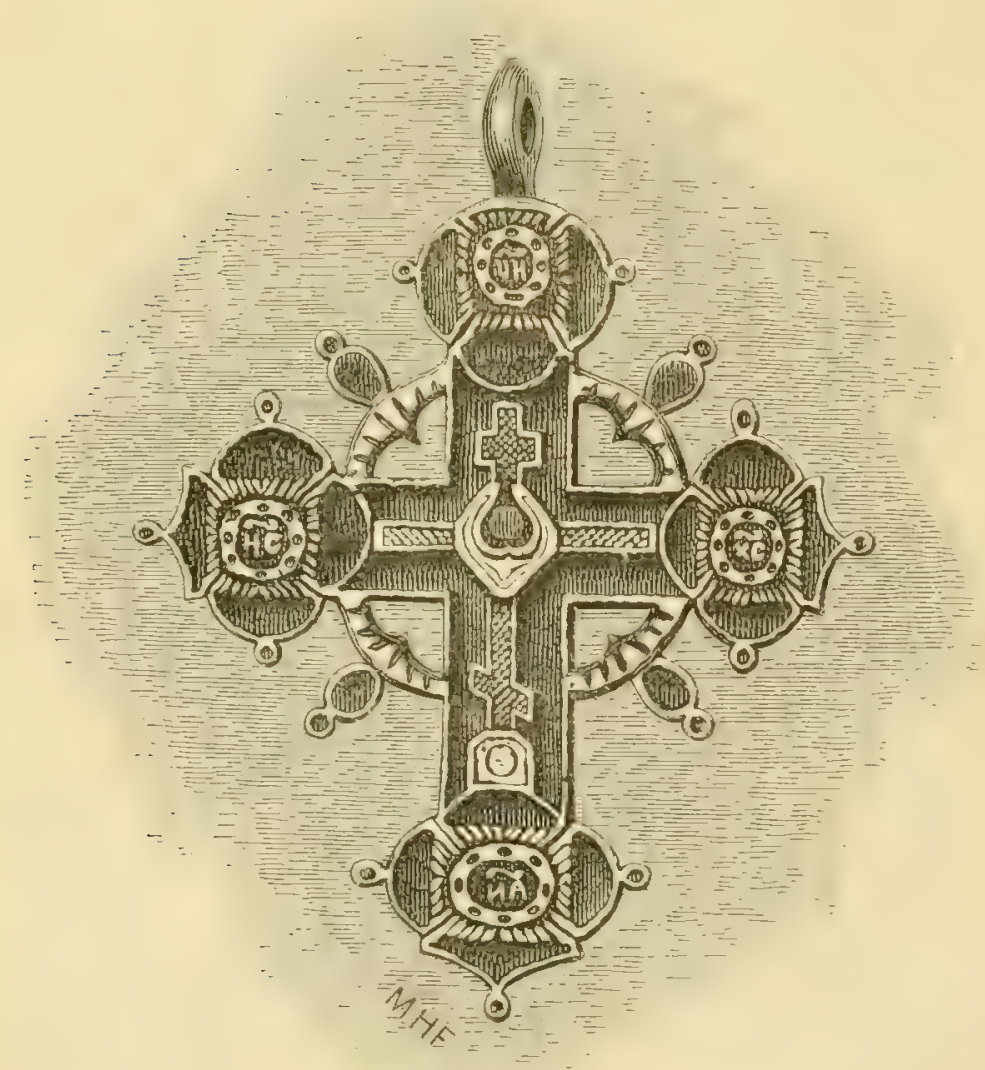


FRINGILLA RUFESCENS, FRINGILLA LINARIA, AND FRINGILLA HORNEMANNI.

\section{LESSER REDPOLE, MEALY REDPOLE, and GREENLAND REDPOLE.}

(Plate 12.)

The Redpole is subject to considerable variation throughout its wide range, which appears to be circumpolar. Examples from Western Europe are very small (varying in length of wing from $2 \cdot 8$ to 2.5 inches) and are very rufous; the prevailing colour of the margins of the feathers is pale buffish brown, and the stripes on the back, rump, flanks, and under tailcoverts are very distinct, and the breast of the adult male in brecdingplumage is rich carmine. Proceeding enstwards, through North Europe, North Asia, and North America, to Greenland, the tendency is to become larger and whiter, the extreme form in Greenland varying in length of wing from 3.3 to 3.1 inches, intermediate continental forms measuring from $3 \cdot 0$ to $2 \cdot 65$ inches. In the Greenland bird the red on the breast is a delicate pink, the streaks on the rump, under tail-coverts, and flanks are nearly or quite obsolete, and the margins of the feathers are pure white. In Arctic Europe, Asia, and America every intermediate form between these two occurs; and the variety of plumage thus occasioned is further complicated by the differences which are attributable to age, sex, and season. The West-European form is known as F. rufescens, and the Greenland form as $F$. hornemanni. The intermediate forms are known as $F$. linaria, which may be considered the typical form, of which the two extremes just mentioned are varieties. Some ornithologists, as Dresser and Newton, have attempted to separate these intermediate forms into two species; others, as Ridgway, make three; whilst Cones and Homeyer make four. Each of the characters relied upon, whether it be the size of the bill, the colour of the breast, the absence or otherwise of streaks on the rump or under tail-coverts, or the extent of white on the plumage, would draw a line in a series in a different place; but as none of these lines would be geographical ones, it seems the wisest course to regard the intermediate race as very variable, the two extremes of variation alone having any geographical limits distinct from those of the typical form. The synonymy of the three forms is as follows :-- 


\section{FRINGILLA RUFESCENS.}

\section{LESSER REDPOLE.}

Passer linaria minima, Briss. Orn. iii. p. 142 (1760).

Fringilla cabaret, Miill. Natursyst. Suppl. p. 165 (1776).

Fringilla linaria, var. $\beta$, Lath. Ind. Orn. i. p. 459 (1790).

Linaria rufescens, Tieill. Mcm. Real. Accad. Tor. xxiii. Sc. Fis. p. 202 (1816-18); et auctorum plurimorum-Degland, Gerbe, Gray, (Irby), (Neuton), (Diesser) \&c.

Linaria minor, Selby, Brit. Orn. i. p. 320 (1833).

Acanthis rufescens (Vieill.), Bonap. Consp. i. p. 540 (1850).

Agiothus rufescens (Vieill.), Cab. Mus. Hein. i. p. 161 (1850).

Linacanthis rufescens (Vieill.), DesMurs, Encycl. d'Hist. Nat. v. p. 304 (1855-58).

Linota rufescens (Vieill.), Newton, ed. Yarr. Brit. B. ii. p. 146 (1876).

Linota linaria (Linn.), apud Yarrell, Cordeaux, Stevenson, Gray, Saxby, \&c.

Fringilla linaria (Linn.), apud Mudie, Harting, \&c.

\section{FRINGILLA IINARIA.}

\section{MEALy Redpole.}

Passer linaria rubra minor, Briss. Orn. iii. p. 138 (1760).

Fringilla linaria, Limn. Syst. Nat. i. p. 322 (1766); et auctorum plurimorumGmelin, Bonaparte, (Cabanis), Temminck, TVilson, Audubon, (Pallas), (Newton), (Dresser), \&c.

Spinus linaria (Linn.), Koch, Syst. baier. Zool. i. p. 233 (1816).

Linaria borealis, Vieill. Mem. Real. Accad. Sc. Tor. xxiii. Sc. Fis.p. 199 (1816-18).

Fringilla borealis, Vieill. Gal. Ois. i. p. 78, pl. 65 (1825).

Passer linaria (Linn.), Pall. Zoogy. Rosso-Asiat. ii. p. 25 (1826).

Linaria holboellii, Brehm, Vög. Deutschl.p. 280 (1831).

Linaria vulgaris, Rüpp. Neue Wirb. Vög.p. 101 (1835).

Linaria canescens, Gould, B. Eur. iii. pl. 193 (1834).

Linota canescens (Gould), Bonap. Comp. List B. Eur. \& N. Amer. p. 34 (1838).

Linota borealis (Vieill.), Bonap. Comp. List B. Eur.\&. N. Amer. p. 34 (1838).

Cannabina linaria (Limn.), Rü̈pp. Syst. Uebers. p. 77 (1845).

Acanthis linaria (Linn.), Bonap. Consp. i. p. 541 (1850).

Acanthis holbölli (Brehm), Bonap. Consp. i. p. 541 (1850).

Aegiothus linarius (Linn.), C'ab. Mus. Hein. i. p. 161 (1850).

Aegiothus holboellii (Brehm), Cab. Mus. IIcin. i. p. 161 (1850).

Eggiothus fuscescens, Coues, Proc. Phil. Acad. 1861, p. 222.

Egiothus exilipes, Coues, Proc. Phil. Acad.1861, p. 385.

Cannabina canescens (Gould), Swinhoe, Ibis, 1861, p. 335.

Egiothus canescens (Gould), Blakiston, Ibis, 1863, p. 71.

Aegiothus borealis (Vieill.), Swinhoe, Ibis, 1874, p. 160.

Linota linaria (Linn.), Newton, ed. Yarr. Brit. B. ii. p. 133 (1876).

Linota exilipes (Coues), Newton, Zoologist, 1877, p. 6. 


\section{ERINGILLA HORNEMANNI.}

Greentand Redpole.

Linota hornemanni, Holb. Naturh. Tidsk, iv, p. 398 (1843).

The Lesser Redpole breeds more or less commonly in all the counties of England north of Norfolk and Leicestcr. South of this boundary it is not so common in summer, but, nevertheless, has been found breeding in the greater number of countics east of Somerset. In Scotland its distribution appears to be regulated by the presence of woods and thickets, especially birch-plantations; and Mr. Gray has never been able to trace it where such shelter is absent. It is a visitor to Iona and Islay, and Dixon met with it in Skye. It also visits the Orkneys on migration in considerable flocks. In Ireland it is as common as in the rest of the British Islands, but is most numerous in the north.

The only known instance of the Lesser Redpole breeding out of the British Islands is that recorded by Professor Gigioli ('Ibis,' 1881, p. 204), who obtained a nest from the Veglio Alps in Italy, about 7000 feet above the sea-lerel. In winter it has been obtained in France, Spain, Italy, and Western Germany, and passes through Belgium and Holland on migration.

The Mealy Redpole is an irregular winter visitor to our islands, chiefly to the northern portions. It is of less frequent occurrence in the eastern and south-eastern counties, and does not appear to have occurred west of Sussex. In Scotland it is chiefly met with in the east, and rarely in the south-western districts; it is, however, a regular winter visitor to the Orkneys.

The Miealy Redpole is a circumpolar bird, breeding at or near the limit of forest-growth, and possibly in some of the alpine districts of central Europe. In winter it is found in various, localities throughout the whole of Central and Southern Europe. Eastwards it wanders as far as Turkestan, South Siberia, North China, and Japan. On the American continent it winters in South Canada and the Northern States.

The Greenland Redpole has only once been obtained in our islands. An example was knocked down on the 24th of April, 1855, on the sea-banks near Whitburn, where it had been observed for several days previous to its capture. This specimen is in Mr. Hancock's collection, and is figured in his 'Catalogue of the Birds of Northumberland and Durham' (p. 54, pl. 5).

The Greenland Redpole breeds in Greenland, Iceland, and Spitzbergen, where it is said to be resident; but Mr. Brooks informs me that it appears in winter in Canada; and, in addition to the specimen captured in England. 
one example has been obtained in France and another in Heligoland. In Greenland it does not breed south of lat. $69^{\circ}$, and Holböll found it still common in lat. $73^{\circ}$.

The Redpole is a very interesting bird, especially to British ornithologists, who have opportumities of studying its habits during the breedingseason denicd to the field-naturalists of other countries. The variations in its plumage at different ages have given rise to much controversy, and the specifie value of those due to geographical distribution to still more. In its appearance it is an immature Limmet; but in its habits it resembles more the Siskin, a bird to whose society it is very partial in winter. It has the easy buoyant flight of the latter bird, and there is a considerable similarity in their songs. The British Redpole, or, as it is more generally called, the Lesser Redpole, is a resident in our islands; but after the breeding-season is over these birds collect together in flocks, some of which seem to cross the Channel for the winter. In either case they become gipsy migrants, wandering here and there in seareh of food, very uncertain in their appearance, common one year and rare the next. The Mealy Redpole scarcely differs in its habits in this respect. In Finmark Collett says that though the majority leave the country and wander south in winter, many remain behind and feed upon the buds of the birch and alder. In Siberia, however, the greater degree of colrl probably compels them all to migrate. In the valley of the Yenesay I found them in large flocks feeding on the droppings of the horses on the snow at Yenesaisk in lat. $58^{\circ}$, in the first week of $\Lambda$ pril ; but on the banks of the Koorayika, on the Arctic circle, I saw nothing of them until the last week in May. So true are they to their character of gipsy migrants that, according to Naumann, they are popularly said to appear in Germany only once in seven years, arriving in Norember and leaving again early in February. The Greenland or Arctic Redpole is said to be a resident in that country; but it appears also to be a partial migrant; for my friend $\mathrm{Mr}$. Brooks assures me that it visits him in Canada in winter, and Ilolböll describes its erratic wanderings, occasionally appearing in great numbers near the Danish colonies.

All the three varietics are principally ground-feeders in winter, and if cautiously approached show very little fear. In the plantations and forests they are much more difficult to obscrve, frequenting, like the Siskin and the Serin, the tops of the trees. They pass rapidly over the trees, twittering to each other as they fly along. It is a beautiful sight to see a large flock of these little birds hopping about on the snow, picking up seeds from the droppings of the horses, almost allowing the sledge to run over them before they rise in a cloud and drop down again a hundred yards in advance. Nor are their habits in this country any less interesting, as they alight in a flock on a bed of dead thistles, and tear the remains of the flowers to pieces, like Goldfinches, scattering the fragments in every direction, or twist and twine 
amongst the branches of a birch, placing their little bodies in every conceivable position, like Willow-Wrens or Tits.

The three races of Redpoles differ but slightly in their notes. Besides the twittering note which they have in common with most Finches, and which is constantly heard as they fly in small parties or large flocks, they lave a very distinct call-note, which, as far as I know, is only heard when the bird is perched. It is very difficult to express the notes of birds on paper; but the call-note of the Lesser Redpole sounds in my ears as much like the French word henri as a whistle can produce. The note of the Mealy Redpoles which winter in Germany cannot be very different. Naumann represents it by the word hoing, long drawn out, and says that it is frequently heard at the nest, probably quoting Bechstein, who found them breeding in Thuringia. These Redpoles, which sometimes breed in Germany, are probably not Mealy Redpoles at all, but Lesser Redpoles; for in Siberia the note is certainly different. I had abundant opportunities of listening to it, both in the valley of the Petchora and in that of the Tenesay. During the long weary waiting for summer to come, one of our favourite methods of lilling time was to watch the flocks of Snow-Buntings and Redpoles. The note of the latter was by no means the clear, liquid henri of our bird, but a thick and far less musical note, like the sound of $z h$, so modulated and drawn out as to appear bisyllabic. The note of our bird is nearly allied to the note of the Canary or Siskin, that of the Siberian bind to the note of the Grecnfinch, Brambling, or Snow-Bunting. The notes of the Redpoles in the Engadine in autumn resembled the word mee-ik, and evidently significd "My dear, where are you?" "My love, come here." This note is quite distinct from the ordinary clit, chit, chit, which seems to mean "Come on, come on ; there's a noise."

Of the note of the Grecnland Redpole Brooks writes to me:- "As it flies it utters quite a different note from that of the Mealy Reclpole, more of a prolonged Sparrow-like chirp, but shriller. When it alights it utters the Canary-like 'too-wee' call-note, as the Mealy Redpole also docs." From this we might conclude that it is the Siberian bird which has a distinct note (an argument which might be used for the distinctness of $F$. exilipes). I unfortunately neglected to make any memoranda of the notes of this bird in Lapland.

Our information respecting the song of the Redpoles is also very unsatisfactory. I have listened scores of times to what I call its song in the neighbourhood of Sheffield, where the bird is very common and breeds regularly within three miles of the centre of the town. I describe it as a short monotonous trill, clear, shrill, and not altogether unmusical. It is one of those songs whose charm cannot be analyzed; but, for some reason or other, it has always been a great favourite of mine, possibly on account of the extreme beauty of the nest of the utterer, an 
mstance of the association of ideas with parallel cases to which every fieldornithologist must be familiar. Prosaically described, it might be said to resemble the rattling of loose cog-wheels. Naumann, who only knew the Mealy Redpole in winter, eridently rever heard the song; nor is there any thing in Newton or Dresser's descriptions to lead one to suppose that either of them ever heard more than the winter twitterings of the Redpole. Collett, speaking of the Mealy Redpoles in Norway, mentions "a prolonged trill" which is only heard in the breeding-scason; and I noticed cxactly the same in Siberia, except that the trill was of a slightly different character. The trill of our bird is caused by the rapid repetition of a double note, whilst that of the Siberian bird is produced by the repetition of a single note, and thus the character of the rattling of loose cog-wheels is gone. Our information respecting the song of the Greenland race is still more meagre. Any one who compares my description of the song of the Waxwing published in 1873 (Dresser, ' Birds of Europe,' iii. p. 436) with Holböll's description of the note of the Greenland Redpole translated and published by Dresser in 1876 (op. cit. iv. p. 56) will, however, come to the conclusion that it does not differ much from that of our bird. I wrote of the Waxwing, "The only note I heard was a sort of cir-ir-ir-ir-re, very similar to a well-known note of the Blue Tit. Occasionally this succession of notes was repeated so rapidly as to form a trilla, like the song of the Lesser Redpole." Holböll wrote of the Arctic Redpole, "Its callnote, which is never responded to by $F$. linaria, is shrill, and is not unlike that of the Waxwing."

In the ncsting-habits of the Redpoles there is no difference amongst the three races. As a rule the nest is placed in low bushes. At Sheffield I have taken it in the brushrood during a ramble from my house before breakfast. It is especially common on the birches and alders overhanging the Derwent near Ashopton. I have also found it in the same district in trees fifteen to twenty feet from the ground. At Tromsö, on the Norwegian coast, I have taken the nest in birch trees; but on the tundras of both Siberia in Europe and Siberia in Asia, as well as in Grecnland, this bird breeds exclusively on willow or birch bushes three or four feet from the ground, for the sufficient reason that in these regions loftier trees do not exist.

Even in England the Redpole is a late breeder, a somewhat remarkable fact in the history of a resident bird. In Yorkshire I have seldom taken eggs before the first of June, but in the south of England it is said to breed a month earlier. In the valley of the Petchora we took fresh eggs in the last week of June, but in the valley of the Yenesay, in lat. $70 \frac{1}{2}^{\circ}$, I found fresh cggs in the middle of July; but these were a second laying, the first, which were laid in the middle of June, having been destroyed by the floods which covered every bush on the island: so that the Redpole is amongst 
the earliest birds to breed in this locality. In Alaska Dall found fresh eggs in the first week of June. In Greenland the bird appears to be an early breeder, as I have a nest and eggs taken on the 10th of June ; and Krüper found nearly fledged young birds of the Aretic Redpole on an island near Iccland on the 12th of June. IIe also found other nests with eggs on the same day. There is no difference whatever in the nests from various localities; they are all composed of a ferv slender twigs in the foundations, and built up of dry grass-stalks and a little moss, profusely lined with the down from the cotton-grass, or from willow-catkins, or, if these materials are not obtainable, with white Ptarmigan feathers, hair, or wool. The lining is generally more or less interwoven into the sides of the nest, which can scarcely be matched for delicacy and beauty. In size there is not much local variation. The inside cup varics in England and Siberia from $1 \frac{1}{2}$ to 2 inches in diameter by 1 to $1 \frac{1}{4}$ inch deep. My Greenland nest does not exceed my largest English nest in size. In England the size of the eggs varies from $\cdot 65$ to 6 inch by $\cdot 5$ to 42 , in Sibcria from $\cdot 75$ to $\cdot 65$ inch by $\cdot 55$ to $\cdot 5$, and in Greenland from $\cdot 8$ to $\cdot 7$ inch by $\cdot 56$ to 52 . The ground-colour varies from bluish green to greenish blue, and does not differ locally. The overlying specks, spots, and blotches, principally at the large end of the egg, are dark reddish brown, and those which are underlying pale reddish brown. Some eggs are much more marked than others, and some in my collection from the vallcy of the Petchora are very boldly streaked.

The seeds of the birch are the favourite food of the Redpole; but it will eat almost any other kind of seed, and in summer it feeds on insects. It is a favourite cage-bird, becoming very tame, and will learn tricks like a Goldfinch, and is very fond of climbing all over its cage.

The adult male Lesser Redpole in breeding-plumage has the general colour of the upper parts rufescent brown, with a dark centre to each feather; the wings and tail are brown, with obscure pale margins; the median and greater wing-coverts with broad tips, and the innermost secondaries with broad margins of pale rufous-brown. It has a crimson patch on the crown and a distinct trace of crimson on the rump; the underparts are buffish white, suffused with crimson on the breast and shading into rufescent brown on the flanks, the feathers of which have dark centres; the chin and upper throat are dark brown. Bill yellow, brown at the point; legs, feet, and claws nearly black; irides hazel. Females have no red on the breast or rump, and are more streaked on the breast and flanks, but otherwise resemble males. After the autumn moult the margins to the feathcrs lide the obscure traces of crimson on the breast, head, and rump, causing the male scarcely to differ from the female; but as the season advances these margins drop off, and the crimson gradually intensifies, not by a moult, but by a change in the colour of the 
featlicr, but very scldom strongly marked before the end of February or early in March. Males of the year resemble females, but occasionally have traces of red on the breast and rump. Young in first plumage are much more streaked on the underparts and have no red on the crown. The characteristics of the allied forms have already been pointed out in the preliminary remarks to this species. The Redpole may always be distinguished after the antumn moult by its red hear, dark chin-spot, and pale wing-bars.

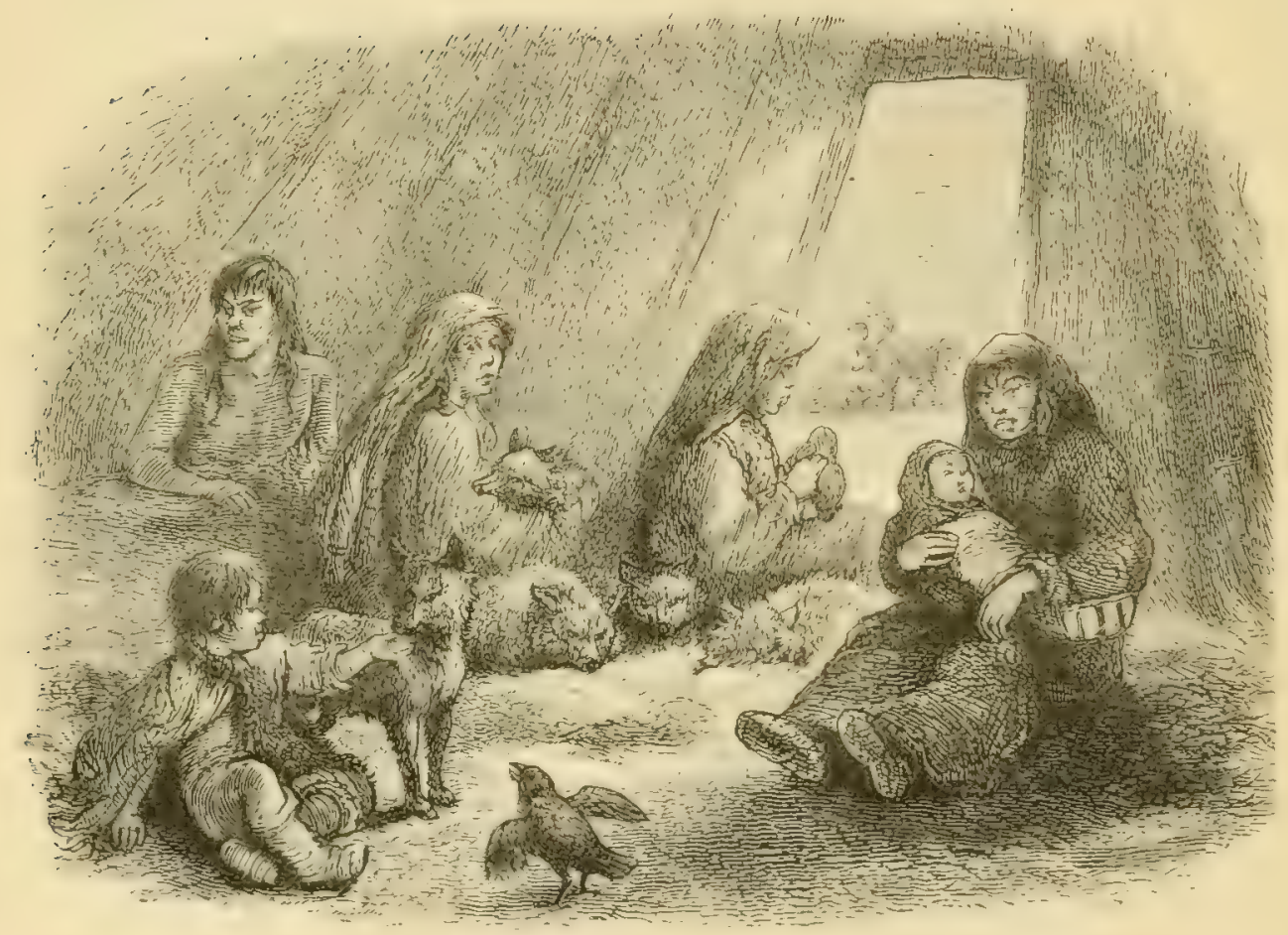




\section{Genus EMBERIZA.}

The genus Emberiza was included by Linnxus in the twelfth edition of his 'Systema Naturæ,' published in 1766 (i. p. 308). The Yellow Hammer' (E. citrinella), being the Emberiza emberiza of Brisson, has every right to be regarded as the type, though some writers advocate the claims of the Corn-Bunting to that distinction.

The Buntings may be distinguished by their gape-line (which is not straight, as in most birds, nor arched, as in Pyrrhula and Carpodacus, but has an angle in the centre) and by their having the palate furnished with a hard horny knob. The lower mandible is laterally compressed, so as to form a sort of anvil for this knob. The nostrils are partly hidden by short feathers, and the rictal bristles are almost obsolete. In a few of the species the hind claw is elongated something like that of a Lark or a Pipit.

This genus contains about forty species, which are distributed throughout the Palrarctic and Nearetic Regions. By far the greatest number of species are confined to the Palrarctic Region, many of which extend their range southwards into the Oriental Region in winter. In this latter region one or two species breed at high elevations. Several of the Nearctic species also wander southwards to the Neotropical Region in winter. Eighteen species are found in the Western Palaearctic Region, of which four are resident in, and six accidental stragglers to, the British Islands. Of these six accidental stragglers no less than four are from the Arctic regions of Europe and Asia, one breeds throughout the greater part of Europe, and one is confined during the breeding-scason to Southeastern Europe.

The Buntings frequent open places, in this respect showing more affinity to the Larks than the true Finches. Their haunts are fields, commons, bare mountain-sides, cultivated districts, marshy places, and moors. In winter they are more or less gregarious. Their flight is strong and slightly undulating, and on the ground they both hop and run. Their powers of song are not very great, and their call-notes are usually harsh and monotonous. Several of the species sing whilst flying. Their food consists principally of seeds; but this diet is varied in summer with insects and in autumn with fruit. The nests are cup-shaped, and placed either in a depression on the ground beneath a tuft of herbage or a bush, in a bush or tree, or in holes and crevices amongst rocks, walls, or drift-wood; 
they are made of twigs, roots, dry grass, moss, hair, wool, feathers, \&c. The eggs differ considerably both in colour and character of markings. In the typical Buntings the markings take the form of bold streaks and fine lines, but in others these streaks are replaced by small blotches and spots. The ground-colour varies from pale bluish white to reddish brown and olive-green, and the surface-spots vary from rich reddish or purplish brown to dark olive-green. The underlying markings are in some cases violet-grey, in others rather paler than the surface-spots.

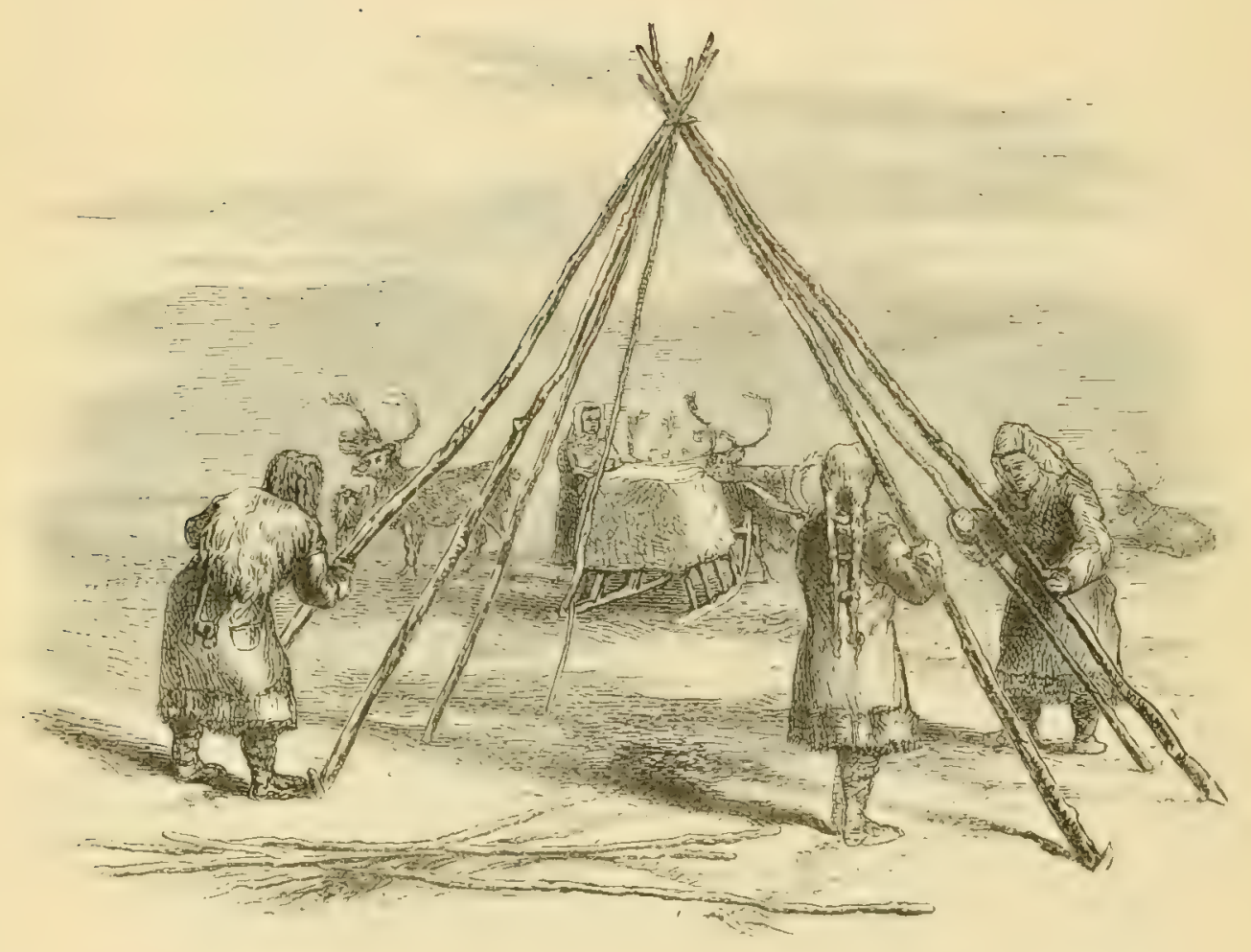


EMBERIZA NIVALIS.

SNOW-BUNTING.

(Plate 15.)

Emberiza hortulanus nivalis, Briss. Orn. iii. p. 285 (1760).

Emberiza nivalis, Linn. Syst. Nat. i. p. 308 (1766); et auctorum plurimorumGmelin, Scopoli, Latham, Temminck, (Bonaparte); (Degland \& Gerbe), Naumann, (Newton), (Dresser), \&c.

Emberiza notata, Mïller, Natursyst. Suppl. p. 157 (1776).

Emberiza mustelina, Gmel, Syst. Nat. i. p. 867 (1788).

Emberiza montana, Gmel. Syst. Nat. i. p. 867 (1788).

Emberiza lotharingica, Gmel. Syst. Nat. i. p. 882 (1788, partim).

Emberiza glacialis, Lath. Ind. On. i. p. 398 (1790).

Passerina borealis, Vieill. N. Dict. d'Hist. Nat. xxv. p. 8 (1817).

Passerina nivalis (Limn.), Vieill. Faun. Franç. p. 86 (1820).

Plectrophanes nivalis (Linn.), Meyer, Zus. u. Ber. z. Taschenb. p. 57 (1822).

Plectrophanes hiemalis, Brehm, Vög. Deutschl. p. 304 (1831).

Emberiza borealis (Vieill.), Degland, Orn. Eur. i. p. 273 (1849).

The Snow-Bunting was known as a British bird as long ago as the days of Willughby, who shot it in Lincolnshire, and also obtained it from the northern parts of Yorkshire through his friend Mr. Johnson. In Ray's edition of his ' Ornithologia,' published in 1676, it is described and figured under the name of the Great Pied Mountain-Finch. In England and Ireland this handsome little bird is only known as a comparatively rare winter visitor, and its chief haunts are the rough open grounds near the sea. In stormy weather, however, many of the birds occasionally wander far inland, and they have been obtained in almost every county. In Scotland the "Snowflake" is commoner, and a few remain to breed on the higher mountains. Saxby found it breeding in Shetland, and Capt. Feilden observed it during the breeding-season in the Faroes. There appears to be no authenticated instance of the nest of the Snow-Bunting ever having been found on the mainland of Scotland, but there is indirect evidence of its having bred in some of the lighest parts of the Grampians.

The Snow-Bunting is a circumpolar bird, brecding on the tundras of the Arctic regions beyond the limit of forest-growth, in Iceland, Nova Zembla, and Spitzbergen, and in similar climates at high elevations further south, in the snow-regions of the Norwegian fells. The Snow-Bunting is a gipsy migrant during winter, occurring in larger or smaller flocks in Central Europe, South Sibcria, North China, Japan, and the Northern States of America. Mr. Godman mentions a flock of about twenty of these birds which visited the Azores in the winter of 1861-65. It has not been recorded from the Spanish peninsula, but is a regular, though 
rare, winter visitor to Italy. It is not known to have occurred in Turkey, Grecee, or Asia Minor, but occasionally wander's as far as South Russia. It does not appear to visit Persia, but Severtzow records it as a rare winter visitor' to North-west 'Turkestan. On the American continent it has been known to wander as far south as Georgia. It has no very near ally.

Of all the Aretic birds which visit the British Islands in winter the SnowBunting is perhaps the favourite. The brilliant contrast between his snow-white head and breast and deep black back, and the similar contrast on his wings and tail, cause the male in full breeding-plumage to be the most conspicuous of all small birds. No bird goes further north than the Snow-Bunting to breed. Capt. Feilden found a nest in Grinuell Land in lat. $82^{\circ} 33^{\prime}$; it contained four eggs on the 24 th of June, and was built within twenty feet of the nest of a Snowy Owl, with some of whose feathers it was lined. Further south it breeds much earlier. It is the earliest spring migrant. Early in April Harvie-Brown and I found them common enough at Mezen in lat. $66^{\circ}$, and by the end of May the last Snow-Bunting had left Ust Zylma in the same latitude on the Petchora. In the valley of the Yenesay they were somewhat later, the last flock passing the Koorayika, in lat. $66 \frac{1}{2}^{\circ}$, on the 7 th of June. In the former valley we saw no signs of their breeding until we reached lat. $68^{\circ}$, and in the latter I did not meet with them again until I reached lat. $81 \frac{1}{2}^{\circ}$. When Collett and I went to Lapland in 187. we did not meet with the Snow-Bunting until we reached Vadsö, in the Varanger Fjord, about lat. $70^{\circ}$. On the 27 th of June we found a nest with young, perhaps a week old. In Iceland, where it is said that many Snow-Buntings remain throughout the winter, it breeds much earlier, for Krüper found well-incubated eggs on the 25th of May. I have a clutch of eggs in my collection obtained by Middendorff on the 'Taimur peninsula (about lat. $73 \frac{1}{2}^{\circ}$ ) on the 15 th July $18+3$; they were laid by birds whose first nest, completed about the middle of June, had been destroyed by the flood when the ice on the river broke up.

The Snow-Bunting sceks the wildest districts and the roughest ground in which to rear its young. High up on the rocky fells, far beyond the pines and above the birches and willows, among the loose stones and fallen crags, where the snow still lies in large patches, or away to the north on the wild tundra, not above but beyond the limit of forest-growth, surrounded by rivers and swamps and lakes and bogs, amongst the piles of drift-wood that strew the banks of the mighty rivers, or the half-rotten logs which lie above high-water mark on the shores of the Arctic ocean, left there ages ago, when the sea-level was much higher than it is now, are the breeding-places of this bird. Perhaps it is the comparatively even temperature enjoyed in summer, where the sun never sets, that tempts the Snow-Bunting into these wild regions, or it may be the abundance of food, the clouds of musquitoes, and the unlimited supply of ground-fruit, 
or, after all, it may be the solitude which constitutes the charm, the comparative immunity from disturbance, though even to these remote wilds the Snow-Buntings are followed by their rolentless encmies, the Peregrines and the Merlins. But whatever may be the cause, the true home of the Snow-Bunting lies beyond or above the limit of forest-growth. Winter home it has none. At this season it leads a roving gipsy life, perpetually trying to migrate northwards with every appearance of milder weather, and perpetnally driven southwards with each recurring frost or heavy fall of snow. It cannot be said to have any line of migration, the flocks wander here and there as fancy leads them; but in the high north they naturally follow the few roads that are kept trodden in winter, because abuudant food is always to be procured from the droppings of the horses. In sledging over the suow across the steppes of Soutll-western Siberia from Ekatcrecnburg to Tomsk, a distance of about a thousand miles, the Snow-Bunting was the only bird we saw, except a few Sparrows, Jackdaws, and IIooded Crows near the villages. The Snow-Buntings were in small flocks, and many of them had almost lost their winter dress. It was a charming sight to watch them flitting before the sledge as we disturbed them at their meals. Sometimes in the sunshine their white bodies were invisible against the white snow, and we could almost fancy that a flock of black butterflies were dancing before us. The flight of the Snow-Bunting is peculiar, and is something like that of a butterfly, as if the bird altered its mind every few seconds as to which direction it wished to take. It can scarcely be called an undulating flight. The bird certainly does rest its wings every few seconds; but either they are expanded when at rest, or they are rested for so short a time that the plane of flight is not sufficiently altered to warrant its being called undulatory. The Snow-Bunting is almost entirely a ground-feeder, and is consequently continually seen on the ground. These birds rtin along the snow with the celerity of a Wagtail on a sand-bank; but they can hop as easily as a Sparrow, and I have very often seen them do so. The idea that they seldom or never perch in trees is a mistake, which has no doubt arisen from the circumstance that on the steppes, where they delight to winter, and on the tundra, where they breed, there are no trees $*$ In the

* It is a remarkable fact that there should be a difference of opinion amongst ornithologists on this subject; but so many wild-goose stories have been told by writers on the habits of birds, and copied again and again, that cantions oruithologists are apt to disbelieve any statement that they have not themselves verified. Even the great Naum:un, who was by far the greatest field-ornithologist who ever lived, falls into error on this point, and doubts Bechstein's statement, supported by that of Nilsson, that Snow-Buntings perch in trees, and also denies that they ever hop. Newton, who has had many opportunities of watching these birds, mentions nothing about their hopping, and says that in Western Europe they seldom perch on a tree or bush. I should not venture to differ from such high authorities if I had not spent hours, I might say weelis, watching these birds during 
valley of the Petchora we had abundant opportunity of seeing them in trees. My companion writes in "The Ibis" :- "During the migration we constantly saw Snow-Buntings alight on trees, both singly and in flocks, and both on spruce-firs, willows, and bare high larches. They perehed frecly and flew from tree to tree, alighting without the slightest hesitation." In the valley of the Yenesay I made similar observations; and in the winter of 1879-80 Dixon saw a flock of Snow-Buntings rise from a newly manured ficld outside Endcliff Wood, near Shefficld, and alight in the trees. They were followed by some men who were shooting, and flew from tree to tree to avoid them, and some of them were shot from trees and are now in the Sheffield Museum. They frequented the place several days. In Ust Zylma, Mezen, and in the village of Koorayika, I have seen Snow-Buntings perched on rails, and often on the roofs of the houses. In their breedingquarters they choose the most elevated situations they can find, perching on some projecting rock or ou the piles of drift-wood. During migration they frequently commence to sing whilst waiting in the sumshine and the suow for summer to come; but at their breeding-quarters the song is very charming. Whilst the female is busy with the duties of imcubation the male sings freely, sometimes as he sits upou the top of a rock, but often flinging himself up into the air like a shuttlecock, and then descending in a spiral curve with wings and tail expanded, singing all the time. The song is a low and melodious warble, not unlike that of the Shore-Lark, but still more like that of the Lapland Bunting. 'They have a variety of call-notes. As they fly together in flocks they continually twitter to cach other like other Finches. The alarm-note is a loud tweek, allied to the spink of the Chaffinch, and the call-note a long-drawn-out $\approx h$, not unlike that of the Brambling or Greenfinch.

The food of the Snow-Bunting consists of seeds of various kinds in winter, and of insects in summer. On the rocky island opposite Vadsö, where MIr. Foyme has his whale-fishing establishment, the Snow-Bunting breeds in some numbers. All the birds I shot on this island had their gizzards full of the remains of flies. They seemed to be shore-fecding birds in this locality, and to find a variety of insects on the various decaying matter hy the sea. They were constantly frequenting the houses near the whale-fishing establishment, and doubtless found plenty of insects attracted by the offal of the whales. This bird has also been linown to eat small shellfish and the buds of the Saxifraga oppositifolia-a beautiful violetcoloured alpine plant which grows ou the shores of the Polar Sea, both in America and Siberia, and may also be found in the valley of the Engadine, at an elevation of about 8000 feet.

the long dreary waiting for the sudden arrival of the aretic summer, and if $I$ could not substantiate my statements by careful nutes written on the spot, and corroburate them by the observations of my companions. 
The nest was built in a heap of stones and rocks, and we had to remove a considerable quantity before we could see it. This seems to be their favourite site; but on the Yenesay, where there were no rocks, the nests were built amongst the piles of drift-wood near the shore. 'The nest is a bulky structure and adapted to the cavity in which it is placed, and is composed of dry grass, with occasionally a few roots or a little moss or even twigs of the dwarf birch and other alpine shrubs if the cavity is large; the lining consists of feathers, hair, or down.

The eggs of the Snow-Bunting are from five to eight in number; six or seven is a usual clutch. 'They vary from yellowish white to pale bluish green in ground-colour, spotted and blotched with rich reddish brown and sometimes fincly streaked with deep blackish brown; these rich surfacemarlings are intermingled with numerous and large underlying blotches aud spots of pale reddish brown and pinkish grey. On some specimens most of the markings are underlying ones, and the surface-spots are very deep in colour. The spots are generally most numerous at the larger end of the egg, sometimes forming an irregular zone or often a semi-confluent mass. They vary from $1 \cdot 05$ to $\cdot 82$ inch in length, and from 67 to $\cdot 6$ inch in breadth. The eggs of the Snow-Bunting differ considerably in size and colour; they are, on an average, larger than those of the Lapland Bunting, and are readily distinguished from them by their much paler ground-colour. Certain eggs of the present species more closely resemble some varieties of those of the Corm-Bunting; but they are never so heavily and richly marked, never so streaked, and the spots are always paler and redder.

The Snow-Bunting does not generally appear on our eastern coasts until the beginning of October. Mr. Cordcaux has seen it as early as the middle of September; but it very often delays its appearance until the end of October. The date seems to depend entirely on the state of the weather, and its arrival in some districts is regarded as the forerunner of a severe snowstorm. On some parts of the Lincolnshire coast there is a tradition that the early appearance of this bird is a sure sign of a long hard winter. The Snow-Bunting usually remains in this country until the end of March or early in A pril, ere it sets out on its northern journey. Except during the breeding-season it is a gregarious bird. Soon after their arrival, flocks of these little "Snowflakes" may be seen on the low land near the coast, or on the beach itself, where they nestle very closely amongst the shingle, as if resting themselves after their long and perilous journey. Few sights are more interesting on a lowering day in November, when each moment you expect to see real instead of feathered "snowflakes" coursing through the air, than to watch the actions of a flock of these charming little Aretic strangers; they seem to bring some of the romance attaching to the northern regious with them, and have an interest that few other birds

voL. II. 
posscss. Their principal haunts during their sojourn in this country are the lands near the sea; they do not usually wander far from the coast, and are rarely seen inland save when an exceptionally sharp or long spell of stormy weather drives them to more sheltered localities. In their habits they much resemble Bramblings, and are often seen on stubbles and weedy pastures. They fly in very compact flocks, and often whecl and turn about with great rapidity before they alight. They cannot be called rery shy birds, but are somewhat wary, and soon become wild if repeater!ly fired at. Their food at this season is largely composed of grass-seeds; and when these are difficult to obtain (as, for instance, in heavy snows) they will even risit the stackyards or pick up a scanty sustenance from the droppings on the roads. In this country the Snow-Bunting is very crratic in its appearance, and is incessantly changing its ground, after the mamner of a true gipsy migrant. The frost brings them to the sheltered districts; but the first thaw disperses them again.

The adult male snow-Bunting in full breeding-plumage is black and white; the mantle, scapulars, innermost secondaries, the terminal half of the primaries, the four centre tail-feathers, most of the next, and the tips of the three outside feathers on each side are deep black; all the rest of the plumage is snowy white. Bill black; legs, toes, and claws black; irides hazel. The adult female in brecling-plumage differs from the male in having the black replaced by dark brown, which extends also onto the head and wing-coverts, and in having traces of the pale edges still left on all the dark feathers. The soft parts are similar to the male. After the autumm moult every feather on the upper parts and the feathers of the breast and flanks have broad edgings of chestnut-brown, and the bill changes to orange-yellow, darker at the tip. The young in first plumage is an entirely different-looking bird. The wings and tail closely resemble the adult in autumn plumage; but all the small feathers are greyish brown, paler on the belly and under tail-coverts, and all except those on the belly and under tail-coverts have obscure dark centres. In spite of numerous assertions to the contrary, there does not appear to be any difference between adult birds and birds of the year.

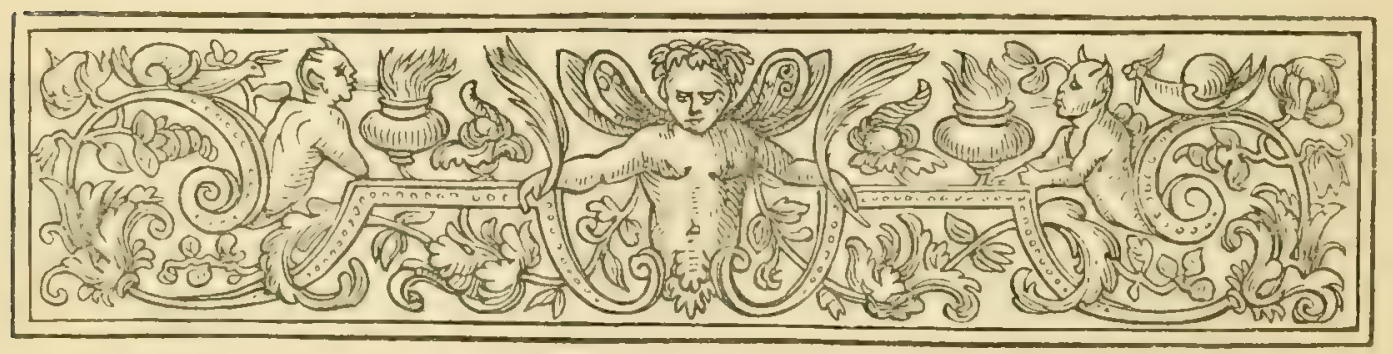




\title{
EMBERIZA LAPPONICA.
}

\section{LAPLAND BUNTING.}

\author{
(Plate 15.)
}

Fringilla montana, Briss. Om. iii. p. 160 (1760).

Fringilla lapponica, Limn. Syst. Nat. i. p. 317 (1766); et auctorum plurimorumGmelin, Latham, (Nilsson), (Bonaparte), (Salvadori), (Degland \&. Gerbe), (Savi) (Dresser), (Newton), \&c.

Fringilla calcarata, Pall. Reise Iruss. Reichs, ii.p. 710, pl. E (1773).

Plectrophanes calcaratus (Pall.), Meyer \& Wolf, Taschenl. i. p. 176 (1810).

Hortulanus montanus (Briss.), Leach, Syst. Cat. Mamm. \&c. Brit. Mus. p. 16 (1816).

Passerina lapponica (Linn.), Vieill. Nouv. Dict. d'Hist. Nat. xxv. p. 12 (1817).

Emberiza calcarata (Pall.), Temm. Man. d'Orn. i. p. 322 (1820).

Passer calcaratus (Pall.), Pall. Zoogr. Rosso-Asiat. ii. p. 18, pl. 39 (1826).

Plectrophanes lapponicus (Linn.), Selby, Trans. Linn. Soc. 1827, xv. p. 156.

Centrophanes lapponicus (Iinn.), Kaup, Nat. Syst. pp. 158, 192 (1829).

Plectrophanes grœenlandicus, Brehm, Vög. Deutschl. p. 307 (1831).

The first instance of the occurrence of the Lapland Bunting in this country, to which it is only a rare accidental winter visitor, was early in the year 1826, the fact being announced by Selby to the Linnean Socicty. This specimen was discovered in Leadenhall Market, where it had been sent with Larks from Cambridgeshire. Since that date about a score solitary examples have been obtained in Great Britain, most of them in the southern counties; but it is not known that any flock of these birds has ever reached our islands. In Scotland it appears hitherto to have only been detected in Caithness, where it has twice been found. It has not yet occurred in Ireland. It is very rarely observed in Iccland, and has never been known to visit the Faroes.

The Lapland Bunting is a circumpolar bird, breeding on the tundras of both hemispheres beyond the limit of forest-growth, and in a similar climate at high elevations in Norway as far south as Dovre Fjeld, about lat. $62^{\circ}$, where it breeds in the willow-region above the birch-region. It does not go so far north as the Snow-Bunting, and is apparently absent from Spitzbergen and Nova Zembla; but Middendorff found it breeding on the Taimur river in Siberia, about lat. $73^{\circ}$, and in Greenland it breeds at least as far north as lat. 70 . It wiuters in Mongolia, North China, aud the Northern States of America, a few individuals straying every year into Central and Southern Europe. It has occurred in South Scandinavia, Denmark, Holland, Germany, France, and Austria. It has not been known to visit the Spanish peninsula, but during severe winters is occasionally observed in Northern Italy. It does not appear to visit Turkey, Grecee, or Asia Minor, or ever to cross the Mediterranean, and is very rare in 
South Russia and is only a straggler to Turkestan. The Lapland Bunting lias been met with as far south as New Mexico, on the American continent, where it has sereral allies, from all of which it may easily be distinguished by its black throat.

The Lapland Bunting does not belong to the class of gipsy migrants like the Snow-Bunting, but appears to have a distinct winter home and to be comparatively regular in its migrations. It is, perhaps, the commonest bird on the tundras. It is described as being extremely abundant in Arctic America; from Alaska to Greenland. East of the North Cape I found it very common in Lapland. Both at Ust Zylma on the Petchora and at Koorayilia on the Yenesay an almost endless succession of flocks passed northwards on migration; and on both sides of the Ural Mountains, when we reached the tundra, we found it to be not only the commonest but also the most widely distributed bird. The migrations of the Lapland Bunting are, however, somewhat peculiar. Like the Petchora Pipit and the Arctic Willow-Warbler, its winter home lies in the far east. Its occurrence in Central and Southern Europe during winter appears to be only accidental. Individuals wander westward-birds who have joined the wrong stream of migration, and lost their way; but the main flocks migrate eastwards, crossing the Ural Mountains morth of the valley of the Kama, and, following their eastern slopes, cross the steppes to the Altai Mountains, and find their way to Eastern Mongolia and North China, where Prjevalsky and Swinhoe found them wintering in great numbers. The East-Siberian birds probably winter in the same district. Dybowsky states that they pass Lake Baikal on the spring migration during the second half of April, and in autumn during the first half of september.

The Lapland Bunting is quite as much a bird of the tundra as the SnowBunting, and, like that species, is only known to breed beyond or above the limit of forest-growth. In many other of its habits it also resembles the Snow-Bunting, and is equally gregarious, but does not breed quite so far north. It is also much later in arriving at its breeding-grounds. In the valley of the Petchora we did not meet with it at Ust Zylma, in lat. $66^{\circ}$, milil the 18th of May; and in the valley of the Yenesay, on the Koorayika, in lat. $66 \frac{1}{2}^{\circ}$, a solitary Lapland Bunting appeared for the first time on the 4th of Jume-in each case at least six weeks after the arrival of the SnowBunting. In both cases I had an excellent opportunity of watching their habits. The first birds to arrive were males, principally in company with Shore-Larks; they passed through on migration for about a fortnight, the later flocks being almost entirely composed of females. They seemed to be cutirely ground-feeders, and ran about very actively wherever there was any bare ground; but before the snow had entirely disappeared the Lapland Buntings had also taken their departure, and we did not meet with 
them again until we had passed the limit of forest-growth. On migration they repeatedly perched in trees, and when disturbed generally sought refuge in a tree. Like the Shore-Lark and the Snow-Bunting, the Lapland Bunting occasionally hops; its flight is quick and powerful, but more undulating than that of the Snow-Bunting. In its song the Lapland Bunting reminds one both of the Snow-Bunting and the Tree-Pipit. The notes are not very loud, but are musical and are continued for some time; and every now and then a curious note is introduced which sounds like cheng, the consonants, both at the beginning and the end, being pronounced gutturally, as in German. This note is also frequently repeated alone, and is probably the note of endearment between the sexes. The song is generally heard when the bird is flying in the air, soaring like a Lark, and is continued until the bird alights on some grassy knoll or stunted bush, descending with outspread wings and tail. What I take to be the alarm-note of the bird is a plaintive but loud chee-up, often heard near its nest. The female has a song almost as rich as that of the male. The Lapland Bunting is not such a coast-bird as the Snow-Bunting, and seeks the swampiest ground it can find so long as there are dry tussocks of grass full of flowers where it can breed; if there are also a few stunted willows or birches upon which it can perch, so much the better. The nest is almost always placed in some hole in the side of one of the little mounds or tussocks which abound on the marshy parts of the tundra; it is composed of dry grass and roots, and profusely lined with feathers. The eggrs of the Lapland Bunting are from four to six in number, and differ very much both in size and colour. They vary in ground-colour from pale grey to pale brown, more or less obscured by a profusion of underlying blotches and streaks, which vary in colour from yellowish brown to reddish brown; the overlying markings are generally much fewer, and are principally streaks mixed with a few blotches and spots of dark reddish brown. They vary in length from .87 to .75 inch, and in breadth from .68 to .57 inch. The only eggs with which they are likely to he confounded are those of the Tree-Pipit and Red-throated Pipit, neither of which use feathers in the lining of their nests.

The adult male Lapland Bunting in breeding-plumage has the entire head, throat, and upper breast black, except a nearly white streak, which, beginning behind the eye and passing at the back of the ear-coverts, forms a white patch on the sides of the neck. A rich chestnut collar reaches from behind the head onto the upper back; the rest of the feathers of the upper parts, including the wing-coverts, innermost secondarics, and centre tail-feathers, are brownish black margined with white and buff; the quills and tail-feathers are brown, with narrow pale margins, the two outer tailfeathers with more or less smoky white at the tip. The black on the upper breast extends onto the flanks; and the rest of the underparts is nearly 
white. Bill ycllow, black at the tip; legs, fect, and claws dark brown; iriles hazel. The hind claw is more than twice as long as any of the other claws and only slightly curved, resembling somewhat that of the MeadowPipit. The adult female in breeding-plumage differs from the male in having pale margins to the black feathers of the head, throat, and flanks, and the feathers of the chin and upper throat are buffish white, with halfconcealed black bases; the chestnut feathers on the nape have also dark centres and pale margins. After the antumn moult all the feathers have pale edges; but adult males may be distinguished by the concealed black centres to the feathers of the throat and the absence of the dark centres on the feathers of the nape. IIales of the year closely resemble adult females, but differ from them in having no dark centres to the feather's on the nape. Females of the year scarcely show any concealed black bases to the feathers of the throat or breast. Young in first plumage resemble females of the year, but are more rufous above and more streaked on the upper parts and back.

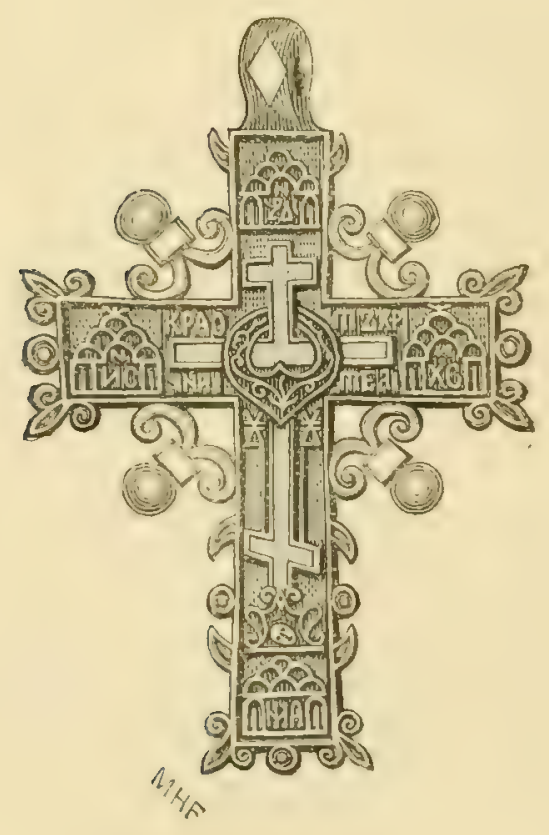




\section{EMBERIZA SCHCENICLUS.}

\section{REED-BUNTING.}

(Plate 15.)

Emberiza hortulanus arundinaceus, Briss. Orn. iii. p. 274 (1760).

Emberiza schoniclus, Linn. Syst. Nat. i.p. 311 (1766); et auctorum plurimorum -Gmelin, Latham, (Kaup), Temminck, (Degland \&. Gerbe), Naumann, Dresser, Newton, \&c.

Emberiza arundinacea, S. G. Gmelin, Reise Russl. ii.p. 175 (1774).

Cynchramus schœeniclus (Linn.), Boie, Isis, 1826, p. 974.

Schønicola arundinacea (Briss.), Bonap. Rev. Crit. p. 164 (1850).

The Reed-Bunting is one of the most widely distributed of the British Buntings and breeds more or less commonly in all marshy districts throughout England and Wales. It is also as common and widely dispersed in Scotland, both on the mainland and on most of the adjacent islands, extending to the Outer Hebrides. It becomes rarer in Orkney; where it is occasionally known to breed; and to the Shetlands it is merely a straggler, three examples only being recorded by Dr. Saxby-a female and two males. In Ireland it is also very common and distributed over the whole island, where it is a resident.

The Reed-Bunting in one of its three or more forms is found throughont the Palæarctic Region, with the exception of Palestine and the tundras of the north beyond the limit of forest-growth. It is generally a resident, but in the northernmost portions of its range is only a summer visitor, and further south it is probable that many migrate south on the approach of winter, whilst in North Africa, Greece, Asia Minor, Turkestan, China, and the central and southern islands of Japan it is only a winter visitor. In such a large range it is not to be wondered at that the Reed-Bunting is subject to considerable local variation, especially in the size of the bill. The smallest form, E. schonichus, var. passerina, breeds in Eastern Siberia and winters in China. The typical form is found throughout Europe and West Siberia, both varieties occurring in the valley of the Yenesay. A form which is called E. schoonichus, var. palustris, is found in Japan, Italy, and Spain; whilst the largest and palest form, E. schoeniclus, var. pyprlutloides, having a bill so large that Finsch has placed it in a different genus, is a resident in the upper vallcy of the Irtish in South Siberia, in Turkestan, and the deltas of the Volga and the Danube. The selection of four forms to be honoured with a name is purely arbitrary. Although the extreme forms appear to be almost generically distinct, they are counected 
together by an unbroken series and are geographically distributed in a very irregular manner. The differenees between these forms may be expressed as follows :-

$$
\begin{aligned}
& \text { Bill large. }\left\{\begin{array}{l}
E \text {. pyrrhuloides. Large and very pale. } \\
E \text {. palustris. }
\end{array}\right. \\
& \text { Bill small. }\left\{\begin{array}{l}
\text { E. schoniclus. } \\
\text { E. passerina. }
\end{array}\right\} \text { Intermediate in size and rufous }
\end{aligned}
$$

The difficulty of discontinuous areas of distribution may be overcome by regarding the large-billed form as one race and the small-billed form as another. The small-billed form will then range across the Palrarctic Region, the larger rufous birds of the west meeting the smaller black-andwhite birds of the east in the valley of the Yenesay. The large-billed form will be a resident in Italy, Turkey, the deltas of the Damube and the Volga, Turkestan, the Altai Mountains and the Ussuri. Intermediate forms between the two are found at each extreme limit of the range-in Japan and in Spain, in the former country having exterminated both extreme forms. A somewhat similar difference of colour to that we have noticed in the small-billed form is also found in the large-billed form, and shows the usual climatic variation-the eastern and western forms, where the climate is humid, being rufous, and the central forms, where the climate is comparatively dry, being pale.

The haunts of this bird in summer are near water-either the reedgrown willow-studded banks of sluggish river's, the rushy sides of canals and large or small marshes, or, in wilder country, the banks of little streams, drains by the roadside, and swampy moorland. The Reed-Bunting, although a local bird, is one that frequents marshy places in wild as well as in cultivated districts, and seems as much at home in the roughest parts of the Highlands as on the wide-stretching reedy broads in the lowlying counties. The birds are usually seen in pairs in summer-each pair apparently kecping to a recognized beat, from which they seldom stray until the young are reared. The cock is a very pretty bird, and rarely fails to arrest the attention as he either clings to some tall rush, or flitting in jerking flight over the placid waters, perches on some overhanging spray and pours out his simple little song. Sometimes he may be scen sitting on walls or rocks, more frequently upon a scrubby bush or on the solitary telegraph-wire stretching far away over the moors, or even on some tall shrub of heather, in all which situations he repeatedly warbles his song. It is a true Bunting's song, very monotonous; but very often his homely strain, heard in places where sweeter music is absent, proves grateful to the ear and imbues the wilderness with life. It consists of a double note, repeated three or four times and concluded with a long-drawn one, which it seems to have considerable difficulty in uttering, and which resembles the note of the Com-Bunting. Its call-note is a harsh and prolonged 
chee. The Reed-Bunting commences to sing in the beginning of April and continues until late into the summer. It is a very lively bird, more so than the Yellow Hammer, and is almost as tame. Its flight is undulating, like that of all the Buntings, and it also possesses the habit of abruptly alighting, spreading out its tail, and, should it be about to perch on a reed, often fluttering its wings until firmly scated. As you wander along the banks of the water the birds will flit from stem to stem or bush to bush before you for a considerable distance, and then return to their old haunt by crossing the water. It is very fond of clinging to an upright stem or reed.

The Reed-Bunting pairs rather early in the year, and begins nestbuilding late in April or early in May. The nest is rarely built at any height above the ground, although Jardine states that he has very frequently found it, in plantations bordering some marshy spot, on a young spruce-fir as much as from one to three yards above the ground; and in the valley of the Petchora I found a nest of this bird built inside an old Ficldfare's nest in an alder-swamp nine feet from the surface of the water. The usual site is upon the ground beneath the shelter of a tuft, in a clump of rushes, or on a bank amongst rank vegetation. I have found it between the slender stems of young willows close to the ground, and it is usually well concealed by surrounding grass, lushes, or moss. Hewitson says that he has, although rarely, seen the nest at an elevation of two feet or more above the water and supported by a bunch of the common reed. This bird, however, never suspends its nest from the reeds, as some of the older writers imagined was the case. The nest is made of various materials: in some districts dry grass, moss, and withered leaves of rushes form the outside, and fine grass and hairs finish off the interior; whilst in more swampy places it is almost exclusively made of dry bents and recd-stems, the feathery tops of which form the lining. The eggs are from four to six in number, sometimes only three. They vary in ground-colour from greyish olive to purplish buff, spotted, streaked, and blotched with rich purplish brown, almost black. Many of the streaks are underlying and pale violet-grey in colour, and most of the surface-spots are more or less blurred at the edges. The streaks are much thicker and much less tortuous than those on the eggs of the Yellow Hammer, nor are they so long, as a rule, or so numerous; they are very bold, some of the spots being as large and round as No. $\$$ shot, and they are generally distributed over the entire surface of the egg. They are not subject to any considerable amount of variation, and are not easily confused with those of any other British species. They vary in length from 85 to 68 inch, and in breadth from ' 6 to $\cdot 54$ inch. The Reed-Bunting rears, in many cases, two broods in the season. The male bird, while the female is upon her nest, takes up his perch close at hand and there incessantly warbles his simple 
lay; but his mate is far more shy, and when disturbed generally hides herself as soon as possible. She is a very close sitter, and the nest is often almost trod upon ere she will quit her charge. When thus frightened off her eggs or callow young she will feign lameness, and fluttering with sceming broken wings and legs before the observer, try by this cunning artifice to lure him away. Sometimes the male will join his mate in these alluring actions. The young birds are almost exclusively fed on insects.

The Reed-Bunting is partly insectivorous and partly granivorous. In summer it chiefly eats insects and small freshwater shells, together with larve of different kinds. It may often be seen in the air chasing passing flies, returning when the capture is effected to its favourite perch. In winter seeds of various kinds are eaten, such as those of grasses, but it will also feed on grain.

It is only in summer that the proximity of water seems necessary to the Reed-Bunting. In winter it wanders far from its summer resorts and sociably joining other Finches frequently comes to the stackyards in severe weather to pick up what chance grains it can find. It may then be seen on the fields and hedges, and is sometimes flushed from weed-grown wastes in company with Larks and Corn-Buntings. In very severe weather they are often seen, as $\mathrm{Mr}$. Cordeaux remarks, in company with Wagtails and Pipits near the sheep-folds. The bird, however, is not so gregarious as many of the true Finches, and the flocks are rarely large, and usually partly composed of other species. Mr. Gray remarks that there appears to be a large accession to the numbers of this bird in autumn in the north of Scotland. These migratory flocks, he says, mix with flocks of Corn-Buntings. Flocks of these birds are also met with on our eastern coasts in September, sometimes in association with Chiffchaffs and Whitethroats, as recorded in the 'Migration Report' for 1882.

The male Reed-Bunting in summer has the head and throat deep black, a white collar passes round the back of the neck and joins the white on the breast, and another broad white stripe extends from the base of the lower mandible and joins the white collar. The general colour of the rest of the upper parts is bright chestnut, shading into bluish grey on the rump and upper tail-coverts, each feather with a brownish-black centre. The wings are blackish brown, margined with light red; the two centre tailfeathers are similar in colour to the back, the rest are brownish black with narrow reddish margins, except the two outer webs of the two outermost feathers on each side, which are obliquely marked with white. The general colour of the underparts is white, striped with dull brown on the flanks and tinged with grey on the breast. Bill brownish black above, paler below; legs, toes, and claws brown; irides hazel. The female differs considerably from the male and has no black on the head and throat; the head 
and ear-coverts are dark brown, each feather margined with reddish brown; the lores and a stripe over the eye and round the car-coverts are pale buff; the back, wings, and tail are similar to those of the male; the throat is dull white; the lower throat, breast, and flanks are striped with brown, and a broad brownish-black line passes from the bill down each side of the throat. Males of the year have much less black on the throat, and the stripes on the flanks are much more distinct and the breast also is striped. In all stages of plumage the male may be distinguished from the female by the concealed black bases to the feathers of the head and throat and the white collar. The adult male in winter is not nearly so handsome and conspicuous as he is in summer: the black on his head and throat is almost entirely concealed with broad reddish-brown margins to the feathers; the white parts are tinged with buff, and the dark parts of the plumage are almost hidden by light margins. These margins abrade or drop off as the spring comes on, leaving the bird in full breeding-plumage. The male ReedBunting may be distinguished from every other British Bunting (in fact, from every other European species) by its black head and throat and white moustachial line. The female Reed-Bunting very closcly rescmbles the female Lapland Bunting, but may at once be identified by its much shorter hind claw, the much darker tips of the wing-coverts, and the much purer white on the outside tail-feathers. From the female Rustic Bunting the female Reed-Bunting differs in having the upper tail-coverts less chestnut, the tips of the wing-coverts less distinct, and the outside web of the second tail-feather white instead of brown. The latter character will distinguish both sexes of the two species at all ages, and also the female Reed-Bunting from the female Little Bunting.

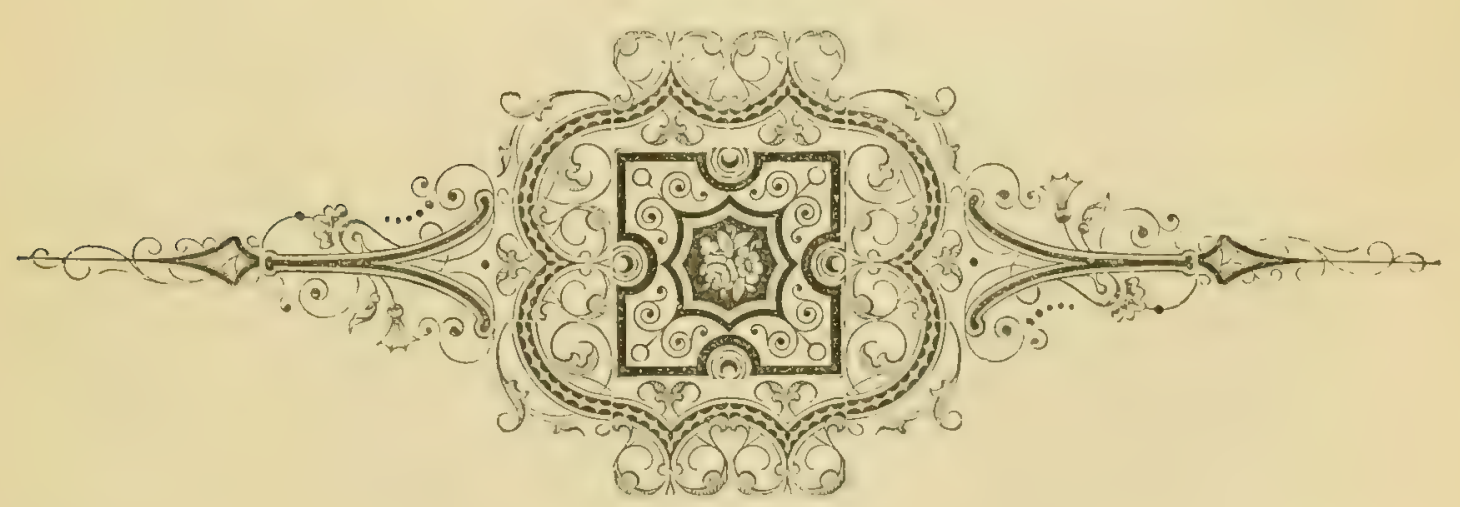




\section{EMBERIZA RUSTICA.}

\section{RUSTIC BUNTING.}

\section{(Plate 15.)}

Emberiza rustica, Pall. Reis. Russ. Reichs, iii. p. 698 (1776); et a uctorum plurimorum-Temminck \& Schlegel, Bonaparte, Middendorff, Naumann, Salvadori, Gray, Newtom, Dresser, isc.

Emberiza lesbia, Gmel. Syst. Nat. i. p. 882 (1788).

Emberiza borealis, Zett. Resa Sver. och Norr. Lappm. i. p. 107 (1822).

Spina lesbia (Gmel.), Kaup, Natiirl. Syst. p. 153 (1829).

Hypocentor rusticus (Pall.), Cab. Mus. Hein. i. p. 131 (1850).

Cynchramus rusticus (Pall.), Degl. et Gerbe, Orn. Eur. i. p. 329 (1867).

Three specimens of the Rustic Bunting, another East-European and Siberian species, have been captured in the British Islands, thus well establishing its claim to rank amongst our accidental visitors. The first specimen was recorded by Mr. Gould in 'The Ibis' for 1869 (p. 128). It was canght near Brighton on the 23rd of October 1867, and was seen alive by Mr. Dawson Rowley on the day of its capture. It is now in Mr. Monk's collection. The second specimen was shot at Easington, in Holderness, in September 1881, and was recorded in the 'Zoologist' for that year (p. 465), by Mr. Eagle Clarke. The third example was recorded in the same periodical for 1883 (p. 33) by Lord Lilford. It was netted by a birdcatcher at Elstree reservoir, in Hertfordshire, on the 19th of November 1882, and it was sent to Mr. Burton, the bird-stuffer, in the flesh, and on dissection proved to be a young male.

The range of the Rustic Bunting is very similar to that of the Little Bunting, but extends slightly further to the west. It does not go so far north to breed, neither does it winter so far south. In Finland it has not been found further north than lat. $64^{\circ}$, but in Archangel it is common in lat. $65^{\circ}$. Hoffmann found it on the Ural Mountains in lat. $62^{\circ}$; but it was not olstained by Finsch in the valley of the Obb. Professor Slovzow obtained an example in 18\% 7 , near Omsk, on migration; and in the valley of the Yenesay I did not sce it further north than lat. $62^{\circ}$. Middendorff found it breeding on the Stanovoi Mountains, and Dyborsky confirms the records of earlier ornithologists of its appearance in Kamtschatka. It passes through Dauria, Japan, and Mongolia on migration, and winters abundantly in China. It occasionally occurs in Turkestan on passage, and a few maty remain to breed on the mountains as well as on those of South Siberia. Like the Little Bunting, occasional stragglers visit Western, Central, and Southern Europe almost every year. It has been obtained in South 
Sweden, Heligoland, Germany, Austria, Southern France, Northern Italy, and Turkey. The Rustic Bunting has several near allies, but none of them approach it very closely in the coloration of the males.

Of the habits of the Rustic Bunting but little appears to be known. According to Piottuch it is said to arrive near Archangel in small flocks about the first of May. It is very local and generally met with in the bushy parts of the woods, in the spots that are clear of snow. Its habits in some respects resemble those of the Reed-Bunting. Like that bird, it is said to haunt the marshy portions of the forest. Alston and Harvie-Brown met with this bird near Archangel, but state that it was much rarer than the Little Bunting; they found it in the marshy pine-woods and in openings in the forest. It appears to be a very restless bird, incessantly flitting about or hiding itself amongst the thickest parts of the cover. Meves found the Rustic Bunting, or "Willow-Sparrow" as it is locally called, rather common in some places on the Onega river. He shot lis first specimen in a swampy fir-wood, his attention being called to it by its sharp cry to its mate, a note which was not unlike that of the Redwing. Early in July he met with two broods of this bird, some of which had not completed their plumage, but others were full-grown. He saw the old birds occasionally through the thick bushes calling very anxiously to their young ones, endeavouring to get them away to a safer retreat. Although he often found it amongst the willow bushes, its brecding-grounds seemed to be in the swampy pine-woods. The young birds he often found frequenting the corn- and oat-fields, where they preyed upon the grain. Middendorff describes the song of this bird as rich and melodious, a characteristic which readily distinguishes it from other Buntings.

Radde states that the Rustic Bunting is the earliest Bunting to arrive in East Siberia, the first pioncers appearing on the 26th of March, and frequenting the vegetable gardens and places sheltered from the wind. Although the weather was very stormy, the birds still continued to arrive, often so fatigued as to be easily caught or knocked down with stones. On the 13th of April, 1859, he also met with large flocks of Rustic Buntings, even in the wildest forests, on the post-road which passes over the Baikal Mountains to the river Irkut. It sometimes migrates southwards in autumn, in company with Bullfinches. The chief point of interest in the migrations of this species is that it belongs to a little group of birds which have, within comparatively recent times, evidently extended their breedingrange, which now reaches from the Pacific almost, and in some cases quite, to the Atlantic, whilst their winter-quarters remain confined to Eastern Asia.

Scarcely any thing is known of the nesting-habits of this species. The only information at all reliable is that published by Dresser in his 'Birds of Europe' (iv. p. 233), who gives a description of its nest and eggs from 
specimens that were sent to lim from the ncighbourhood of Archangel. The nest is made entirely of fine wiry grass, and is not very carefully built. The cggs, according to Dresser, are quite distinct from those of any other European Bunting. Ife deweribes them as having great affinity with eggs of the Reed-Bunting; but the ground-colour is white, with a warm, almost rectlish tinge. The markings are similar in character to those on the eggs of the Recd-Bunting; but are retder, bolder, and chiefly collected in a zone round the larger end of the egg. The underlying markings are light purplish or violet-purple and moderately large. Dresscr states that his eggs do not vary much, and are about as large as those of the ReedBunting; whilst Newton gives ' 84 by 6 inch as the measurement of one in his possession presumed to be of this species. The egg which I lave figured was obtained on the Altai Mountains, and will be seen to differ considerably from those already described. It may possibly be an egg of the Yellow-breasted Bunting ( $\boldsymbol{E}$. aureola).

The food of the Rustic Bunting is probably similar to that of its near congencrs, composed of insects in summer, and grain and sceds in winter. This bird has several times been kept in confinement for considerable periods.

The male Rustic Bunting, in full brecding-plumage, has the crown and sides of the head black, a stripe over the eyes and a patch on the nape white; the hind neck, lesser wing-coverts, rump, and upper tail-coverts are chestnut; the back is palcr chestnut, each feather with a broad dark brown centre; the median and greater wing-coverts are blackish brown, margined with buff and broadly tipped with white, forming two bars across the wing; the wings are brown, darkest on the innermost secondaries, the primaries narrowly margined on the outside web with buff, the secondaries with pale chestnut, broadest on the innermost; the tail is brown, the two centre feathers paler than the rest and with buffish margins, the outside feather with a broad clongated patch of white extending on both webs, and the next feather with a similar but shorter patch, and only on the inner web; the general colour of the underparts is white; across the breast is a band of rich chestnut, and the feathers on the sides and flanlss have a broad centre of the same colour; a line of spots passes from the bill downwards, forming a somewhat obscure moustache. Bill brown above, paler below; legs and feet yellowish brown, claws darker brown; irides brown. The female somewhat resembles the male, but the colonrs are not so pure, the black on the head is replaced by brown, the eye-stripe and nape-patch are smaller and not so pure, and the band across the breast is narrower. Young birds in nestling plumage have the upper parts somewhat similar to the female; but the underparts are white with elongated black spots, and the chest-band is only indicated by buff. In winter plumage, the feathers on the upper parts, including the wings, are very broadly margined with 
buff, which conceals the black on the head of the male, and the underparts are also tinged with buff, especially on the breast; the eye-stripe and napepatch are also buffy white. Birds of the year appear to be distinguished from adults by having the throat spotted and the chest-band intermixed with blackish brown; and males may be known from females by having black bases to the feathers of the head. The female Rustic Bunting differs from the female Little Bunting in having less chestnut on the head and more on the rest of the upper parts.

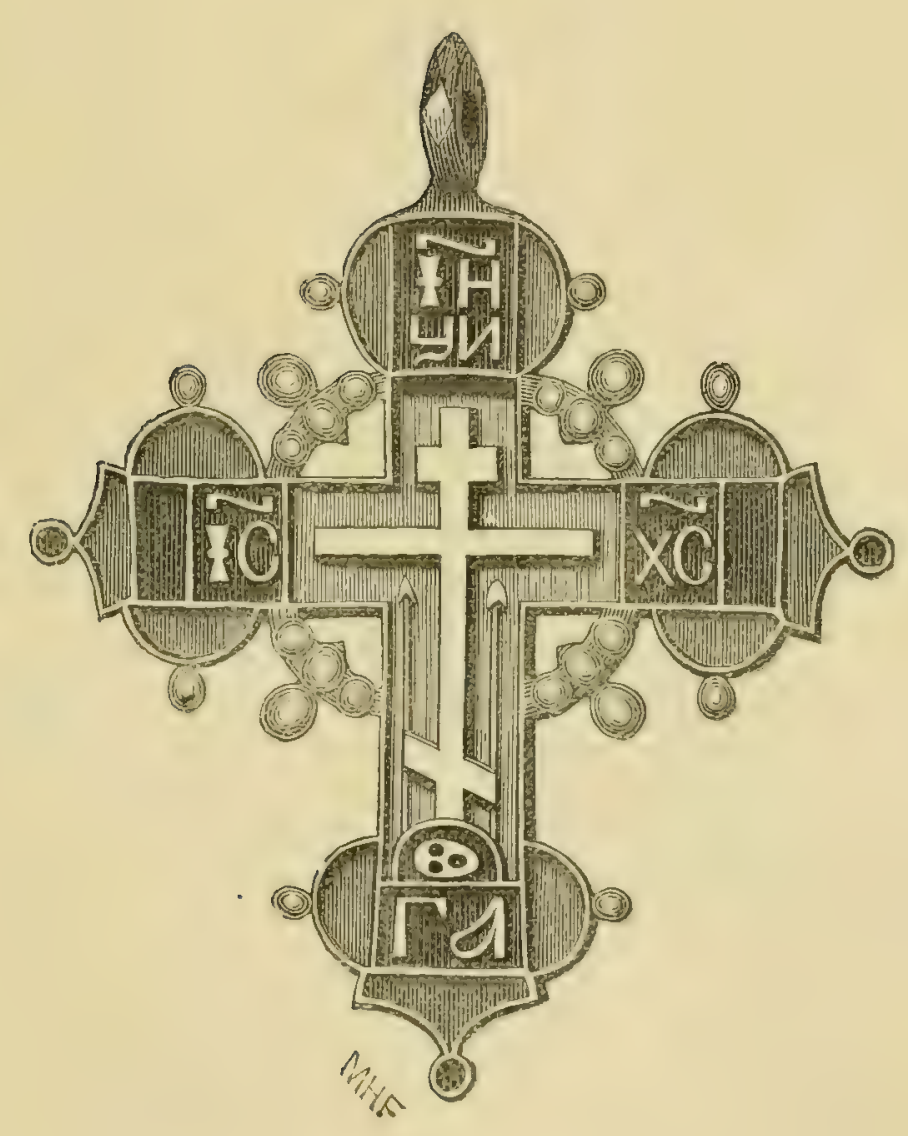




\section{EMBERIZA PUSILLA.}

\section{LITTLE BUNTING.}

(Plate 15.)

Emberiza pusilla, Pall. Reis. Russ. Reichs, iii. p. 697 (1776); et auctorum plurimorum-Salvadori, Gray, Radde, Schrenck, Jerdon, Swinhoe, Dresser, Newton, se.

Fmberiza schoniclus, var. minor, Nilss. Orn. Suce. i. p. 170 (1817).

Emberiza durazzi, Bonap. Icon. Faun. Ital. Ucc. pl. 35. figs. 1 \& 2 (1832-41).

Buscarla pusilla (Pall.), Bonap. Rev. et Mag. de Zool. ix. p. 163 (1857).

Cynchramus pusillus (Pall.), Degl. et Gerbe, Orn. Eur. i. p. 327 (1867).

Notwithstanding the fact that this rare little Siberian Bunting visits IIeligoland almost every year, only a single example has been obtained in the British Islands. It was exhibited at a meeting of the Zoological Society by the late Mr. Gould, who stated that it had been taken in a clap-net near Brighton (Proc. Zool. Soc. 1864, ]. 37\%). In 'The Ibis' for 1865 (p. 113), Mr. Dawson Rowley furnished further particulars of its capture; and from him we learn that it was brought to Swaysland, the Brighton bird-stuffer, by a boy on the 2nd of November, 1861, and that it bore no evidence of ever having been in captivity. It is now in $\mathrm{Mr}$. Monk's collection.

The Little Bunting is an Arctic bird, occasionally breeding on the tundra above the limit of forest-growth, and rarely found in summer south of the Arctic circle, except at considerable elevations. Its range extends from the valley of the Dwina eastwards to the Pacific. It is common near Archangel; Harvie-Brown and I found it in considerable numbers in the valley of the Petchora, as far north as lat. $68^{\circ}$; Finsch observed it north of Obdorsk up to the limit of forest-growth (about lat. $67_{\frac{1}{2}}^{\circ}$ ); I found it common in the valley of the Yenesay up to lat. $71^{\circ}$; Middendorff obtained it on the Taimur peninsula, in the same latitude, and on the Stanovoi Mountains; and in the St.-Petersburg Museum are skins collected by Baron Maydell in the Tschuski Land. It also breeds in some of the mountain districts of Eastern Siberia; Dybowsky found it during summer in the mountains near Lake Baikal; and Schrenck obtained a nest on the Lower Amoor on the 17th of June, before the snow had all melted. It passes through MIongolia, South Siberia, and Turkestan on migration, and winters in North India, Burma, and China. It has not been recorded from Kamtschatka or Japan; but Captain Wardlaw Ramsay obtained a single example on the Andaman Islands. In Europe its appearance during winter may almost be considered accidental; but it has been found once in Sweden, oceasionally in Holland, and frequently in the sonth of France. Several specimens are recorded from North Italy; and it has been net 
with in Germany, Austria, Turkey, Asia Minor, and Syria. Loche records a solitary example from Algcria. The Little Bunting has no very near ally, but most closely rescmbles the Rustic Bunting, E. rustica. The males in breeding-plumage are perfectly distinct, and after the autumnal moult they may easily be distinguished by the points alrearly noticed in the article on the Rustic Bunting as characterizing the females of the two species.

The Little Bunting is a migratory bird, and breeds in the high north. Like the preceding species, it migrates cast in autumn, and is another of those Asiatic birds which have apparently recently extended their breedingrange into Europe. I first made the acquaintance of this charming little bird on our expeclition to the great river Petchora in 1875. In this valley it was one of the latest birds of passage to arrive at its breeding-grounds. We obtained the first example on the 31 st of May, in lat. $66^{\circ}$, eleven days after the ice began to break up; and we afterwards found them common down to the tundra. A few even reach the willow-swamps on the islands of the delta, as far north as Alexievka. It was most common in the pineand birch-forests, and was frequently seen fceding on the ground on the mossy and marshy open spaces in the woods, on the swampy edge of the forest tarns, searching for insects in company with Green and White Wagtails, Temminck's Stints, Fieldfares, Bluc-throated Warblers, and other Arctic birds. Two years afterwards I again met with the Little Bunting in the valley of the Yenesay, nearly a thousand miles further east. Summer may have been unusually late that year' for on the Arctic circle the ice on the river did not begin to break up until the 1st of June, when migratory birds arrived in great numbers. On the 7 th of June the Little Bunting arrived, in company with the Golden Plover, the Wood-Sandpiper, and Temminck's Stint, nearly in the middle of the great spring migration.

Alston and Harvie-Brown met with the Little Bunting, in the summer of 1872 , in the neighbourhood of Archangel. They found it a very common bird, but somewhat local in its distribution. It frequented the pine-woods of large growth and thickets, but seemed to prefer the younger woods composed of a mixture of pine, fir, alder, and birch trees. They often heard its low sweet song, which they compare rather to that of a Warbler than of a Bunting, and they describe its call-note as resembling the words tick, tick, tick. They did not, howerer, suceed in finding any nests, although they obtained the young in several stages of plumage. Professor Lilljeborg also met with it near Archangel, and describes it as a vely lively bird, incessantly moving and gliding about amongst the bushes and reeds. He also describes its song as very sweet, most nearly resembling that of the Robin, and uttered as the bird sits perched on the top of a bush, where it can easily be seen.

The Little Bunting pairs soon after its arrival at its breeding-grounds. VOL. II. 
In the valley of the Yenesay it was extremely abundant, and its unobtrusive and quict song was constantly heard before the snow, which was lying to the depth of five or six feet up to the 1st of June, had sufficiently melted to make the forest penetrable. I found the first nest of this bird on the 23rd of June. I was on the south bank of the Koorayika, a tributary of the Yenesay, and was scrambling throngh the forest down the hill towards my boat, amongst tangled underwood and fallen trec-trunks, rotten and moss-grown, when a Little Bunting started up out of the grass at my feet. It did not fly away, but flitted from branch to branch within six feet of me. I knew at once that it must have a nest; and in a quarter of a minute I found it, half hidden in the grass and moss. It contained five eggs. I have seldom seen a bird so tame. Thie nest was nothing but a hole made in the dead leaves, moss, and grass, copiously and carefully lined with fine dead grass. I took a second nest in the forest, on the opposite bank of the river, on the 29th of June, containing three eggs; this nest was in a similar position to the foregoing, and the behaviour of the parent bird precisely the same. On the 30th of June we east anchor about 110 versts below the Koorayika, and I went on shore to shoot, and found a third nest of this interesting little bird, containing five egges, which were slightly incubated: this nest was lined with reindecr-hair. On the 6th of July, a few miles further down the river, I went on shore again, and found another nest of the Little Bunting, this time containing six eggs; it was similar to the last, rather more sparingly lined with reindeerhair, but the tameness of the bird was just the same.

The eggs in the first nest are very handsome, almost exact miniatures of those of the Corn-Bunting. The ground-colour is pale grey, with bold twisted blotches and irregular round spots of very dark grey, and equally large underlying shell-markings of paler grey. The eggs in the second nest are much redder, being brown rather than grey, but the markings are similar. Those in the third nest have the markings similar to those previously described, but the ground-colour is browner, being less olive than those of the first cluteh and less red than those of the second ; whilst those in the fourth liest are intermediate in colour between those of the second and third clutches. They vary from $\cdot 78$ to 68 inch in length, and from $\cdot 6$ to .53 inch in breadth.

The nest of this bird found by Schrenck on the Lower Amoor was placed on the ground between tussocks of moss, and made of grass-straws intermixed with the spines of the lareh and fir. Middendorff found two nests of this bird on the Boganida river, one containing five and the other four eggs, three of which he figures in his 'Säugethicre, Vögel und Amphibien' (pl. xiii. fig. 4) *.

* Niddendorf"s measurements agree with mine. His largest egg was 20 millimetres loug. Newton's measurement of 88 is probably a misprint. 
In summer the food of the Little Bunting is probably principally composed of insects of various linds; but in winter its diet is, like that of the rest of the Buntings, almost entirely seeds or grain. In winter the Little Bunting collects into flocks of greater or less extent; and Jerdon states that in India it frequents bare spots of ground studded with low bushes. In winter it is evidently much shyer than in the breeding-season. Davison, in his ficld-notes on the Birds of Tenasserim ('Stray Feath.' vi. p. 407), writes of this species:- " $A$ bout the steep precipitous rocks, immediately below the cone of Alooleyit, I saw a few flocks of this Bunting. They were excessively wild, and it was with difficulty that I managed to secure a single specimen. They settled about the rocks and on the grass, and when disturbed separated, and gencrally settled on the tops of stunted trees growing about." In China Swinhoe also states that it is gregarious during the winter. It is sometimes kept in a cage.

The male Little Bunting in full breeding-plumage has the entire head rich chestunt, with a broad distinct black band on each side of the erown, a narrow indistinct one round the ear-coverts, and an ill-defined moustachial line of the same colour on each side of the throat; the feathers of the rest of the upper parts are brown with dark centres, those on the mantle and the scapulars, the innermost secondaries, and the greater wingcoverts having pale chestnut margins; a bar is formed across the wing by the median wing-coverts having pale tips; the quills and tail-feathers are brown, the two ontermost feathers of the latter with an elongated white stripe on the inner web rumning out at the tip of both feathers and onto the basal portion of the outside feather, but the white on the second feather is frequently alsent; the underparts are nearly white, shading into chestnut on the chin and upper throat, and conspicuously streaked with black on the breast and flanks. Bill dark brown, almost black; legs, feet, and claws pale brown ; irides hazel. The female somewhat closely resembles the male, but the black on the head is duller and the chestnut paler. After the autumn moult the pale margins to the feathers partially conceal the black on the head, and cause the stripes both on the upper and under parts to be less distinct; and the breast, flanks, and under tail-coverts are slightly suffused with buff. The bill also becomes paler, especially the under mandible. Birds of the ycar scarecly differ from adults; but young in first plumage are much more streaked both on the upper and under parts.

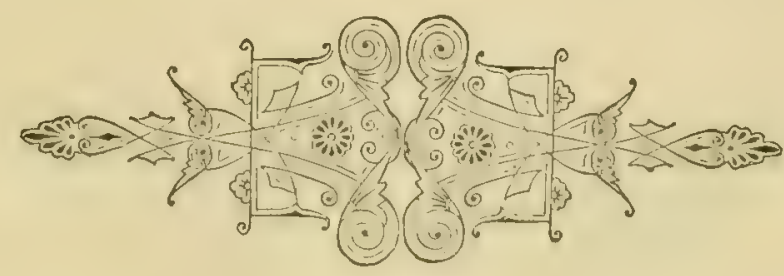




\title{
EMBERIZA MILIARIA.
}

\section{CORN-BUNTING.}

\author{
(Plate 13.)
}

\author{
Emberiza cynchramus, Briss. Orn. iii. p. 292 (1760). \\ Emberiza miliaria, Lim. Syst. Nat. i. p. 308 (1766); et auctorum plurimorum- \\ Gmelin, Latham, Temminct, Naumann, (Iteuglin), Gould, Newton, Dresser, Sc. \\ Fringilla projer, Miill. Natursyst. Suppl. p. 164 (1776). \\ Miliaria septentrionalis, Brelım, Vog. Deutschl.p. 291 (1831). \\ Miliaria europsea, Swains. Classif. B. ii. p. 290 (1837). \\ Cynchramus miliaria (Limn.), Bonap. Comp. List B. Eur. and N. Amer. p. 35 \\ (1838). \\ Spinus miliarius (Limn.), Gray, Tist Gen. B. p. 61 (1841). \\ Cryptophaga miliaria (Lim.), Cab. Mus. Hein。 i. p. 127 (1850). \\ Citrinella miliaria (Limn.), Gray, Hand-l. B. ii.p. 114 (1870).
}

The Corn-Bunting; often inappropriately called the Common Bunting, is by no means the commonest or best known of the British species of this genus. It is common enough in some localities, rare in others, and its distribution is certamly local. Owing to its preference for well-cultivated districts, it is a comparatively common bird in the south of England, including Guernsey; and in the north it is by no means rare, although local. In Scotland, according to Mr. Gray, it is less local in the western districts than in the castern, and extends in the latter from the south of Wigtownshire to the north of the Outer IIcbricles, and even to St. Kilda. In the east it is by no means so common in summer; but very large flocks are sometimes met with in winter. It also breeds in the Orkneys and the Shetlands, in the latter islands being much commoner in winter than in summer. It is found throughout Ireland in suitable districts, where it is also a common resident, becoming to a certain extent gregarious in winter.

The Corn-Bunting has a somewhat restricted range, and inhabits the south-western portion of the Palrearetic Region, where it is for the most part a resident. Beyond the British Islands its range extends throughout Central and Southern Europe. It is only found in the extreme south of Norway and Sweden; and east of the Baltic its northern limit appears to be Riga. It is doubtful if it has ever occurred as far north as Moscow or the Ural Mountains; but it is very locally distributed in Southern Russia, where it is a partial migrant. It is a resident in the Caucasus and Western Turkestan, and there is an cxample in the muscum at Omsk said to have been obtained in the neighbourhood. It is a resident in the Canaries and North-western Africa; hut in Egypt and Arabia Petrea it is only found 
during winter, whence it probably migrates to Central Europe to breed. It is a resident in Palestine, Asia Minor, and North Persia, as far south as Shiraz. The Corn-Bunting has no very near ally, nor docs it exhibit any important variation in the colour of its plumage, except that British examples are usually somewhat dingy. In the extreme southern and castem portions of its range, where the climate is tropical in summer, the general colour is slightly more sandy than in examples inlabiting wetter districts. The difference, however, is not of sufficient importance to constitute a desert form, and is so slight as to be scarcely worthy of notice.

The Corn-Bunting has little in its appearance to attract the attention; its notes, though peculiar, are not very musical, and as the bird is not very active it is easily overlooked. This is not because it is retiring, but because it is unobtrusive. It is a resident bird in our islands, and the haunts it prefers are the breezy ficlds and open corn-lands. It may be seen commonly in the richer and well-cultivated districts inland, on the semiwaste grounds bordering the moors, and is very abundant on seaside farms.

The Corn-Bunting is essentially a bird of the steppes. The momntains have no charm for it; nor does it care for the forests. It is commonest on the wide open plains, which have not inaptly been called the "granaries of Europe." On many of these steppes you may travel for hundreds of miles without seeing a tree, although the soil is very deep and rich, and wheat and other grain is cultivated in unlimited (puantities. In localities such as these it is often, next to the various species of Latrks, the commonest bird; consequently in our islands it is somewhat local, comparatively few districts being sufficiently open or fertile to suit it.

This bird is by no means shy, and will almost invariably allow you to approach sufficiently near to identify it beyond a doubt; but its presence is usually first betrayed by its peculiar song, and the bird may soon be detected in a conspicuous place perched on the top of some tall plant or low bush, or perhaps on a wall or telegraph-wire. The song is uttered either as the bird sits but little concerned at your approach, or as it takes a slow laboured flight into the air to another bush or stump. It is a very monotonous strain, but may, from the favourable position in which it is uttered, rather than from its loudness, be heard at a considerable distince. It is rather short, and I can best express it by tees, tees, tees, tis-is-is-s-s$r$-r-re. It is uttered apparently with great difficulty, and sounds as if the bird were trying to sing with its bill elosed. It is somewhat harsh, and puts you in mind, as Mr. Gray remarks, of the jingling of a chain or the sound of breaking glass. This simple song is most pertinaciously kept up. Every few minutes the bird sings, and then waits as if to listen to its rivals, then warbles again, often sitting for an hour or more on one perch. The ordinary call-note of this bird is very loud, and resembles the word tzit; 
the note between the sexes is a long-drawn-out kack, and frequently the two notes are heard together, tzit-kaak.

Dixon writes of the Corn-Bunting in Algeria:- "If this bird does not sufficiently merit the title of 'Common' Bunting in England, it most assuredly does so in Algeria, and from the coast to Batna is, I think, the commonest bird of the country. It may be seen in all kinds of scenery, the half dried-up river-beds, the rich barley-fields, the gardens, the roadsides, the plains, the wooded slopes of the Aurès, the farmsteads, and even near the Arab dwellings. In some parts almost every bush was crowned with a heavy and ungainly-looking Corn-Bunting, or they were perched, at intervals of a few yards, on the telegraph-wires, all singing lustily. It was as tame as in England, even more so, and in some instances it allowed me to approach within a few feet ere taking wing. This bird often utters its short harsh song when flying in the air. As we rode past them on the wayside, the rumble of the heavy diligence repeatedly startled them, and they flew off over the fields, singing as they went, and, as they possess the singular habit of allowing their legs to hang downwards, they looked even more clumsy and lazy than when at rest. It was very interesting to notice the distribution of this bird in this part of Africa. From the coast to Batna the country is pastoral, and in places very well cultivated. Here the bird was evidently in its favourite hamnts; but as we left Batna behind us, and went south towards the Sahara, we left the Corn-Bunting too, and in the oases we searehed suitable places for it in vain-it had vacated them in favour of the Sahara Bunting, the Grass-Warblers, and the Crested Larks."

I found it equally common in the Dobrudscha, on the steppes which lie between the Danube and the Black Sea, and in the similar districts of Wallachia to the north of that river.

Early in spring the Corn-Bunting pairs, the flocks that have congregated during the winter separate, and the birds retire to their breedinggrounds. Although paired so early, this bird is a late breeder, and its nest is seldom found before May or the beginning of June. The site is variously selected in an open field amongst the growing corn, under a tuft of grass or the shelter of a bush. Sometimes it is under the shelter of a large plant, or amongst brambles and briars, but is perhaps most frequently found when the grass is being eut for hay. The nest is generally placed on the ground in a little depression, but sometimes it is slightly above it; it is rather loosely put together, and made of dry grass, a scrap or two of moss, sometimes roots or tufts of twitch, and is lined with fine grass and, in most cases, a few hairs. The eggrs are from four to six in number; and although they differ considerably amongst themselves, their size prevents them from being confused with the eggs of the other Buntings that breed in this country. The ground varies from pale clay- 
colour to dull white, and the spots, streaks, and blotches vary from rich purplish brown, almost black, to pale brown, and the underlying markings, which on some eggs are large and numerous, are violet-grey or greyish purple. As before stated, the eggs of this bird vary greatly; but each clutch generally partakes of uniform characters. Some eggrs are very boldly streaked and dotted, and have paler blotches almost over the entire surface, others have the mass of markings in a broad band round the larger end. On some eggs the ground-colour can scarcely be seen, so thick and numerous are the surface-markings; whilst others more resemble those of the Cirl Bunting, and are only sparingly spotted and streaked, chiefly on the large end. Other specimens have most of the markings underlying ones, with one or two large irregular masses of colour here and there. They vary in length from 1.05 to .87 inch, and in breadth from $\cdot 75$ to 67 inch. The Corn-Bunting sits very closely, and sometimes when disturbed, especially if the nest contain young, will flutter round the head of the intruder, or hop anxiously from stem to stem. The bird appears to rear only one brood in the year.

The food of the Corn-Bunting is composed of grain and seeds of various kinds, and in summer principally of insects and their larva. Its young are almost exclusively fed on small caterpillars and insects. This bird may frequently be seen in corn-fields when the grain is nearly ripe, where it breaks down the straws by clinging to them, picking out the corn upon the ground. In autumn and winter the Corn-Bunting is more or less gregarious, and often associates with Sky-Larks and Finches. It may at this season be seen in the stackyards clinging to the stacks and feeding with the Sparrows. It also frequents the stubbles and wild weedy pastures, where it is very often mistaken for a Lark. It will sometimes skulk in the close herbage until almost trodden upon, and as it roosts on the ground numbers are regularly caught in nets with Larks. Its flight is powerful and undulating; and although the bird seems heavy and clumsy in the air, it is capable of flying very long distances.

In autumn, especially during the latter part of October, our resident Corn-Buntings are largely increased in numbers by migratory flocks. In some parts of this country the bird is better known in winter than in summer. In the Shetland Islands Saxby states that it comes in winter in flocks; and he observed that certain birds ammally came to the same district, by seeing a bird with a white patch of plumage on its back amongst them for several winters in succession. The bird is far more numerous also in the eastern counties in winter than in summer.

The Corn-Bunting has the general colour of the upper parts liair-brown streaked with dark brown; the wing-coverts and immermost secondarics are dark brown, with broad pale rufous margins; the wings and tail are blackish brown, with pale edges; the gencral colour of the underparts is 
greyish white, with arrow-headed spots of dark brown on the breast and sides of the neck, and with streaks of the same colour on the flanks. The bill has the upper mandible dark brown, except the edges, which, together with the lower mandible, are ochre-yellow; legs, feet, and claws pale brown; irides hazel. The female resembles the male in colour. After the autumn moult the general colour of the plumage is a richer and darker brown, more suffused with buff. Young in first plumage have the spots deeper in colour, larger and more profuse on the underparts, and the general colour is still more suffused with rich buff than in that of the adults.

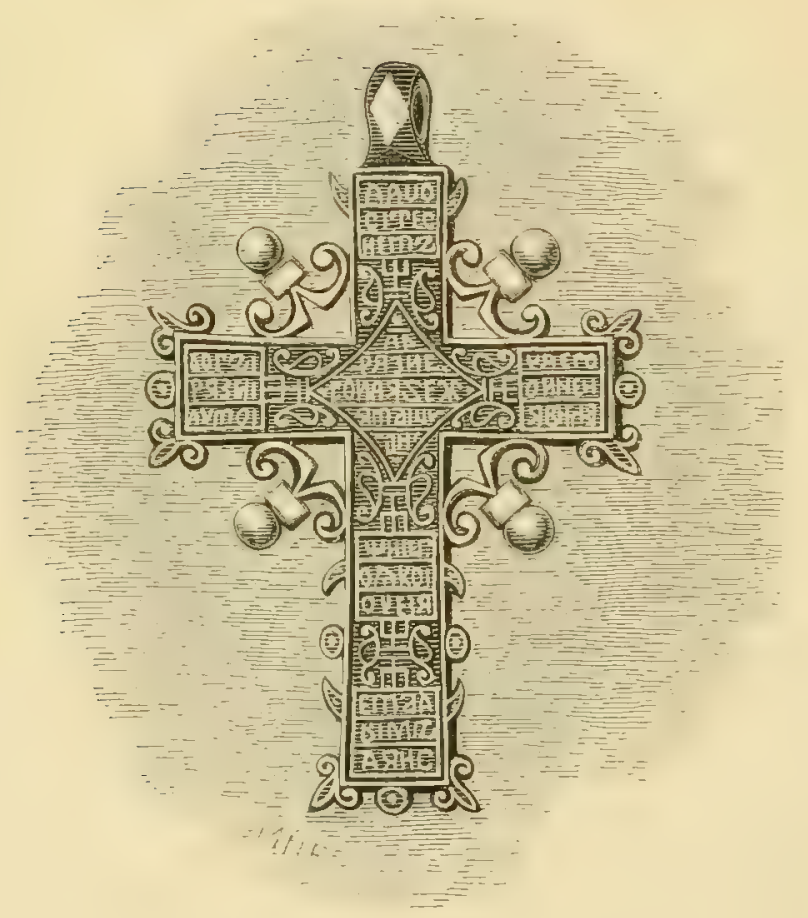




\section{EMBERIZA HORTULANA.}

\section{ORTOLAN BUNTING.}

(Plate 15.)

Emberiza hortulanus, Briss. Orn. iii. p. 269 (1760); Linn. Syst. Nat. i. p. 309 (1766); et auctorum plurimorum-Gmelin, Latham, Temminck, Bonaparte, Salvadori, Degland \&. Gerbe, Dresser, Newton, \&c.

Emberiza mrelbyensis, Sparm. Mus. Carls. pl. 21 (1786).

Emberiza badensis, Gmel. Syst. Nat. i. p. 873 (1788).

Emberiza tunstalli, Lath. Ind. Orn. i. p. 418 (1790).

Citrinella hortulana (Briss.), Kaup, Natiirl. Syst. p. 142 (1829).

Emberiza pinguescens, Brehm, Tög. Deutschl.p. 295 (1831).

Emberiza buchanani, Blyth, Journ. As. Soc. Beng. xiii. p. 957 (18t4).

Euspiza hortulana (Briss.), Blyth, Cat. B. Mus. As. Soc. p. 129 (18t9).

Glycyspina hortulana (Briss.), Cab. Mus. Hein. i. p. 128 (1850).

Emberiza shah, Bonap. Consp. i. p. 465 (1850).

Hortulanus chlorocephalus, Bonap. Cat. Par:ud.p. 4 (1856).

As the Ortolan Bunting is imported alive into England in great numbers every year, there can be no doubt that many of the examples captured in this country are escaped birds. The first record of the Ortolan Bunting in this country is that of a bird figured by Brown in 1776, in his 'Illustrations of Zoology,' which was taken alive in Marylebone Fields, and is now in the Newcastle Museum. Another specimen, also in this museum, was caught in May 182:2 on board a vessel when off the Yorkshire coast. This specimen was figured by Bewick, who also states that a pair were seen about this date in a garden at Cherryburn, on the river Tyuc. In November 1827 a male bird was obtained near Manchester, and came into the possession of Yarrell. Since this date, upwards of a score of Ortolan Buntings have been obtained in England, of which a detailed account is unnecessary. In Scotland it is much rarer than in England. Mr. Gray states that the first Scotch specimen of this bird was procured in Caithness previous to 1836. In November 1863 two others were obtained in Aberdecnshire, said to have been captured in a turnip-field near the sea. This species does not yet appear to have been observed in Ireland.

The Ortolan Bunting is one of the many species of Palæarctic birds which find the eastern limit of their distribution in Central Asia. In Scaudinavia the northern limit of its breeding-range extends to the Arctic circle; it has not been recorded from Archangel; and in the Ural Mountains it is not found further north than lat. $57^{\circ}$, nor does it appear to go further north in the Baltic Provinces. In Siberia, the eastern limit of its range appears to be the valley of the Irtish, as far as its source in the 
Altai Mountains; thence it extends westwards through Turkestan and Persia to Palestine and Asia Minor. In all these countries it is a summer migrant, and in the two latter it is principally known as passing through on migration, though a few retire to the mountains to breed. This appears to be the case also in Grece and Italy; but to the rest of Europe, south of the northern limits above mentioned, it is a regular summer visitor. A few remain to breed in North-west Africa, but the majority pass southwards in antumn and doubtless winter somewhere in West $A$ frica. It also passes through Egypt on migration, and winters in Abyssinia: a few also winter in North-west India. The nearest ally of the Ortolan Bunting is $E$. casic, which only differs in not having the slate-grey head, ear-coverts, and breast suffused with yellowish green, and in having the yellow of the throat replaced by pale chestnut.

It is somemhat remarkable that a bird so common on the Continent, in all the countries adjacent to the British Islands, should be so rare in this conntry. I found the Ortolan Bunting breeding on the mountains in the pine-regions both of Greece and Asia Minor. When I was at Valconswarrd, we constantly heard its jlaintive monotonous song, as it sat perched for a long time on the branch of a tree in the lanes, or in the hedges that surround the fields close to the village; and in the wilder districts of Norway, when driving in our carioles from Lillehammer towards the Dovre Fjeld, it was by no means uncommon in the trees by the roadside. It is not a shy bird, and frequently remains for a very long time on the same twig, generally near the top of the tree, especially in the evening, when its simple song harmonizes with the melancholy stillness of the outskirts of the country village. 'The song begins somewhat like that of the Yellow Hammer, but ends quite differently. It may be roughly expressed by the words tsee-ah, tsee-ah, tsee-ah, tyur-tyur. Sometimes there is only one tyur at the end. It seeks most of its food on the ground, where it hops with great ease, and probably picks up small seeds and insects of various kinds.

Throughout Europe it is a strictly migratory bird. In Greece and Asia Minor, where the season of spring migration may be said to be the months of March and April, it appear's during the second week of April amongst the later migrants. Further north, in South-west Russia, Gocbel gives the second half of April (new style) as the date of its arrival. In South Holland, the season of 1876 was a somewhat late one, and the arrival of migratory birds began during the last week of March and ended during the last week of May; and it was not until the middle of the latter month that we heard the song of the Ortolan Bunting. These birds leave Europe in September, arriving in North Africa in large flocks. On their way south great numbers are caught in nets and fattened for the table, and many are sent to this country alive from Holland and Belgium. 
The brecding-season of the Ortolan Bunting is in the sceond half of May, when fresh eggs may be obtained. The nest is always placed on the ground amongst herbage, generally in a slight hollow, and is formed of dry grass and roots, lined with fine roots or hair. The eggs of the Ortolan Bunting are from four to six in number. They vary from the palest of bluish white to pale salmon-colour, spotted, streaked, and blotched with rich purple-brown almost black, and with underlying spots of pale violet. The ground-colour of some eggs is very pink. Many of the spots are very large and round, and the streaks are generally short and isolated. Most of the markings are on the large cnd of the egg, where they form an irregular zone. The eggs vary in length from 88 to 75 inch, and in breadth from 67 to 58 inch. They vary considerably in shape, some specimens being almost round, whilst others are considerably elongated, and some are oval. The cgges of the Ortolan Bunting do not resemble very closcly those of any other British species. Perhaps they approach most closely to those of the Reed-Bunting; but the groundcolour is always clearer and paler, and the markings usually consist of spots not streaks.

The adult male Ortolan Bunting, immediately after the autumn moult, has the general colour of the entire head, neck, and upper breast slategrey, strongly suffused with yellow. The chin, throat, and a moustachial line, the lores and the feathers round the eye are yellow. The general colour of the rest of the plumage, except the wings and tail, is dull chestnut, the feathers of the upper parts having dark brown centres, which are most obscure on the rump and upper tail-coverts; the wings and tail are brown, the two outside feathers of the latter on each side having large patches of white extending nearly over the terminal half of the inside webs; there are two obscure bars across the wings formed by the greatcr and median wing-coverts being tipped with pale chestnut. Bill flesh-colour, in summer changing to reddish flesh-colour; legs, feet, and claws reddish brown; irides dark brown. The breeding-plumage is attained by casting the ends of the feathers, thus causing the yellow almost to disappear from the slate-grey parts of the head and breast; the chestnut on the lower breast becomes much decper in colour from the same cause. The female differs from the male in having the colour's generally paler and not so rich, the head and nape being browner and streaked with dark brown; and the grey on the sides of the neck and on the breast is replaced by brownish grey, streaked with dark brown; the yellow throat is also sparingly spotted with brown; and the rest of the underparts are much paler than in the male. Males of the year somewhat resemble females in having dark shaft-lines to the feathers of the head. Young in first plumage resemble the female, but are more spotted. 


\section{EMBERIZA CIRLUS.}

\section{CIRL BUNTING.}

(Plate 13.)

Emberiza sepiaria, Briss. Orn. iii. p. 263 (1760).

Emberiza cirlus, Linn. Syst. Nat. i. p. 311 (1766); et auctorum plurimorumGmetin, Latham, Temminck, Degland \& Gerbe, Gould, Salvadori, Dresser, Newton, sc.

Emberiza elæathorax, Bechst. Orn. Taschenb. p. 135 (1802).

Citrinella cirlus (Linn.), Gray, Hand-l. B. ii. p. 113 (1870).

The Cirl Bunting is one of the most local of our resident birds. It is strictly a southern species, and has been found breeding in all the comnties of the sonth coast, from Cornwall to Sussex, being apparently absent from Kent. It also breeds in Surrey, Middlesex, Hereford, Buclingham, Berks, Wilts, Gloucester, Woreester, and Warwick. Specimens are from time to time taken or observed in many other parts of the country, even as far north as Aberdeenshire. It appears to have been unknown in Ireland in Thompson's day; but, on the authority of Mr. Blake Knox, it has been seen at Wexford (Zoologist, 1866, p. 95).

The geographical distribution of the Cirl Bunting is very restricted. On the European continent it does not appear to breed north of Dresden or east of the Crimea. It is a resident in Central and Southern Europe, but in Sonth Italy, Greece, and Asia Minor it breeds in the mountains, wintering in the plains. It is a partial migrant, many individuals leaving the most northern breeding-grounds during winter; and its numbers in the souther'n portion of its range are considerably increased at that season. It is principally a winter visitor to North-west Africa; but Salvin found it breeding in Algeria. It has not been found in Palestine or Egypt. The Cirl Bunting has no ally for which it can possibly be mistaken.

With English ornithologists the name of Montagu must ever be associated with the Cirl Bunting; and his discovery of this and other birds, and the careful account of their habits which he gave to his brother naturalists, might well serve as an example to those whose only efforts nowadays appear to be to get a new bird enrolled on the British list, and pass its life-history by as nuworthy of further notice. Montagu tells us, in his 'Ornithological Dictionary,' that he first discorered the Cirl Bunting near' Kingsbridge, in Devonshire, in the winter of 1800 . He says that it was not uncommon amongst flocks of Yellow Ilanmers and Chaffinches, and that he obtained several specimens of both sexes.

The Cirl Bunting frequents similar localities to those selected by the Yellow Bunting, but is said to prefer loftier trees. It is also much shyer, and secms to kecp out of sight as much as possible; cousequently there 
can be little doubt that it is often overlooked. Its habits otherwise very closely resemble those of its congener the Yellow Hammer. It chiefly frequents the tops of tall trees, and there it usually utters its short and unobtrusive song. Montagu states that this bird pairs in $A$ pril, and consequently about that period its song is at its best. It generally trills its simple song whilst concealed amongst the thick leaves. Sometimes it may be noticed on a bare spray, but it usually takes refuge in the cover should it be too closely obscrved. The song of the Cirl Bunting is only a few notes, a monotonous trill, something like the song of the Lesser Redpole, or still more like that of the Lesser Whitethroat. It resembles that of the Yellow IIammer, but is never ended with the long-drawn note which marks the song of that bird. It appears to sing almost as much as its commoner ally, and is often heard warbling its monotonous strain in the early part of September. The call-note is similar to that of the Yellow Hammer, but is not so shrill or prolonged, and sounds like a monotonous and plaintive chea-che.

The eggs of the Cirl Bunting are laid early in May, and the nestingsite is usually in a low bush or shrub or amongst briars and brambles. Montagu states that it is generally built in furze bushes. At other times the bird will select a site similar to that chosen by the Yellow Hammer, almost invariably near some trees, where the male bird serenades his sitting mate below. It varies in the height it is placed from the ground; some nests are as much as six or seven feet, others only one or two feet, whilst, more rarely, it is placed on the ground itself. The nest is generally composed of dry grasses, roots, a little moss and twitch, and is lined with hair and finer roots. A nest of this bird in my collection is somewhat loosely put together, and made externally of various plant-stems, blades of grass, roots, and quantities of dead leaves. It is lined with one or two scraps of moss, a few pieces of fine grass, and a great quantity of short hair. It measures about four inches in outside diameter, and is about one and a half inch deep inside. Some nests of this bird contain no hair, and are lined with rootlets only, whilst others are almost exclusively made of moss and coarse herbage. The eggs of the Cirl Bunting are four or five in number, and do not vary very much; they are gencrally bluish or greenish white in ground-colour, blotched, spotted, and streaked with very dark brown, almost black. The streaks are usually very bold and blotchy, and most numerous on the large end of the egg. The underlying spots are generally small and indistinet, and violetgrey in colour. Some eggs have the ground-colour dull white, and the markings are more of a reddish brown. They vary from $\cdot 92$ to $\cdot 8$ inch in length, and from $\cdot \gamma$ to $\cdot 6$ inch in breadth. The markings on the egges of the Cirl-Bunting are much darker (almost black) than those on the eggs of the Yellow IIammer, and in shape are much rounder and blunter. Other 
points of distinction are alluded to in the article on that species. The young birds are fed on similar food to those of the Yellow II ammer, principally insects, and the observant Montagu remarks that the common grasshopper is especially selected. By observing this fact he was cnabled to rear the young of this species; and he remarks that when they could peck, small sceds, especially canary-seed, were caten, and that they greedily devoured oats, shelling off the outer husk.

The food of the Cirl Bunting, like that of all the Finches, is composed of insects and sceds; it is said also to cat berries. Blyth found the remains of beetles in its stomach, and in autumn it will eat grain. He also remarks. that in winter it will feed on almost all the smaller seeds, especially on those of sorrel, whilst Mr. Blake Knox has remarked its preference for grass-seeds.

In autumn and winter the Cirl Bunting becomes more or less gregarious. Small flocks are sometimes seen in winter, and are repeatedly seen in the company of other Buntings and Finches. At this season it wanders somewhat from its usual summer haunts. Although it is a southern species, and a migratory bird in parts of Europe, as, for instance, in Germany, where, Naumamn says, it leaves in November and returns in April, in this country it is a resident. In the severest winters it probably finds a haunt congenial to it in the south-western counties of England, and there, in company with other seed-cating birds, it frequents the stubbles and the ploughed ficlsts. Like the Jellow IIammer, this bird hops ou the ground, but occasionally walks or runs a few steps. It is by no means shy, and when alarmed soon settles on the nearest bush. Its flight resembles that of the Yellow I-ammer, with which bird it is said often to quarrel.

The Cirl Bunting very closely rescmbles the Yellow Hammer. The general colours of the npper parts of the adult male in breeding-plumage are similar to those of that bird, except that the head and nape are olivegreen, the feathers of the former with a broad streak of black in the centre, and the rump and upper tail-coverts are olive-gecen streaked with dusky. A bright yellow stripe extends over the eye, and another below it; the lores and a stripe extending behind the eye are dark brown. The wings and tail are similar to those of the Yellow Hammer, but the lesser wing-corerts are olive-green instead of chestnut. 'The throat, extending to the sides of the neck, is dull black, below which is a broad patch of yellow; across the breast is an olive-green band shading into bright chestunt; the remainder of the underparts are bright yellow, duskier on the flanks, which are streaked with brown. Bill brown abore, pale hom-colour below; legs, feet, and claws brownish yellow; irides hazel. The female is much duller than the male, the head is browner, and the throat and breast are pale, with dark streaks. She very closely resembles the female Icllow Hammer, but may always be distinguished by the following characters:-The head 
never shows any trace of yellow, the underparts are not so bright a yellow, and are more definitely streaked, and the rump and upper tail-coverts are dull olive instead of rich chestnut. Young birds resemble the female, but are much duller in colour. In winter the black on the head and throat of the male is partially concealed by the pale margins of the feathers, which are cast in the following spring. At all ages and in both sexes the Cirl Bunting is easily distinguished from its near ally by its olive-green wingcoverts and by the dull olive rump and upper tail-coverts.

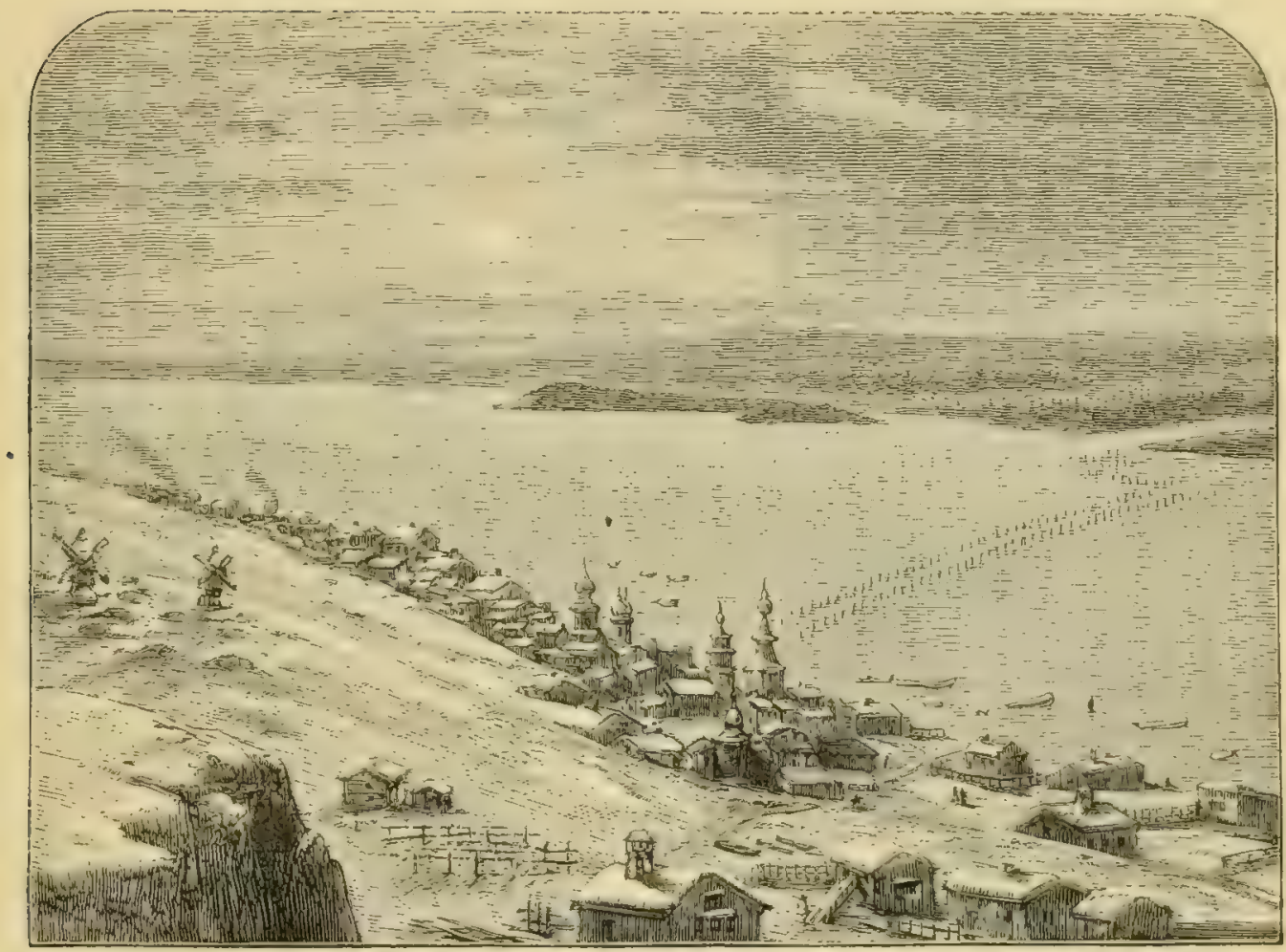




\title{
EMBERTZA CITRINELLA.
}

\section{YELLOW HAMIMER *}

\author{
(Plate 13.)
}

\author{
Emberiza emberiza, Briss. Om. iii.p. 258 (1760). \\ Emberiza citrinella, Linn. Syst. Nat. i.p. 309 (1766); et auctorum plurimorum- \\ Gmelin, Scopoli, Latham, Temminck, Degland \& Gerbe, Dresser, Newton, Sc. \\ Emberiza sylvestris, Brehm, Tög. Deutschl. p. 294 (1831). \\ Emberiza septentrioualis, Brehm, Vög. Deutscht. p. 295 (1831). \\ Citrinella citrinella (Limn.), Gray, Hand-l. B. ii. p. 113 (1870).
}

The Yellow Hammer is by far the commonest and most widely dispersed of all our native Buntings. Its brilliant dress and monotonous song are almost as well known as the sombre garb and harsh notes of the Sparrow. At all seasons of the year it enlivens the field, the moor, the garden, or the farmyard. It breeds in almost every part of Great Britain, even in the Outer Hebrides and in Orkney; but it appears not to do so in the Shetlands, although it is an occasional visitor to those islands. In Ireland it is as common as in Great Britain; but it docs not appear to have ever visited the Faroes or Iceland.

The range of the Yellow Hammer is somewhat similar to that of the Corn-Bunting, but extends further to the north and east, and not quite so far to the south. On the continent of Europe it breeds throughout Scandinavia, at least as far north as lat. $70^{\circ}$. It is found throughout Russia nearly up to the Arctic circle; and in the valley of the Petchora Harvie-Brown and I met with it as far north as lat. $65 \frac{1}{2}^{\circ}$. In Siberia Finsch met with it in the valley of the Obl) up to lat. $64^{\circ}$; and it appears to extend southwards in the valley of this river to its sources in the Altai Mountains. Radde saw it in winter near Krasnoyarsk; but this must be exceptional, as I did not meet with it, nor have I received it from my collector living in that town. In the extreme northern portions of its range it is only a summer visitor. It is resiclent in North France, Holland, Belgium, Denmark, Germany, North Italy, and Austria; but to the south of France, Spain, Portugal, the south of Ttaly, Turkey, Asia Minor, the extreme northwest of Persia, and North-west Turkestan it is only a winter visitor. In the south it is a resident in the island of Tenerifle; but there is no satisfactory evidence of its ever having been found on the African continent. Several of the Buntings are nearly allied to the Yellow Hammer, but none of them can be confounded with it. The Yellow IIammer is the only species

* Yellow Hammer signifies Yellow Bunting, the word "Hammer" being derived from the same source as the German word "Ammer," which denotes a Bunting. The addition of the letter $h$ is probably an English corruption of the original word. 
of the genus which shows so much yellow on the head, and has at the same time a yellow throat and belly.

If the Yellow Hammer was not so common, its varied and brilliant dress would be far more highly appreciated than it is; but as it crowns almost every bush and hedgerow, we are apt to pass it by with the most cursory of glances. Its favourite haunts are well-cultivated districts, fields, country lanes, and commons; but it is by no means a scarce bird near the moorlands, on wild upland pastures, and on the patches of broken rocky ground locally known as "roughs," thick with bilberry and heath and with a sprinkling of stunted thorus and gorse bushes, a few mountainashes, and silver birches. It is not an inhabitant of woods, but frequents their borders, and is common in well-timbered districts if there be plenty of open ground between the trees. The monotonous song of the Yellow Hammer in carly spring often directs attention to the bird, and it may be seen sitting on the topmost spray of a hawthom just bursting into leaf. Its yellow and brown plumage glistens in the bright sunlight as the bird flicks its tail a little uneasily; then, uttering its harsh long-drawn chich, it flits in drooping flight to safer quarters, spreading out its tail like a fan the moment before it alights; another monotonous chicle is uttered, then the bird pour's forth his oft-repeated song. There is nothing particularly sweet in his strains, but there is something about them that has a great charm in the opening year, and lends a sense of life to the surrounding scenery. The song consists of one note repeated sereral times in (puick sucecssion, concluding with two others drawn out to a cousiderable length. Sometimes these finishing notes are omitted, as if the bird were alarmed before he could finish his song. The reason, however, is very often because a rival makes a sudden appearance, and, without waiting to finish, he darts like lightning from his perch to chase and give battle to the intruder. The Yellow IIammer in the pairingseason is a most excitable little bird, and two males may repeatedly be scen chasing each other with great rapidity through the branches. At this season the call-note of the male is chich, chich, churr. The Yellow Hammer is a most pertinacious songster; what he lacks in quality he makes up in quantity, and throughout the summer his music is heard in untiring strains. No other bird sings so late into the autumu, except the Robin and the Wren. He commences carly in February, and continues in song until September. When singing he usually perches on some conspicuous place on a hedge, a wall, or a tree, or sometimes even on the ground; and there, if not disturbed, he will sit for a considerable time singing lustily at intervals, and being answered by the other Yellow Hammers in the vicinity. Although the song is not very loud, it may be heard at a long distance.

The Yellow Iammer pairs in the middle of March, but is nevertheless a somewlint late breeler, and egrgs are seldom laid before the middle, or 
even the end, of $\Lambda$ pril ; it, however, rarely leaves its favourite district when once paired, and seldom wanders far until the young can fly. The site for the nest is chosen in a great variety of places : it is very often on some liedge-bank, gay with bluebells and other flowers, in a similar place to that which the Robin often chooses; it is sometimes in tangled herbage at the foot of tall bushes, or amongst nettles and other coarse vegetation growing on waste land. The nest is most frequently built on the ground in a little cavity; but it is sometimes placed a considerable distance from it, in a gorse bush or amongst brambles and briars. The Yellow Hammer seems to be much attached to its nesting-site. Dixon has known a nest of this bird built in one situation for years, although it was repeatedly taken. Should the first egr be removed as soon as laid, the bird will gencrally continue to lay in the same place, even on the bare ground if the nest be destroyed; and an instance is on record where the bird hatehed its egges in such a situation. The nest, although somewhat slight, is well put together, and is made of dry grasses and a little moss, and lined with fibrous roots and horsehair.

The eggs of the Yellow Hammer are four or five in number, purplish white in ground-colour, streaked, spotted, and dashed with rich purplish brown; the underlying markings, which are very numerous on some cggs, are pearly grey. The eggs vary considerably: some are dull purplish brown in ground-colour, faintly strealied and scratched with brown; others are so thickly pencilled as to form an irregular network over the entire surface; whilst a clutch of three in my collection are almost uniformly clouded with pale brown, over which are a few dark streaks. 'The streaks vary in brealth; some of them are fince than the finest hairs, others are very broad, and all are distributed in the most irregular manner, liere and there appearing in a tangled mass conuceted together by one or two bold lines. The eggs vary in length from 95 to $.8 \mathrm{inch}$, and in breadth from '69 to ' 6 inch. Yellow Hammer's eggs may be readily distinguished from those of the Cirl Bunting, the only eggs with which they are at all likely to be confused, by their much more purple colour; the eggs of the Cirl Bunting are much greener, the spots are generally more bold and decided, and the thin streaks are not so numerous. The eggs of the Meadow-Bunting (a South-European species) sometimes much resemble those of the Yellow Hammer; but in that species the lines are generally more continuous, passing round and round the egg, and the smaller spots are seldom as numerous. 'The male bird frequently sits upou the eggs, relieving the female; and even when not so engaged he is usually close at hand, warbling forth his droning song at intervals. When the mest is approached the bird often sits so elosely as to allow herself to be touched by the Irand ere flying off the eggs; and sometimes the old bird feigns lameness to attract attention from its eggs or unfledged youmg. 
The young are fed exclusively on insects and eaterpillar's; and whilst they are in the nest the bird is of great service to man. Throughout the summer, and even far into the autumn, they are insectivorous; and as two broods are often reared in the year, and fresh eggs may be found in August, it is evident that the quantity of insects captured must be enormous. As soon as the young can take care of themselves the Yellow Hammer becomes more or less a nomad, and wanders far in scarch of food. In autumn they visit the grain-ficlds; but in seed-time they-are perhaps seen there in the largest numbers. As autumn approaches, they congregate into flocks, and throughout the winter live entirely on various kinds of seeds. In the depth of winter they may be often seen in farmyards clinging to the corn-stacks, or picking a scanty sustenance from the manure-heaps; they will also hop round the barndoor even whilst thrashing is going on, and pick up the grains that are scattered. In winter a favourite haunt of the Yellow Hammer is the fields of autumn-sown corn; there they congregate in a somewhat scattered flock in company with Bramblings, Chaffinches, and Grecnfinches, retiring, it may be, to those portions of the field where the wind has swept the snow away, and where a few yards of open ground offers them a scanty and precarious table. At this season of the year the bird's flight can be witnessed to perfection. They wheel in the air with great regularity, almost like Starlings, and pass overhead chirping to each other as they go; with a sudden movement they will sometimes dart downwards, as if shot from a bow, and alight in the branches of some tall tree directly under them. They seek the ficlds again very cautiously; first one bird will fly off, then another, or two or three together, until the whole flock is down again feeding as before. This singular mode of alighting on trees directly beneath them is almost unique, and is often indulged in just about dusk, when the birds are about to seek a roosting-place. Yellow Hammers roost in evergreens at this season, and sometimes on the ground with Larks.

There are few prettier sights than a flock of Yellow Hammers in the snow, when their rich plumage contrasts with the frosted branches and the whiteness all around. They very often frequent newly manured fields at a time like this, and sometimes the whole flock will congregate on a small bush. They are somewhat shy, and when a flock is feeding there are usually one or two birds perched on the look-out near at hand, who rarely fail to give the alarm by a chirping note. Great numbers of Yellow Hammers visit this country in autumn, and it is of these migrants that the larger flocks of this species secn in winter are probably composed. As previously stated, the Yellow IIammer is partiy inscetivorous and partly granivorous. It will eat most kinds of grain, much of which is obtained on the ground; whilst the smaller seeds, including those of the 
most troublesome weeds, are greedily deroured. In the carly winter this species is often remarkibly fat; and in Italy great numbers are caught with Ortolans, and fattened for the table.

The adult male Yellow Hammer in the breeding-season has the head and nape bright yellow, more or less streaked with dusky brown, the remains of autumn plumage; the rest of the upper parts are chestnut, broadly streaked on the back and scapulars with very dark brown; the primaries are dark brown, externally margined with yellow; the immermost secondaries and wing-coverts are dusky black, the former broadly margined and the latter margined and tipped with chestnut-brown. The tail is dark brown, the two centre feathers broadly margined with reddish brown, the rest narrowly with yellowish, the two outer feathers on cach side having a conical patch of white on the inner web. The general colour of the underparts is bright yellow, shading into dusky olive on the breast, and streaked on the cheeks, breast, and flanks with rich chestnut. Bill with the upper mandible brown, the lower horn-colour; legs, feet, and claws light brown; irides hazel. The female has the yellow much less in extent, almost absent from the head, and paler than in the male; the underparts are much more streaked, and the colours generally are much duller. Young in first plumage very closely resemble females, the young males not obtaining their yellow heads until the first moult. Males of the year have the head more streaked than adults. After the autumn moult the Iellow IIammer has dark tips to the feathers of the head, and broad pale margins to the feathers of the rump and to the upper tail-coverts; most of these are abraded or drop off in spring, leaving the bird in brilliant nuptial dress.

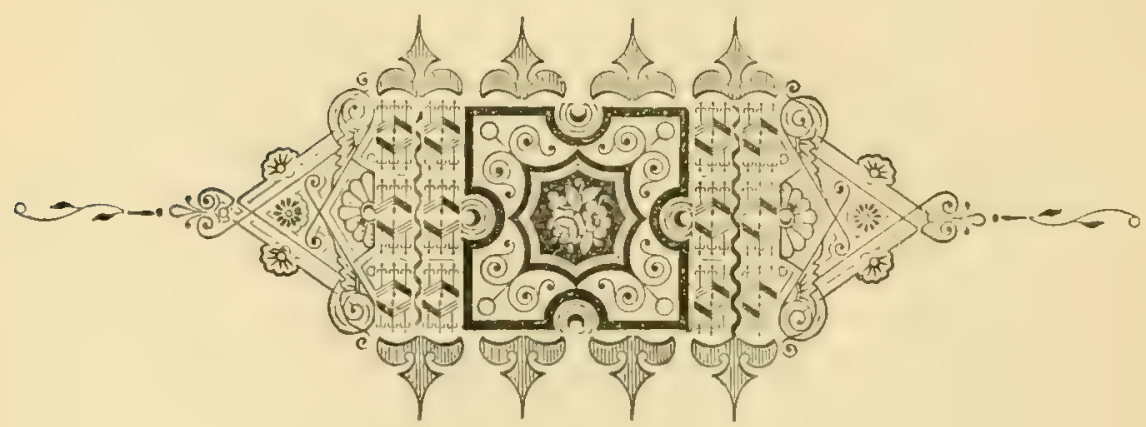




\section{EMBERIZA MELANOCEPHALA.}

\section{BLACK-HEADED BUNTING.}

(Plate 15.)

Emberiza melanocephala, Scop. Amn. I. Hist. Nat. p. 142 (1769); et auctorum plurimorum-Gmelin, Latham, Temminck, (Degland \& Gerbe), (Salvadori), (Savi), Newton, Dresser, \&c.

Tanagra melanictera, Giild. N. Comm. Acad. Sci. Imp. Petrop. xix. p. 466 (1775).

Fringilla crocen, Vieill. Ois. Chant. pl. 27 (1805).

Passerina melanocephala (Scop.), Vieill. N. Dict. d' Hist. Nat. xxv. p. 28 (1817).

Xanthornus caucasicus, Pall. Zoogr. Rosso-Asiat. i. p. 428 (1826).

Emberiza granativora, Ménétr. Cat. Ricis. Cauc. p. 40 (1832).

Euspiza melanocephala (Scop.), Bonap. Comp. List, B. Eur. \&. N. Amer. p. 32 (1838).

Euspiza simillima, Blyth, Joum. As. Soc. Beng. xviii. p. 811 (1849).

Euspiza atricapilla, Brehm, Naumannia, 1855, p. 277.

Granativora melanocephala (Scop.), Bonap. Cat. Parzud.p. 5 (1856).

The claim of the Black-headed Bunting to be considered a British bird rests upon a solitary example said to have been shot near Brighton. Its alleged appearance was recorded by the late $\mathrm{Mr}$. Gould, who in 'The Ibis' for 1869, p. 128, writes respecting it as follows:- "I have now to inform you of the occurrence of Emberiza (Euspiza) melanocephala, of which a very fine old female specimen, in perfect plumage, is now before me. It was brought to me by Mr. Robert Brazener, of 23 Lewes Road, Brighton, by whom it was shot about the 3rd of November last, near Mr. Ballard's windmill, on Brighton racecourse, while, as he stated, 'it was following a flock of Yellow Hammers.' His two sons were with him at the time. On an examination of the bird, a number of eggs were found in the ovarium. This is all the information I was able to obtain respecting it." Whatever doubt may rest upon this statement, the fact that the Black-hcaded Bunting has unquestionably occurred on Heligoland makes it probable that it has also visited our shores, and is sufficient excuse for including it in the present work.

The geographical distribution of the Black-headed Bunting is a very extraordinary one, the line of migration taken by this species, although not unique amongst European birds, being very exceptional. In Italy it breeds in the Riviera and on both shores of the Adriatic. It is a common summer visitor to Greece and Turkey; and I have shot it as far north as the Dobrudscha. It is equally common in Asia Minor, the Caucasus, Palestine, and Persia, passes through Afghanistan and Scinde on migration, and winters in Western and Central India. Since it has never occurred in Africa, and such a conspicuous bird could scarcely be over- 
looked, we must assume that India is its only winter-quarters; but it is possible that future explorations may prove that the European cxamples of this species winter in Arabia. Further north and west in Europe it appears to be only an accidental visitor. It has been occasionally met with in the south of France, Germany, and Austria. In South Russia an example has been recorded from Kiev. I noticed a fine male in the museum at Archangel, said to have been shot in the neighbourhood; and it has occurred several times on IIeligoland. It has no ally with which it can easily be confounded.

As might be expected from the unusual line of migration taken by the Black-lieaded Bunting, it is one of the latest birds of passage to reach its breeding-grounds. In Greece and Asia Minor it does not arrive until the end of April, amongst the last half-dozen summer migrants. As soon as it comes nest-building commences; and during the last half of May its eggs are so abundant in the olive- and vine-region of the Paruassus that when I was there I had not time to blow more than half of the clutches which I found or saw. One reason may perhaps have been that the nest of this bird was the casicst of all nests to find. The males were so extremely handsome and so very conspicuous that whilst it may perhaps be scarcely correct to say that no other species of bird was so common, certainly no other appeared to be so. In the pine-region, from four to six thousand feet above the level of the sea, they were, however, very rare. As you look down from the ruins of the temple of Apollo at Castri, the ancient Delphi, over the forest of olives which stretches away beyond Chrisso down to Itea on the shores of the Gulf of Lepanto, the grey trees look like a dense mass of wood impenetrable to the hot sunshine; but when you are strolling in the forest itself, down in the plain, you find that each tree is isolated, and that endless vineyards, and now and then a cornficld, intervene. Sometimes the valley is bounded by a cliff, the home of the Rock-Sparrow and the Dalmatian Nuthatch and where Vultures and Eagles breed; but more often the plain joins a steep rocky slope, where the olives are smaller and more scattered, and where clematis and white and pink roses half conceal the stony ground, and dwarf oleanders, pomegranates, figs, almonds, and other shrubs compose a half-wild landscape, the only sign of cultivation being a vine-terrace here and there. This scems to be the paradise of the Black-headed Bunting; and it is not an uncommon thing to sce three or four males perched conspicuously on the top of as many isolated trees, singing in rivalry. When disturbed it seldom flies far, but dlops down from its perch, and after a short flight, low and undulating, rises up again to the nearest trec-top, on which it is so anxious to perch that its legs may be seen extended for the purpose long before the desired haven is reached. In spite of what has been written to the contrary, I camot but consider this bird a typical Bunting in its habits. 
Its song is very characteristic of the geuus, and, though more musical and less monotonous than that of the Yellow Hammer, is always the same, very short, consisting of only two or three slight variations of a not very loud nor yet very melodious note, rapidly repeated, with a slight pause in the middle. The ordinary call-note is a loud chit chit, and the call-note of one sex to the other a more plaintive and longer-continued tsee- $a$. In autumn the Black-headed Bunting makes some havoc in the corn-fields; but in summer it is said to vary its seed-diet with grasshoppers and fruit: its depredations do not last long, for Dr. Kriiper states that many leave for their winter-quarter's before July is over, and by the middle of August they have nearly all disappeared.

The nest of the Black-headed Bunting is seldom placed at any great height above the ground; it is rery frequently in a small bush, but the favourite situation is amongst trailing plants such as clematis, briars, and vines. In the gardens near Constantinople it is built principally amongst the rows of peas or beans. Canon Tristram states that he has frequently found it on the ground. It is rather a bulky structure, and though neatly finisher inside, has a somewhat loose and ragged appearance outside. The foundation is made of dry grass, thistle-leaves, and other coarse material; but the main portion of the nest is constructed entirely of the yellow dry stalks of various small flowering plants, the seed-capsules on which are the most prominent object, and conjoined with the stiffness of the stalks, which prevents them from bending easily, gives the nest a very slender and unfinished look. The lining is of entirely different materials, brown instcad of yellow, and consists of dry grass, roots, and slender stalks without any sced-capsules, with not unfrequently a final addition of goat's hair or a few horse-hairs. The inside diameter is 23 inches, with a depth of 2 inches.

The eggs of this bird are usually four in number, not unfrequently five; but on the island of Corfu it is said to lay as many as six. Few eggs vary so much in size or shape : a typical egg measures 85 by $\cdot 7$ inch, an unusually long and narrow egg is $1^{\circ} 0$ by ${ }^{\circ} 6$ inch, and an unusually small egg is - 84 by 6 inch. There is scarcely any difference in the ground-colour, which only varies from pale greenish blue to very pale greenish blue; the overlying spots are brown, and the underlying spots are grey. On some eggs all the spots are small, on others they are all large; but more generally both large and small spots are found on the same egg. They are gencrally most thickly distributed on the large end, sometimes confluent, but occasionally are evenly distributed over the entire surface. The fact that these eggs are so different from those of any other European Bunting has induced some field-ornithologists to acquiesce in the removal of this bird and its Asiatic ally, E. luteola, whose eggs are very similar, to the genus Euspiza, a heterogencous group of birds possessing no characters 
in common to distinguish them from the Buntings, and some of them, anongst which is probally the type, belonging to a really distinet genus.

During winter the Black-headed Bunting is found in large flocks (generally in company with the Red-headed Bunting), which do great damage to the wheat and other grain-crops of Western India. Whilst passing through Scinde on migration, it has been observed not only to feerl on corn but on the pollen of the flowers of the wild caper, which covers wide tracts of waste ground in that country.

The adult male Black-headed Bunting in breeding-plumage has the head, lores, and ear-coverts black; the wings are brown, with pale brown tips to the coverts and broad pale edges to the inmermost secondaries; the tail is uniform brown, without the white spots to the outside feathers, a character which will clistinguish it at all ages and in both sexes from the Yellow Hammer and Cirl Bunting. The rest of the upper parts is chestnut, which extends to the sides of the breast. The remainder of the underparts is brilliant sulphur-yellow, which extends round the ear-coverts and obscurely to the nape. Bill greyish lead-colour; legs, fcet, and claws pale brown; irides hazel. The female possesses none of the brilliant colours of the male: the general colour of the upper parts is brown, streaked with dark brown, and slightly suffused with yellow on the rump; the underparts are pale brown, slightly suffused with yellow on the belly and under tailcoverts. The adult male in autumn plumage somewhat resembles the female, all the brilliant feathers being obscured by having a dull grey margin; and the rump is more or less suffused with yellow. In males of the year distinet traces of the autumn plumage are retained throughout the summer. Young in first plumage very closely resemble the female.

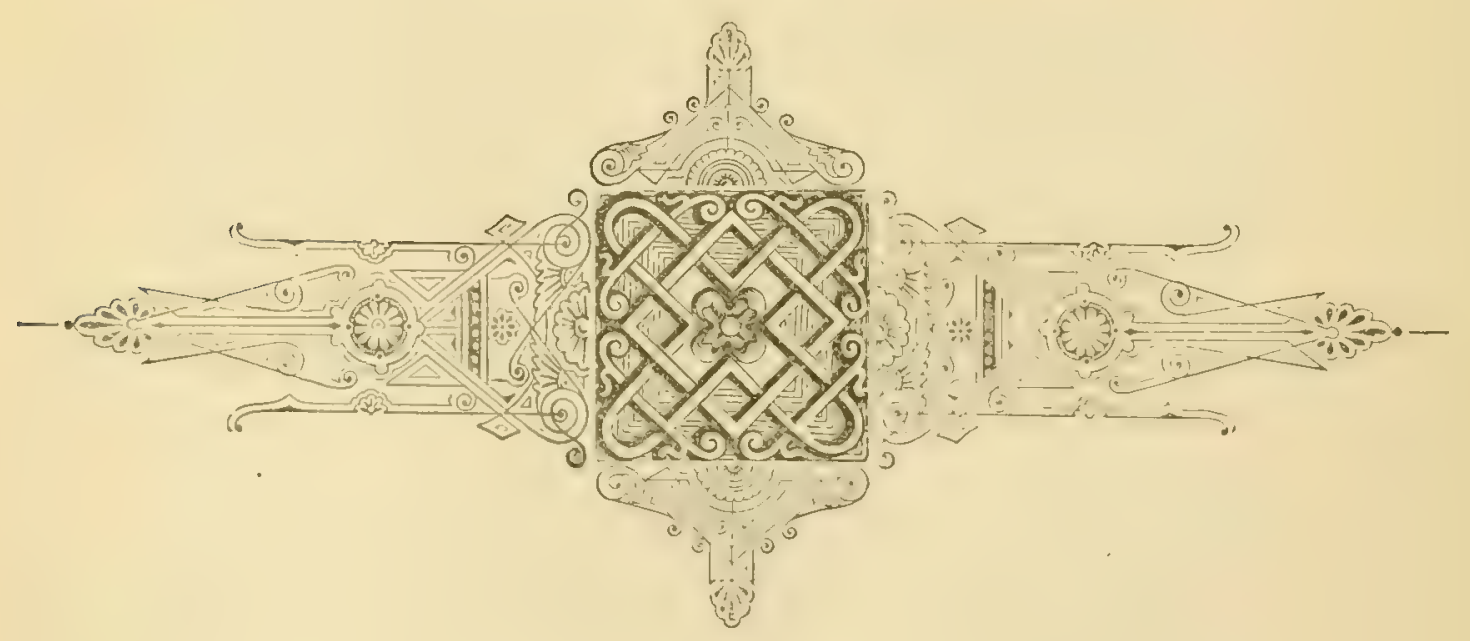




\section{Subfamily HIRUNDININ E, on SWALLOWS.}

The Swallows are distinguished by their long, pointed wings, slendrer, wide bills, and small legs and feet. They have no bastard primary, and the second primary is generally the longest. The tarsus is scutellated in front, and the tail is generally forked. The most marked feature in the Swallows is that they have no autumn moult, their new dress bcing assumed in February*.

In their distribution the Swallows are cosmopolitan. The number of species and subspecies known is nearly a hundred, which have been by some ornithologists divided and subdivided into more than five and twenty gencra. Eight species are found in the Western Palaearctic Region, four of which are included in the British list.

\section{Genus HIRUNDO.}

The genus Hirundo was admitted by Linnæus, in 1766, in the twelfth edition of his 'Systema Naturæ,' vol. i. p. 343. The Barn-Swallow, the species named first both by Linnaeus and Brisson, has been by common consent accepted as the type.

The chief characteristic of the species in this genus is said to be that the nostrils are not only bordered behind and inside, but also overhung. internally by a membrane. Many species have the upper parts glossy blue-black, but others are plain brown. The rictal bristles are almost obsolete.

This genus probably contains about sixty species, and is cosmopolitan in its distribution. Only five species are found in Europe, three of which are regular summer migrants to the British Islands.

In tropical countries Swallows are generally resident, but are only summer visitors to colder countries. They chiefly frequent the well-cultivated districis, and are especially fond of the neighbourhood of water.

* In treating of the Shrikes, I remarked that the Woodchat, the Red-backed Shrike, and the Lesser Grey Shrike appear to moult only in spring; but I did not at the time realize the significance of the fact. It appears to me that these birds, which have no autumnal moult, must be comparatively recent importations from the southern hemisphere. On their arrival in their new northern home they were compelled to change their time of breeding with the changed seasons, but they have not yet altered the period of their annual moult to correspond. 
They are gregrarions in their habits, and often congregate into cnormous flocks to perform their migrations. Swallows perch but little, and spend most of their time in the air, except when incubating or sleeping. Their powers of flight are rery great; but on the ground they can only progress in a very awkward manner, owing to the shortness of their tarsi. Their usual note is a twitter, but many species are also capable of singing very swectly. Their nests are built of mud, straw, feathers, \&c., and placed on beams or ledges in buildings, under eaves, in caves, and on rocks; but some species burrow decp into carthy cliffs, and make very slight nests at the end of the passage. Their eggs are white, sometimes unspotted, but more frequently marked with rich brown and lilac-orey. Their food consists entirely of insects.

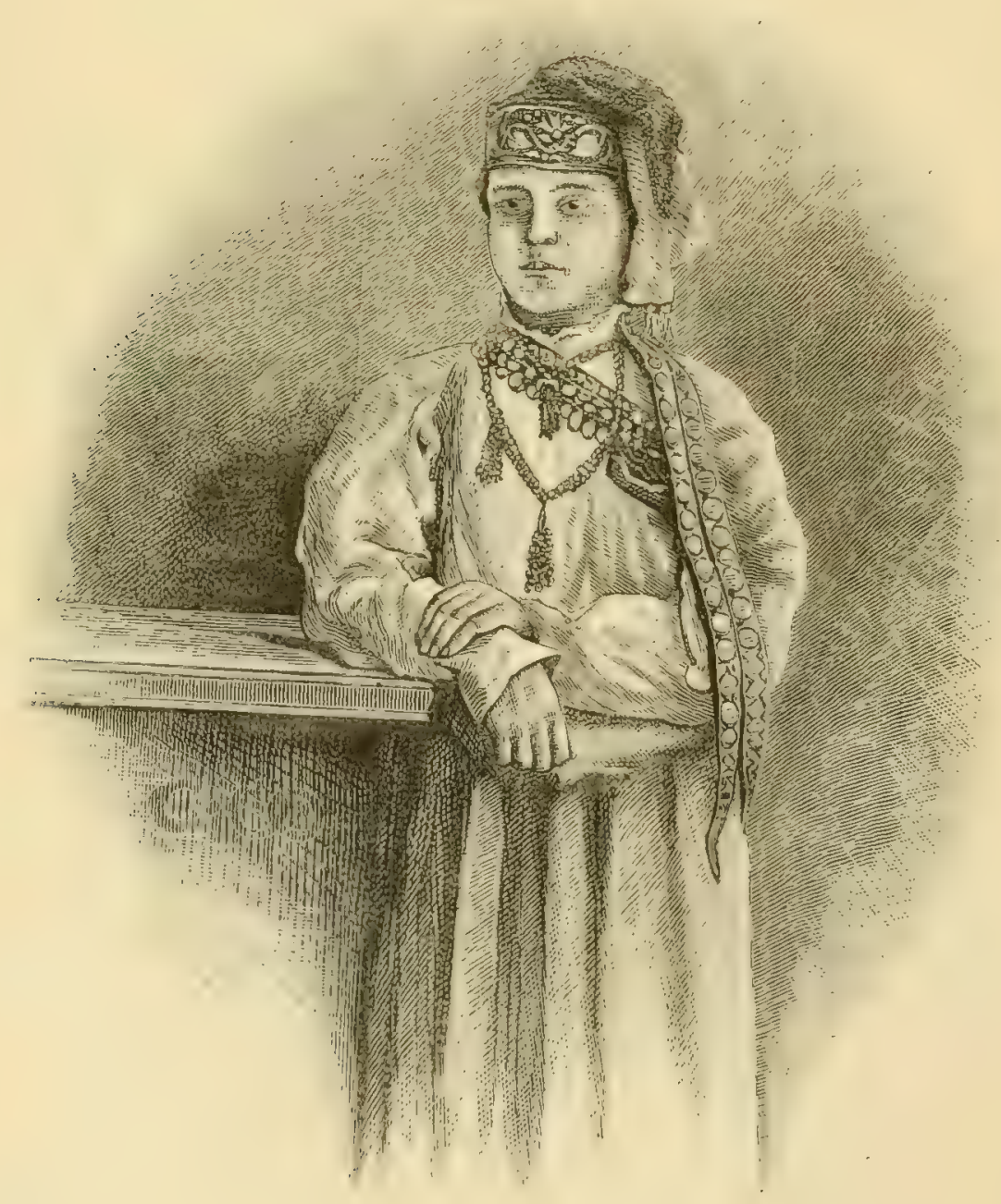




\section{HIRUNDO RUSTICA.}

\section{SWALLOW.}

(Plate 17.)

Ilirundo domestica, Briss. Orn. ii. p. 486 (1760).

Iirundo rustica, Lim. Syst. Nat. i. p. 343 (1766); et auctorum plurimorumGmelin, Scopoli, Latham, Bonaparte, Temminck, Naumann, Degland \& Gerbe, Newton, Dresser, \&c.

Cecropis rustica (Linn.), Boie, Isis, 1826, p. 971.

The Barn-Swallow, one of the best known and most familiar of our native birds, is generally distributed throughout the United Kingdom, including the Channel Islands. It is almost as common in Scotland as in England, but is said not to breed on the Outer Hebrides, although seen there every year. It is a regular summer visitor to Shetland, but the instances of its breeding there are rare. In Ireland the Swallow is quite as common and widcly distributed as in England; it is a rare straggler to Iceland; and Capt. Feilden states that in the Faroes considerable numbers appear in May, but are never known to nest there.

The Barn-Swallow, in one of its forms, is found throughout the Palæaretic and Nearctic Regions. The typical form breeds in Scandinavia up to lat. $68^{\circ}$; Finsch obtained it in West Siberia as far north as lat. $65^{\circ}$; Middendorff states that it occasionally occurs in lat. $63^{\circ}$, on the Yenesay; and I shot a solitary example in lat. $66 \frac{1}{2}^{\circ}$ in the same valley. North of the Desert of Saliara it is a summer migrant; but, according to Canon Tristram, occasionally winters in the oases. Throughout Africa sonth of the Desert it appears to be only a winter visitor. In Asia it breeds in Asia Minor, Persia, Afghanistan, Gilgit, Turkestan, and West Siberia as far east as Krasnoyarsk, and winters in Scinde and West India. In the valley of the Yenesay it meets and apparently interbreeds with $H$. rustica, var. gutturalis, which differs in being slightly smaller and in having the dark pectoral band interrupted in the middle by the chestnut of the throat. This form breeds throughout Mongolia, the Himalayas, China, and Japan, and winters in India and Burma. Iu East Siberia, ranging as far west as Lake Baikal, and eastwards across Behring's Straits and throughout the Nearctic Region as far south as the plateaux of Mexico, H. rustica, var. horreorum, breeds. The East-Siberian birds winter in Burma, where they have been re-christened $H$. tytleri; but the Mexican Swallows are said to be resident, whilst those brecding in North America are said to migrate to 
Central America and Brazil. This form differs from the preceding only in having the underparts below the breast pale chestnut. In Egypt and Palestine a form occurs having the underparts below the breast a slightly darker chestnut than in the American form, from which it differs most conspicuonsly in haring the broad dark band across the breast like the typical form. This form may be called H. rustica, var. cahirica; it is probably only subspecifically distinct, as intermediate forms frequently occur in Europe. In Australia H. rustica, var. frontalis, breeds and winters in New Guinea. This is probably the parent stock from which all these Swallows are derived, and may be easily distinguished by the almost total absence of the pectoral band, the lower breast and belly being nearly white, as in the European and Chinese forms.

No bird is more highly prized or more jealously protected than the Swallow; and of all the harbingers of spring it is the most warmly welcomed. Very rarely indeed is it molested; the bird-nesting schoolboy will tell you that it is "unlucky" to take its nest, and even the gamekeeper, that arch slaughterer of all our fairest and most interesting birds, can bring no accusation against it, and suffers it ummolested to wing its happy way in peace. Wherever this charming little bird takes up its quarters it is always welcomed and protected, especially amongst our rural population, who regard its annual risits to their humble cottages as foretelling good fortune, and in many cases will inconvenience themselves rather than turn the little southern wanderer away.

The Swallow generally arrives in this country a little earlier than the House-Martin. It arrives in some parts of Southern Europe, as, for instance, at Gibraltar, about the middle of February, and continues to cross the Straits up to the middle of April; but in the extreme north of Europe it is said not to arrive until the first week of June. Its first arrival in the south of England takes place early in April, but it does not reach the north of England until about the middle of that month. In the south of Scotland it does not arrive before the last wcek of April, and in the north of that country seldom before May. The Swallow loves to frequent the neighbourhood of houses, and is consequently the commonest and most widely dispersed in well-cultivated districts. Not that the bird dislikes the wilder country; for where is the shepherd's cot, the mountain-farm, or the gamekceper's house, even on the barren moors, where this little bird is not to be seen? It is very common in all country villages, but does not enter the large towns as much as the House-Martin. Like the rest of our British Swallows, the present species is a gregarious bird, and not only lives in company with its own species, but repeatedly flocks with House-Martins, and also with Sand-Martins and Swifts. The Swallow is usually seen on the wing. Sometimes they skim orer the ground only a few inches above the surface, seldom attempting a higher flight; but more 
often, especially in clear fine weather, they may be secn high up in the air, almost like specks, whecling in everelıanging gyrations. The Swallow catches as much of its food over the dry land as it does over water, more so pcrhaps than the Martin, and is fond of large meadows sprinkled with trees, especially those containing a fish-pond or a sluggish stream. The Swallow certainly has more command over itself in the air than the Martin; its wings and tail are longer, and enable it to twist and turn with surprising quickness. Its general flight also scems performed with less labour; it appear's to swim through the air propelled by an invisible power. Dixon thus writes of the flight of this bird:- " How gracefully the Swallows fly. See them coursing orer the daisy-spangled grass-fieldsnow skimming just over the surface of the grass, then with a rapid stroke of their long wings mounting into the air and horering a few moments just above your head, displaying their rich white and chestnut under plumage. Then they chase each other seemingly for very joyfulness, uttcring their sharp twittering notes as if exulting in the bright sunshine and the abundance of food. Nuw they hover for a moment just like a little Kestrel, or, closing their wings, dart downwards with the velocity of a Sparrow-Hawk; anon they flit rapidly over the neighbouring pool, dipping themselves in its unruffled surface, and marking each dip with a ring on the water. How easily they turn and glide over the hedges, speed across the pastures and return, dart under the hanging branches of the tall elms, or chase the flies round the feeding cattle; never resting, never weary. You frequently see them glide rapidly along a few inches from the ground, then with a sidelong motion mount aloft, to dart downwards, like an animated meteor, their plumage glowing like silver in the sun, and the row of white spots on the fully spread tail coming out in bold contrast with the darker feathers." The Swallow not unfrequently alights upon the ground, on a roof, or the dead branch of a tree, but is exceedingly awkward, especially when on the ground. Its short legs prevent it from walking or hopping, and every movement that it essays is always accompanied by a motion of the wings. It sometimes alights at little pools on the, roadside, but usually drinks on the wing when skimming over the water. The Swallow is a very early riser, and may be seen abroad at dawn almost before the Goatsucker has gone off to its retreat; and he continues his labour's into the dusk, until he can no longer detect the passing flies. Swallows often amuse themselves by mobbing large birds, and at such a time their power's of flight may be witnessed to perfection. It is a pretty sight to see a swarm of these little creatures in wrathful but perfectly harmless chase of a IIawk or a Cuckoo high up in the blue sky.

The usual note of the Swallow is loud, somewhat resembling the word hwet, occasionally, if the bird is excited, repeated once or twice; but 
it also possesses a song both rich, sweet, and varied. It may be heard breaking out into snatches of melody as it courses through the air, especially the young birds in autumn; but it often warbles when at rest, either sitting on a bare twig or a building.

'The food of the Swallow consists entirely of insects. It feeds perhaps more on coleopterous insects than the Nartin does-a fact noticed long ago by Gilloert White. In proof of this the bird is very often seen to alight in fields on heaps of dung, or on turnips, where it catehes little beetles; and it not mufrequently alights on the roads, and even on the fields, especially in dull windy weather, to pick up these insects, which will not fly in such a state of the atmosphere. Sometimes it catches an insect lying on the water as it passes rapidly overhead. Gnats are very much sought after by this bird, as are also crane-flies, and sometimes dragon-flies. Its mouth is filled with a sticky saliva, which holds the insect when caught; and it seems that the bird does not swallow its captures until it has got a mouthful. Certainly when the birds are feeding their young they do not return to the nest after capturing each successive fly, but only when a considerable number are collected together in a sticky mass in the mouth.

There can be little doubt that the Swallow pairs for life. Unlike so many of our migratory small birds, the sexes appear to travel in company (in pairs) and return each season to their old haunts.

The nest of the Swallow is generally placed on the joist which supports the rafters of a barn or other outhouse, a few inches below the tiles or slates which form the roof. In this position it rests upon the horizontal surface of the joist, and is a ring of mud lined with dry grass and a few feathers. By far the greater number of Swallows' nests which I have scen in this country have been built in this position and on this model. Curiously enough, this is not the case on the continent. There the Swallow generally builds against a perpendicular wall, but also only a few inches below some horizontal shelf or roof; in this situation the nest is in the shape of a quarter of a hollow globe of mud. To increase the sccurity of the structure it gladly avails itsclf of any little projection or nail or peg to begin upon. But the usual nest of the Swallow on the continent only differs from that of the Martin in having the sides as well as the front open instead of built up to the projecting shelf or roof. At the railway-station at Rustchuk dozens of Swallows' and Martins' nests may be seen side by side, and differing only in the manner I have described. In the large buildiug where my friend Oberamtmann Nehrkorn stall-feeds his cattle, near Brunswick, the roof is supported by iron pillars, and many siwallows build their nests under the heavy beams which rest upon them, nsing the iron ring which does duty as a capital to lay the foundation mud upon. The continental system approaches nearest to the habits of the 
Swallow in a state of nature. When Mr. Young and I were in the Dobrudscha we twice had the good fortune to find small colonies of these birds, so to speak, wild. In one case the nests were built against the perpendicular cliffs under an overhanging ledge of rock, leaving perhaps an inch of space all round for the ingress and egress of the bird. In the other case the nests were built in exactly similar situations on the roofs of caves. In one nest the eggs were nearly hatched, and we watched the birds flying in and out, so that no possible doubt as to the species could arise. One of the nests was in the occupation of a Sparrow. Several other instances of the breeding of the Swallow in cliffs and caves have been recorded. Edivard made similar observations on the coast of Banffshire; and Ridgway found the American form of the Swallow breeding in caves in Nevada, one of the Pacific States, and also mentions that in America it often builds against a perpendicular wall if it cannot find a suitable horizontal rafter. Other localities are also chosen in England. It often breeds in a chimney, and oceasionally down a well or an old mine, or under a bridge or a doorway, in all of which situations the nest is generally built on the continental model. Dixon has seen its nest in buildings on stones projecting from the wall several feet from the roof or any other shelter. Blyth records one instance of the Swallow building in the hole of a tree about thirty feet from the ground; and Yarrell figures a nest built in the fork of the branch of a syeamore tree. To make the nest strong, the Swallow mixes with the mud of which the walls are composed dry grass, straw, or hair. The mud-made shell or cup is neatly lined with dry grass and a few feather's, generally obtained as the bird flies through the air. In shape the nest is very shallow, and, unlike the IIouse-Martin's, is always open, leaving the sitting bird exposed to view. Some nests are much more carefully made than others, depending to a great extent on the peculiarities of the chosen site. In some cases little more than a rim of mud is formed, in which the softer materials are placed, whilst in others a perfect saucer is formed of mud, straws, and little sticks before the lining is put in.

The Swallow builds a fresh nest every year, generally close to the one of the previous year, consequently many old nests may be seen close together. The eggs of the Swallow are from four to six in number, and vary considerably in shape and markings. The ground-colour is always pure white, and the markings are rich coffec-brown, violet-grey, and light reddish brown; these are usually distributed over the entire surface of the egg, but most thickly at the large end. The grey underlying markings are far more numerous and larger on some eggs than on others. The spots vary considerably in size: on some eggs they are small specks, on others large spots and blotehes, sometimes confluent on the larger end, forming a broad irregular zone. The eggs vary in length 
from 9 to $\cdot 75$ inch, and in breadth from 58 to 52 inch. The eggs of the Barn-Swallow very closely resemble those of the Rock-Martin (C. rupestris), indeed so much so that they cannot with certainty be distinguished.

The sitting bird is fed by its mate, who constantly visits her with joyous twittering cries during the whole period of incubation. The Swallow usually rears two broods in the season. The eggs of the first clutch are gencrally laid early in May, and the young are able to fly by the end of June; those of the second clutch are laid carly in July, and the young are, in most cases, fully fledged by September; but exceptionally late broods are frequently deserted by their parents. The young are tended some little time after they quit the nest, and are often fed on the wing.

The young of the first broods soon leave their birthplace and collect into flocks, spending their time in incessant search for food, or sitting twittering to each other on tclegraph-wires, fences, or dead branches. At this time they roost in trees, and often in rushes near water. The earlier broods are probably the first to migrate, leaving this country very early in September, whilst those of the second brood with their parents linger on into late autumn. The sccond broods and the old birds form the large flocks which are scen in autumn, and at this season of the year their gatherings are most interesting. A great number are young birds, which are fed and tended assiduonsly by their parents, who catch insects for them whilst they sit and wait on the fences and wires. Most Swallows leave this country early in October, but many still tarry-some still too weak to attempt the long journey, and others whose young are not yet able to fly; whilst a few may be loth to leave some favoured spot where insect-life is still abundant. A few Swallows are generally seen in this country in November, and they have been recorded at different times in December, January, and February; so that it secms that individuals occasionally almost succeed in braving the rigours of a northern winter. Respecting the supposed hibernation of Swallows, little need be said. My friend Dr. Elliott Coues, to whom I could not pay a higher compliment than to call him the American Naumann, still considers the subject an open question; but all other ornithologists have long ago consigned the theory to the limbo of forgotten superstitions.

The Swallow in summer plumage has the forehead and throat rich chestnut; all the upper parts and a broad band across the breast are steelblue, with a purplish gloss; the wings and tail are brown, glossed with bluish green on the outer webs; the inside web of the innermost greater wing-covert is greyish white; all the tail-feathers, except the two centre ones, have a large spot of white on the imner web about a third from the end. The general colour of the underparts is nearly white. Bill black; legs, fect, and claws brownish black; irides hazel. The female some- 
what closely resembles the male in colour, but the chestnut on the forehead and throat are not so rich, the chest-band is narrower, and the outermost tail-feathers are shorter. Young in first plumage have the forehead, throat, and eye-stripe pale chestnut, which fades during the winter into nearly white; the upper parts are not so bright as in adults, the spots on the tailfeathers are tinged with rufous, and the outermost tail-feathers are much shorter. These long tail-feathers do not assume their full length until after the first moult in February, when the adult plumage is assumed. After the spring moult the underparts below the pectoral band are slightly suffused with rufous, which gradually fades in to the adult summer plumage. The Swallow may be readily known from its congeners by its uniform steelblue upıer parts, its chestnut throat and forehead, and its acutely forked tail-characters which on the wing serve at a glance to distinguish it from the Martin or the Sand-Martin.

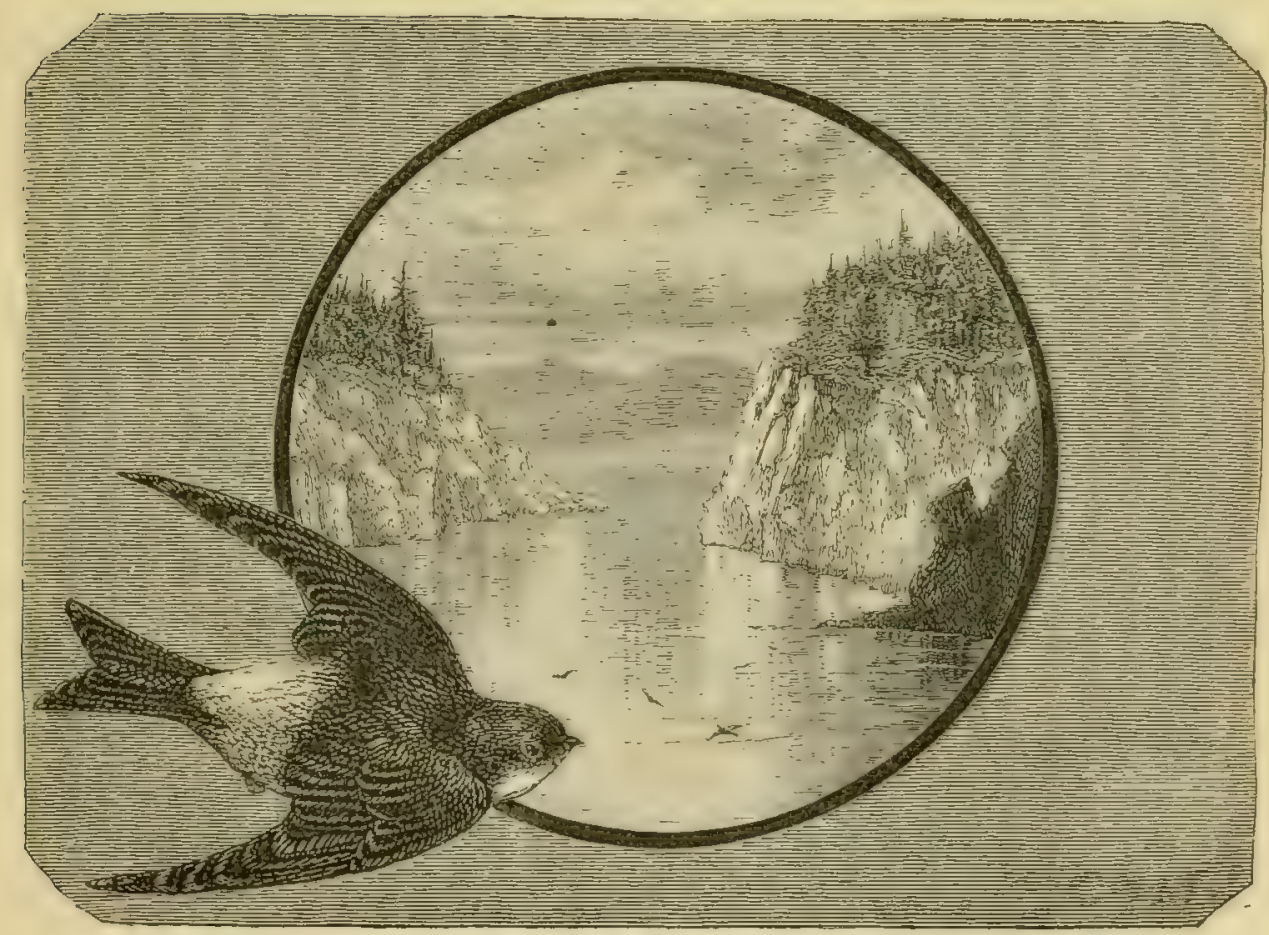




\title{
HIRUNDO URBICA.
}

\section{HOUSE-MIARTIN.}

\author{
(Plate 17.)
}

Hirundo minor, Briss. Orn. ii. p. 490 (1760).

Hirundo urbica, Linn. Syst. Nat. i. p. 344 (1766); et auctorum plurimorumGmelin, Scopoli, Latham, Temminck, (Bonaparte), Naumann, (Degland \& Gerbe), (Salvadori), (Dresser), (Nevoton), \&c.

Chelidon urbica (Limn.), Boie, Isis, 1822, p. 550.

The Housc-Martin, better known as the Martin, is almost as popular a favourite as the Swallow, for which it is often mistaken; but it may be readily distinguished from that bird, even on the wing, by its white rump and shorter tail. It is distributed throughout England, and is a common summer visitor to the Chammel Islands. In Scotland it is almost as widely dispersed as in Englaud; but, according to Mr. Gray, it is absent altogether from the Outer IIcbrides, although common enough in the inner islands. It is said by Baikie and IIeddle to breed in Orlincy; and although most numerous in Shetland at the periods of migration a few remain to breed. In Ireland it is quite as well known and as common as in England. It is said to be a rare visitor to Iceland, where, in 1819, Faber states that nests of this bird were commeneed, but left unfinished. It is also found on the Faroes in spring, but does not appear ever to remain to breed.

The House-Martin breeds throughout Europe, ranging somewhat further north than the Barn-Swallow. It has been recorded in Scaudinavia as breeding in the most mortherly towns, for example in Vardö in lat. $70 \frac{1}{2}^{\circ}$, and in Vadsö in lat. $70^{\circ}$. In Archaugel, however, it is much rarer than the Barn-Swallow; and Harvie-Brown and I did not meet with it in the valley of the Petchora. It occasionally straggles to the Canaries and Madeira, and breeds abundantly in North-west Africa. In Egypt and Nubia it is only known on migration; but it breeds in Palestine, Asia Minor: and Persia. Scarcely any thing is known of its winter-quarters, which probably are somewhere in Central Africa. A few birds are supposed to winter in Algeria, and stragglers are said to occur in 'l'urkestan and India.

Some doubt attaches to the occurrence of the House-Martin east of the Ural Mountains. Finsch observed a colony in the valley of the Obb in lat. $61^{\circ}$; but, as he neglected to obtain any specimens, it is impossible to say to which species they belonged. They probably were the European species, 
as he failed to detect any difference from our bird in some examples in the museum at Omsk.

The House-Martin has no ally so near as to make it probable that it interbreeds with any other species; but in Eastern Siberia it is replaced by Pallas's Martin, H. lagopoda, which has frequently becn mistaken for it. This is a well-defined species, with a shorter and squarcr tail than our bird: it also differs in having the longest upper tail-coverts white instead of black, and the axillaries and under wing-coverts dark brown instead of very light brown. I found it extremely common in the valley of the Yenesay, swarming in thousands on the Arctic circle, and brecling as far north as lat. 69. It probably breeds throughout Easteru siberia, as Middendorff observed it in the Stanovoi Mountains, aud Pallas records it from Kamtschatika. It breeds throughout South-castern Siberia, and is probably the species found in such numbers by Prjevalsky in Mongolia. Severtzow records it as passing through Turkestan on migration; but it breeds in North China, and probably winters in the Burma peninsula, where it has been mistaken for the European species*.

Between these species two intermediate sjecies occur, doubtfully distinct from cach other, but both of them distinct both from the House-1 Lartin and Pallas's Martin. The larger of the two, H. dasypus, with a wing cxcecding four inches in length, breeds in Japan and winters in Bornco; the smaller one, $H$. castemiriensis, with a wing less than four inches, appears to be confined to the Himalayas, breeding in the higher valleys and wintering in the lower ones. Both these forms have the short, slightly forked tail of the castern Martin, and the black upper tail-coverts of the western species. The only other Swallow with feathered tarsi and feet is the Himalayan Martir, H. nipalensis, a much smaller bird, which may at once be distinguished by its black under tail-coverts. Our knowledge of the geographical distribution of this section of the genus Hirundo is in great confusion, owing to the carelessuess of collectors, who in too many instances have not thought it worth their while to shoot such a common bird, taking it for granted that no mistake could possibly arise in the ideutification of so well known a species as the House-Martin.

'The Housc-Martin is a spring migrant to our islands, and reaches us about a week after the Swallow has announced the coming of summer. In the south of England it usually arpives about the middle of $\Lambda_{\text {pril }}$; but in cold and backward seasons it sometimes does not appear until the end of that month. In Greece and Asia Minor, Dr. Krïper informed me that it arrived regularly during the first week in March; whilst in the north of

* In Colonel Ticliell's manuscript Iliustrations of Indian Ornithology, presented by him to the Zoological Society of London, the firure and description of the example of Chetidon urbica obtained in Tenasserim unquestionably refer to Pallas's Iouse-Martiu. The upper tail-coverts are not only described as white, but are also figured so. 
Norway, in the fear places where it is found, as in the sheltered villages on the Varanger Fjord, Mrr. Nordvi told me that it did not make its appearance until Nay. It departs from this country in autumn, many hirds learing Scotland in the last week of September, but most of them leaving England during the first half of October. Many birds, however, linger even longer than this, especially if their broods are unable to fly. Martins hare been seen repeatedly in Norember, and in very rare instances in December.

The Martin is perhaps even more gregarious in its habits, especially during the breeding-season, than the Strallor. The nesting-colonies of the latter bird are usually smaller, and the numbers which form the flocks during migration are less. The Martin does not fly so rapidly as the Swallow, nor is its flight marked with so many turnings and twistings. It sometimes flies at a considerable height, at other times it skims the surface of the meadow or pool, ever and anon dipping in the water to drink. The elcration of its flight varies according to the state of the atmosphere, which affects the insects on which it feeds. It frequents its breeding-place from the time of its arrival; and those fortunate birds whose nests have withstood the bufietings of winter roost in them at night. The song of the Martin is rarely heard. It is uttered as the bird sits on the dead branch of a tree or on a roof, or even when it is on the ground. It is a low twittering song varied by a few full rich warbling notes, and much resembles that of the Swallow, but is not so rich or so varied. Its call-note is entirely different from that of the Swallow, a sort of spritz, impossible to express by letters. Although the Martin spends the greatest part of its time in the air, it frequently alights. When at rest it usually perches on ledges, roofs, dead brauches, or on telegraph-mires. When it is collecting mud for its nest on the roads its wings are erer in motion, and when they are at rest it never attempts to progress by its feet. Its legs are too short to allow it to walk; and eren if the bird only move for a few inches its wings are invariably erected to assist it.

There can be little doubt that the Martin pairs for life, and every season returns to its old nest and uses it again. This interesting fact has been proved by marking birds in various ways, and in some instances they have been found in their old haunts the following year. There can be little doubt that the bird formerly used to breed exclusively on rocks, and that its habit of frequenting buildings is comparatively only a recent one. Thousands of llartins breed on the limestone rocks in Doredale and in other parts of the P'eak of Derloyshire, at Malm Cove near Settle in Yorkshire, and in many other places, especially on the cliff's of the sea-coast at Flamborough and other places in England and Scotland. It frequents alike the wildest portions of the country and the highly cultivated districts, and very often breeds in considerable numbers even in our largest towns. 
There is a curious nesting-place of this species in the Peak. The stone railway-bridge that spans Monsal Dale is liner with Martins' nests, and the birds seem to be not at all inconvenienced by the passing trains. The nests are built outside the bridge, under the coping which projects over the walls.

In the Parnassus they breed both on rocks and on houses. At Castri (the ancient Delphi) the nests of this bird are common under the eaves of the houses in the village; and there is a large colony occupying the cliffs, in company with the Rock-Sparrow (Passer petronia), in the picturesque gorge from which the famous spring flows. I have also seen other large colonies in the mountain-limestone cliffs at Agoriane and Belitza; but by far the largest colony I have ever seen is in a romantic glen in the mountains orerlooking Missolonghi. The rocks overhang very much; and when I was there hundreds of nests were to be seen under the orerhanging part, whilst outside and in the valley the bircls were flying in thousands, like a swarm of hees. In a cleft of the rock, in the midst of the Nartins' nests, was a huge nest of the Thite-tailed Eagle, and many of the Martins' nests were in the possession of the common HouseSparrow.

The Martin breeds in enormous numbers in some parts of Algeria. Dixon writes as follows:- "It was rery common in the Aral) settlements in the mountains, and also in the palm-oases on the plains. At Batua the bird is far more frequent than in any other place where I have met with it. The greater number breed on the barracks there; every coping, every window, in fact erery ledge that could support a nest was occupied, in some parts in rows three or four decp. At Philipperille most of the mud was baked hard by the hot sun; and it was only in one or two places on a bauk, where some water trickled slowly down, that the birds were able to obtain their materials. It was a very curious sight to see these charming little creatures clustering on the mud, giving it the appearance of a moving mass of birds; the air was also full of them busy catching insects in the bright African sunshine, and every moment they were either alighting on or learing the mud-bank. It secmed to me that all the Martins in Philippeville had congregated here to get mud for their nests. The Arabs never molest the Martin or the Swallow; they are almost as sacred to them as the Stork and the Ibis, and breed on their mud houses in abundance."

In this country the bird usually builds under the eares of houses or othor overhanging ledge. In May they may be seen gathering the mud which forms the outside of their nests; they risit the little pools, the roads, and, in fact, every situation where they can collect mud, and many birds repair to the same place. In dry seasons they are often sorely pressed to obtain this material, and have to fly considerable distances to find 
it. Sometimes they will visit heaps of mortar, or the dusty roads which have just been watered. The outside shell of the nest is almost entirely composed of mul. The birds do not build much at a time, but allow one layer to dry before another is placed, so that each nest takes ten days or a fortnight to finish. The mud is brought in little pellets, and a few straws or dry grass, or even hair, are intermixed to bind it together. Sometimes two or threc nests are built together; and in some localitics they are placed in rows one under the other. The inside is lined with dry grass and a few feathers. The nest is rounded in form, the quarter of an upright oval globe, and the hole which admits the birds is at the top, generally in the middle, but often in one corner. The lining materials are chiefly collected as the bird is on the wing-straws and feathers which the wind blows into the air. If their nest is destroyed the birds soon commence another on the ruins of the old one, and this has been known to be repeated many times in succession. The nest is a somewhat large structure, often measuring eight or nine inches in external diameter; the mud walls vary from half an inch to three quarters of an inch in thickness. It has bcen said that the bird sticks the little mud pellets that form the outside of its nest together with its saliva.

The MIartin begins to build its nest or to repair its old one about a month after its arrival, and fresh cggs may be obtained in Greece and Asia Minor as early as the end of April, but seldom in this country before the end of May. In the extreme north of Europe eggs are not to be obtained until several weeks later. Curiously enough, in Algeria the Martin does not appear to breed any earlier than in this comntry ; at Philippeville, on the coast, Dixon remarks that their nests were unfinished in the middle of MIay.

The eggs of the Martin are from four to six in number. They are pure glossy white, and the shell is very smooth. They vary in length from $\cdot 8$ to .$\%$ inch, and in breadth from 55 to $\cdot 52$ inch, and very closely resemble those of the Saud-1Tartin, but are a trifle larger, somewhat coarser grained, but more polished.

Both birds assist in incubating the eggs ; and when the young are hatched the exertions of the parents are taxed to the utmost to find them a sufficient supply of food. A correspondent of Macgillivray's (Mr. T. D. Weir) states that in one day they fed their young three hundred and seren times! During the whole period of incubation the male roosts in the nest with the female. When the young can leave the nest they are fed and tended by the old birds until they are strong on the wing, and during this time the little family-party always sleep in the nest at night. The young birds are fed upon the wing by their parents, and often pereh on posts, feuces, or even telegraph-wires, waiting for the old birls to eatch flies for them. Probably most pairs of birds attempt to rear a sccond brood in the season; but in some cases the hereditary impulse to migrate 
overcomes the parental instinct, and the young birds are left to perish in the nest.

In autumn the gregarious habits of these birds are especially striking, and they may often be seen in large flocks on houses, trees, or telegraph-wires. As the season advances these flocks increase in numbers, and the birds are far more garrulous than at any other time of the year, as if they were busy preparing for departure. The nests are frequently deserted, and they roost at night in trees and bushes. They take more or less prolonged journeys, and as the eve of their departure draws nigh they congregate in twittering masses on the house-tops. These large flocks, mostly young birds, are the first to migrate southwards, and are afterwards followed by the young of the second brood and their parents, a few stragglers only being left behind, probably weakly birds, or those whose broods are still in the nest. The food of the Martin is composed entirely of insects; and the refuse of this food, such as wing-cases \&re, is cast up in the form of pellets. In June it may often be seen alighting in turnip-fields, for the purpose of feeding on small beetles and flies; whilst it often catches various insects by hovering above the tall grass-stems and dexterously picking them off. It feeds largely on gnats, which often swarm in clouds over the water.

The Martin in spring plumage has the head, nape, back, scapulars, and some of the small wing-coverts glossy steel-blue, with greenish and purplish reflections; the wings and tail are blackish brown, with a greenish tinge; the tail is considerably forked, but the outermost feathers are not elongated like those of the Barn-Swallow; the rump and some of the upper tail-coverts are white, but those next the tail are blackish blue; the whole of the uncerparts are pure white. Bill black; legs and feet covered with hair-like white feathers, claws yellowish grey; irides hazel. The female does not differ in colour or size from the malc. Young in first plumage have the dark parts brown, with scarcely any gloss, the white parts tinged with pale brown; the innermost secondaries are broadly tipped, and most of the quills narrowly margined, with white, and the tail is shorter and not so forked. The pale tips of the ininermost secondaries are retained until the second or third moult. The Martin moults in early spring, whilst in its winter-quarters and during its residence in this country no important change takes place in the colour of its plumage.

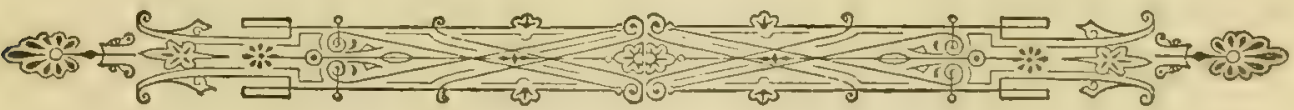




\title{
HIRUNDO RIPARIA.
}

\section{SAND-MARTIN.}

\author{
(Plate 17.)
}

Hirundo riparia, Briss. Orn. ii. p. 506 (1760); Linn. Syst. Nat. i. p. 344 (1766); et auctorum plurimorum-Gmelin, Latham, Temminck, (Bonaparte), Naumann, (Degland \&. Gerbe), (Henglin), (Newton), (Dresser), \&c.

Hirundo cinerea, Vieill. N. Dict. d Hist. Nat. xiv. p. 526 (1817).

Cotyle riparia (Lim.), Boie, Isis, 1822, p. 550.

Cotyle littoralis, Hemp. \& Ehr. fide Licht. Nomencl. Av. p. 61 (1854).

The Sand-Martin is perhaps the least known of the Swallows, and is very often orerlooked, or confused with its larger and more showy relations. From the peculiarity of its haunts, it is more local in its distribution than the Swallow and the Martin; nevertheless it is found throughout the British Islands, in some districts in immense numbers. It appears only to risit the Channel Islands on migration; but it is as common and as widely distributed in Scotland and Ireland as in England. It breeds in the Outer Hebrides and in the Orkneys, but is only seen occasionally in the Shetlands, and has not been recorded from the Faroes.

The Sand-Martin is a circumpolar bird, except that in Greenland the sererity of the climate appears to have driven it out of the country. In Scandinavia its colonies are found as far north as lat. $70^{\circ}$; but in the valleys of the Petchora, the Obh, and the Ienesay the most northerly colonies are in about lat. $6 z^{\circ}$. Middendorff found it on an island on the Pacific coast of Asia, in lat. $55^{\circ}$; and Dybowsky olstained it in Kamtschatka. In North America it breeds from Behring's Straits to Baffin's Bay, up to about lat. $68^{\circ}$. South of these limits it breeds throughout Europe and North Africa, and in Asia as far south as Palestine, Central Persia, Turkestan, South Siberia, East Mongolia, Japan, and the uorthern half of China. Very little is known respecting its winter-quarters; but occasional stragglers are met with in Teneriffe; and on the east coast of Africa it has occurred at Zanzibar, and as far south as the Transraal. In Asia it is sparingly found during the cold season in India and Burma; and the obserrations of l'Abbé David tend to prove that it also winters in Central and South China. On the American continent Dall found enormous colonies in Alaska up to lat. $65^{\circ}$; and Richardson found it equally abundant at the mouth of the Mackenzie river, in lat. $68^{\circ}$. Its southern breeding-range on this continent is not very accurately determined; but it is said to winter in Mexico, and is found at that season in Central America and iu the valley of the Amazon. In the Ethiopian and Oriental Regions the Sand-Martin has several allies, but none with which it is likely to be con- 
fused. Its nearest ally is probably $H$. cincta, from Africa, a larger bird with white instead of brown axillaries, and a white patch on each side of the forehead.

The habits of the Sand-Martin differ in several points from those of the House-Martin and the Swallow. The comparative rarity of suitable breeding-places makes it a much more local bird, and causes it also to appear much more gregarious; and the fact that it rarely breeds except in perpendicular earth-cliffs, which are seldom found except on the banks of rivers or lakes, makes it appear to be more partial to the neighbourhood of water than is really the case, though in this country the increasing number of railway-cuttings provides the Sand-Martins with other breedingplaces, of which they are ready enough to avail themselves. In some localities the Sand-Martin is said to be the first Swallow to arrive in this country; but in most places where migratory birds are observed on passage it is recorded as being somemhat later than our other two species. The arrival of all the Swallows in spring is somewhat irregular: they seem to cross the water in small parties, and to fly very low, frequently even following the sweep of the wares. Krüper gires the end of March as the earlicst appearance of the Sand-Martin in Asia Minor; but Irby frequently saw them at Gibraltar before the end of February. Wright says that they pass through Malta a little later than the other Swallows; and Naumann asserts that they seldom arrive at their breeding-quarters in Germany until early in Mar. In England they are frequently seen early in April. There seems to be little doubt that the Sand-Mrartins are the earliest Swallows to leave this country in autumn. During August their numbers rapidly decrease, and by the middle of September rery few remain, though I have seen them on the Susser coast as late as the middle of October.

Immediately after its arriral in this country the Sand-Martin repairs to its breeding-place, and the old holes are used as sleeping-places at night. These holes are made in perpendicular earth-cliffs on the banks of rivers or lakes, on the sea-shore, or in railmay-cuttings, sand-pits, grarel-quarries, or wherever a stecp enough bank of suitable soil can be found. Sandy ground is usually chosen because it is easiest to cxcarate; but it must not be too loose, othermise the sand would fall and bury the bird or her eggs. Sometimes very curious sites are chosen. I have seen Sand-Martins flying in and out of their holes which they had excarated in some enormous heaps of half-rotten sawdust lying near the Brandon station of the Great Eastern Railway. In Norway, between Lillehammer and the Dorrefjeld, many of the peasants' houses are roofed with turf, and some of these thick roofs of dry sandy peat are burrowed with nests of the Sand-Martin.

In all cases the bird excarates its own abode, and generally returns to it sereral years in succession; but I noticed on the banks of the Danube many deserted colonics close to others where the birds were swarming. 
Both male and female assist in the process of excavation, which usually occupies only the early hours of the day, the rest being devoted to coursing through the air in search of food. The little creatures begin by forming a small hole with their bills as they cling to the surface of the bank, sometimes with head downwards. As this hole increases in size they stand in the excavation, and throw out all the loose sand or chalk with their feet, boring away at times as much as four feet into the solid bank, but at others only two or three feet. In some cases a single pair of birds make two or three holes before they are suited. Occasionally a large boulder stops the way; or perhaps the sand is too hard or too soft; whilst many holes are abandoned at a depth of a few inches for no apparent cause whatever. The birds seem well arvare of the principles of drainage, and provide for it by making their holes slant slightly upmards. The holes vary considerably in size and shape; some will run almost straight, others turn to the right or left, not in acute angles, but scemingly by accident or to avoid obstructions in their way. Sometimes the holes are perfectly round, at others they will be rectangular, and often oval, and are usually two or three inches in diameter. The end of the hole is widened and hollowed into a kind of chamber, about six inches in diameter; and here the nest is formed. It is usually very slight-a mere bed of dry grass, coarse twitch, a few straws, and lined with one or two large feathers. The eggs of the Sand-Martin are from four to six in number. They are scarcely so polished as the eggs of the Housc-Martin, but are as pure a white, and vary in length from $\cdot 76$ to 62 inch, and in breadth from $\cdot 51$ to 46 inch.

Early in June or late in May, in favourable seasons, is the time to collect fresh eggs of this bird; but many Sand-Martins have a second brood, which are rarely on the wing before the middle of August. Some of the colonies of these birds consist of enormous numbers, and on the front of the cliffs where they breed they have all the appearance of bees in the process of swarming. On the banks of the Danube, the Volga, and the great Siberian rivers the numbers are sometimes almost incredible. One of these colonies is a most animating sight; the air is full of birds coming and going, and in front of the nests the crowd is so great that it is difficult to understand how each bird can thread the labyrinth. The Sand-Martin is almost as nimbile on the wing as the Swallow, perhaps more so than the House-Nartin; and, like both these birds, it often dips for a moment in the water as it skims over the surface to drink or to bathe. Now and then the birds cling to the face of the cliff, and the nearly flergerl young often sit at the mouth of the hole to be fed by their parents. SandMartins are bold in defending their colony from intruders; and I have seen them leave the bank in a borly to drive away a Merlin, which they pursued with great pertinacity. 
I have never heard the Sand-Martin sing, but it is said to twitter occasionally. Its call-note is a loud and harsh cry, almost a faint scream. Naumann represents it by the word share; but the consonants, to my cars, are imaginary.

The food of the Sand-Martin is composed entirely of insects, chicfly the smaller ones, such as gnats, which fly most abundantly over water. Gilbert White, however, states that the young are sometimes fed on large dragonflies. The inside of the mouth of the Sand-Martin is full of a viscid saliva, which aids it in capturing its prey, the little flies sticking to it as the bird courses through the air.

As soon as the young of the first broods can take care of themselves they unite into large flocks, and flit all day long over the fields and waters, feasting upon the boundless store of insect food. These young birds probably never visit the nest again, and roost at night in reed-beds, marshy plantations, and other suitable places; they are the earliest birds astir in the morning, and almost the last to retire to roost at night. After the young have flown, they and their parents often desert the sand-banks altogether, and wander about in search of the best localities for food; they gather in immense flocks, skimming over the large rivers and lakes, or sometimes perching on the telegraph-wires. Stevenson gives some intcresting particulars of these autumn flights of Sand-Martins, which roost like Starlings in the reed-beds.

The Sand-Martin is a very sombre-coloured little bird. The general colour of the upper parts and a broad band across the ehest are an almost uniform mouse-brown, very slightly darker on the head and somewhat paler on the rump. The wings and the somewhat forked tail are blackish brown; the underparts generally, except the chest-band already alluded to, are dull white. Bill black; legs, tocs, and claws dark brown; irides hazcl; at the back of the tarsus are a few feathers. The female does not differ from the male in colour, nor is there any seasonal change of importance. Young in first plumage resemble the adults, but have most of the feathers of the upper parts, especially the wing-coverts, the innermost secondaries, the feathers of the rump, and the upper tail-coverts tipped with pale buff, and the chin and throat are suffused with buff; but in many cxamples this buff fades into almost white, even bcfore the birds leave this comutry. This species is easily distinguished from the HouseMartin by its bare fect, and both from this bird and the Swallow by its dingy-brown plumage.

It has been said that examples from Siberia and Arctic Europe are somewhat darker above and whiter below than our birds. This idea has probably arisen from the excessive cleanness of the underparts of birds living in very thinly populated districts where no coal is burnt. 


\section{Genus PROGNE.}

The genus Progne was established in 1826 by Boie, in the 'Isis' for that year (p. 971), for the reception of the Purple Martin, which thus became the type. The birds in this genus may be distinguished by having the nostrils opening upwards and exposed, without any internal overhanging membrane. Some of the species have a metallic gloss on the feathers of the upper parts, whilst others are uniform brown. It is impossible to state how many species there are in this genus, many Swallows prescnting characters intermediate between it and Hirundo. On the widest estimate the number of species would be between thirty and forty, which are confined to the Nearctic, Neotropical, and Ethiopian Regions. The narrowest estimate would reduce the number of species to four, belonging to the Nearctic and Neotropical Regions only. The sole representative of this genus in Europe is the Purple Martin, which is supposed on more than one occasion to have accidentally strayed as far as the British Islands.

It is not known that the species of this genus differ from those of Hirundo in habits, food, or nidification. 


\title{
PROGNE PURPUREA.
}

\section{PURPLE IMARTIN.}

\author{
(Plate 18.)
}

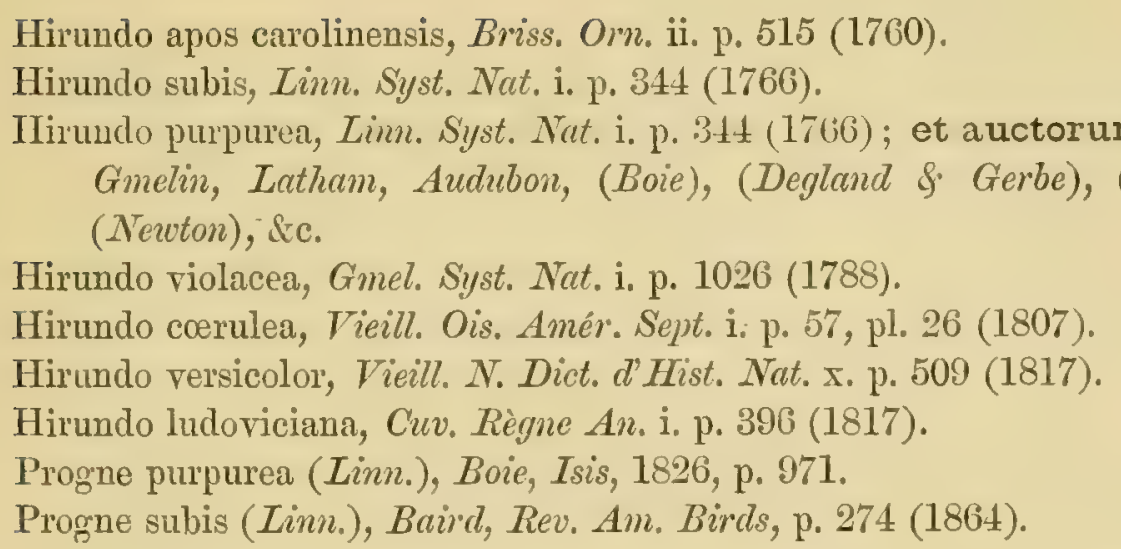

The Purple Martin has a very slender claim to be considered a British bird. A single specimen is said to have been shot, early in the year 1840, near Kingstown, co. Dublin. The late Dr. Scouler examined and dissected it, and it eventually found a place in the Royal Dublin Society's Museum, where it still is. Two other examples were said to have been obtained at Kingsbury Reservoir, Middlesex, in September 18t2, one of which went into Mr. Bond's possession. Another example is said by Mr. Clarke ('Handbook of Yorkshire Vertebrata,' p. 39) to have been shot at Colne Bridge, Huddersfield, in 1854; but the statement requires confirmation.

The Purple Martin is a summer visitor to the United States and Canada, ranging northwards above the Aretic circle. It winters in Mexico, where, however, a few retire to the mountains to breed. Stragglers have occurred in the Bermudas.

The Purple Martin is as well-known and familiar a bird in America as the House-Martin is in England. It arrives, according to Wilson, on the south-eastern borders of the United States, from its winter-quarters, late in February or early in March, reaches Peunsylvania about the first of April, but does not arrive at Hudson's Bay until May, and leaves the latter district again in August. Richardson states that it arrives within the Arctic circle before the snow is off the ground, and when the waters are still ice-bound. The Purple Martin seems almost as closely associated with man in America as the House-Sparrow is in England, with the difference that it is a very popular favourite and is encouraged in various ways. Wilson states that even the solitary Indian seems to have a particular respect for it, and fits up hollow gourds on the tops of the trees near his cabin for its reception. It haunts the largest and busiest towns of America and seems 
as much at home amidst the bustle and confusion as in the quict country districts.

Wilson states that about the middle or the 20th of April, the Purple Martin sets about preparing its nest; and the first brood appears in May, and the second late in July. It used formerly to breed in holes in rocks and trees, but now buildings seem to possess the greatest charm for it. The nest appears to be a very loosely made structure of dry leaves and grass, fine straws and twigs, and is lined with a considerable quantity of feathers. Baird, Brewer, and Ridgway state that rags, string, and other rubbish often form part of the nest, which is thoroughly repaired after the first brood has flown, and is occupied, presumably, by the same pair of birds every year. The eggs are from four to six in number, pure white and very glossy, and measure from 1.0 to 93 inch in length, and from $\cdot 8$ to $\cdot 65$ inch in breadth. Baird, Brewer, and Ridgway state that eggs from Florida are proportionately smaller than those from the Northern States. Wilson writes :- "During the period in which the female is laying, and before she commenees incubation, they are both from home the greater part of the day. When the female is sitting she is frequently visited by the male, who also occupies her place while she takes a short recreation abroad .... He sits on the outside, dressing and arranging: his plumage, occasionally passing to the door of the apartment as if to enquire how she does. His note at this time seems to have assumed a peculiar softncss, and his gratulations are expressive of much tenderuess."

The Purple Martin is said to be a very bold and courageous bird, and never fails to attack an intruajer on its domain. He is even said to mob such large birds as Crows, IIawks, and Eagles, attacking them with such vigour as to make them instantly resort to flight. The song of this bird is a succession of twittering notes heard at the earliest dawn, and during the early period of incubation incessantly uttered. Its flight is very rapid; and it glides very often like our Swift. Wilson writes:-_" IIe passes through the most crowded parts of our strects, eluding the passengers with the quickness of thought; or plays among the clouds, gliding about at a vast lieight, like an aerial being. His usual note, peno, peno, peno, is loud and musical; but is frequently succeeded by others more low and guttural."

The food of the Purple Martin is principally composed of bees, wasps, and large beetles, a fare very different from that of most Swallows. These birds do not winter in the United States; and their departure is said to vary according to the state of the season. They more southwards in large flocks, occasionally halting for a few days on the hill-sides near the sea, then passing on again.

The Purple Martin has the general colour of the plumage lustrous steelblue with a purplish gloss; the wings and tail are dull black; on the sides 
under the wings is a concealed patch of white. Bill black; legs, feet, and claws dark brown; irides brown. The female very closely resembles the male in colour, but is much duller above and the underparts are browner and greyer, sometimes almost white on the belly. Young birds are said to resemble the female. The general black colour and large size readily distinguish this bird from our British species.

Three other Swallows have been included in the British list, but on evidence that is altogether unsatisfactory. The Red-rumped Swallow, Hirundo rufula, was recorded in the 'Zoologist' for 1853 (1. 3753) by Mr. Rodd, as seen by him at Penzance, in Cornwall. It may easily be distinguished from the Barn-Swallow by its chestuut-coloured nape and rump and its streaked underparts. It breeds in South-eastern Europe, Asia Minor, and Palestine, wintering in North-cast Africa. Its eggs are indistinguishable from those of the House-Martin.

An example of the Baru-Swallow more rufous than usual on the underparts was erroneously recorded in 'The Ibis' for 1866, p. 4.23, by Mrr. J. H. Gurney, Jun., as a Chestnut-bellied Swallow, H. canirica, the geographical distribution and description of which is given amongst the allied species of the Barn-Swallow. The eggs of the two species are indistinguishable.

The White-bellied Swallow, H. bicolor, was recorded as a British bird by Wolley, in the 'Zoologist' for 1853 (p. 3806), from a specimen said to have occurred near Derby in 1850. It is a bird somewhat resembling the House-Martin in general appearance, but is without the white rump and the feathered legs and feet. It is common throughout North America, brecding from lat. $38^{\circ}$ to the Aretic regions, and is also a resident on the tablelands of Mexico. It winters in the West Indies, in Central America, and the northern portions of South America. Its eggs are pure white.

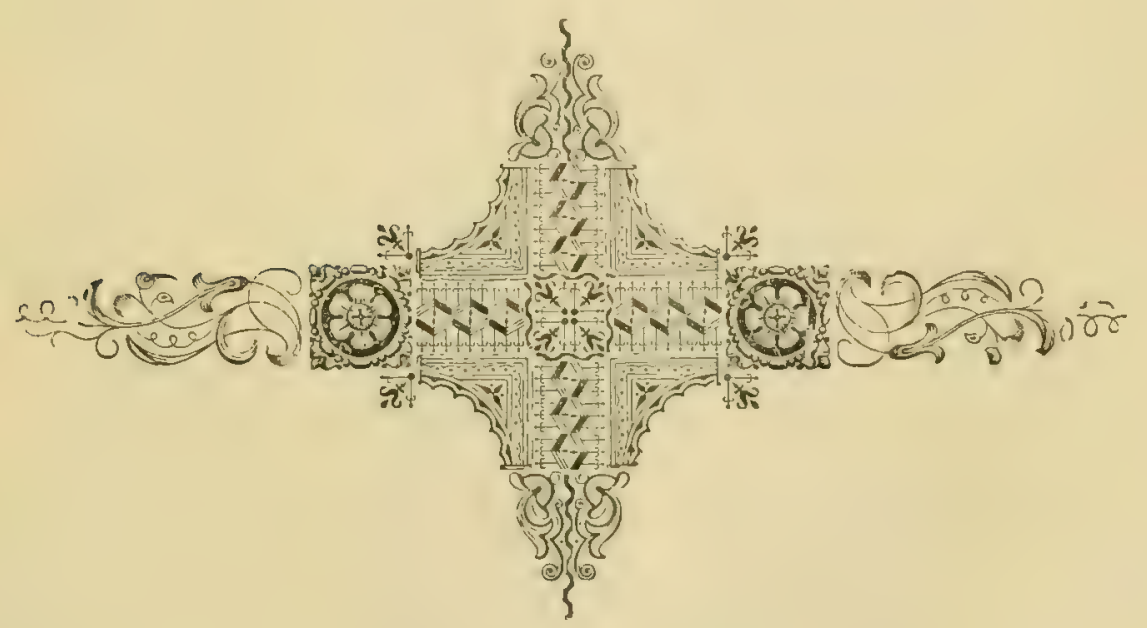




\section{Subfamily MOTACILLIN E, or WAGTAILS.}

The Wagtails and the Pipits are a group of slender-billed insectivorous birds. The absence of a bastard or first primary sufficiently distinguishes them from the Thrushes, Warblers, Tits, Crows, or Shrikes, and also from the Waxwings and Starlings, in which the bastard primary, though very small, is always present. From the Finches the slender bill is a distinguishing character, and from the Swallows the narrow bill and longer legs separate them sufficiently.

The Larks, which are probably their nearest allies, differ in having the back of the tarsus scutellated, and in only moulting once in the year. The Wagtails and Pipits have a partial spring moult, which does not, however, extend to the quills and tail-feathers. In both genera the tarsus is scutellated in front.

The Motacillinæ are almost cosmopolitan, and are found throughout the world, except in the Polynesian Subregion, which consists of all the tropical Pacific islands. They are most abundant in the Paliearctic, Ethiopian, and Oriental Regions, and least so in the New World. Only one species of Wagtail enters the New World, in the extreme north-west of the Nearetic Region; but the Pipits are rather more numerous. There are upwards of eighty species and subspecies in this group of birds, which has been subdivided into numerous genera, many of which are founded upon characters of a more or less trivial nature. Eighteen species are found in the Western Palsearetic Region, fourteen of which are included in the British list. Of these, two have been included on insufficient evidence.

\section{Genus MOTACILLA.}

The genus Motacilla, as defined by Linnæeus in the twelfth edition of his 'Systema Nature,' vol. i. p. 328, published in 1766, was a very comprehensive one, including the Robins, the Accentors, the rarious groups of Warblers, some of the Flycatchers, the Chats, the Wagtails, the Wrens, 
and the Goldcrests. It is impossible to guess what species was considered typical by Limnæus; but subsequent writers in subdividing the genus have restricted it to the Wagtails, the White Wagtail being accepted as the type because it is the Ficedula motacilla of Brisson.

It is not known that there are any structual characters by which the Wagtails may be separated from the Pipits, except that the former have longer tails in comparison with their wings than the latter. In the gencral style of coloration there is, however, a great difference between the two genera. There are two extreme types of coloration in the Wagtails, between which are several intermediate ones. In one extreme the rpper parts are black or grey, the throat and breast black, and the remainder of the underparts white; in the other extreme the upper parts are olivegreen and the underparts yellow. On the other hand the prevailing. colours of the Pipits are brown, more or less spotted above and below.

The Wagtails are found throughout the Old World, with the exception of the Australian Region; but one species crosses Behring's Straits into Alaska. This genus contains about thirty species and subspecics, of which eight are European; of these, five are included in the British list.

The Wagtails frequent open and well-cultivated distriets, the bauls of streams, and pastures; they are most frequently seen on the ground, where they run with great ease, continually vibrating their tails. 'Their' flight is very undulatory, and their powers of song are very fecble. They feed, so far as is known, upon insects and small shellfish. Their nests are built upon the ground or in holes in rocks and buildings; and their eggs vary from bluish white to brown in ground-colour, profusely spotted with brown or grey of various shades.

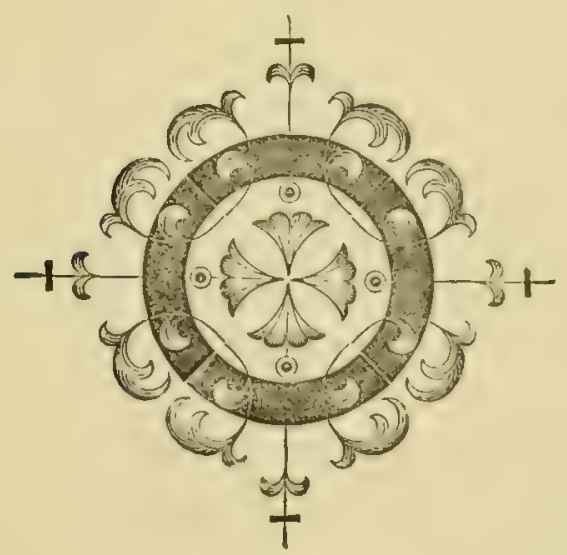




\section{MOTACILLA YARRELLII.}

\section{PIED WAGTAIL.}

(Plate 14.)

Motacilla alba, Limn. Syst. Nat. i. p. 331 (1766, partim).

Motacilla lugubris, Pallas, fide Temm. Man. d'Orn. i. p. 253 (1820, partim).

Motacilla lotor, Rennie, Mont. Onn. Dict. p. 377 (1833).

Motacilla yarrellii, Gould, Proc. Zool. Soc. 1837, p. 74; et a uctorum plurimorum - Bonaparte, Degland \& Gerbe, Salvadori, Savi, Homeyer, Blasius, Taczanowstey, Tarrell, Gray, Macgillivruy, Thompson, Irby, Sharpe, Harting, Stevenson, \&c.

Motacilla alba lugubris, Schlegel, Rev. Crit. p. 37 (1844).

The Pied Wagtail is very widely distributed throughout the British Islands, and, except in the extreme north, is a resident species. It appear's to be migratory in the Hebrides, and is also a summer visitor to St. Kilda. To the Shetlands it is a spring and autumn visitor, most numerous at the latter season; but it is not known to have visited the Faroes or Iceland.

On the coutinent the distribution of the Pied Wagtail is extremely limited. It breeds sparingly in the south-west of Norway, frequently occurring on Heligoland on migration; and it occasionally breeds in Holland, and more abundantly in North-west France. It is a common winter visitor to South-west France, Portugal, and Western Spain, and occasionally crosses the straits into Tangiers. Stragglers have been obtained in Belgium, and as far east as Italy and Sicily.

Although Temminck and Vieillot were acquainted with the Pied Wagtail as early as 1820, and recognized its distinctness from the White Vagtail, English ornithologists confounded the two together until 1837, when Gould, with his habitual keen eye for a species, pointed out the difference between them. The confusion arose from the imperfect diagnosis of Linnreus, who doubtless himself knew both forms, and considered them identical, since he not only refers both to the Motacilla alba of Willughby and of Albin, which are unmistakably black-backed birds, but also adopted the name which these ornithologists had used, and apparently so wordcd his apology for a description as to include them both.

The Pied Wagtail, although it is so common, from its neat appearance and lively cheerful habits is always admired. It loves to frequent the neighbourhood of water, which is almost as essential to its presence as it is to the Dipper. It frequents every variety of scenery, and may be seeu daintily running round the margins of mountain-pools and upland-lakes as well as near the horse-ponds, brooks, and large sheets of water in the 
low-lying and richly-cultivated districts. It is very fond of frequenting meadows and old pastures, is often seen in the farmyard or running along: the roofs of out-buildings or on the country roadside, bathing in or wading through the little puddles, busy in search of food. Although many Pied Wagtails remain in this country throughout the year, its favourite haunts rarely being quite deserted even in midwinter, many retire southwards in autumn and leave our islands. These birds return in flocks very early in the following spring. During the cold days of early March, when the air is still frosty and bracing, and the cold east winds are drying up the moisture of February, the Pied Wagtails may be often seen in flocks on the ploughed fields, sometimes accompanied by Meadow-Pipits, on their way from the lowlands to the moors. They run along the ridges, dipping into the furrows, then appearing again, tame enough to pass under the horses' noses, or come within arm's length of the ploughman as he rests his team at the headland. Few birds are more tame and confiding than these fairy-like little creatures. Stevenson, in his 'Birds of Norfolk,' mentions a migratory arrival of these birds which he noticed at Teignmouth in Devonshire. They appeared on the morning of the 20th of March, and the grassy slopes near the sea were soon covered with them; but on the following day they had passed on, probably to their breeding-grounds further north. The Pied Wagtail may be often seen wading in the shallows near the shore, or running nimbly along the little islets of mud in the centre of the stream, passing over the treacherous surface without the slightest inconvenience. It is never seen to hop; but always runs, sometimes aided by its wings. Its tail is constantly in motion, as if serving as a kind of balancing-pole, and is usually spread out like a fan when the bird alights or takes wing. Its flight is a drooping one, performed in a long succession of curves or dips. It is capable of flying with very great rapidity, as, for instance, in the spring, when it is chasing its mate or a rival to her affections, or when in pursuit of some predacious bird. Pied Wagtails stand well upon their legs, the tail is held almost horizontal to the body, consequently they can wadle to some little distance without wetting their plumage, or run over the softest mud without soiling it. They run hither and thither with wonderful case, tripping daintily along, ever and anon taking little flights to eatch passing flics, or turning incessantly from left to right in busy search for food. Now they run into the shallows for a little way and snap at a gnat on the surface; then, returning, they will pause for a moment, with rapidly quivering tail, to preen their plumage. Sometimes they rise into the air and settle on the branches ovcrhcad, perching just as comfortably as a Sparrow, and evidently quite at home amongst the twigs. They are very fond of alighting: on the roof of some out-building, and of running nimbly along calling incessantly to each other, or making little sallies into the air like a Fly- 
catcher. Then perhaps they will flutter down to the mud-banks in the centre of a pool or half-cmpticd mill-dam, alighting gracefully, without soiling a feather of their pure white under plumage.

The Pied Wagtail is often seen in the meadows, and runs about quite fearlessly amongst the grazing cattle, sceming to know full well that they will not harm it, and that they are conscious of its good offices in ridding them of their insect pests. In the antumu many Pied Wagtails may be seen on the sca-coasts, even wading in the shallow water. Here the chief objects of their quest are the small sand-flies, swarming in countless myriads on the heaps of decaying seaweed or sporting over the sands.

The song of the Pied Wagtail is only heard at rare intervals, most frencntly in the spring; it is a short, loud, and varied strain, putting you in mind of the twitter of a Swallow, and is generally uttered when the bird is fluttering in the air like a Pipit. Sometimes he will sing when daintily poised on a water-encircled stone or even on a clod of eartl. Its call-note is gencrally a sharply-uttered chiz-zit; but it has also a prolonged note, which is probably used from one sex to the other.

The Picd Wagtail is a somewhat early breeder, generally begimning operations in April ; and Gray remarks, in his 'Birds of the West of Scotland,' that he has observed young birds in full feather as early as the middle of May. The nest is built in various situations. Sometimes it is placed far under a convenient stone, at other times under a tile in a brick-field or even in a disused drain-pipe. More general situations for it are in holes of walls or rock-crevices, amongst the gnarled roots of trees, on the margin of a stream, in a rugged bank, or on the wall-plate of a cattle-shed, whilst less frequently a hole in thatch, a pile of wood, a haystack, or a heap of stones will be chosen. The nest is a somewhat bulky structure, thickly matted together, and made of dry grass, roots, moss, and leaves, and lined with wonderful neatness with wool, hair, and often with feathers. The eggs of the Pied Wagtail are from four to six in number, greyish white or the palest of blue in ground-colour, profusely speckled and spotted with greyish brown, and with underlying markings of French grey. Some specimens have the markings more or less streaky, and on many there are a few hair-like streaks of rich blackish brown. They vary in length from 86 to .55 inch and in breadth from 63 to 56 inch, and many specimens closely resemble certain varieties of those of the HouseSparrow, but are seldom so e. ongated.

Dixon writes:- "Young Pied Wagtails stay in their. parents' company some time after they quit the nest; indecd in some eases they will kecp in company through the autumn and winter. It is a pleasing sight to see a yomig brood of these Wagtails and their parents. The little creatures, some time before they are able to fly, will leave the nest and wait patiently the arrival of their parents with food; but npori the least alarm 
they take refuge in the nesting-hole, as they do at nightfall. In the breeding-season the trustfulness of this Wagtail is often very considerable, and it will repeatedly build its nest in the most frequented and busy situations. I once knew a nest of this bird in a hole of a wall bordering a large sheet of water, in fact the nest was but a few inches from the margin. It contained four young ones, which were continually runuing in and out of the hole which contained their nest; and by keeping perfectly stili they approached me closely, and I had the pleasure of secing the birds feed their offspring with a few crumbs that I scattered for them. Wheri the young have gained the full use of their wings the nest is abandoned for ever, and we see them on the fallows and pastures. Here they are still fed by the old birds; and it is pleasing to observe the actions of both old and young at this period, as the latter with drooping wings welcome the arrival of their parents with food. See them, now walking, now running, in all directions, making sad havoc amongst the clouds of insects. Gifted with the most acute sight, the Wagtails can distiignish the smallest insect at incredible distances. Now running, aided by their wings, they capture an insect, and with notes of exultation call their young, nestling closely and motionless amougst the earth-clods at haud. With quick motion the little creatures bound forward and receive the profiered food with all the graceful actions so prominent in this charming group of sylph-like birds."

The food of the Pied Wagtail consists of insects of various kinds, both picked up from the ground and caught whilst fiying in the air. It will also eat small beetles, for which it searches amongst manure and the leaves of plants, and it finds great quantities of larve whilst following the plough.

Numbers of Pied Wagtails move southwards in autumu. They appear to migrate principally along the coast-line; and Gray remarks that immense numbers may be observed passing down the Clyde at Glasgow. This gentleman has scen in September and October as many as three or four hundred assembled on the timber-rafts in that river. In this way the birds probably wander down the coast southwards, great numbers being regularly observed on the sonthern shores of England, whence they cross to their winter-quarters on the continent. On the return migration I noticed them very common both at Biarritz and at Bordeaux early in March; and Mr. Knox records the arriral of small parties of these birds on the coast of Sussex in the middle of that month.

The adult male Pied Wagtail in full breeding-plumage has the forehead extending along the sides of the head and ncek pure white; the rest of the upper parts is black, except the tips of the median wing-coverts, the malgins of the greater wing-coverts and immermost sccondaries, and the greater portion of the two outside tail-feather's on cach side, which are pure white, 
and the wings, which are dark brown. The chin, throat, and upper breast are black, which joins the black of the back at the shoulder, isolating the white on the sides of the neck from the white of the rest of the underparts. Bill black; legs, feet, and claws black; irides dark brown. The female in summer plumage closely resembles the male; but the upper parts are much greyer and mottled only with black. After the autumn moult the black on the throat and breast is reduced to a crescentic band across the latter, and the white on the throat is only separated from the white of the underparts by the grey on the back, which extends to the sides of the neck and flanks.

The changes of plumage which this bird undergoes appear never to have been fully described, though it is somewhat extraordinary that they should have been overlooked, since those of the nearly allied White Wagtail have hecn so accurately pointed out by Naumann. Young in first plumage liave every feather of the upper and underparts, except the wings and tail, grey, shading into nearly black on the upper and into nearly white on the under tail-coverts. They moult this plumage in the first autumn; but the colour of the upper parts is scarcely changed, except that the forehead and the sides of the head have become white, more or less suffused with ycllow*. The underparts are much whiter, the chin and throat being white, more or less suffused with yellow, the black crescentic band appears on the breast, and the head is more or less mottled with black in the male, but not in the female. In the following spring they moult into fully adult plumage, except that the black on the back is more or less mottled with grey. At the second autumn moult, when the birds are a little more than a year old, the fully adult winter plumage is assumed.

Apparently, at all scasons and at all ages, after the first moult, the Pied Wagtail may he distinguished from the White Wagtail by its very dark rump, the upper tail-coverts only being dark in the latter species. Strange to say, in the extreme east of Asia, breeding in the lower valley of the Amoor and North China, and wintering in South China and the Burma peninsula, M. leucopsis, a still nearer ally of the Pied Wagtail, occurs. When fully adult it appears to differ only in having the white on the wing sleveloped to a much greater extent.

* Some writers have attempted to discriminate between $M$. alba and M. dukhunensis on the ground that the young of the former are yellowish about the head, whilst the young of the latter never have this yellow tinge. There can be no doubt that birds of the year, both from Eastern Asia and from Western Europe, are sometimes with and sometimes without this yellow tinge. 


\title{
MOTACILLA ALBA.
}

\section{WHITE WAGTAIL.}

\author{
(Plate 14.)
}

Ficedula motacilla, Briss. Orn. iii. p. 461 (1760).

Ficedula motacilla cinerea, Briss. Orn. iii. p. 465 (1760).

Motacilla alba, Linn. Syst. Nat. i. p. 331 (1766, partim); et a uctorum plurimorum -Gmelin, Scopoli, Latham, Bonaparte, Naumann, Degland \& Gerbe, Savi, Salvadori, Newton, Dresser, \&c.

MLtacilla cineren (Briss.), Gmel. Syst. Nat. i. p. 961 (1788).

Motacilla albeola, Pall. Zoogr. Rosso-Asiat. i. p. 506 (1826).

Motacilla dukhunensis, Sykes, Proc. Zool. Soc. 1832, p. 91.

Motacilla brissoni, Macgill. Man. Brit. B. i. p. 160 (1840).

Motacilla baicalensis, Swinhoe, Proc. Zool. Soc. 1871, p. 363.

The White Wagtail was first noticed in England in May 1811 by Mr. Bond, who found it brecding at Kingsbury reservoir. Since that date many other specimens have been obtained, chiefly in spring, leading to the conclusion that a few come every year to this country to breed. Amongst other localities where it has been found brecding may be mentioned Nortls Devon, the Isle of Wight, Sussex, Kent, and Huntingdonshirc. It is of far less frequent occurrence in Ireland, but may have been overlooked. In Scotland the only specimen which has come under Mr. Gray's notice was shot in the winter of 1847 at Dunbar, in East Lothian, whilst Saxby states that he saw a pair at Lerwick in 1854. A specimen of this bird has been sent from Greenland; and it is common in summer in Iceland and the Faroes.

The White Wagtail breeds throughout Europe as far north as land extends. In the northern portions of its range it is a migratory bird, and winters in South Europe, where some remain to breed on the mountains. It also winters in North Africa, in the west as far south as Senegal, and in the east as far south as Zanzibar; but a few are said to remain to brced in Egypt. It occasionally visits the Canaries in winter. It breeds in Siberia, as far east as the valley of the Yenesay and as far north as land extends. In Palestine, Asia Minor, and Persia it is principally known as a winter visitor, but many remain to breed in the highlands. Its breeding-range also extends throughout South-west Siberia; but in Turkestan it is chiefly known as passing through on migration, except in the south-west, where a few remain to winter. A somewhat nearly allied species, $M$. personata, having the grey back of the White Wagtail, but the white on the head joined to the white on the throat as in the Pied Wagtail, ranges 
from Persia, through Turkestan and Cashmere, along the mountains of South-west Siberia as far east as Krasnoyarsk and Yenesaisk; and in the latter locality appears to have driven out the White Wagtails and to have divided them into two colonies. As I ascended the Yenesay from the Aretic circle the White Wagtail abounded on the banks of the river until I neared Yenesaisk about lat. 59 $9^{\circ}$, when suddenly it disappeared, and its place was taken by $M$. personata; but about halfway between Yenesaisk and Lake Baikal, IIiddendorff found the White Wagtail again, and Taczanowsky describes it as common near Lake Baikal and in West Dauria. The isolation of this colony appears to have been facilitated by the fact that in autumn the birds migrate eastward instead of westward to winter in West China, Burma, and India. Some ornithologists have described birds from this colony as distinct under the name of $M$. dukhunensis; but I am unable to detect any difference between examples from Lalie Baikal, North Siberia, India, or Spain. North-west European eximples have somewhat narrower white margins to the wing-coverts.

The British ornithologist who leaves his native island and crosses over to the continent may ramble over any farm on the shores of the German ocean without finding much difference between the birds of the tro countries. Most of them he will recognize as old acquaintances; a few which he looked upon as great rarities in England he will find to be common on the other side of the water; and some which at the first glance he may suppose to be common British birds, he will find on closer examination to differ slightly from their insular representatives. To the latter group belongs the White Wagtail. On the eontinent from Calais to IIamburg this bird everywhere takes the place of the Pied Wagtail. The two birds have the same habits, nearly the same song and call-notes, make a similar nest, and lay similar eggs. There seems to be no difference between them whaterer, except in the colour of the back and the sides of the neck. The Pied Wagtail is obviously an island form of the White Wagtail, and has probahly been differentiated since the passing away of the Glacial epoch. During the warm climate which appears to have succeeded this cold period in these latitudes, the White Wagtails of the British Islands were probably isolated from their continental brethren, and pussibly having fewer encmies (both birds and beasts of prey being comparatively less abmudant on islands than on continents) sexual selection was not prevented by protective selection from providing them with a special bridal dress at the spring moult. In those days the isolation of the two areas of distribution was probably complete; and we may fairly assune that the two species only began to invade each other's territory in comparatively recent times, since the winters have become sufficiently cold to compel them to be more or less migratory in their habits. Hence we find that although the White Wagtail is so rare in our islands, it is not, like 
most common continental birds who seldom visit us, a late migrant to its breeding-grounds. On the contrary it is one of the earliest birds to arrive in North Germany, frequently appearing before March, and even occasionally remaining during the winter.

In Siberia I found that the White Wagtail was the first of the softbilled birds to arrive on the Aretic circle in any numbers, the great breakup of the ice on the 1st of June being the signal for its appearance on its breeding-grounds. In the valley of the Petchora it appeared for the first time on the 12th of May, and we got the first eggss on the 15th of June. The nesting-site selected by the White Wagtail is precisely similar to that chosen by the Pied Wagtail, and the nest is made of similar materials. A nest of this bird I found at Alexievka was lined entirely with reindecr's hairs and two or three spider's cocoons. The eggs of this species are five or six in number and vary considerably. The specimens I have in my collection may be fairly divided into three distinct types. The first and ordinary type is pale greenish blue in ground-colour, spotted and thickly speckled, chicfly at the large end, in the form of an irregular zone, with greyish brown and with umderlying markings of French grey. The second type has the ground-colour almost pure white, and the spots and speckles, distributed in the same mamer as in those already described, are a much richer brown. The third type is dull white in ground-colour, thickly marbled, splashed, and spotted over the entire surface with reddish brown and pale brown. This latter type might almost again be subclivided into two, for sometimes the markings are very rich brown and finely powdered over the surface, leaving the ground-colour very strongly apparent, and at the larger end of the egg are sometimes a few streaky spots of dark brown almost black. The eggs vary in length from 88 to $\cdot 7$ inch, and in breadth from 62 to 55 inch. It is very difficult to distinguish the eggs of the White Wagtail from those of the Pied Wagtail ; but generally the latter are not so blue in ground-colour, and the brown, or third type above mentioned, does not seem to occur at all. In temperate Europe the White Wagtail rears two broods in the year, the first eggs generally being laid in April, the second in June.

The habits of the White Wagtail are not known to differ in any important respect from those of its very close congener the Pied Wagtail, and the haunts it frequents are similar. There can be little doubt that this pretty little bird is overlooked in this country and confused with the common species. Mr. J. Cullingford writes to me, respecting Lincolnshire and Cambridgeshire, that the bird is much more plentiful than formerly. IIe has seen uests of this species, and, as far as his experience goes, he says that it breeds later than the Pied Wagtail. Among the spring flocks of Pied Wantails an occasional White Wagtail may not unfrequently be seen on the fields with the Roolis following the plongh; they rum abont 
as nimbly as their congeners, often chasing each other through the air and very often flying in search of an insect. The White Wagtail often perches on trees and is fond of running along roofs of buildings or on walls. It roosts in trees, generally selecting some bare slender twig for the purpose, and before and after the breeding-season frequently repairs to old reed-beds, where it spends the night with the Starlings and other birds. Its food consists of insects, small beetles, larvæ and small worms, mollusks, and grubs. It is a very active lively little bird, running hither and thither, and repeatedly taking a short flight like a Flycatcher. Its song- and call-notes appear scarcely to differ from those of the Pied WVagtail, although some naturalists have asserted that there is a recognizable difference in the call-note of the two species.

The adult male White Wagtail in breeding-plumage has the forehead, the sides of the head and neck, and the underparts below the breast pure white, shading into slate-grey on the flanks. The rest of the head and the nape is jet-black; the general colour of the upper parts below the nape, including the lesser wing-coverts, is slate-grey, shading into nearly black on the upper tail-coverts; the quills are brown; the innermost secondaries and the greater wing-coverts are brownish black, broadly margined with white, and the median wing-coverts are tipped with white; the tail is black, except the greater portion of the two outermost feathers, which are white. The chin, throat, and breast are black. Bill, legs, feet, and claws black; irides dark brown. The female somewhat closely resembles the male; but the black on the hear does not cxtend so far on the nape and is suffused with brown, and the slate-grey of the back is not so blue. The changes which take place in the plumage of this bird are similar to those of the preceding species.

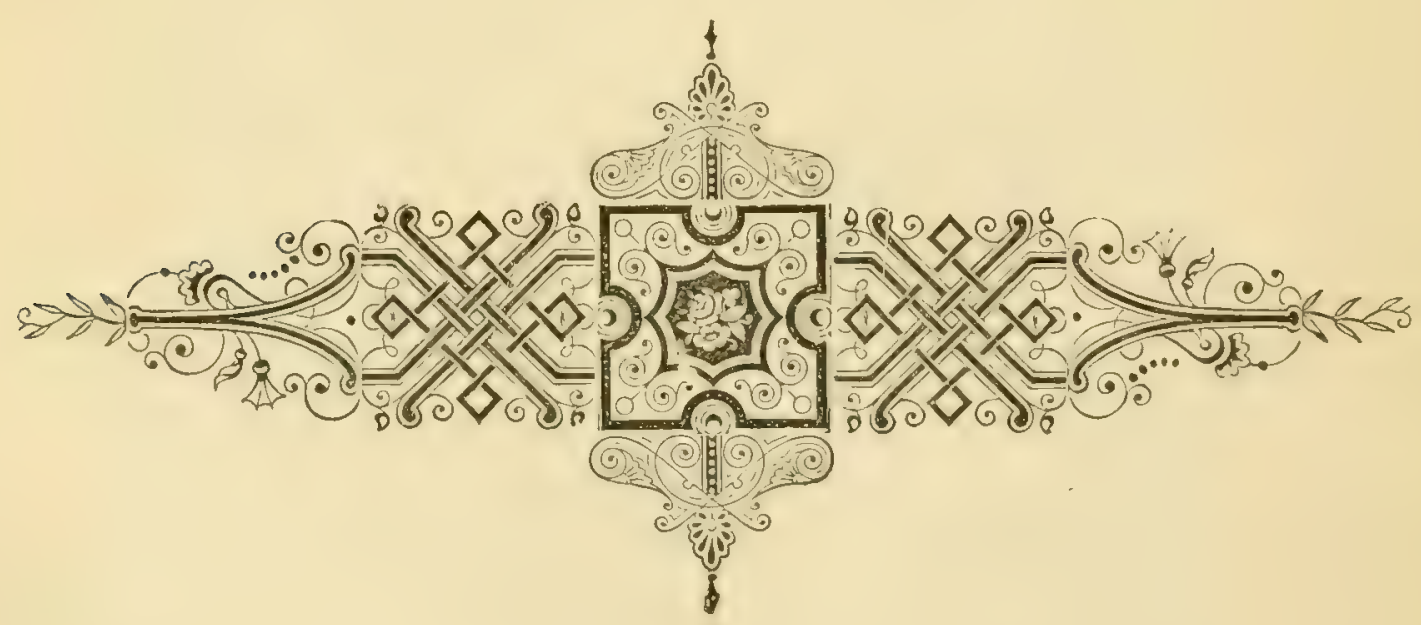




\title{
MOTACILLA SULPHUREA.
}

\section{GREY WAGTAIL.}

(Plate 14.)

\begin{abstract}
Ficedula motacilla flava, Briss. Orn. iii. p. 471, pl. xxiii. fig. 3 (1760).
Motacilla melanope, Pall. Reis. Russ. Reichs, iii. p. 696 (1776).

Motacilla tschutschensis, Gmel. Syst. Nat. i. p. 962 (1788).

Motacilla boarula, Scop. apud Gmel. Syst. Nat. i. p. 997 (1788).

Motacilla sulphurea, Bechst. Naturg. Deutschl. ii. p. 459 (1807); et auctorum plurimorum-(Kaup), Bonaparte, Degland \& Gerbe, (Horsfield \& Moore), (Jerdon), (Holdsworth), (Legge), (Hume), Irby, Shelley, Newton, \&e.

Motacilla cinerea, Leach, Syst. ,Cat. Mamm. \&c. Brit. Mus. p. 22 (1816).

Motacilla bistrigata, Raffles, Trans. Linn. Soc. xiii. p. 312 (1821, partim).

Calobates sulphurea (Bechst.), Kaup, Natiirl. Syst. p. 33 (1829).

Budytes boarula (Scop.), upud Eyton, Cat. Brit. B. p. 15 (1836).

Motacilla xanthoschista, Hodgs. Gray's Zool. Miscell. p. 83 (1844).

Pallenura sulphurea (Bechst.), Bonap. Consp. i. p. 250 (1850).

Pallenura javensis, Bonap. Consp. i. p. 250 (1850).
\end{abstract}

The Grey Wagtail is sparingly distributed throughout England and Wales, breeding in the mountainous districts and migrating into the lower valleys and into the plains for the winter. In the Channel Islands it is probably a resident. In Scotland it is more generally distributed than in England, and though not found on the Outer Hebrides it occurs on several of the inner islands. It occasionally visits Orkney in summer, and is frequently driven by storms to the Shetlands in autumn. In Ireland it is widely although locally distributed.

The range of the Grey Wagtail extends from the Atlantic to the Pacific, but does not appear to include either the Scandinavian or Kamtschatkan peninsulas. It breeds throughout Central and Southern Europe, the northern limit of its range being Ifolstein, West Russia south of Moscow, and East Russia south of lat. 59 $9^{\circ}$ In Siberia Finsch found it in the valley of the Obb in lat. $67^{\circ}$; but in the valley of the Yenesay I only obtained one cxample in lat. $66 \frac{1}{2}^{\circ}$, and Middendorff did not find it east of the Lena north of lat. $62^{\circ}$. It breeds in Asia as far south as Persia, Turkestan, Cashmerc, South Siberia, and Japan. It is a resident in the Canaries, Madeira, and the Azores ; but in most parts of its range it is a partial migrant, breeding on the mountains and wintering in the plains, and many of the European birds cross the Mediterranean to winter in North Africa and Palestine. To Siberia it is only a summer visitor, passing through Mongolia on migration and wintcring in India and Ceylon, the Andaman Islands, Java, the Burma peninsula, some of the Philippine Islands, Formosa, and China. Some ornithologists distinguish the eastern race of this bird from 
the western, the former having on an average a slightly shorter tail than the latter. The extremes vary from $3 \frac{1}{2}$ to $4 \frac{1}{4}$ inches; but every intermediate measurement is found, and occasionally the measurements do not agree accurately with the geographical distribution.

The haunts of this fairy-like and graceful little bird are never far from rumning waters. It appears to love them best when in their wildest moods; and it frequents the rocky banks of mountain-rivers and streams, especially if they are well wooded, living in seattered pairs, each appearing to have its own range.

The Grey Wagtail has always been one of my special favourites. In spite of its name, the delicate brilliancy of its plumage entitles it to be considered one of our most elegant native birds. All its movements correspond; nothing can be more graceful than the way in which it will run along the margin of a still pool, leaving the impression of its delicate feet on the sand, or daintily flit from stone to stone in the runuing stream. It rarely, if ever, frequents pastures, as the other Wagtails are fond of doing; nor have I ever seen it on the lawn or in the farmyard; it confines itself almost cutircly to rivers and brooks. I first became acquainted with these charming birds in the neighbourhood of Saffron Walden. Between this town and Audley End lies Lord Braybrooke's park; a winding brook runs through it, by the margin of which you might stroll any winter's morning with the certainty of secing one or two pairs of Grey Wagtails. They were regular winter migrants, appearing about the middle of October and disappearing as regularly towards the end of March. Every antumn the Fieldfare, the Redwing, the Royston Crow, and the Grey Wagtail were the most conspicuous heralds of winter; and every spring they vanish as completely. I next met with this bird amoug the Derbyshire moors, near Sheffield, but this time as a summer visitor. You may stroll along the banks of the Derwent any summer day, from Ashopton to Yorkshire Bridge, with the certainty of seeing one or two pair's of Grey Wagtails, and with almost equal certainty of finding one of their nests. The river is broad and full of rocks and stones, and the banks are often steep and rocky. A good fly-fisher wading up stream will, on a lucky day, soon fill his ereel with trout, and have ample opportunities of watching the Common Saudpiper, the Dipuer, and the Grey Wagtail, which all breed close to the river-side. The Pied Wagtails are especially numerous, flitting from stone to stone, allowing you to approach almost close to them before they will fly off to another stone or perhaps to a tree, uttering their alarm-note of chiz-zit, chiz-zit. The Grey Wagtails are much less numerous and very much more shy; and if you wish to wateh their graceful movements you must conceal your'self or be very quiet. In their habits they resemble the other Wagtails, ruming very rapidly and gracefully, continually moving their tails up and down, and now and then taking a snatch at an insect, assisted 
by a slight effort of the wings, and displaying at the same time the yellowish green of the upper tail-coverts and the conspicuous white feathers in the tail. When alarmed they will generally fly up from the stream with an undulating desultory flight, and, as often as not, take refuge in a tree, from which, if you happen to be too near their nest, they will keep up an incessant chiz-zit, often preceded by a prolonged plaintive note, like hoo-in. As the summer advances they leave the localities where they hare reared their young, as I believe most other birds do, and, still following the streams, slowly migrate towards warmer regions. Late in the summer I have seen them on the stones in the Porter and the Don, sometimes running along the roof of a steel warehouse by the river-side in the centre of Sheffield. I have almost always found the nest of the Grey Wagtail under an overhanging ledge of rock, built upon the clay or rocky bank, and well concealed behind grass and other herbage. Once only I saw one built in the fork of three stems of an alder, close to the ground, almost overhanging the river. I remember once being shown the place in which a Grey Wagtail's nest, containing four eggs, had been taken the day previously by my friend Mr. Charles Doncaster, who substituted for them four Wren's eggrs. We were surprised to find the four Wren's eggs gone, the white cow-hair lining having been ejected with them. A fifth Grey Wagtail's egg had been laid in the damaged nest, which turned ont to have becn built upon the ruins of an old Thrush's nest containing broken egg-shells. The Grey Wagtail secms to have a great attachment for its favourite breeding-places. I have found the nest year after year upon the same ledge of a rocky bank. The eggs are laid towards the end of April or early in May. The nest is very similar to that of the Pied Wagtail, a trifle smaller inside, and perhaps a little deeper, and even more carefully made. It is almost entirely composed of fine roots, with a few stalks of dry grass in the outer and coarser portions, and is lined with cow-hair, the preference being given to white. I have never seen any feathers used, although Macgillivray, Yarrell, and other naturalists assert that such help to form the lining of the nest.

In the spring of $1873 \mathrm{I}$ had the pleasure of renewing my acquaintance with this charming bird in the classic region of the Parnassns, in a locality very similar to the wilder Derbyshire dales. The little village of Agoriane, between three and four thousand feet above the level of the sea, enjoys a climate very similar to that of the High Peak of Derbyshire. 'The folliage in the neighbourhood is also very similar; you meet with the hawthorn, the oak, and the holly, as well as the bramble, ivy, and the dog-rose. Many of the birds, too, are the same. Not far from the village flows a mountainstream, convering the melted snow of the Parnassus down to the Topolais Marsh, the Dead Sea of Greece. This stream runs at the bottom of a deep mountain-gorge, singularly wild and pieturesque, in many places all 
but inaccessible and frequently concealed by dense foliage. I explored its course for some distance up into the pine-region and down almost into the valley, the region of the vine, and could almost fancy myself to be scrambling along one of the wilder branches of the Derwent. I found my old friend the Dipper breeding exactly as if he were in Derbyshire, and kecping him company was my special favourite the Grey Wagtail. The nests of the latter were in similar situations to those I have described, but the materials slightly varied. Moss and soft grass took the place of roots, and the lining of hair was very thick, as if to protect the young birds from the night air, which is much colder in the Parnassus than in Derbyshire. Of one nest I noted down at the time that it was profusely lined with black goat's hair, but that the bird followed the Derbyshire fashion of a final lining of white hair. I obtained several nests of fresh-laid egors in the middle and end of May; but these appeared to be second broods, as I shot several young birds of the year. Dr. Krüper told me that the migrations of the Grey Wagtail in Grecce are similar to those of our English birds. In summer it frequents the mountain-gorges, and in winter is found on the banks of the streams in the valleys.

The eggs of the Grey Wagtail are five or six in number, generally five, and may be divided into two distinct types-one in which the groundcolour is pale French grey mottled with light brown, and the other of a much warmer tint, more nearly approaching cream-colour, mottled and spotted with a much richer brown. On many specimens there are one or two rich dark brown, almost black, streaks on the large end. 'The eggs vary in length from $\cdot 79$ to $\cdot 65 \mathrm{inch}$, and in breadtỉ from $\cdot 59$ to $\cdot 54$ inch. It is extremely difficult to distinguish the cggs of this bird from those of the Yellow Wagtail or the Blue-headed Wagtail; but those of the Grey Wagtail are, on an average, slightly smaller. The Grey Wagtail rear's two broods in the year, the second, according to Macgilliviay, being abroad in July. The male relieves the female in the duties of incubation.

The song of the Grey Wagtail, like that of its congeners, is mot very often heard, but it resembles very much the twittering of a Swallow. Its food, which is sought for both in the air and on the pebbly shores of its favourite waters, consists principally of insects, small beetles, and freshwater mollusca. In autumn the young birds and their parents form little family-parties, which often keep together far into the winter. At this season the bird often repairs to the neighbourhood of the coast, following the river from its mountain-sources to its junction with the sea. The Grey Wagtail is perhaps more often seen in trees than any other species of British Wagtail; it seems to prefer to alight in them, and, in spring especially, its monotonous call-note is heard incessantly from the branches.

The adult male Grey Wagtail, in full breeding-plumage, has the general colour of the upper parts slate-grey, darkest on the head, and shading into 
greenish yellow on the rump and upper tail-coverts; the wings and wingcoverts are blackish brown, the latter with pale margins; the secondaries, including the immermost, with the basal half white and the outer web of the latter margined with buffish white; the six centre tail-feathers are brownish black margined with greenish yellow, the outermost feather on each side white; the next two with the immer web white, but the greater portion of the outer web brownish black; a narrow white eye-stripe extends from the base of the bill to about half an inch bchind the eye, and another stripe of the same colour extends downwards from the base of the lower mandible along the sides of the throat and the upper breast, which are black; the remainder of the underparts are canary-yellow. Bill black; legs, feet, and claws brown ; irides dark brown. The female closely resembles the male, but is rather duller in colour, and generally has the throat nearly white; but occasionally more or less dark brown feathers appear, principally on the sides.

After the autumn moult there is very little difference between the sexes; the upper parts are slightly suffused with olive, and the throat and upper breast are white. Young in first plumage and birds of the ycar closely resemble their parents in winter plumage; but the upper parts are suffused with sandy brown, and the eye-stripe and the underparts are suffused with buff. After the spring moult, when the black throat is assumed, each black feather has a white margin, broad in males of the year, but narrow in adults. In the latter these margins disappear almost entirely during summer.

The Grey Wagtail of both sexes, and at every age and season, may be distinguished from all the other British Wagtails by its uniting the characters of a grey back with a green rump and upper tail-coverts. It has no very close ally; but its nearest relation is probably $M$. flaviventris, from Madagascar, which difiers in having the black on the throat confined to a crescentic gorget, and in having the upper tail-coverts black.

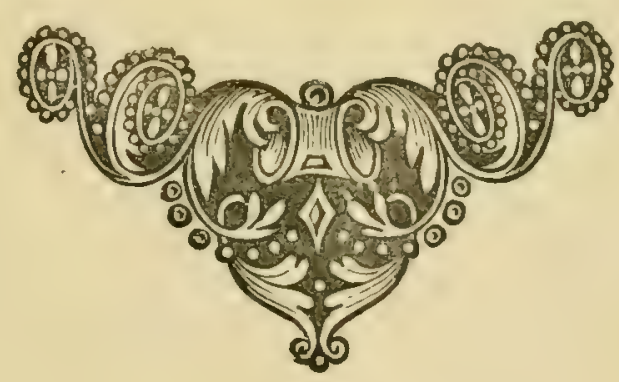




\section{MOTACILLA FLAVA. BLUE-HEADED WAGTAIL.}

(Plate 14.)

Ficedula motacilla verna, Briss. Om. iii. p. 468 (1760).

Motacilla flava, Limn. Syst. Nat. i. p. 331 (1766); et auctorum plurimorumGmelin, Latham, Naumann, Temminck, (Salvadori), (Degland \&. Gerbe), Newton, Dresser, \&c.

Motacilla boarula, Scop. Ann. I. Hist. Nat. p. 154 (1769).

Parus luteus, S. G. Gmel. Reise, iii. p. 101, pl. 20. fig. 1 (1774).

Motacilla campestris, Pall. Reise Russ. Reichs, iii. p. 696 (1776).

Motacilla chrysogastra, Bechst. Naturg. Deutschl. ii. p. 406 (1807).

Motacilla flarescens, Steph. Shaw's Gen. Zool. x. p. 559 (1817).

Motacilla bistrigata, Raffes, Trans. Linn. Soc. xiii. p. 312 (1821, partim).

Motacilla flaveola, Pall. Zoogr. Rosso-Asiat. i. p. 501 (1826).

Budytes flarus (Linn.), Brehm, Vög. Deutschl. p. 344 (1831).

Budytes beema, Sykes, Proc. Zool. Soc. 1832, p. 90.

Motacilla neglecta, Gould, Proc. Zool. Soc. 1832, p. 129.

Motacilla flara, var. vulgaris, Sundev. Vet. A\%. IIandl. 1840, p. 53.

Budytes gouldi, Macgill. AIan. Brit. B. i. p. 163 (1840).

Budytes schisticeps,

Budytes dubius, $\}$ Hodgs. Gray's Zool. Misc. p. 83 (1844).

Budytes anthoides,

The first British ornithologist who appears to have discovered that the Yellow Wagtail of our islands was distinct from the "Gelbe Baclistelze" of Germany was Gould, who as long ago as 183:2 pointed out the difference between the two species. Two years later Doubleday shot an example of the continental species at Walton-on-the-Naze, and since then it has been frequently observed in various parts of the country.

The Blue-headed Wagtail is chiefly known as an accidental straggler on migration to our islands. It is usually found in the southern, southwestern, and castern counties of England, generally in the spring or early summer. Nests of this species have been found near Gateshead, and doubtless it breeds in several other localitics. It is a much rarer visitor to Scotland, only one or two specimens laving been recorded; and Saxby states that it has been observed late in autumn in Shetland. Although not known to 'Thompson, it has been ascertained to occur' in Ireland by Mr. Blake Knox. It is said to have been twice found on the Faroes.

The Blue-headed Wagtail, subject to some local variation, has by far the largest area of geographical distribution of any species in the genus, extending from the British Islauds across Europe and Asia at least as far as the Rocky Mountains of America. It is common across the Channel, and is found in Scandinavia south of lat. $60^{\circ}$, which appears also to be the 
northern limit of its range in Russia. In Western Europe it is found down to Gibraltar, and crosses the straits into Tangiers; but in Eastern Europe it does not breed so far south. It passes through South Russia, Greece, and North-east Africa on migration, and winters in South Africa, whence it has been received from Damara Land, Natal, and the Transvaal. In Asia it is said to have about the same range to the north, but in Alaska it breeds up to lat. $64^{\circ}$. It breeds throughout South Siberia, Mongolia, and North China, wintering in India and Burma. In Turkestan it is ouly known on migration. It is doubtful whether it has occurred in Persia, but it breeds in the Caucasus. The Asiatic form, to which Pallas gave the name of Motacilla flaveola, differs slightly from the European form. The green on the back is yellower; the white on the chin extends to the upper throat and more or less to the ear-coverts; the grey on the head is paler and bluer, and on an average the tail is slightly shorter. At most it can only claim subspecific rank, as many examples from Eastern Europe and Western Asia are intermediate. A more marked local race, which may possibly be specifically distinct, is resident in the island of Formosa and on the adjoining mainland of China, and is distinguished by its canaryyellow eye-stripe. The olive-green of the back is slightly darker than in European examples, and also replaces the slate-grey of the head. Swinhoe named this form M. taivanus; but as Dybowsky found two examples near Lake Baikal, and Meves obtained one near Stockholm, its specific distinctness can scarcely be regarded as established. An Arctic form of the Blue-headed Ycllow Wagtail, M. cinereocapilla, breeds in North Europe and Asia, between lat. $63^{\circ}$ and $68^{\circ}$, passes through Central and Southern Europe on migration, and winters in Africa somewhere south of Abyssinia. A colony of these birds also breeds in the Lombard Alps. The Asiatic birds pass through Turkestan and China on migration, and winter in India, Ceylon, and Burma. This form lias not yet been recorded from the British Islands, although it was erroneously inserted in the British fauna by Mr. Gould. It differs in having no eye-stripe, and in having the lores and ear-coverts nearly black. A tropical form, M. melanocephala, also with no eye-stripe, and having the crown as well as the ear-coverts and lores black, is a summer visitor to Italy, Grecce, Asia Minor, the Caucasus, Persia, and Turkestan. The European birds winter in Nortlieast Africa, where a few remain to breed; whilst the Asiatic birds pass the cold season in India. Intermediate forms between this bird and both $M$. flava and $M$. cinereocapilla occur, so that probably none of them are specifically distinct.

The Blue-headed Wagtail is strictly a migratory bird in Europe, and does not reach the southern shores of the German Ocean until April, a month later than the arrival of the White Wagtail in the same locality, and long after the Yellow Wagtail has found its way to our islands. The

VOL. II. 
last Wagtail to arrive, it is the first to leave, most of them having disappeared by the middle of September. Every meadow in IIolland abounds with these charming little birds, rmming along the banks of the dykes or among the grazing cattle, and occasionally perching on the wooden boundary-posts, whence they will suddenly take wing to catch a passing fly. But perhaps their beauty is seen to still greater advantage on the marshy banks of the lower Danube, where the brilliant sunshine gilds the deep rich yellow of their breasts as they sit on the top of a willow or tall thistle, or other rank herbage which flowrishes in this semi-tropical climate, displaying the white outside feathers of their quivering tails as they balance themselves on their uncertain perch.

The habits of the Blue-headed Wagtail are very similar to those of the other Wagtails. It is partial to swamps, and frequents wet grass-lands, especially meadows containing cattle. In these situations it may be seen ruming hither and thither, incessantly beating its tail up and down, and feeding in the same manner as the other Wagtails. Its flight is also performed in a succession of droops or long curves.

The song of this bird, like that of its congeners, is scarcely more than a musical twitter. Its common call-note is a chit-up, similar to that of the Yellow Wagtail, but certainly shriller than that of the Pied Wagtail. It has also a prolonged plaintive double note, occasionally heard when the bird is perched. The food of the Blue-headed Wagtail is composed of insects, beetles, small freshwater mollusca, caterpillars, and grubs.

The Blue-headed Wagtail is a rather late breeder, and its eggs are seldom laid before the middle or latter end of May, often not until the beginning of June, so that probably one brood only is reared in a season. The nest is built on the ground, and is generally well concealed amongst rank herbagc. A bank is a favourite situation, beneath a tuft of grass or amongst the gnarled and half-exposed roots of trees standing in open fields. The nest is made of dry grass, rootlets, and scraps of moss, and lined with fine bents, hair, and sometimes a little wool, and more rarely a few feathers. The eggs are from five to six in number, yellowish white or pale bluish white in ground-colour, mottled, spotted, freckled, and clouded with pale brown, and sometimes streaked on the larger end with rich blackish brown. They vary in length from 83 to .73 inch, and in breadth from 59 to . 53 inch. Many of the eggs of this bird are absolutely indistinguishable from those of the Yellow Wagtail and the Grey Wagtail.

The Blue-headed Wagtail often joins flocks of the Yellow Wagtail, and there can be no doubt that the two birds often keep company during winter. The most northern birds generally quit their haunts in August and September, retreating slowly southwards.

The adult male Blue-headed Wagtail in breeding-plumage resembles the other British Wagtails in the colour of the wings, wing-coverts, and tail. 
The general colour of the rest of the upper parts is yellowish grecn, shading into greenish brown on the upper tail-coverts, as in the Yellow Wagtail; but, unlike that bird, the forehead, crown, nape, ear-coverts, and lores are slate-grey, with a conspicuous white eyc-stripe. There is no difference in the colour of the soft parts or of the underparts; but the brilliant yellow of the latter often shades into white on the chin and upper throat. The female has the head greenish brown, with a white cye-stripe; the yellow of the underparts is not so brilliant, and the breast is more or less mottled with brown. The male of the year scarcely differs from the female; but in the adult male after the autumm moult the slate-grey of the head may be detected under the brownish green.

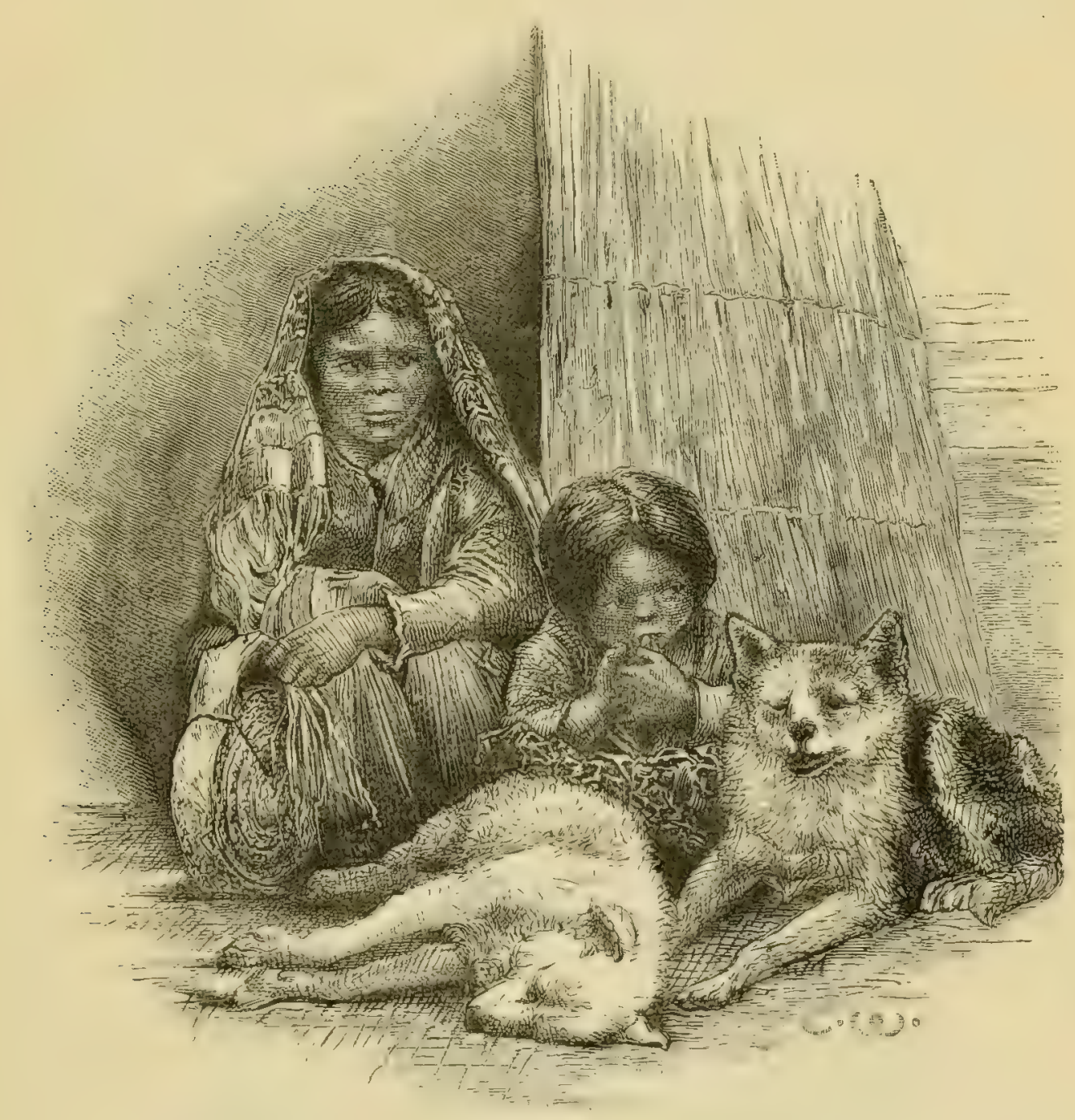




\title{
MOTACILLA RAII.
}

\section{YELLOW WAGTAIL。}

\author{
(Plate 14.)
}

\begin{abstract}
Motacilla flava, Linn. apud Donovan, Hist. Brit. B. i. pl. xv. (1794).
Budytes flavissima, Blyth, Mag. Nat. Hist. vii. p. 342 (1834).

Budytes flava (Limn.), apued Eyton, Cat. Brit. B. p. 15 (1836).

Budytes rayi, Bonap. Comp. List B. Eur. and N. Amer.p. 18 (1838); et auctorum plurimorum-Yarell, (Degland), (Gerbe), (Macgillivray), Gray, Dresser, Nevoton, \&c.

Motacilla flava, var'. anglica, Sund. Vet. Ak. Handl. Stocki. 1840, p. 53.

Motacilla flava rayi, Schlegel, Rev. Crit. p. xxxviii (1844).

Motacilla anglorum, Florent Prévost, fide Degl. Orn. Eur. i. p. 442 (1849).

Budytes rayi, var. flavifrons, Severtz. Turk. Jevotn. p. 67 (1873).
\end{abstract}

The Yellow Wagtail is a summer visitor to the British Islands, but only appears to pass the Chamnel Islands occasionally on migration. It is commonly distributed in England, except in the extreme south-west. In Scotland it is most common in the southern countics; but it breeds sparingly in Inverness and Aberdeen, and has been met with in Sutherlandshire. It has occurred several times in Orkney, and is a rare straggler in autumn to the Shetlands. In Ireland it is only known to breed in one locality, Lough Neagh; but has occurred as a straggler in other places.

On the continent of Europe it breeds in the north of France, passes through the south of France, Spain, and Portugal on migration, and occasionally strays into North-west Italy, in all of which districts it is possible that a few remain to breed. In Africa it has been found in winter as far south as the Transvaal on the east coast, and has occurred in Gambia, the Gold Coast, and the Gaboon on the west. An isolated colony appears to exist in South-east Russia and West Turkestan.

The Yellow Wagtail has no very near ally with which it is likely to be confused. From the green-headed variety of Motacilla flava found on Formosa it may at once be distinguished by the colour of its ear-coverts, which are yellow or yellowish green instead of greenish brown.

The Yellow Wagtail bears the same relation to the Blue-headed Wagtail that the Pied Wagtail does to the White Wagtail. There is scarcely any difference between the two former birds, except in the colour of the head. It would be impossible to say to which species an albino of either of them belonged. Their habits are precisely the same, and their nests and eggs are inclistinguishable. Their favourite haunts scarcely differ. A meadow amongst the Norfolk Broads is, or used to be, an almost exact duplicate in 
its bird-life of a meadow amongst the Dutch dykes, except that in the former the commonest bird is the Yellow Wagtail, and in the latter the Blue-headed Wagtail. The Yellow Wagtail is the island form of the Blueheaded Wagtail; but unfortunately the hypothesis which seems to explain the relative positions of the Pied and White Wagtails will not account for the existence of the Yellow Wagtail in Britain. The Yellow Wagtail is an eastern bird; its gcographical distribution, like that of the White Wagtail, presents the anomaly of a discontinuous area. The true home of the Yellow Wagtail is in the basin of the Caspian Sea, and the colony in Great Britain appears to be comparatively small and isolated. Two explanations of this remarkable geographical distribution present themselves. So far as is known, the birds from both districts winter only in Africa, south of the Great Desert. From this vast winter home of so many Palnarctic birds it is well known that there are two great streams of migration, one reaching Great Britain and the other Central Asia. It is possible that, in some distant age, a large body of Yellow Wagtails took the western instead of the eastern line of migration, and finding a suitable breeding-ground in the British Islands, returned thither every succeeding year : or we may imagine that an emigration of Yellow Wagtails from Turkestan, similar to the great emigration of Pallas's Sand-Grouse from the same district in 1863, reached our islands before the Blue-headed Wagtail had crossed the Channel in any numbers. The latter theory is supported by the fact that even at the present time stragglers occur on this route, and occasionally are captured on the island of Borkum, as well as on Heligoland.

This common and graceful little bird is one of the first to make its appcarance in spring. It arrives early in March in England, but does not appear to reach its Scotch haunts before April. The Wagtails yield the palm of gracefulness to none of the fenthered tribes, and the present species is one of the most graceful. Its active sylph-like movements and its delicate form and lovely plumage make it a general favourite. It is found in well-cultivated districts, in pastures, open downs, sheep-walks, and commons. Early in the year, immediately after its arrival, it often frequents the open country near the sea on the lowlying coasts; but the locality in which it may always be found at this season is the fields where spring sowing is going on. From this fact observant countrymen have given it the local name of "Sced-bird;" and in Scotland it is known by the name of "Seed Lady."

The Yellow Wagtail is fond of associating with cattle. In summer almost every ficld, in its accustomed haunts, where cattle are grazing, is tenanted by a pair of these birds. They daintily run amongst the grazing animals, round their legs, under their bellies, and often within a few inches of their mouths, all the time searching busily for the insects which are so 
troublesome to the cows, the sheep, and the horses. Its actions are precisely similar to those of the other Wragtails. It possesses the same active movements, its tail is also incessantly beating up and down, and it runs about with the same marvellous speed, and repeatedly flies into the air to catch passing insects. It is not at all a shy bird, and shows great agility in picking insects from the tall grass-stens, often fluttering up to the top of a stalk to take them from a flower.

The Yellow Wagtail follows the plough with as much perseverance as the Rook, often approaching within a yard of the ploughman, rumning up and down over the rugged upturned ground, every now and then taking a short flight to another part of the field, where its useful labours are resumed. It is not at all of a wandering disposition, and when once it makes its appearance on a pasture it usually remains there until its broods are safely reared. It often alights in trees; but is not so frequently secn on the roofs of buildings, for it secms to prefer the open fields rather than the neighbourhood of houses, although I have often seen it near country railway-stations.

The song of the Yellow Wagtail is a short and lively little strain, something like that of the Pied Wagtail. Dixon thus writes of it:- "In the breeding-season this bird is occasionally heard to sing. Only occasionally is his melody given forth. No moruing or evening lay escapes from this Wagtail, and his notes are uttered seemmgly in sudden outbursts of gladness. Suddenly, and as it were by resistless impulse, he soars from the meadow-grass, and, fluttering in the air, warbles a delightful strain and alights, probably to remain silent for days ere another thrill of gladness causes him to carol forth anew." Its call-note is a double one, a shrill and sharply-uttered chit-up. This note is almost invariably uttered as the bird takes wing. The flight of the Icllow Wagtail is, like that of all the Wagtails, very undulating, performed in large and equal curves; and when the bird alights it usually spreads out its tail like a fan.

The Yellow Wagtail pairs annually, a little after its arrival in spring. It is, however, possible that many pairs never separate; for some often return yearly to their old haunts, and the pairing which takes place in spring may be confined to the young birds, or to those that have lost their mates. It is rather an early breeder, and the nests destined for the use of the first broods are usually made by the middle or third week in A pril, and the young birds may often be noticed abroad by the latter cud of May. The nest is always built upon the ground, generally in a well-sheltered situation, and concealed by a clod of turf or a clump of herbage. Sometimes it is built in the tall grass at the foot of a rough stone wall bordering a grain-field; at others it is on a mossy bank gay with spring flowers, and clothed with a luxuriant growth of herbage. The materials of which the nest is composed viry according to the locality; externally 
it is generally made of dry grass or twitch. Mr. J. Cullingford writes to me respecting the nest of this bird in South Lincolnshire:-"This is a bird whose nest varies very much, and scarcely ever do you find two nests made of the same materials, even if within fifty yards of each other. I have had some lined with feathers, some with hair, and some with roots." The eggs are five or six in number, greyish white in ground-colour, very thickly mottled and speckled with pale brown or olive-brown, often so thickly as to hide all traces of the ground-colour. Many specimens have one or two rich blackish-brown streaks on the larger end. The eggs in a clutch in my collection from Hickling Broad are suffused with a delicate rosy tinge. Many of the eggs of this bird cannot with certainty be distinguished from those of the Serge-Warbler, and it is absolutely impossible to separate them from those of the Blue-headed Wagtail. They vary in length from 82 to .73 inch, and in breadth from 63 to 55 inch. The young are tended by the old birds for a short time after they leave the nest, when they are left to take care of themselves, and their parents rear a second brood, always building a fresh nest for the purpose.

The Yellow Wagtail feeds on insects, grubs, and small worms; it also eats a considerable number of small beetles, for it scems to search the stems and leaves of vegetation more closely than its congeners do. It may also be seen repeatedly amongst the droppings of the cattle-places where considerable numbers of beetles may be found. In spring it searches eagerly for larvæ of different kinds.

When the second broods are capable of taking care of themselves, Yellow Wagtails often congregate into flocks of considerable size and wander away from their usual haunts. In autumn numbers of these birds may be seen at the mouths of tidal rivers, doubtless following the stream to the sea. These flocks have congregated for the purpose of migrating to their winter-quarters. Many birds leave us in September; others remain lingering in seductive haunts until October ere they pass southwards. It is, however, a fact that this bird does not entirely quit our shores in winter. Dixon has repeatedly seen it in the depth of winter in the hardest weather, frequenting the banks of rumning strcains; and when the snow has been lying inches decp, he has noticed this gay little bird tripping over the frosted surface apparently as much at ease as if on the summer pastures. Macgillivray states that it leaves Scotland about the middle of August. It is very common on the south coast at the periods of migration, probably crossing the channel at its narrowest part.

The aduit male Yellow Wagtail in breeding-plumage has the general colour of the upper parts yellowish green, brightest on the forehead and darkest on the upper tail-coverts; the wings, wing-coverts, and tail scarcely differ in colour from those of the other British Wagtails. A streak over the eye 
and the entire underparts are bright yellow. Bill, legs, feet, and claws black; irides hazel. The female is much browner above and paler helow than the male, and the eye-stripe is buffy white; the wing-bars are also much less distinct and buffy white. Birds of the year have the upper parts similar to the female, but browner, the throat is buffy white tinged with yellow, the breast is brownish buff, and the remainder of the underparts are pale ycllow. After the autumn moult the old birds resemble the young somewhat, but are without the dark band across the breast. A very important character of this species is that the ear-coverts and lores are pale yellowish green, like the crown.

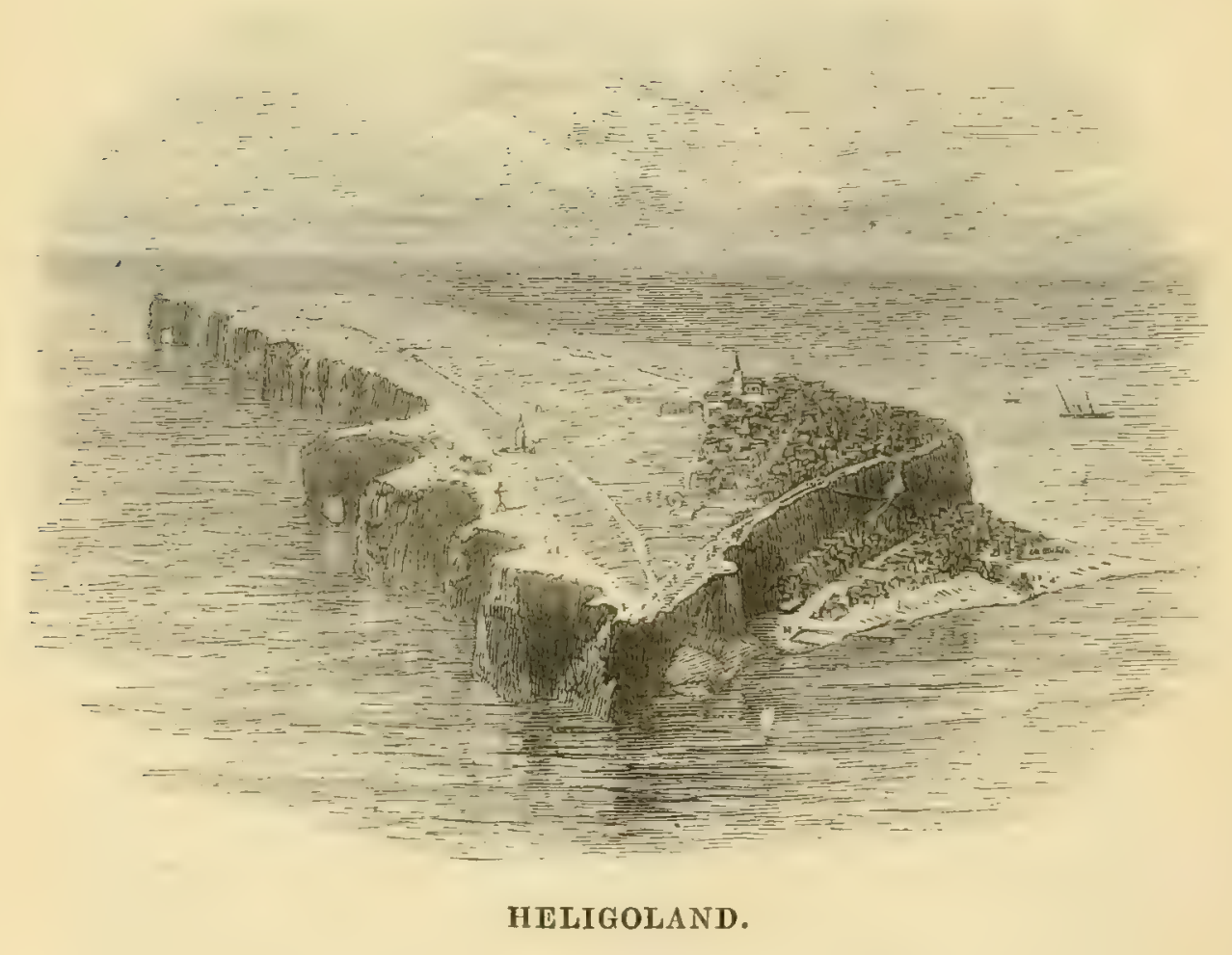




\section{Genus ANTHUS.}

Linnæus and some of the other earlier ornithologists included the Pipits amongst the Larks in the genus Alauda. Bechstein appears to have been the first writer who separated them from this genus. In the second edition of his 'Naturgeschichte Deutschlands' (published in 1807), vol. iii. p. 704, he established the genus Anthus, placing the Meadow-Pipit as the first species of his new genus. This bird has consequently been generally accepted as the type.

There are no structural characters by which the Pipits may be distinguished from the Wagtails, and even in the pattern of colour they have many characters in common. In both genera the bills are slender and insectivorous. The Wagtails generally have dark feet, and the Pipits pale feet; but in both genera the hind claw is sometimes short and much curved, and sometimes long and only slightly curved. The general colour of the upper parts varies in the Wagtails from brownish green to slategrey and black, whilst in the Pipits it is always brown of some shade, either greenish or sandy. In the Pipits the head is generally of the same colour as the back, and the feathers of both have more or less conspicuous dark centres; whilst in the Wagtails the head is often quite different in colour from the back, but cach feather of both is uniform in colour. The pattern of colour of the wing is nearly the same in both genera. The Pipits have the quill-feathers a uniform brown, without the white bases which are often found in the Wagtails; but in both genera the outside webs have narrow pale edges and the inside webs broad pale edges. In both genera the wing-coverts and innermost secondaries are darker than the quills, the median wing-coverts have pale tips, and the greater wingcoverts and innermost secondaries pale margins to the outside webs. In both genera the two centre tail-feathers are generally concolorous with the back, and the rest very dark brown, with the exception of the two outermost on each side, which are almost wholly white in the Wagtails, but vary much in this respect in the Pipits. The underparts of the Wagtails are either white or yellow, shading into brown or grey on the flanks, with black on the throat or breast in some species, but spotted on these parts only in the young; whilst the underparts of the Pipits are uniform light or dark buff, darkest on the flanks, occasionally without spots in the adult, but often streaked on the sides of the throat and across the breast and along the flanks in the adult, and 
always so in the young. The Pipits always have a pale eye-stripe, but the Wagtails vary in this respect.

The Pipits being so constant in their pattern of colour, it is not necessary to give a long detailed description of each species, which would only confuse the student. All that is necessary is to point out the specific character's of each.

This genus contains about forty species, and may be practically regarded as cosmopolitan, being only unrepresented in the Polynesian subregion, which consists of all the tropical islands in the Pacific. Seven species breed in Europe, and two others are occasional visitors. Three only breed in the British Islands; but four others accidentally visit our shores.

In their habits the Pipits do not differ much from the Wagtails. They frequent most kinds of scenery, the well-cultivated districts, the uplands, the rocky coasts, mountains, and broad plains. They are moderate songsters, but differ considerably in this respect. Their nests are always placed on the ground, and are made of dry grass, hair, roots, \&c.; and the eggs are from five to six in number. The ground-colour is generally almost concealed by a profusion of markings of various shades of brown. Their flight is rapid and undulating, and most of the species sing on the wing. They are partly insectivorous and partly granivorous.

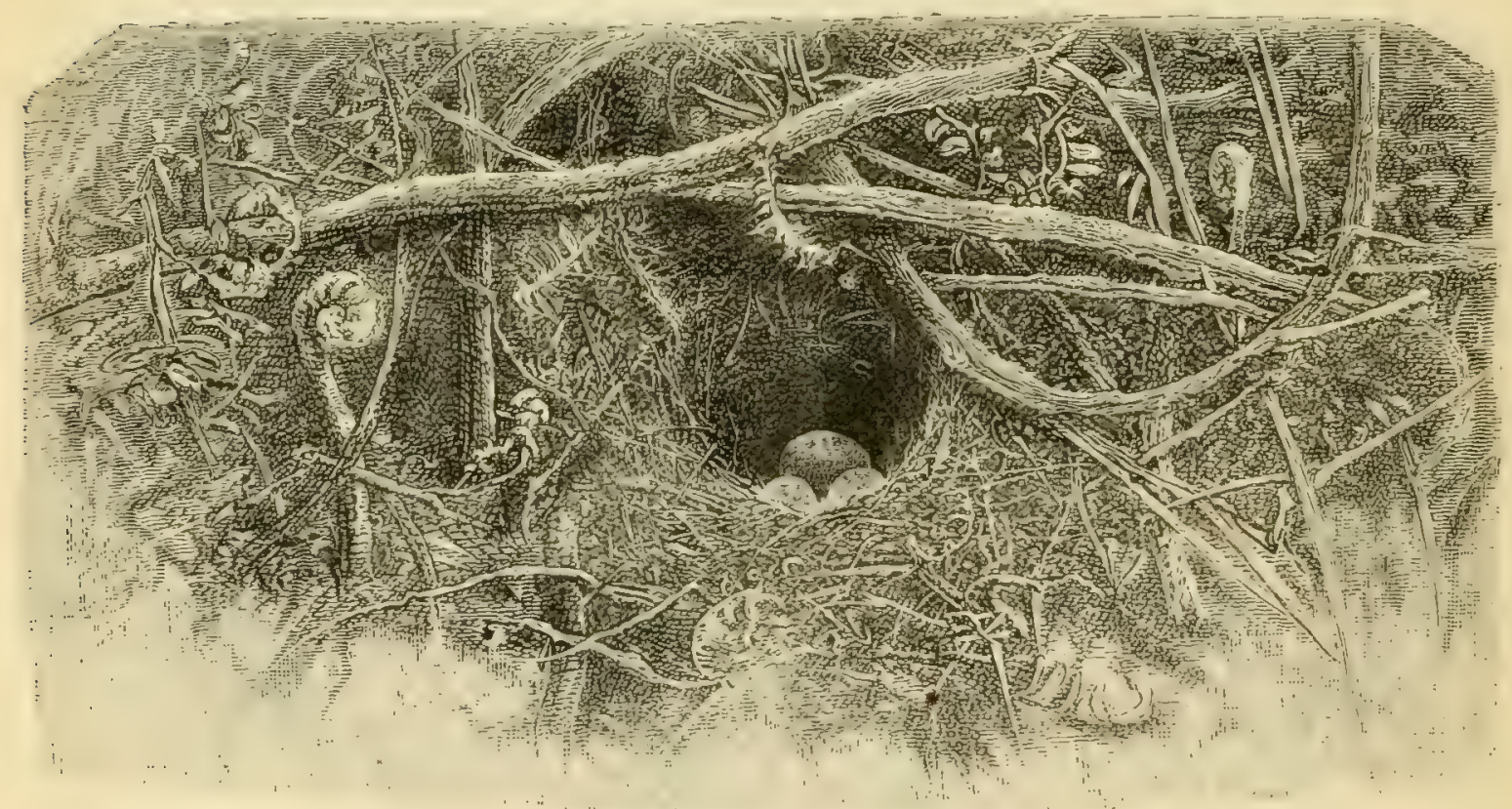

MEADOW-PIPIT'S NEST. 


\title{
ANTHUS ARBOREUS.
}

\section{TREE-PIPIT.}

\author{
(Plate 14.)
}

Alauda arborea, Briss. O'n. iii. p. 340, pl. xx. fig. 1 (1760); et auctorum plurimorum-(Temminck), (Naumann), (Degland \& Gerbe), (Bonaparte), (Salvadori), (Gray), (Stevenson), (Macgillivray), (Savi), (Jerdon), (Tristram), (Godman), (Hume), (Severtzow), (Goebel), (Krï̈per), (Sachse), \&c.

Alauda trivialis, Linn. Syst. Nat. i. p. 288 (1766).

Alauda plumata, Miill. Natursyst.p. 187 (1776).

Alauda minor, Gmel. Syst. Nat. i. p. 793 (1788).

Spipola agrestis, Leach, Syst. Cat. MLamm. \&.e. Brit. Mus. p. 22 (1816).

Motacilla spipola, Pall. Zoogr. Rosso-Asiat. i. p. 512 (1826).

Anthus trivialis (Limn.), Fleming, Brit. An. p. 75 (1828).

Pipastes arboreus (Briss.), Kaup, Nutiirl. Syst. p. 33 (1829).

Anthus agilis, Sykes, Proc. Zool. Soc. 1832, p. 91.

Fringilla agilis (Sykes), Tickell, Journ. As. Soco ii. p. 578 (1833).

Dendroanthus trivialis (Linn.), Blyth, Cat. B. Mus. As. Soc. p. 135 (1849).

Pipastes agilis (Sykes), Gould, B. Asia, part xvii. (1865).

Pipastes montanus, Blyth, Ibis, 1867, p. 312.

Anthus plumatus (Miill.), Shelley, B. Egypt, p. 130 (1872).

Pipastes plumatus (Miill.), Hume, Stray Feathers, 1873, p. 202.

The Tree-Pipit is a summer migrant to our islands and is very widely distributed. It is found commonly in all suitable localities in England with the exception of the extreme south-west, but becomes far less common in Wales. It also breeds in the Channel Islands. In Scotland Gray remarks that the only place in which he found this species at all abundant was within a few miles' radius of Glasgow, although it is distributed from Inverness to Galloway, but nowhere in great numbers. On the east coast he remarlis that it is dispersed from Berwick to Banffshire, and is also found in some of the inland counties. It occasionally wanders as far as the Orkncys, but does not appear to have been noticed in Shetland. In Ireland the Tree-Pipit is a very rare species, although it is quite possible that it has been overlooked. Thompson had no satisfactory evidence of its occurrence there; nor was it with certainty detected until Mr. C. W. Benson met with a pair on the north side of the city of Dublin ('Zoologist,' 1878, p. 348). In the same periodical for the same year (p. 454), $M_{1}$. H. Chichester Hart, in referring to the above, states that he found a nest near Raheny, co. Dublin, about thirteen years previously, which, there can be little doubt, belonged to this species.

The Tree-Pipit, like many other Palearetic birds, has two forms, an eastern and a western, which meet together in the valley of the Yenesay. 
Newton and Dresser regard them as one species; but in autumn plumage the two birds are very distinct. The eastern form, $A$. maculatus, has the general colour of the upper parts very much greencr, and the dark centres of the feathers of the back are almost obsolete. In spring plumage they resemble each other very closely, and in summer much more so-a fact which has given rise to much confusion between them. It is not known that any intermediate forms occur.

The Tree-Pipit breeds in Northern and Central Europe, and in Western Sibcria as far cast as Krasnoyarsk. In Norway it exteuds as far north as lat. $69^{\circ}$, in the valley of the Petchora to about lat. $65^{\circ}$, and in the Ural Mountains and the valley of the Yenesay to lat. $62^{\circ}$. South of these limits it is a summer visitor throughout Europe north of the Pyrences and the Balkans, and eastwards throughout Turkestan as far as the Altai Mountains. In Spain, Portugal, and Italy it is principally known as a winter visitor, but a few remain to breed on the mountains. It passes through Greece and Asia Minor on migration, and winters in Palestine, Egypt, Nubia, Abyssinia, and Algeria, and has been recorded from Africa as far south as Caffreland. The eastern Tree-Pipit breeds throughout Siberia south of lat. $62^{\circ}$ and east of Krasuoyarsk. It also breeds in Japan. It passes through Mongolia on migration, and winters in China, Burma, and India.

Although the Tree-Pipit bears a very close resemblance to the MeadowPipit, it may generally be distinguished, even on the wing, by its slightly longer tail and larger size. The Meadow-Pipit does not perch much on trees, hence its hind claw is long and comparatively straight, whilst that of the Trec-Pipit is short and curved to enable it to perch securely on the branches. In spite of these distinctions, and the great difference in the haunts and the eggs of the two birds, they were very often confused together by carly ornithologists. So far as is known, the TreePipit was first distinguished from the Meadow-Pipit by Francis Jessop, of Shefficld, who carefully pointed out the differences between the two species to Mr. Willughby, in whose 'Ornithologia' it appeared under the name of Lesser Field-Lark. Both species are still common within half an hour's walk of Jessop's old residence, which is still known by the name of Broomhall.

The Tree-Pipit arrives in the southern parts of England during the second or third week of April, a week later in Yorkshire, and in the south of Scotland not until the beginning of May. Mr. Cordeaux has observed it in North Lincolnshire on two occasions as carly as the 5th of April. It is a woodland bird, and is fond of open pieces of forest-land well studded with old trees intermixed with birches. It is also very partial to the outskirts of woods, and is especially common in ficlds where there are tall trees in the hedges. It is rarely seen in bare and exposed tracts of 
country, and is common near houses and in parks. Soon after its arrival in its breeding-haunts the cock bird devotes the greater part of his time to his charming and characteristic song. It is a very beautiful sight in carly spring to watch the Tree-Pipit essaying his short flight on his arrival from a warmer climate. He springs up from the topmost twig of some branch, and mounts nearly perpendicularly into the air, warbling his pretty song. He soon begins to hover in the air, and, as if fatigued by his recent journey, almost immediately descends, with tail and wings expanded like a parachute, and at last finishes his song on the ground, in a tree, or on a wall. His downward course is in a semi-spiral curve, and be alights where the curve of his flight would make a tangent to the surface of the ground. All this time he has been singing melodiously, the clear, rich, joyous motes following each other in rapid succession until, as he reaches his perch, he concludes his song with several long-drawn notes, expressive of almost impatient anxiety. These plaintive notes may be expressed by $t$ see- $a$, tsee- $a$, tsee- $a$. If the season be not far advanced he will often glide from one tree to another, singing as he goes; and thus he continues soaring and warbling the whole day through, occasionally visiting the ground for food or fluttering after a passing insect like a Flycatcher. The Tree-Pipit often warbles on his perch; but Dixon has noticed that he does not utter the long-drawn concluding notes unless in the air. The Tree-Pipit continues his song until the moulting-season commences, in the middle of July; it may be heard at all hours of the day, and sounds particularly charming after a summer shower. Its call-note bears some resemblance to that of the Greenfinch, and the alarm-note is a sharp and oft-repeated tick, tick.

When once the Tree-Pipit has paired, which it does usually by the end of April, it rarely strays far from its haunt all the summer. It gencrally selects some tree as a starting-place for its song-flights, and may be scen there during the whole breeding-season. It is not improbable that this bird pairs for life; and in some localities a pair of these birds will be found every season for years in succession, the same favourite tree being returned to with unfailing certainty. The nest is always built on the ground, generally amongst herbage, sometimes on a bank in a wood, and often in the grass or corn-fields, fifty yards or more from the hedge. Sometimes a site is selected on a bluebell-covered bank in a secluded lane, or in a littleused cart-road, or beside a "drive" in a wood. The nest is usually made in a little hole, often excavated by the parent birds, and is constructed of dry grass, moss, a few rootlets or a tuft or two of twitch, and is lined with finer grass and a little horsehair. Some nests are much more elaborately made than others, and sometimes dry grass forms the whole structure. It is moderately deep and well rounded, and does not differ much in gencral appearance from the nest of the Meadow-Pipit. 
The eggs of the 'Tree-Pipit are from four to six in number', and differ so much that it is almost impossible adequately to describe their variations. The eggs in each clutch are nearly alike, and it is most probable that each bird lays a peculiar type, which it has inherited from its parents and transmits to its offspring. The eggs of this bird may be classified into two groups-one in which the spots are very small and so profusely scattered over the surface as almost entirely to conceal the ground-colour, frequently becoming confluent at the large end; the other in which the spots are bold blotches and streaks, principally confined to the large end of the egg, leaving the rest of the ground-colour distinctly visible where the spots are smaller and further apart. Each of these two groups may again be subdivided according to colour, one extreme being pinkish white and the other pale greenish blue in ground-colour, the spots on the former being reddish brown and on the latter sometimes olivebrown and sometimes dark reddish brown. Between these extremes numerous intermediate varieties occur. The eggs vary in length from 9 to $\cdot 7$ inch, and in breadth from 65 to $\cdot 58$ inch. What purpose this great diversity of colour serves is hard to divine, but it is probably a protective one. Dixon has noticed that the darker-coloured eggs are generally found in nests in dark situations, as, for instance, under trees or by hedges, whilst those of lighter tints are found in the barest situations in the bright sunlight, and almost invariably in pasture-ficlds. The Tree-Pipit may sometimes rear two broods in the year; but this is by no means generally the case, for after the young are fledged they keep in company with their parents for a considerable time.

The Tree-Pipit is a very wary bird in approaching its nest, and rarely betrays its whereabouts. When visiting it the parent bird generally drops into the cover some distance from it, and runs through the grass to the nest. The female sits very closely, often allowing the mowers to pass their scythes over her ere she takes wing. During the whole time the female is engaged in incubation the male rarely wanders far from the nest. He keeps to his favourite tree, spending his time in song-flights, every now and then conveying food to his sitting mate. He also roosts on the ground near his nest; and when the young are able to fly they always roost amongst the herbage on the ground. In early autumn the TreePipits do not resort to the trees as much as in the carlier part of the year, and are never scen to engage in those soaring flights so characteristic of the bird in the breeding-season.

The food of the Tree-Pipit is largely composed of insects, picked up from the ground or from the stems of herbage. The bird may often be seen on the pastures near grazing cattle, turning over the droppings in seareh of little beetles; and its young are chicfly fed on catcrpillars, small worms, and flies. Upon the ground it is very active in its search for food, run- 
ning about like a Wagtail, but seldom so quickly. Dixon writes:- "In August, when the corn is soft and milky, and, indeed, up to the period of ripening, the Tree-Pipit is repeatedly scen amongst it. Formerly I was somewhat puzzled by the visits of several soft-billed birds to the corn-fields, and it was not until I had spent much time in observation and dissection that I discovered that these visits were for the purpose of feeding on the corn. The Tree-Pipit is one of the insectivorous birds most commonly found in corn-fields, and by exercising a little caution you may see it shelling out the wheat with as much dexterity as the Sparrow. This observation is also confirmed by the observant Macgillivray, who found in the stomach of a bird of this species husks of small sceds and a considerable amount of mineral fragments."

The Tree-Pipit congregates into little parties early in September, and leaves our shores by the end of the month or early in October; but a few linger still later, and examples have been shot in November.

The general colour of the upper parts of the Tree-Pipit in spring plumage is an almost neutral brown, and the dark centres of the feathers are well defined except on the rump; the general colour of the underparts is buffish white, which fades considerably during the summer; the spots on the breast are always well developed, but those on the flanks less so. Nearly half of the outside tail-feather is white, but that on the penultimate feather measures little more than half an inch, and in both the white is very slightly suffused with brown. Bill brown, paler at the base of the lower mandible; legs, feet, and claws pale yellowish brown, much lighter than those of the Meadow-Pipit; irides dark hazel. The tarsus is somewhat short, measuring less than an inch. The most important character in the Tree-Pipit is its short hind claw, which only measures ' 35 inch and is much curved. The female is scarcely distinguishable from the male. After the antumn moult the brown of the upper parts is somewhat richer in colour, and the breast is more decidedly suffused with buff. Birds of the year are somewhat more profusely spotted on the breast and flanks, which is still more the case with young in first plumage.

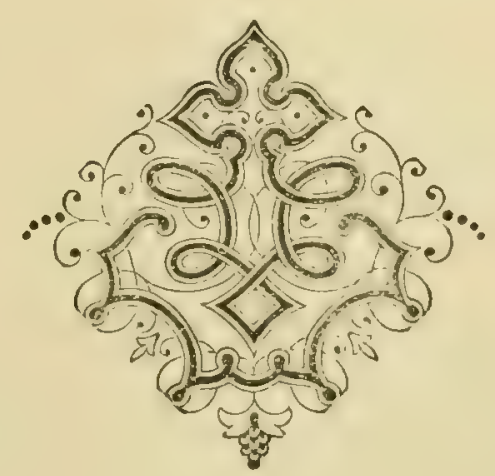




\title{
ANTHUS PRATENSIS.
}

\section{IMEADOW-PIPIT.}

\author{
(Plate 14.)
}

Alauda pratensis, Briss. Orn. iii. p. 343 (1760); Linn. Syst. Nat. i. p. 287 (1766); et auctorum plurimorum-Latham, (T'emminck), (Naumann), (Degland \& Gerbe), (Bonaparte), (Salvadori), (Dresser), (Newton), \&c.

Anthus pratensis (Briss.), Bechst. Orn. Taschenb. iii. p. 564 (1812).

Spipola pratensis (Briss.), Leach, Syst. Cat. Mamm. \&c. Brit. Mus. p. 21 (1816).

Alauda sepiaria, Briss, apud Steph. Shaw's Gen. Zool. x. p. 542 (1817).

Leimoniptera pratensis (Briss.), Kaup, Natiirl. Syst. p. 39 (1829).

Anthus tristis, Baill. Mém. de la Soc. d'émul. d'Abbev. p. 14 (1833).

Anthus communis, Blyth, White's Nat. Hist. Selborne, p. 261 (1850).

The Meadow-Pipit is common throughout the British Islands, including the Channel Islands, the Orkmey and Shetland Islands, the Hebrides, and St. Kilda, in all of which it is more or less a resident, merely shifting its quarters in winter from the mountains to the low-lying districts. It is also a very common bird on the Faroes and Iceland, and a single example has been met with in Greenland.

The Meadow-Pipit appears to be strictly confined to the western portion of the Palaearctic Region from Iceland to the Ural Mountains in the north, and from Morocco to Nubia, Asia Minor, and Palestine in the south. In North Europe it is principally known as a summer visitor, but a few remain during winter in Germany. In the south of France, as with us, it is a resident; but in Spain, Italy, Greece, Asia Minor, Palestine, and North Africa it is a winter visitor, a few only remaining to breed in the mountains. It has been recorded from 'Turkestan, and even from India and Siam; but it seems probable that in all these cases the Red-throated Pipit in winter plumage has been mistaken for it.

The Meadow-Pipit is very nearly allied to the Tree-Pipit; and Severtzow says that on the mountains of Turkestan a Pipit breeds which is intermediate between them. In comnexion with this it may be remarked that Harvic-Brown and I were surprised to find that in North-east Russia the Meadow-Pipit was so much more arboreal in its habits than it is in this country. The Meadow-Pipit is still more nearly allied to the Red-throated Pipit, and examples in winter plumage are difficult to determine. The few distinctive characters are carefully pointed out in the description of the bird. It is notknown that intermediate forms between the two lastmentioned species occur. There are resident Pipits both on the Canaries and Madeira; those from the latter island are a dwarf form of the Meadow-Pipit, measuring only from $2 \cdot 3$ to $2 \cdot 6$ inch in length of wing, that of the Meadow- 
Pipit varying from 2.9 to 3.3 inch. Pipits of similar size from the Canary Islands are probably dwarf forms of the Water-Pipit; but the Pipits from the islands on the west coast of Africa have never yet been examined by any competent ornithologist, and at present they are confused together under the name of Anthus bertheloti.

Few birds are so common or well known as the Meadow-Pipit, or Titlark as it is usually called. Although great numbers of MLeadow-Pipits may be found in summer in the low-lying and richly cultivated districts, in marshy pastures, on commons, and lands near the sea, they are most abundant during the breeding-season on the moors. In the wildest solitudcs of the mountain-heights, in company with the Dottcrel and the Ptarmigan, or lower down the hill-sides on the broad tablelands of heath with the Rcd Grouse and the Curlew, this bird is equally at home, and there is scarcely a marshy spot that does not contain a pair. In the remotest parts of the Highlands and on the islets of the rough wild western sea the Meadow-Pipit is often the only land-bird to be seen. It is a restless little creature, and seems bent on thrusting itself into notice.

The favourite haunt of this bird is the breezy moors, and there, perhaps, its habits, at the most interesting period of its existence, are best observed. In early April, when the uplands first show signs of spring, the MeadowPipits in great numbers quit their low-lying winter-quarters and repair to them for the purpose of rearing their young. Soon after their arrival the male bird commences his song, and in some districts so abundant are they that the air is alive with fluttering Pipits, and their simple little strain is heard borne on the breeze from all parts of the moors. They may be seen sitting on low walls, boulders of rock, stunted bushes or heather-stems, ever and anon sallying into the air, flutteriug upwards for a short distance, then returning to their perches, warbling as they descend. Sometimes, but not often, the bird will warble as it sits. In many respects the song and habits of the Meadow-Pipit resemble those of the Tree-Lipit, but are much less interesting. The song is not nearly so rich nor so loud, and is much less varied; it is also much shorter, and, according to Dixon's observations, is ouly warbled on the bird's downward flight, the preliminary notes which it often utters in ascending being repetitions of its call-note. Its call-note is a low but very clear ist, often rapidly repeated, and its alarmnote is a short whit. The Meadow-Pipit does not perch on trees so much as the Tree-Pipit, and its flight is swift and undulating, somewhat like that of a Wagtail, but the curves are shorter.

The Meadow-Pipit pairs very early in the season, soon after its arrival at its breeding-place, but the nest is not generally commenced before the middle or end of April. The nest is always on the ground, and generally well concealed; it is often placed on a slope amongst rank herbage, sometimes at the foot of a little willow bush, or under a bank, in a similar

VOL. II. 
situation to that often chosen by the Robin. Sometimes it is placed in a meadow amongst the grass, at others in a hollow under a stone, and very often under the shelter of a reed-tussock in a little swampy patch of ground. Dixon has known this bird build its nest amongst a tuft of reeds surrounded by water, where the foundation of the nest was saturated with moisture. The nest is made of moss and dry grass, and lined with finer grass, hairs, and sometimes a few rootlets; it is rather loosely put together, but always carefully finished inside, and varies considerably in size and form, according to the peculiarities of the site. The eggs of the Meadow-Pipit are from four to six in number, and are pale bluish or brownish white in ground-colour, profuscly mottled and speckled with spots of brown, amongst which the paler underlying markings can usually be detected. The variations are not very important, and the cggs of each clutch are gencrally alike. When the eggs are very thickly spotted, many of the spots become confluent and there is little variation in colour; but when the spots are fewer the difference in the ground-colour makes an important difference in the appearance of the egg. On many eggs fine hair-like streaks occur, principally on the large end. They vary in length from 95 to $\cdot 75$ inch, and in breadth from 62 to .55 inch. The eggs of the Meadow-Pipit very closely resemble those of the Water-Pipit and many varietics of the Rock-Pipit; but the eggs of both are usually a more olivebrown, and those of the latter species are larger and rounder. The Mcadow-Pipit is said occasionally to rear two broods in the season. The male is often very bold when the nest is approached, and flutters in the air, uttering his alarm-notes in anxious tones. The female sits very closely, and often allows herself to be almost trodden upon cre she quits her eggs or liclpless young. Sometimes, when she is disturbed, she feigns lameness, and endearours to lure the intruder away by fluttering helplessly along the ground as if wounded. The Cuckoo often selects the nest of this bird for its nursery; in fact in many localitics there are no other suitable nests at hand, as, for instauce, on the Grouse-moors and mountain-tops, in both of which situations the Cuckoo is a common bird. The MLeadow-Pipit may be seen tending her young for some time after they have left the nest, aud, in some cases, the family-party lieep together during the winter.

Dixon writes:- "The summer passes quickly away, and the hill-sides don their purple tints, an unfailing sign of autumn. The Lapwings and Curlews leave the bleak uplauds as the season wanes, and descend to the coasts for the winter; the Meadow-Pipits also retire to the lowlands, appearing on the pastures in September and October. Here they go about solitary or in little parties. As you stroll over the turnip-fields and grass-lands you will often see them flying up before you, uttcring their feeble and complaining notes of peep, peep, peep, to alight a little distance away, and again tarry till almost trodden upon ere they take wing, their sober garb harmon- 
izing with surrounding tints. In the autumn by far the greater number of Meadow-Pipits frequent the turnip-fields, where, with feeble call-notes, they alight on the broad leaves in search of grubs and insects. When disturbed, as, for instance, by the report of a gun, the whole flock will rise into the air and flutter here and there in a very uncertain way, the wind often beating them about like leaves. They soon settle again into the cover, flying down two or three at a time. When thus disturbed they are never seen to alight in trees; they keep fluttering about in the air, flying hither and thither until they alight again on the ground. The MeadowPipit is a very active little bird, and runs about almost as quickly and gracefully as a Wagtail, and repeatedly jerks its tail like those birds. It is by no means shy, yet if repeatedly disturbed will either skulk amongst the herbage or flit rapidly away long before you are within gunshot. Sometimes in winter the Meadow-Pipits are very hard pressed for food. When the ground is covered deep in snow they repair to the manure-heaps, kept free from snow by the licat of the manure, to catch the small flies and worms and beetles. This bird when in a helpless state will often try to hide itself. I have seen one when wounded bury itself for some considerable distance in a snow-drift, and then remain motionless, allowing itself to be taken in the hand without the least movement. It is only in autumn that the Meadow-Pipit is gregarious to any great extent, the flocks at that season often being of immense size. In winter rarely more than half a dozen birds flock together; but in the spring the bird again becomes to a certain extent gregarious, and may then be seen in company with the spring flights of Wagtails."

The food of the Meadow-Pipit is largely composed of insects, larve, small worms, and freshwater shells. It may often be scen catching sanclflies on the const, and repeatedly sallies into the air like a Flycatcher to chase an insect on the wing. In winter it varies this fare with little sceds, and has been known to feed on grain; but at all seasons an insect diet is undoubtedly preferred, for when the weather is severe, and insects are scarce, almost every little swampy place in its haunts will be searcher for food, and it then frequents the sides of ruming streams and manure-licaps. and often comes to sheepfolds and farmyards to seek for insects.

In autumn vast numbers of Meadow-Pipits pass along our eastern and southern coasts, cridently on their migration southwards. During September and October countless numbers frequent the Sussex coasts previous to their departure for the continent, generally moving from west to cast, About the middle of March the return flights are noticed, not so large as the autum ones, for the perils of migration cause many of the birds to perish. There can be little doubt that numbers of Meadow-Pipits leare this country in autumn and return in spring, but many may possibly be birds passing our coasts on their way south from Northern Europe. Mrr. 
Booth, in his 'Rough Notes,' gives many interesting remarks on the migration of this bird from his own observations, to wlich I would refer those of my readers who wish to enter more fully into this portion of the bird's life-history.

The Meadow-Pipit has the general colour of the upper parts olive-brown, and the dark centres of the feathers are well pronounced, except on the rump and upper tail-coverts. The white on the outside tail-feathers rescmbles that of the Tree-Pipit, lout is generally purer and less developed on the penultimate feather. The general colour of the underparts is nearly white, thickly streaked with blackish brown on the sides of the neck, breast, and flanks. Bill dark brown above, pale at the base of the lower mandible; legs, fect, and claws palc brown, the hind claw being much clongated (as long as the toe) and slightly curved; irides deep blackish brown. The female resembles the male in colour. After the autumn moult the general colour of the upper parts is a yellowish olive-brown, and of the underparts a yellowish buff. Birts of the ycar are suffused both on the upper and under parts with chestnut-buff, and are more profusely streaked on the breast and flanks-characters which are still more pronounced in young in first plumage.

The Meadow-Pipit may be distinguished from the Red-throated Pipit by the following claracters:-Adult $A$. cervinus in full breeding-plumage, with its pale buffish-chestnut throat and breast and nearly white margins to the feathers of the mantle, appears to be very distinct from the same

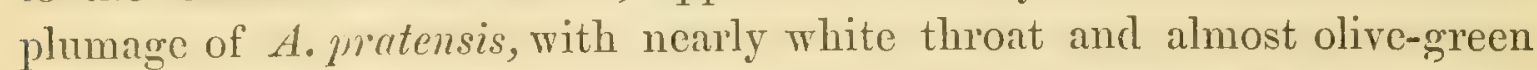
margins to the feathers of the mantle. Adult A. cervinus in winter may be distinguished by the white margins to the feathers of the mantle; but the underparts are the same in both species at this scason of the year, execpt that in very rare instances the chestnut is retained on the throat. Birds of the ycar of the two species are scarcely distinguishable, both laving very buff underparts and olive-green margins to the feathers of the back, but the general colour, especially of the rump and upper tailcoverts, is greyer in $A$. cervinus than in A. pratensis. Examples occasionally occur in spring of birds which from the gencral colour of the upper parts are evidently $A$. cervinus, but which have no chestnut on the throat. These are unquestionably examples of $A$. cervinus which, from some reason or other, have not moulted the feathers of the under parts in spring; but they may be distinguished at once by the dark shaft-lines on the under tailcoverts and the almost black centres of the upper tail-coverts, as well as of those of the rest of the rpper parts-two characters which are, perhaps, the best to discriminate between the two species, though the latter is not so marked in birds oi the year. 


\section{ANTHUS CERVINUS.}

\section{RED-THROATED PIPIT.}

(Plate 14.)

Motacilla cervina, Pall. Zoogr. Rosso-Asiat. i. p. 511 (18:6); et auctorum plurimorum-(Bonaparte), (Degland \& Gerbe), (Savi), (Salvadori), (IIume), (Oates), (Dresser), \&c.

Anthus cecilii, Aud. Descr. de l'Egypte, p. 360, pl. 5. fig. 6 (1823).

Anthus pratensis nubicus, Hempr. \& Ehr. Symb. Phys. fol. dd (1829).

Anthus rufogularis, Brehm, Vög. Deutschl. p. 340 (1831).

Anthus cervinus (Pall.), Keys. u. Blas. Wirb. Eur. p. xlviii (1840).

Anthus ruficollis, Vieill. fide Heugl. Orn. N.O.-Afr. p. 323 (1869).

The Red-throated Pipit has scarcely any valid claim to be regarded as

British bird. The only authority upon which it is inserted in the British list is that of a single individual in the possession of $\mathrm{Mr}$. Bond, who obtained it from the Troughton Collection, labelled "Isl. Unst, May 4th, 1854." There can, however, be very little doubt that it occasionally visits our islands, as it has frequently occurred on Heligoland and in most other countries in Europe.

The Red-throated Pipit breeds on the tundras above the limit of forestgrowth from the Atlantic to the Pacific, but it becomes rarer west of the Ural Mountains, and in North Scandinaria is very local. It passes through Finland and Russia, Turkey, and Asia Minor on migration, and winters in Egypt, Nubia, and Abyssinia. To the west of these limits it can only be considered a straggler; but it has occurred in autumn on Heligoland, and in Germany, France, Spain, and Italy. A few of the Sibcrian birds pass through Turkestan and winter in Persia and India; but the main stream apparently passes through South-eastern Siberia into China, Burma, and the Andaman Islands.

I first made the acquaintance of the Red-throated Pipit on a bit of swampy ground not far from the little village of Kistrand, on the shores of the Porsanger Fjord in Finmark. I had everywhere found the Meadow-Pipit very common, when I suddenly came upon a little colony of the red-throated species, and shot three of them in five minutes. At Vadsö I had abundant opportunity of watching the bird. The spring was very late; and in the last week of June the birds were only just beginning to breed, and were in full song. The Red-throated Pipit is not so shy as the common species, does not take alarm so easily, and is much less difficult to approach within easy gunshot. Its song is more melodious and prolonged, more nearly resembling that of the Tree-Pipit, which bird it 
also much more resembles in the colour of its eggs. Its call-note is very similar to that of the Meadow-Pipit, but is rather louder and a little baser in tone. It is very decidedly a swamp-bird, being rarely seen on the dry, grassy hills or on the rocky slopes.

In the valley of the Petchora Harvic-Brown and I found it very abundant. At Ust Zylma it arrived a couple of days after the sudden breakup of winter, together with the Golden Plover, Fieldfare, Redwing, Greyheaded Yellow Wagtail, Lapland Bunting, \&c., on the 1\%th of May, a weck later than the Swans, Geese, and Shore-Larks, and a week earlier than the Stints and Sandpipers. They were in small parties, generally flying up wind, the bright sun glancing on their breasts, cuabling us casily to identify them. They seemed to be in a hurry to get to their breedinggrounds, and rarely alighted to feed. During twelve days we only succeeded in shooting now and then an odd bird. On the 29th of May the wind was nearly east and warm. In the afternoon it was very hot, but there had been a smart frost during the night. We turned out at five, aud worked hard till ten without getting a bird. I had taken down notes of the songs of the Arctic Blucthroat and the Siberian Chiffehaff, but otherwise had au empty bag. After breaklast and a pipe in our hammocks, I turned out again along the banks of the Petchora, which was then full, almost to overflowing. On "l'autre côté" (as Piottuch and we always called the west bank) it had in many places orerflowed, and we could see some square miles of willow and birch forest under water. I bageged a brace of WoodSandpipers and a Ring-Dotterel, aud then crossed a sandbank to a marshy pool, where numerous frogs or toads were croaking in a muffled tone like bubbling water; they were extremely shy, and hid themselves in the mud at my approach. After waiting some time, three noses appeared above the water. I fired, but without effect on the reptiles; but started seven or eight Sandpipers and a Red-throated Pipit. I went in pursuit of the latter bird, and found myself upon a flat marshy piece of ground covered with hillocks of grass almost close to each other. Many Pipits were sitting in the narrow trenches between these hillocks, and rose at my feet on all sides as I walked on, and very soon half a dozen were within thirty paces of me. I chose a double shot, reloaded, and, as I ralled up to my birds, actually rose two or three Pipits between me and them; they had allowed themselves to be shot over, but eridently objected to be walked over. Unfortunately I had only two cartridges left, so I shot another brace and returned to our quarters for more ammunition. Once again on the marsh I found the Pipits still there, and bagged half a dozen more. My attention was then taken off for some time in securing a Sparrow-Hawk, the only specimen we shot in the Petchora. A couple of days afterwards we twice cressed the same piece of ground, but did not see a bird; they had evidently been resting after a long 
stage of migration, and probably continued their journey northwards the same night. In twelve days, although we had seen plenty of birds, we were only able to secure five males and one female. On this occasion we bagged ten males and one female in a couple of hours. Occasionally we heard them singing on the ground. When disturbed, after repeated shots they settled, some on the railings, some on the houseroofs, and some in a willow tree. We saw nothing more of this bird at Ust Zylma nor for a hundred and fifty miles down the great river. When we reached the tundra the Red-throated Pipit was again common and busily engaged in breeding. We found plenty of their nests. The commonest bird on the tundra was the Lapland Bunting, and the next commonest the Red-throated Pipit. The nests of both these species were placed in recesses on the sides of the tussocky ridges which intersected the bogs. The eggs of the latter bird varied from the reddish variety of the eggs of the Tree-Pipit to those of the Lapland Bunting; but the nests were always easily to be distinguished from those of the last-mentioned bird, being lined with fine dry grass instead of a profusion of feathers. The Red-throated Pipit was very foud of perching in the willow bushes in the sheltered hollows of the tundra and on the islands of the delta.

I found the Recl-throated Pipit equally common in the valley of the Yenesay. It arrived on the Aretic circle on the 6th of June, in the second half of the great spring migration in this district, a month after the Swans and the Geese, about the same time as the Plovers and Sandpipers, but a week or more earlier than the Sedge-Warbler, the Arctic Bluethroat, and the Petchora Pipit.

The nest of the Red-throated Pipit is entirely made of dry grass, the coarser pieces being used for the foundation and the finest reserved for the lining. The eggs of the Red-throated Pipit are from four to six in number; they bear a general rescmblance to those of the Tree-Pipit, and, like the eggs of that bird, may be divided into two types. One of these, like its representative in the Tree-Pipit's eggs, is very similar to the eggs of the Meadow-Pipit, but the markings are seldom so profusely distributed over the whole surface of the egg; the other type, in which the spots are darker and much more distinct, and partake frequently of the streaky character of a Bunting's egg, resembles more the eggrs of the Lapland Bunting than the other type of the eggs of the 'Tree-Pipit. The ground-colour in both types varics from buffish or pinkish white to very pale greenish blue, and the surface-markings vary from neutral brown to reddish brown; the underlying markings vary from pale brown to pale grey. On one type the spots are large aud confluent, but sufficiently wide apart to show a considcrable amount of the ground-colour between them; but on the other the spots are small, and so thickly dispersed over the entire surface as almost to conceal the ground-colour. Ou some eggs 
the surface-colour is evenly clouded over the entire surface, with here and there a few spots of darker colour. Sometimes the markings take the form of streaky lines and spots. Occasionally one egg in a clutch is much paler than the rest. The eggs vary from 82 to 68 inch in length, and from 62 to 55 inch in breadth.

The food of this bird consists principally of insects, small worms, and larve, and is not known to differ from that of the Meadow-Pipit. In winter the Red-throated Pipit becomes gregarious. Writing of this species in Tenasserim, in winter, Mr. Davison remarks ('Stray Feathers,' vi. p. 367):- "I have only found this species in flocks. As a rule they keep to the rice-fields, or other planted ficlds where there is cover. When disturber they rise quickly one after the other with a very sharp clear note, which they continue to utter as they fly. They generally fly a couple of hundred yards or so and drop again, one after the other, and commence to creep about among the stalks, one occasionally showing itself for an instant on the top of a dyke or clod of earth, but diving rapidly again into cover. Occasionally I lave seen them on the banks of rivers along the mater's edge. I have always found them very shy; and after they have been fired at a few times, they fly right away out of sight."

The adult male Red-tliroated Pipit in breeding-plumage differs from the Meadow-Pipit by having the gencral colour of the upper parts much more rufous (sandy instead of olive), and the whole of the upper parts have dark centres to the feathers. The white on the two outside tail-feather's is the same in both species; but the throat and breast are pale buffish chestwut, the remainder of the underparts being pale buffish brown, palest on the under tail-coverts, the longest of which have dark centres. The streaks on the underparts are not so numerous as in the Meadow-Pipit, and are chiefly confined to the flanks. Bill brown above, pale below; legs light brown; eet and claws darker brown ; irides hazel. The female and male of the yearf in breeding-plumage very closely resemble the male on the upper parts ; but ou the underparts the pale buffish chestnut is confined to the throat, and the remainder of the underparts are pale buffish brown, boldly streaked on the flanks and breast with brownish black. After the autumn moult the upper parts are a slightly richer brown, and the chestnut on the throat and breast is absent, the underparts being yellowish buff, streaked on the breast and flanks with dark brown. Birds of the year are suffused both on the upper and under parts with chestnut-buff, and are more profusely streaked on the breast and flanks. The points of distinction between the present species and the Neadow-Pipit in these latter plumages have already been pointed out in the article on the preceding species. 


\title{
ANTHUS RICHARDI.
}

\section{RICHARD'S PIPIT.}

\author{
(Plate 14.)
}

Anthus richardi, Fieill. N. Dict. d'IIist. Nat. xxvi. p. 491 (1818); et auctorum plurimorum - (Bonaparte), (Degland \&. Gerbe), Salvadori, (Jerdon), Dresser, Nevoton, \&c.

Corydalla richardi (Vieill.), Vigors, Zool. Journ. i. p. 411, pl. xiv. (1825).

Anthus macronyx, Gloger, Handl.Vög. Eur. i. p. 269 (1834).

Anthus longipes, Hollandre, Faune de la Moselle, p. 85 (1836).

Cichlops monticolus, Hodgs. Gray's Zool. Misc. p. 83 (18t4).

Corydalla sinensis, Bonap. Consp. i. p. 247 (1850).

Anthus maximus, Blyth, White's Nat. Hist. Selborne, p. 262 (1850).

Agrodromas richardi (Vieill.), Saunders, Ibis, 1871, p. 216.

This fine Pipit was discovered in 1815 by M. Richard, of Lunéville, who sent examples from Lorraine to Vicillot, who named it in honour of its discoverer. Richard's Pipit was first described as a British species by Vigor's, who exhibited, at a meeting of the Zoological Club of the Limnean Society, on the 13th of April, 1824, an example which had been netted in the ficlds near London, in October 1812. Rennie, in 1831, in his edition of Montagu's 'Ornithological Dictionary,' records a second British example taken at Oxford; and Yarrell was informed by Mrr. Proctor, of Durham, that he had shot one near Howick, Northumberland, on the 13th of February, 1832. Since that date so many examples of this bird have been obtained, that we may now regard it almost as a regular straggler on autumn migration to our islands. It has been obtained in Norfolk and Shropshire, but more frequently on the south coast. Edward states that he once saw this bird in Banffshire, but there is no other Scotch record. It does not appear to have ever been obtained in Ireland.

So far as is known, Richard's Pipit is confined during the breedingseason to the central portions of Asia. The northern limit of its range appears to be lat. $58^{\circ}$ in the valley of the Ycnesay, whence it extends south-east through Dauria as far as the mountains of Eastem Thibet on the confines of China, and south-west as far as Eastern Turkestan on the confines of Cashmere. It winters in India, Ceylon, the Burmese peninsula, and South China. A considerable number, principally birds of the year, appear annually to join the western stream of migration, and find their way into Europe. It has occurred accidentally in Persia, and passes Heligoland regularly every year. It has also been found in Norway, Sweden, France, Spain, Italy, Germany, Russia, Asia Minor, and even in Algeria. Richard's Pipit has several near allies, with some of which it 
may be conspecific. The most distinct of these is Anthus rufulus, a small race, which appears to be confined to India, Burma, Siam, the Malay peninsula, Sumatra, and possibly some of the other islands of the Malay archipelago. It is not kuown that this form differ's from its near ally in any particular except in size. It varies in length of wing from 3 to $3 \frac{1}{4}$ inches, whilst that of Richard's Pipit varies from $3 \frac{1}{2}$ to 1 inches. Intermediate forms, however, occasionally oceur both in India and in China, which vary in length of wing from $3 \frac{1}{4}$ to $3 \frac{1}{2}$ inches. In the latter country they have been named $A$. chinensis. Another species which has been still more confused with Richard's Pipit is not quite so nearly allied. $A$. striolatus * has almost the same geographical distribution, breeding in Dauria and Lastern and Western Turkestan, and wintering in India, British Burma, Ceylon, and the Andaman Islands. This species differs in being on an average slightly smaller than $A$. richardi, and varies in length of wing from $3 \frac{1}{4}$ to $3 \frac{3}{4}$ inches. It has also a relatively shorter tarsus, which varies in $A$. striolatus from 95 to $1 \cdot 1$ inch, and in $A$. richardi from $1 \cdot 1$ to $1 \cdot 3$ inch. The hind claw of $A$. striolatus varies from 42 to 6 inch in length, whilst that of $A$. richardi varies from 6 to 75 inch. The amount of white on the penultimate tail-feather is generally less than an inch in $A$. striolutus, and from an inch and a half to two inches in A. richarii ; but exceptions to this rule often occur. The other character's are scarcely more constant, and it is often impossible to say to which species some examples ought to be referred. A. striolutus is represented in South Africa by $A$ caffer, a species so closely allied to it that I am unable to find the slightest difference between them.

Richard's Pipit is essentially a steppe bird, like the Tawny Pipit, but, unlike that species, it neglects the dry and sterile plains and chooses only those which are well watered. It delights in wet pastures and rich meadows left for hay in northern climates, where the larvest is late and it can build its nest in the long grass, and rear its young before the mowers come to disturb it, and where it can find abundance of food on the short grass after the hay is cleared away, just when its young are most voracious. These conditions it finds to perfection in the flat meadows that stretch away, often for miles, on the banks of the great river's of Central Siberia, and which are overflowed for some days when summer suddenly comes, and the snow melts, and the ice on the river breaks up. I found Richard's Pipit extremely abundant in the meadows on the bauks of the lenesay, near Yenesaisk. The country is almost a dead flat for miles, and is intersected with half dried-up river-beds and chains of swampy lakes, full of tall sedges and reeds aud water-plants of various kinds, and half concealed by willow bushes and alders, whilst far away in the distance the horizon is

* This species is the $A$. godlewskii of Taczanowsky and Severtzow, also probably the A. campestris of Prjevalsky, and possibly the $A$. campestris of Finsch. 
bounded on every side by the forest. These oases of grass in the boundless forest are the paradise of Richard's Pipit. As I wandered away from the town this bird became more common. I found them difficult to shoot on the ground, as they ran about in the grass; but I soon obtained as many examples as I wanted as they hovered in the air, almost like the Kestrel.

It is absolutely impossible to express the note of this bird on paper; but some idea of it may be formed by trying to whistle the Italian word degli melodiously and loudly.

Dybowsky found them equally common on the plateaux near Lake Baikal, at an elevation of 5000 feet above the level of the sea. They arrive about the middle of May, and build their nests on the ground in the grass. They usually choose a hollow in the mearlows, such as the footprint in the soft earth of a cow or a horse. The first nest is made in the first half of June; and frequently a sccond brood is reared, the eggs being laid in the second half of July. The nests are said to be very difficult to find. 'The male keeps watch, and on the approach of danger he gives the alarm to the female, who leaves the nest and runs along the ground for some distance, when she rises and joins the male in cndeavouring to entice the intruder from the nest with anxious cries. If their little manœuvres are successful the fomale drops to the ground and runs back to the nest through the grass. In this district the nest of Richard's Pipit is the one usually selccted by the Cuckoo in which to deposit her egg. They leare for their winter-quarters late in September.

Prjevalsky met with Richard's Pipit breeding on the steppes of Eastern Mongolia, on the north-west fronticr of China. He describes it as tolerably abundant from the end of April till the beginning of September, and notices that it avoided the tall and thick grass of the marshes and frequented the wet grassy land sprinkled over with bushes. He states that, when rising in the air, its movements are similar to those of the Meadow-Pipit.

Richard's Pipit was met with during the breeding-season on the plateaux of Eastern Turkestan by my friend Dr. Scully, whose careful bird-mork stands out in marked contrast to so much of our recent slipshod ornithological literature*. He found this bird near Yarkand, in Junc, frequenting moist ground covered with short grass, and observed young birds at the end of July. He describes its note as it rises from the ground as a sweet soft twitter, and also notices the shyness of the bird.

* The gold medal for the best example of slipshod literature must be awarded to the volume popularly lnown as the 'Ibis List of British Birds,' which bristles with errors on almost every page. It is difficult to say which part of the work is the worst. No sort of judgment has been exercised in the selection of species to be included, and birds are admitted or rejected in the most arbitrary manner. The nomenclature adopted follows 
L'Abbé David also met with Richard's Pipit in Mongolia, a little to the south of where Prjevalsky found it, and describes it as breeding on the ground in the grass near water, and as frequently perching on bushes and tall plants. Early in the breeding-season it may often be seen rising in the air after the mauner of other Pipits, and singing a short song, which is said to be extremely commonplace. L'Abbé David describes these birds as quarrelsome, especially during migration.

When I was in Heligoland we met with several small parties of Richard's Pipits during the last week of September; they were easy to recognize by the loudness of their call-notes. They came with north-east and southwest winds in company with Golden Plover, Little Stints, Blucthroats, Dunlins, and other birds, and were very wild and difficult to shoot.

Richard's Pipit is common in the plains of India and Burma in winter. It arrives early in October in flocks which disperse over the country, and remains during the winter in small parties or scattered pairs, which frequent marshy, swampy land, and are specially partial to the rice-fields. Col. Legge, describing its habits in Ceylon, says that it frequents pastures, especially those on which cattle are much fed, and is very fond of dusting itself on the roads. Soon after its arrival, and also shortly before its departure, he found it common in the long grass on the marshes. $\mathrm{He}$ describes it as a landsome bird in its carriage, holding itself crect, running swiftly, and frequently mounting on some little cminence, where it stands pluming itself. It is constantly uttering its solt but loud note both on the ground and when flying. Brooks, spealing of this bird in Bengal, writes:- "The usual note of this species is not a loud, harsh, discordant one, as described by some author or other, I forget whom now, but is a soft double chirp, reminding one strongly of the note of a Bunting. The flight is very undulating and strong. Of all small birds this one is the most difficult to shoot from its excessive shyness; and unless the ground permits of a successful stalk, an approach within shot of a small-bird gun, such as I use, is almost impossible. There the large wary Pipit stands, with his head as high as possible, and his neck stretched to the uttermost to enable him to keep the best of all look-outs; and the moment forty

no scientific rule, unless we admit that the law of compromise comes under that category. The classification adopted is of the same kind, a compromise between what has been called the old rostral system and some of the more modern attempts to place ornithological classification on a scientific basis, none of which have yet passed beyond the stage of provisional or tentative hypotheses, and the recognition of which is, at the least, premature. The etymology of the scientific names is pronounced by competent authorities to be generally very weak, often wrong, and sometimes peduntic. 'The geographical distribution, both home and foreign, is carelessly written, full of errors, and often very misleading. The whole work is a splendid example of the truth of the old proverb, that "too many cooks spoil the broth." The volume is well worth purchasing as a literary curiosity. 
yards is passed, that moment he flies, accompanied by any others within hearing of his note of alarm. However, by dint of extra heavy charges, and by creeping along under the edge-bunds of the paddy-fields, I managed to secure a few of this very fine Pipit. The places frequented were low grounds occurring below jhecls or talaos; the water constantly percolating through the reservoir-bank kept the low grounds adjacent rather damp, and in many places quite wet. Over a greater part of this low ground, the rice-crop having been gathered, there now grew a small vetch with blue flower, entirely covering what had been the paddy-field a couple of months before; and in these vetch-fields, the Jarger Pipit of which I am speaking delighted. Before retiring among the vetehes to feed, they sat for some time, as a rule, upon the little bunds which divided the fields; and when they did this, I found the best plan was to wait till the look-out was over, and the birds had retired among the crops to feed. It was then possible to creep up within shot."

The nest of Richard's Pipit has never been described, but probably differs very little from that of other Pipits. The eggs vary in number from four to six. Some are profusely spotted all over with minute specks and blotches of greenish brown upon a pale greenish-white ground-colour, whilst in others the spots are reddish brown upon a pinkish-white groundcolour. They vary in length from $\cdot 9$ to $\cdot 82$ inch, and in breadth from $\cdot 7$ to -65 inch. Except in size, the eggs of the present species scarcely differ from those of the Rock-Pipit and the Water-Pipit.

Like all the other Pipits, this species is principally insectivorous. Colonel Legge says that in Ceylon it feeds on worms and grasshoppers, and often seizes a passing butterfly on the wing.

Richard's Pipit is one of those Siberian birds that are in the habit of migrating eastwards in autumn to China and India, but which occur so regularly in Europe that, in many localities, its appearance may be looked for with confidence every year. The positive statements of Dresser and others that this bird breeds in Europe are entirely unsupported by evidence; and it is much to be regretted that Oates, in his excellent ' Handbook to the . Birds of British Burmah,' should have repeated the myth. The birds described and figured by Dresser, from Antwerp, in his 'Birds of Europe,' are adult and young immediately after the autumn moult. The opinion that these birds breed in Europe has arisen in consequence of their late stay in spring. Ornithologists secm to have been quite unaware that the breeding-grounds of Richard's Pipit, the Red-throated Pipit, the Bluethroated Warbler, the Little Stint, and many other birds are buried in snow until late in May or early in June.

The adult male Richard's Pipit in breeding-plumage has the general colour of the upper parts an almost neutral brown; the dark centres on the feathers of the head and back are well developed, but are absent from 
those of the rump, although obscurely defined on the upper tail-coverts; the underparts are very pale buffish white, darkest on the breast, which is streaked with dark brown; the white on the two outermost tailfeathers is almost pure. Bill dark brown, paler on the lower mandible; legs, feet, and claws pale brown; irides hazel. The female resembles the male in colour. After the autumn moult the whole of the plumage of both upper and under parts is more sandy. Birds of the year are very dark brown, the pale margins of the feathers are very white, and the spots on the breast are larger. Loung in first plumage have the pale margins of the feathers still whiter, and the flanks as well as the throat and breast are streaked. Richard's Pipit may always be recognized by its long tarsus, enormously developed hind claw, the nearly pure white on the outer tailfeathers, and the streaked breast.

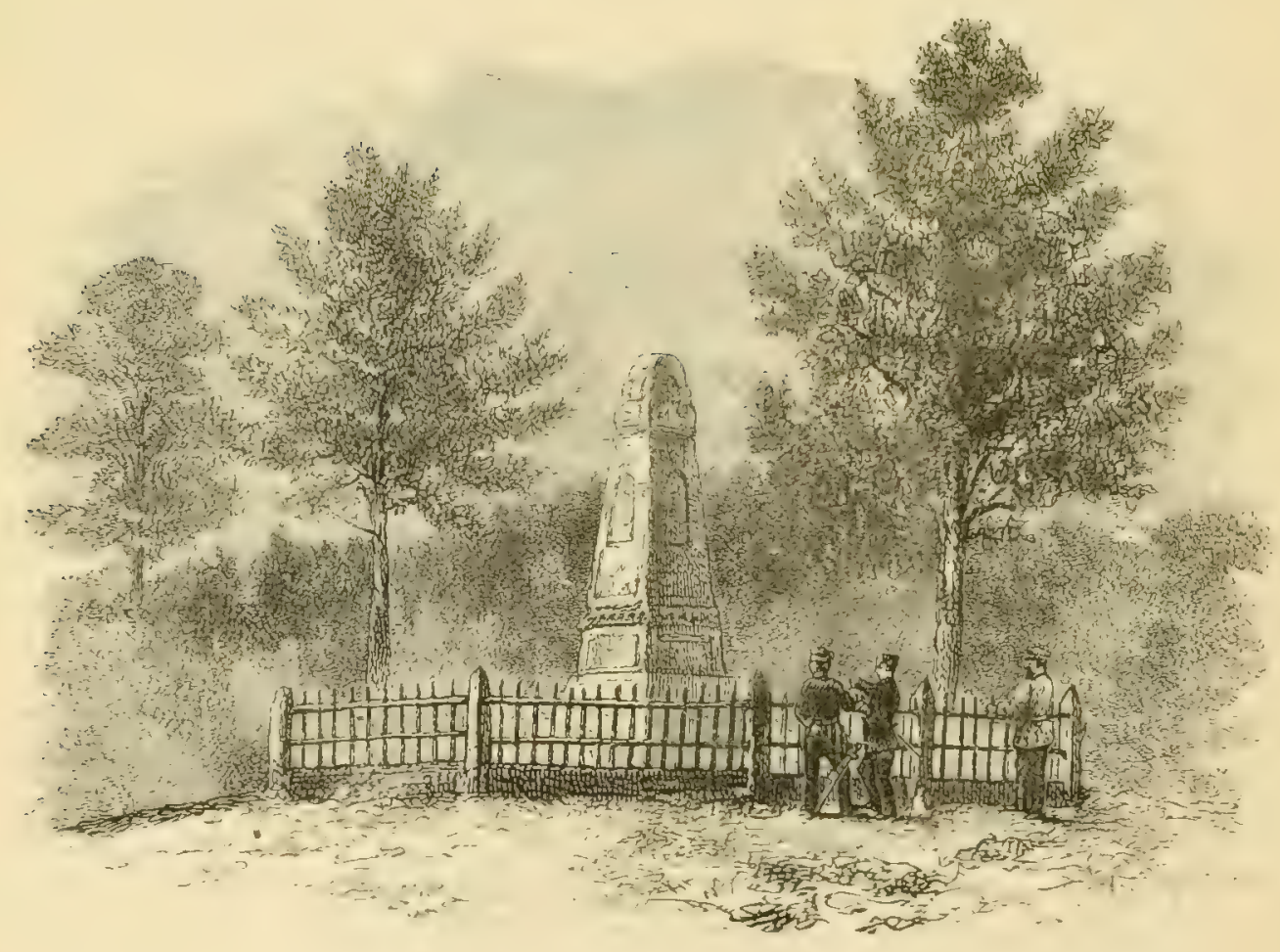




\title{
ANTHUS CAMPESTRIS.
}

\section{TAWNY PIPIT.}

\author{
(Plate 14.)
}

Alauda campestris, Linn. Syst. Nat. i. p. 288 (1766); et auctorum plurimorum -Gmelin, Latham, (Naumann), (Bonaparte), (Degland \& Gerbe), (Newton), (Dresser), \&c.

Alauda mosellana, Gmel. Syst. Nat. i. p. 794 (1788).

Motacilla maculata, Gmel. Syst. Nat. i. p. 965 (1788).

Motacilla massiliensis, Gmel. Syst. Nat. i. p. 965 (1788).

Sylvia massiliensis (Gmel.), Lath. Ind. Orn. ii. p. 531 (1790).

Sylvia maculata (Gmel.), Lath. Ind. Orn. ii. p. 532 (1790).

Anthus campestris (Linn.), Bechst. Orn. Taschenb. ii. p. 561 (1812).

Vitiflora massiliensis (Gmel.), Steph. Shaw's Gen. Zool. x. p. 570 (1817).

Vitiflora maculata (Gmel.), Steph. Shaw's Gen. Zool. x. p. 571 (1817).

Anthus massiliensis (Gmel.), Vieill. N. Dict. d'Hist. Nat. xxvi. p. 503 (1818).

Anthus maculatus (Gmel.), Vieill. N. Dict. d'Hist. Nat. xxvi. p. 504 (1818).

Anthus rufescens, Temm. Man. d'Om. i. p. 267 (1820).

Agrodroma campestris (Linn.), Swains. Classif. B. ii. p. 241 (1837).

Corydalla campestris (Linn.), Brehm, Vogelf. p. 138 (1855).

Corydalla rufescens (Temm.), Brehm, Vogelf.p. 138 (1855).

The first British specimens of the Tawny Pipit were recorded by $\mathrm{Mr}$. Dawson Rowley in 'The Ibis' for 1863 (p. 37). A male was shot by a man named Harding, on the 17th of August, 1858, close to a shallow pool near Shoreham Harbour, the man's attention being drawn to it by its peculiar note. A second specimen of this bird was brought on the 24th of September, 1862, hy a person named Wing, to Swaysland of Brighton, for preservation. Swaysland saw at once that it was some " distinguished stranger," and acquainted Mr. Dawson Rowley of the circumstance. It was shot on the cliff, about a mile and a half from Rottingdean, near Brighton. Since this date about a dozen other examples have been obtained, mostly near Brighton; one was shot on Trescoe, one of the Scilly Isles; and a specimen, said to be of this species, was shot near Bridlington by Mr. Boynton. This species does not appear to have been observed in Scotland or Ireland.

The Tawny Pipit is a summer visitor to Europe, and breeds in suitable localities as far north as lat. 57\%. It winters in Algeria, where, however, many remain to breed, and passes through Egypt on migration to winter in Nubia and Abyssinia. It is a summer visitor to Asia Minor, but is a resident in Palestine. In Asia this species is on an average smaller in size, the western race varying in length of wing from 3.8 to 3.4 inch, and the eastern race, $A$. campestris var. similis, from 3.5 to $3 \cdot 2$ inch. The latter 
breeds throughout Turkestan and South Siberia, as far east as Krasnoyarsk, and winters in South Persia and India. It seems probable that examples of the eastern Palæarctic race occasionally wander into Europe, as I have a specimen from Heligoland of which the wing measures only 3.3 inch. The reputed occurrences of this species in Eastern Siberia, Mongolia, and China appear to refer to $A$. striolatus, which may easily be distinguished by the pure white instead of sandy brown on the outer tail-feathers.

There are two tropical forms of the Tawny Pipit, one of them (A. pyrrhonotus) being a resident in South Africa, and the other $(A$. jerdoni) in India. Both these species are slightly larger than the Tawny Pipit, and in both of them the striations on the upper parts are almost obsolete, except on the head. In both species the fourth primary is nearly as long as the first, second, and third; and the fifth primary is emarginated on the outer web; whilst in the Tawny Pipit the fourth primary is relatively somewhat shorter, and only the second, third, and fourth are emarginated. These tropical forms have been considered identical by Blyth and Blanford; but they may be distinguished from each other by the prevailing colour of the upper parts, which in the Indian bird varies from neutral brown to isabelline brown, whilst the South-African bird is at all seasons of the year much more fulvous, and may be further distinguished by the dark centres to the longest under tail-coverts and by its shorter innermost secondaries.

The Tawny Pipit is almost a desert-bird, and is rarely seen except on dry saudy heaths and plains. England appears to have too damp a climate to suit its constitution, and is also situated almost at the extreme limit of its breeding-range. Even on the sandy plains of South Holland, where the soil is so poor that in the most fertile districts the farmers are seldom able to live entirely on the land, and possess a few tan-pits as an additional source of income, the Tawny Pipit is a somewhat rare bird, though it is common enough on the "dunes" or sand-hills on the southern shores of the Baltic as far north as Riga. It must be looked upon as a southern bird which never winters north of the Mediterranean, and only migrates in spring as far north as our latitude to exceptionally fivourable localities, where something approaching a desert may be found.

I found it very common in Greece, and it is the only species of this genus that breeds there. The Meadow-Pipit, and probably also the Redthroated and Water-Pipits, spend their winters in that comntry; the TreePipit passes through in spring and autumn on migration; but the Tawny Pipit makes Greece its summer home. This bird frequents the valleys in Greece and $\Lambda$ sia Ninor, and is rarely seen in either country much more than a thousand feet above the level of the sea. It seems to prefer the open plains, and is very common in the almost treeless valley between the Parnassus and Thermopyle; but in the valleys sonth of the Parnassus, 
where olives and vines are cultivated, wherever the rocks permit, I did not meet with it at all. It is especially common on the undulating prairie country, half rock and half grass and heath, between Athens and Marathon.

The Tawny Pipit is a somewhat carly migrant for a bird having such a southern range. It crosses the Mediterranean during the month of A pril, a few even appearing as early as the last week of March. It arrives on the southern shores of the North Sea and the Baltic late in April; but Nilsson says that it does not reach South Sweden before May. The return migration commences late in August, and is said to be all over by the end of September.

In many respects the habits of the Tarway Pipit rescmble those of a Lark. It runs with great swiftness on the ground, then suddenly mounts some stone or little elevation, looks round, calls to its mate in a prolonged double note (something like zer-vee), moves its tail up and down, disappears, and runs on again. This monotonous double note is often heard during the breeding-season, as the male is perched on a bunch of heath or some other conspicuous tuft of herbage. Of its habits in Algeria Dixon writes:- "The Tawny Pipit in the more elevated parts of Algcria is very common, and is a bird that cannot casily be passed unseen. To look at its plumage one might almost expect to meet with it only in the Desert; but in summer, at any rate, it does not frequent that sandy waste, and we only met with it on the clevated plateaux beyond Constantine and in the neighbourhood of Batna and Lambessa. The road between these two latter places runs through rich meadows and barley-fields, and abounded with Tawny Pipits in abundance. I saw them only in pairs; they were very tame, and often allowed themselves to be almost trodden upon before they would take wing. I often saw them ruming about very quickly over the bare pieces of ground, stopping now and then to look round to see if they were being pursued. When flushed they would often fly for a little distance in a very straightforward manner, not undulating, as their usual flight is, and perch on a little tuft of higher vegetation, or on a boulder, or even a paling. Many of the birds were on the road, where you could witness their actions very closely as they ran up and down like a Wagtail, often giving their tail a sharp jerk, accompanied by a flicking movement of the wings. They seemed to especially prefer a large unenclosed plain of rough land on which no crop was sown, what we should call summer fallow in England. Here I repeatedly saw the birds soar into the air for a little way and sing their loud but simple song, which put me in mind of the Sky-Lark's notes, although not so rich or so sweet. It does not soar so high as the Tree-Pipit, and seems anxious to get to the ground again. When alarmed by the report of a gun, the birds close at hand would generally rise for some distance into the air and betake themselves to safer quarters in a drooping flight, uttering

VOL. II. 
a short whit or yhit as they went. I found an empty nest, which could only have belonged to this bird, placed amongst the growing barley, which was about twelve inches high, in exactly a similar place to that in which the Sky-Lark often builds, made of dry grass lined with hair."”

The Tawny Pipit breeds only once in the year, and fresh eggs may sometimes be obtained in Greece late in May, but in Germany seldom before carly in June. The site for the nest is sometimes under a bush, sometimes bencath a tuft of dense herbage or under the shelter of a clod of earth; at others in the open plain amongst the growing crops, and often near a dricd-up streamlet on a bank beside a convenient stone. The nest is made of dry grass, often intermixed with a few stems of coarse herbage or straws, together with roots, and lined with borsehair, although in many cases fine roots alone serve the purpose. The eggs are five or six in number, and are subject to some little variation; the more boldly spotted eggs very closely resemble those of the Rufous Warbler, whilst others might be mistaken for eggs of the Crested Lark. The ground-colour varics from very pale greenish blue to creamy white, which is always profusely spotted, but never sufficiently so to hide it. The overlying spots are reddish brown, and the underlying spots are grey. The spots are generally elongated, more or less, into streaks, and largest at the large end of the egg; they are sometimes large, bold, irregular-shaped blotches, but not unfrequently small streaks or nearly round spots, and are sometimes dark and rich in colour, but more often somewhat paler and duil. The number of variations is very great, but the range of variation is comparatively small. They vary in length from 95 to $.8 \mathrm{inch}$, and in breadth from 69 to 6 inch.

'T'he food of this bird consists of various kinds of insects, especially small beetles, larvæ, \&c., for which it searches amongst the herbage on the ground, and it is said seldom, if ever, to eat seeds.

The habits of the Tawny Pipit in winter are very similar to those in summer. There does not scem any record of its collecting into large flocks cren during the periods of migration. In its minter-quarters it is described as a comparatively solitary bird, occasionally consorting with Crestcd Larlis, and frequenting the borders of the desert, but also visiting the stubbles, the fallows, and eren bare places in forests and the banks of lagoons and canals, but preferring sandy wastes where some scant vegetation is to be found.

The Tawny Pipit varies very much in the colour of its plumage, even in the same locality. The general colour of the adult male in breedingplumage varies from an almost neutral brown to a sandy brown; the dark centres of the feather's of the upper parts are conspicuous on the head, very obscure on the back, and entirely absent on the rump, and almost so 
on the upper tail-coverts; the underparts are uniform buffish white, darkest on the breast; the lores are very dark brown; the white on the two outside tail-feathers is suffused with sandy brown; bill with the upper mandible dark brown, paler at the tip, and the lower mandible pale brown; legs, fect, and claws light brown; irides dark brown. The female very closely resembles the male in colour. After the autumu moult both the upper and under parts are somewhat more rufous. Birds of the year are more or less streaked on the breast and the sides of the throat, a character which is still more pronounced in young in first plumage. The hind claw is somewhat more developed than that of the Meadow-Pipit, but not so much so as that of Richard's Pipit.

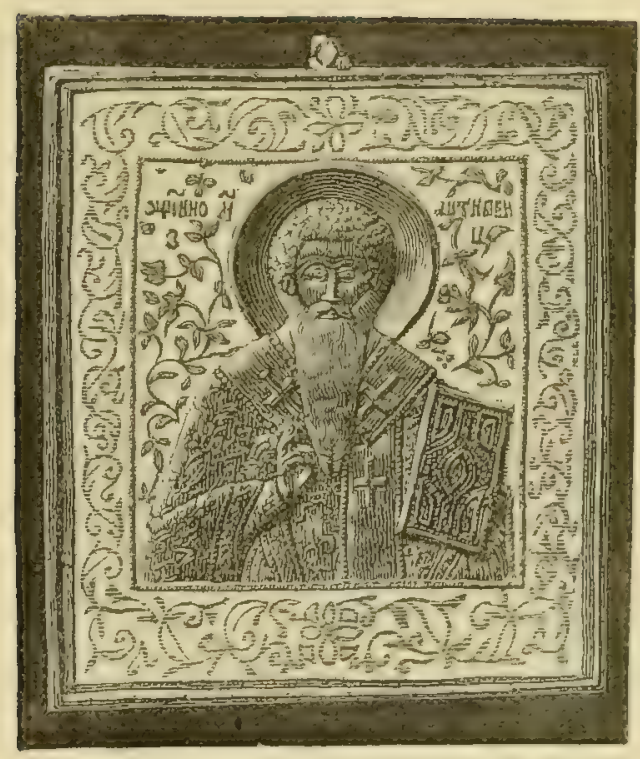




\section{ANTHUS OBSCURUS.}

\section{ROCK-PIPIT.}

(Plate 14.)

Alanda obscurn, Lath. Ind. Orn. ii. p. 494 (1790); et auctorum plurimorum(Bonaparte), (Leach), (Gould), (Keyserling \& Blaisus), (Salvadori), (Newton), (Dresser), \&c. Alauda petrosa, Mont. Trans. Linn. Soc. iv. p. 41 (1798). Spipola obscura (Lath.), Leach, Syst. Cat. Mamm. \&c. Brit. Mus. p. 22 (1816). Anthus rupestris, Nitss. Orn. Succ. i. p. 245 (1817).

Alauda campestris (Linn.), apud Bewick, Brit. B. i. p. 217 (1826).

Anthus petrosus (Mont.), Flem. Brit. An. p. 74 (1828).

Anthus littoralis, Brehm, Vög. Dextschl. p. 331 (1831).

Anthus aquaticus, Bechst. apued Selby, Brit. Orn. i. p. 258 (1833).

Anthus obscurus (Lath.), Keys. \&. Blas. Wirb. Eur. p. xlviii (1840).

Anthus spinoletta (Linn.), apud Macgill. Man. Brit. B. i. p. 169 (1810).

Anthus immutabilis, Degl. Orn. Eur. i. p. 429 (1849).

The Rock-Pipit is a resident on all the coasts of the British Islands, with the exception of the low-lying eastern shores south of Spurn, where it only appears as a straggler or on migration. It is found commonly in the Channel Islands, in the Hebrides, St. Kilda, the Orkneys, and Shetland, and is also common in the Fraros, although not known to visit Iceland or Greenland.

The Rock-Pipit is little more than a coast-form of the Water-Pipit, and appears to be confined to the rocky portions of the coasts of Northwestern Lurope, from the White Sea to the Bay of Biscay. It is found on the shores of the Baltic; but there is no satisfactory evidence of its frequenting those of the Mediterranean. It is a resident throughout its range, except in the extreme north.

The haunt of the Rock-Pipit or, as Macgillivray more aptly terms it, the "Shore-Pipit," is on rocky coasts, even the most dreary and desolate being enlivened with the presence of this soberly dressed little bird. It is strictly a bird of the rocks, and during the breeding-scason only frequents that part of the coast close to the sea betwcen the incoming tide and the summits of the cliffs, on which the true sea-birds cluster in myriads. It frequents rocky islands as much as the mainland; and numbers breed, and are resident throughout the year; on the Farnes, the Bass Rock, the Isle of May, and perhaps every other rocky islet beyond, including the most isolated ones, far into the stormy Atlantic. When its haunts are invaded it becomes very restless, and flits fom rock to rock before you, the wind often driving it along like a fleck of foam. It 
is not a very shy bird, and will usually allow you to approach it within gunshot. Sometimes when disturbed from the beach, it will flutter into the air and fly about in a very erratic manner, often hovering above the obscrver's head, incessantly uttering its call-note, and will often finally wing its way to the eliff's, and perch midway up them on a little ledge, where you can see it moving its wings and tail in an uneasy manner. Its flight is wavering, very uncertain, and sometimes it seems as though the bird were either perfectly helpless or willingly allows itself to be tossed hither and thither by the stiff ocean breeze. It is not gregarious during the breeding-scason; but in winter it is gencrally seen in small parties, which become large flocks at the two periods of migration. It is very active, and runs up and down over the shingle in true Pipit style, and repeatedly perches on rocky boulders, masses of seaweed, or even on portions of wreckage washed ashore.

The Rock-Pipit pairs in the middle of March, and a day or two previous to that event its song is renewed for the season. Like all the other Pipits, the Rock-Pipit seldom sings except on the wing. When it is in full song its notes are very musical, and rival those of the Meadow-Pipit, but can scarcely compare with those of the Tree-Pipit, either in variety, richness, or duration. In the pairing-season the Rock-Pipit sings incessantly, mounting into the air and gliding down again to his rocky perch on fully expanded wings and tail. The first really fine day in early spring is the signal for the commencement of the song, and it is continued until the young are hatched. The call-note of this bird is a shrill hist or pst, most pertinaciously kept up if it is seriously alarmed or its nest is in danger. This call-note is uttered both when the bird is sitting on the rocks or the ground or when fluttering in the air; and it often soars to the zenith of its flight uttering it quickly, and then returns to its perch in full song. In the Varanger Fjord, in the extreme north of Norway, where the bird is as common as it is in this country, I have heard them in full song at the end of May.

Although the Rock-Pipit pairs so early it does not begin nesting until

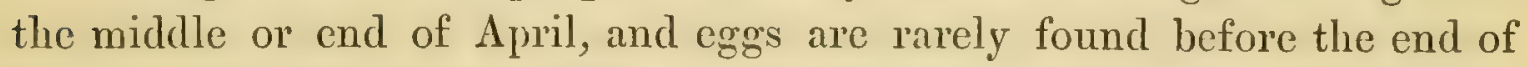
that month or early in May. The nesting-site is always selected not far from the sea, sometimes almost within arm's length of the waves; it is generally in a well-sheltered situation, such as under a stone, in a crevice of the rocks, or in a hole in a bank, behind a tuft of seacampion or under a heap of seaweed; and on one of the Farne Islands I found its nest on the wreck of a boat washed ashore. Sometimes a rabbit-burrow is selected or a loose stone wall; whilst in some instances it is quite inaccessible, in a niche on the face of a beetling cliff. Sarby states that he has occasionally found the nest several hundred feet above sea-level amongst grass and heather. The nest differs considerably in the 
material of which it is composed. Sometimes it is entirely made of dry fine grass, at others scawced is intermixed or the stalks of various plants growing near the sea, and it is frequently lined with hair. Some nests have a considerable amount of moss in them; and Dixon has taken a nest on one of the Fane Islands in which there was a large white Gull's fenther in the lining. This difference of material is to a great extent dependent upon locality. Where the birds can obtain hair they do so; where fine grass only can be obtained it is generally used; whilst in localities affording a more exteusive choice the materials are more varied. The eggs of the Rock-Pipit are four or five in number, but do not differ very much in colour. The ground-colour is generally so much obscured by the profusion of spots and streaks as to be scarcely discernible, but appears to be nearly white, oceasionally slightly tinged with brown or green. The overlying spots vary from reddish to greyish brown, but the underlying spots are always pale grey. On most eggs the markings are very small and almost confluent, sometimes forming a zone round the large end. Examples which are somerthat more boldly blotched, and others which are more sparingly spotted, are not uncommon. Occasionally a few rery dark hair-like streaks occur, principally on the large end. They vary in length from 9 to 8 inch, and in breadth from 66 to 6 inch. The eggs of this bird very closely resemble those of the WaterPipit, but are on an average much browner and a trifle larger. Two broods are commonly reared in the season. The old birds are often very anxious when their nest is menaced. The female usually sits very close, often allowing herself to be almost touched ere she quits the nest, when she will sometimes flutter along feigning lameness to draw attention from her eggs or young.

The food of the Rock-Pipit is chicfly composed of insects and their larrae and small shells, but it also feeds to some extent on small seeds. Much of its food is obtained on the seaweed which has been east up by the storm above the usual high-mater mark, and which in the glaring sun soon putrifies and abounds with millions of a little black fly. These flies are eagerly sought after by this industrious little bird, who sometimes pursues them a little way into the air. It also searches about on the sandy spots amongst the boulders, especially when the tide is out; and in winter Saxloy states that it will even come to the doors and feed with the poultry, sometimes perehing on the winlow-sills. The same writer also states that he has obscrved it regularly in autumn under the trees scarching for insects, and especially for a small land-shell, amongst the dead leaves and twigs. It will sometimes follow the receding wares so closely as to be compelled to warle, and is doubtless often mistaken for the moment in such a situation for a small Sandpiper or Stint, until it rises and drifts away, uttering its complaining hist as it goes. 
After the breeding-season the Rock-Pipit often wanders from its accustomed haunts; and in autumn especially it is often seen on the lowlying marshes on the coasts of Lincolnshire, Norfolk, and Sussex. Many of the birds seen in such situations are probably migrants from the high north, either passing our islands on their journey southwards or staying here for the winter. In low-lying districts their favourite haunts appear to be marshes and shingle-banks and the grassy portions of mud-flats. Early in March these birds generally forsake such places for the more rocky portions of the coast, where their young are reared, or they pass on to similar localities further north.

The ordinary form of the adult male Rock-Pipit in breeding-plumage has the general colour of the upper parts olive-brown streaked, except on the rump, with dark brown; over the eye is a dull and indistinct buffish stripe; the outermost tail-feather ou each side has a broad oblique spot of smoke-grey on the inner web; the chin is dull white, the throat and remainder of the underparts are sandy buff, most pronounced on the breast and shading into olive on the flanks; the throat, breast, and flanks are streaked with dark brown; bill dark brown, paler at the base of the lower mandible; legs, feet, and claws brown; irides hazel. The female does not differ in colour from the male. After the antumn moult the upper parts are much greener, and the underparts more strongly suffused with yellow. Birds of the year rescmble adults in autumn plumage, but are more streaked on the flanks, a character which is still more apparent in young in first plumage. The smoke-coloured patch on the outermost tail-feathers in this species will always readily distinguish it from the Water-Pipit, in which this patch is pure white.

In addition to the form the summer plumage of which has already been described with the streaked sandy-buff underparts, two others oceasionally occur. One of these, which I found together with the typical form in the Varanger Fjord, has the ground-colour of the underparts almost pure white, possibly the effect of continuous daylight; the other, which is connected by a series of intermediate examples with the typical form, has the underparts scarcely differing from those of $A$. spinoletta, the streaks being nearly obsolete and the colour of the breast pale chestnutbuff. The explanation of this singular variation can scarcely be reterred to interbreeding, because the colour of the outer tail-feathers remains quite typical. It seems to me that the fully adult male of the Ruck-Pipit, like those of its very near allies the Water-Pipit and the renusyranian Pipit, has the underparts unspotted; but from the rarity of sucn examples in collections, I am disposed to think that the fully adult plumage is only attained by very old birds in exceptionally sunny climes. 


\title{
ANTHUS SPINOLETTA.
}

\section{ALPINE PIPIT.}

\author{
(Plate 14.)
}

\begin{abstract}
Alauda campestris, Briss. Orn. iii. p. 349 (1760).
\end{abstract}
Alauda spinoletta *, Linn. Syst. Nat. i. p: 288 (1766); et auctorum plurimorumGmelin, (Bonaparte), (Degland \& Gerbe), (Salvadori), (Nevton), (Dresser), \&c. Anthus aquaticus, Bechst. Om. Taschenb. iii. p. $56 \pm$ (1812).

Anthus montanus, Koch, Syst. baier. Zool. i. p. 179 (1816).

Anthus coutellii, Aud. Descr. de l'Eyypte, p. 360, pl. 5. fig. 5 (1828).

Anthus spinoletta (Limn.), Bonap. Comp. List B. Eur. \& N. Amer. p. 18 (1838).

Anthus nigripes, Ehr. fide Dresser, B. Eur. iii. p. 335 (1874).

The Alpine Pipit has only been obtained in our islands, without doubt, three or four times. 'The first elearly identified specimens were recorded by Mr. J. Pratt in the 'Zoologist' for 1864 (Gould, 'Ibis,' 1865, p. 114). One was killed near Worthing, and another some time previously on the beach near Brighton. A third specimen was killed at Shoreham on the 26th of Octobel', 1868 (Dawson Rowley, 'Zoologist,' 1869, p. 1682).

The Alpine Pipit may almost be said to be a circumpolar bird. It will, however, be more convenient to subdivide it into three forms-a Western Palaarctic, an Eastern Palæarctic, and a Nearctic form, the first two differing only in size and the last two differing only in colour, and all of them connected by intermediate forms and overlapping each other's ranges in a very cxtraordinary manner. The European Alpine Pipit (A. spinoletta) is a very local resident in most parts of mountainous Europe. It has not been recorded from Scandinavia or North-west Russia; but it is said to pass through Denmark and Heligoland on migration, and it appears to breed in the Ural Mountains up to lat. $6 t^{\circ}$. It winters in South Germany, Holland, Belgium, Asia Minor, Palestine, Algeria, and Egypt. In the mountainous parts of Spain, France, North Germany, and especially in the Alps, it is found in winter only on the plains, breeding on the mountains. It breeds in the highlands of Persia and Baluchistan, and winters in Afghanistan. It is a resident in Turkestan, and has been obtained from the Altai Mountains. The eastern form of the Alpine Pipit, A. spinoletta var. blakistoni, is a very common summer visitor to the mountains near Lake Baikal, but is a resident in China, retiring to the mountains to breed. In Mongolia it is said to be a summer visitor. in some parts, and to remain during the winter in others. It also winters in Scinde and the

* Linnæus founded this species upon. "the bird called Spipoletta at Florence" of Ray and Willughby. It is spelt "spinoletta" both in the tenth and twelfth editions; and as the name has been so universally employed it does not seem worth while to alter it. 
plains of North-west India. The Nearctic form of the Alpine Pipit, A. spinoletta var. ludovicianus, breeds in Alaska, Canada, and Labrador, and the most northern and westerly United States. It winters in the States and Central America, and has occurred in Greenland and the Bermudas. Its alleged occurrences in the British Islands appear to be doubtful; but it has certainly been found on Heligoland, and I have therefore deemed it expedient to figure its egg (Plate 14). Westwards its range extends across Behring's Straits into North-cast $\Lambda$ sia, as it is a common winter visitor to the Kurile Islands and Japan, and was obtained by Swinhoe in South China. Strange to say, Brooks found this form in winter in the Himalayas and the valley of the Indus: one of these examples in my collection is absolutely indistinguishable from skins from Japan and Massachusetts. The European Alpine Pipit varies in length of wing from 3.6 to 3.3 inch, and in length of tail from 2.85 to 2.55 inch. Indian birds vary in length of wing from 3.4 to 3.1 inch, and in length of tail from $2 \cdot 65$ to $2 \cdot 45$ inch. The Nearctic and Japanese birds do not differ from the eastern birds in size, but are darker and less sandy in colour on the upper parts, and in winter plumage slightly buffer on the underparts *.

The Alpine Pipit has often been called the $W^{\prime}$ atcr-Pipit, a title which is not only misleading, but has so often becn applied to the Rock-Pipit, which really deserves the appellation, that, to avoid confusion in the future, I have adopted a name which is expressive of the habits of the bird.

Although the Alpine Pipit is very closely allied to the Rock-Pipit, the breeding-haunts of the two birds are very distinct. The latter keeps to the rocky coasts throughout the year; but the Alpine Pipit, although

* The affinity between $A$. spinoletta and $A$. Tudovicianus has been overlooked by ornithologists, in consequence of the omission of American writers to describe the summer plumage of the latter bird. It is very extraordinary that two such careful writers as Messrs. Baird and Ridgway should have been guilty of such an unpardonable omission. It is true that a bird in nearly full summer plumage was figured by Swainson and Richardson (Faun. Bor.-Amer. ii. pl. 44); but so absolutely ignorant were English ornithologists of the summer plumage of this species that Dresser, in his 'Birds of Europe,' actually suggests that the figure is taken from a European example of the Alpine Pipit which was exchanged for the original skin after the collection was forwarded to England. Fortunately, however, Mr. Frank M. Drew, in his "Field Notes on the Birds of San Juan County, Colorado" (Bull. Nutt. Orn. vi. p. 88), remarks that "some birds," doubtless adults in full breeding-plumage, "have not the least trace of a spotting on the breast," while others, doubtless September and October birds and young birds in breeding-plumage, " are heavily spotted."

It is impossible to suggest any explination of the unaccountable blunder of Professor Newton, who states positively, in his article on the Meadow-Pipit, that the Anthus pratensis japonicus of Temminck and Schlegel is the Red-throated Pipit. To this species the Japan bird has no resemblance whatever; it is absolutely indistinguishable from the Pennsylvanian Pipit, but might be confused by a careless observer with the Alpine Pipit. 
more or less a rock bird, breeds on the highest mountains, above the limit of forest-growth, on the borderland of a region of perpetual snow. It is said to leave its lowland haunts in March or early in April, ascending the mountains in small flocks, and waiting on the borders of the frost until summer clothes the mountain-sides with brilliant flowers and a luxuriant alpine flora. It is a somewhat shy bird, frequenting the ground or perching on the rocks, rumning about like a Wagtail in search of its food, and ever and anon essaying short fluttering flights into the air to warble its song, which somewhat resembles that of the Meadow-Pipit, but is louder, though not so swect. Its call-note resembles the word ist, and scarcely differs from that of the Meadow-Pipit or the Rock-Pipit. Its song-flights are often taken from the top of a stunted bush, a boulder, or large stone. Like all the rest of this subfamily of birds, it rums along the ground, never hops, and often wades into the little pools in search of its food. Its flight is undulating and uncertain, like that of its congeners.

The Alpine Pipit is very common in the Engadine, and frequents the higher mountain-slopes above the limit of forest-growth, seven or eight thousand feet above the level of the sea. At a distance these mountain-slopes look like barren rock and snow; but when you climb up to them the alpine flora, though somewhat sparsely scattered, is brilliant enough. On the outskirts of each snow patch the delicate little Soldanella abounds, and its pale purple flowers may often be seen growing out of the snow itself. In the more sheltered crevices in the rocks the crimson rhododendron blooms, but is represented on the more exposed knolls by the richly scented Daphne. On the dry limestone slopes the Edelweiss is common enough, and on the banks of the streams the gentians almost dazzle the eye by the deepness and intensity of their brilliant blue. Other flowcrs not less remarkable abound-the delicate bird's-eye primrose with its pale pink flowers, and a dozen others, saxifrages, asters, and the white and the blue aconite, reminding one continually of the flowers of the Siberian tundras. Here the Alpine Pipit is by far the commonest bird, and you may contrast his gentle ist with the loud mee-it of the Marmot, which are almost the only signs of animal life in these regions. A few other birds, however, are occasionally seen. The Wheatear ranges up to the snow-line, and by extremely good luck you may see a Snow-Finch, an Alpine Accentor, or a Ptarmigan. In its habit the Alpine Pipit resembles the Mearlow-Pipit. Late in summer they seem to be more or less gregarious, and often half a dozen or more are seen together.

The breeding-season of the Alpine Pipit commences in May, and its eggs are often laid by the sccond week of that month, sometimes late in April. Its nesting-site is selected on the ground or in a crevice of the rocks: sometimes a site is chosen amongst the stones; but it is usually amongst the herbage in its marshy haunts. The nest is made of dry grass, moss, 
and rootlets, and lined with finer roots, and sometimes with horsehair or wool. The eggs are four or five in number, generally the latter, very rarely six, and resemble closely those of the Rock-Pipit. Some specimens are French-white in ground-colour, finely mottled and spotted over the entire surface with dull purplish brown, and with one or two hair-like blackislbrown streaks on the large end. The markings on this variety are so close as to show very little of the ground-colour between them. Another variety is pale greenish white in ground-colour, more sparingly mottled, blotched, and spotted with olive-brown of various shades, intermixed with numerous underlying markings of lilac: this variety also exhibits a few dark lines on the larger end of the eggs. Another variety is yellowish white in ground-colour, and the spots are rich olive-brown, confluent at the large end, and concealing all trace of the ground. The markings on most eggs are very small, often confluent on the large end, but in a few specimens they are less numerous and larger. Some eggs are very green in general appearance, others are very purple, whilst many are rich olive-brown. They vary in length from 93 to 8 inch, and in breadth from 65 to 6 inch. The Alpine Pipit is said to have two broods in the year.

The food of this bird consists of insects, larva, small worms, and landshells; it will also eat small seeds in winter. The Alpine Pipit quits its mountain haunts in September or October, according to the state of the season, and in little parties repairs to the lowlands, where it frequents the low-lying meadows and marshes. Many of the Luropean birds seek more distant climes, and penetrate far into Africa at this scason. Dixon met with this bird in its winter-quarters at Biskra, on the borders of the Great Desert; their haunts here were beside the Oued Biskra, and in a little marsh which was also alive with Wagtails, all on their journey northwards to breed. Canon Tristram also met with a small flock of Alpine Pipits in the marshes at Laghouat, another oasis still further in the Desert, and also saw another flock, which he supposed to be this species, at Tuggurt.

The Alpine Pipit in brecding-piumage has the gencral colour of the upper parts sandy brown, suffused with slate-grey on the back and upper tail-coverts, and shading into almost pure slate-grey on the head and nape; the feathers on the head and back have obscure dark centres; a pale buff streak passes from the base of the bill over the eye; the outermost tailfeather on each side has the greater part of the outer web and an elongated triangular patch on the imner web white, the next feather on each side has only a narrow streak of white ruming down the shaft from the tip. The chin, centre of the belly, and under tail-coverts are buffish white; the rest of the underparts are pale chestnut-buff', shading into olive-brown on the flanks. Bill very dark brown above, paler below; 
legs, feet, and claws blackish brown; irides dark brown. The female resembles the male in the colour of her plumage. In autumn the general colour of the upper parts is a richer brown, and lacks the slate-grey on the head and nape, which are almost uniform with the back; the dark centres are somewhat more pronounced; the general colour of the underparts is white, tinged with buff, shading into brown on the flanks, and marked on the sides of the neck and across the breast with large dull streaks of brown. Birds of the year resemble adults in this plumage, but are more streaked on the underparts. In autumn plumage the Alpine Pipit very closely resembles the Rock-Pipit, but may easily be distinguished by the colour of the outer tail-feathers; in the present species they are marked with white, whilst in the Rock-Pipit they are marked with smoke-brown.

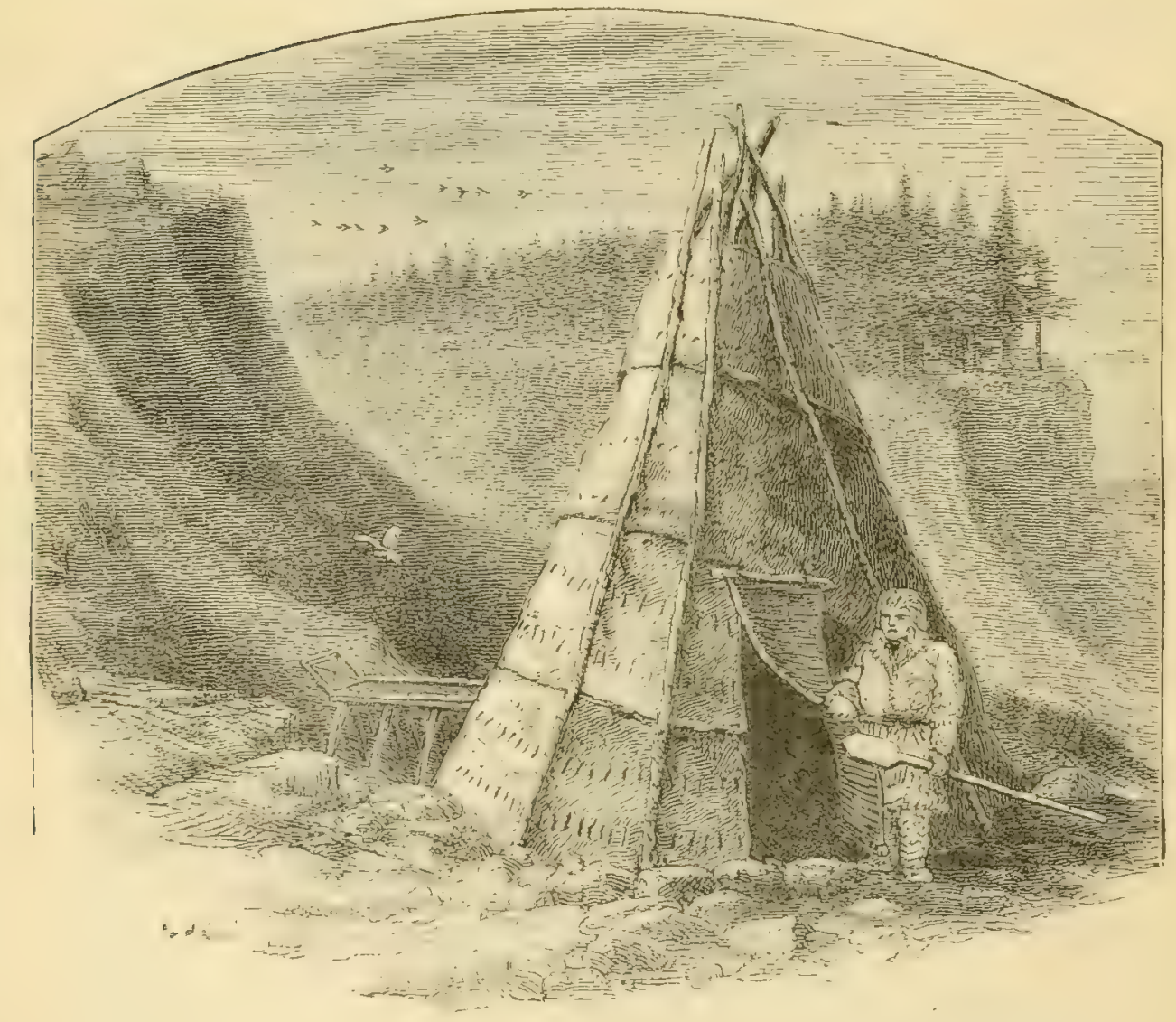




\section{Subfamily ALAUDIN正, or LARKS.}

The Larks are a small group of birds which may at once be distinguished from all the other subfamilies of the Passerida by the scutellations at the back as well as the front of the tarsus. In what appear to be old birds these scutcllations are, however, almost obsolete. The hind claw is very slightly curved, and frequently much elongated. The wings are long and pointed, the second, third, and fourth primaries being nearly equal in length. The first primary is generally very minute, but in some genera it is more developed. The bill varies greatly in this subfamily, being in some genera almost as slender as in the Tree-Creeper, whilst in others it rivals in stoutness the bill of the Pine-Grosbeak. In spite of the scutellations of the back of the tarsus, there can be little doubt that the Larks are very closely related to the Pipits, though they further differ from those birds by having no spring moult, the breeding-plumage, where it differs from that of winter, being assumed by casting the ends of the feathers. Young in first plumage do not resemble their parents, but are spotted all over. The Larks appear to bear the same relation to the Pipits that the Thrushes do to the Warblers.

There are probably about seventy species of Larks, which are divisible into several genera*, one only of which is represented in Europe. The Larks belong to the Old World, and are chiefly confined to the Palrarctic, Ethiopian, and Oriental Regions. One of the Palacarctic species is circumpolar, and each of the Australian, Neotropical, and Nearctic Regions contains a solitary species.

\section{Genus ALAUDA.}

The genus Alauda was included by Linnæus, in 1766, in the twelfth edition of his 'Systema Nature,' vol. i. p. 287, the Sky-Lark (the Alauda alauda of Brisson) having been by common consent admitted to be the type.

* In the 'Proceedings of the Zoological Society of London' for 1874 (pp. 614-651) my friend Mr. Bowdler Sharpe published an elaborate article on the Larks of Southern Africa. It is written with all the careful elaboration of the details of the colours of the plumage 
The characters of this genus consist in the smallness of the first primary, which is less than the primary-coverts, and sometimes apparently absent altogether.

It contaius about twenty species, all confined in the breeding-season to the Paliearetic Region, except one species, which is circumpolar, and two nearly allied species, one of which is Nearetic and the other Neotropical. Six species are included in the British list, but only two of them breed in our islands. Four other species are European.

The Larks chicfly frequent sandy open plains, and are also found on cultivated land, but a few species are more arboreal. They do not perch much on trees, but walk and rum along the ground with great ease and quickness. 'The Larks furnish a most interesting instance of protective colouring, and their plumage harmonizes very closely with surrounding objects. MIost of the species are fond of dusting themselves. They separate into pairs in spring, but are more or less gregarious in autumn and winter. Many species are migratory. They are moderately good songsters, and generally sing whilst fluttering in the air, often ascending to an immense height. Their flight is powerful, slightly undulatory, and performed with rapid beatings of the wings with occasional cessations. 'Their food consists of insects, worms, and small seeds in summer; but in winter they are almost exclusively granivorous. All the specics breed on the ground, and their nests are slightly made of dry grass, lined with roots

and of the complicated synonymy of each species which are so characteristic of the author' of the principal volumes of the 'C'atalogne of Birds in the British Museum.' This raluable and important contribution to our linowledge of the ornithology of the Ethiopian Region is prefaced by a key to the genera of the subfamily Alaudinx, which is elevated to the rank of a family, and is subdivided into no fewer than nineteen genera. The so-called structural characters on which these genera are based are no more ridiculous than are most of the characters which modern ornithologists select in their mania for genusmaking; ; and I only point to this article as a fair illustration of the absurdity of the system. Many of the so-called generic charncters are not even of specific value, and vary in individuals of the same species; others, though true of typical species, do not hold good of the aberrant nembers of the genus; whilst most of them are of such a trivial nature that it is impossible to read them without a smile. The whole key to the genera reads like an ornithological jeu d'esprit. It is scarcely conceivable that generic distinctions founded on the relative length of the culmen and the middle toe, or of the crest-feathers and the tarsus, can be meant to be taken seriously. Of the seventy or more species of Larks, many are so nearly related that they can only be regarded as local races, whilst others have become specifically distinct; but the whole group is of such recent origin that there has not been time for a sufficient number of species to have become extinct to make gaps wide enough to be recognized as well-defined natural genera. We may perhaps separate the flat-winged Palrarctic Larks from their Preglacial round-winged confières in the Ethiopiau and Oriental Regions; but the two groups are connected together by the intermediate groups of the Larks which were driven to the confines of these regions during the Glacial period. 
or hair. Their eggs are from three or four to six in number, and vary in ground-colour from white to pale bluish green, more or less thickly mottled and speckled with brown of different shades, and with underlying markings of violet-grey.

The species of the genus Alauda may be subdivided into three groups, differing in size and pattern of colour. The truc Alaude, or Sky-Larks, have the general colour of the upper parts brown of some shade, each feather, including the wing-coverts and innermost sccondaries, having a dark centre; and the underparts are nearly white, streaked only on the breast, and sometimes on the flanks. The Melanocorypha, or Steppe-Larks, are distinguished by their large size and thick bills, and vary in pattern of colour, some differing but little in this respect from the Sky-Larks, but others having many of the secondaries pure white. Most of them have more or less black on the breast, and the adult male of one species is almost a uniform black. The Otocoridx, or Shore-Larks, are more distinct, having always black breasts, and in the adult males a black patch across each ear-covert, and another on the crown, ending on each side in elongated tufts or horns. With the exceptions already mentioned in the Melanocoryphe, the wing-feathers in this genus are brown, with pale edges; the two centre tail-feathers are coloured like the back, the next four on each side are dark brown, but the colour of the two outside feathers is variable.

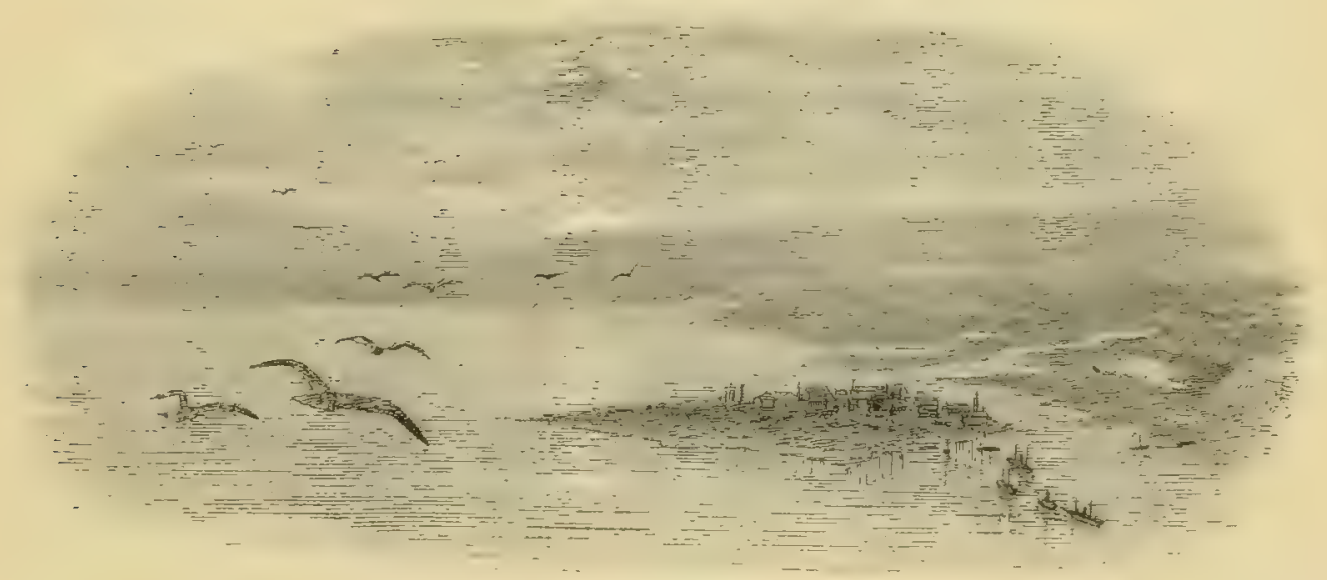




\title{
ALAUDA ARBOREA.
}

\section{WOOD-LARK.}

\author{
(Plate 15.)
}

Alauda arborea, Linn. Syst. Nat. i. p. 287 (1766); et auctorum plurimorumGmelin, Latham, Scopoli, Temminck, Degland \& Gerbe, Salvadori, Dresser, Neuton, \&c.

Alauda nemorosa, Gmel. Syst. Nat. i. p. 797 (1788).

Alauda cristatella, Lath. Ind. Orn. ii. p. 499 (1790).

Lullula arborea (Linn.), Kaup, Natiirl. Syst. p. 92 (1829).

Galerida nemorosa (Gmel.), Brehm, Vög. Deutschl.p. 316 (1831).

Galerida arborea (Linn.), Brehm, Vög. Deutschl. p. 317 (1831).

Few British birds are more widely but locally distributed in our islands than the Wood-Lark. It seems to be nowhere very common, but is found in well-planted districts where the soil is sandy or at least dry. It avoids wet or clay land, but probably breeds in suitable districts throughout the southerm half of England and Wales. In the north of England it is more local and less abundant than in the south, but has been known to breed in most counties. In Scotland it is a rare bird, and is only known to have bred in one locality-at Torwood in Stirlingshire, where its nest was taken by my friend Harvie-Brown. It has, however, occurred more or less frequently in many other parts of the country, as far north as Caithness; and a specimen was killed in Mr. Dumn's garden at Strommess in Orkney. Thompson says that it is very local in Ireland, appearing principally to be found in those counties bordering the eastern and southern coasts, from Antrim in the north to Cork in the south-west.

The Wood-Lark is locally distributed throughout Central and Southern Europe. In Scandinavia and West Russia it only occurs accidentally north of lat. $60^{\circ}$, and in East Russia it does not apparently range further north or east than the valley of the Volga. In the north of France, Holland, Belgium, Germany, and in the rest of its range to the north and the east it is a summer visitor only. In the south of France, Spain, Portugal, North-west Africa, Italy, Turkey, Greece, Asia Minor, the Caucasus, and North-west Persia it is principally known as a winter visitor, but a few remain to breed in the mountains. It occasionally straggles into North Egypt in winter. The Nood-Lark has no near ally, and is subject to scarcely any local variation in colour.

In this country the Wood-Lark appears to be an irregular or partial migrant, often leaving its summer haunts at the approach of winter to retire to districts where it is unknown in the breeding-season. Neverthe- 
less in some places it is a constant resident, and its charming song may be heard almost throughout the year. The Wood-Lark frequents very different places to those chosen by the Sky-Lark, and is principally found on the borders of woods and groves, in open spaces in forests, or in the immediate neighbourhood of plantations. In some localities it frequents parks and fields; in others it is seen on the borders of heaths and commons; but in every situation the presence of trees seems indispensable to this charming little bird. Like the Tree-Pipit it seldom wanders far when once it has selected a summer home, and the observer may almost be certain of finding it in its chosen locality throughout the season. It also appears to return, if migratory, every season to its old summer-quarters. During the winter the Wood-Lark is more or less gregarious; but its sociability seems to cease very early in the year, and about the end of liebruary or beginning of March it pair's and betakes itself to its breeding-quarters. Its habits in spring more resemble those of the Tree-Pipit than the Sky-Lark, and there can be little doubt that the two birds are often confused by careless observers.

At its breeding-grounds in carly spring the Wood-Lark spends much of his time in song. Ife often chooses a perch on the dead branch of a tree, sometimes on the very summit, from which to warble his delightful song, which he continues for hours. At other times he sings as he soars in circling flight above his favourite trees; and will sometimes even sit on the ground and warble almost as sweetly as when in the air. The song of the Wood-Lark is certainly supcrior to that of the Sky-Lark; it is not quite so loud, but is even more continuous; and if it be more monotonous, the richuess of the tone almost approaches that of the Blackeap, whilst sometimes one is tempted to compare its plaintive melody with that of the Nightingale. The song-flight is very similar to that of the Sky-Lark, but performed more in circles; and the bird seldom soars so high, and usually warbles for some time whilst hovering in the air. Its song is commenced before dawn and is kept up at intervals throughout the day and even into the dusk of evening.

The Wood-Lark sings until the moulting-season and regains its song in September, warbling at intervals throughout the winter if a warm sumny day occurs. As might be expected, the Wood-Lark is in great request by the bird-fancier; and the practice of trapping it for confinement has been the primary cause of its scarcity or total absence from some districts, especially in the neighbourhood of large towns. The call-note of the Wood-Lark is a double one, very musical and something like that of the Sky-Lark.

The Wood-Lark is very active upon the ground, ruming about in search of food and often crouching so closely to the earth as to allow itself to be almost trodden upon ere it takes wing. When rising into the air it usually

VOL. II. 
utters its musical note (common to both male and female) and takes refuge in the trees. The Wood-Lark is a thorough ground-bird, notwithstanding the fact that it is in nine cases out of ten first observed in a tree, and only repairs to the branches to sing, or as a starting-place for its aerial wanderings. It roosts on the ground, obtains the greater part of its food upon the ground, and on the ground it builds its nest.

Dixon met with this bird in Algeria and writes :- "I only saw the WoodLark in one locality in the country, and that was amongst the wooded heights of the Aures, west of Batna. My first Algerian experience of this interesting little bird was made in early morning; and so common were they in a little clearing in the cedar-forest that the air seemed resonant with their songs. Although my attention was too much confined to the rare little Algerian Coal-Tit, so much so that I scarcely heeded such a common hird as a Wood-Lark, beyond shooting one for identification, I could not help noticing how tame and trustful they were-so different from my experience of them in England. I never saw them in the forest; they preferred the open spaces-places where the trees had either been blown down by tempests or cut down by the French foresters. I could count as many as six in the air together, all singing lustily ; and very often one would sit on a low bush and allow me to approach it within a few yards. They did not perch in the thickest part of the trees, but generally selected a dead branch, from which they would sit and warble in spite of the reports of our guns in the neighbouring forest. I saw one of these birds assisting some Firecrests in mobbing a poor Kestrel that had quite unintentionally disturbed them, and then soar into the air and utter a song of triumph as the big bird took refuge amongst the cedars."

In this country the Wood-Lark appears to be an early breeder. Newton states, in his edition of Yarrell's 'British Birds,' that the first eggs are often laid by the middle of March; but in the Parnassus I have taken nests with fresh eggs as late as the third week in May. The nest is always built upon the ground, and is generally well concealed under the shelter of a tuft of herbage or a little bush, or amongst tall grass; whilst Professor Newton states that it is sometimes placed on the smoothest turf, and that he has seen one in a stump of heather. It is made of coarse grass, scraps of moss, and a few bits of twitch, and is lincd with fincr grass and sometimes a little hair. The nest is generally placed in a little cavity, and is much more firmly constructed than that of the Sky-Lark or the Tree-Pipit. The eggs of the Wood-Lark are four or five in number ; sometimes those of the second elutch are only three. The ground-colour varies from buffish white to very pale greenish white, but the spots are always reddish brown with underlying markings of violet-grey. On some eggs the markings are very small and evenly distributed over the entire surface; others have the majority of the spots collected in a zone, sometimes round the middle, 
but more frequently round the large end; whilst some have most of the markings in a scmi-confluent mass at the large end. They vary in length from 9 to $\cdot 78$ inch, and in breadth from $\cdot 7$ to $\cdot 6$ inch. The eggs of this bird differ very considerably from those of the Sky-Lark, the only eggs with which they are at all likely to be confused. The ground-colour is more exposed and whiter, and the spots are reddish brown instead of oliveor neutral brown, and generally much smaller, better defined, and have not such a tendency to become confiuent. If the eggs of birds are any guide to the affinity of the birds themselves, the Wood-Lark must be very nearly related to the Crested Lark. The eggs of the two birds resemble each other very remarkably; those of the Crested Lark are larger and on an average grecner, but the pattern of the spots and the general resemblance is very striking. As soon as the young of the first brood are able to take care of themselses, they appear to be abandoned by their parents, who often rear a second brood. Like most ground-building birds, the Wood-Lark is a very close sitter, and often allows herself to be almost trodden upon before she quits her charge.

The food of the Wood-Lark does not differ, so far as is known, from that of its congeners. In the summer, or in fact whenever it can obtain them, insects are most sought after; but in winter it eats secds of various kinds, and also tender shoots of herbage.

After the young of the second brood can fly they generally leave their birthplace, and in company with their parents roam about in quest of food. These little family-parties often join others; but the Wood-Lark is never seen in such vast flocks as the Sky-Lark. At this season the bird keeps chicfly to the ground, scarching for its food amongst the dead leaves and herbage below the trees or even in the open fields; but sometimes a few days of fine mild weather or a gleam of sunshine will send the cock birds to the trees, whence they warble just as sweetly as in early summer. On being approached these small partics of Wood-Larks gencrally rise into the air one or two at a time, always uttering their liquid musical call-note, and fly off to some distance, some taking refuge in the tree-tops, others alighting on the ground again. Sometimes a bird or two of the present species may be noticed in company with Sky-Larks. Apparently few, if any, Wood-Larks come to our islands to winter ; for the bird is seldom or never observed in those parts of the country which are recognized landing-places for migratory birds, although the autumnal flights of the Sky-Lark are an "event" noticed by even the most casual of observers.

The adult male Wood-Lark in breeding-plumage has the general colour of the upper parts brown; the dark ecntres of the feathers are well defined and almost black on the head and back, somewhat more obscure on the nape, and entircly absent from the rump and upper tail-coverts; the primary-coverts are tipped with white; the cye-stripes are nearly white and 
almost mect on the nape; the outer tail-feathers are brown on the terminal half, and the three next on each side have white terminal triangular spots. The underparts are pale buffish white, and the streaks on the breast are very distinct. Bill dark brown above, paler below; legs, feet, and claws light brown; irides hazel. The female resembles the male in colour. After the autumn moult the general colour of the upper parts is rich buffish brown, and the underparts are suffused with pale olive-brown. Birds of the year have the streaks on the breast more numerous and extending to the flanks. Young in first plumage are spotted on the upper parts with black and buff', and the underparts are very yellow and profuscly spotted with blackish brown, except on the centre of the belly and under tailcoverts.

The Wood-Lark may be recognized on the wing by its short tail. In the hand its bastard primary, which is well developed, almost as long as the primary-coverts, and the white spots at the end of the tail-feathers are its chief characteristics; and its nostrils are quite distinct from those of any other British species of Lark, being half exposed and overhung by an operculum. The peculiarities of this bird have induced some ornithologists to recognize it as generically distinct under the name of Lullula ; and if it was advisable to split up the genus Alauda, this genus would certainly be the most distinct of the subgencra contained in it. Strange to say, it is not recognized by Newton or Dresser, both of whom recognize Otocoris, Calandrella, and Melanocoryphla, and the latter Galerita also, none of which are nearly so distinct.

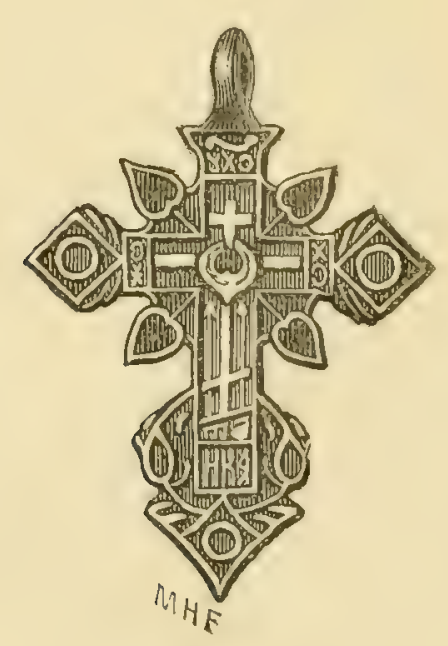




\title{
ALAUDA CRISTATA.
}

\section{CRESTED LARK.}

\author{
(Plate 15.) .
}

Alauda senegalensis cristata, Briss. Orn. iii. p. 362 (1760).

Alauda cristata, Limn. Syst. N'at. i. p. 288 (1766); et auctorum plurimorumGmelin, Scopoli, Latham, Temminck, Naumann, (Bonaparte), (Degland \&; Gerbe), Newton, (Dresser), \&c.

Alauda cocheris, Miill. Natursyst. Suppl. p. 134 (1776).

Alauda senegalensis, Muill. Natursyst. Suppl.p. 137 (1776).

Alauda matutina, Bodd. Tabl. Pl. Enl.p. 40 (1783).

Alauda undata, Gmel. Syst. Nat. i.p. 797 (1788).

Alauda galerita, Pall. Zoogr. Rosso-Asiat. i. p. 524 (1826),

Galerida cristata (Linn.), Boie, Isis, 1828, p. 321.

Lullula cristata (Linn.), Kaup, Nat. Syst. pp. 92, 192 (1829).

Galerida viarum, Brehm, Vög. Deutschl. p. 315 (1831).

Alauda chendoola, Franklin, Proc. Zool. Soc. 1831, p. 119.

Heterops cristatus (Linn.), Hodgs. Gray's Zool. Misc. p. 84 (1844).

Certhilauda chendoola (Frankin), Blyth, Journ. As. Soc. Beng. xiii. p. 962 (1844).

Certhilauda boysii, Blyth, Joum. As. Soc. Beng. xv. p. 41 (1846).

Galerida chendoola (Franklin), Blyth, Cat. As. Soc. Mus. p. 133 (1848).

Galerida abyssinica, Bonap. Consp. i. p. 245 (1850).

Galerida senegalensis (Gmel.), Bonap. Consp). i. p. 245 (1850).

Galerida boysii (Blyth), Bonap. Consp. i. p. 245 (1850).

Galerita cristata (Linn.), Cab. Mus. Hein. i. p. 125 (1851).

Galerita theklae, Brehm, Naumannia, 1858, p. 210.

Galerida arenicola, Tristram, Ibis, 1859, p. 58.

Galerida brachyura, Tristram, Proc. Zool. Soc. 1861, p. 435.

Alauda cristatella, Heuglin, fide Cab. Journ. Orn. 1868, p. 223.

Alauda (Galerita) arenicola?, Tristram, var. fusca, Blanford, Geol.\&. Zool. Abysinia, p. 387 (1870).

Alauda marginipennis, Pr. Wiirt., fide Heuglin, Ornn. Nordost-Afr. p. 681 (1871).

The Crested Lark probably visits our islands more frequently than is supposed; for partly owing to its habits and partly to its resemblance to the Sky-Lark it is often overlooked. It was first recorded as a British bird in 1836 by an anonymous writer in the 'Dublin Penny Journal,' who asserted that he had shot an example not far from the Irish capital. Examples have subsequently been obtained in this country, which render its claim to be considered a British bird complete. The first example of this species obtained in England was recorded in the second edition of Yarrell's 'British Birds,' and was killed at Littlehampton, in Sussex; but the precise date does not seem to be known. Another example was obtained in the same county, at Shoreham, by a bird-catcher, on the 20th of October, 1863 (Dawson Rowley, 'Ibis,' 1864, p. 224). Five examples 
have been obtained at different times in Cornwall. Two were procured near Penzance, in September 1816 (Rodd, 'Zoologist,' 1846, p. 1497), and another was obtained in the same neighbourhood on the 21.th of October, 1850 (Rodd, 'Zoologist,' 1851, p. 3033). 'The fourth was captured near Falmouth in the latter part of 1865, and was killed by $\mathrm{Mr}$. Gill of that town (Bullmore, 'Cornish Fauna,' p. 20) ; and on the 12th of June, 1880, the fifth example was shot in a garden at Helston, in Cornwall (Hart, 'Zoologist,' 1880, p. 302). 'This bird is also said to have occurred near Blackheath (IIutchinson, 'Zoologist,' 1868, p. 1167), at Macclesfield (Painter, 'Nature,' 1873, is. p. 132), and on the Isle of Wight (Hadfield, 'Zoologist,' 1877, p. 450).

The examples of this species which have been obtained in this country have chicfly occurred in autumn, and have probably been migrants from South Sweden or Denmark via Heligoland; but an alleged instance of the Crested Lark having bred near Cambridge in 1881 is recorded (Harting, 'Zoologist,' 1883, p. 178). This bird does not appear to have occurred in Scotland.

The Crested Lark is a common though local resident in Central and Southern Europe; it does not occur in Norway, and is very rare in South Sweden, but it occasionally strays as far north as Upsala, in lat. $60^{\circ}$. In Russia it has occurred at St. Petersburg (lat. 60 ) in the west, and breeds up to lat. $54^{\circ}$ in the east. It has not occurred in Siberia, but is a resident in Palestine, Asia Minor, Persia, Turkestan, Afghanistan, Baluchistan, and North-west India. Prjevalsky records it from South-east Mongolia, and it is a resident in North China, and probably also in Tibet. It is a resident in Europe south of the Baltic, and in North Africa as far south as Abyssinia. In winter its numbers are decreased in the northern and increased in the southern portions of its range.

The Crested Lark varies considerably both in size, colour, and dimensions of bill; but the variations appear to be purely protective, and are referable to the nature of the country on which the birds are found rather than to differences of geographical distribution. The extreme desert form, A. cristata var. isabellina, has hitherto ouly been recorded from the desert regions of North Africa. A slightly less rufous, but still very sandycoloured form, A. cristata var. magna, is found in Turkestan, Scinde, Algeria, and elsewhere on semi-desert ground. In Algeria the bill of this form is occasionally more or less elongated, constituting a race worthy of recognition as $A$. cristata var. macrorhyncha. The typical form, which is greyer, is principally found in Europe; but intermediate forms between it and the scmi-desert form occur in India. Chinese examples, A. cristata var. leautungensis, are generally reddish brown, but some are scarcely distinguishable from the semi-desert form. According to Heuglin, all these varieties of coloration are found at different clevations in Abyssinia. 
It is somewhat remarkable that the Crested Lark should be so very rare in our islands. Across the Channel it is common enough, especially so where the soil is sandy. It is said to be very common in the north of France, and I have seen it repeatedly on the sandy heaths of South IIolland. In the valley of the Rhine I have remarked its special abundance near Diisscldorf, where it may be seen every day in the Zoologieal Gardens, dusting itself in the sandy soil ; and to the west, the district round Brunswick is remarkable in the eyes of an Englishman for its Crested Larks and its asparagus. The reason it so seldom crosses the Channel is probably to be found in the fact that in all these districts it is a resident bird. In its habits it differs considerably from the Sky-Lark. It is even more of a ground-bird than that species. It is very rarely seen to perch in a tree, nor does it frequent the tops of the thistles and other rank herbage as the Sky-Lark often does. It generally sings on the ground, and its song is very short and monotonous, not unlike that of the Corn-Bunting. Occasionally the song may be heard as the bird makes short Pipit-like excursions into the air ; but I have never seen it soar like a Sky-Lark. It is very tame, and is fond of dusting itself on the country roads and lanes, and even comes into the gardens and the farmyards, oceasionally perching on the garden-wall, or sometimes on the roofs of the farm-buildings, and even on the telegraph-wires.

The Crested Lark begins to sing very early in the spring, and continues until the moulting-season in September. Its call-note is very similar to that of the Sky-Lark, a very liquid note, as if it was trying to whistle with its mouth full of water.

The Crested Lark is very common in Algeria; and Dixon made the following notes on it there:- "It is most interesting to trace the distribution of the Crested Lark in Algeria ; for by following this bird from the coast to the desert, you pass through considerable diversity of scenery, and find a variation in the colour of the bird corresponding with the changes of its habitat. From the coast to Constantine the birds are almost typical of the European race; for the country is well watered and well cultivated. South of Constantine a perceptible difference is to be seen in the birds, which also become much commoner. As the scencry gradually changes from cultivated fields to wilderness, from vegetation to desert, the Crested Larks become much more sandy-coloured; and on the shifting sands of the desert we have a bird very different in coloration from those haunting the districts where vegetation is abundant. These colours are eminently protective; on the rich soil the grey or olive-brown plumage is in strict harmony with the surroundings, whilst on the sandy wastes the rufous tints are equally sucecssful in shielding the birds from danger. I have repeatedly flushed these birds from my feet in the barest of situations without seeing them until they were in the air. The Crested Lark 
frequents the roads, the open ficlds, the dried-up beds of watercourses, the broad sand-plains, and the mountain heights; and in the latter situation I took its nest 5000 feet above the level of the sea, hidden amongst the pieces of rock and scanty vegetation of the mountain-sides. In some localities this bird was almost the only sign of life, as it alternately flew and settled before us as we went along. Upon the ground it runs very quickly, and its crest is more often kept close lown to the head than held erect; nevertheless it can always be seen. Although the Crested Lark does not, so far as I know, associate with Desert-Larks, it frequents the same places, and in the lialf dried-up Oued Biskra both species were very common. I often saw this bird soar into the air for perhaps a hundred yards or so, all the time warbling its simple song; and I have watched it for some time in the act of singing when perched on an oleander bush. It is rather a skulking liud, and if shot at much soon becomes rery wild and shy. I seldom noticed it near houses; it seemed quite independent of man, and apparently able to get a sustenance in localities that seemed incapable of supporting any bird-life at all."

The hrecting-season of the Crested Lark commences early in April, sometimes later. In many cases the bird will build its nest quite close to houses, on ploughed land, in corm-ficlds, and in gardens; and Naumann says that it is sometimes placed on an old earth-wall or amongst the thatch of a low shed in the ficlds. In less cultivated districts the bird's choice is often made amongst the scanty herbage on the mountain-sides or bencath the shelter of a little stunted bush; whilst on the bare and sterile desert it places its nest amongst the stones and scanty regetation struggling for cxistence against the fierce sum and the arid waterless soil. The nest is almost always built upon the ground, either in a little hole scratched out by the parent bird or in the footprint of some animal: it is somewhat loosely made of dry grass, twitch, rootlets, and a few straws, and is often lined with a few hairs; but the latter material is not always used, for sometimes it cannot be obtained. The male is said to kicep company with liv mate and to assist her in collecting materials when the nest is being built, but he does not take any share in its construction. The eggs of the Crested Inark are four or five in number, and differ considerably in the colour and character of the markings. The ground-colour varies from the palest of creamy white to very pale greenish white, spotted, mottled, and blotcher with almost nentral browu, and with numerous underlying marking Lark, the brown spots being well defined, and the grey markings large and conspicuous. The spots on this type are evenly distributed over the entire surface, but do not hide more than half of the ground-colour. Another type is very fincly dusted and speckled with hair-brown, most numerously at the large end of the egg, where many of the markings are confluent, 
forming a zone. Others sometwhat closely resemble those of the Sky-Lark, and the markings are so thickly distributed as to conceal most of the pale ground-colour. Some eggs are much yellower than others, and they differ considerably in shape. They vary in length from 1.0 to 9 inch, and in breadth from $\cdot 71$ to $\cdot 6$ inch.

The food of the Crested Lark does not differ from that of its congeners. In the spring and summer it is chiefly composed of insects and larve, and in the autumn and winter of various small sects and grain. The Crested Lark is much prized as a songster, and is often kept in confinement. In India, according to Jerdon, it is the practice to keep the poor little captive in darkmess by wrapping several layers of cloth round the cage, in which state it not only sings very smectly but learns to imitate various sounds.

After the breeding-season the Crested Lark becomes to some cxtent a social bird; but it is never observed in such large flocks as those of the Sky-Lark.

The typical form of the Crested Lark in breeding-plumage has the general colour of the upper parts greyish brown, with a tinge here and there of buff, especially on the upper back and nape; the dark centres of the feather's are obscurely defined, except on the crest, and are entirely absent from the rump and upper tail-coverts, which are very buff; over the cye is a buffish-white stripe; the outermost tail-feather on each side is light brown with the outer web buff, and the next is narrowly margined with buff on the outside web. The general colour of the underparts is buffish white, sharling into rich buff on the flanks and thighs; the sides of the throat and the breast are spotted with dark brown, and the flanks are sparingly streaked with the same colour. Bill brown, paler on the under mandible; legs, feet, and claws pale brown; irides hazcl. The female resembles the male very closcly in colour, but has a shorter crest. In autumn plumage the pale margins of the feathers are much broader, and partially conceal the dark centres, and the whole plumago is more suffused with buff. Young in first plumage are much paler than adults and have the feathers of the upper parts barred with blackish brown near the tip, which is pale buff. The Crested Lark may always be distinguished by its crest, by the well-developed first primary (which is nearly as long as the primary-coverts), and by the absence of white on the two outer tailfeathers.

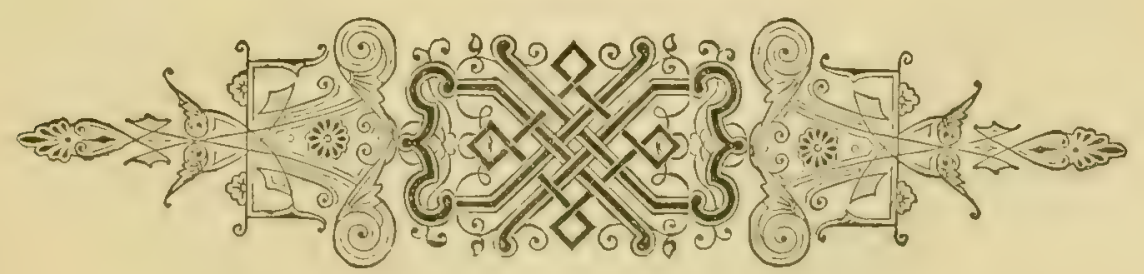




\title{
ALAUDA ARVENSIS.
}

\section{SKY-LARK.}

\section{(Plate 15.)}

\author{
Alauda alauda, Briss. Om. iii. p. 335 (1760). \\ Alauda arveusis, Limn. Syst. Nat. i. p. 287 (1766); et auctorum plurimorum- \\ Scopoli, Latham, Temminck, Naumann, Bonaparte, Salvadori, Newton, Dresser, \\ sc. \\ Alauda italica, Gmel. Syst. Nat. i. p. 793 (1788). \\ Alauda vulgaris, Leach, Syst. Cut. Mamm. Sc. Brit. Mus. p. 21 (1816). \\ Alauda coelipeta, Pall. Zoogr. Rosso-Asiat. i. p. $52+$ (1826). \\ Alauda cantarella, Bonap. Comp. List B. Eur. \&; N. Amer. p. 37 (1838). \\ Alauda montana, Crespon, Faun. mérid. France, p. 319 (1844). \\ Alanda triborhynchus, Hodys., Gray's Zool. Misc. p. 84 (1844). \\ Alauda dulcivox, Hodlys., Gray's Zool. Misc. p. 84 (1844). \\ Alauda japonica, T'emm. \& Schley. Faun. Japon. p. 87, pl. xlvii. (1847). \\ Alauda pekinensis, Swinhoe, Proc. Zool. Soc. 1863, p. 89. \\ Alauda intermedia, Swinhoe, Proc. Zool. Soc. 1863, p. 89.
}

The Sky-Lark is very widely distributed throughout the British Islands, and is a resident except in the extreme north. It is as common in Scotland as it is in England, extending to the Outer Hebrides, the Orkmeys, and Shetland. The same remarks apply to Ireland, where it is as widely dispersed as in the rest of the United Kingdom.

The Sky-Lark inhabits nearly the whole of the Palaretic Region, from England to Kamtschatka. As is the case with so many other birds, its range becomes more restricted both to the north and the south as it proceeds eastwards. In Western Europe it breeds up to latitude $70^{\circ}$ (although it is comparatively rare north of the Aretic circle) and in North Africa as far south as the southern slopes of the Atlas Mountains. In Archangel it is comparatively rare; in the valley of the Petchora HarvicBrown and I only obtained two stragglers, in lat. $65 \frac{1}{2}^{\circ}$; in the valley of the Yenesay I only obtained one specimen, in lat. $66_{2}^{10}$; and in East Siberia it has not been obtained north of lat. $60^{\circ}$. In Japan, the valley of the Amoor, South-east Mongolia, Turkestan, and Persia it only breeds at high elevations. To Asia Minor, Palestine, Greece, and Egypt it is only a winter visitor, and comparatively rare in the latter country. It also winters in North-west India and North China. To Europe north of the Baltic, and probably throughout Siberia, it is only a summer visitor. It passes through Afghanistan on migration, and has accidentaliy occurred on Greenland, the Bermudas, and Madeira.

Few small birds difler more in size than the Sky-Lark, the length of 
wing varying from 4.9 to 3.9 inch, both large and small forms being found from England to Eastern Siberia. The variation in colour is also considerable, independently of the fact that freshly moulted autumn birds are much more rufous than birds in abraded summer plumage. Summer examples from East Siberia, and winter examples from North-west India, Asia Minor, and Palestine (presumably from loealities where the rainfall is comparatively small), are much greycr in plumage and have been described as distinct under the name of $A$. dulcivox, but are evidently nothing more than a climatic race of the Common Sky-Lark. In Japan, where the influence of the Pacific produces a climate somewhat similar to that of Western Europe, the Sky-Larks again become more rufous in colour; and freshly-moulted examples may possibly be a shade more rufous on the margins of the wing-feathers and on the rump and upper tailcoverts, and a somewhat purer white on the belly, than English birds at the same season, and might be regarded as a distinct variety, under the name of $A$. japonica, by those ornithologists who, as Dr. Coues expresses it, are anxious to determine the difference between the north and the northwest side of a hair. The difficulty of recognizing these varieties of the Sky-Lark is that they are climatic rather than geographical; and if the three forms we have named be recognized, it would probably also be necessary to admit many other intermediate forms from widely distant localities. In Turkestan, India, and South China a decidedly smaller race of the Sky-Lark occurs, which varies in length of wing from 3.7 to 3.2 inch. This race is also subject to the same climatic variation in colourexamples from Turkestan and India (A. gulgula) being paler and greyer, and those from South China and Ceylon (A. colivox) being darker and more rufous. These two latter forms are no doubt conspecific.

No bird is better known or more frequently kept in confinement than the Sky-Lark. It is easily caught, readily tamed, and bears its captivity well, singing as sweetly on the sod in its little cage as when soaring in boundless freedom high up amongst the clouds. It is found in all kinds of places, from the coast to the inland moors and mountains, but is perhaps most abundant in well-cultivated districts. It delights to frequent arable land, rich meadows, and commons, but is never seen in woods or places where trees are very close together. It is also very partial to the most elevated pastures, and often deserts a sheltered valley to remain on them throughout the year. During winter the Sliy-Lark is gregarious; but very early in the spring the large flocks break up, and it retires to its breeding-grounds. In March, when the cold winds are drying up the fallows, and the first spring-flowers are appearing in the hedges, the SkyLark pairs. At this season several males may often be seen chasing a female with great rapidity through the air and every now and then bursting out into sweetest song. Sometimes a male will hover above the 
female, who crouches low amongst the herbage, and in various ways he will seek to display his charms. She will then often rise into the air, when several males will toy with her and flutter round and round or dart hither and thither with great speed, singing all the time. Sometimes the males will chase cach other, and even fight for the possession of the prize.

At this season of the year the Sky-Lark's song is particularly loud and charming. A few hirds will often be tempted to sing by an unusually mild day in winter, but the song is seldom fully resumed before March. The manner in which the Sky-Lark sings, in the full view of all observers, is probably the sccret of the bird's popularity. Who has not scen this sombre little bird rise from the meadow-grass or the heath, and has not watched its soaring flight as upward and upward it goes until it appears but a speck or is entirely lost in the sky? He bounds up from the cover on fluttering wings and with outspread tail, rising a little way in silence, then bursting into song he pursues his upward course. At first the wings are beaten very rapidly, in a fluttering way; but when the bird gets higher the movements are more regular. Sometimes it rises directly upwards, but very often goes far away from the place of its first ascent, sailing over the fields, but in an ever-rising course. When the zenith of its flight is reached it will sometimes fly about for a short time, singing; but more usually it comes down again directly. The song is continued until the ground is neared, when the bird usually drops like a stone or flutters off over the grass ere seeking the cover. These aerial movements are not essential to the bird's song; it will sing quite as sweetly when perched on a clod of earth or on the ground, and it often warbles a few notes when running about amongst the grass or over the fallows. The height of the song-flights also varies considerably. Sometimes the bird may be seen fluttering at a moderate height, singing very sweetly, and remaining in the air for some considerable time; and it will occasionally sit and sing on a small bush or a wall. When engaged in his soaring flights the little songster will cease his strains and drop to the ground if a Merlin makes its appearance, and if a Sparrow-Hawk do so he soars still higher; but a Kestrel is never regarded as an enemy.

The Sky-Lark has no great variety of notes, his compass is small, nor are those he possesses either powerful or rich in tone; but he pours forth his song so industriously, so continuously, and arranges his notes so harmoniously that the songs of few lirds are listened to with more pleasure. The song of the Sky-Lark is preeminently checrful; and if the monotony and continuousness of the music reminds you of that of a bagpipe, it has at least no melancholy in its tone: it is not continued for so long a time as is gencrally supposed, ranging from two minutes to about a quarter of an hour. The call-note of the Sky-Lark cannot be expressed on paper; it may best be described as a liquid musical 
double note, somewhat resembling the sound made by a whistle half full of water.

The Sky-Lark is not very shy, and will often allow the observer to watch it within a distance of a few yards. It rums about with great ease, often pausing for a moment to look warily around, stretching out its neck and standing as high on its legs as possible; but it often skulks very closely in the herbage. Its flight is quick and powerful, and when passing from place to place is straight or only very slightly undulating. The Sky-Lark is very foud of dusting itself, for the purpose of getting rid of troublesome parasites; it may often be seen on a sandy road, or in a little bare patch in the fields, lying on its side, shaking its wings, and thoroughly dusting its plumage. It always roosts upon the ground amongst tall herbage, and is seldom or never seen to perch in a tree.

Although the Sky-Lark often pairs early in March, nesting-duties do not generally commence before the middle of April. In exceptional cases eggs may be found as early as the first week in April. The nest is always built upon the ground amongst herbage, and is usually well concealed: gencrally it is placed amongst the meadow-grass or the growing corn, but sometimes it is built in the coarse herbage on commons and weedy pastures, or amougst the wiry heath-branches on the moors. It is often built behind a tuft of herbage, and is usually placed in a little depression often scratched out by the bird. The nest is a simple little structure, made extemally of dry coarse grass and a scrap or two of moss, and it is lined with finer grass, rootlets, and sometimes a few hairs. These materials are very loosely put together, as is usually the case in most nests built on the ground. The eggs of the Sky-Lark are four or five in number, sometimes only three. The ground-colour varies from dull white, to white with just a tinge of olive, and the markings are olive-brown or neutral brown, the underlying ones being pale grey. The spots are generally so thickly distributed over the entire surface as to conceal most of the ground-colour, and on the large end they are often confluent and form an irregular zone. On those eggs where the markings are not so thickly dispersed the zone is nuch broader and darker. A rare but very beautiful varicty of the egg of this bird is white in ground-colour, thickly mottled and spotted with brownish red, and with numerous underlying markings of grey. The eggs are not subject to any great variation in colour, but differ somewhat in shape, some specimens being very round, other's pyriform, and many oval; they vary in leugth from $1 \cdot 0$ to .87 inch, and in breadth from $\cdot 72$ to 63 inch. The Sky-Lark usually rears two broods in the year, the young of the first being generally abroad by the middle of June, and those of the second in August. 'The female performs most of the duties of incubation, and is a very close sitter, usually allowing herself to be almost trodden 
"pon before quitting the nest. In returning to the nest both birds usually drop into the herbage some little distance from it, and run through the grass the remainder of the distance. During the whole period of incubation the male bird is incessantly soaring upwards to warble his song, from the first streak of morning till dusk.

The Sky-Lark's song is usually hushed in the moulting-season; and after the young are safely reared the gregarious habits are assumed for the winter, the flocks of birds being sometimes very large. 'The food of the Sky-Lark in summer consists principally of insects, small grubs, and worms; but in winter seeds of various kinds, berries, and grain are almost its only fare. Many of the scerls upon which it feeds are those of the most troublesome weeds; and there can be no doubt that the bird is of great service to the agriculturist. In autumn a favourite haunt of the Sky-Lark is on the stubbles which have been sown with clover- "seeds," as they are technically called by the farmer. As the observer wanders over such a locality the birds will repeatedly rise at his feet, and uttering their liquid note, join into a straggling flock, and after whecling about for some time again alight. They do not all rise together like Starlings, but one or two at a time, and invariably alight in the same manner. When once the SkyLark has taken up its quarters in a field of this description in autumn, it rarely quits it until the following spring, except in the event of a severe fall of snow. Even then the birds return to their old quarters at the first signs of a thaw, when the plants on whose seeds they feed are again exposed. In winter Sky-Larks are often very irregular in their movements, which are to a great extent affected by snow-storms. When once a district is covered with snow the Sky-Larks usually leave it and retire to other places where the ground is still bare. They never appear to wander further than they are absolutely compelled, and invariably settle on the first bare ground that is suitable to them. In this manner the birds often foretell a coming storm, as they are driven before it to more congenial haunts. The Sky-Lark seems very much attached to its winter haunts, and no matter how much it is disturbed will seldom quit them except when compelled by hard weather. $\Lambda$ s they roost upon the ground great numbers are netted at night, their flesh being prized as a table delicacy. Other seedcating birds often congregate with Sky-Larks in winter, such as Buntings, Linnets, and Redpoles; but the present species is the only Lark which congregates in such enormous numbers; it is by far the most gregarious of its kind.

As might naturally be expected, the migrations of this bird can be admirably studied on Heligoland. During the migration period of the SkyLark, as many as 15,000 have been caught on this island in a single night; and this must of necessity be but a trifling pereentage of the number which passed. When in Heligoland in 18\%6, I shot on the 11 th of October three 
Shore-Larks; and Acuckens, the bird-stuffer, told me that the appearance of this Arctic species was a very good sign, as he had often noticed that a few birds always preceded the favourable weather, and that we might soon expect a change in the wind, and with it an abundance of birds. The next day the west winds which had prevailed for a week slackenerl a little. In the afternoon it was calm with a rising barometer; in the evening a breeze was already springing up from the south-east. I called upon Gätke, who advised me to go to bed and be up) before sumrise in the morning, as in all probability I should find the island swarming with birds. Accordingly I turned in soon after ten. At half-past twelve I was awakened with the news that the migration had already begum. IIastily dressing myself, I at once made for the lighthouse. The night was almost pitch-dark, but the town was all astir. In every street men with large lanterns and a sort of angler's landing-net were making for the lighthouse. As I crossed the potatoe-fields birds were continually getting up at my feet. When I

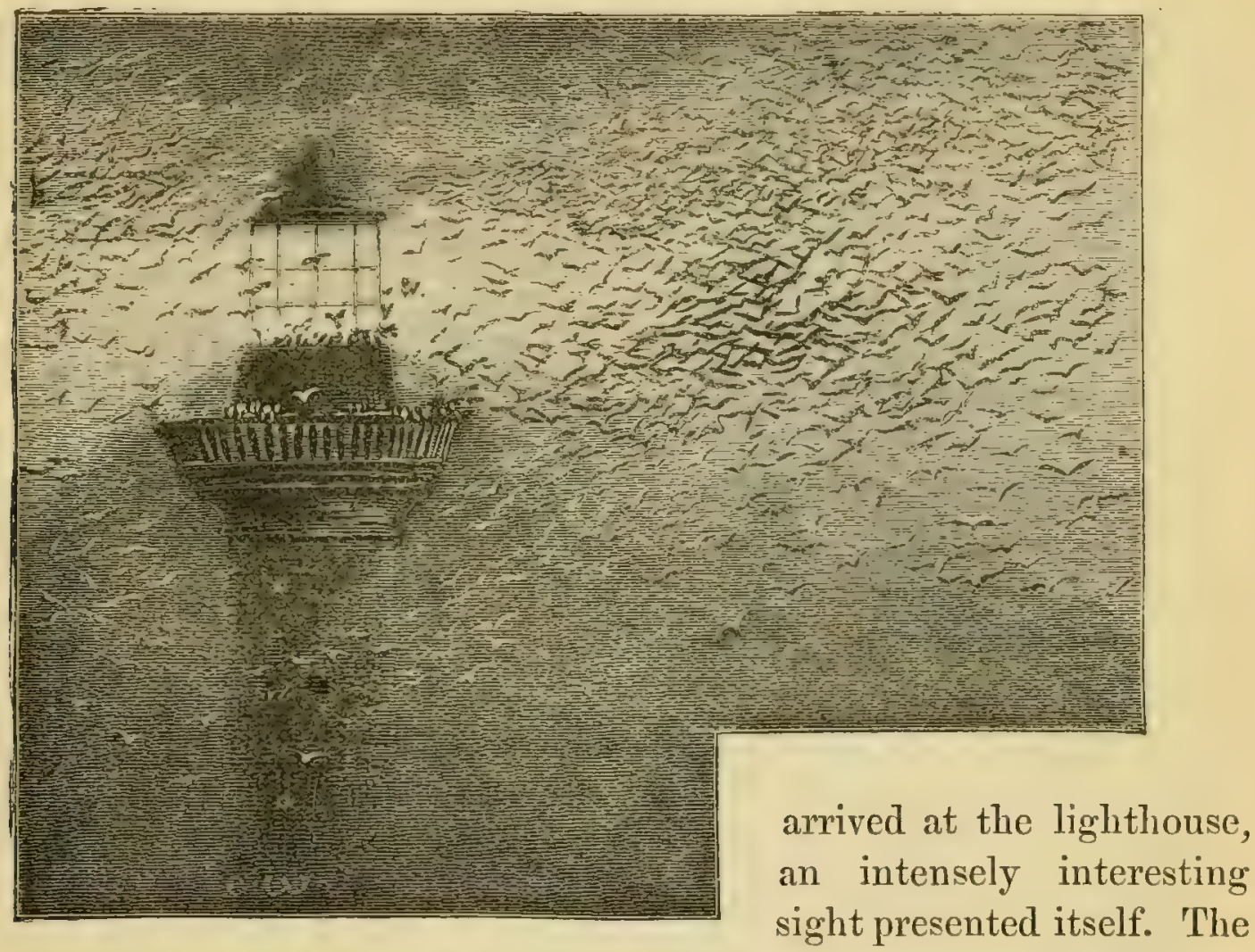
whole of the zone of light within range of the mirrors was alive with birds coming and going. Nothing else was visible in the darkness of the night but the lantern of the lighthouse vignetted in a drifting sea of birds. From the darkness in the east, clouds of birds were continually emerging in an uninterrupted stream; a few swerved from their course, fluttered for a moment as if dazzled by the light, and then gradually vanished with the rest in the western gloom. Occasionally a bird wheeled round the lighthouse and then passed on, ant sometimes one fluttered against the glass like 
a moth against a lamp, tried to pereh on the wire netting, and was caught by the lighthouse man. I should be afraid to hazard a guess at the liundreds of thousands that must have passed in a couple of hours; but the stray birls which the lighthouse man suceceded in securing amounted to nearly 300. The scene from the balcony of the lighthouse was equally interesting; in every direction birds could be seen flying like a swarm of bees, and every few seconds one flew against the glass. All the birds seemed to be flying up wind, and it was only on the lee-side of the light that any birds were caught. They were nearly all Sky-Larks; but in the heap captured there was one Redstart and one Reed-Bunting. The air was filled with the warbling cry of the Larks; now and then a Thrush was heard; and once a Heron screamed as it passed by. The night was starless and the town was invisible, but the island looked like the suburbs of a gas-lit city, being sprinkled over with brilliant lanterns. Many of the Sky-Larks alighted on the ground to rest, and allowed the Heligolander's to pass their nets over them. About three o'clock in the morning a heavy thunderstorm came on, with deluges of rain; a few brealis in the clouds revealed the stars, and the migration came to an end, or continued above the range of our vision.

Equally interesting is the arrival of the Larks on our shores, not only on the east coast of England, but also on the same coast of Scotland. The 'Migration Report' for 1882 mentions a rush of Sky-Larks at Sumburgh Head, on the Shetlands, from the 11th to the 18th of September. On the Isle of Mry, in the Firth of Forth, a "vast rush" of Larks and other birds passed westwards in October; whilst hundreds are described as being drowned in the sea or killed on the balcony of the lighthouse at Bell Rock, on the coast of the mainland, on the night of the 12th of October. Enormous numbers are reported as arriving at twenty-nine stations in various parts of the east coast of England in October and up to the end of the year.

Dixon thus writes of the autumn movements of this bird:- "Perhaps no locality in the British Islands is more suitable or better adapted to observe the incoming stream of Sky-Larks than the low-lying coast of Lincolnshire, on the northeru shores of the Wash. The rush of Sky-Larks that land on our castern coasts in autumn is almost past belief. Towards the end of October, or during the first week in November, the number that pass over these marshes is enormous. When the migration is on, you may see the great army of birds passing at a moderate height for days together; and you may lnow that the grand flight is still continued during the night, by constantly hearing the little travellers calling to each other as they pass on, coming from over the sea, to the inland pastures. In the daytime many of the birds break out into song the moment they are over dry land, as if full of joy at making the passage safely. Comparatively 
few of the birds alight here, the great majority pass down the coast at once. I do not think the Sky-Lark flies very close to the sea when migratiug, for it is very seldom caught in the flight-nets."

Probably some of these newly arrived birds drift inland at once; but by far the greater number continue their migrations, following the coast-line to the south, and at many of the stations the stream of migratory birds passing from north to south along the coast in autumn is greatcr than that arriving from the east over the sea. The coast-line secms to be followed for some distance, for at Brighton the migrations of Sky-Larks in Octoljer is very remarkable, on account of its direction being exactly opposite to that of the Greenfinches, Linnets, Redpoles, and other birds which cross the Channel when the opposite coast ean easily be seen. The Sky-Larlis and other birds coming into the country to winter all migrate from east to west; the Linnets and other birds going out of the country after the breeding-season is over all migrate from west to east.

The typical form of the Sky-Lark in breeding-plumage has the general colour of the upper parts brown; the dark centres of the feathers are well defined throughout; the outside tail-feather on each side is entirely white except the outside half of the inner web, and the next feather on each side is only white on the outer web. The underparts are pale buffish white, darkest on the breast, and the spots on the breast are very distinct. Bill dark brown above, paler below; legs, feet, and claws yellowish brown; irides hazel. The female resembles the male in colour. After the autumn moult the general colour of the upper parts is rich buffish brown, the underparts are suffused with pale olive-brown, and the throat is faintly spotted. Birds of the year rescmble adults, but have nearly white narrow tips to the ends of the feathers of the upper parts. Young in first plumage are spotted on the upper parts with black and buff, and the underparts are creamy buff, profusely spotted with blackish brown, except on the centre of the belly and under tail-coverts. The Sky-Lark may be distinguished by its very small bastard-primary, well-developed hind claw, and spotted breast.

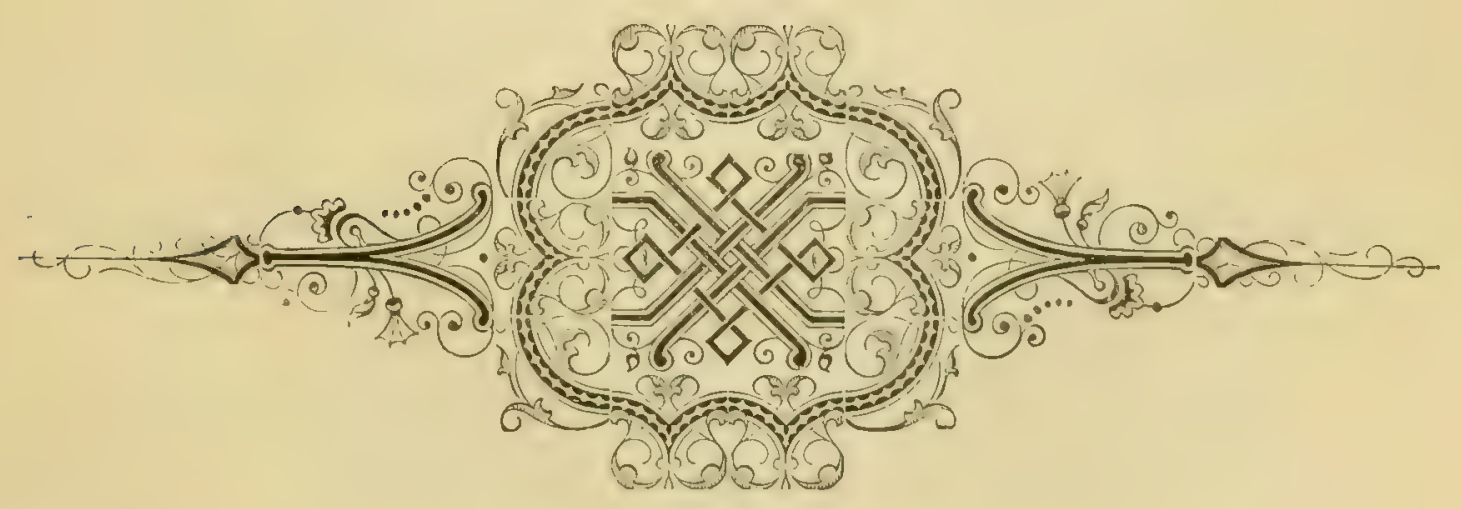

VOL. II. 


\title{
ALAUDA BRACHYDACTYLA.
}

\section{SHORT-TOED LARK.}

\author{
(Plate 15.)
}

Alauda brachydactyla, Leisl. Wett. Annul. iii. p. 357 (1809); et auctorum plurimorum-Temminch, Naumann, (Salvadori), Degland \& Gerbe, (Newton), (Dresser), ic.

Alauda arenaria, Vieill. N. Dict. d'Hist. Nat. i. p. 343 (1816).

Alauda testacea, Steph. Shaw's Gren. Zool. x. p. 521 (1817).

Alauda calandrella, Bonelli, fide Savi, Orn. Tosc. ii. p. 67 (1829).

Melanocorypha brachydactyla (Leisl.), Brehm, Vög. Deutschl. p. 311 (1831).

Emberiza baghaira, Frantilin, Proc. Zool. Soc. 1831, p. 119.

Alnuda dukhumensis, Sykies, Proc. Zool. Soc. 1832, p. 93.

Emberiza olivacen, Tickell, Joum. As. Soc. Beng. 1833, p.578.

Alauda kollyi, Temm. Man. ll Orn. iii. p. 202 (18:35).

Melanocorypha areuaria (Vieill.), Bonap. Comp. List B. Eu. \& N. Amer. p. 38 (1838).

Phileremos brachydactyla (Leisl.), Keys. u. Blas. Wirb. Eur. p. xxxvii (1840).

Phileremos kollyi (Temm.), Keys. u. Blas, Wirb. Eur. p. xxxvii (1840).

Phileremos moreatica, Von der Miihle, Orn. Griechenl. p. 38 (1844).

Calaudritis brachydactyla (Leisl.), Cab. Mus. Hein. i. p. 122 (1850).

Calandritis kollyi (T'emm.), Cab. Mus. Hein. i. p. 123 (1850).

Melanocorypha macroptera, Brehm, Journ. Orn. 1854, p. 77.

Calindrella hermonensis, Tristram, Proc. Zool. Soc. 1864, p. 434.

Calandritis macroptera (Brehm), Heugl. Orn. N.O.-Afr. p. 695 (1871).

The Short-toed Lark has occurred at least half a dozen times in our islands. The carliest record is that of a bird caught in a net near Shrewsbury on the 25th of October, 1811 (Yarrell, Hist. Brit. Birds, i. p. 488). 'Two examples were afterwards obtained near Brighton, one about September 1851, and the other in April 1858 (Dawson Rowley, 'Ibis,' 1859, p. 330). A fourth specimen was shot on the Scilly Islands on the 23rd of September', 1854 (Rodd, 'Zoologist,' 1854, 1. 4177 ); and a fifth was caught in a net near Southampton about the close of the year 1861, its captor asserting that he had caught a similar bird ten years previously (Pemberton Bartlett, 'Zoologist,' 1862, p. 7930). The most recent instance of the occurreuce of this bird in England is that of one caught near Cambridge in the middle of November, 188: (Inarting, 'Zoologist,' 1883, p. 33). It has never been recorded from Scotland or Ireland, nor has it been known to visit the Channel Islands.

'The Short-toed Lark is a summer visitor to the south of France; but in Spain and Portugal it is a resident. It is a summer visitor to Italy, 'l'urliey, Grcece, Asia Minor, and South Russia, occasionally occuring in 
winter. It is a rare summer visitor to South Germany, but has been obtained on Heligoland on migration. It is a resident in the Canaries and North-west Africa; but to North-east Africa it is only a winter visitor, occurring as far south as Abyssinia. It breeds in Persia, Turkestan, and South-west Siberia, at least as far east as Scrgiopol (long. $80^{\circ}$ ), where it was obtained by Finsch. It passes through Afghanistau on migration, and winters throughout India *, but has not been recorded from Ceylon. It is possible that it may occur in East Siberia; but travellers from that country have not discriminated between this species and $A$. pispoletta $\dagger$, which differs in having the innermost secondaries half an inch shorter than the primaries instead of the same length.

Like all the other Larks, the Short-toed Lark varies in colour from greyish brown to rufous brown. The palest examples I have seen are from Samarkand, and the most rufous from Spain, Greece, and Palestine. The only very near ally of the Short-toed Lark is the Tibet Short-toed Lark, A. tibetana, which has been found in the North-west IFimalayas at Sikkim, and on the northern slopes of the Karakoram Pass. It differs in having a slightly longer bill, white instead of smoke-brown outside tail-feathers, and in having the general colour much less sandy. It is probably specifically distinct, because it has the first four primaries nearly cqual in length, whereas in $A$. brachydactyla the fourth primary is considerably shorter than the three first.

Although the Short-toed Lark is very common in South Europe, it must be included in the list of Siberian birds which occasionally appear on our shores in autumn among the regular visitors which form part of the great stream of migration from the east. Fed by detachments from the north up the valleys of the Yenesay, the Obb, and the Petchora, this mighty wave of birds sweeps across Europe every autumn, losing itself for the most part on the shores of the Mediterranean; but its most

* I have a specimen collected by Oates, labelled " $\sigma^{*}$, Peg"u, 25 Sept. 1880."

+ This species, like most of the other Larks, is subject to great climatic variation, which has caused it to be subdivided into numerous imaginary species. The darkest of these forms, $A$. pispoletta var, batica, appears to be confined to Spain. The typical form is found in South Russia and Persia. A slightly more sandy form, A. pispolette var. minor, occurs in North Africa, Palestine, and Asia Minor. A still paler form, A. pispoletta var. lencophcea, occurs in Turkestan, along with intermediate forms between it and the preceding race. I have not had an opportunity of examining examples from East Siberia ; but a rufous form, $A$. pispoletta var. cheelensis, occurs in North China. These varieties are doubtless climatic rather than geographical, and might be supplemented by many intermediate local forms from different localities; but they all have short innermost secondaries, a character which makes them specificully distinct from the Short-toed Lark and its allies. Dresser, who appears to have had access to a large series of $A$. brachydactyla, recognizes but one species; whereas of $A$. pispoletta his series appear's to have been small, and, in the absence of intermediate forms, he has allored specific ranls to eath of its climatic varieties. 
northerly current breaks on the east coast of England, and is visible to any observer who will take the trouble to visit the Sussex downs in October when the wind is blowing gently from the north. Strangers which visit us from South Europe arrive in spring, and are wanderers who have overshot the mark in company with the birds which form the other great army of migrants which starts from Africa, and crossing the Mediterranean at Gibraltar, Malta, Cyprus, and other points, spreads over Europe and Western Asia, the left wing converging on the British Islands. The Short-toed Lark is an autumn visitor to our shores, and clearly belongs to the group of Eastern birds which reach us across the steppes of South Russia and South-western Siberia, where it is common.

The Short-toed Lark is essentially a bird of the steppes; and the drier and more sandy they are, the better it is pleased. It revels in the sand, and a bed of dry sand in which it may bathe in the dust is as essential to its happiness as is his morning tub to the modern English gentleman. It is a very common bird on the sandy plains between Athens and Marathon, where it may be seen in company with the Tawny Pipit and Cretzschmar's Bunting (the Grecian representative of the Ortolan), whilst grasshoppers abound on every side, and large green lizards flash past the traveller, and tortoises of all sizes creep slowly out of his way. I found it equally common on the steppes of the Dobrudscha, especially on the sandy plateau which rises gently behind Kustendji, where it shared the ground with Wheatears, Calandra Larks, and a few Crested Larks and Sky-Larks. It mounts into the air like the latter species, and sings its short monotonous song. Its call-note is similar to that of the Sky-Lark, but weaker and shriller. It is essentially a ground-bird, and runs along the sandy plains with great quickness; and though the Sky-Lark and the Calandra Lark are constantly seen perched on some thistle or tuft of tall herbage, I have never seen the Short-toed Lark otherwise than on the ground or on the wing. Its flight is very slightly undulating, but is constantly intercepted with sudden bounds forward. It will sometimes perch on a stone, and I have seen it on the top of the earthworks thrown up by the Russians in the last Turkish war; but in spite of its short hind claw it does not perch on trees. Alexander von Homeyer says that in Majorca he has oftem. heard it sing on the ground. Its food is said to be entirely small seeds; but in summer it probably feeds also on insects.

The Short-toed Lark arrives at its breeding-grounds in Greece and Asia Minor early in April, and I have taken its eggs in the Parnassus on the 11 th of May, but in clie Dobrudscha it breeds at least a month later. I was surprised to find nearly all the small birds breeding very late in the valley of the Lower Danube; and Dixon noticed the same of the smaller Algerian birds. 
The nest appears always to be built upon the ground, sometimes under a clod of dry dung or earth, or frequently on the lee-side of a bush amongst the herbage. It is usually made in a little cavity in the ground, either scratched out by the bird itself, or the mark of a stone or footprint. It is a simple little structure made of dry grass, rootlets, \&c., very closely resembling the nest of the Sky-Lark. One which I obtained on the sandy steppes near Kustendji is made of short bits of grass, a feather or two, and a large amount of vegetable down, lined with a few hairs.

The eggs of the Short-toed Lark are four or five in number, sometimes only three, creamy white in ground-colour, profusely mottled and speckled with pale neutral brown, and with underlying markings of grey. Some eggs are much more richly coloured than others. On some the ground. colour is almost hidden by the profusion of spots; whilst on others the markings are fewer, although evenly distributed over the entire surface, but occasionally they form a zone round the end. They vary from 987 to 99 inch in length, and from 62 to 55 inch in breadth. The eggs are much smaller than those of the Sky-Lark, but otherwise bear considerable resemblance to them, except that the general tone of colour is much yellower.

In winter the Short-toed Lark congregates into flocks. Jerdon writes that in India it appears " in October and November in flocks, frequenting the bare grass downs, frequently damp spots near tanks, also grain-fields and ploughed land; and it almost always retires to corn-fields or grass for shelter during the heat of the day, whence it does not in general issue again till next morning, for they are seldom seen flying about or feeding in the afternoon or evening. It feeds almost entirely on seeds; both runs and hops on the ground, and has a call-note like that of the real Larks. Towards the end of March in the south, April in the north of India, different flocks often unite into vast troops containing many thousand birds, and quite darkening the air, so close do they keep together, even when flying. Great numbers are netted in some parts of the country, or taken by bird-lime, or shot; for when feeding they keep close to each other. On one occasion, on the cavalry parade-ground at Kamptee, I bagged twelve dozen birds after discharging both barrels, and many wounded birds escaped. They get quite fat about this time, and are really very excellent eating, and they are always called Ortolau by Europeans in India. They leave the north of India about the end of April or beginning of May." In Algeria Canon Tristram states that it congregates in flocks for the winter, and frequents the neighbourhood of the oases on the northern borders of the desert.

The adult male Short-toed Lark in breeding-plumage has the general colour of the upper parts pale sandy brown, the dark centres being very 
obscure on the rump, and rather narrow on the head; the light patches on the two outside tail-feather's are similar to those of the Sky-Lark, but the colour is pale sandy brown instead of white. The underparts are pale buffish white, the streaks being confined to a few large ones on the sides of the breast, which is suffused with buffish brown. Bill dark brown, paler below; legs, feet, and claws yellowish brown; irides hazel. The female does not differ from the male in colour. After the autumn moult the plumage is slightly more sandy. Birds of the year have a few obscure streaks on the breast. Young in first plumage are somewhat similar to the young of the Sky-Lark. The Short-toed Lark may be distinguished from the other British species by its small size, short hind claw, and almost entire absence of spots on the underparts.

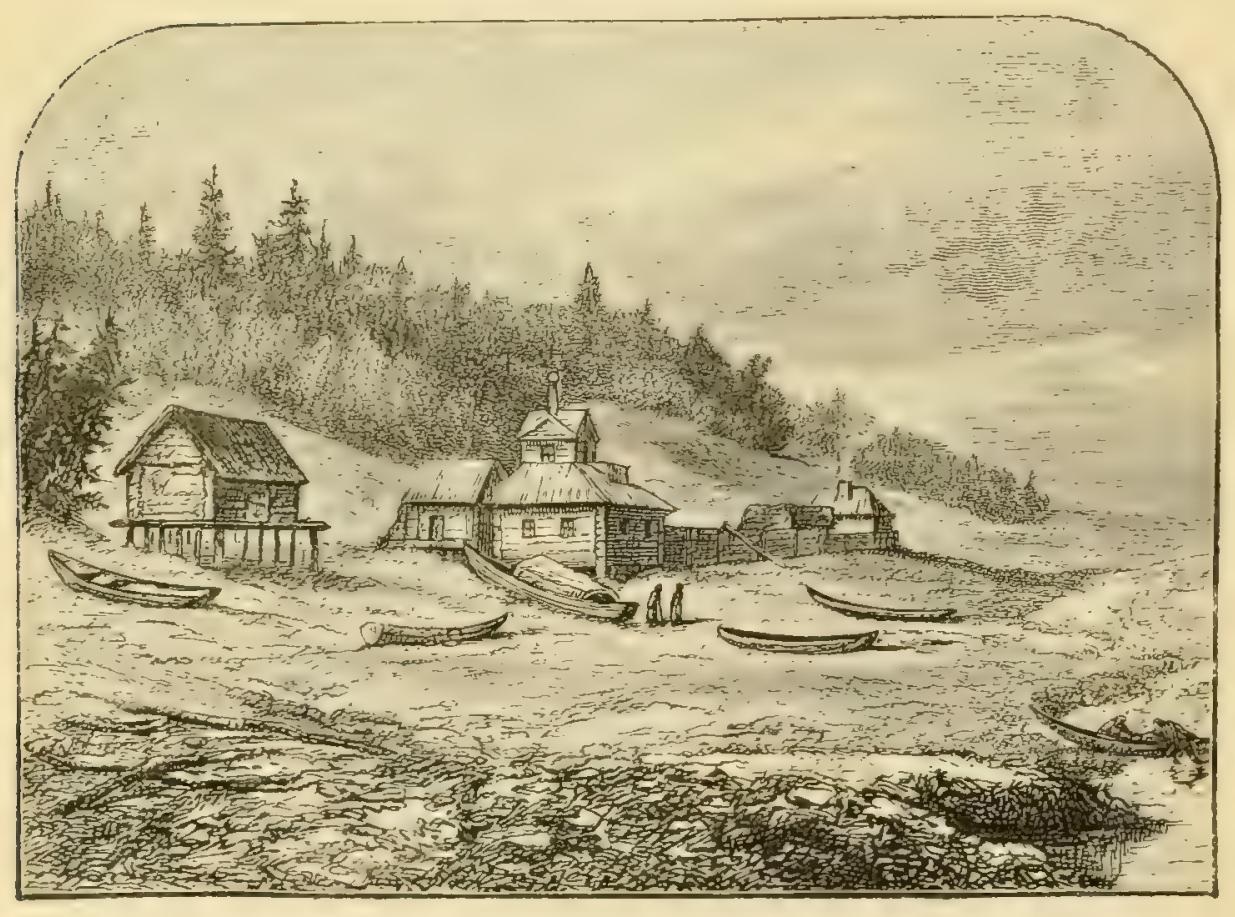




\section{ALAUDA SIBIRICA.}

\section{WHITE-WINGED LARK.}

(Plate 15.)

Alauda calandra affinis, Pall. Reise Russ. Rcichs, ii. p. 708 (1773).

Alauda sibirica, Gmel. Syst. Nat. i. p. 799 (1788); et auctorum plurimorumSchlegel, (Degland \& Gerbe), (Danford \& Harvie-Brown), Harting, (Dresser), (Newton), \&c.

Alauda calandra, Linn., var. $\beta$, Lath. Ind. Orn. ii. p. 497 (1790).

Alauda leucoptera, Pall.'Zoogr. Rosso-Asiat. i. p. 518, pl, xxxiii. fig. 2 (1826).

Phileremos sibirica (Gmel.), Keys. u. Blas. Wirb. Ear. pp. xxxvii, 153 (1840).

Melanocorypha leucoptera (Päll.), Bonap. Consp. i. p. 243 (1850).

Calandrella sibirica (Gmel.), Brandt, fide Bonap. Consp. i. p. 243 (1850).

Calandrella leucoptera (Pall.), Dubois, Ois. Belg. pl. 102 в (1858).

Pallasia leucoptera (Pall.), HIomeyer, Juum. Oin. 1873, p. 190.

The White-winged Lark has not the slightest claim to be considered a British bird; but, like many other Siberian species, it is included in the British list because it has once been obtained in this country. On the 22nd of November, 1869, a female White-winged Lark was caught near Brighton out of a flock of about two dozen Snow-Buntings, and was brought alive, together with some of the latter, to Mr. Swaysland, from whom it passed into the collection of Mr. Monk, of Lewes. It is probable that others may be discovered; for my friend $\mathrm{Mr}$. Gätke writes to me that he obtained an example on the island of Heligoland on the 2nd of August, 1881. The only other records of the occurrences of this species in Western Europe* are in Belgium and the Alps. An example was caught in October 1855 near Liege, and a second at Mechelen, a small village north of Liège, in Octojer $1856^{\circ}$ (Dubois, Journ. Orn. 1856, p. 505), whilst a third specimen was shot near Trento, in the Italian Tyrol, about the middle of November 1869 (Giglioli, 'Ibis,' 1881, p. 200). In Poland and Galicia it is only an accidental visitor. It is said by Count Casimir Wodzicki to have beeu observed frequently in Poland; and he records three examples which were seen in East Galicia, of which one was shot.

The White-winged Lark breeds on the steppes and is a common resident in the extreme south-east of Russia. Bogdanow says that it is found as far north as Saratov on the Volga and Oreuberg ou the Ural, and as far

* There is no reason whatever to suppose that Bechstein's Alauda arvensis ruficeps refers to this species. No mention is made of the white patch on the wing, and the description differs in other particulars. 
west as Stavrapol in North Caucasia ; whilst Hencke describes it as very common on the Kirgiz steppes north of Astrakan. In severe winters it occasionally strays into South-west Russia, and even as far as Constantinople. Finsch met with it in the Barabinska steppes and eastwards up to the Altai Mountains, beyond which it has not been found. In Westeru Siberia it has occurred as far north as Omsk. In Siberia it is a migratory bird, wintering in Turkestan.

When Pallas first discovered this fine Lark on the banks of the Irtish he thought it was merely a variety of the Calandra Lark, and described it as such ; but Gmelin, recognizing its specific distinctness, named it Alauda sibirica. Pallas afterwards renamed it A. leucoptera when he wrote his book on the zoology of Asiatic Russia, and gave some particulars of its habits and its distribution. Since the days of Pallas but little has been added to the natural history of the White-winged Lark. He states that, like the Calandra Lark, it frequents the roadsides and that its song is shorter than that of the Sky-Lark and is uttered as the bird is hanging in the air, but that it does not often rise so high as that bird. Sabanäeff states that it frequents the grassy and open districts. It appears not to be very shy, and often allows the obscrver to approach it quite closely. In the early part of the breeding-season it is incessantly soaring into the air for a short distance on fluttering wings, very gracefully warbling its short song, then returning to the ground.

Professor Slovzow says that the White-winged Lark first arrived at Omsk on the 16th of May; but Finsch, on his journey south from that town to Semipalatinsk, met with it in the last week of April. He also saw it in large flocks on the Barabinska steppes. The birds were very tame, and looked most picturesque as they whecled and curved in graceful flight. He describes the song as very like that of the Sky-Lark.

The breeding-season of the White-winged Lark is said sometimes to commence as early as the end of April, but sometimes not until the middle of May, according to the state of the scason. The nest is built in a little cavity on the ground under a tuft of herbage or bencath a little bush, and is said to be made of grass. The eggs are four or five in number, and apparently do not differ much. Specimens in my collection from the Volga are yellowish white in ground-colour, spotted with a light and dark shade of almost neutral brown and with numerous underlying markings of violet-grey. The spots are large and almost evenly distributed over the entire surface; but some specimens have most of the markings round the large end, many of them being confluent. They vary in length from 96 to $\cdot 86$ inch, and in breadth from 69 to $\cdot 61$ inch. The eggs of the White-winged Lark, although they resemble those of the Sky-Lark very closely in size and colour, are, however, easily distinguished; they 
are much more pear-shaped, and the spots are much larger, more boldly defined, and not so numerous. They resemble those of the Calandra Lark much more closely, as might be expected, but are, on an average, smaller.

Of the food of this bird we know nothing; but it is probably similar to that of the Calandra Lark, and consists partly of insects and their larvæ and partly of grain and other seeds, according to the season.

The adult male White-winged Lark in breeding-plumage has the head and ear-coverts pale chestnut; the lores and the feathers round and behind the eye are white; the remainder of the upper parts are greyish brown with a sandy tinge, darkest on the back, each feather with a dark-brown centre; the upper tail-coverts are the most rufous, and the dark centre of the feathers is little more than a shaft-line; the lesser wing-coverts are chestnut; the median and greater ones are chestnut-brown, with pale margins; the primaries are dark brown tipped with white, the eighth, ninth, and tenth, with the greater part of the inner web and the tip of the outer web, white; the terminal half of the secondaries is pure white, the basal half brown, and the innermost secondaries are dark chestnut-brown with rufous margins. The tail is brownish black, the two centre feathers with broad pale chestnut margins, and the next three pairs edged with white; the second pair white on the outer web, and the outermost pair all white. The general colour of the underparts is dull white, shading into buffish on the breast and into brown on the flanks ; many of the feathers on the sides of the throat, and all on the upper breast, have a terminal spot of brown. Bill dark horn-coloured above, pale yellowish below ; legs, feet, and claws brown; irides brown. The female resembles the male in colour, but is duller, and the feathers on the head are pale rufous with dark brown centres. After the autumn moult the white tips of the primaries and the margins of the innermost secondaries are pale chestnut, and the breast and flanks are suffused with buff. Young in first plumage are spotted somewhat like a young Sky-Lark, but are easily distinguished by their much stouter bill, larger size, and the feathers of the upper parts being tipped with pure white.

The White-winged Lark belongs to a little group of large Larks which are emphatically Steppe-Larks, and by some ornithologists are placed in a separate genus. There are half a dozen species of Melanocoryphce; but it is impossible to find any generic character common to the group, except that of size. In the Steppe-Larks the height of the bill at the base is $\cdot 3$ inch, whilst in the Sky-Larks it is only ' 2 inch. Of all the SteppeLarks the White-winged Lark and the Black Lark are the most likely to occur in our islands, because they breed the furthest north and thus come within the range of the great stream of migration, which may carry off a 
few of them westwards in autumn. The following table will enable any one to discriminate between the species of this group :-

Prevailing colour of outermost $\left\{\begin{array}{l}\text { A. maxima. } \\ \text { tail-feather white . sibrica. } \\ \text { A. mongolica. } \\ \text { A. calandra. } \\ \text { A. bimaculata. } \\ \text { A. tatarica. }\end{array}\right\} \begin{gathered}\text { Prevailing colour of secondaries } \\ \text { white. } \\ \begin{array}{c}\text { Large black patches on the sides } \\ \text { of the neck. }\end{array}\end{gathered}$

The White-winged Lark has only once been deteeted in Heligoland, but the Black Lark has oceurred several times. The Calaudra Lark (Alaurla calandra) is also in Gätke's collection, and has twice been recorded as a British bird; but in both cases the examples were discovered in the shop of a local bird-stuffer. There can be little doubt that this bird has visited England and may visit it again; but being a South-European bird it must be looked for in spring. It cannot, however, be included in the British list until the capture of an cxample has been recorded, with particulars of date and locality authenticated by some competent witness. The first example recorded (Gatcombe, 'Zoologist,' 1863, p. 8768) was sail by the Plymonth bird-stuffer in whose shop it was found, mounted and cased, to have been killed near Deronport; and the second (Gurney, 'Zoologist,' 1869, p. 1599) was said by an Exeter bird-stuffer to be a Lapland Bunting shot in the neighbourhood.

The Calandra Lark is a common resident in the basin of the Mediterrancan wherever there are sandy plains; but it is not linown to breed north of Venice. It is very rare in Egypt. In South-east Europe its range extends slightly more to the north, but the hird is very local. East of the Caucasus it breerls throughout Persia and Turkestan as far as Lake Saisan.

In its habits the Calandra Lark does not differ very much from the Sky-Lark. It loves to frequent broad fertile sandy plains and large fields, especially of growing grain. Its song usually commences in March, and is similar to that of the Sky-Lark, but is not so pleasing nor so prolonged. It is usually uttered when the bird is in the air. It is a very industrious singer, and is incessantly soaring into the air, often rising for a few yards, then dropping again, without uttering any sound save its call-note, which somewhat resembles that of the Sky-Lark. In the pairing-season the males soar and chase cach other like Sky-Larks. It is a somewhat carly brecder, usually commencing its nest in April in Spain and Greece, but not until June in the Dobrudscha. The nest is always built upon the ground amongst herbage, and is made of dry grass, rootlets, \&c., and lined with finer materials. The eggs are four or five in number, and somewhat resemble those of the Sky-Tark, but are indistinguishable from those of the White-winged Lark figured on Plate 15, except that, on 
an average, they are slightly larger. They vary in length from 1.0 to .85 inch, and in breadth from $\cdot 75$ to 65 inch.

After the breeding-season the Calandra Lark is gregarious, and lives in flocks throughout the winter. Its food consists of insects and seeds in summer, but in winter it is principally granivorous. In the south of Europe it is in great request as a cage-bird.

This fine bird resembles a gigantic Short-toed Lark, with the spots on the neck coalescing into a black patch on each side.

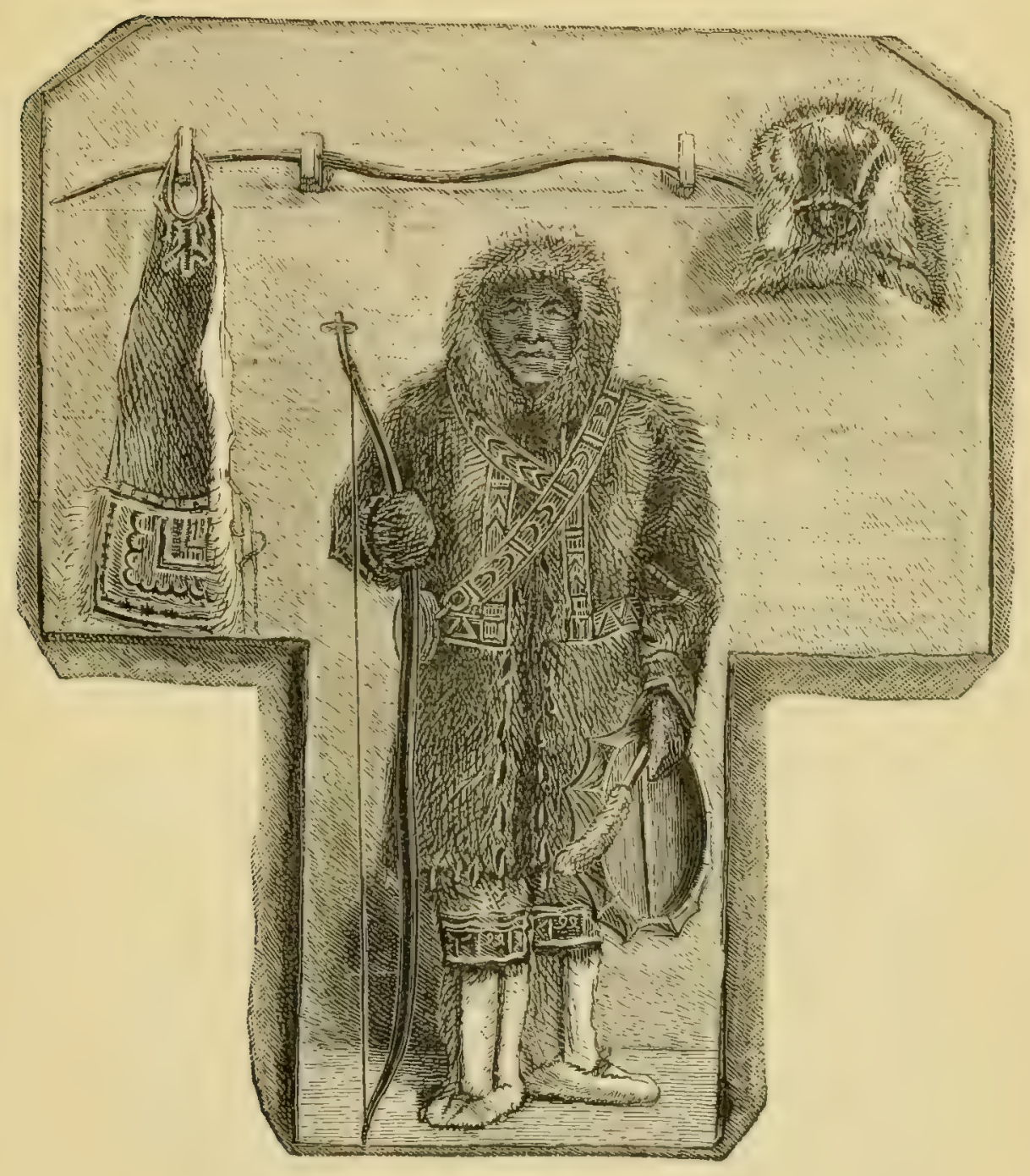




\title{
ALAUDA ALPESTRIS.
}

\section{SHORE-LARK.}

\author{
(Plate 15.)
}

Alauda virginiana, Briss. Om. iii. p. 367 (1760).

Alauda alpestris, Linn. Syst. Nat. i. p. 289 (1766); et auctorum plurimorumGmelin, Latham, (Bonaparte), Naumann, Temminck, (Salvadori), (Dresser), (Newton), \&c.

Alauda flava, Gmel. Syst. Nat. i. p. 800 (1788).

Alauda cornuta, Wils. Am. Orn. i. p. 87, pl. v. fig. 4 (1808).

Alauda nivalis, Pall. Zoogr. Rosso-Asiat. i. p. 519 (1826).

Eremophila alpestris (Linn.), Boie, 1sis, 1828, p. 322.

Eremophila cornuta (Wils.), Boie, Isis, 1828, p. 322.

Phileremos alpestris (Linn.), Brehm, Vög. Deutschl. p. 313 (1831).

Otocoris alpestris (Linn.), Bonap. Fauna Ital., Ucc. Introd. (1832-1841).

Phileremos cornutus (Wils.), Bonap. Proc. Zool. Soc. 1837, p. 111.

Philammus alpestris (Linn.), Gray, List Gen. B. p. 47 (1840).

Alauda minor, Giraud, Amn. Lyc. Nat. Hist. N. York, 1841, no. 16.

Alauda rufa, Audub. B. Am. viii. p. 236, pl. 497 (1843).

Otocoris cornuta (Wils.), Bonap. Consp. i. p. 246 (1850).

Otocoris occidentalis, MacCall. Pr. Ac. N. Sc. v. 1851, p. 218.

The Shore-Lark was formerly a very irregular visitor to the British Islands, but during the last few years has occurred annually, sometimes in considerable numbers, about sixty examples having been obtained on the Norfolk and Suffolk coasts in the winter of 188.2-83. Yarrell, in 1856, only recorded six English examples. The first specimen recorded as British was shot on the beach at Sherringham, in Norfolk, in March 1830, and is now in the Norwich Museum. It is of frequent occurrence in Scotland, and was first made known as a visitor to that country in 1859. Several flocks have been observed at different times; and Gray remarks that he has no doubt that it is a frequent, if not an anmual, visitor to the eastern coasts of that country. It does not appear to have been noticed in Ireland.

The Shore-Lark is a circumpolar bird, breeding on the tundras of both hemispheres beyond the limits of forest-growth. In the Palrearctic Region it breeds in the extreme north-east of Norway, and as far south as Quickiok in lat. $67^{\circ}$, where it is said to breed in the fells; it passes through Finland and Archangel on migration, breeding only north of the forests. In the valley of the Petchora at Ust Zylma, in lat. $65^{10}$, it passed through in great numbers on migration, but we did not again see it until we reached sat. $67_{\frac{1}{2}}{ }^{\circ}$. In the valley of the Obb, Finsch first met with it in lat. $671_{2}^{\circ}$; 
whilst in the valley of the Yenesay, I observed it in lat. $66 \frac{1}{2}^{\circ}$ passing in great numbers on migration, but only found it breeding above lat. $69 \frac{1}{2}^{\circ} *$. Eastwards it probably breeds above the limits of forest-growth to Behring's Straits. In the valley of the Lena, Middendorff observed flocks on the Arctic circle migrating northwards to breed. In the Palrarctic Region there is no evidence of this bird ever having bred below the Arctic circle.

In winter the Shore-Lark is an accidental visitor to the south of Norway, Germany, Denmark, Belgium, France, and Italy, but appears to have never been observed on the Spanish peninsula. It is also a rare winter visitor to Hungary, Turkey, and South Russia ; and castwards is found at that season in South-west Turkestan, South Siberia, and North China; although it does not appear to have ever occurred in Japan. On the American continent, the breeding-range of the Shore-Lark is probably confined to the tundras above the limit of forest-growth, which on this continent extends somewhat further to the south than in the. Old World.

The Shore-Lark has several very near allies. The most distinct of these, A. penicillata, is a resident in Asia Minor and Palestime, the steppes of South-east Russia, South-west Siberia, and Turkestan, extending eastwards as far as the Altai Mountains. This species may at once be distinguished from every other Shore-Lark by its having the black on the ear-coverts joined to the black on the throat, thus isolating the white on the throat. It is doubtful if any of the other Shore-Larks are specifically distinct from our bird; but throughout the Himalayas, in Turkestan, the Altai Mountains, Dauria, and Mongolia, occasionally wandering in winter into North China, a pale form occurs, $A$. longirostris, which also differs in having the forehead, eye-stripe, and throat white, instead of yellow. A still more isabelline and slightly smaller form, $A$. bilopha, inhabits the deserts of Northern Africa and Arabia. In America a southern form occurs, $A$. occidentalis, breeding on the plains of the upper valley of the Mississippi and the valley of the Missouri, which is scarcely distinguishable from $A$. longirostris; but it is said that intermediate forms between this and $A$.alpestris are not uncommon. In Mexico and the adjoining United States, extending southwards into the extreme north-west of South America, A. chrysolcema is said to be a resident. It is a very remarkable fact that this tropical form is scarcely distinguishable from $A$. alpestris,

* There can be little doubt that the Shore-Lark mentioned by Eversmanu as extending only to $53^{\circ}$ morth latitude, and alluded to by Sabanäeft as breeding in the Perm Gorernment (a statement which is quoted by Dresser and apparently endorsed by Newton), is the West-Asiatic Shore-Lark, A. penicillata. The Shore-Larlis mentioned by Radde as breeding above the limit of forest-growth in the Thian-Shan Mountains are unquestionably $A$. longerostris. 
except in being slightly smaller in size, and possibly somewhat richer in colour $\%$

The Shore-Lark is as much a bird of the tundra as the Snow-Bunting and the Lapland Bunting; but it breeds at a lower latitude than the former species, and though almost as abundant as the latter, is more local. It avoids the marshy districts and confines itself to dry sandy plains or rocky hills, though it comes down to the mud-shores of the rivers to drink. It is one of the carliest of the small birds to arrive at its breeding-grounds. The Snow-Bunting and the Mealy Redpole arrive first, and may be seen running about on the snow some weeks before the ice breaks up; but as soon as the thaw begins in earnest a batch of small birds arrive, amongst which is sure to be the Shore-Lark. In lat. $66^{\circ}$, in the valley of the Petchora, we saw the first on the 10th of May; but in lat. $66 \frac{1}{2}^{\circ}$, in the valley of the Yenesay, I did not sce this bird until the and of June. They afterwards passed through both stations in great numbers.

The Shore-Larks seem to be entirely ground-birds. On the banks of the Petchora I have seen both the Common Gull and the Common Snipe perched in trees, and in the valley of the Yenesay I have shot a Golden Plover from the summit of a lin'ch; but I have never seen the Shore-Lark perch in a tree or even on a bush. It seems to be even more exclusively a ground-bird than the Sky-Lark. It ruus along the sand with the greatest ease; but when watching a flock of Lapland Buntings and Shore-Larks feeding on an oasis of grass in the snow, I noted down that both species occasionally advanced a few steps by a series of hops, and that the ShoreLark did so more than the Lapland Bunting. During migration the ShoreLark is a gregarious birl, and though the first flocks consisted of Shore-

* Dresser, in his 'Birds of Europe,' has so confused the synonymy of the Asiatic species and races of Shore-Larks that I have had some considerable difficulty in disentangling the skein; but with the assistance of Scully's admirable paper on the Birds of Gilgit (Ibis, 1881, p. 581), I have unravelled the puzzle as follows:-

The West-Asiatic Shore-Lark.

Alauda penicillata, Gould, Proc. Zool. Soc. 1837, p. 126.

Phileremos scriba, Gould, fide Bonap. Comp. List B. Eur. and N. Amer. p. 37 (1838).

Alauda albigula, Brandt, fide Bonap. Consp. i. p. 246 (1850).

Otocoris albigula (Brandt), Bonap. Consp. i. p. 246 (1850).

Otocoris larvata, De Filippi, Arch. per la Zool. ii. fasc. 2, p. 381 (1863).

The East-Astatic Shore-Lark.

Otocoris longirostris, Gould, fide Moore, Proc. Zool. Soc. 1855, p. 215.

Otocorys sibirica, Eversmann, fide Swinhoe, Proc. Zool. Soc. 1871, p. 390.

Otocorys elwesii, Blanf. Journ. As. Soc. Beng. 1872, p. 62.

Otocorys brandti, Dresser, B. Eur. iv. p. 401 (1874).

Otocorys parvexi, Taczan. Bull. Soc. Zool. France, 1876, p. 161.

Otocoris nigrifrons, Prjevalsiy, Mongolia and Thibet, ii. p. 103 (1876).

Otocoris albigula, auctorum nec Brandt. 
Larks only, as soon as the Lapland Buntings begar to arrive they seemed to be on the best of terms together, and the later flocks usually consisted of both species. Flocks of Pipits were migrating about the same time, and it was very striking to contrast the wildness of these birds with the tameness of the Shore-Larlis.! The Shore-Lark often sings on the ground, and when apparently too busy feeding to mount in the air for the purpose, will occasionally utter snatches of song. At their breeding-places they sing continuously, mounting up into the air like a Sky-Lark, and singing their charming song as they sail about with wings and tail expanded. The song is very melodious, though short; and amongst its few variations a longdrawn-out note often occurs, which resembles much the song of the CornBunting. It often remains some time in the air, and sings its little song several times over before it descends. It will also sing from the roof of the wooden houses. Its call-note is loud and clear, but scarcely capable of being expressed by a word.

In Lapland the Shore-Lark lays its eggs from the middle of May to the middle of June, but in Siberia not before the latter date. The nest is always built on the ground, generally in some slight hollow. I found one in Finmark in the middle of a mountain-path, in the hollow formed by the foot of a horse in the solt mud, which the sun had afterwards hardened. Others were amongst stones on the bare ground, and one under the shelter of some rushes in the grass. The nest is loosely made of dry grass and stalks, and the inside, which is rather deep, is lined with willow-down or reindecr-hair. Four is the usual number of eggs; but very often only three are laid, and sometimes as many as five. They may be said to be charactcristic Lark's eggs, and only differ from those of the Sky-Lark by their more olive shade of colour. 'The ground-colour is a pale grecnish or pale brownish white, often so covered by the profusion of marlings as to be scarcely visible. The overlying spots are small and irregular in shape, of an almost neutral brown colour, and nearly conceal the paler and greyer underlying spots. Sometimes the markings form a confluent zone round the large end of the egg: they are never very bold, and are often so evenly diffused over the surface as to make it an almost uniform brown; but at other times they are more thinly distributed, and allow the bluishgreen ground-colour to be more conspicuous. In some eggs a few black spots and hair-like streaks appear near the large end, sometimes in a scattered zone, and, in rare instances, sparingly distributed over the whole surface. They vary in length from 95 to 9 inch, and in breadth from $\cdot 7$ to 6.2 inch. The Shore-Lark frequently rears a second brood in Lapland; but in Siberia the summer is too short for it to do so.

When I was in Heligoland small Hocks of Shore-Larks arrived on the island on the 11th, 15th, and 17th of October, and I had no difficulty in securing eight specimeus. It is said that the Shore-Lark was formerly a 
very rare bird in Lurope, and that it is only within the last lhalf-century that it has appeared in Lapland. Our knowledge of the oinithology of Arctic Europe is so recent, and even now so imperfect, that these statements must be receired with caution; but there can be no doubt that it has become much commoner of late years on migration on Heligoland, so much so that an example now costs only as many pence as it formerly did shillings. The Shore-Lark appears to belong to the class of gipsy migrants who have no settled home in winter, and we should consequently expect that as its breeding-range extended westwards its winter range would be similarly affected. Of its habits in winter scarcely any thing is known. It seems to be nowhere common. It collects into flocks after the moult, and appears to lead a roving life, like the Snow-Bunting, feeding principally on small seeds. In summer it varies its diet; for Collett found the remains of small beetles in the stomachs of both old and young; and lidgway describes it as catching insects on the wing. It has also been linown to eat the buds of small plants and minute crustaceans on the sea-shore.

The adult male Shore-Lark, in breeding-plumage, has the forehead and a stripe over each eye, the chin, and upper throat, extending on to the sides of the neck below the ear-coverts, dull yellow; the fore part of the crown, extending in an elongated tuft over each eye-stripe, the lores, extending below the cye and across the fore part of the ear-coverts, and a band across the lower throat and upper breast are black. The two patches of dull yellow are partly connected together by the hind portion of the ear-coverts (which are dull yellow with brown tips), and isolate the black moustachial patch both from the black crown and the black throat. The general colour of the upper parts is greyish brown, shading into pinkish brown on the nape, lesser wing-coverts, and upper tail-coverts; the feathers on the back have obscure clark centres. The two centre tail-feathers are coloured like the back; the rest are nearly black, the two outermost on each side margined on the outer web with white. The rest of the underparts are nearly white, shading into pinkish brown on the sides of the neck and flanks. Bill, legs, feet, and claws black; irides dark brown. The female differs from the male in having the black on the crown of less extent, and the whole of the feathers of the upper parts with dark centres, those of the back being more conspicuous than those on the back of the male. After the autumn moult the feathers on the head and nape have yellow margins, which obscure the black on the crown as well as the pinkish brown on the nape of the male. Males of the year are indistinguishable in colour from adult females in autumn plumage; but females of the year, both in winter and summer plumage, may be distinguished by the absence of the yellow on the forchead and the black bases to the feathers of the crown. Birds in first plumage bear little or no resemblance to their parents, being uniformly spotted with dull yellow. 


\section{Family CYPSELIDÆ, or SWIFTS *}

The Swifts are a very well-defined group of birds, which most ornithologists regard as being nearest related to the Ifumming-birds. Sclater and Gadow suppose them to be also closely allied to the Goatsuckers, but Forbes hesitated to confirm this opinion. There seems, however, to be many points in which they are closely allied to the Passerine birds. Huxley says that they esscntially resemble the Swallows in the general form and arrangement of the bones which enter into the composition of their palates; on the other hand, they do not possess the clefts on the posterior margin of the sternum which characterize the Passerine birds, the Goatsuckers, the IIoopoes, the Cuckoos, and many other families. In their pterylosis they also differ much from the Passerine birds, approaching nearest in this respect to the Goatsucker's; but in their digestive organs they resemble very nearly the former family and differ widely from the latter. In their myology they are said to be nearest allied to the Owls, and not distantly so to the Birds of Prey.

The Swifts moult twice in the year, in spring and autumn. Newton and Dresser do not allude to this subject; and Naumann states positively, both of the Common and Alpine Swifts, that, like the Swallows, they only moult once in the year, in their winter-quarters, shortly before they leave for their breeding-grounds $\dagger$.

In their external characters the Swifts very closely resemble the

* The Swifts and the six families that follow them were formerly included among the Passeres; further researches showed that they differed in many important respects from this group of birds, and for some time they were lnown by the Iudicrous appellation of "Non-Passerine Passeres." Sclater associates them with several families, not represented in the British fauna, in an Order which he calls Picarix. Probably this is a natural group, but should include the Owls. It contains a number of birds which appear to be not very distantly allied to the Passerida, and may represont the least changed descendants of their common ancestors.

$\uparrow$ That this is not the case I have satisfied myself by a careful examination of a series of skins. Two examples in my collection of the Alpine Swift (one shot by MLr. Robson on the 3rd of August, 1875, near Coustantinople, and the other on the 12th of April, 1878, by Captain Napier, in the ralley of the Atreck river) are both moulting a quill-feather in each wing. This is also the case with an eximple of Ifacroptery.r comatus collected by Wallace in Malacen in the autumm of 1854. The probability of a double moult is also confrrmed by the appearance of many other examples which are very slightly abraded

voL. II. 
Swallows; they have the same long pointed wings, the same tendency to have a forked tail, and the same very small bill, combined with a very wide gape. They differ from this group of birds in haring ten primaries instead of nine, and ten tail-feathers instead of twelve. The hind toe, especially its claw, is proportionately smaller in the Swifts than in the Swallows, and is often directed forward.

There are about fifty species of Swifts, which are distributed throughout the world except in the Aretic regions and in New Zealand. Two species breed in Europe, one of which is a regular summer migrant to our islands; but the other can only be regarded as an accidental risitor, in which category may also be included one of the Siberian species.

The Swifts may be divided into two groups, the Cypseline and the Chreturina. In the former the middle and outer toes have ouly three phalanges, a character which is correlated with feathered tarsi; in the latter the middle toc has four and the outer toe five phalanges, a character which is correlated with bare tarsi.

\section{Genus CYPSELUS.}

The Swifts were associated with the Swallows by Limneus in his genus Hirundo; but in $167 \%$ his specific name for the Common Swift was raised into a generic title for the Swifts by Scopoli (Intr. ad Hist. Nat. 1. 183). This name camnot be retained for the Swifts, Schäffer having, in 1556 , established a genus Apus for a group of Crustaccans. Although Limurus degraded this generic name to a specific one, later writer's re-established it; and not only was it in use between the year's 1766 and $17 \% \%$, but it is still retained for the same group. In 1810 Wolf established the genus Micropus to contain the Swifts; but his name was equally unfortunate, for it had already been used by Limmeus in 1767 (Syst. Nat. ii. p. 580) for a genus of plants. In the following year, however, the Swifts were

both in spring and autumn. In this Family, the members of which are so entirely dependent for their food on their powers of flight, the moult tales place rery slowly. An example of C'ypselus affinis collected by Dr. Scully in Nepal on the rth of June has apparently only just commenced its autumn moult; whilst two examples of C. apus from South Africa, in the british Museum, appear to be nearly completing their moult-the one shot on the 14th of October, and the other on the 9th of December. 'The moulting of the rvingfeathers probably takes place as slowly as in the Birds of Prey, so that after the first plumage it is impossible to obtain an example, especially in tropical climates, in which the pale black of the new feather's has not become faded, by exposure to sunshine, to a more or less rusty grey. 
fortunate enough to receive a generic name which they were able to retain, Illiger having rechristened the genus under the appellation of Cypselus in his 'Prodromus systematis Mammalium et Avium,' p. 229. He designated the Common Swift, the Hirundo apus of Linnæus, as the type.

The true Swifts are characterized by having the tarsus feathered to the base of the toes, which are all directed formard. The prevailing colour of the Swifts is a brownish black, in some specics variegated with white. The similarity in the pattern of colour between the Swifts and the Swallows is very remarkable; in both families the sharply defined white rump and dark pectoral band are occasionally met with.

Sclater, in his monograph of the Cypsclidre (Proc. Zool. Soc. 1865, p. 593), enumerates fiftecn species belonging to this genus, most of which breed in the southern portions of the Paliearctic Region, and in the Ethiopian and Oricntal Regions. One species visits Australia in winter, and four others are confined to the Neotropical Region. Two species only occur in Europe, one of which is a regular summer visitor to the British Islands, and the other is a rare accidental visitor.

The Swifts live almost entirely on the wing, rarely perching in trees or on the ground, and consequently frequent open country. They feed exclusively on insects, and are therefore unable to remain in any locality where the winter is at all severe. They breed in holes of various linds, the crevices of rocks, crannies in buildings, hollow trees, or the recesses of palm-foliage. The nest is very slight; the materials are made to adhere to each other by the glutinous saliva of the birds. Their eggs are few in number, elongated and blunt in shape, and unspotted dull white in colour.

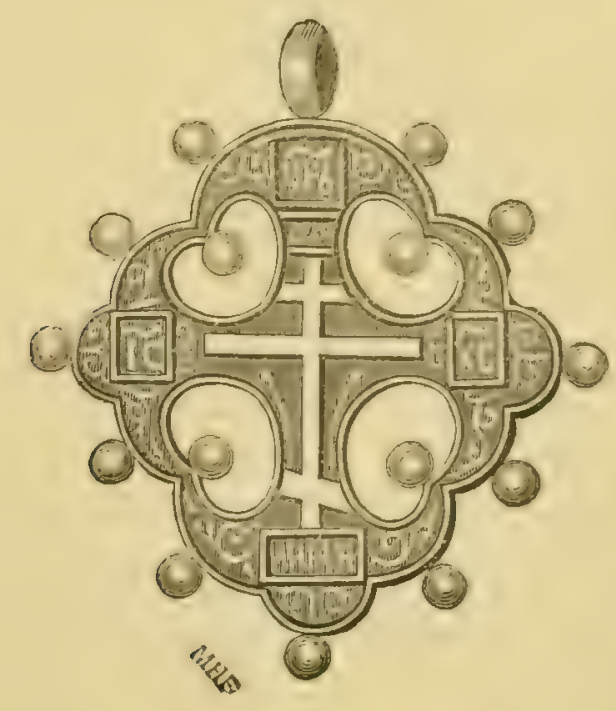




\section{CYPSELUS APUS. \\ COMIMON SWIFT.}

(Plate 18.)

Hirundo apos, Briss. Orin. ii. p. 512 (1760).

Hirundo apus, Linn. Syst. Nat. i. p. 344 (1766); et auctorum plurimorum-

Latham, Gmelin, (Bonaparte), (Naumann), (Newton), (Dresser), \&c.

Apus apus (Linn.), Scop. Intr. ad Hist. Nat. p. 483 (1777).

Micropus murarius, Wolf, Taschent. i. p. 281 (1810).

Cypselus apus (Linn.), Illig. Prodr. p. 230 (1811).

Brachypus murarius (Wolf), Meyer, Vög. Liv- $u$. Estht. p. 143 (1815).

Oypselus niger, Leach, Syst. Cat. Mamm. \&c. Brit. Mus. p. 19 (1816).

Apus cypselus, Forst. Syn. Cat. Br. B. p. 55 (1817).

Cypselus vulgaris, Steph. Shaw's Gen. Zool. x. p. 72 (1817).

Cypselus murarius (Wolf), Meyer, Taschenb. Zus. u. Ber. p. 255 (1822).

Apus murarius (Wolf), Lesson, Traité d'Orn. p. 267 (1831).

Micropus apus (Linn.), Boie, Isis, 1844, p. 165.

Cypselus murinus, Brehm, Vögelfang, p. 46 (1855).

Cypselus aterrimus, Heugl. Journ. Orn. 1861, p. 423.

Cypselus acuticauda, Blyth, fide Jerdon, B. Ind. iii. p. 870.

Cypselus dubius, Antinori, Cat. Ucc. Afr. Centr. p. 25 (1864).

Cypselus barbatus, Temm. fide Sclater, Proc. Zool. Soc. 1865, p. 599.

Cypselus pekinensis, Swinhoe, Proc. Zool. Soc. 1870, p. 435.

Cypselus pallidus, Shelley, Ibis, 1870, p. 445.

The Swift, although one of the latest birds of passage to arrive and one of the earliest to leave, is found in suitable districts in almost all parts of the British Islands, with the exception of the Outer Hebrides, where it has only once been seen. It is somewhat rare on the inner islands, and is only an accidental visitor to the Orkneys and Shetland. It is rather common in the Channel Islands; but is said by 'Thompson to be absent altogether from certain parts of the west of Ireland.

The Common Swift has a very extensive range, reaching from the Atlantic to the Pacific. In Norway it has been found brecding as far north as lat. $69^{\circ}$, and has been seen up to lat. $70^{\circ}$. It occasionally strays as far as the Faroes, and is also an accidental visitor to Archangel; but has not been found in the Ural Mountains beyond lat. 60\%. It has occurred once at Omsk in lat. $55^{\circ}$, and breeds regularly in Dauria in lat. $50^{\circ}$. It also breeds in Mongolia and North China; but has not been recorded from Japan. It is a summer visitor to the Canaries; but is a resident in Madeira. It breeds throughout South Europe and North Africa, being most abuudant in rocky districts. It is a common summer visitor to 
Palestine, Asia Minor, Persia, Turkestan, Afghanistan, Cashmere, and probably Nepal, and has once occurred on the Andaman Islands. It winters in the Punjaub and throughout the Ethiopian Region as far as it is known. In Cape Colony and Natal it is said to be found all the year round; but no reliable instance of its breeding there has been recorded. Throughout the southern limits of its breeding-range a slightly paler form of the Common Swift occurs, which is generally known by the name of C. pallidus; but as every intermediate form is found in the intervening localities, it can only be regarded as a climatic race, found in isolated localities where the sun is unusually powerful. In the Canaries and Madeira, besides the Common Swift, a small island form occurs, C. unicolor, with a wing less than six inches in length, which is probably specifically distinct. Still smaller Swifts of nearly the same colour occur in India and elsewhere.

The arrival of the Swift in this country is almost as important an event in spring as that of the Swallow and other well-known birds of passage, although it seldom remains in our islands longer than four months. It is seen at Gibraltar as early as the end of March; and in Palestine, Greece, and other parts of Southern Europe it arrives late in that month or early in April. It seldom arrives in Central Europe and the south of England before the end of April; and in the north of England and the south of Scotland it does not usually appear before the beginning of May, although an example was once seen by Dr. Saxby in the Shetlands as early as the 27 th of April. It does not reach South Sweden before the middle of May, and does not arrive in Lapland before June. Last of migratory birds to arrive in spring, it is one of the first to take its departure in autumn. By the end of August most of the young birds have left this country; but late broods and their parents linger on into September, and stray examples have been occasionally seen in October and even in November.

The Swift frequents almost all kinds of places, from the plains in the neighbourhood of the sea, where it breeds in the cliffs and old ruined towers and fortresses, to the upland moors and mountain-lochs, where a pair or two may frequently be seen near a shooting-box or gamekeeper's cottage. It loves the town as well as the country, and is especially fond of frequenting cathedrals, church-spires, and other lofty buildings. It is a very common bird in country towns, but does not occur so plentifully in those where large manufactures are carried on; but it haunts almost every village. It cannot be called as common a bird as the Swallow or the Martin, but it occurs in considerable numbers, sometimes in isolated pairs, but more often in small colonies. By far the greater part of its time is spent in the air; but it roosts in its nest, and sometimes repairs thither during heavy rain. It is an early riser, and its shrill cry may often be 
heard before dawn. It is a very interesting sight to see a company of Swifts busy in search of food, or merely toying with each other high up in the blue sky, far above the lofty spires and towers, coursing hither and thither with marvellous speed and grace.

Few birds have more perfect command over their movements in the air than the Srrift. Its flight is performed by a series of rapid beats of its long scythe-shaped wings alternated with smooth glidings, during which the wings are held out almost at right angles with the body. The shape of a Srift as it slims in the air resembles that of an anchor. Its wings are narrower and more curved than those of the Swallow, and the neck is shorter and the head apparently smaller. Sometimes the birds glide for a long distance, then with a few powerful sweeps of their pinions they mount higher in the air, or flutter for a few moments ere darting off at full speed to the right or left; they wheel round or fly rapidly along, their wings often appearing to beat alternately as the birds themselves dart from side to side. Throughout the day the Swift continues on the wing. In calm fine weather, as well as when it is rough and stormy, it busily scarches for prey, sometimes at a great altitude, at others near the ground; and the fact that it often hawks for flies in rough stormy weather has caused it to be called the Devil Swallow in some localities. The Swift is very rarely indeed seen to perch, and then usually on the face of a perpendicular cliff or wall or on the rough bark of a hollow oak-trunk. It may often be seen passing in and out of the steeples, towers, and rocks; but this is usually for the purpose of feeding its mate or young, and seldom to rest. Its wings seem never to tire. The Swift is a bird which often changes its feeding-ground. On some days it may be seen in great numbers in one locality; on others in quite a different one. Occasionally it frequents the pastures or skims over the growing crops, gliding along the liedgerows or flying just above the mown grass; and at these times the bird is most easily approached, otherwise it is somewhat shy.

The Swift is generally a comparatively sileut bird, but when a large number are flying about together it is often very noisy. Its usual note is a very shrill and somewhat prolonged scream. This note appears to be uttered most frequently when the birds are chasing each other through the air in early summer, and when flying in and out of their nests. It makes an attempt at song more feeble than that of the Srallow or the Martin, but this twitter is seldom heard except when the bird is on its nest.

The Swift is never seen to attempt any progress on the ground; it camnot walk, and has been said to be unable to rise from a flat surface; but this is a popular crror. Hancock, in his 'Birds of Northumberland and Durham,' relates that he placed a bird on the floor of a room, when it rolled from side to side and appeared quite helpless, but when placed on 
the garden-walk it instantly took wing; whilst on another occasion one was placed on the floor of a room, but took flight at once and flew against the window. Naumann had previously recorded a similar experiment.

Swifts often chase each other in the pairing-season, and harmless combats between rival males are sometimes noticed. The Swift most probably pairs for life. Every year the old familiar hole is tenanter presumably by the same pair of birds; and Filhnert White long ago noticed how regularly the same number of Swifts frequented certain haunts for years. The Swift does not tarry long after its arrival in this country before nesting-duties are commenced. It is a late bird to come; its stay is short, therefore no time can be wasted. The scanty nest is usually commenced by the middle of May; eggs are laid by the end of the month; and the young are usually hatched by the middle of June. The nest is built either in the crevice of a wall, a hole in a rock, or, where there are no rocks, in a mud cliff or tower, or under the roofs of buildings, in a similar situation to that so often chosen by House-Sparrows. When the Swift builds in the latter situations, it is probably because a loftier site cannot be had, for the bird likes to build in as elevated a position as it can find. It is also said to occasionally nest in a crevice in the face of a chalk-pit. It breeds regularly in the limestone cliffs facing the sea at Llandudno and elsewhere; and it sometimes builds in the hollow branches of old and decayed oaks.

The nest of the Swift is a very slight structure, almost flat, composed of bits of straw and other vegetable fibres, placed together with very little art, and lined with feathers; these materials are covered with a viscid saliva which solidifies like glue, and renders the nest hard and eaked together. The Swift obtains most of the materials with which it builds its nest whilst on the wing, seizing a feather here or a bit of dry grass there, as they may happen to be blown into the air. It also finds hay, straw, \&c. under the tiles and in the crevices which it frequents, conveyed thither by Sparrows; indeed the nest has even been found on a nest of this bird containing eggs! the Swift having, doubtless, ejected the usurping tenant. The eggs of the Swift are two or three in number, generally the former, but sometimes as many as four are laid. They are elongated in shape, the small end almost as blunt as the large end, rough in texture, with little gloss, and almost pure white in colour. They vary from 1.08 to '93 inch in length, and from ' 7 to ' 62 inch in breadth. Swifts' eggs are readily distinguished from those of the Martin by their larger size, more oval shape, and rougher texture; from those of the White-bellied Swift, the species next to be described, their smaller size distinguishes them at once. The female alone apparently performs the duties of incubation, and the male oftcn conveys food to her. According to Gilbert White, whose account of this bird is very complete, she only leaves her 
charge at dusk to seek a scanty meal for a fer minutes, and to relieve her cramped and weary limbs; but Naumanu says that she is by no means a close sitter, and often leaves her eggs in scarch of food during the day. The Swift only rears one brood in the year; there is no time for a second, for the young birds are seldom hatched before the middle of June. Should the first eggs be taken, a second clutch is sometimes laid; but these are frequently so late in coming to maturity that the young are abandoned and left to starve in the nests by the old birds, whose impulse to migrate is stronger than thir parental love. The young birds remain in the nest for a considerable time, longer than those of the Swallow and the Martin, and are not tended much by their parents when once they are able to take wing, though Dixon has seen them being fed by the old birds in the air. The Swifts do not visit the nest so frequently as Swallows do; they have fewer young to cater for, and probably amass a larger number of insects in their mouths ere they return.

The food of the Swift is composed entirely of insects, all of which it catches in the air; they are usually of the smallest kind, such as gnats, millges, small beetles, \&c. Gilhert White states that they also feed on may-flies and dragon-flics. The indigestible portions of the food, such as wing-cases \&ce, are cast up in pellets, and the nests often contain a great many of thcm. The young birds are much troubled with parasites, and the nests often swarm with them, but are seldom deserted from this cause.

The Swift quits this country early in the year; and is often seen passing in great flocks along the east coast of England in the autumn. Gray mentions that this bird congregates in enormous flocks in Scotland in August; but it is possible some of these birds are merely passing along our coasts from the continent on their way southwards, and are not indigenous to this country. They are secn at the various lighthouses on our cast coasts, not only on migration, but also during the summer; and at Spurn lighthouse a flock has been known to remain on the gallery of the lantem at night. Like the Swallows, the Swifts are specially noisy before they finally leave. They depart en masse in the night; and on the day following their departure their usual haunts secm quite lonely after their sudden and complete disappearance.

The Swift in summer has the general colour of the plumage uniform blackish brown, with a bronze tinge on the upper parts. The throat is dull white; bill black; feet and claws very dark brown; irides dark brown. The female does not differ in colour from the male. Young in first plumage have the chin a purer white, because the feathers are newer, and most of the feathers of the upper parts are narrowly margined with buffish white. The colour of the plumage after each moult is dark and rich, but the "bloom" is soon bleached away by the action of the sun and weather. 


\section{CYPSELUS MELBA.}

\section{ALPINE SWIFT.}

\section{(Plate 18.)}

Hirundo major hispanica, Briss. Orn. ii. p. 504 (1760).

Hirundo melba, Linn. Syst. Nat. i. p. 345 (1766); et auctorum plurimorumLatham, Gmelin, (Bonaparte), (Naumann), (Brehm), (Dresser), (Newton), \&c.

Hirundo alpina, Scop. Ann. I. Hist. Nat. p. 166 (1769).

Micropus alpinus (Scop.), Wolf, Taschenb. i. p. 282 (1810).

Cypselus melba (Linn.), Illig. Prodr. p. 230 (1811).

Hirundo gularis, Steph. Shaw's Gen. Zool.x. p. 99 (1817).

Cypselus gutturalis, Vieill. Tabl. Encycl. Méth.p. 534 (1822).

Cypselus alpinus (Scop.), Meyer, Taschenb. Zus, u. Ber.p. 255 (1822).

Micropus melba (Limn.), Boie, Isis, 1844, p. 165.

Micropus gutturalis (Vieill.), Boie, Isis, 1844, p. 165.

The Alpine Swift has been obtained so frequently in the British Islands that a detailed account of each capture is unnecessary. The earliest instance known is that of an example which was shot off the south coast of Ireland about the middle of the year 1829, and came into the possession of Mr. Sinclaire, by whom it was sent to Selby, who recorded the particulars of its capture (Edinb. Journ. Nat. and Geogr. Sc. n. s. iii. p. 170, 1831). Since this date about a score of specimens have been obtained, many of which were procured in Ireland, but the greater number in England, where it has occurred as far north as Durham; but it appears never to have been noticed in Scotland.

The Alpine Swift breeds in the alpine districts of Europe south of the Baltic, in the Ural Mountains its range extending up to lat. $55^{\circ}$. South of the Mediterranean it breeds in the mountains of North Africa and Abyssinia*. Eastwards its range extends through Asia Minor, Palestine, West Turkestan, the West Himalayas, and the mountain-ranges of West India and Ceylon. In Abyssinia, India, and Ceylon it is said to be a resident; but further north it is only a summer visitor, leaving in autumn to winter in Damara Land, the Cape Colony, and Natal. In the cold season it is occasionally seen in most parts of India as far east as Calcutta; and it has occurred more or less accidentally on migration in Denmark, Heligoland, and various parts of the plains of Germany as far north as Berlin. The Alpine Swift has no near ally in Asia; but in the Bogos

* Dresser, in his 'Birds of Europe,' states that Blanford met with this bird in the plains of Abyssinia; but this is a blunder, Dresser having inadvertently transferred Blanford's remarks on the Common Swift to the Alpine Swift. 
country and Central Abyssinia C. aquatorialis occurs, which is somewhat intermediate between it and the Common Swift. In its dimensions it is exactly intermediate between these two species, and has the dark belly of the latter, but the less forked tail of the former.

The Alpine or White-bellied Swift very closely resembles the Common Swift in its habits. It is, however, much more of a rock bird, and is rarely scen except amongst mountains. It delights to frequent the bare heights, the stupendous passes and ravines, the perpendicular cliffs and rocks, where, secure from all enemies, it can rear its young in peace. It is generally a gregarious bird, and is usually met with in large or small flocks. Like its congener it is a somewhat late summer visitor to Europe, seldom arriving in Spain and Asia Minor before the last half of March, and in Switzerland not before May, generally leaving again in August. In Palestine Canon Tristram says that it arrives much earlicr than the Common Swift. The first time he noticed them was on the 12th of February, when at Jerusalem he saw large flocks, apparently on migration, flying north at a great height and with amazing rapidity. It is probably a partial resident in the valley of the Jordan, which may be regarded as an outlying island or a peninsula of the Ethiopian Region which stretches northwards far into the Palæaretic Region. The zoological regions are bounded longitudinally by seas which are geographical boundaries, but their extent to the north or south is simply a question of climate. The valley of the Jordan enjoys a tropical climate because it lies below the level of the sea, and it consequently belongs to the Ethiopian Region.

As might naturally be expected from a bird which, small as it is, measures nearly two feet in expanse of wing, the Alpine Swift is capable of very rapid and powerful flight. It sometimes flies near the ground, especially in the morning and evening and in rainy weather, but at other times it searches for its insect food in the highest air, occasionally going beyond the range of human vision.

The Alpine Swift is rarely seen on the ground and scarcely attempts to walk, its long wings and short legs causing its mode of progression to be little better than shuffling or creeping; but if alarmed it has not the slightest difficulty in instantly taking wing. The structure of its feet makes it difficult for it to perch on a branch or horizontal surface, but against the perpendicular face of a cliff or tower it clings with the greatest ease. The hole in which the nest is built serves as a roostingplace for both birds, and, after the young are hatched, for the whole family.

Like its British ally it is an early riser, and is often seen abroad before darn. It dashes in reckless haste along the face of the rocks, or darts down like a feathered meteor to the plains; then ascends far up into the sky, wheeling in large circles, gliding smoothly along, turning suddenly 
almost at an acute angle, or hovering with rapid beat of wing with equal ease. It ranges far and wide, appearing in one place and apparently remaining until the food-supply is exhausted, then moving on to another. Sometimes it hawks for food over the water, and often drinks on the wing. It wanders far in the course of a day from its nightly retreat; but a hundred miles or so to this intrepid little bird are of little consequence.

The cry of the Alpine Swift is shrill and tremulous, differing from that of the Common Swift, but quite as loud. It utters its note, which is a long-continued trill slightly varied, most frequently when chasing its companions through the air, especially in the evening, a habit which is quite as conspicuous in this bird as in the Common Swift. It is not known to have a song or musical twitter like the Swallows, unless the chattering which precedes its departure on migration may be thus regarded.

In suitable localities the Alpine Swift is by no means a rare bird. There are very fer passes in the Alps where it may not be seen in summer; and it seems as much at home whecling amongst the minarets of Stamboul as circling round the Gothic spires of Geneva or Berne.

Dixon describes its habits in Algeria as follows:- "We saw this fine Swift at Constantine and El Kantara. The breeding-place at Constantine is partly situated in the stupendous cliffs above the city, and is shared with Storks and Falcons, and partly in the crevices of the magnificent natural arch of rock above the river Roumnel. The birds live in small colonies, and many nests are near to each other. We met with a great number of birds flying up and down above the river-bed in a ravine below the city, incessantly passing to and fro, and mingling with Common Swifts, Martins, and Swallows. The flight of the Alpine Swift is much more rapid and powerful than that of the other Swifts; it darts with incredible speed, turns and twists, hovers, mounts aloft, and dips down with a rapidity that renders attempts to shoot it almost useless. Like the Common Swift the altitude of its flight varies exceedingly. Some days it will rise to a great elevation almost out of sight, on others it will be seen close to the ground, rarely going more than sixty or a hundred yards high. The noble pass of El Kantara is another home of the Alpine Swift, and its shrill exhultant notes may be heard far up above amongst the almost inaccessible cliffs, distinctly audible above the roar of the river below."

The food of the Alpine Swift is composed exclusively of insects, which it catches on the wing. All the hard parts of its food, such as the wingcases of beetles, are cast up again in the form of pellets, as is the case with many insectivorous birds.

The Alpine Swift generally breeds in the crevices of rocks, though it will sometimes make its nest in a church or cathedral tower or in a convenient cranny of some other building. Canon Tristram says that in Algeria it breeds in the towers of the mosques as well as in the rocks. 
The nest is built in a hole or crevice, generally in the most inaccessible part of the cliffs, sometimes where they overhang. It is usually at some distance from the entrance; and even if this can be approached, the eggs, often within sight of the collector, are beyond his reach. The nest is a very similar structure to that of the Common Swift, rather small, and made of dry grass, straws, and feathers, very flat, and cemented together with the saliva of the bird. Most of the nest materials are obtained whilst the bird is ou the wing, but the remains of other nests may sometimes be utilized. Hume, in his 'Nests and Eggs of Indian Birds,' writes of the nest of this bird:- "Three or four nests at least appear to have been grouped together in one mass. One chamber, which is perfect, measures about 5 inches in diameter, and was about three to four inches in height. The walls of the nest average about an inch in thickness, but jn many places, owing to the necessary fillings-in where the more or less circular chambers meet each other, there is a much greater thickness of material; and where two chambers are nearest to each other, the partitionwall rarely exceeds half an inch." Canon Tristram thus describes a nest of this bird in a very unusual situation:- "Once only did we find this Swift breeding near the ground and in an accessible position, and then we had the vexation of actually touching the eggs without being able to take them. On the 2nd of May we had climbed to the summit of Jebel Jilad (Mount Gilead), overlooking the deep Jordan valley from the east side, one of the grandest panoramic views in Palestine. After standing for some time on a projecting platform of rock which forms the western brow of the mountain, we descended to examine the face of the cliff, and discovered three large and partly artificial caves immediately below us. They were a mass of fossilized ammonites; and while hammering away at these in one of the caves out flew two Alpine Swifts, whose nest we soon discovered in a crevice about six feet above the floor of the cavern. The chink, which was about three inches in perpendicular diameter, was contracted by a plastering of very hard mud*, which cost us some labour to work out. Inside, the cavity enlarged as it descended; and after scooping away the clay and portions of the rock with a small hammer, I was at length able to touch the two eggs with the tips of my fingers. Anything for a scoop! A kingdom for a spoon! But in vain; and when we went up again to scarch for an available stick, we found our companions gone aud out of sight in the forest. Grievous as was the disappointment, it would have been yet worse to be benighted in that. wild and lawless region; and there was nothing for it but, while daylight served, to mount and follow the track of the horses as rapidly as we might. We never

* It is not known that any Swift uses mud in the construction of its nest. In this case the old nest of a Rock-Nuthatch had probably been utilized by the Alpine Swift. 
again met with an accessible nest. Indeed this was the only instance in which we observed $C$. melba breeding not in large colonies."

The eggs of the Alpine Swift are deposited late in May, and are usually two or three in number, but it is said that four or even five sometimes occur. They are elongated, and the small end is almost as blunt as the large end. They are pure white in colour, and vary from 1.3 to 1.2 inch in length, and from 8 to .72 inch in breadth. The eggs of this bird occasionally have more gloss on them than is usual with those of the Common Swift; but, as a rule, they are without polish. Their size easily prevents them being confused with those of the Common Swift.

The young are fed assiduously by their parents. The food is collected in a mass in the mouth, so that a considerable amount is obtained ere the old birds convey it to their young; and it is said they thus collect all their food into a little round ball before swallowing it. The young are sometimes fed on the wing by their parents. Like other Swifts and Swallows, the present species is much infested by parasites. The Alpine Srvift only breeds once in the year, and disappcars from its Europeau haunts during September. It passes Gibraltar on migration from late in August to early in October; but has been sometimes met with there as late as November and as early as February.

The male Alpine Swift in breeding-plumage has the general colour of the upper parts, the flanks, the under tail-coverts, and a broad band across the breast hair-brown, the feathers of the upper parts having a faint purplish tinge, especially on the back and tail. The throat and belly are pure white; and the lores very dark brown, almost black. Most of the brown feathers have indistinct narrow pale margins. Bill black; feet and claws black; irides dark birown. The female does not differ in colour from the male. Birds of the year are similar to their parents; but the feathers have more conspicuous pale margins, and the pale feather's of the underparts have dark shaft-lines. Nestlings are said to be covered with grey down. After the autumn moult the colour of the plumage is much darker and richer, and the pale margins are more conspicuous; and after the spring moult there is more iridescent gloss on the feathers. The extent to which this species sometimes bleaches during the summer is most remarkable. I have an example from Switzcrland in which most of the dark parts of the plumage are the colour of sand and extremely abraded; many of the feathers of the underparts have already been changed, and the wing-coverts are apparently just commencing to be so. The autumn moult has usually only just begun when the birds leave us, but the spring moult is completed before they again arrive in Europe. The Alpine Swift is subject, like most other birds, to the same climatic variation of colour which is found in the Common Swift, some examples from arid localities being very pale. 


\section{Genus CHzTURA.}

The Spine-tailed Swifts were included by Limnæus in the genus Hirundo with the other Swifts and the Swallows. From the latter the Swifts were separated as early as $1 \% \% \%$ by Scopoli; and in 1825 Stephens placed the Spine-tailed Swifts in a new genus, which he called Chetur (Shaw's Gen. Zool. xiii. pt. 2, p. 76). The American Chimney-Swallow (C. pelasgia), the first enumerated by Stephens, has been generally accepted as the type.

The Spine-tailed Swifts may be at once recognized by having the shafts of the tail-feather's prolongated like needles or spines beyoud the web. The tail is very short, considerably less than half the length of the wing, and the wings are very long and powerful. Unlike the true Swifts, in the foot of the Spine-tailed Swifts three toes are directed forwards and one backwards. The plumage of the upper parts is generally glossed with metallic purple and green.

Sclater (Proc. Zool. Soc. 1865, p. 607) euumerates fifteen species belonging to this genus, of which seven belong to the Neotropical and two to the Nearctic Region; three breed in the Oriental and two in the Ethiopian Region; whilst one breeds in the Palrarctic, wintering in the Australian Region. One species is an accidental visitor to Europe and the British Islands.

The Spine-tailed Swifts are gregarious, chiefly frequenting open country, and living almost entirely on the wing. Few, if any, birds exceed them in the rapidity of their flight. They feed exclusively on insects. They breed in hollow trees, holes in rocks, or in chimneys, using no mud in the construction of their nests, but cementing the materials, which consist of straw, hay, or twigs, with their glutinous saliva. The eggs are few in number and dull white in colour. 


\section{CH ÆTURA CAUDACUTA.}

\section{NEEDLE-TAILED SWIFT.}

Hirundo caudacuta, Lath. Ind. Orn., Suppl. p. lrii (1801); et auctorum plurimorum-(Radde), (Schrenck), (Jerdon), (Swinhoe), (David \& Oustalet), (Diesser), (Newton), \&c.

Hirundo fusca, Steph. Shaw's Gen. Zool. x. p. 133 (1817).

Chætura australis, Steph. Shaw's Gen. Zool. xiii. pt. 2, p. 76 (1825).

Chrtura fusca (Steph.), Steph. Shaw's Gen. Zool. xiii. pt. 2, p. 76 (1825).

Hirundo ciris, Pall. Zoogr. Rosso-Asiat. i. p. 541 (1826).

Acanthylis spinicauda (T'emm.), fide Boie, Isis, 1826, p. 971.

Chrtura macroptera, Swains. Zool. Ill. ser. 2, i. pl. 42 (1829).

Chrtura nudipes, Hodgs. Joum. As. Soc. Beng. v. p. 779 (1836).

Hirundapus nudipes (Hodgs.), Hodgs. Journ. As. Soc. Beng. v. p. 780 (1836).

Pallene giganteus, Temm., fide Less. Compl. Buff. viii. p. 493 (1837.).

Cypselus leuconotus, Delessert, Mag. Zool. 1840, Ois. pl. 20.

Acanthylis caudacuta (Lath.), Gray, Ann. Nat. Hist. xi. p. 194 (1843).

Pallene macroptera (Swains.),

$\left.\begin{array}{l}\text { Pallene caudacuta (Lath.), } \\ \text { Pallene leuconotus (Deless.), }\end{array}\right\}$ Boie, Isis, 1844, p. 168.

Acanthylis nudipes (Hodgs.), Gray, Gen. B. i. p. 55 (1845).

Hemiprocne leuconotus (Deless.), Struebel, Isis, 1848, p. 362.

Chætura caudacuta (Lath.), Gould, Handb. B. Austr. i. p. 103 (1865).

'The Needle-tailed Swift, or' White-throated Spine-tail, was first described by Latham in 1801 from examples obtained in Australia, whither they had gone to spend the winter; but it had previously been discovered by Steller in its breeding-quarters near Irkutsk (Pall. Zoogr. Rosso-Asiat. i. p. 541). It has been obtained twice in the British Islands. The first example was shot at Great Horkesley, near Colchester, on the 8th of July, 1846, and was examined in the flesh by Nerman, Doubleday, Yarrell, and other ornithologists (Catchpool, ' 'Zoologist,' 1846, p. 1492). The secoud example was shot near Ringwood in Hampshire in July 1879, and was exhibited at a meeting of the Zoological Society of Loudon on the 6th of January, 1880, when I had an opportunity of examining it (Corbin, 'Zoologist,' 1880, p. 81, pl. i.). Mr. Corbin writes :- "On the evening of July 27 th I saw two strange birds flying about over the river in company with Swifts; but they kept a long way off, so that I could see nothing very peculiar about them, except that they appeared to be larger than the rest of the company, and their flight, although resembling that of their fellows, was somewhat different. My curiosity was awakened, and the next evening I was at the same place watching for the strangers, but the dull cold 
weather prevented my seeing them. In the course of a week, however, I had the gratification of seeing one so near that the white throat, the white under the tail, as well as the pale patch on the back, were plainly visible. I noticed then that it sought its food indiscriminately amongst the Swifts, Swallows, and Mirtins, and was not particular about confining itself to one stratum of atmosphere as the other species did; for it is well known that if Swifts and other species are feeding at the same time, they seldom mingle with each other or occupy the same height in the air. I also obscrved that the bird in question often had a sort of poising flight, reminding one of the Nightjar, but at other times it had an equal, if not superior, dash of wing to the Common Swift; and I could well understand this when, a few days later, I held in my hand what I have every reason to believe was one of the two birds I had seen; for its length of wing, coupled with its superior weight, would give it such an impetus as I have described."

The Needle-tailed Swift breeds in South-east Siberia, East Mongolia, Japan, North China, East Tibet, and the Eastern Hinnalayas; it passes through South China, and probably New Guinea, on migration, and winters in East Australia and Tasmania. Darid and Oustalet state that this species is found in Kamtschatka, but I am mable to find any authority for this locality; Schrenck and Radde found it on the Amoor; Dybowsky records it from Lake Baikal; and my Siberian collector has sent me several specimens from Krasnoyarsk, which appears to be the most westerly limit of its breeding-range in Siberia.

Comparatively little is known of the habits of this charming and interesting bird. It is said to arrive at its breeding-quarters about the end of April or the first half of May. On migration the Needle-tailed Swift does not appear to fly in compact flocks, but in a scattered party, keeping close to the ground, and at these periods is often seen in company with other Swifts. It leaves for the south again early in autumn, mostly going in August; but a ferw still linger into September after the great bulk have departed, as is the case with our own Swift. Prjevalsky saw this bird on autumn migration in Mongolia in such numbers that they were passing overhead for a whole day in one almost incessant stream. The haunts chosen by this singular bird are amongst the mountains, ou forestclad hills, deep ravines, and passes; but as it possesses such cnormous powcrs of flight, it may frequently be scen on the plains, on a visit from its rocky home far above them. It is also very probable that the bird in many cases only haunts the rocks for breeding purposes, and haths for its prey over the wooded low-lying country. It is often seen in small parties busily skimming about in search of food, sometimes quite low, and at others at an immense height, according to the whereabouts of the insects on which it feeds. 
Gould writes on the flight of this bird:--" The keel or breast-bone of this species is more than ordinarily deep, and the pectoral muscles more developed than in any bird of its weight with which I am acquainted. Its whole form is especially and beautifully adapted for extended flights; hence it readily passes from one part of the world to another, and, if so disposed, may be engaged in hawking for flies on the continent of Australia at one hour, and in the next be similarly employed in Tasmania. So exclusively is this bird a tenant of the air, that I never, in any instance, saw it perch, and but rarely sufficiently near the earth to admit of a successful shot; it is only late in the evening and during lowery weather that such an object can be accomplished. With the exception of the Crane, it is certainly the most lofty as well as the most vigorous flier of the Australian birds. I have frequently observed in the middle of the hottest days, while lying prostrate on the ground with my eyes directed upwards, the cloudless blue sky peopled at an immense elevation by hundreds of these birds, performing extensive curves and sweeping flights, doubtless attracted thither by the insects that soar aloft during serene weather; on the contrary, the flocks that visit the more humid climate of Tasmania necessarily seek their food near the earth." My friend Mr. E. P. Ramsay tells me that he once saw three or four of these birds perched on the edge of a hollow tree-trunk in Australia. All observers agree in describing the rapid flight of this Swift. It is incessantly on the wing, sailing and darting about on never-tiring pinions, sometimes retiring to the inaccessible cliffs or clinging to their steep sides, aided by the spines on its tail-feathers.

Of the nidification of this bird nothing positive is known. Some writers state that it nests in holes of rocks and trees, whilst others assert that it builds a glutinous nest like that of the Edible Swallow. D'xing the pairing-season the Needle-tailed Swift often chases his mate through the air, and at these times it is said by Prjevalsky to utter a weak note, more like that of a Swallow than a Swift. Several pairs are said by this naturalist to nest close together; and although he informs us that they breed in the cliffs, on the shores of rivers, and in hollow trees, he unfortunately omits any details. Of its eggs nothing is known at present; but they are most probably white in colour, as are the eggs of all the Swifts so far as is known.

The food of the Needle-tailed Swift is composed entirely of insects of different kinds, the indigestible parts of which are cast up in pellets.

The Needle-tailed Swift in breeding-plumage has the forehead dull white; the rest of the head, the nape, the wing-coverts, and the upper tail-coverts and tail are dark shining green; the feathers of the nape have concealed white bases, and the inner webs of the innermost secondaries are white. The rest of the upper parts are brown, shading into pale brown or'

VOL. II. 
nearly white on the centre of the back; the wings are black, with purple and greenish reflections. The throat and upper breast, a patch on the lower flanks, and the under tail-coverts are white, the remainder of the underparts being rich brown. Bill black; legs, feet, and claws dark brown; irides hazel. The female resembles the male, but is a trifle smaller.

Most of the species belonging to this genus are small, the wings measuring less than $6 \frac{1}{2}$ inches in length. Besides the Needle-tailed Swift there are four other large species, in which the length of wing ranges from 8 to 10 inches; but none of these have the throat white.

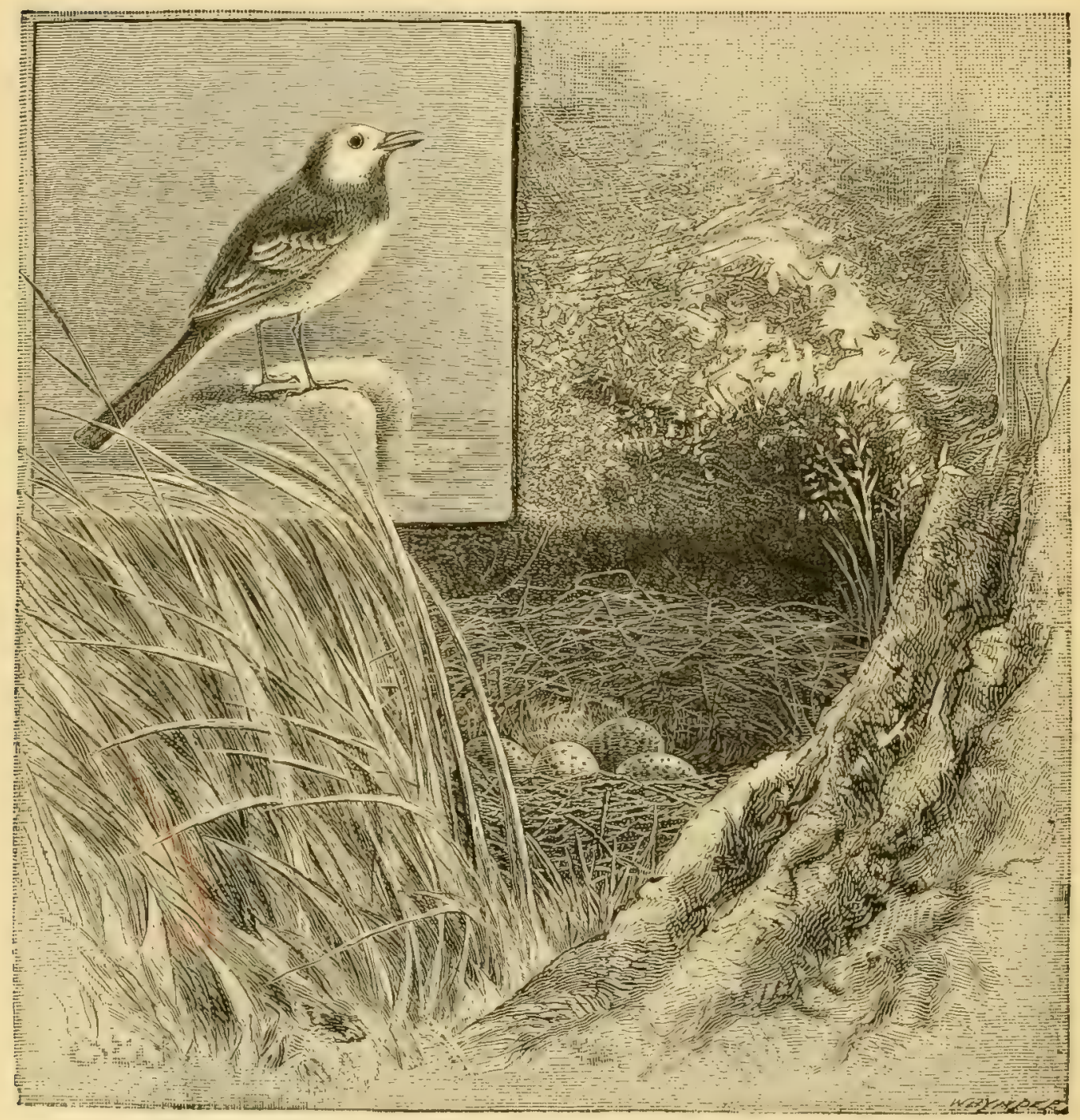

NEST OF PIED WAGTAIL. 


\section{Family CAPRIMULGID $\approx$, or NIGHTJARS.}

The Nightjars or Goatsuckers are a group of birds bearing a remarkable family likeness, but divisible into two subfamilies, the Caprimulgine and the Podarginæ, which are placed by Sclater in different suborders. In the former, the claw of the middle toe is pectinated, the outer toe is composed of only four phalanges, and the sternum has only one notch on each side of the posterior margin. In the latter, the claw of the middle toe is not pectinated, the outer toe consists of five phalanges, and the sternum has two notches on each side of the posterior margin*. The Caprimulginæ were associated by Forbes with the Bee-eaters, Rollers, and Owls, in juxtaposition with the Passerine birds; but Sclater places them with the Swifts and the Humming-birds.

Though they are associated by Huxley with the Swifts, the Woodpeckers, and the Passerine birds, this writer states that in many respects they present a marked contrast to these families in the modifications of their cranial bones. Nitzsch says that they very nearly approach the Swifts in their pterylosis ; but in their myology and digestive organs they are supposed to be most nearly allied to the Bee-eaters and Rollers.

The Nightjars moult twice in the year, in spring and autumn.

In their external characters they are intermediate between the Swifts, the Owls, and the Cuckoos, having the small bill and wide gape of the Swifts, the soft pencilled plumage of the Owls, and the long tail of the Cuckoos. The wing contains ten primaries, and there are only ten tail-

* This character does not appear to be constant. Although the Caprimulgine are supposed to agree with the Passerida in having only one notch in the posterior margin of the sternum, that of an American species, Chordeiles popetue, is figured (Baird, Brewer, and Ridgway, N. Amer. Birds, ii. p. 420) with two notches, and a South-American Nightjar, Steatornis caripensis, forms an intermediate link between the two subfamilies, having the five phalanges on the outer toe and the unpectinated clars of the middle toe of the Podarginæe, but nevertheless agreeing with the Caprimulginæe in only having one notch on each side of the posterior margin of the sternum. A hasty study of both the internal and the external characters of the various families of birds might almost lead to the conclusion that every bird is related to nearly every other bird, that no characters are constant, and that it is impossible to determine whether any of them have any taxonomic value cr not. 
feathers. The hind toe, like that of most other Picarian birds, is much shorter than any of the fore toes.

There are about ninety species of Nightjars (Caprimulginæ) and twenty of Frog-mouths (Podargina), so that the Family of Caprimulgidæ, if it really embraces both these groups, will contain about 110 species. The Nightjars are cosmopolitan, except that they are absent from the Aretic regions, and from the New Zealand and Polynesian Subregions of the Australian Region. Three species only are found in Europe and North Africa, one of which is a regular summer visitor to our islands, and the other two are said to have visited us once.

\section{Genus CAPRIMULGUS.}

The genus Caprimulgus was recognized by Linnæus in the 12th edition of his 'Systema Natura,' i. p. 346, published in 1766. C. europaus (the Caprimulgus caprimulgus of Brisson) has been universally accepted as the type.

The species belonging to this genus may be distinguished from those belonging to allied genera by having well-developed rictal bristles. In other respects the differences are comparatively trifling.

The genus contains about seventy species, about half of which belong to the New World, and the remaining half to the Old World. They are only absent from the Arctic regions, the Pacific Islands, and New Zealand. Two species only breed in Europe, one of which is a regular summer visitor to the British Islands, and the other has occurred once. A third species, breeding in North-east Africa and South-west Asia, has on several occasions strayed into Europe, and even wandered as far as this country.

The Nightjars frequent open heaths, but are also found in wooded districts. They are almost entirely nocturnal in their habits, and feed principally on insects, which they catch on the wing. They make no nest, but deposit their eggs on the bare ground. Two is the usual number of their eggs, which are much clongated, and almost as blunt at the small as at the large end; they are dull white in colour, blotched and spotted with brown or grey. 


\section{CAPRIMULGUS EUROP无US.}

\section{COMIMON NIGHTJAR.}

\section{(Plate 17.)}

Caprimulgus caprimulgus, Briss. Orn. ii, p. 470, pl. 44 (1760).

Caprimulgus europæus, Lim. Syst. Nat. i. p. 316 (1766); et auctorum plurimorum - Gmelin, Scopoli, Bonaparte, Temminck, Naumann, Newton, Dresser, \&c.

Hirundo caprimulgus (Briss.), Tunst. Orn. Brit. p. 2 (1771).

Caprimulgus punctatus, Wolf, Taschenb. i. p. 284 (1810).

Caprimulgus vulgaris, Vieill. Faun. Franç. i. p. 140 (1828).

Caprimulgus maculatus, Brehm, Vög. Deutschl. p. 131 (1831).

Nyctichelidon europæus (Linn.), Rennie, Mont. Orn. Dict, p. 335 (1831).

The Common Nightjar or Goatsucker is a summer migrant to the British Islands, and is found more or less commonly in almost every county, but is more numerous in the south of England than in the north. It is, nevertheless, tolerably common on many of the inner islands on the west coast of Scotland, and is an accidental visitor to the Orkneys and Shetland; but on the Outer Hebrides it has only been known to occur once, in North Uist. In Ireland it is more local than in England, but is found in suitable districts throughout the country. In the Channel Islands it is best known on autumn migration, but a few are said to breed there.

The Common Nightjar breeds throughout Europe and South-west Siberia. In Scandinavia and West Russia it is found as far north as lat. $63^{\circ}$; ; but in the Ural Mountains and the valley of the Yenesay it has not been recorded further north than lat. $59^{\circ}$, nor does it appear to occur further east than Irkutsk. It also brceds in Turkestan, the extreme northwest of India, Afghanistan, the Persian highlands, Palestine, and Asia Minor. It passes through Scind, Arabia, and North-east Africa on migration. It winters in North-west Africa, where a few apparently remain to breed; and in South Africa, where it has been recorded from the Cape Colony, the Transvaal, and Natal. Examples from Central Asia appear to be slightly paler in colour than those from Europe, and have been distinguished as C. europaus, var. unwini. The Common Goatsucker has many

* Dresser"s statement that the Common Nightjar " is not uncommon, and breeds near Archangel," which Newtow slightly expands by saying that it reaches Archangel, appears to be solely based upon the existence of some eggrs of this species in the museum at that town, most probably picked up on the roadside by some traveller from St. Petersburg. This evidenco cannot be considered satisfactory, inasmuch as this bird is not recorded from Archangel by Lilljeborg, Alston and_Harvie-Brown, Goebel, Meves, or Hencke, the latter of whom devoted several years to the ornithology of this district. 
other near allies, all of which appear to be separable by well-marked characters.

We have fer more interesting birds in this country than the Nightjar. Like the Swift, it is one of the latest migrants to arrive, and one of the carliest to depart, seldom appearing in our islands before the middle of May, and leaving in September. It is seen in Malta as early as the cnd of March or the beginning of April; but Irby says that at Gibraltar the earliest record of its arrival is the 5th of May; and Krüper states that it arrives in Greece and Asia Minor during the last week of April. It has also been met with in this country as early in the year as the third week in February and the second week in April; but these, as well as its occurrence as late as November, must be regarded as very exceptional cases.

The Nightjar has been called the Fern-Owl, and is almost as closely associated with bracken as the Red Grouse is with heather. It haunts moors and extensive heaths, the outskirts of forests on the open places where the brambles strive with the bracken as to which shall occupy the most space: in such places it is fond of frequenting the driest and stoniest spots. It is often flushed in open places in the forest, and loves the shelter of a pine-wood on the borderland of the moors. It is strictly a night bird, and is never seen in the daytime on the wing unless disturbed; for it roosts during the day, like most of the Owls, and only comes out at night in search of food, when its singular note may be heard at all hours between sunset and sunrise. When flushed it dashes off in a bewildered manner, and often seeks refuge in the nearest large tree, where, alighting on one of the broad branches, it squats close down, perching along the branch, not across it; at other times it chooses a sheltered spot on the ground, where it can sleep, undisturbed by the wind or the sunshine, until dusk.

The habits of the Nightjar are perhaps more easily studied than those of any other of our nocturnal birds. It is astir early in the evening; the sun has scarcely set before its singular note is heard in different parts of its haunts; and as the dusk increases the bird comes out to the open heath, and begins to beat about in a very Hawk-like manner for its meal. It is not a gregarious bird, but in districts where it is common half a dozen may often be seen on the wing at once. It is said to migrate in pairs or in small parties, never in large flocks.

Dixon, describing its habits near London, says :- "Few things are more pleasant in the refreshing cool of a July evening than to stroll into the Nightjar's haunt and watch the aerial gambols of this sombre yet handsome little bird of night. It is very common on the miniature moor lnown as Shirley Heath, some three miles south-east of Croydon, and also on Wimbledon Common. In either of these places you may be sure of 
meeting with it between the months of May and September. When the evening's gloom is falling, in the dreamy ' aftergloy' of a summer sunset, you may hear the Goatsucker's well-known churr from the woods; and as the darkness deepens and the glowworms' little lamps twinkle in the dewy grass, they come forth and search the air above the broken ground for their favourite food. This nightly beat of the 'Fern-Ow' is partly heath, partly bracken, and partly furze, intermixed with a few stunted trees. You may see the birds repeatedly hover in the air above your head, the soft flapping of their wings being scarcely audible, and their forms coming strongly out against the clear western sky as they mount for a moment above the trec-tops. If you keep very quiet they will probably alight on one of the poles of the wire fence which divides the wood from the heath. Here their actions are very like those of a Flycatcher. They sally out into the air to catch a passing moth or beetle, then return to their perch : a few moments' pause, then another sally into the air, turning, twisting, and hovering with charming gracefulness and with scarcely any noise whatever. Sometimes when one bird is thus perched it is joined by its mate, and I have seen them thus conrey food to each other. As night draws on their activity seems to increase; and, darting and gliding swiftly amongst the trees, or out into the open, they appear to hold high carnival in the gloom, and as they tum amongst the trees the light under surface of their wings is very distinct. On the wing the Goatsucker's common note is a clear and somewhat rapidly repeated co-ic co-ic, whilst the 'churring' noise is made only when the bird is at rest."

The Nightjar does not appear to be much incommoded by the light, and instances are on record where it has been seen searching for its prey during the middle of the day, probably when it has arrived hungry after a night's migration. As is the case with so many birds whose habits are not readily observed, the Nightjar has few friends. The name of Goatsucker is derived from an ancient superstition that the bird is capable of drawing milk from the goat, probably arising from the wideness of its gape, and from the fact that the poor harmless bird flies over the sleeping herds to catch the insects usually found in their vicinity. Gamekeepers either shoot it in the belief that it is a species of Hawk, or they nail it up in their museums along with Cuckoos and Kestrels to increase their show of destroyed vermin, under the impression that their employers will not discorer that these birds are not Hawks of some kind that are injurious to game. In its noiseless flight this bird resembles most the Owls; but it can twist and turn on the wing, or skim along the side of the wood, or hawk for its insect prey over the tops of the trees with almost the facility of a Swallow, a bird which it also resembles in its helplessness on the ground, where it can only walk with difficulty. 
The presence of the Nightjar in a district is generally made known by its singular notes. These have been likened by numerous writers to the noise made by some kind of machinery. They remind one of the note of the Grasshopper Warbler, but are much louder and deeper. If tigers purr like eats, I should imagine they would make a noise something like the Goatsucker. Its ordinary note may be very closely imitated by sounding the letter $r$ sufficiently rapidly to makc the tonguc vibrate, and then, endeavouring to gire it a slightly guttural sound, making it occasionally swell and sink in loudness, and slightly alter in tone, as it is produced by inhaling or exhaling the breath. The note is very powerful, and on a still evening may be heard at a long distance. This churring note is uttered at irregular intervals, and usually lasts a minute or so, sometimes as much as four or five minutes, and is said to be confined to the male bird, and only uttered when it is perched. It is generally heard in the dusk and at night; but in the height of summer, especially in the pairing-scason, it is occasionally heard during the day. In addition to the notes already described, the male bird occasionally makes a whooplike sound; but how this is performed, whether by the throat or the wings, is at present unknown. It is often heard when the birds are chasing each other in early summer.

The food of the Nightjar is supposed to consist exclusively of insects of various kinds. It is very fond of catching cockchafers, and eats many of the large moths and night-flying beetles; and Macgillivray discovered that it fecds on catcrpillers. It is said to snatch the Ghost-Swift Moth from the grass-stems; but more often takes this species as it flutters above them. The Nightjar is a voracious bird, and captures a great many insects in a single night. It is also said to eat slugs. The refuse of its food is cast up in the form of pellets. The bird has been said to hunt for its food with its large mouth wide open; but this is ccrtainly an error. It can open and close its bill in a moment, and does so as occasion requires, resembling in this respect $\mathrm{S}$ wallows and Swifts. There has been much controversy as to the use of the large bristles at the gape of the Nightjar, and more as to the uses of the serrated claw. The bristles may aid it considerably in capturing its prey, and are usually found on the gapes of most insect-fecding birds; but there are many Nightjars in different parts of the world that have no such appendages. The use of the serrated or combed claw remains still unknown, though many ingenious theories have been invented to explain it. Some writers have thought that it was used to aid the bird in capturing its prey; others have said that it was employed to comb out its long rictal bristles, or to rid its plumage of parasites; whilst Naumann was of opinion that it was of service to the bird when perched lengthwise on the branches.

The Nightjar may possibly pair for life; and each successive season 
often returns to the same spot to rear its offspring. It is a late breeder, and its eggs are not usually deposited before the beginning of June. In some seasons they may be found as early as the end of May, but this is exceptional. It makes no nest, and deposits its eggs upon the ground, sometimes at the foot of a tree, in rare instances on a fallen trunk covered with moss and lichen, often in a slight depression on the far-stretching heathy wastes, but most commonly on a small naked flat patch of ground amongst the bracken and the brambles. Here the female deposits her two eggs; and as incubation advances a little hollow is often worn into the earth by the incessant sitting of the bird, but no preparation is ever made. Only one brood appears to be reared in the year; but if the first clutch of eggrs is taken or destroyed others are usually laid, and this accounts for the late eggs of this species that are sometimes found in July and even in August. In such cases, however, a single egg only is generally found. The eggs of the Nightjar possess certain characteristics which easily distinguish them from the eggrs of all other British birds. They are very similar in shape to those of the Swifts and Pigeons, and still more so to those of the Sand-Grouse. They are long and oval, the widest part of the egg being ncarly in the middle, and the small end being scarcely more pointed than the large cnd. They are pure white in groundcolour, sometimes with a faint creamy tinge, mottled, blotched, vcined, streaked, and clouded with brown of various shades and with underlying markings of violet-grey. They differ considerably in the extent and character of the markings. Some eggs have the spots very large, sparingly but evenly distributed over the surface, but the surface ones are rich brown, and the underlying ones violet-grey. On other eggs most of the markings are underlying violet-grey blotches and spots, with only a few small surface ones of rich brown. Some eggs are intricately streaked and scratched with brown surface-colour, with large streaky blotches of grey underneath; whilst in others this is exactly reversed, the underlying grey markings being principally composed of streaks and lines, and the surface ones mostly of blotches and spots. The shell has very little polish. The eggs vary in length from $1 \cdot 4$ to 1.1 inch, and in breadth from 95 to $\cdot 8$ inch. It is not possible to distinguish the eggs of the nearly allied Russet-necked Goatsucker from those of the present species; but as a rule the former are larger and are not quite so streaked.

The Goatsucker sits very closely, often allowing herself to be almost trodden upon ere she quits her charge. When flushed she will sometimes flutter along the ground, feigning lameness, and trying, by many artifices, to draw attention from her eggs or newly-hatched young. The colours of the plumage are eminently protective, and effectually conceal the bird by harmonizing with the tints around - the dead fern-lcaves, moss, and herbage. When perched lengthwise on a branch the Goatsucker appears like the 
stump of a dead broken-off branch which has been grown over with lichen. The young of this bird, when able to crawl about, show remarkable ability to conceal themselves by running into nooks and comers, where they remain quite still until the danger has passed. They are fed and tended for some time after they are able to fly; and the old birds may be repeatedly scen catching food for them in the evening, the young birds perching on the stumps or fences and waiting to be fed.

The plumage of the Common Goatsucker is as difficuit to describe as that of an $\mathrm{Owl}$. The ground-colour of each feather is greyish white, occasionally varied to buff, but generally nearly concealed with delicate pencillings of dark grey and shaft-lines and obscure bars of nearly black. The shaft-lines are broadest on the head and scapulars, the latter of which have broad buff margins to the outside webs. The male is distinguished from the female by having the two outside tail-feathers on each side broadly tipped with white, and by having a large white patch near the centre of the three first primaries of each wing. There is also a small white patch on the cheeks and a larger one on each side of the throat of the male, which are pale buff in the female.

Young males in first plumage have the large spots on the wings and tail smaller than in adults, and buff instead of white. At cach succeeding moult these spots appear to become larger in size and purer white in colour. There seems to be little or no difference between summer and winter plumage. The horny development at the side of the claw of the middle toe is whole in the young nestling, but appears to split into pectinations as the bird grows, a half-fledged bird having only three or four slits, which afterwards double in number.

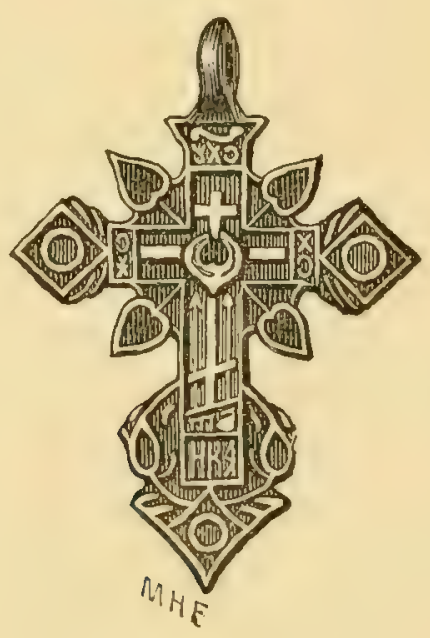




\title{
CAPRIMULGUS RGYPTIUS.
}

\section{ISABELLINE NIGHTJAR.}

\author{
Caprimulgus ægyptius, Licht. Ter $\approx$. Doubl. p. 59 (1823); et auctorum plurimorum \\ -Heuglin, Dresser, Shelley, Sharpe, Severtzow, \&c. \\ Caprimulgus isabellinus, Temm. Pl. Col. 379 (1825). \\ Caprimulgus arenicolor, Severtz. Ibis, 1875, p. 491.
}

Ten years ago the occurrence of the Isabelline Nightjar in Europe was entirely unsuspected, but on the 22nd of June, 1875, an example was shot on Heligoland. When Mr. Sharpe and I visited this island in 1876 we bought the specimen from Aeukens, the bird-stuffer, in whose shop it was displayed as a pale variety of the Common Goatsucker. I brought it to England and compared it with examples from Egypt and Turkestan; and finding it to be identical with them (though some of the former were smaller in size), I recorded it as a European bird (Ibis, 1877, p. 163), and presented the specimen to my friend Gaetke, of whose magnificent collection it now forms a not unimportant ornament. In $1878 \mathrm{my}$ friend Professor Giglioli discovered no less than three examples in the University Museum at Malta (Ibis, 1881, p. 192). Of the correctness of the identification of two of these specimens I can speak from personal inspection.

The claim of the Egyptian Nightjar to be considered a British bird is still more recent. A specimen was obtained near Mansfield, in Nottinghamshire, on the 23rd of June, 1883 (Whitaker, 'Zoologist,' 1883, p. 374). Mr. Whitaker writes :- “On the 23rd of June last my keeper shot at a rabbit in Thieves Wood, near Mansfield, and at the report of the gun a Nightjar flew out of the edge of the wood. Its light colour attracting his attention, he fired his other barrel at it and brought it down. Thinking it only a young bird he did not send it to me, but kept it two days in his house, and then threw it into the back yard, where it lay until the afternoon of the same day, hens, pigeons, and children in the meantime doing their best to spoil its appearance. By good luck I went up to see him, and hearing that it was a light-coloured bird I went to look at it, and found what I thought was a pale variety of the Common Nightjar. I need hardly say how vexed I was that it had not been brought to me, but I cut off the wings and tail and brought them home. On comparing them with Caprimulgus europaus I saw a striking difference, and sent back for the body, with which my bird-stuffer has contrived to make a skin."

I have carefully compared this example with a skin in my collection from Samarkand, and have not the slightest doubt either as to the determination of the species or of the identity of the specimen in Mr. Whitaker's 
collection with the bird shot by his gamekeeper. An old proverb says "that it never rains but it pours." On the 31st of December last Giglioli wrote to me from Florence that he had secured an example of $C$. cegyptius from Sicily, making the sixth recorded occurrence of this bird in Europe.

The breeding-rauge of the Isabelline Nightjar is very l'estricted. Hitherto it has only been obtained in Western Turkestan, Baluchistan, Egypt, and Nubia. Both Heuglin and Severtzow say that it is only a summer visitor to its breeding-grounds, which probably also include Arabia. Its winterquarters arc unknown, but may probably be somewhere in the valley of the Upper Nile.

Scarcely any thing has been recorded of the habits or nidification of this, to British ornithologists, now most interesting species. It is a bird of the desert and the sand, on which it almost cxclusively lives, and where its pale isabelline plumage effectually conceals it from enemies. From the meagre details of its life-history that have already been published it would appear to rescmble very closely in its habits our Common Nightjar. Like that species it skulks during the day, coming out in search of its meal in the twilight. It passes the day cronched low on the sand, where it is said to make a little hollow, or amongst cracks and excavations in the earth. It is said not to be a very shy bird, and as evening approaches it may be seen flitting about on almost noiscless wing chasing insects, and every now and then uttering a croaking cry. Severtzow says that the haunts this bird affects in Turkestan are the sandy parts of the country, never very far from water, and amongst bush and scrubby vegetation. Captain Shelley met with it in Egypt, where he says they are most numerous in spring and autumm, appearing at these scasons usually in flocks. He met with a party of four individuals, all males, in the month of March, and suggests that these birds travel to their breeding-grounds in flocks or partics of the same sex, aud do not pair until their arrival. These four birds were sitting on the sand, and when disturbed flew off and took refuge amongst some tamarisk-bushes, frequently uttering a slight snapping sound as they went. He sometimes saw them flitting over the water near sunset. Heuglin also met with this species on migration in April, May, and Septcmber in Lower Egypt; and the fact that he only shot females from one large flock of more than fifty individuals confirms the previously expressed opinion that the sexes separate to migrate. He found them frequenting the small acacia-groves on the borders of the desert, and also amongst the halfa- or ulfa-grass. Here they rise very reluctantly; and he states that they often ran from one bush to another with puffed-out throats, uttering their curious cry.

Very little is known respecting the nidification of the Isabelline Nightjar; but now that it has received the dignity of being included in the British list, it is very probable that the new and increased interest 
attaching to it will cause British ornithologists to pay more attention to this little stranger. Heuglin says that they breed in some numbers on the sand islands in the province of Dongolah in Nubia, and that its nestingseason is during July and August. He describes the nest as a mere depression in the sand near a tuft of halfa-grass, or under the shelter of a stunted bush. Its eggs appear to be two in number, which he describes as more yellow in tinge than the eggs of the Common Goatsucker, also smaller and palcr. He states that the old bird sits very close, and when disturbed only runs a little distance from the nest. Severtzow says that the young keep in company with their parents until about the end of August, and that after quitting them they are found in pairs.

The food of the Isabelline Nightjar is composed exclusively of various kinds of insects, so far as is at present known. Nothing definite appears to have been written on its song or call-notes; but they probably resemble in a great measure those of the common species.

Pale varietics of the Common Nightjar occasionally occur which may be mistaken for the Isabelline Nightjar, but the two species are perfectly distinct. In the Isabelline Nightjar the sexes are alike, and neither have the white patches on the wings and tail which distinguish the male of the Common species. From the female of that bird the Isabelline Nightjar may at once be distinguished by the colour of the inside webs of the primaries. In the Isabelline species the pale portion is pure white and continuous, the dark bars only reaching about halfway across the webs; in the Common species the pale portion is chestnut-buff, and forms a series of spots, the dark bars reaching entirely across the webs. The general colour of the Isabelline species is much paler, and the dark centres to the feathers of the upper parts are almost obsolete.

The claim of the Red-necked Nightjar* to be included in the list of British birds rests upon a single example which was shot on the 5th of Octobcr, 1856, at Killing worth, near Newcastle, and was purchased on the following day in the flesh by Mr. Joln Hancock from Mr. Pape, a gamedealer in that town (Hancock, 'Ibis,' 1862, 1. 39). This species has a very restricted range, and is only known to breed in North-west Africa

\section{* CAPRINULGUS RUFICOLLIS.}

\section{RED-NECKED NIGHTJAR.}

(Plate 17.)

Caprimulgus ruficollis, Temm. Man. d'Om. i. p. 438 (1820); et auctorum plurimorum-Gould, Degland \&. Gerbe, Saunders, Newton, Dresser, \&c.

Caprimulgus rufitorquis, Vieill. Encycl. Méth. Orn. p. 546 (1823).

Caprimulgus rufitorquatus, Vieill. Faun. Franç. p. 142 (1828).

Caprimulgus torquatus, Brehm, Nanmannia, 1855, p. 270. 
and in the Spanish peninsula, though it has occurred several times near Marseilles and in other localities in the extreme south-east of France. It has also been twice obtained on Malta, and is said to be a regular summer visitor to the Canaries. Its winter-quarters are unknowu; but may probably be in some of the oases in the Sahara. In its labits it is not known to differ from the Common Nightjar; and, like that species, it lays two eggs on the bare ground, which can scarcely be distinguished from those of the European bird. It may be distinguished from the Common Nightjar by the colour of the nape, which is chestnut-buff instead of grey; but in other respects the two species very closely resemble each other, though the Red-necked Goatsucker is slightly the larger bird, and is also much more buff on the wing-coverts and on the underparts. In this species the female as well as the male has the two outer tail-feathers on each side broadly terminated with white, and both sexes have the large white spots on the three outer primaries.

The occurrence of this bird in autumn on the east coast of England is very extraordinary. A summer visitor to Spain might attach itself to a party of migrants from Africa, flying north in spring, and thus overshoot its mark, and arrive with its fellow travellers on the south coast of England. Most of the accidental visitors to the east coast of our islands in autumn are stray migrants from Siberia, and scarcely a year passes without instances of the kind; but there is no stream of migration northwards in autumn in any part of Europe. From Eastern Europe there is a stream flowing westward in autumn; but from Western Europe the only line of migration at this season of the year is from north to south. We must therefore assume, if the occurrence of this species in our islands be a fact, of which there does not seem to be any room to doubt, that the individual in question most probably migrated from West Africa, in the company of a party of Common Goatsuckers from Northumberland, in the preceding spring. We may assume that it passed the summer near the breedinggrounds of its cousins, but fell a victim to some sportsman a few weeks after shooting had commenced.

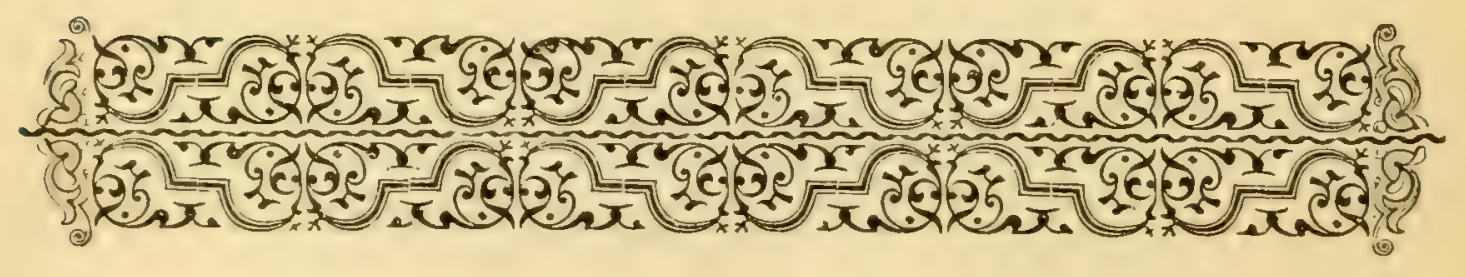




\section{Family MEROPIDÆ, or BEE-EATERS}

The Bee-eaters and their close allies the Rollers are associated by Sclater with the Kingfishers and the Hoopocs; but Forbes included them in a group with the Owls and the Goatsuckers. The posterior margin of the sternum of the Bee-eaters and Rollers has two notches on each side, as is also found in the Kingfishers and Woodpeckers. In Huxley's classification, based primarily on the cranial bones, the Bce-eaters and Rollers are associated with the Hoopoes, the Kingfishers, and the Cuckoos, in a different group to that which contains the Swifts, the Woodpeckers, and the Goatsuckers. Nitzsch places the Bee-eaters and Rollers between the Goatsuckers and the Cuckoos; and in their myology and digestive organs they are said to be very nearly allied to the Goatsuckers.

The Bee-eaters and Rollers only moult once in the year, in late autumn.

The most conspicuous external character of the Bee-eaters and the Rollers is their metallic blue and green plumage frequently associated with chestnut. Except in their small feet, scutellated hind tarsi, and more pointed wings, the general appearance is very similar to that of the Corvinæ, the Bee-eaters resembling the Choughs in the shape of the bill and the Rollers that of the typical Crows in this respect. The wing contains ten primaries, the first primary being long in the Rollers and very small in the Bee-eaters, and the tail consists of twelve feathers.

There are about twenty Rollers and thirty-five Bee-eaters, making fiftyfive species in the Family of Meropida. They are confined to the Old World; but are absent from the Arctic regions, New Zealand, and the Pacific Islands. One species of each group breeds in Europe, both of which are rare stragglers to our islands.

\section{Genus MEROPS.}

The genus Merops was recognized by Linnæus in the 12th edition of his 'Systema Naturæ,' i. p. 182, published in 1766. M. apiaster (the Apiaster apiaster of Brisson) is the type.

The Bee-eaters may be distinguished by their long pointed wings and very minute bastard primary. The tail is also long and the two centre 
feathers frequently elongated ; the tarsus is short, scaled in front and reticulated behind. The hind toe and claw is shorter than any of the fore toes.

This genus contains about twenty species, which are distributed in the southern portions of the Palearctic Region and the Ethiopian, Oriental, and Australian Regions. One species is a common summer visitor to Europe; but is only an accidental straggler to the British Islands, and another occasionally wanders as far as South-east Europe.

The Bee-eaters are birds of the plains, and feed almost exclusively on insects, which they catch on the wing. They breed (like Sand-Martins) in holes in banks, which they excavate themselves, making no nest, and lay round, glossy, white eggs.

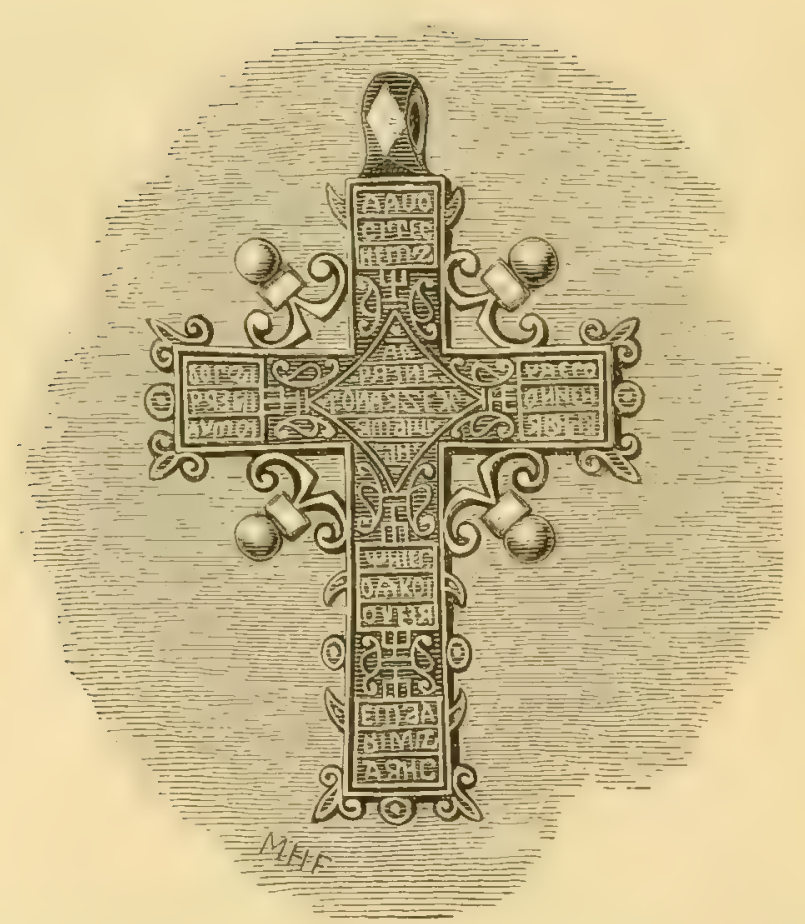




\section{MEROPS APIASTER.}

\section{COMIMON BEE-EATER.}

\section{(Plate 18.)}

A piaster apiaster, Briss. Orn. iv. p. 532 (1760).

Merops apiaster, Linn. Syst. Nat. i. p. 182 (1766); et auctorum plurimorumLatham, Temminck, Naumann, Bonaparte, Newton, Dresser, \&c.

Merops hungarix, Brehm, Vög. Deutschl.p. 146 (1831).

The Common Bee-eater is only an accidental straggler to the British Islands. It was first recorded as a British bird (Lewin, 'Birds of Great Britain,' i. p. 28) from an example which was shot out of a flock of about twenty, which was seen near Mattishall, in Norfolk, in June 1793. Since then it has been obtained in all the southern countics of England, and in those of Norfolk, Suffolk, Lincoln, Derby, and Pembroke. In Scotland it has occurred in Forfarshire and Aberdecnshire; and in Ireland in the counties of Wexford and Wicklow. In most cases it was seen in small flocks during the months of May and June, which had evidently strayed beyond their usual breeding-grounds on their spring migration from South Africa.

The Bee-eater is a regular summer visitor to Europe sonth of the Carpathians. It occurs as a straggler in North France, Holland, Belgium, Heligoland, Denmark, Sweden, North Germany, and the Baltic Provinces. In Russia it does not appear to breed north of lat. 52 $\frac{10}{2}$; but in summer it is found throughout 'I'urkestan as far east as Lake Saisan and the Altai Mountains. It visits the Canaries and Madeira, and is said occasionally to breed there. Throughout North Africa it is principally known as a spring and autumn migrant; but many remain to breed, especially in Algeria and Morocco. It is a common summer visitor to the whole of South Europe, Palestine, Asia Minor, Persia, and Cashmere. It passes through Afghanistan, North-west India and Scind on migration, and winters in South Africa.

The Common Bee-eater has no ally near enough to be confused with it. If Layard is to be believed, our bird breeds during its visit to the Cape Colony, which, if true, is certainly a very remarkable and anomalous fact. Layard's account is circumstantial enough. He says that he limself found it breeding in great abundance on the Berg river in September and October, and quotes the authority of Mr. Hemry Jackson for its breeding near Nels Poort. There is no evidence that the Bee-cater is a resident in South Africa; and if the statements above referred to really apply to the 
present species, the explamation will probably be that there exists a southern colony of this bird whose breeding-range is orerlapped by the winter range of the main colony in Europe, and that the birds of this southern colony winter somewhere in Central Africa.

The migration of the Common Bee-eater from Africa to its breedinggrounds in Southern Europe commences in April. Irby sass that at Gibraltar they may be generally seen in the morning in successire flocks from the end of March to the begiming of Mas, the earliest birds to arrive, as is the case with other migratory species, being those that breed in the immediate neighbourhood, the later arrivals migrating further north. In the east of Europe the period of its migration is during the month of April. In Greece and Asia Minor it arrives about the 1 st of April ; and Shelley saw it passing through Egrpt on its way north on the 10th of that month. Heuglin sars that it is common throughout North-east Africa from the end of March to the begiuning of Mas. They leare Europe for their minter-quarter's during August and September, many even departing by the end of July. They appear to migrate at night in the autumn.

Unlike so many showy birds that seck to hide their charms amougst the deepest foliage, the Bec-cater is extremely partial to the open country, quite as much so as Swallows and Swifts, which birds it resembles in many of its habits. It haunts those sitnations which aftord it a suitable breeding-place; and it takes up its quarters whererer there are conrenient bankis or carth-cliffs, especially if they are near to water, although this is not imperative. In these localitics it is incessantly coming before the observer's notice, either gliding about in graceful Hight, wheeling round and round, or perching conspicuously on the trees or bushes or the telegraph-mires. The raliey of the Damube is a farourite retreat of the Bee-eater; and as the traveller journeys down this river, this bird is frequently to be seen whererer the banks are steep and sandy. It is gregarions, and great mumbers live together, making a charming effect as the sum glances on their brilliant plumage, which is constantly being exposed in different positions as the birds gambol and wheel and turn.

The flight of the Bee-cater is eas and broyant in the extreme. They have a curious habit of shooting themselres formard by jerks, and remaining for a fer moments suspended in the air, with wings and tail expanded, apparently for no other reason than to amuse themselves. Ther perch freely on sticks and reeds and as often on the ground. On the 24 th of May last year, on the banks of the Danube, near the large island below linstchuk, I saw a colouy of these birds. Nie tried to dig out sereral of their mests, but they were too deep for our pocket-linires or seemed to be unfinished. Horering in front of their holes, or seated on a ledge of sandy eurth, or un the ploughed field abore, or on the branch of some willow 
belor, they were most conspicuous and handsome birds. As we examined their nest-holes, they often uttered a note resembling whir, whirr-rup, or whip, as the cry was prolonged or cut short. They seemed to hare farourite perching-places, which were white with their droppings, and on one we found half a dozen castings of beetles' wing-cases, \&c.

The food of the Bce-eater seems exclusirely composed of rarious kinds of insects, especially bees, wasps, locusts, and beetles. It is much disliked by the bee-keeper, and in some cases whole hives are despoiled through its incessant watch for their inhabitants as they pass to and fro. Its food is principally captured on the wing; but it not unfrequently searches for it on the ground, or picks it from the leares aud trigs. Irbs attributes the Bee-eater's rather early departure from Gibraltar in the autumn to the fact that the flomer's are off bloom, the bees have ceased to rork, and its principal food is no longer obtainable.

Of the habits of this bird in Algeria, Dixon writes as follows :- "We met with the Bee-eater specially abundant at Biskra, eridently on migration from its winter-quarters. It was indeed a charming sight to see these birds in scores gliding gracefully orer the tall palms or' resting on the dead leaf-stems, their brilliant colours coming out in bold relief against the dark green regetation. In their flight they put me much in mind of Smifts; but their actions were slower and the birds themselves rather shy. I hare frequently seen them giide about for sereral minutes without any perceptible motion of the wings. The only place in which we sam them in this oasis was the ruins of the large government gardcn-a place full of lusuriant regetation and swarming with birds. They were busy hamking for insects and mingling with Swifts and Swallows. The Blue-cheeked Bee-cater also cousorts with the present species, but is a much rarer bird."

Almost directly after their arriral at their breeding-grounds, the Beeeaters set to work excarating their holes. Many pairs of birds nest side by side, and a bank is often as much tunnelled by them as it is by SandMartins. They seem to make a fresh hole every year. Their long slender bill is chiefly employed in this work of excaration, and, according to Irby, is often worn down to half its usual length by the process! Sometimes the bird tumels as much as eight or uine fect into the solid bank; and Irby says that if a bank is not arailable, it will bore almost straight down into the ground. Sometimes the passage is rather irregular, and the first chamber is occasionally connected by a narrom passage with a secoud. The Bee-eater is a late breeder. Then at Kustendji last pear, in compayy with ALr. Young, I dug out, on the loth of June, half a dozen of their nests from the old Russian trenches formed during the last war between that power and Turkey; they were from two to four feet from the surface, and penetrated about four feet in to the ground, nearly straight and nearly horizontal. 'T'ro of the nests we dug out coutained eggs, one four aud 
the other six, all fresh. The old nests contained nothing but fine earth and decomposed castings. The eggs in the four clutch were on the bare earth; those in the six clutch were surrounded with beetle-cases and wings of dragonflies. The latter did not appear to have been swallowed; so that it scems probable that the male feeds the female on the nest. The birds sat very close, and did not leave the hole until it was half dug out. The nests were in a small chamber at the end of the hole. Further south the Bee-cater breeds much earlier. Irby obtained eggs taken in the south of Spain as carly as the 29th of April ; but the usual laying-time both in Spain and Greece is late in May, and I have taken nearly fresh eggs near Corinth as late as the 6th of June. The eggs of the Bee-eater are from five to eight or nine in number, nearly round, and pure glossy white, the shell being as highly polished as that of the Kingfisher's or Woodpecker's eggs. They valy in length from 1.05 to 95 inch, and in breadth from 93 to $\cdot 8$ inch.

The Bee-eater appears to rear only one brood in the year; and as soon as the young are strong upon the wing they make preparations for their departure south.

The adult male Bee-eater is an extremely handsome bird. The forehead is white at the base of the bill, and shades through virdigris-blue and emerald-green into dark chestnut on the head, which gradually becomes paler on the mantle; this again gradates into dark yellow on the centre of the back and rump, and into nearly white on the scapulars. The upper tail-coverts and tail vary from green to blue, as do also the immermost secondaries; the primaries are blue suffused with green and narrowly tipped with dark brown, and the secondaries are chestnut, broadly tipped with dark brown. The wing-coverts are green at the shoulder, blue on the primaries, and chestnut on the secondaries*. The lores and ear-coverts are black; the checks are greenish blue, and the chin and throat yellow, separated by a black band from the metallic blue-green of the rest of the underparts; the axillaries and the under surface of the wing are buff. The two centre tailfeathers have a narrow tip projecting an inch beyond the rest of the tail. Bill black; legs, feet, and claws reddish brown; irides red. The female rescmbles the male; but the two centre tail-feathers are not quite so long, the plumage is not so brilliant, and the chestnut on the back in many places is suffused with green. Young in first plumage + differ remarkably from adults. There is no blue or green on the forchead, the chestnut on the

* This is one among many instances of the remarkable correlation of colour with structure.

+ Dresser appears to have been unacquainted with the young of the Bee-eater. In his 'Birds of Europe' he fails to point out the most important characters which distinguish the male from the female, and describes those of the young bird incorrectly. Nerwton copies Yarrell's description of the young, which is in the main correct. I have described 
head is suffused with green on the crown and does not extend beyond the nape, and the chestnut and yellow on the rest of the upper parts are replaced, the one by dark green, and the other by light green. The underparts are also much duller in colour, and the black band between the throat and the breast is almost obsolete. The two centre tail-feathers are uniform in length with the others. Male birds of the year scarcely differ from adult females.

An example of the Blue-tailed Bee-eater (Merops philippinus), said to have been shot by Mr. Thomas Hann, of Byer's Green near the Snook, Scaton Carew, in Durham, in August 1862, is in the collection of the Rev. T. M. Hicks (Hancock, 'Birds of Northumberland and Durham,' p. 28). This specimen was exhibited at a meeting of the Zoological Socicty of London, and proved to be a male in adult plumage (Proc. Zool. Soc. 1883, p. 1). This species is a resident in South-east Asia. It is found throughout the Indian and Malay peninsulas, South China, and Formosa, extending to many of the islands of the Malay archipelago, Sumatra, Java, Timor, Borneo, Celebes, and the Philippines. The improbability of a species inhabiting a district so remote and so far to the south ever visiting the British Islands is so great that it is difficult to avoid coming to the conclusion, either that the individual in question had eseaped from an aviary, or that the skin of an Indian bird was substituted for that of a Common Bee-cater by the bird-stuffer through whose hands it passed.

It may be distinguished from the Common Bce-cater by having the throat chestnut instead of yellow, and gradually shading into the green of the breast instead of being separated from it by a black band.

an example in my collection from Italy; and it is needless to say that a correct description of this species in all stages of plumage is to be found in Naumann's 'Birds of Germany,' a work the superiority of which to all modern books on birds becomes the more apparent the more closely it is studied.

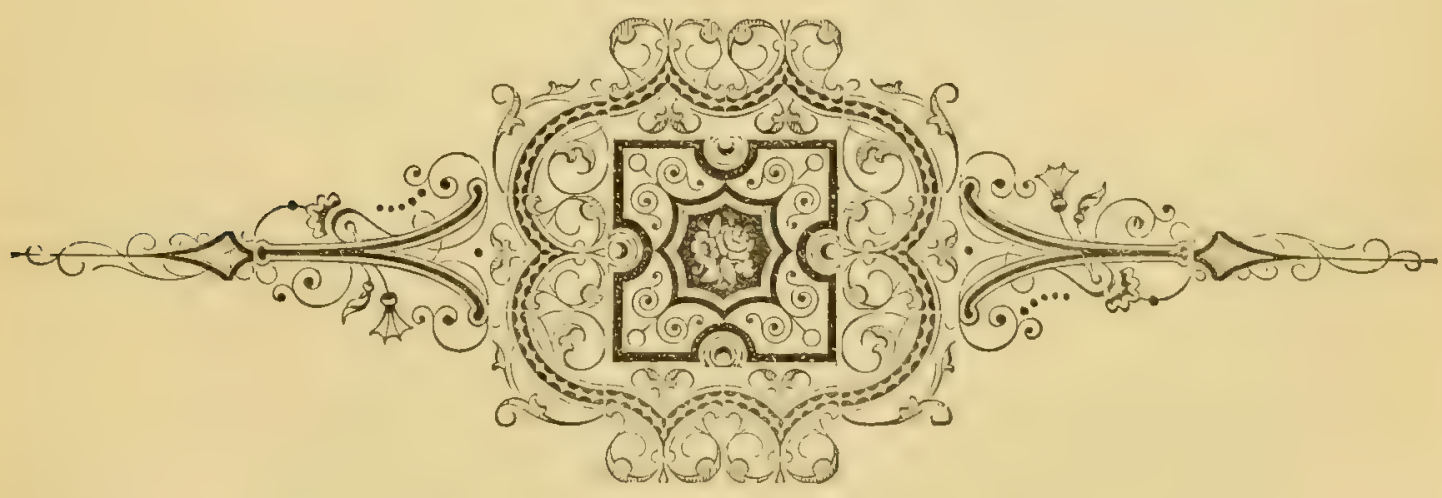




\section{Genus CORACIAS.}

The genus Coracias was recognized by Linnæus in the 12th edition of his 'Systema Nature,' i. p. 159, published in 1766. C. garrula (the Galgulus galgulus of Brisson) is the type.

The species belonging to this genus may be distinguished by their combining the characters of a long, flat, pointed wing with a comparatively narrow bill. The tarsus, which is very short, is scaled in front and reticulated behind; and the hind toe and claw are smaller than any of the fore toes.

There are not more than a dozen species of Rollers, which are confined to the southern portion of the Palrearctic Region, and the Ethiopian and Oriental Regions, extending beyond the latter into the island of Celebes. One species only is a common summer visitor to Europe, and occasionally strays as far as the British Islands.

The Rollers chiefly frequent wooded districts in the vicinity of open plains, especially in the neighbourhood of rocks. Their flight is extremely like that of a Jay, and their notes are almost as harsh as the note of that bird. Their food consists of insects, worms, small mammals, and reptiles. They breed in holes in rocks, old buildings, and decayed trees; and their eggs are pure white, very round, and glossy. 
CORACIAS GARRULA.

\section{COMIMON ROLLER.}

\section{(Plate 18.)}

Galgulus galgulus, Briss. Om. ii. p. 64, pl. v. fig. 2 (1760).

Coracias garrula, Linn. Syst. N'ct. i. p. 159 (1766); et auctorum plurimorumLatham, Temminck, Naumann, Bonaparte, Newton, Dresser, \&c.

Galgulus garrulus (Linno), Vieill. Tabl. Enc。 Méth. p. 866 (1823).

Coracias loquax, Licht. Nomencl. Av. p. 68 (1854).

Coracias bengalensis, Keul. Ned. Tijdschr. iii. p. 380 (1866).

Although this conspicuous bird occurs almost every year in our islands, it can only be regarded as an accident straggler to them chiefly on autumn migration. The earliest known occurrence of this species in the British Islands is that of an example obtained by Sir Thomas Browne near Crostwick, in Norfolk, in May 16 1. More than a hundred examples have since been obtained, principally on the east and south coasts of England and Scotland, but including nine examples from the Orliney Islands, two from the Shetland Islands, one from St. Kilda, and half a dozen from Ireland. A bird so brilliant in its plumage as the Roller has hardly a chance of breeding in our islands, even if it was disposed to do so. The examples obtained in this country are probably migrants from South Sweden to Africa that have wandered from their usual course.

The Roller breeds in most parts of Europe south of lat. $60^{\circ}$, but is only of accidental occurrence in the north of France, Belgium, 1Iolland, and the British Islands; it has also occurred accidentally on the Faroes and in the extreme north of Norway. It is a summer visitor to Algeria, but is only known during winter in Egypt. To Palestine and Asia Minor, Persia, Turkestan, Afghanistan, Cashmere, and the Punjaub it is a summer visitor. It breeds in South-west Siberia as far north as Omsk and as far east as the Altai Mountains. It winters in Arabia, the valley of the Upper Nile, and throughout South Africa *

The nearest ally of the Common Roller is the Abyssinian Roller (C. abyssinica), which will be referred to at the close of this article. It has also a somewhat near ally in Asia, C. indica, which dilfer's principally in having the throat and breast chestnut instead of blue, and the back green

* The Roller, like the Bee-eater, appears to have extended its range eastwards within a comparatively recent period. Both these birds breed as far east as Cashmere; but neither of them are known to winter, as would naturally be expected, in India. This fact can only be accounted for on the theory that their habit of migrating in autumn to South Africa was formed before the breeding-range had been extended and is still retained. 
instead of chestmut. This species is a resident throughout the Indian peninsula and Ceylon, extending westwards into Afghanistan and Persia. In the two latter countries, as well as in Cashmere and the Punjaub, its range overlaps that of the Common Roller, which is said by Blyth to interbreed with it (Blyth \& Wald. B. Burm. p. 72). I have not been able to find any evidence of the accuracy of this statement, and am inclined to think it is an crror; but there can be no doubt that the Indian Roller interbreeds with the Burmese Roller in Eastern Bengal, where the ranges of these two species overlap. The latter species, $C$. affinis, is a resident throughout the Burma peninsula, including Siam and Cochin China. These two species are very nearly allied; but, in addition to some minor characters, the Indian Roller may at once be distinguished by the tailfeathers being broadly tipped with purple.

The migration of the Roller into Europe commences generally about the end of March and lasts until the beginning of May; whilst its migration southrards in autumn begins as early as August in the extreme northern portions of its range, and lasts until the end of September in the south. This conspicuous bird is by no means confined to the forest districts. It loves to haunt those localities which are well timbered, but only those which have plenty of open space between the trees, and it is specially fond of broad open plains which are studded here and there with trees. It also frequents broad stretches of reeds, on which it is said to perch on the look out for the frogs below; and I have frequently seen it sitting on earth-clumps in ploughed ficlds on the look out for beetles. The Roller appears to journey from its winter-retreats in large flocks which, when they have reached their breeding-grounds, seem in no hurry to disperse. Tristram observed this species in Palestine on the 4 th of April near Mount Tabor; and on the 12th of that month great flocks of these birds congregated just before sunset on the trees near a fountain, where they were as noisy as Rooks, but not so orderly in their movements. These birds were evidently on migration, and were probably pairing as they went, for at the end of a week they had all dispersed. After a volley of discordant screams one or two birds were observed to start from their perch and commence a series of gambols and somersaults in the air; then in a moment or two the whole flock followed their example, this strange performance being repeated many times in succession. In that country, as well as in Asia Minor, the Roller is very fond of haunting the villages, and it often takes up its quarters in the ruined churches and mosques.

The Roller is a very restless bird, incessantly changing its quarters, flitting from tree to tree, now alighting on the ground for a few moments, then flying onwards again with a discortant cry if alarmed. In a tree it generally uses its wings to convey it from branch to branch; and on 
the ground it is very clumsy, and hops with great effort, owing possibly to its extremely short legs and weak fect. It flies very quickly, but occasionally tumbles like a Pigeon, whence its common name "Roller." The note of this bird is extremely harsh, something like the sound made by a ratchet-drill-a loud harsh wrack wrack. Although these birds were rather silent when I observed them in the valley of the Danube last year, the Roller is a noisy bird, especially in the early months of spring, when the important business of pairing is in progress. At this season angry males will often chase each other with great speed through the trees; and their aerial evolutions are probably for the purpose of displaying their briliant tints to advantage whilst wooing the females.

The food of the Roller is largely composed of insects and beetles, which it chiefly obtains on the ground amongst manure. It also searches eagerly for caterpillars and worms, and catches frogs, for which it will wait and watch from some convenient perch in those places which abound with these reptiles. There seems to be no evidence that it ever eats grain, or in fact any vegetable substances. Naumann asserts that caged birds, when given any vegetable matter to eat, die from its effects; but this requires further confirmation. A favourite morle of feeding adopted by the Roller is to sit on some clod of earth or other vantage-ground, and wait patiently until it sees a beetle or a locust moving, then to suddenly pounce down and capture the prize.

The breeding-season of the Roller generally commences about the middle of May, though sometimes it appears that they do not begin laying until much later. This is certainly the case in some parts of Algeria, where possibly the long duration of suitable weather for the purpose renders them in no hurry to commence. The Roller generally chooses a hole in a rock or a tree in which to lay its eggs; but it often makes use of a hole in a bank or in a wall or building. Except on migration, it cannot be regarded as a gregarious bird; but Tristram says that he unce met with a colony of Rollers in Palestine that were brecding in holes excavated by themselves in a bank. Where the eggs are laid in an old nest of a Woodpecker they are deposited upon the bare wood-clust at the bottom of the hole; but in other places it makes a slight structure of twigs, grass, and even feathers. The height of the nest from the ground, when in trecs, varies considerably, no choice being apparently shown in the matter: so long as a suitable hole is found, the bird does not trouble itself at what height it is placed. Both birds assist in incubation; and during the time it is in progress the male often performs various evolutions in the air, as is the case with the Jay, the Snipe, and many other birds. The eggs of the Roller are from three or four to six in number, somewhat globular in form, and pure and glossy white in colour. They vary considerably in size, typical examples measuring from $1 \cdot 55$ to 
$1 \cdot 4$ inch in length, and from $1 \cdot 2$ to $1 \cdot 1$ inch in breadth, whilst unusually small specimens only measure 1.2 by 1 inch. Their beautifully polished surface and globular form distinguish them from those of the Pigeons; and their large size prevents them being readily confused with those of the British Wroodpeckers; but many examples are absolutely indistinguishable from those of the Belted Kingfisher and its allies.

In some parts of South-eastern Europe the Roller is shot during its migrations, and much prized as an article of food. Dixon writes of this bird in Algeria :- "This gaudy bird appears to prefer the upland districts to the plains in this part of the world. I do not remember to have ever scen it near the palms in any of the oases; but in the evergreen-oak forests that thickly clothe the sides of the Aurès it is very commonly distributed, and you may see at irregular intervals a pair of birds flitting off, or one or two solitary individuals perched sentinel-like on the top of some stunted juniper- or olive-tree. They are very conspicuous birds, and this, coupled with their excessive noisiness, rarely fails to attract the attention of the ornithologist, especially the British one, who only knows the Roller as a very rare bird. To him their habits are full of fresh and unwouted interest; and as he sees the birds in dozens round him, the scanty records of its occurrence in our books on British birds are irresistibly called to mind. The Roller has many singular traits. Its flight is varied and full of strange manœurres; its voice is most discordant. It is excessirely fond of perching on the topmost branches of the trees, always preferring a dead limb if it can find one, where its showy dress ean be secn for half a mile or more. It cannot be called a shy bird, although it is a wary one, and usually takes wing hefore you get within range of a safe shot. I have often seen this bird soar to a great height, and then drop perpendicularly down, something like the 'shooting' of the Rook, to a perch directly below it. Sometimes it turns over in the air like a Tumbler Pigeon; and in the pairing-scason two birds often chase each other and gambol in the air. The Roller is often seen on the ground in search of its food, which in these regions is largely composed of heetles, locusts, grasshoppers, and any garbage it may find; for it is no more particular in its diet than a Crow or a Jay, which latter bird it resembles very closely in its habits. The flight of the Roller is very unsteady; but I camnot help thinking that the peculiar pattern of the bird's brilliant plumage gives its flight the appearance of being more irregular than it really is. It is rather a late brecker, and in the month of May it had evidently not commenced to sit."

The Roller may be described as a brilliant metallic grecnish-blue bird, with chestnut mantle and innermost secondaries, and with the under surface of the wings rich purplish blue. Bill black; legs and feet pale brown; irides dark chestnut. The female does not differ from the male 
when fully adult; but females of the second year are duller in colour. Males, and especially females, of the year have the whole of the plumage more or less suffused with brown, which is still more the case in young in first plumage, almost entirely obscuring the chestnut and brown.

The Roller often shows a tendency to an elongation of the outside feather on each side of the tail, a feature which scems to be permancntly developed to a remarkable extent in a very nearly allied species, C. abyssinica, which does not otherwise materially differ. An example of a male of this species was presented to the Paisley Muscum by Mr. Small (the father of the well-known bird-stuffer in Edinburgh), who stated that it was shot near Glasgow about the year 1857, and brought to him in the flesh. He also stated that the female was obtained, a short time afterwards, about forty miles from the locality where the male was shot. It is a resident throughout Africa south of the Desert and in Southern Arabia. It has never been known to occur in any part of continental Europe; and it is difficult to avoid coming to the conclusion that the bird in the Paisley Museum had escaped from confinement.

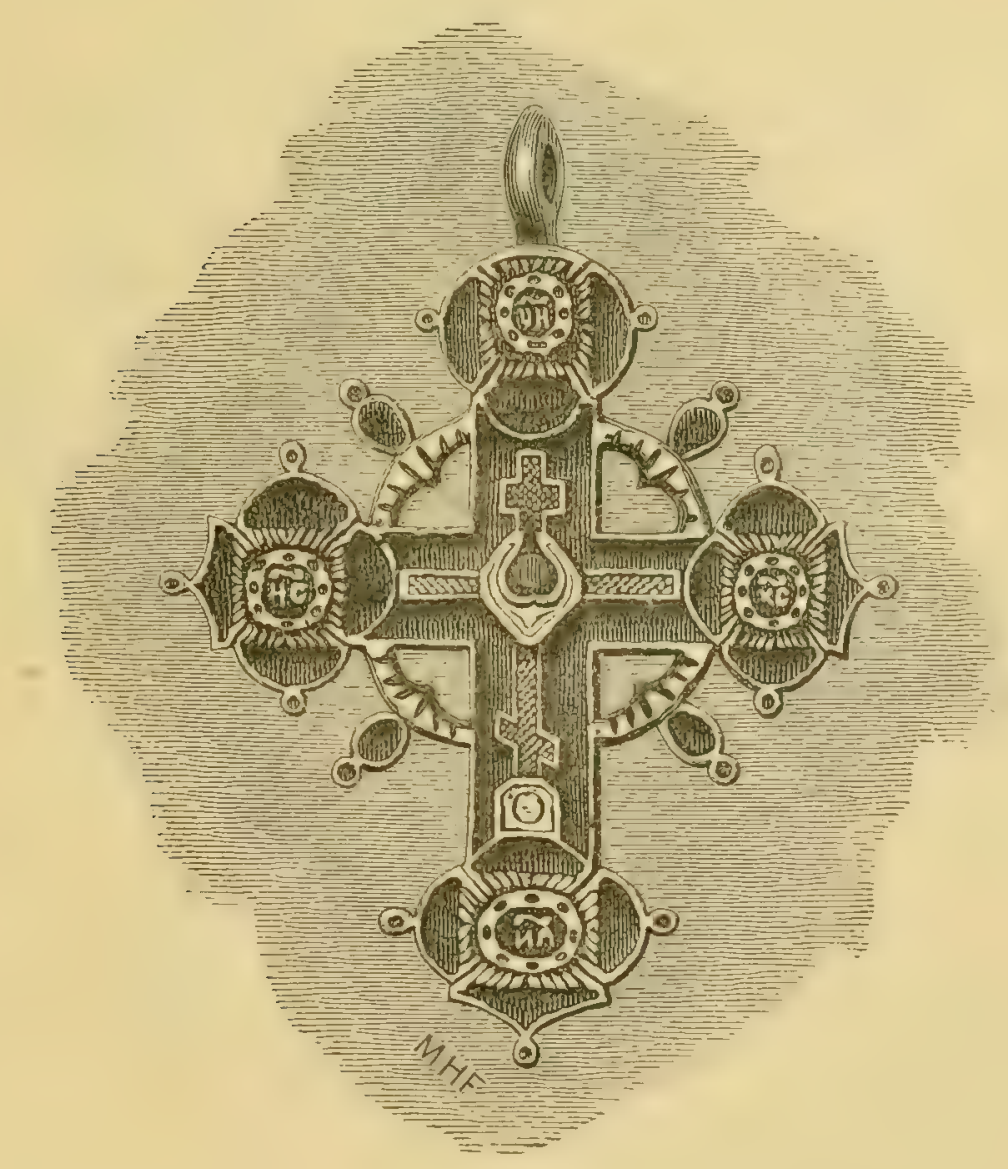




\section{Family UPUPID $A$, or HOOPOES.}

The Hoopoes are a very small and very isolated family. They are associated by Sclater with the Kingfishers, the Rollers, the Bee-eaters, the Hornbills, and some other birds; but Forbes placed them with the Kingfishers and the Woodpecker's, whilst Gadow regards them as nearest allied to the Hornbills and the Kingfishers. The sternum has only one notch on each side of the posterior margin, as in the Passerine birds. Huxley places them between the Hornbills and the Bee-eaters; but in their pterylosis they are said to resemble the Kingfishers more than the Hornbills. In their digestive organs they resemble both these families; they are also said to resemble the Hornbills in their myology.

The Hoopoes have two complete moults in the year, in March and September.

Sclater removes the African Wood-Hoopoes into a separate family, Irrisorida, which differ in many respects from the true Hoopoes, being without crests and having metallic colours on the plumage. The notch on each side of the posterior margin of the sternum is closed at the entrance. If we divide the Upupida into two subfamilies, the Upupinæ and Irrisorina, the true Hoopoes will be comprised in one genus. Both subfamilies agree in having a slender curved bill, rounded wings composed of ten primaries, tail of ten feathers, and the hind toe and claw well developed, as in the Passeridr.

Only half a dozen species of Hoopoes are known, which have a very restricted range. They inhabit the southern portion of the Palæarctic Region, and the Ethiopian and Oriental Regions, but in the latter they are absent from the Indo-Malayan Subregion. One species only is found in Europe, which occasionally visits our islands.

\section{Genus UPUPA.}

The genus Upupa was recognized by Linneus in the 12th edition of his 'Systema Natura,' i. p. 183, published in 1766. U. epops (the Upupa upupa of Brisson) is the type.

The Hoopoes have long, slender, ard slightly curved bills, but may be distinguished by their well-developed erectile crests. The wings are long, 
but somewhat rounded, and the tail is long and ncarly even; the tarsus is short and scutellated, both in front and at the back.

There are only three species in this genus, which are confined to the southern half of the Palæarctic Region, and to the Ethiopian and Oriental Regions.

The Hoopoes principally frequent open country, and are remarkable for the singularity of their voice. They fly in a desultory manner, and feed on insects and worms. They breed in hollow trees and holes in walls, making a very simple nest, and laying eggs greenish blue in colour and very rough in texture.

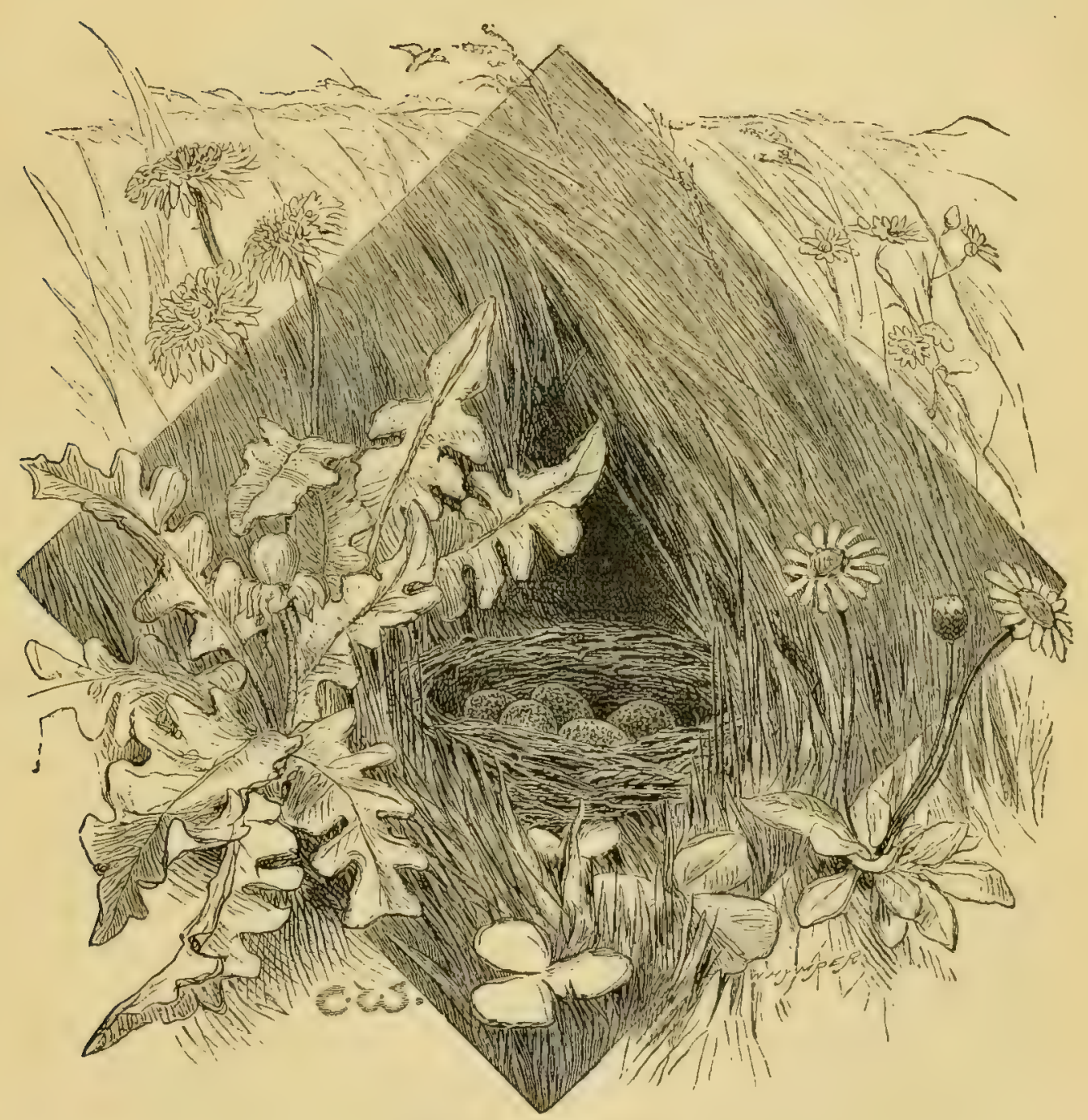

NEST OF SKY-LARK. 


\title{
UPUPA EPOPS.
}

\section{HOOPOE.}

(Plate 15.)

\author{
Upupa upupa, Briss. Orn. ii. p. 455, pl. xliii. fig. 1 (1760). \\ Upupa epops, Linn. Syst. Nat. i. p. 183 (1766); et auctorum plurimorum- \\ Latham, Temminck, Naumann, Bonaparte, Newton, Dresser, \&c. \\ Upupa vulgaris, Pall. Zoogr. Rosso-Asiat. i. p. 433 (1826). \\ Upupa bifasciata, Brehm, Vög. Deutschl. p. 215, t. 15. tig. 2 (1831). \\ Upupa senegalensis, Swains. B. WV. Afro ii. p. 114 (1837). \\ Upupa indicus, Hodgs. Gray, Zool. Miscell. p. 82 (1844). \\ Upupa maculigera, Reich. Handb. Scansorice, p. 319 (1853). \\ Upupa ceylonensis, Reich. Handb. Scansorie, p. 320 (1853). \\ Upupa nigripennis, Gould, fide Horsf. \& Moore, Cat. B. Mus. E.I. Co. ii. p. 725 \\ (1856).
}

The Hoopoe may almost be regarded as a regular summer migrant to the British Islands, but one which has been nearly exterminated on account of its beauty. Nevertheless it continues to visit this country, scarcely a year passing without its being obtainerl, and it has bred in most of the southern comnties of Eugland. It has occurred in almost every county of both England, Wales, Scotland, and Ireland. It has been obtained more than once both on the Orkncy and Shetland Islands. Gray records it from the Outer Hebrides; and I shot an example on one of the Blasquet Islands in the extreme south-west of Ireland. It also occurs on the Channel Islands.

The Iloopoe, although not a northern bird, has a very extensive range, and breeds commonly in temperate and Southern Europe south of lat. $56^{\circ}$, but appears to have been almost exterminated from England and Denmark. North of this limit it has occurred accidentally in Christiania, St. Petersburg, and even on Spitsbergen. To the extreme south of Sweden it appears to be a regular summer visitor. East of the Ural Mountains it occurs up to about the same latitude $\left(56^{\circ}\right)$ and throughout the valley of the Amoor. It is a partial resident in the Azores, the Canaries, and Madeira, and is a permancnt resident throughout North Africa. To Palestine, Asia Minor, Persia, Turkestan, Mongolia, and North China it is a summer visitor. It is a resident in India, Ceylon, the whole of the Burmese peninsula exeept the Malay portioni, and South China. It winters in $\mathrm{T}^{\top}$ est Africa and $\Delta$ byssinia, and Africa south of the Sahara to within about 500 miles of the equator, and, strange to say, in Madagascar. Abont 500 miles south of the equator it is replaced, in many 
parts of South $\Lambda$ frica, by a very distinct species, Upupa africanc, easily distinguished by the absence of the white bar across the primaries*.

As might be expected in a species having such an extensive breedingrange, numerous climatic races occur. The typical race varies in length of wing from 6.0 to $5.3 \mathrm{inch}$, and ranges throughout the Palæarctic Region, including the Himalayas and South China, but cxcluding Algeria, where intermediate forms occur varying in length of wing from $5 \cdot 7$ to $5 \cdot 1$ inch. The Indian race, Upupa nigripennis, is the smallest, the wing varying from 5.3 to 4.7 inch. This race is further distinguished by being somewhat richer in colour, and would constitute a good subspecies were it not that the distribution of the intermediate forms points to a climatic race rather than to a geographical variety. Examples from the Burma peninsula and Hainan, $U$. longirostris, agree in colour with the Indian form, but are intermediate in size between it and the typical form, varying in length of wing from 5.6 to $4.9 \mathrm{inch}$, and have on an average a slightly longer bill, which varies in length from $2 \cdot 7$ to $2 \cdot 2 \mathrm{inch}$, the typical and Indian races varying from $2 \cdot 4$ to $1 \cdot 6$ inch. The latter form appears to be to a certain extent geographically distinct; but it is only the extreme examples that can be distinguished. A local race, $U$. marginata, which appear's to have become specifically distinct, is resident in Madagascar, and is intermediate between the European and Asiatic races, combining the large dimensions of the former with the rich coloration of the latter. It differs from the European species in having a somewhat longer and broader bastard primary without any white spot. It has a much narrower white bar across both the wings and the tail, and in both cases this is placed considerably nearer the base of the feathers. Though the winter range of our bird extends to Madagascar, there does not scem to be any evidence that the two races interbreed:

'The Hoopoe is a migratory bird in Europe, and arrives in Spain, Greece, and Asia Minor towards the end of March, and reaches its breedinggrounds in Germany and other parts of Central Europe early in April. Notwithstanding its early arrival, it does not, as is usually the case with early spring migrants, remain late in autumn, but leaves again for the south in August, and the last has usually disappeared before the end of September. In the oases of the Great Desert, which appear to be the winter-quarters of the Hoopoes that breed in the Algcrian mountains, the birds are very tame and familiar, many of them frequenting the torns, where Canon Tristram says they strut about with little more concern than barndoor fowls, entering the courtyards of the houses, or ruming amongst the tents quite-at ease and unmolested, for with the Arabs the Hoopoc is a sacred bird:

* I cannot admit that the evidence on which this species is said to range as far north as West Africa is reliable (Shelley, Proc. Zool. Soc. 1881, p. 570). 
In Europe the Hoopoe frequents the open fields and small woods, where it is usually seen just on their borders. It is fond of haunting open glades of old timber near to pastures, and also lives on the plains and high up on the bare mountain-sides. In its habits it is shy and wary, but very active, and its movements on the ground may be described rather as a strut than a. walk, and it may be seen moving about, bobbing its head backwards and forwards as it goes, stopping every now and then to probe into the soft earth in search of a worm, or to pick up some tempting morsel laying on the surface. It is most frequently seen on the ground, often on a manure-heap or other mass of refuse; but it is said to search old timber for insects. It does not often venture any distance from cover; and although it is capable of long and powerful flight, it does not usually fly far at a time, but contents itself with flitting, in an apparently careless manner, from one place to another, or takes refuge amongst the trees when it is disturbed. It is said to be a very timid bird; and Naumanu asserts that if a bird of prey, a Crow, or any other large bird should pass overhead, it immediately crouches on the ground and endeavours to make itself look as little like a bird as possible, as with outspread wings and tail and upturned bill it awaits the cause of its alarm to pass over. Although so timid it is rather pugnacious, and in the pairing-season combats often take place between rival males.

The food of the Hoopoe consists, so far as is known, exclusively of animal substances. It feeds chiefly on insects and worms, for which it searches amongst manure, in pastures, or even on the roads. It is very fond of the various specics of coleopterous insects, and also eats ants, caterpillars, grubs, grasshoppers, \&c. In its search for food, especially for worms, it is said to tap the ground with its fect to frighten its prey from their holes; but this is very doubtful. The bird most probably hunts by smell, and when the presence of a worm or grub is thus detected the long bill is thrust into the ground, and the struggling captive drawn out, tossed into the air, in many cases, and caught as it falls, and then swallowed. The bill is said to be always elevated when the bird swallows its food.

The note of the Hoopoe is very singular, it might be said almost unique, and can be heard at a great distance. The bird often takes up its station on the branch of a tree or on a fence, and there utters his guttural and hollow-sounding note, which resembles the word hoop uttered several times in succession. Swinhoe, who has written some interesting particulars on the subject (Proc. Zool. Soc. 1871, p. 348), noticed that as it utters this sound the throat is puffed out and the bill is struck against the ground or the perch at each note. Before it repeats this singular call it repeats the puffing of the neck or throat with a low gurgling noise. When it is able to strike its bill the sound resembles the syllables hoop-hoop-hoop; but when 
perched on a rope, and only jerking out the song with nods of its head, the notes more resemble hoh-hoh-hoh. Naumann says that in addition to this note, which represents the bird's song, it has a hoarse note resembling' $k h r$, and another, which may be the call-note, like vake, vake.

The Hoopoc is casily kept in confinement, and it has been known to breed in captivity. It soon becomes familiar with its kecper, often feeding: from his hand. It is also said to be extremely fond of dusting itself, like the Larks, in the sand on the floor of its cage.

The breeding-season of the Hoopoe commences in the niddle of May, and eggs may be found from that time onwards until the sccond week in June. Paired probably for life, the bird rears its young in holes in trees, especialiy willows, or in a suitable hollow in a rock or old wall. It makes scarcely any nest, merely placing a few straws, roots, and often pieces of dried cow-dung as lining to the hole; but sometimes the eggrs rest on the dead wood alone, or on the remains of the old nest of a Starling or other bird that had previously been in possession of the site. In China Swinhoe states that the bird often breeds in the holes of exposed Chinese coffins, a proceeding which brings the bird into evil repute by the natives, who call it the "Coffin-bird." The nest of the Hoopoe frequently smells offensively; the droppings of the young are suffered to remain in the hole, and the materials used in the lining often make matters worse. The male feeds the female on the nest; but there seems to be no doubt that the latter often leaves her charge to pass her droppings and returns without delay. The eggs are from five to seven in number, and many of them when newly laid are pale bluish green, but they soon fade or become stained in the mest. They vary considerably in colour: some are pale greenish blue, almost the colour of those of the Starling, others are different shades of olive; some are lavender-grey, and others stone-colour. Some specimens have a considerable amount of gloss, and the surface is full of small pits and streaky hollows, which gives them the appearance of being dusted over with minute white specks. The eggs in each clutch do not differ much amongst themselves. They vary in length from 1.15 to $96 \mathrm{inch}$, and in breadth from $\cdot 77$ to 65 inch. It is not easy to confuse the eggs of the Hoopoe with those of any other European bird, the peculiar texture of the shell being sufficient to identify them at a glance. When I was at Valconswaard in the season of 1876 , several nests of the Hoopoe were brought to me with the parent birds, which sit so close that they allow themselves to be caught on their eggs. When they were released the black and white on the wing gave to the flight of the bird a desultory butterfly appearance, but at a distance it was comparatively steady aud only slightly intermittent and undulating.

The Hoopoe only rears one brood in the year. The young birds are said to have a hissing note, and when alarmed in the nest to snap their

VoL. 1 I. 
bills at an intruder. Although they very closely resemble their parents in the colour of their plumage, the young are readily distinguished by their short and nearly straight bills, which do not acquire their full length until the following year. In the winter the Hoopoe is gregarious to a great extent, a dozen or more birds often being seen in a very small area.

The head of the Hoopoe in spring plumage is ornamented with a fine crest, the feathers of which are buffish chestnut broadly tipped with black, which in the hindermost feathers is emphasized by a narrow white subterminal band; the rest of the upper half of the bird is chestnut-buff, darker and browner on the back and paler and pinker on the breast. The lower half of the bird is almost as pied as a Spotted Woodpecker: the lower back, scapular's, and innermost sccondaries are pale buff variegated with black; the primaries are black, with a broad subterminal white band across them, and the sccondaries are black, with four white broad transverse bands*; the rump is white, and the tail is black, with a broad white transverse band almost in the centre of the middle feathers, and gradually approaching the tip until on the outer feathers, especially on the outside web, it nearly reaches it. The belly and under tail-coverts are white, streaked with dark brown on the flanks. Bill black, paler at the base of the lower mandible; legs, feet, and claws dark brown; irides pale brown. The female scarcely differs from the male, but the colours may be slightly less pronounced. Autumn plumage differs slightly from spring plumage; the colours are not so rich, the underparts are paler, and the upper parts slightly greyer. These differences slightly emphasized are the only characteristics of the young in first plumage, except that the beak is only about half the length of that of the adult.

* This is another instance in which there is a striking difference in the pattern of the colour of the secondaries and primaries.

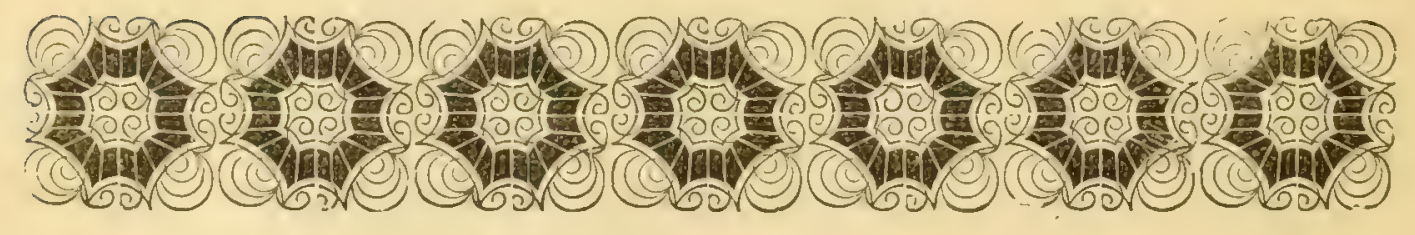




\section{Family ALCEDINID $Æ$, or KINGFISHERS.}

The Kingfishers are a well-defined group of birds, and were associated by Forbes with the Woodpeckers and Hoopoes; but Sclater places them with the Rollers, Bee-eaters, and Hoopoes. They agree with the Woodpeckers, Rollers, and Bee-eater's in having two notches on each side of the posterior margin of the sternum, thus differing from the Hoopoes, though Huxley places them in close proximity to the latter family, which they are also said to resemble in their pterylosis. In their myology and digestive organs they are nearly allied to the Bee-caters, and still ncarer to the Rollers.

The Kingfishers are said to moult only once in the year, in autumn; but some spring examples are in such perfect plumage as to lead to the supposition that they must have moulted very recently.

The most prominent external characters of the Kingfishers are the powerful Heron-like bill and small tarsus and feet, especially the hind toe and claw. They vary greatly in general style of coloration, but chestnut and metallic blues and greens are the predominant colours. The tail is generally short; but in some genera abnormally long, usually consisting of twelve feathers, but occasionally only of ten. The wing is somewhat long, slightly rounded, and contains ten primaries.

There are albout 130 species of Kingfisher's, which are distributed throughout the world, with the exception of the Arctic regions. They are most abundant in the Austro-Malayan Subregiou, and least so in the Nearctic and Neotropical Regions. One species only breeds in Europe, and is a resident in our islands. Two other species occasionally visit South-east Europe; whilst an American species has occurred in Ireland.

\section{Genus ALCEDO.}

The genus Alcedo was recognized by Linweus in the 12th edition of his 'Systema Naturee' (i. p. 178), published in 1766. A. ispida (the Ispida ispida of Brisson) is the type.

The Kingfishers in this genus belong to a group which are distinguished by having a depression on cach side of the upper mandible from the nostril to the tip, causing the ridge of the upper mandible to have the appearance of a keel. The species belonging to the genus Alcedo may be separated 
from those of the nearly allied genera by their short tails, which are never longer than the bill.

This genus may be subdivided into two subgenera, the species of which very closely rescmble each other in generul appearance, but differ in the number of their toes-twelve of them having three toes in front, and seven of them only two. The general colour of the plumage of the upper parts is blue and green with metallic reflections, occasionally crossing the breast, and the underparts are generally rich chestnut, but occasionally white. The wings are short, concave, and rounded, and the tail is very. short and rounded.

The birds in this genus are found throughout the Old World except the Arctic regions and New Zealand. They number about twenty species, only one of which is European and is a resident in the British Islands.

The birds belonging to this genus frequent almost exclusively the immediate neighbourhood of streams and lakes, into the waters of which they plunge to secure their food, which consists principally of small fish and water-insects. Their flight is straight and quick, their wings beating with great rapidity. They breed in holes in banks, which they generally excavate themselves, and make no nest. Their eggs are very round, pure white, and very highly polished.

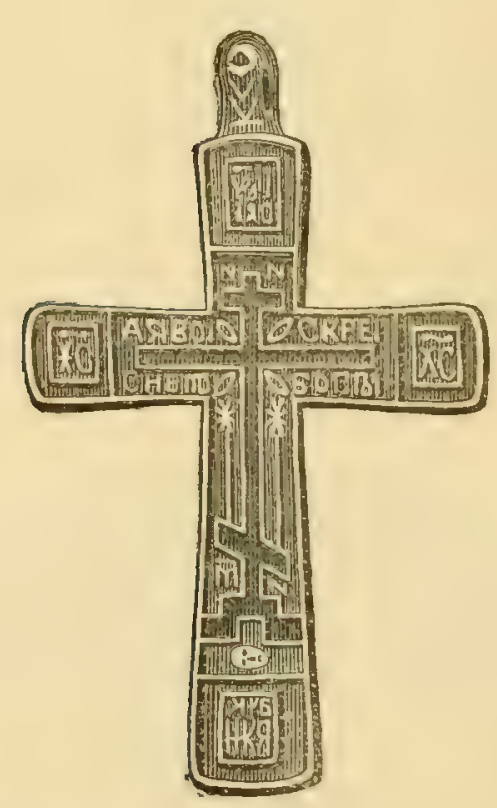




\title{
ALCEDO ISPIDA.
}

\section{COMIMON KINGFISHER.}

\author{
(Plate 18.)
}

Ispida ispida, Briss. Orn. iv. p. 471 (1760).

Alcedo ispida, Linn. Syst. Nat. i. p. 179 (1766); et auctorum plurimorumLatham, Temminck, Naumani, Bonaparte, Newton, Dresser, \&c.

Alcedo hispida, Tunst. Orn. Brit. p. 2 (1771).

Alcedo subispida, Brehm, Vög. Deutschl.-p. 149 (1831).

Alcedo advena, Brehm, Vög. Deutschl.p. 150 (1831).

Alcedo pallasii, Reich. Handb. Alced. p. 3 (1851).

Alcedo sindiana, Hume, Stray Feath. i. p. 169 (1873).

The Kingfisher is a resident on the banks of most lakes, rivers, and brooks throughout the British Islands, except in the Outer Hebrides and the extreme north of Scotland. It is somewhat common in the Channel Islands; but does not appear to have occurred on the Orkney or Shetland Islands.

The typical form of the Kingfisher has a comparatively restricted range, being confined to the southern half of the Western Palæarctic Region, where it varies in length of wing from $3 \cdot 2$ to $2 \cdot 95$ inch. In birds from Egypt, Palestine, Asia Minor, Persia, Scind, Turkestan, and South-west Siberia the wing only measures from $3 \cdot 0$ to $2 \cdot 8 \mathrm{inch}$, and they have received the riame of Alcedo pallasii; whilst in those from South-east Siberia, India, China, Japan, and the Malay Archipelago the wing measures only from 2.95 to $2 \cdot 65$ inch, a form which has received the name of A. bengulensis. The typical form only occurs accidentally north of the Baltic, and has not been known to breed regularly further north in any part of Europe than lat. $55^{\circ}$. It is a resident on the Canaries and Madeira; and Loche says that it breeds in Algeria and Morocco. In Egypt it is principally known as a winter visitor. It is a resident throughout South Europe.

Like most birds of brilliant plumage, the Kingfisher prefers a quiet and secluded haunt. It loves the little trout-streams with wooded and precipitous banks, the still ponds and small lakes, ornamental waters in parks, where it is not molested, and the sides of sluggish rivers, drains, and millponds. It does not always frequent wooded districts; if there is plenty of underrood, stunted bushes, and brambles on the banks of a stream it is quite content; yet at other times it takes up its quarters on the banks of a stream in a wooded dell where the tall trees meet overhead, and its brilliant plumage flashes in the gloom. Here, in such a haunt, the bird often flits past like an indistinct gleam of bluish light; or the orni- 
thologist may be fortunate enough to come upon it unobserved, and watch its actions when scarching for prey. The Kingfisher is, however, a shy and wary creature, and too often the rapidly vibrating twig is the only race of the bird, which, like a flash, has disappeared amongst the overhanging branches. Fortune may sometimes favour the observer, and the bird may alight on some twig over the stream, its weight causing it to swing gently to and fro. It eagerly scans the shoal of young trout sporting in the pool below, when suddenly it will drop down into the water, and, almost before the spectator is aware of the fact, is back again to its perch with a struggling fish in its beak. A few blows on the branch, and its prey is ready for the dexterous movement of the bill which places it in a position for swallowing. Sometimes the captured fish is adroitly jerked into the air and caught as it falls; and sometimes the bird flies off with it to a quiet nook or to its nest to feed its hungry young. The Kingfisher may often be seen to pause in its rapid flight, and hover like a pygmy Kestrel above the pool ere plunging down; and it may not unfrequently be noticed thus fluttering above the water as if searching for food, tarrying a moment here and there.

The Kingfisher is a solitary bird, and each pair will often have a certain beat, from which all intruders are driven off. It appears to be nowhere very common, and is generally seen alone. A bird will often have a favourite perch in some particular part of its haunt, where it spends most of its time; and by a careful study of this habit it can generally be observed when desired. This perch is sometimes a long stout bramble growing over the stream, a stump or an old root on the bank, a dead stick in the middle of a pool, or a rock, or an old wall, or the masonry of a water-wheel or sluice. You may frequently disturb the Kingfisher from such a haunt, and find it there again a short time afterwards. There it silently sits for hours, patiently on the watch for food, every now and then plunging down into the water to secure a little fish or an insect. When disturbed it darts rapidly off, following all the windings of the stream, and usually uttering a feeble piping cry as it goes. The flight of the Kingfisher is very rapid. The bird's wings are small and much rounded; but by rapidly beating them it is enabled to progress with great speed. The flight is not generally long sustained, only sufficiently so to convey the bird to a place of safety; and in this respect it resembles the Wren and many other round-winged birds, who seldom fly far. It is wonderful how a Kingfisher will glide and turn and twist at full speed through the branches without coming in contact with them. It seldom flies very high, though Dixon has once seen it mount up into the air after being fired at, and fly round and round above the trees. The Kingfisher probably roosts at uight in its nest-hole, or in some hole in the bank of the stream, for its feet are scarcely adapted to roosting in bushes. 
The note of the Kingfisher is a shrill peep, and when repeated several times in succession, which is usually when the bird is alarmed or disturbed from its perching-place, is shortened into pip, pip, pip. Sometimes this note is uttered in a much more plaintive tone than at others. As a rule the Kingfisher is a comparatively silent bird, and its notes are often so low as to be scarcely audible at a short distance.

The Kingfisher lives principally on small fish; but it also eats various kinds of insects and their larva. It also captures shrimps, and has been known to take small crabs; and Naumann states that when hard pressed it will take leeches. Stevenson, in his 'Birds of Norfolk,' mentions an instance of a Kingfisher taking a small shrew-an act, however, which cost the poor bird its life. All the indigestible portions of its food are cast up in pellets, most, if not all of them, in the roosting- or breedingplace.

The Kingfisher is said to pair very early in the year ; but these unions are probably confined to young or single birds, for there can be little doubt that the bird pairs for life. It is a somewhat early breeder, and the eggs are laid by the end of April or begiuning of May; in exceptional cases it has been known to lay as early as February; and Mr. Carter, of Bedale, has written to inform me of a nest containing young ones on the 12th of May. Not only are eggs sometimes found very early in the year, but others are often discovered very late, no doubt the produce of birds whose earlier efforts had been unsuccessful, for they appear to have only one brood in the season. The Kingfisher rears its young in a hole, which it gencrally makes for itself, or less frequently adapts for its purpose one ready made. This hole is made in the bauks of the stream it frequents; but the presence of water is not absolutely necessary, for several instances are on record where it has reared its young at some distance from a stream. For many years one or two pairs of Kingfishers have bred regularly in small gravel-pits in a plantation adjoining my brother's garden in the town of Hitchin, at a considerable distance from water. It has also been known to lay its eggs in a hole in a wall. The usual situation is under a bank of moderately soft soil, often amongst the gnarled roots or under the shelter of overhanging bushes. It is at various heights from the ground, the bira not appearing to have any special choice. Mr. Carter also informs me that in his neighbourhood "they constantly build in company with a colony of Sand-Martins, the earth being suitable for both birds." When the spot has been selected (if the birds are not already in possession of a hole, for they will return year after year to the old quarter's if left unmolested), they immediately begin operations; but if disturbed they will often forsake their work and commence another hole close at hand. Sometimes a large stone or a root stops the way, and it often happens that several attempts are made before the little birds are suited. The Kingfisher breeds 
commonly on the banks of the Derwent in Derbyshire; and this little bright feathered gem is, with the Grey Wagtail, the Dipper, and the Sandpiper, one of the most interesting river-side birds of this wild romantic district of limestone crags and steep rocky glens and moor's. I once took the nest of this bird on the banks of this stream near Ashopton. Some of the birds' droppings near the entrance of the hole caught the attention of my friend Mr. Charles Doncaster and myself, although we had for some time previously been aware that the bird was building in the immediate neighbourhood, screral holes haring bcen commenced and abandoned. The hole in question was ncarly straight, and we put a walking-stick up it for nearly three feet; it was of an irregular tunnel-shape rising gradually from the entrance. Having enlarged the hole for about a foot, I thrust my hand in as far as I could reach. I found the bottom of the passage lined with a black or dark green gluey substance smelling strongly of fish, and almost as sticky as bird-lime. After digging and enlarging the passage nearly a foot further we reached the end-a chamber about cight inches in diameter, with two handfuls of white dry fish-bones at the hottom, apparently those of very small fish (vertebræ, jaw-bones, and a profusion of ribs like short hairs, most likely of the fry of the trout). Underneath the fish-bones was a lining of the same glue as in the passage, and upon them three round shining pink eggs. The Kingfisher, in spite of its brilliant dress, is a slatternly bird. It may fairly be called an "ill bircl," since it fouls its own nest and its peerless cggs, but not a speck of the filthy glue was to be secn on them. This substance is composed of decaying fish and the droppings of the birds, and in many nests swarms with maggots. The Kingfisher does not make any more nest than that which the ejected fish-bones supply. No grass, straws, or feathers serve as a bed for the eggs; and in the exceptional cases where such material has been found, it was most probably the remains of a Martin's nest or that of a water-rat, in whose holes the Kingfisher sometimes rears its young. The hole is hored rather slowly, and takes from one to two weeks to complete.

Upon this nest of fish-bones, if nest it can be properly called, the female Kingfisher deposits her round shining-white eggs, from six to cight or nine in number; I have a clutch of the latter number, taken in Oxfordshire. As is the case with most white eggs before they are blown, the yolk inside gives them a beautiful pink appearance. They vary in leugth from 95 to 87 inch, and in breadth from 8 to $7 \% 2$ inch. Kingfishers' eggs are not easily confused with those of any other British bird; for their rotund shape distinguishes them from those of the Woodpeckers, and their size from those of the Bec-eaters, with which latter birds they, however, show considerable affinity.

Both parents assist in incubation, and when the young are hatched they 
are fed assiduously. Mr. Carter says that he has watched them carry fish to their young every quarter of an hour, and that he once found a loach $3 \frac{1}{4}$ inches long laid in the mouth of a hole containing young. When able to leave the nest they are fed and tended for some time by their parents. They take up their stations on the bushes or stumps near their birthplace, and there wait for the food which is being brought every few minutes by the old birds. When able to forage for themselves they are driven off by their parents, compelled to seek haunts for themselves, and it is possible that many of these young birds wander southwards in the autumn.

In Western and Southern Europe the migrations of the Kingfisher are confined to short journeys in search of food. As soon as its fishing-grounds are frozen, it is compelled to leave them; and thus it is obliged to descend from the mountains in search of open water in the valleys and plains. In Eastern Europe the severity of the winter compels it to migrate ; and some find their way to Egypt, whilst others join the great western stream of migration in autumn and reach our shores. They are occasionally mentioned in the "Migration Reports" of the lighthouse-kcepers on the east coast of England; and Dixon writes as follows respecting their appearance on the Lincolnshire coast at that season:- "They arrive on this coast about the same time as the Woodcock, usually remaining in the district during the winter and disappearing again in spring-that is, those fortunate individuals who have escaped the never-ceasing persecution of the gunners on the coast. Their favourite haunts are the open drains which divide the fields and the sluggish dykes behind the sea-banks. These localities seem strange haunts for such a species. I always associate a well-wooded stream with the home of this acrial gem; but here they have no cover, and are obliged to take up thcir quarters amongst the masonry or woodwork of the sluices and bridges which span the dykes. These dykes swarm with suitable food, and the bird would be well-suited were it not so incessantly shot at. I have often been obliged to stamp or knock heavily on one of these bridges before the bird would leave it, to glide like an arrow down the stream. Though they are so common here, they are not at all gregarious. Each pair keeps to its favourite retreat; and though there may be several birds within half a mile or less, they never seem to intrude upon the domain of their neighbours. In such a locality the bird's habits can be easily studied. There are no branches or bushes to hide the little fisherman from view; and you may see him plunge again and again into the shallow waters in quest of his fish or insect food. I have watehed him fishing most industriously from an old stump sticking out of a pool, on whose banks a Heron was standing, lost, as it were, in thought, and on whose unruffled surface Coots and Waterhens were plashing about right heartily. Probably some of the Kingfishers that haunt the coast in winter are only migrants from the interior, where the streams are often 
frost-bound, and their storm-driven inhabitants obliged to seek the open waters near the sea. Even here the poor Kingfisher often fares badly, and after an unusual spell of frost numbers of them are picked up starved to death. Examples are sometimes found frozen to the branch on which they have been sitting."

Few birds are connected with more fables than the Kingfisher. The superstition that a dead Kingfisher, when suspended by a thread, would turn its beak* to that particular point of the compass from which the wind blew, is now fortunately as dead as the Kingfishers on whom the experiment was tried. The classical fable that the breeding-season of the Kingfisher was in midwinter, when the sea remained calm and undisturbed by tempests $\dagger$, is equally as inexplicable and as profoundly forgotten.

The Kingfisher is so well known that it scarcely needs description. The upper parts, including the cheeks, vary from metallic cobalt-blue, especially brilliant on the back, to emerald-green, barred on the head and spotted on the wing-coverts. The underparts are rich chestnut, shading into white on the throat; and the lores and the ear-coverts are also chestnut, shading into white on the sides of the neck. Bill black; legs and feet red; irides dark brown. There are no differences in the colour of the plumage attributable to age, sex, or season of any importance, except those of the young in first plumage, in which the bill and fect are brown, all the colours paler and suffused with brown, especially on the breast, which is barred with greenish grey.

* "But how now stands the wind?

Into what corner peers my halcyon's bill?"

Manlowe: Jew of Malta.

† "This night the siege assuredly I'll raise:

Expect Saint Martin's summer, halcyon days."

ShaKespeare : Henry $V I$.

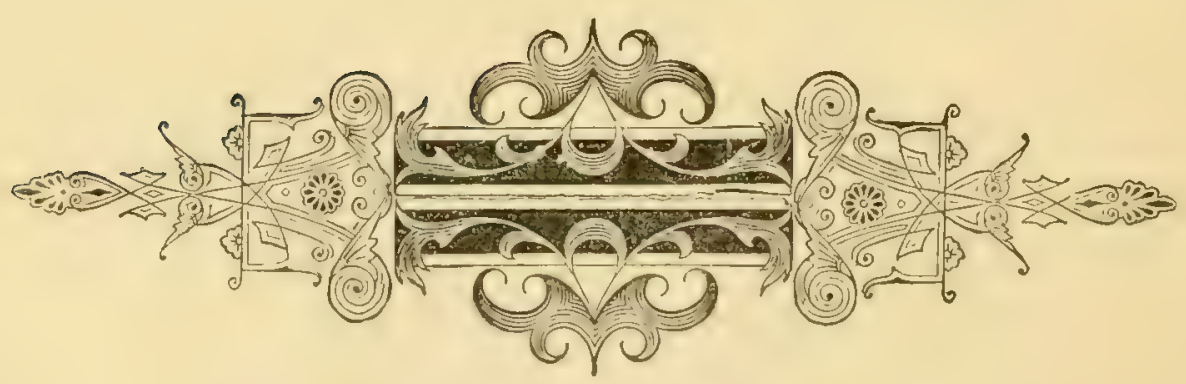




\section{Genus CERYLE.}

The species belonging to this genus were removed from the rest of the Kingfishers by Boie (Isis, 1828, p. 316), who established the genus Ceryle for their reception, designating $C$. rudis as the type.

They agree with the birds in the genera Alcedo and Pelargopsis in having the ridged or kecled upper mandible. From the birds of the former genus they are distinguished by their long tails and longer, flatter, and more pointed wings, and from the birds of both genera by their more or less spotted or barred wings and tail.

This genus contains about a dozen species, which are residents in the Nearctic and Neotropical Regions, the Ethiopian and Oriental Regions, and in the extreme south of the Palæarctic Region. One species is a rare straggler into South-east Europe from Africa, and a second species has once or twice strayed as far as the British Islands from its home on the North-American continent.

The birds belonging to this genus do not differ much in their habits from those of the preceding one. They frequent streams, lakes, creeks, and the sea-shore, where they often perch on some favourable site, whence they pounce down upon their prey. Their food is composed of fish, crabs, lizards, \&c. Their flight is rapid, and their notes are loud and harsh. They breed in holes in banks, making no nest, and laying round glossy white eggs. 


\title{
CERYLE ALCYON.
}

\section{BELTED KINGFISHER.}

\author{
(Plate 18.)
}

Ispida carolinensis cristata, Briss. Orn. iv. p. 512 (1760).

Alcedo alcyon, Lim. Syst. Nat. i. p. 180 (1766); et auctorum plurimorumWilson, Audubon, Brewer, (Sharpe), (Newton), \&c.

Ispida Iudoviciana, Gmel. Syst. Nat. i. p. 452 (1788).

Alcedo jaguacate, Dumont, Dict. Sci. Nat. i. p. 455 (1816).

Alcedo guacu, Vieill. N. Dict. d'Hist. Nat. xix. p. 406 (1818).

Ceryle alcyon (Linn.), Boie, Isis, 1828, p. 316.

Ispida alcyon (Linn.), Swains. Classif. B. ii. p. 336 (1837).

Megaceryle domingensis, Reich. Handb. Alced. p. 25, t. ccecx. fig. 3105 (1851).

Megaceryle alcyon (Linn), Reich. Handb. Alced. p. 25, t. ccccxii. figs. 3108-9 (1851).

Streptoceryle alcyon (Linn.), Cab. Mus. Heine, ii. p. 151 (1860).

Chloroceryle alcyon.(Linn), Sclater, Cat. Am. Birds, p. 264 (1862).

The Belted Kingfisher may fairly claim to be inserted in the list of British birds as an accidental straggler on migration. In the northern portion of its range it is migratory, and is said to be one of the most regular winter visitors to the Bermudas. It is therefore not by any means impossible that birds may occasionally lose their way on migration, and cven reach the United Kingdom. Two examples of the Belted Kingfisher have occurred in our islands, both of them in Ireland. The first specimen, said to be a female, was shot at Annsbrook, in the county of Meath, on the 26th of October, 1844, by F. A. Smith, Esq.; and the second example on the banks of a stream connecting Lake Luggela with Lough Dan, in the county of Wicklow, in November of the same year (Thompson, Ann. Nat. Hist. 1845, p. 69). Other cxamples have been recorded from Ireland, but the evidence is not equally satisfactory.

The Belted Kingfisher is found throughout the continent of North America, from the Atlantic to the Pacific and from the Aretic Ocean to Central America and Trinidad. In the northern portions of its extensive range, where the winters are severe, it is only a summer visitor; but further south it appears to be a resident. It visits the Bermudas in winter, and is said to be a resident in some of the West-Indiau islands.

The Belted Kingfisher very closely resembles the Common Kingfisher in its habits; but the haunts it frequents are somewhat different. It delights to take up its quarters on the banks of swift-flowing streams, in mangroveswamps, or near lakes and ponds, especially near mill-dams; and it is 
otten seen in maritime districts, where it obtains much of its food from salt water. It is a very unsociable bird, and rarely more than one is seen at a time, even in the breeding-season. Each pair seem to have their recognized beat and favourite perching-places, from which all intruders are jealously driven off. They are most frequently seen sitting on some convenient stump, rock, or other "coign of 'vantage," eagerly on the look-out for prey in the water below. Swift-flowing streams, particularly those having hard clayey perpendicular banks, are said by Wilson to be the favourite haunts of this bird. Its flight is rapid, and it passes along: the winding stream a little distance above the water, sometimes pausing to hover for a moment with rapidly-beating wings above some school of fry, and then perching for a little while on a dead branch or some overhanging bough, where it sits glancing here and there, scamning closcly the turbulent flood, or preening its plumage after a successful plunge. In the nonbreeding-season the Belted Kingfisher often wanders far in search of food, and is said to pass from one stream to another in a direct line, flying over the intermediate forests. Its flight is performed by a scries of rapid beats, followed by a smooth gliding motion.

The usual note of the Belted Kingfisher, uttered when the bird is disturbed or flying from place to place, or when about to plunge into the watcr after a fish, is a very singular one, resembling, according to Mr. Gosse, the word churr, but likened by most American ornithologists to the noise made by a watchman's rattle. It is said to utter this weird harsh cry at all hours of the day and night, especially the latter during the brecding-season, and whenever it returns to its nest with food for its young or sitting mate.

I found the Belted Kingfisher very common at Millwankee. On the shore of the lake at the foot of the bluff there was a wooden breakwater and a pier. A pair of these birds were almost always to be seen, generally perched on the wooden edge of the pier. They sat very upright, almost like a Guillemot, with the tail flat on the ground. I never saw them walk or run. However short a distance they wanted to go, they seemed always to fly. The flight is very different from that of our Kingfisher, more like that of a Nutcracker or a Jay. Their wings are powerful, and they can fly deliberately. They do not fly as straight as our species, but the flight can scarcely be called undulatory. They are very fond of chasing each other, and then double and turn with great rapidity, usually uttering a harsh grating scream. Sometimes they hover over the water like a Tern. Sometimes they plunge after fish, appearing to strike the water at an angle, and occasionally disappear altogether beneath the surface for a second or two. On the banks of the rivers or in the park by the margin of the lake I saw them watch for fish from the branch of a tree. If a stump is near the water they often choose it as a perch. They are not shy, and can very easily be shot. 
The Belted Kingfisher rears its young in a hole, which is usually made in the clayey banks of a stream or pond, near the bird's favourite fishinggrounds. The hole always appears to be excavated by the birds, and much time is spent over the task. Both birds perform the work, one relieving the other, and burrowing incessantly until the hole is completed. Sometimes the excavation is finished in a single night; but if the bank is not so suitable and readily tunnelled, a much longer time is taken. The hole varies considerably in depth, sometimes being only four feet from the opening to the nest-chamber, at others as much as fifteen feet. Some holes are perfectly straight, whilst others turn from side to side, usually when near the end. All the holes are enlarged at the end into a sort of chamber, and in this the eggs are deposited. The balance of evidence seems to be in favour of the fact that this bird does not build any nest; but earlier writers on American birds have stated that dry grass \&c. is placed in the nest-chamber. The Belted Kingfisher does not always nest near water, and instances are on record where it has bred more than a mile from it. It is very much attached to its favourite hole, and when once a pair have selected a place for their nest, they are with difficulty driven away from it, and will continue to use their hole even if their eggs are taken from time to time. The eggs of the Belted Kingfisher, usually laid in April or May, are generally six in number, rarely seven, and are, when blown, pure and glossy white, and vary in length from $1 \cdot 4$ to $1 \cdot 3$ inch, and in breadth from 1.06 to 1.02 inch. Their size, of course, prevents them from being confused with those of the Common Kingfisher; but they are indistinguishable from the eggs of the Pied Kingfisher and the Smyrna Kingfisher, species found in South-east Europe and Asia.

'The Belted Kingfisher is devotedly attached to its young; and Audubon states that the female will drop into the water as if wounded, and flutter along as if unable to rise from the surface, to lure an intruder away, and that the male erects his crest and flies to and fro with angry cries when the nest is menaced. The young birds remain in the nest-hole until fully fledged, and are said, when able to fly, to roost in it at night, and to return there in stormy weather for shelter. The young appear to be tended for some little time after they leave the nest by their parents, who often feed them; but they are deserted before the time of migration arrives, when they leave their parents and their birthplace for ever. In the northern parts of its range only one brood appears to be brought up during the year; but in the south two are said to be reared.

The Belted Kingfisher preys upon small fish, crabs, lizards, \&c., whilst its large size and powerful form allow it to cope successfully with mice. All the hard and indigestible portions of its food are cast up in the shape of pellets, and its nest-hole often contains a great number of them. In that portion of its range where the winters are severe enough to freeze up 
its favourite streams, the Belted Kingfisher is only a summer migrant, and leaves in autumn for the south. They are said to migrate singly, and the young birds leave before their parents.

The male Belted Kingfisher has the general colour of the upper parts and a broad band across the breast slaty blue, without any metallic lustre. The head is adorned with a bushy crest. The primaries have the basal half white, the sccondaries and wing-coverts have white tips, and the tail is transversely barred with white. The gencral colour of the underparts (with the exception of the slate-grey chest-band and flanks) is white, with a small white streak from the base of the bill to the eye. Bill black; legs and feet brown, claws black; irides dark brown. The female differs from the male in having the chest-band mottled with brown, and the flanks and a band across the belly are chestnut. Young birds are said to resemble the female.

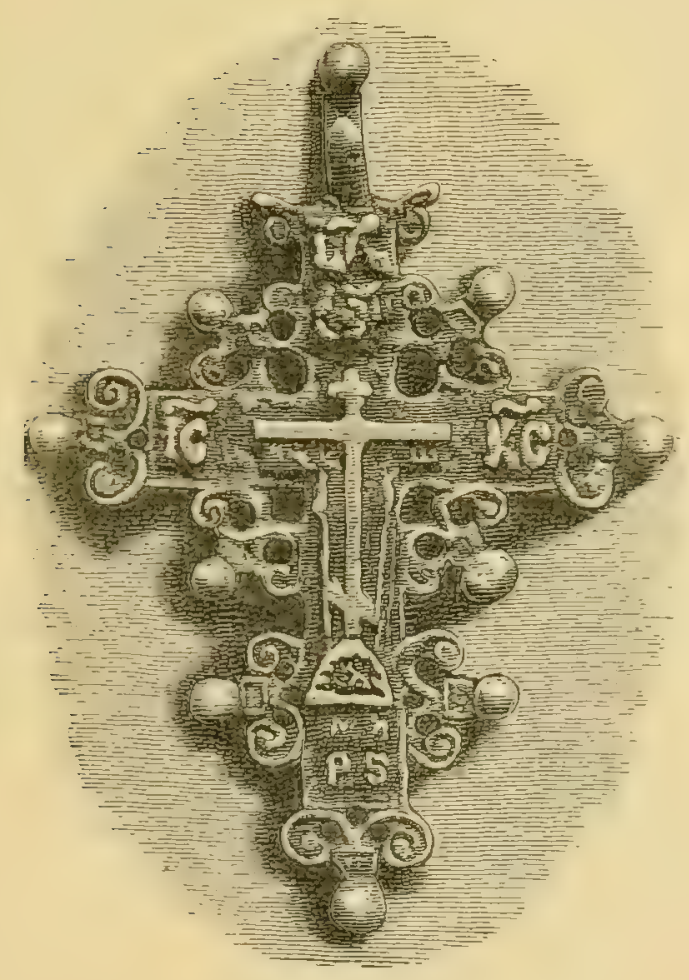




\section{Family PICIDÆ, on WOODPECKERS.}

The Woodpeckers are a well-defined group of birds, and were associated by Forbes with the Kingfishers and Hoopocs, but are placed by Sclater in a suborder by themselves. Like the Kingfisher's, Rollers, and Bee-eater's, they have two notches on each side of the posterior margin of the sternum; but Huxley docs not seem to regard them as nearly allied to these familics in the modification of their cranial bones, but rather to the Swifts, the Goatsuckers, and the Passerine birds. They exhibit considerable variation in their pterylographic characters, which are said by Nitzsch to resemble those of the Kingfishers in some respects. In their myology and digestive organs they are said to be allied to the Kingfishers and the Hoopoes.

The Woodpeckers have only one moult in the year, which takes place in autumn, progressing very slowly, so as not to inconvenience the bird. It lasts through July and August frequently into September, and in some species is only completed in October.

The principal external characters of the Woodpeckers are the long wedgeshaped bill and the distribution of the toes, which are placed two in front and two behind. The wings are rounded, containing ten primaries, and the number of tail-feathers is either ten or twelve. They may be divided into three subfamilies-the Picinæ, or true Woodpeckers, the Picumninæ, or soft-tailed Woodpeckers, and the Yunginæ, or Wrynecks, which have also soft tails. The true Woodpeckers may be distinguished by their wedge-shaped tails, the feathers of which are rigid and pointed. Like the Sun-birds and the Humming-birds, the Woodpeckers have a peculiar development of the tongue, which is capable of being extended to a great length, to assist them in catching their prey.

There are about 330 species of Woodpeckers, which are distributed throughout the world, except that they are absent from Madagascar and the whole of the Australian Region east of Celebes and Flores. Ten species are found in Europe, of which four are British.

\section{Genus PICUS.}

The genus Picus was recognized by Linnæus in the 12th edition of his 'Systema Naturæ' (i. p. 173), published in 1766, and, with the exception of the Wryneck, embraced the whole of the then-known Picidæ. Unfortunately Brisson did not designate any type for his genus Picus, and orui- 
thologists cannot agree as to which species would have been regarded by Linnæus as typical. Of the eighteen species with which he was acquainted, seven belong to the black-and-white group. If we add to these the Black Woodpecker and its three allies, which seem to me to be generically inseparable, there can be no possible doubt that Linnæus must have considered this group of eleven species the typical one, the other eight species being obviously aberrant members of the family. In the absence of any rule to guide me, I accept $P$. major as the type, on the ground that it has been so regarded by the majority of ornithologists.

The distinguishing characteristic of the Woodpeckers belonging to this genus is the coloration of their plumage, which in typical examples is pied black and white, with more or less scarlet or, in rare instances, yellow ou the head of the male; but in some aberrant species the white disappear's altogether, leaving the colours black and crimson.

The limits of this genus have not yet been accurately determined, and it is impossible to say how many species it contains. It is principally confined to the Palæarctic and Nearctic Regions, extending into the northern portions of the tropics.

The birds in this genus frequent large woods, groves, parks, and orchards, where they climb about the trees, digging into the bark and decaying timber with their stout bills in search of food. Their flight is moderately quick and very undulatory, but seldom long sustained. Their notes are loud, harsh, and piercing. Their food is almost exclusively composed of insects and larve. They breed in holes of timber, which they generally excavate themselves, making no nest, and lay white and lighly polished eggs.

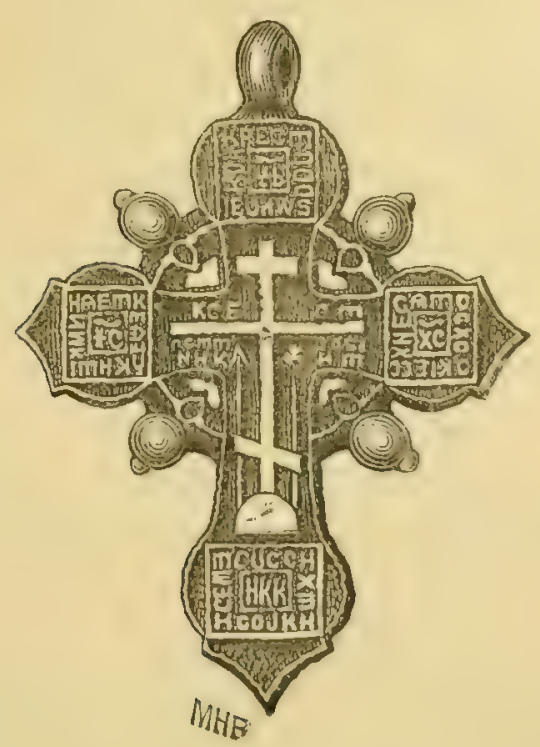

VOL. 11 . 


\section{PICUS MAJOR. \\ GREAT SPOTTED WOODPECKER.}

(Plate 18.)

Picus varius major, Briss. Orn. iv. p. 34 (1760).

Picus major, Limn. Syst. Nat. i. p. 176 (1766); et auctorum plurimorumLatham, Temminck, Naumann, Bonaparte, (Newton), Dresser, \&c.

Dendrocopus major (Linn.), Koch, Syst. baier. Zool. p. 72 (1816).

Picus varius, Linn. apud Forst. Syn. Cat. Br. B. p. 49 (1817).

Picus cissa, Pall. Zoogr. Rosso-Asiat. i. p. 412 (1826).

Dryobates major (Limn.), Boie, Isis, 1828, p. 326.

Picus pipra, Macgill. Hist. Brit. B. iii. p. 80 (1840, nec Pallas).

Picus alpestris, Reich. Handb. Picince, p. 365 (1851).

Picus mesospilus, Reich. Handb. Picince, p. 365 (1851).

Picus brevirostris, Reich. Handb. Picince, p. 365 (1851).

Picus baskiriensis, Verreaux, fide Bonap. Consp. Vol. Zyg. p. 8 (1854).

The Great Spotted Woodpecker is principally a forest-bird, and probably breeds in every county in England and Wales wherever the woods are sufficicntly extensive and the trees large enough. In Scotland it is not so abundant, and appears to be to a great extent confined to the central counties, neither the wild moorlands of the north nor the carefullyfarmed lowlands of the south offering it the shelter and seclusion which it loves. The scarcity of forest in Ireland probably accounts for its rarity in that country and for the fact that it is not known to breed there.

In most parts of England the Great Spotted Woodpecker is a resident; but its numbers are largely increased in autumn by immigrants from the continent. Several small flocks of these birds, mostly birds of the year which had not completed their moult, passed over Heligoland during the month that I visited the island *, and it is well known as a regular autumnal migrant to the east coast both of England and Scotland. In the autumn of 1861 unusual numbers risited Norfolk and Cambridgeshire (Stevenson, 'Birds of Norfolk,' i. p. 289), when they also appeared on the Orkney and Shetland Islands and even on the Faroes.

The Great Spotted Woodpecker is a partial resident in the wooded districts throughout Europe, Siberia, and Japan. In Scandinavia it is rarely found north of the Aretic circle; in Russia it is a common resident up to

* My friend Mr. Gaetle informs me that this is the only species of Woodpecker which passes Ifeligoland regularly, never in large quantities, but most numerous in autumn. The only other Woodpeckers that have been observed on Heligoland during the last fortyfive year's are a single example of Gecinus viridis and a single example of Picus leuconotus. 
Archangel, and was obtained by Hoffmann in the Ural Mountains as far north as lat. $63 \frac{1}{2}^{\circ}$. In West Siberia, Sloffzow obtained it at Omsk in lat. $55^{\circ}$; Theel obtained it in the valley of the Yenesay as far north as lat: $60^{\circ}$; and Middendorff procured it on the Pacific coast of East Siberia in lat. $55^{\circ}$. It is a resident in the Canary Islands; but in North-west Africa it is replaced by Picus numidicus, which differs in having more or less searlet on the breast *. In Egypt there appear to be no Woodpeckers ; but in Palestine and Persia P. syriacus occurs, which, besides frequently having traces of scarlet on the breast, differs from the Great Spotted Woodpecker in not having the white on the sides of the head and neck separated into two parts by a black band across the end of the ear-coverts. In Asia Minor both $P$. syriacus and $P$. major are found. In the Great Spotted Woodpecker of the Caucasus the general colour of the underparts is so chocolate-brown that the bird has been separated under the name of $P$. poelzami. In Turkestan various forms occur between $P$. syriacus and $P$. leucopterus, the latter differing from $P$. major in having the white on the secondaries so much developed that the black is reduced to four spots connected by a broad black shaft-line. In Mongolia and China P. cabanisi and its allies occur, which may be distinguished by their black scapulars. Examples from North Russia and Siberia are larger and much whiter on the underparts than typical examples of $P$. major from Western Europe, and have been called $P$. cissa; but intermediate forms occur both in Scandinavia and the valley of the Amoor. In Japan P.japonicus oceur's, in which the white on the innermost secondaries is developed into broad transverse bars. It is probable that none of these forms are more than subspecifically distinct from the Great Spotted Woodpecker.

The Great Spotted Woodpecker is a somewhat peculiar bird in the choice of a haunt, and often shuns districts apparently well suited to it or frequents others in which we should scarcely expect to find such a species. Due regard being made for its caprice in this respect, we find the Great Spotted or Pied Woodpecker in large woods and old forests, in plantations, both evergreen and deciduous, in fields which are well studded with timber, and contaiu here and there a clump of trees, in parks, orchards, or amongst the pollard willows by the side of sluggish rivers and large ponds. Like all the Woodpeckers it is rather shy, and is more often heard than seen. It loves to frequent the tops of tall trees, the deepest and secluded parts of its haunt, and generally strives to keep that side of a tree furthest away from the observer. It is not often scen on the ground, and during autumn and winter occasionally wanders far from its

* Mr. Hargitt informs me that he has a British specimen of the Great spotted Woodpecker showing distinct traces of red on the breast, and similar instances have been recorded by continental ornithologists. 
brecding-place. A pair of birds or a solitary individual will sometimes take up their quarters in a little plantation or an extensive shrubbery, remaining there for months, but disappearing as soon as the spring arrives. In this manner it will often enter gardens and orchards or pleasure-grounds far from its usual haunts, doubtless tempted to them by some favourite food. It is of a solitary, shy, and retiring disposition, and seldom more than a pair are seen in one locality, more often only a solitary bird.

It is an interesting sight to watch the Great Spotted Woodpecker at work on some large tree, especially in winter, when the leaves are off the branches and most of the bird's movements ean be observed. Sometimes it commences operations at the foot of the tree, beginning its search close to the ground, climbing about in cvery direction, tapping here and there, pausing a sccond or so now and then, and frequently running out on to the larger limbs, working round and round them in busy search for the myriads of insects lurking beneath the loose bark and in its crevices. Sometimes it turns ronnd and with head dommward creeps back a little way, then runs rapidly to the right or left, disappearing behind the trunk, and again coming into view some distance higher up. During this minute search the bird scarcely ever utters a sound, the only moise to be heard is the sharp taps of the bill against the tree from time to time as fresh prey is dislodged or searched for. After remaining some time on one tree, if not previously disturbed, it passes on to another, sometimes in straightforward rapid flight, but more often in a drooping desultory manner. It may often be observed in the slender topmost branches of a tree, and even perches crosswise on the twigs like one of the true Passeres. From tree to tree is the search eagerly pursued, and long after the interesting bird has passed from view its loud tapping or startling call may be heard.

The note of the Great Spotted Woodpecker is a sharply uttered chik or chink, given forth at intervals. It has also another cry which is said to resemble the syllable tra. The attention of the listener is most often arrested by the sound of the bird tapping with its bill on the trunks of the trees, which when they are hollow resound to such an extent that it can be heard at a great distance. Sometimes the taps succeed each other so rapidly that they form a harsh trill. This rapid tapping appear's to be used as a signal between the sexes, and is common to both, and takes the place of a vocal note. It has been suggested that this startling whirr was made to frighten out the insects lurking bencath the bark; but this theory is not supported by any evidence. This noise is often made when the sitting bird is frightened off the nest, and is generally answered by its mate with a similar one.

The food of the Great Spotted Woodpecker is very raried, but consists principally of insects in their various stages of growth. It feeds on the 
larvæ of many wood-haunting moths; but is said not to eat ants or their eggs, and this may explain why the bird is so seldom seen on the ground. In fruit-time it often pays the orchard a visit to regale itself on cherries and plums; and in autumn and winter it largely subsists upon nuts, acorns, beech-mast, fir-cones, and berries of differcnt linds. It has also been known to feed on earthrorms. This species, as well as the other Woodpeckers, are of the greatest service in ridding trees of injurious insects that in too many cases cause premature decay; and they ought to be encouraged and protected by all tree-owners. It has been saic that the Great Spotted Woodpecker damages the timber by boring into it; but the bird never burrows into a healthy tree, the wood is far too hard and the inducement to do so small. Waterton's masterly defence of the Woodpecker will be fresh in the memory of most of my readers.

The Great Spotted Woodpecker is a somewhat late breeder. It is said to pair in March and April ; but it seldom has eggs before the middle of May. It is most probable that this bird pairs for life, and that the birds that mate in the spring are the young of the previous year, or birds who have lost their mates, for in many cases the old hole is tenanted year after year. The hole in which its cggs are deposited is nearly always made by the bird, but it is said that a ready-made one is sometimes utilized. Occasionally it is made in a large branch, but more frequently in the trunk, and a decayed part is invariably selected. It is often made where a branch has been blown away and the rain has rotted a small hole into the trunk. This is often enlarged if it be not already big enough for the purpose. The hole varies in extent, sometimes being as much as eightecn inches decp, but frequently only a foot, and, more rarely, the eggs are within reach of the hand. The passage is wonderfully round and smooth, and the end is enlarged a little into a sort of chamber, and here the eggs are deposited. The bird makes no nest; the eggs lie upon the powdered wood at the bottom of the hole. They vary from five to seven or eight in number, and are creamy white with no spots or markings, save an occasional nest-stain. They vary in length from $1 \cdot 15$ to 95 inch and in breadth from 82 to $\cdot 75$ inch. The eggs of the Great Spotted Woodpecker are easily distinguished from all the other British species of this group of birds; they are much too small to be ever taken for those of the Green Woodpecker, whilst they are equally too large to be confused with those of the Lesser Spotted Woodpecker or Wryneck, and their warmer white colour is different from that of either. The eggs of the Kingfisher and Bec-eater are much rounder, whiter, and have more polish; those of the Dipper resemble them the nearest, indeed it is rather difficult to distinguish some specimens, but, as a rule, the eggs of this bird are duller and not so highly polished. Both birds assist in incubating the egrgs and sit very close, often allowing themselves to be removed by the hand. The young are hatched in about a fortnight- 
that is, by the end of May or early in June. Usually only one brood is reared in the year.

During winter the Great Spotted Woodpecker wanders far from its summer haunt; and in its journeys through the woods at this season and in autumn it is, although solitary as far as its own species is concerned, often followed by, or secn in company with, Nuthatches, Creepers, or Tits. Respecting the annual immigration of this bird to our islands, Saxby gives many interesting details of its habits on the dreary, storm-swept, treeless Shetlands. They appear to have closely searched the cliffs for food, and to have preyed upon small bectles which were very abundant there; they also visited the roofs of houses, dunghills, cornstacks, walls, and even the heather. The conduct of these birds in accommodating themselves to their strange and unusual quarters shows how very casily the habits of a species may be changed and new traits developed.

The general colour of the upper parts of the typical form of the male Great Spotted Woodpecker is glossy black. The forehead is brownish buff; the lores and the car-coverts are white; the cheeks extending downwards onto the sides of the neck are black; a black band extends from the nape to the sides of the neck, separating the white on the lores and earcoverts from a white patch beyond the latter. The nape is scarlet; there are five obscure bars across the wings formed by white spots on each web, which become nearly obsolete on the innermost secondaries; the scapulars are also white; the four centre tail-feathers are black, and the three outer ones on each side barred with white on the terminal half. The underparts are buffish white, shading into scarlet on the lower belly and under tailcoverts. Bill slaty black; legs, feet, and claws dark brown; irides red. The female differs from the male in having no scarlet on the nape. In young in first plumage * the scarlet on the underparts is much duller; there is no scarlet on the nape of either sex; but the crown of the male is scarlet from the forchead almost to the nape, whilst on that of the female it does not extend quite so far. Birds of the year, after the completion of the first autumn moult, scarcely differ from adults.

* The fact that the scarlet on the head of young birds of both sexes is more developed than in the male seems to prove that a not rery remote ancestor had a scarlet crown like the Middle Spotted Woodpecker and the White-backed Woodpecker. The scarlet on the nape of the male Grent Spotted WVoodpecker would therefore seem not to have been acquired by sexual selection, but to be the remnants of its ancestor's scarlet crown, which had been partially removed from the male and entirely so from the female by protective selection-a supposition which is strengthened by the fact that the male occasionally assists the female in the duties of incubation. 


\section{PICUS MINOR.}

\section{LESSER SPOTTED WOODPECKER.}

\section{(Plate 18.)}

Picus varius minor, Briss. Orn. iv. p. 41 (1760).

Picus minor, Linn. Syst. Nat.i.p. 176 (1766); et auctorum plurimorum-Latham, Temminck, Naumann, Bonaparte, (Newton), Dresser, \&c.

Dendrocopus minor (Linn.), Koch, Syst. baier. Zool. p. 73 (1816).

Dryobates minor (Linn.), Boie, Isis, 1828, p. 326.

Picus hortorum, Brehm, Vög. Deutschl. p. 192 (1831).

Picus striolatus, Macgill. Hist. Brit. B. iii. p. 86 (1840).

Picus ledouci, Malh. Mém. Acad. Roy. Metz, 2nd ser. ii. p. 242 (1842).

Pipripicus minor (Linn.), Bonap. Consp. Vol. Zyg. p. 8 (1854).

Xylocopus minor (Linn.), Cab. Mus. Hein. v. p. 51 (1863).

In many parts of England the Lesser Spotted Woodpecker is a commoner bird than the Great Spotted Woodpecker. It is more often scen in small plantations; but, strange to say, north of Yorkshire it is extremely rare, and it is doubtful if it breeds regularly in Scotland. This is all the more remarkable, as on the continent its breeding-range extends at least 250 miles further north than its larger congener. So far as is known, it is a resident wherever it is found, which will probably account for its having only once been obtained on the Orkncys and never having been seen in the Shetland Islands or on Heligoland. In Ireland it is of very rare occurrence, and has not been known to breed.

The range of the Lesser Spotted Woodpecker, like that of its larger ally, is Palrarctic; but it extends somewhat further to the north and, except in the extreme west, not quite so far to the south. This species has not occurred in the Faroes; but in Scandinavia it breeds as far north as lat. 70 . In the forests of Archangel it is a very common resident, and breeds up to lat. $67^{\circ}$ in the valleys of the Petchora and the Obb. It has not been observed further north than lat. $66^{\circ}$ in the valley of the Ycnesay; and on the Pacific coast of Siberia it has not been found further north than lat. $55^{\circ}$; but as it occurs in Kamtschatka it is probable also that it is found in lat. $60^{\circ}$ in the intervening country. Strange to say, it is a resident in the Azores, but does not appear to be found in the Canaries. It breeds in most of the forests of Algeria, but has not been found in Egypt or Palestine. It is a resident throughout South Europe, but is not so abundant as further north. It is common in Asia Minor, but appears to be absent from Persia and Turkestan. It is found throughout the forest districts of South Siberia, East Mongolia, the island of Sakhalin, and the north island of Japan. As might be expected, throughout this extensive range various 
climatic races occur. North-European and Siberian examples are the largest, and the latter have been separated under the name of Picus pipra, in consequence of their being so much whiter, the whole of the underparts (with the exception of the under tail-coverts, which are streaked with black) being unspotted silky white, and the black transverse bars on the lower back and rump being nearly obsolete. Examples from Asia Minor represent the other extreme form, in which the black is greatly developed and extends round the ear-coverts as in Picus major, and in which the underparts are very brown. To this variety the name of $P$. danfordi has been given; but none of these forms can be considered specific, as intermediate forms between the Arctic and semitropical forms occur in intermediate climates. The Scandinavian form is intermediate between that from Siberia and the West-European form; whilst the latter appears to be connected with the Asia-Minor form by an intermediate form in Algeria, which has been called P. ledouci.

The habits of all the Woodpeckers are very similar, and those of the prescnt species do not differ much from those of its larger congener, the Great Spotted Woodpecker. The Lesser Spotted Woodpecker frequents large woods, old forests, plantations, fields in which the hedgerows are well studded with trees, parks, large gardens, and orchards. In winter its haunts are a little more varied than during the breeding-season; for then it wanders about in search of food, and visits many localities, where it only stays for a brief period. It does not appear to frequent conifer-woods much in this country, but is often found in those large fir-woods that are intermixed with non-cvergreen trees. It often haunts trees quite close to houses, and being of small size and shy and retiring habits it is frequently overlooked. You may pass through woods and other districts where this little bird is far from uncommon without ever getting a glimpse of it, the only sign of its presence often being its note or the whirring sound it produces on the trees.

The Lesser Spotted Woodpecker is said to show a preference for the tops of tall trees; and as its labours are often carried on at such a height, it is a very easy matter to pass it unnoticed. It is a restless little bird, putting you in mind of a Tit or a Creeper, flying from tree-top to tree-top, pausing here and there to search the trunks and branches for food. As it flies along, in an undulatory way, the white bars on the wings show out very plainly. Sometimes it alights on the small branches and perches horizontally; but more frequently it settles on the trunk or a broad limb. Its mamner of searching for food is very similar to that of the other Woodpeckers. It crecps nimbly from side to side, now running completely round the trunk, advanees a little way, then pauses a moment, then runs on again. It is as much at home head downwards as the reverse, and will run along the underside of a broad limb with surprising quickness 
and grace. It is not often seen near the ground, and most of its labours are carried on high up in the lofty branches; but it is said sometimes to search amongst the grass for food. In Norway, Collett says that it is often seen on wooden fences, from which the dead bark is easily removed and the tempting store of insects and larva exposed to view; and at such a time the bird will allow itself to be very closely approached. Like the Tits and many other birds, the Lesser Spotted Woodpecker seems to have certain beats over which it passes periodically in search of food. It roosts in a hole in a tree, retiring rather late to rest, and is said to make this hole expressly for the purpose of sleeping in. But this may not be exactly the case, and the nesting-hole is the one that serves for a sleeping-apartment, or the bird will creep into any hole or crevice it can find to pass the night.

The note of the Lesser Spotted Woorlpecker is a not very loud küke or $k \bar{r} r k$, uttered many times in rapid succession. In addition to this note, which appears common to both sexes, the bird also makes a loud whirring sound by rapidly tapping the branches or trunk with its bill. This peculiar noise appears to be a call or signal between the sexes, and is most often heard during the breeding-season.

The food of this bird is composed principally of insects, which it finds under and amongst the bark and on the branches and leaves. It does not appear to eat ants or their eggs. It is often seen in gardens and orchards, but it is not known to prey on the fruit or berries, as its larger congener does. Like the preceding species, it is very fond of the larvæ of the wood leopard moth.

The Lesser Spotted Woodpecker nests in holes in trees; and though it often begins excavations very early in the season, its eggs are not geverally deposited before the beginning or middle of May. Its hole is made in many kinds of trees and at different heights from the ground. Sometimes it chooses a dead stump or the stem of an apple- or a pear-tree, more frequently high up in the branches of a poplar, a beech, or an elm. Sometimes it bores into a pollard willow by the stream or selects a pine or birch tree for its purpose. The hole is bored by the industrious little mincrs for a distance of a foot or more, sometimes only eight or nine inches. The hole is round, gradually cnlarges as it procceds downwards, and at the extremity widens out into a small hollow, where the eggs are laid. The diameter of the passage to this chamber rarics from about an inch and a half to two inches. Sometimes several holes will be commenced and then abandoned from various causes, as is often the case with the Kingfisher and the Sand-Martin. The softest part of the tree is invariably chosen, and any slight hole made by the weather is usually taken advantage of as a basis of operations. It does not always excavate its own hole, and sometimes uses one ready made. 
The Lesser Spotted Woodpecker makes no nest; its eggs are laid on the fine powdered chips and fragments of wood left at the bottom of the hole. They vary from five to eight or nine in number, and are pure white with a considerable amount of polish. They vary in length from .82 to 7 inch, and in breadth from 62 to 55 inch. It is difficult to distinguish between the eggs of the present species and those of the Wryneck, and they require the most careful identification. On an average, however, the Wryneck's eggs are larger, coarser in texture, and not so glossy. Both birds assist in incubating the $\mathrm{cggs}$, and, like most hole-builders, they are close sitters, often allowing themselves to be lifted from their charge, or their eggs laid bare, without making any attempt to leave them. The young are fed and tended for some time after they have quitted the nest; and during the time they remain in the hole they often call or poke their heads out of the aperture. The Lesser Spotted Woodpecker often sits on her eggs as soon as they are laid, and hence some of the young are more forward than the rest. These often leave the hole and are fed on the neighbouring branches; and they probably all roost in it for some time after they are fully fledged.

The Lesser Spotted Woodpecker is a miniature of the Great Spotted species, and differs from it in comparatively few respects. The lower back and rump are transversely barred with white, and the white on the innermost secondaries is developed into conspicuous transverse bar's. The carcoverts are brownish white, and are not separated by a black line from the white on the sides of the neck; and the flanks, and frequently the breast, are streaked with brown. The most important difference between the two species is in the distribution of the scarlet, which is entirely absent from the underparts, and on the head of the male is confined to the crown, as in the young of the Great Spotted Woodpecker, and is replaced by white in the female. Bill, legs, and feet dark slate-grey; irides reddish bromn. The young scarcely differ from adults, except that in the female the crown is slightly tinged with scarlet $\%$

* The presence of scarlet on the crown of the young female, and its absence on that of the adult, is another instance supporting the theory that this brilliant colour has been lost by protective selection in the female rather than acquired by sexual selection in the male. One can hardly credit the male with possessing such bad taste as to prefer his female without " a feather in her cap." 


\section{Genus GECINUS.}

The Green Woodpeckers were included by Linnæus in his genus Picus, and were first separated by Boie ('Isis,' 1831, p. 542) under the name of Gecinus, the Green Woodpecker being designated as the type.

It is not known that there are any structural characters by which the Picinæ may be divided into genera, but they may be separated according to their prevailing colours into groups, which appear to be natural. In the genus Gecinus the prevailing colour is green. As in most Woodpeckers, the wings and tail are more or less barred, and the head is frequently ornamented with scarlet, especially in the males.

There are about twenty species and subspecies of Green Woodpcckers, which are confined to the Palrearctic, Oriental, and Ethiopian Regions. Three species are European, one of which is resident in the British Islands.

The Green Woodpeckers differ very little in their habits from the other members of this family; but they feed more frequently on the ground, where they search for ants and their larvæ. Their note is loud and clear, and thcir flight is very similar to that of the other Woodpeckers, as is also their mode of nidification and the colour of their eggs. 


\section{GECINUS VIRIDIS. GREEN WOODPECKER.}

(Plate 18.)

Picus viridis, Briss. Orn. iv. p. 9 (1760); Limn. Syst. Nat. i. p. 175 (1766); et auctorum plurimorum-Latham, Temminck, Naumann, Bonaparte, (Newton), (Dresser), \&c.

Gecinus viridis (Briss.), Boie, Isis, 1831, p. 542.

Gecinus pinetorum,

Gecinus frondium, Brehm, Vög. Deutschl. pp. 197, 199 (1831).

Gecinus virescens,

Brachylophus viridis (Briss.), Swains. Classif. B. ii. p. 308 (1837).

Chloropicus viridis (Briss.), Malh. Monogr. Picid. ii. p. 118, pl. lxxix. figs. 14 (1862).

The Green Woodpecker is a somewhat local resident, but is generally distributed throughout the woodland districts of England and Wales, becoming rarer north of Yorkshire. In Scotland and Ireland it is only known as a very rare accidental visitor. It is doubtful whether more than two or three examples have ever been obtained in Scotland; it has not occurred in the Shetland Islands, and the evidence of its occurrence in Orkney is very vague. It is not known that more than two examples have ever occurred in Ireland.

The range of the Green Woodpecker is somewhat restricted, being confined to the western portions of the Palæaretic Region, and not extending to the Arctic circle. 'This species has not been found in the Faroe Islands, and is not known to breed in Norway north of lat. $63^{\circ}$. In Sweden and Russia it does not breed north of lat. $60^{\circ}$, and it is doubtful whether it be found even so far north in the east of the latter country. There is no record of its occurrence cast of the Ural Mountains. It has not occurred in Turkestan; but appears to be found throughout Western Persia and Asia Minor, although it has not been met with in Palestine. It is generally distributed throughout Southern Europe; but has not been found south of the Mediterranean. In the Algerian forests it is represented by a nearly allied species, Gecinus vaillantii, differing principally in having the forehead and the region round the eye slate-grey instead of black, and in having no scarlet on the black moustachial line of the male. Examples from Central and Southern Spain are intermediate in colour between this and the typical form, having the moustachial stripe of the latter, but the region round the eye coloured like the former, and are probably the result of interbreeding. They have been called G. sharpii.

The Green Woodpecker has several other very near allies. The eastern 
form, G. canus, is found almost throughout the Palæarctic Region, and is connected with the western form, G.viridis, by the Algerian species, which is somewhat intermediate. The male of the eastern form has no scarlet at the back of the head or on the moustachial stripe, and the black on the head is confined to the lores and the moustachial stripe. The southern form, G. occipitalis, which is found throughout the Himalayas and the Burmese mountains, resembles the eastern form in the distribution of the black and red on the head, except that the lind head and nape are black. An intermediate form, however, occurs in China, G. guerini, differing in having less black on the crown and nape. More distantly allied species from Japan and the Himalayas may be distinguished by having the underparts marked with black, as in the young of the Green Woodpecker.

The Green Woodpecker can scarcely be regarded as a migratory bird; but in winter it often wanders far in search of food. It appears sometimes to cross the sea on its migrations, as it has appeared once on the island of Heligoland.

The Green Woodpecker is the largest of the British Woodpeckers and, in most localities, the best known. It loves the well-wooded districts, and is seldom seen far from trees. The haunts it usually selects are large parks full of old timber, ancient forests, woods, and, less frequentìy, plantations and pleasure-grounds. Such romantic and picturesque districts as Sherwood Forest are a paradise for this fine handsome bird. Here it may often be seen on the noble old oaks, twisted and torn in all manner of fantastic shapes, decayed and weather-beaten, and abounding with insects lurking amongst the decaying bark and timber. The singular laughing cry of this bird and its unusually undulatory flight as it crosses an open glade arrest the attention; and it may be at once recognized by the yellowness of its rump, which is very conspicuous as it flies from the observer. When it wishes to alight it often flies up to a large branch, and clings to the under surface with its long sharp claws and at once begins its search for insects. Sometimes it alights on the rugged trunk, not unfrequently close to the ground, and begins to ascend in spiral course till it reaches the summit, when, uttering its peculiar laugh, it dips down to the foot of another tree to repeat its labours. When on the trunk its mode of progression resembles that of a gigantic fly on a window-pane. It runs forward a little way, pauses a moment or so, then again creeps forward, now to the right, then to the left, every now and then tapping the timber lustily with its stout beak, and darting: its long tongue into the crevices to capture its insect food. It is astonishing how quickly and completely it will search a large tree-trunk, beginning at the foot and working upwards to the top. Sometimes it is lost to view as it searches the side of the tree furthest away from the observer; but it soon reappears, and it may be remarked how easily it 
progresses, how completely it is at home, in all kinds of positions, and how useful its stiff pointed tail-feathers are in supporting it whilst it is hammering away at some promising chink. It rarely, if ever, runs head downwards, like the Nuthatch. Where ants abound the Green Woodpecker may often be observed upon the ground searching the ant-hills for food. With its strong beak it scatters the loose mould to unearth the busy colony, its tongue is shot out with marvellous speed, and the ants and their eggs are consumed in great quantities. On the ground it does not always confine its attention to ant-hills, but sometimes digs quite a considerable holc in the earth, baring the buried bark of a tree-stump, in search of insects. It can walk and hop, though it appears to do both clumsily, in consequence of the shortness of its legs. The Green Woodpecker, like the rest of its tribe, is a shy and solitary bird, and even a pair are rarely seen together, except in the breeding-season. It is only by using extreme caution that its habits may be observed, and it always tries as much as possible to search that part of the tree furthest away from the observer. There can be no doubt that it frequently produces the jarring. sound, which some naturalists assert is for the purpose of disturbing its insect food, but which is more likely a signal between the sexes. It is produced by the rapid beating of the bark or branch with its stout bill; and Sterland says that he has seen it place its bill in a long rent or crack, and by a rapid motion of its head make a sound as if the tree were being torn asunder, and so loud as to make the forest ring again.

The food of the Green Woodpecker is chiefly composed of insects, especially ants and their larve. Naumann says that the bird sometimes visits the newly mown fields in search of food, and that it occasionally attacks a wasps' nest in order to prey upon the grubs. He also says that it feeds on acorns, and other observers state that it frequently cracks hazel-nuts and even catches bees. The usual note of this bird, which is uttered most frequently in spring and early summer, is a loud and clear kyu, $k y u, k y u$, so rapidly repeated as to bear a great resemblance to a hearty laugh. Its loud cries have been said to prognosticate rain; and in many districts the Green Woodpecker is known as the "Rain-bird ;" whilst its singular note has gained for it the name of "Yaffle" in some counties. When alarmed the note of this bird is somewhat modulated, and resembles perhaps less a laugh than a scream.

It is probable that the Green Woodpecker pairs for life, and in some cases the old hole is used for many years in succession. As a rule, however, the birds prefer to make a new hole every spring, leaving the old ones to be used for the rest of the year as roosting-places, or to be annexed by Starlings, Redstarts, or Tits. Occasionally, before the Woodpecker has quite completed its chamber, it is taken possession of by a pair of Starlings, when the rightful owners in an unguarded moment have left it for a short 
time. The Green Woodpecker is a rather early breeder, and its hole is often commenced by the middle of April, in some cases earlier. Many kinds of trees are selected, poplars, elms, oaks, chestnuts, and sycamores being amongst those which are more frequently chosen. A decayed branch or trunk is usually bored for the purpose; but sometimes the bird makes the mistake of cutting into a sound limb, in which case it is obliged to relinquish its labours, and thus numbers of half-finished holes are abandoned. The Green Woodpecker does not invariably breed in standing trees; for Herritson records an instance of its nesting in the wooden spire of a church in Norway: Both birds assist in excarating the hole, one relieving the other. The holc proceeds first in a horizontal direction, usually until the birds meet with the decayed part of the timber, then a shaft is sunk perpendicularly for a distance of ten or twelve inches, and the bottom is enlarged into a little chamber, where the eggs are deposited on no other bed than is afforded by the scraps of wood and dust that have accumulated whilst the birds have been at work. It has been stated that the birds carry the chips aray from the vicinity of the ucst; but this is certainly not usually done, the new chips at the bottom of the tree almost always indicating that the hole above is tenanted. The hole is wouderfully round and regular, and looks as if it had been made with a sharper instrument than a bird's bill. The eggs are usually laid late in April or early in May; they are from five to seven and occasionally eight in number, and pure white, beautifully polished. They vary in length from $l \cdot 4$ to 1.19 inch, and in breadth from 95 to 89 inch. They vary slightly in shape, some being blunter at the small end than others. Their size prevents them being confused with those of any other British Woodpecker; but they are absolutely indistinguishable from those of several of the allied foreign species. Eggs of the Black Woodpccker are sometimes almost as small as those of this species. The young birds as soon as they are able to quit the nest often take up their stations outside on the branches or creep about the trunk, where they are fed by their parents.

The general colour of the upper parts of the Green Woodpecker is olivegreen shading into yellow on the rump, and that of the underparts is nearly uniform pale greyish green. The lores, cheeks, car-coverts, and the feather's round the eye are black, mottled on the checks with scarlet. The feather's of the crown and nape are grey, broadly tipped with scarlet; the wings and tail are dark brown, the primaries barred with white on the outer web. The outer web of the sccondaries is olive-green, with traces of paler bars, and all the tail-feathers, especially the two outer ones, are obscurely barred; there are also traces of bars on the feathers of the vent and under tailcoverts. Bill, legs, and feet dark slate-grey; irides bluish white. The female scarcely differs from the male, except in having no scarlet on the cheeks. Birds of the year have the lower breast and belly barred like the 
under tail-coverts ; and young in first plumage are barred throughout on both the upper and underparts, the black on the lores, ear-coverts, and the space round the eye is absent, and the black on the checks is spotted with pale brown in the female and with scarlet in the male.

Varieties of the Green Woodpecker occasionally occur in which the green colour of the plumage almost approaches orange.

The Black Woodpecker (Picus martius) has been included in the list of British birds by most ornithologists, and long lists of its alleged occurrences in our islands have been published. These have been carefully investigated by Mr. J. H. Gurney, jun. (Dresser, B. Lur. v. p. 12), with the result that no authentic instance of the occurrence of the Black Woodpecker in this country can be found. There is no bird less addicted to migration than this species, and it is a bird of too powerful flight to be driven from its native pine-forests by even the heaviest gales. It is one of the few European birds that have never occurred on the island of Heligoland. The Black Woodpecker may possibly have inhabited the pine-forests of North Britain in the pre-historic ages, when the Capercaillie occasionally fell a victim to the lynx on the banks of the Tees; but, in the absence of any evidence of its occurrence in our islands, this bird cannot be admitted into the British list. This fine species is a resident in the pinc-forests of Central Europe as far south as the Pyrenees and the mountains of Asia Minor. In Europe it is found as far north as the Arctic circle; and eastwards it extends across Siberia to the north island of Japan. It is not found on the main island of Japan, but is a resident in East Mongolia and the extreme north of China. In West Siberia it is found as far south as the Altai Mountains, but does not appear to range further north in Asia than lat. 62 $2^{\circ}$ In its habits and mode of nidification it differs very little from the other Woodpeckers. The egg is figured on Plate 18. The Black Woodpecker is considerably larger than the Green Woodpecker, and is almost uniform black, with a broad scarlet stripe extending over the forehead and the crown to the nape, but in the female not extending onto the forehead.

The evidence in favour of the admission of the Middle Spotted Woodpecker ( $\boldsymbol{P}$. medius) into the British list appears to rest upon no better authority; most of the alleged occurrences resolve themsclves into cases of mistaken identity. The distinguishing feature of this species is the scarlet crown; this character being also found in birds of the year of the Great Spotted Woodpecker is sufficient to account for the mistake made by ornithologists who were not acquainted with the continental species. The Middle Spotted Woodpecker is found throughout Continental Europe south of the Baltic, extending eastwards through Asia Minor into West Persia, though some ornithologists have attempted to prove that the birds from the latter locality are specifically distinct. The Middle Spotted 
Woodpecker differs very little in its habits and mode of nidification from its near allies. It is intermediate in size between the Lesser and Greater Spotted Woodpeckers, and may at ouce be distinguished from both of them by the absence of the black moustachial line extending from the base of the lower mandible.

The White-backed Woodpecker (P. leuconotus) was erroneously included in the British list and figured in Gould's 'Birds of Great Britain' on the authority of a specimen said to have been shet on one of the Shetland Islands in September 1861. I have carefully compared this specimen with birds of the year of the Great Spotted Woodpecker from Heligoland, and have no doubt whatever that it is an example of immature $P$. major in which the nape and the margins of the primary-coverts are slate-grey instead of black-an accidental variety which bears no special resemblance to the young of the White-backed Woodpecker. The question is fully discussed by Professor Newton ('Zoologist,' 1881, p. 399).

The claim of the Three-toed Woodpecker to be admitted into the British list rests solely upon an example said by Donovan to have becn "lately shot in the north of Scotland" (Brit. B. vi. pl. 113, 1809). It is very remarkable that this species does not occur in Scotland, as it is resident throughout Northern Europe and the whole of Sibcria up to the Arctic circle, and even in the mountainous districts of Central and Southern Europe.

Three other Woodpeckers, all of them American species, have been included amongst the birds that occasionally visit this country, but the claims of each are very doubtful. The first of these, the Hairy Woodpecker (Picus villosus), was recorded by Latham (Gen. Syn. Suppl.p. 108), who stated that this species had then lately been found in the north of England, and that he had seen a pair which had been shot near Halifax in Yorkshire by a Mr. Bolton. Another example is said to have been killed near Whitby in 1819 (Higgins, 'Zoologist,' 1849, p. 2496, and Bird, 'Zoologist,' 1849, p. 2527). The Hairy Woodpecker, in one of its several forms, is a resident in the wooded portions of North America, as far north as Sitka, and as far south as Mexico and Central America. It is said to frequent orchards and cultivated grounds, and to be less shy than the other species. Its habits in other respects and its nidification and the colour of its eggs are similar to those of its congeners. It may readily be distinguished from the Great Spotted Woodpecker, the only species in this country with which it is likely to be confused, by the absence of the scarlet on the under tail-coverts.

Of the second species, the Downy Woodpecker (Picus pubescens), a single example is said to have been obtained at Bloxworth in Dorsetshire (Rev. O. P. Cambridge, 'Zoologist,' 1859, p. 644.1)*. Its geographical distribu-

* The occurrence of an example of this species, said to have been shot in an orchard near Elbeuf in France, appears to be well authenticated (Proc. Zool. Soc. 1881, p. 453).

VOL. II. 
tion is similar to that of the preceding species. It is a resident and brecis throughout North $\Lambda$ merica as far north as the limit of forestgrowth and as far south as Mexico. Its habits, nest, and eggs are not known to differ from those of the other Woudpeckers. The only species in this comntry with which it is likely to be confused is the Lesser Spotted Woorlpecker, from which it may easily be distinguished by having the nape instead of the crown scarlet.

Of the third species, the Golden-winged Woodpecker (Colaptes auratus), a specimen was shot in Amesbury Park, Wilts, in the autumn of 1836 (Marsh, 'Zoologist,' 1859, p. 6327). There can be little doubt that the bird was shot in this country, but had most probably escaped from a cage. The Golden-winged Woodpecker is found throughout North America, as far west as the Rocky Mountains, as far north as the Aretic circle, and as far south as the Gulf of Mexico. To the northern portions of its range it is only a summer visitor; but in the central and southern portions it is a resident. The habits and eggs of this Woodpecker do not differ much from those of its congeners.

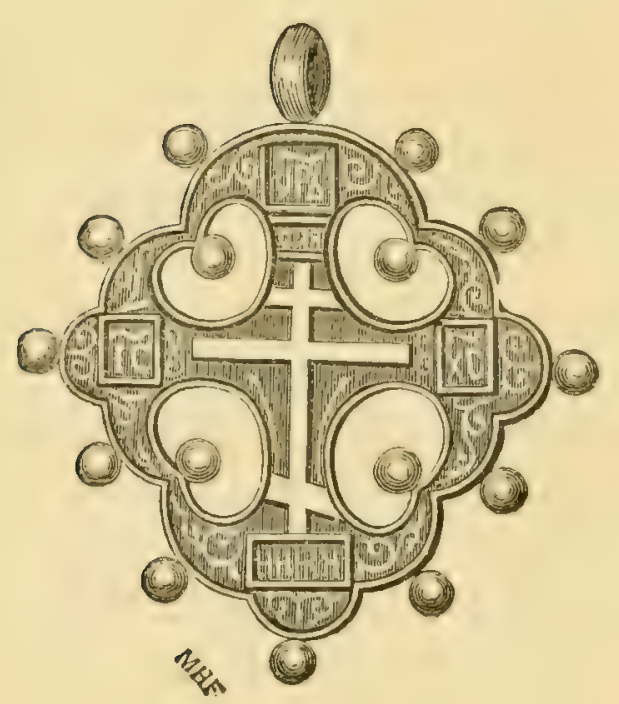




\section{Genus IYNX.}

The genus Jynx of the 10th edition of the 'Systema Nature' of Linnæus was altered in the 12th edition of that work, published in 1766, to $\operatorname{Iunx}$ (i. p. 172); but the correct spelling appears to be Iynx. I. torquilla was the only species known to Linnacus, and is therefore the type.

The Wrynecks possess the wedge-shaped bill and the extensile tonguc of the Woodpeckers, but the tail-feathers, which are ten in number, are not stiff and pointed; the first primary is very minute, and the second, third, and fourth are nearly equal and longest. The toes are placed as in the Woodpeckers, two before and two behind. The tarsus is scutellated both at the front and at the back. The general style of coloration is mottled with various shades of brown like the Owls and the Goatsuckers, but the wing is barred as in the typical Woodpeckers.

There are five species of Wrynecks, three of which are inhabitants of tropical Africa, one of the Oriental Region, whilst the fifth species is a summer visitor to the Paliearetic Region, including the British Islands, and winters in the Ethiopian and Oriental Regions.

In their habits the Wrynecks resemble the Woodpeckers in many respects. They frequent cultivated and wooded districts, and feed chicfly on insects and their larvæ, for which they scarch amongst the chinks of the bark and in the branches. They also frequent the ground, where they search for ants. They only occasionally climb like Woodpeckers, and rarely support themselves with their tail. Their flight is undulating and rather slow. They breed in holes in trees, gencrally sclecting one ready made, and make no nest. Their eggs are pure white and polished. 


\section{IYNX TORQUILLA.}

\section{WRYNECK.}

(Plate 18.)

'Torquilla torquilla, Briss. Orn. iv. p. 4 (1760).

Torquilla striata, Briss. Orn. iv. p. 7 (1760).

Yunx torquilla, Lim. Syst. Nat. i. p. 172 (1766); et auctorum plurimorum-

Latham, Temminck, Naumann, Bonaparte, Newton, Dresser, \&c.

Picus jynx, Pall. Zoogr. Rosso-Asiat. i. p. 416 (1826).

Yunx japonica, Bonup. Consp. i. p. 112 (1850).

The Wryneck is a common bird in the south-eastern counties of England. West of the Severn and north of the Trent it is much rarer, and is very locally distributed. It is a rare summer visitor to most of the counties of Scotland, and has occurred on migration on both the Orkney and Shetland Islands; but in Ireland it has only been obtained once, near Waterford.

The Wryneck has a very extensive range, being found during the breeding-season almost throughout the Palæarctic Region. It has occurred several times on migration on the Faroes. In Scandinavia and West Russia it has been found in summer up to lat. $64^{\circ}$; but in East Russia and West Siberia it does not appear to range further north than lat. $60^{\circ}$. On the Pacific coast of Asia it has not been obtained further north than lat. 55 $5^{\circ}$, but is said by Pallas to occur in Kamtschatka. It is not known to visit any of the Atlantic islands; but it breeds sparingly, and is probably a resident, in Algeria. In Southern Europe it is principally known on spring and autumn migration; many, however, remain to breed, and a few are found even in midwinter. In Egypt it is said only to be scen on migration, and, according to Heuglin, winters south of Abyssinia. To Palestine and Asia Minor it is said only to be a summer visitor. It has not been recorded from Persia, but it breeds sparingly throughout Turkestan, and passes through Afghanistan on migration. It breeds in the Altai Mountains and the Himalayas, and winters in India. It is a summer visitor to the whole of Southern Siberia, but has not been recorded from Mongolia. It is common and breeds in Japan, passes through North China on migration, and winters in South China and Burma. The Wryneck has three tropical allies in Central and South Africa, and one in India, all of which may be distinguished by their chestnut breasts.

The Wryneck is a summer visitor to the British Islands, sometimes appearing in the southern counties of England early in March, but the date of its arrival is generally during the first or second week of April; 
and as this date is almost coincident with that of the Cuckoo's appearance, the bird has received the name of "Cuckoo's mate" or "Cuckoo's messenger." It leaves us rather carly, numbers go southwards in the beginning of September, and most have left by the end of that month. From its shy and retiring habits, and the unassuming colours of its plumage, the Wryneck is often overlooked. It frequents most districts where there is a sufficient number of trees and tall bushes to afford it shelter. It is fond of haunting old orchards, plantations and parks, large gardens, and fields which are surrounded by tall hedges. It sometimes strays as far as the moorlands, where it frequents the little clumps of stunted trees and the bushes on the rough broken ground, the boundary-line, as it were, between the fields and the heath. The Wryneck is not so much a forest bird as the Woodpeckers, and it frequents the slender branches almost as much as the broad limbs and the trunks. Dixon has watched this bird hopping about amongst the slender sprays, picking insects from the leaves, and occasionally fluttering into the air to catch a passing fly. It is a rather shy bird, and it is seldom that more than a pair are seen in company. It is not often seen on the wing, cxcept when passing from tree to tree, and its flight is undulating. It is often seen ta alight on the trunks of large trees, where it will sit for a few moments quite still, with its body placed sideways, and receiving no support from its tail; but it is generally seen perched crosswise on a slender branch.

The Wryneck feeds almost exclusively on insects, especially ants, and may often be observed on the ground, generally on or near an ant-hill, where it busily searches for the larvæ, which appear to be its favourite food. It progresses in a series of short hops or leaps, sometimes assisted by its wings, and the tail is frequently jerked to and fro. When busy feeding it keeps almost motionless; the long tongue, which is covered with a glutinous substance, is shot out and withdrawn so quickly that the ants' eggs seem attracted to it by some magnetic power. Each time the tongue is protruded several eggs adhere to it and are at once conveyed into the mouth, and the tongue is shot out again and again with marvellous speed. As the bird so frequently feeds on the ground, and especially on ant-hills, numerous particles of earth and gravel stick to its tongue, so that its stomach contains a greater amount of grit than is usually the case with insect-feeding birds. The Wryneck is also a sworn enemy of the ants themselves. When in Algeria Dixon several times flushed this bird from the barley-fields, where it had been feeding on the ants, which in a narrow stream of countless millions were passing to and fro conveying the grain to their nests. It also picks these insects from the bark and leaves of trees, and is said sometimes to cat elderberries. Although the Wryneck's bill is stout and strong it does not bore into tho decayed wood in search of food, like the Woodpeckers, but contents itself with picking insects 
from the surface and from the little chinks and crannies into which it thrusts its long retractile tongue. Numbers of Wrynecks are caught in the south of Europe in autumn for the table with other small birds, which are generally very fat at that season.

Although the bird so often hides amongst the foliage or betakes itself to the nearest shelter on the least alarm, its presence in a district is unerringly made known by its singular note. This cry, which bears some rescmblance to the word vite uttered several times in succession, is constantly uttered on the arrival of the bird in spring, so loud as to make the orchard or the hedgerow ring again. But as the season advances the note is less frequently heard, and by the end of June it ceases entirely, and the Wryneck becomes not only a solitary but also a silent bird. In many parts of Surrey the Wryneck is known by the name of "Pay-pay," a name which Blyth says has been derived from its Hawk-like note. During winter in the south of France I have observed the Wryneck in small parties in the leafless trees, my attention being attracted to them by hearing their loud quick tapping on the smooth trunks, as rapid as an electric bell. Their alarm-note was a somewhat Hawk-like cry sounding like kik-kik-kik-kik.

It is very probable that the Wryneck pairs for life. Season after scason they return like Swallows to their old nesting-place, even in spite of much persecution and disturbance. On their arrival at their brecdinggrounds they are very noisy, crying lustily to each other, especially early in the morning. I have scen a pair in an orchard flying from one appletree to another, and at length I watched both birds enter a hole in one of the tree-trunks, in which they had bred the previous year. Dixon has taken its nest from a dead holly-stump on the moors in a clump of these trees, no other suitable place being situate within half a mile. The Wryneck, like the Woodpeckers, lays its cggs in holes of trees. It does not, however, make its own abode, although it often slightly alters the hole which it has chosen. This is often selected in the most exposed situation, not unfrequently in an orchard, and sometimes in a dead stump in a hedgerow. As the bird does not bore its own habitation, the hole varies a good deal in size and depth. Sometimes the eggs may be seen from the opening, at others they are at arm's length down the aperture. They are deposited on the decayed wood at the bottom with no other nest whatever, and are usually laid about the middle of May. They are from six to ten in number, seven or eight being an average clutch, and pure white without any markings. They are not quite so smooth and polished as those of the Woodpeckers, and vary in length from 9 to $\cdot 8$ inch, and in breadth from $\cdot 67$ to 58 inch. They most closely approach the eggs of the Lesser Spotted Woodpecker, but may generally be distinguished by their larger size and less amount of gloss. The Wryneck is one of those birds that by a little judicious 
management may be induced to lay an extraordinary number of eggs in a single season. Like the Starling the hen bird will continue to lay after her eggs are removed, and many instances are on record of great number s of eggs having been taken from a single nest. One of the most extraordinary cases of this kind was communicated to the 'Zoologist' (1872, p. 3227; and 1876, p. 5081) by Mr. J. H. Gurney, Jun. In $1872 \mathrm{Mr}$. Frank Norgate took forty-two eggs from one nest of this bird in an old stump. In 1873 the female again laid forty-two eggs; but in 1874 her reproductive powers were apparently exhausted, only one egg was laid; and in 1875 the place was deserted.

The Wryneck is a very close sitter. Both male and female assist in incubating the eggs, and often remain on them until removed by the hand of the collector. Its common name has been derived from its singular habit of twisting its head from side to side like a snake in its nesting-hole or when wounded. It will also hiss in an alarming manner if surprised on its eggs, and when caught has been known to feign death-a habit alluded to by Sir Thomas Browne, in his 'Account of Birds found in Norfolk,' who writes that it was "marvellously subject to the vertigo," and was "sometimes taken in these fits."

When the young are hatched they are fed and tended with great care by their anxious parents, and when able to leave the nest are accompanied by them for some little time. The Wryneck only rears one brood in the year; but, as already noticed, if its first clutch of eggs are taken others will be laid, and it is such necessarily late broods that are sometimes met with late in the summer.

The general colour of the upper parts of the Wryncek, including the tail, is greyish white, mottled all over with brownish grey, and obscurely barred and streaked with dark brown; the wings are brown, barred with dull chestnut on the outer webs of the feathers. The underparts are buff, each feather having a narrow dark-brown subterminal bar or spot. Bill, legs, and feet brown; irides dark brown. There are no variations in the plumage attributable to age, sex, or season worthy of notice. 


\section{Family CUCULID E, or CUCKOOS.}

The Cuckoos are a large group of birds presenting great diversity of general appearance, but fairly well defined from theip allies, the nearest of which are probably the Musophagidæ, or Plantain-eaters, of the Ethiopian Region. Selater associates them with the Woodpeckers, Kingfishers, Swifts, and other Picarian families; Gadow regards them as a comnectinglink between the Pheasants and the Picarian birds; whilst Forbes placed them amongst the Pheasants, Bustards, and Rails, on account of the presence in the latter groups of birds of the ambiens muscle. Iike the Passerine birds, they have only one notch on each side of the posterior margin of the sternum; but their pterylosis is said not to be Passerine in character, though very variable. Huxley associates them with the Kingfishers, Hoopoes, Bee-enters, and Rollers. Gadow says that in their digestive organs they most resemble the Bee-eaters, Rollers, and Goatsuckers.

The true Cuchoos moult twice in the year, in spring and autumn; but whether this be the case with the more distantly allied genera I am unalule to say.

The Cuckoos may be divided into numerous subfamilies presenting great varicty of appearance, and scarcely possessing any external character in common except that of having two toes in front and two behind. In the true Cuckoos, or Cuculinæ, most of the species show great superficial resemblance to a Sparrow-Hawk, especially in their long and somewhat rounded wing, which contains ten primarics, and long graduated tail, composed of ten or twelve feathers. The shape of the bill somewhat resembles that of the Thrushes.

There are about 180 species of Cuckoos, belonging to various genera, which are distributed all over the world, except in the Arctic regions. Two species only are found in Europe, one of which is a regular summer visitor to our islands, and the other is said to have visited them once. Two American species are also said to have accidentally strayed as far as Ireland.

\section{Genus CUCULUS.}

The genus Cuculus was recognized by Linnaus in the twelfth edition of his 'Systema Naturx' (i. p. 168), published in 1766. C. canorus (the Cuculus cuculus of Brisson) is the type. 
The birds belonging to this genus have very long graduated tails, very short tarsi, and are without metallic colours in the plumage.

This genus probably contains from thirty to forty species, which are distributed throughout the Old World up to the Aretic circle. One species only is found in Europe, which is a regular summer visitor to the British Islands.

The birds in this genus are found in most districts, but chicfly frequent well-wooded country. They are shy and wary, and fly quickly, with a very Hawk-like aspect. Their food is almost entirely composed of insects and their larvac, especially caterpillars. Their notes are loud and full, but sometimes very harsh. In thcir breeding-habits they are most peculiar, for they make no nest, but lay their eggs in that of other birds, leaving their young to be reared by the foster-parents,

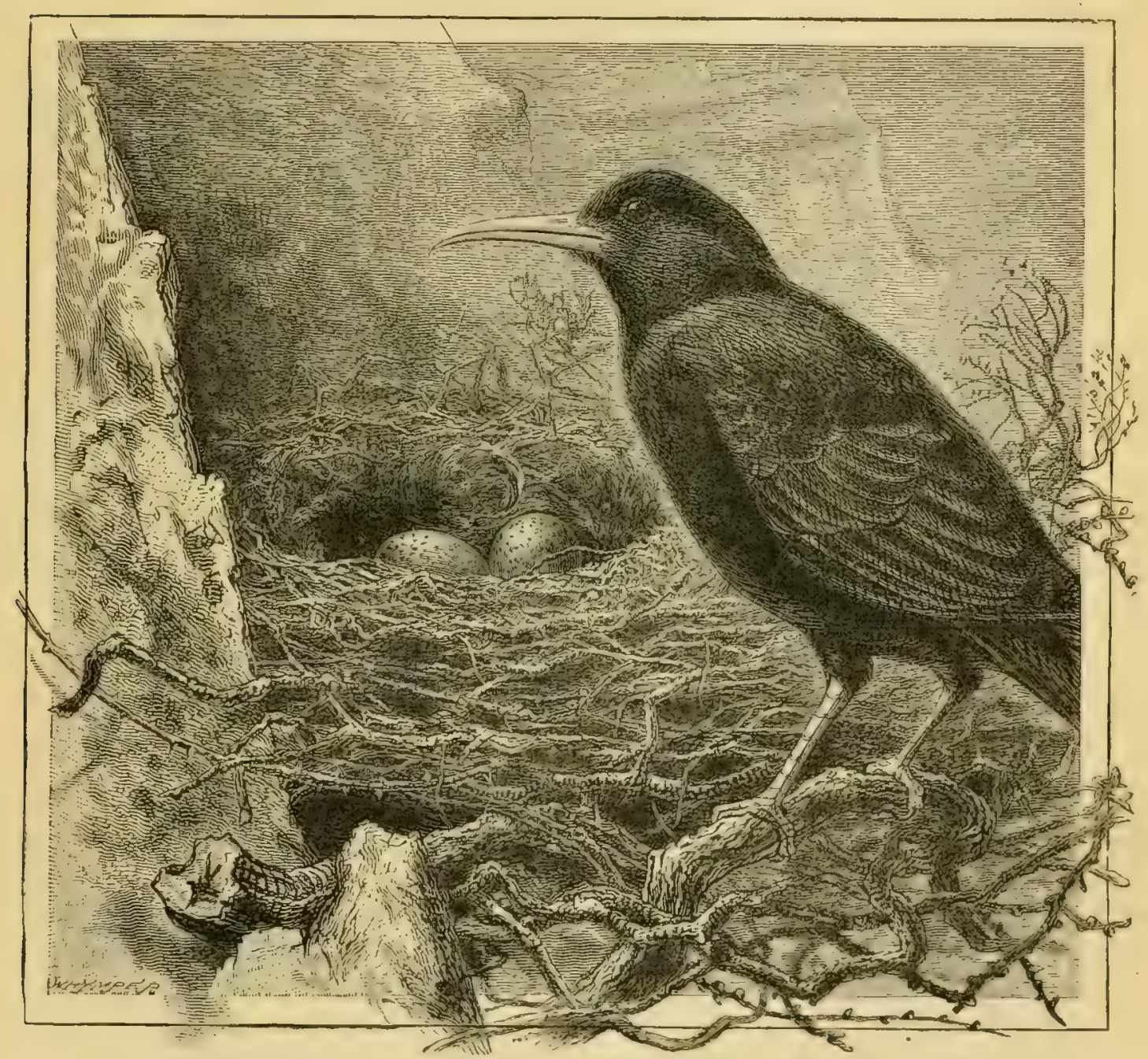

NEST OF CHOUGH. 


\section{CUCULUS CANORUS.}

\section{CUCK00.}

(Plate 20.)

Cuculus cuculus, Briss. Orn. iv. p. 105 (1760).

Cuculus canorus, Linn. Syst. Nat. i. p. 168 (1766); et auctorum plurimorumLatham, Temminck, Naumann, Bonaparte, Newton, Dresser, \&c.

Cuculus hepaticus, Lath. Ind. Orn. i. p. 215 (1790).

Cuculus rufus, Bechst. Orm. Taschenb. i. p. 84 (1802).

Cuculus borealis, Pall. Zoogr. Rosso-Asiat. i. p. 442 (1826).

Cuculus cinereus, Brehm, Vög. Deutschl. p. 152 (1831).

Cueulus indicus, Cab. Mus. Hein. iv. Heft 1, p. 34 (1862).

Cuculus telephonus, Heine, Journ. Orn. 1863, p. 352.

Cuculus libanoticus, Tristram, Proc. Zool. Soc. 1864, p. 432.

The Cuckoo is almost as well known in our islands as the Swallow or the Sparrow. It is a regular summer visitor to every part of the country, and is not only found throughout England and Wales, Scotland and Ireland, but is common on the Channel Islands, the Outer Hebrides, and the Orkneys, and breeds regularly on the Shetland Islands.

The breeding-range of the Cuckoo is strictly Palæarctic, except that it does not include the Siberian tundras, and extends to the Himalayas and mountains of South China. The Cuckoo is an accidental visitor to the Faroes. In Norway, as might be expected, it ranges furthest north, being found above the pine-region wherever the birches are tall enough to afford it shelter, almost to the North Cape. In the valleys of the Petchora and the Obb it has not been observed north of lat. $66 \frac{1}{2}^{\circ}$; but in the valley of the Yenesay, though I did not hear it north of lat. $67^{\circ}$, I was assured that it was occasionally found up to lat. $69^{\circ}$. Middendorff found it common on the Stanovoi Mountains, about lat. $62^{\circ}$; and Dybowsky states that it is very common in Kamtschatka. It is an accidental visitor to the Canaries and Madeira, but breeds throughout South Europe. In North Africa it is principally known as a spring and autumn migrant, but a few remain to breed in Algeria. It is a summer visitor to Palestine, Asia Minor, Persia, Turkestan, and Afghanistan; but a few are said to remain to winter in South Persia. To Mongolia, China, and Japan it is a summer visitor ; but to India, Ceylon, Burma, and the Philippines it is ouly known as a winter visitor, except that a few remain to breed in the Himalayas. It is found throughout South Africa, but only during our winter.

In Last Siberia, Mongolia, Japan, China, and the Himalayas our Cuckoo is found in company with a very nearly allied species, Cuculus 
himalayanus*. This specics differs in no respect from the Common Cuckoo, except in size. Our Cuckoo varies in length of wing from 9 to 8 inches, whilst the eastern form varies from $7 \frac{3}{4}$ to $6 \frac{3}{4}$ inches. So far as is known, large examples of the eastern form can only be distinguished from small examples of the western form by their note, which is not a double one, but a single guttural and hollow-sounding note resembling that of the Hoopoe.

The Cuckoo is a regular summer migrant to Europe, arriving in Spain and Asia Minor late in March or early in April, but in England seldom before the middle of the latter month, and on the Arctic circle not until the first week of June. Its stay in our islands is comparatively short, the old birds usually leaving in August and the young in September. This order of departure is very exceptional (for in most migratory birds the young are the first to leave), and is probably affected by the Cuckoo's peculiar manner of reproduction. This bird has no young to rear or tend after leaving the nest; consequently, after its eggs are safely deposited, it can return southwards as soon as its supply of food begins to fail. The male birds are the first to arrive in spring, and in a few days they are followed by the females.

The Cuckoo is one of the most widely distributed of British birds.

* The synonymy of this species is as follows:-

\section{HIMALAYAN CUCKOO.}

Cuculus striatus, Drapiez, Dict. Class. Sci. iii. p. 144 (1838).

Cuculus canoroides, S. Miill. Verh. Land-en Volkienk. p. 235 (circ. 1840).

Cuculus saturatus, Hodgs. Journ. As. Soc. Beng. 1843, p. 942.

Cuculus optatus, Gould, Proc. Zool. Soc. 1845, p. 18.

Cuculus himalayanus, Vigors, apud Blyth, Cat. B. MIus. As. Soc. p. 71 (1819); et auctorum plurimorum-Jerdon, \&c.

Cuculus horsfieldi, Moore, Cat. B. Mus. E.I. Co. ii. p. 703 (1858).

Cuculus cantor, Illiger, fide Cab. Mus. Hein. iv. p. 34 (1862).

Cuculus canorinus, Cab. Mus. Hein. iv. p. 35 (1862).

Cuculus kelungensis, Swinhoe, Ibis, 1863, p. 394.

Cuculus monosyllabicus, Swinhoe, Ibis, 1865, p. 545.

This species winters in Burma, the islands of the Malay Archipelago, New Guinea, and Australia. I have an example in my collection from Madagascar, which may have migrated from the Himalayas to winter there. The occurrence in South Africa of intermediate forms between this species and $C$. capensis, which only differs in having the upper breast chestnut, suggests the idea that it may be a resident in Madagascar. In North-west Africa Cuckoos are found exactly intermediate, both in size and colour, between $C$. capensis and $C$. canorus.

I met with the Himalayan Cuckoo in Siberia, and remarked the similarity of its note to that of the Hoopoe. I afterwards found that Jerdon had made a similar observation. Ayres makes precisely the same remark respecting C. gularis from Sunth-east Ifrica ; and Edward Newton describes the note of a Cuclioo which he observed in Madagitsear as lilie that of our bird with a bad cold. 
There is not a district inland or on the coast, mountam or plain, open country or forest, in which it may not often be seen in the course of the summer. In Norway I have seen it on the tundras above the limit of forest-growth, where it is only able to find a perching-place on the rocks or the stunted bushes and willows to be found in the sheltered valleys. On the moors in Yorkshire, or in the remotest parts of the Highlands, it may often be seen flitting from one stunted bush to another in a very Hawklike manner, every now and then uttering its loud and well-known cry of cuckoo. Dixon has even met with this bird almost at the summit of the Cullin Hills, in Skye, where there was nothing for it to perch upon but the lichen-covered rocks. On the moors the Cuckoo is very fond of perching on rocks, and especially on the "dry walls," but in cultivated districts is most frequently seen in trees and occasionally on the ground, where it progresses by a series of somewhat awkward jumps. Its flight is usually straight, unwavering, and moderately quick. It carries its long tail straight out; and its rapidly-beaten wings and short neck give it a very Sparrow-Hawk-like appearance. Sometimes it will turn and twist about in a very erratic manner, and often swoop close to the earth or into a treetop. This resemblance to the Birds of Prey is doubtless a protection to the weak and defeneeless Cuckoo from the birds it mimics so closely. At the same time, however, it causes the Cuckoo much annoyance from the various smaller birds that mob it incessantly and follow it abont from place to place. Its resemblance to a Hawk is very often the cause of its death; for the gamekeeper shoots it down at every opportunity, not only in the belief that he is killing an obnoxious creature, but also to prevent it from turning into a Hawk in winter!

The common note of the Cuckoo is almost too well known to need description; but it appears to be confined to the male. The bird begins to utter its note a few days after its arrival, probably when the females have made their appearance. This note is clear, full, and powerful, resembling the syllables $c u c-k o o$, and may often be heard for more than a mile. About the second week of June this note perceptibly alters its tone, as if the bird were labouring under great difficulty in uttering it. $\Lambda$ syllable is also now added to it, and it resembles cuc-cuc-koo, uttered in rather a harsh tone. Its note in early summer is also sometimes prolonged into three syllables, but then it is cuc-koo-koo. The Cuckoo occasionally calls as he flies, generally when within a few yards of an intended perehing-place; but more often the note is heard when the bird is at rest in some tree or on a wall. The male Cuckoo sometimes adds to his cry a few low notes, a sort of chatter or hoarse langh, which is said to be also uttered by the female and appears to be their alarm-note. The call-note of the female in spring is a loud and rapid kwow-ow-ow-ow, intermediate between a whistle, a laugh, and a scream, reminding one of bubbling water. 
It is very remarkable how the various species of small birds are attracter by the note of the male Cuckoo. Dixon has the following note, amongst several of a similar nature :- "I once saw a malc Cuckoo alight in a tall oak tree and commence calling. He had not been there long before several Starlings that had been feeding in a ncighbouring field flew into the same tree. Soon after several Greenfinches arrived; and then a WillowWren, flying over, suddenly altered its course and flew back for some distance into the tree."

The male Cnckoo, when onee it has arrived in a suitable haunt, does not seem to wander far away from it during the summer. It is rather a shy wary bird, and appears to love retirement, kecping as much out of sight as possible. It is more often heard than seen, and is usually observed when flying from one tree to another. Notwithstanding its shyness, gamekeepers often succeed in luring it within shot by imitating its cry. When the Cuckoo alights, it very often depresses its head, spreads out and elevates its tail, and droops its wings. Though clumsy on the ground, it is quite at home amongst the branches, and hops about in search of food, gliding from twig to twig, or sometimes fluttering upwards to take a caterpillar or a fly.

The food of the Cuckoo consists principally of beetles, butterflies, moths, and other insects, with their larve. It is extremely fond of caterpillars, and especially those that are covered with hairs. Vegetable fibres and blades of grass have been occasionally found in its stomach, which is often packed full of the hairs from caterpillars and other insect-remains in a globular mass or pellet, which is afterwards ejected from the mouth. The Cuckoo is often accused of devouring birds' eggs. Gamekeepers say that it sucks the eggs of Pheasants, Partridges, and Grouse; but there is no other evidence that such is the case, and there is not even proof that the eggs of the smaller birds are ever eaten. The food of the young birds is of a slightly more varied nature; for the foster-parents are of many different species, and consequently collect different substances to feed their young. Insects, however, form the chief supply ; but often this fare is varied by worms, grubs, berries, and seeds. The amount of injurious insects and larvæ which the Cuckoo destroys in a single season is almost past belief; and the service this useful bird renders to the farmer, the gardener, and the owner of trees and forests should secure it the greatest protection. Few birds are more interesting, few are so popular or so gladly welcomed in the spring.

The most interesting part of the history of the Cuckoo is the curious fact that it does not rear its own young, but lays its eggs on the ground, and then deposits them with its bill in the nests of other birds, leaving the foster-parents to undertake the task of hatching the egg and feeding the nestling. This habit is not confined to one species, but prevails 
in most, if not all, the true Cuckoos, the Bronze Cuckoos, and the Crested Cuckoos. The Ground-Cuckoos and the species belonging to other aberrant genera all make nests and rear their own young, as do also the American Cuckoos; but it is said (though on very doubtful authority) that some of the latter occasionally adopt the habit of our bird. The only other bird which is known with certainty to place its eggs in the nests of other birds is the American Cow-bird (Molothrus pecoris), a species belonging to the American Orioles or Icterinæ, a subfamily of the Passcridx, connecting the Starlings with the Finches.

The cause of this curious habit is very difficult to discover. It has been suggested that the hereditary impulse to leave its breeding-grounds so carly originally obliged it to abandon the education of its young to strangers; but the same habit is found in many species in India and Africa, which are resident and do not migrate. Others have attributed it to the polygamous habits of the Cuckoo; but the Cuckoo is not polygamous, it is polyandrous. The males are much more numerous than the females. The sexes do not pair, even for the season. It is said that each male has his own feeding-grounds, and that cach female visits in succession the half-dozen males who happen to reside in her neighbourhood. With the Cow-bird the case is said to be different. The males and females live indiscriminately in a flock together, and display neither sexual jealousy nor parental affection. A plausible explanation of the peculiar habits of the Cuckoo is to be found in the fact that its eggs are laid at intervals of screral days, and not, as is usual, on successive days. Very satisfactory evidence has been collected (Bidwell, 'Zoologist,' 1883, p. 372) that the Cuckoo lays five eggs in a scason, and that they are laid at intervals of seven or eight days; but the American Cuckoo and many of the Owls very often do the same. This power has probably been gradually acquired by the Cuckoo so as to give the female time to find a suitable nest in which to deposit each egg. It is possible that this singular habit of the Cuckoo has arisen from its extraordinary voracity. The Cuckoo is a glutton; and the Cow-bird is said by American ornithologists to be insatiable in its appetite. The sexual instinets of the male Cuckoo appear to be entirely subordinated to his greed for food. He jealously guards his fecding-grounds, and is prepared to do battle with any other male that invades them, but he appears to be a stranger to sexual jealousy. He is said to be so absorbed in his gluttony that he neglects the females, who are obliged to wander in scarch of birds of the opposite sex, and appear to have some difficulty in obtaining the fertilization of their ovaries. The sexual organs of the male are probably so weak that the females are obliged to resort to several males before the complement of eggs is laid. The female in this species being thus the prepotent sex, the result, according to a recognized law of nature, is an excess of males in the offspring. The 
extreme voracity of the young bird is an additional reason why the care of the five nestlings should be entrusted to as many pairs of birds. Whatever may have been the cause of this apparently unnatural habit, the result has been remarkably successful in the case of the Common Cuckoo, which must be regarded as a common bird with a very wide distribution, and scattered over almost every variety of country within its range.

In its choice of a foster-parent for its offspring it exercises more discrimination than might be supposed, from the long lists which have been published of birds in whose nests its egg has been found. An insectivorous bird is generally chosen. The Pipits and the Wagtails are pcrhaps the greatest favourites; and in our islands Cuckoos' eggs are most often found in the nests of the Meadow-Pipit and Pied Wagtail. In gardens the Hedge-Sparrow is most frequently entrusted with the charge, and in the fens the Reed-Warbler. In some districts Redstarts have the preference, and in others, curiously enough, the Common Wren. There is probably no insectivorous bird which breeds in the districts where the Cuckoo spends the summer in whose nest its eggs are not occasionally deposited, though preference is given to such as build open nests. Sometimes the Cuckoo is unable to find the nest of a suitable bird, and is obliged to deposit its egg in the nest of a granivorous bird, such as the various species of Finches, Buntings, \&c. ; and occasionally Cuckoos' eggrs have been found in the nests of such totally unsuitable birds as Magpies, Jays, Shrikes, Pigeons, and even the Little Grebe. The Cuckoo's egg is remarkably small in proportion to the size of the bird, and it is generally placed amongst eggs which are smaller than itself; so that the young Cuckoo is usually much larger than its foster-brothers or sisters, and monopolizes the attention of the parents to the exclusion of the other inhabitants of the nest, who dic or are eventually expelled by the young Cuckoo. It has been said, on what appears to be incontestable evidence, that the young Cuckoo soon after it is hatched ejects the young or eggs from the nest by hoisting them on its back; but one feels inclined to class these narratives with the equally well-authenticated stories of ghosts and other apparitions which abound.

The eggs of the Cuckoo are subject to great variation of colour, and they very frequently resemble closely the eggs amongst which they have been placed, so much so that Cuckoos' eggs are often supposed to be double-yolked eggs of the same species. This fact has given rise to the extravagant theory that the Cuckoo possesses the power of determining the colour of her eggs, so as to make them resemble the other eggs in the nest. The explanation probably is that the eggs of each individual Cuckoo vary very slightly. A Cuckoo which lays blue eggs always lays blue eggs, and its descendants will continue to lay blue eggs; it was probably hatched in a nest containing blue eggs, and will, to the best of its ability, 
entrust the care of its eggs to foster-parents of the same species as those which tended it in its infancy. The eggs of the Cuckoo are laid from the last week in May to the first week in July. It would be impossible to describe or figure all the variations to which they are subject. The three commonest types are nos. 11, 12, and 13 in the Plate (which are usually laid in the nest of the Reed-Warbler), nos. 2, 5, 8, 9, and 14 (usually entrusted to the care of the Meadow-and Tree-Pipits), and nos. 10 and 15 (of which the foster-parents are Pied or White Wagtails). It is very seldom that the Cuckoo's egg is found without small round dark markings, like fly-spots. These spots are sometimes almost obsolete; and I have taken a young Cuckoo out of a blue egg on which they were so pale as to almost escape notice ('Zoologist,' 1880, p. 361). They vary in length from $1 \cdot 0$ to 1.8 inch, and in breadth from $\cdot 75$ to 61 inch. The following is a list of the eggs figured on the Plate, giving the locality where they were procured, and the number of eggs found in the same nest:-

1. Pomerania, with 5 of Garden-Warbler.

2. Cheshire, with 3 of Meadow-Pipit.

3. Asia Minor, with 4 of Orpheus Warbler.

4. Malaga, with 1 of Cuckoo and 4 of Orpheus Warbler.

5. Cheshire, with 4 of Meadow-Pipit.

6. Eastbourne, with 1 of Cuckoo and 1 of Reed-Warbler.

7. Holland, with 4 of Redstart.

8. Cheshire, with 3 of Meadow-Pipit.

9. Cheshire, with 1 of Cuckoo and 3 of Meadow-Pipit.

10. Cheshire, with 4 of Pied Wagtail.

11. Pomerania, with 2 of Common Wren.

12. Pomerania, with 3 of White Wagtail.

13. Derbyshire, with 2 of Hedge-Sparrow.

14. Surrey, with 3 of Yellow Hammer.

15. Pomerania, with 4 of White Wagtail.

Most of these eggs closely resemble those bclonging to the fosterparents; but no. 6 was probably intended to be placed in the nest of a Pied Wagtail, nos. 11, 12, and 13 in nests of Reed-Warblers, and no. 1t in that of a Tree-Pipit.

The change of plumage in the Cuckoo is extremely puzzling; but the following appears to me to be the best explanation of the variation to be found in a large series of skins. Young in first plumage have the feather's of the upper parts barred with chestnut and tipped with white, males differing from females in having no chestnut on the rump and upper tailcoverts and very little on the tail, whilst the white tips are purer in colour than in the female. After the first spring moult the difference between 
the scxes is much greater; the male loses nearly all the chestnut on his plumage, but retains the white edges to the feathers, whilst the female moults into what is called the "hepatic" stage, in which the chestnut is increased in brilliancy and the white edges to the feathers disappear. These females just entering their second year do not breed, and seldom migrate far north-a fact which may be observed in many other species. In the following autumn both male and female assume nearly adult plumage, traces of immaturity being still found, especially in the female, on the breast and back. The fully adult plumage is assumed in the following spring, when the bird is scarcely two ycars old. In this plumage the general colour of the upper parts is slate-grey, browner on the wings, which are barred on the inside webs with white, and nearly black on the tail, which is broadly tipped with white and shows obscure traces of white bars, which, however, are often absent on the centre feathers. The gencral colour of the underparts above the breast is pale slate-grey, and below greyish white, with dark-brown transverse bars, which become very indistinct on the under tail-coverts. In immature birds the chin and throat are barred like the breast. Bill slaty black, paler at the base and yellow at the edges; legs, feet, and claws orange-yellow ; orbits and irides yellow. In the fully adult plumage the sexes are alike in colour.

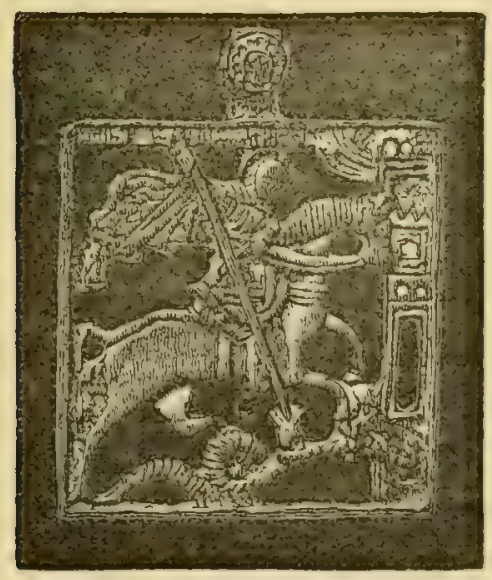

V()I. TI. 


\title{
CUCULUS GLANDARIUS.
}

\section{GREAT SPOTTED CUCKOO.}

\author{
(Plate 68.)
}

Cuculus andalusiæ, Briss. Orn. iv. p. 126 (1760).

Cuculus glandarius, Limn. Syst. Nat. i.p. 169 (1766); et auctorum plurimorumGmelin, Latham, (Gray), (Hartlaub), (Salvin), (Dresser), (Newton), \&c.

Cuculus pisanus, Gmel. Syst. Nat. i. p. 416 (1788).

Cuculus melissophonus, Vieill. N. Dict. d'Hist. Nat. viii. p. 230 (1817).

Coccyzus pisanus (Gmel.) Audouin, Expl. Pl. Savig. Ois. d'Egypte, p. 266 (1825).

Coccysus glandarius (Linn.), Savi, Orn. Tosc. i. p. 154 (1827).

Cuculus macrourus, Brehm, Vög. Deutschl. p. 153 (1831).

Cuculus gracilis, Brehm, Vög. Deutscht. p. 154 (1831).

Coccystes glandarius (Linn.), Gloger, Handb. Vög. Eur. p. 449 (1834).

Oxylophus glandarius (Limn.), Bonap. Comp. List B. Eur. \& N. Amer. p. 40 (1838).

Cuculus phaiopterus, Riipp. fide Bonap. Consp. p. 102 (1850).

The claim of the Great Spotted Cuckoo to be included in the British list is very slender, and rests on two examples only. The first of these was said to have been caught in Ireland on the island of Omagh, co. Galway, in the month of March 18t2. The bird was being chased by Hawks, and took refuge in a hole in a stone fence, where it was taken alive and kept in confincment for several days. This specimen came into the possession of Mr. Creighton, of Clifden, and was ultimatcly sceured for the Trinity College Museum at Dublin, but is now lost (Ball, Aun. Nat. Hist. 1813, xii. p. 119). A sccond specimen was shot near Belliugham, in Northumberland, on the 5th of August, 1870, and is now in the Newcastle Museum (Hancock, 'Birds of North. and Durh.' p. 27).

The Great Spotted Cuckoo is a summer visitor to the Spanish Peninsula, Palestine, Asia Minor, and Persia, occasionally visiting South Russia, Italy, and Greece. It is a partial resident throughout North Africa, and winters throughout South Africa; it is also an accidental visitor to South France and Germany, and occasionally strays to the Canaries.

The Great Spotted Cuckoo is a well-known summer migrant to several parts of South Europe, where it arrives rather earlier than the Common Cuckoo. Irby says that at Gibraltar it generally appears between the 7 th and the 28th of March; in Palestine Canon Tristram obscrved it as early as the 4.th of March; but in Asia Minor it does not arrive before the end of that month. It retires southwards rather carly in the autumn, the latest recorded by Irby at Gibraltar being on the rth of August. During his last journey to Palestine, Tristram met with a flock of this bird which had not yet dispersed on the 22nd of April. Unlike the Common Cuckoo, 
the present species journeys in large flocks. Tristram writes :- "They travelled very leisurely, and while scattered along the whole length of the valley which they were crossing, kept up ccaseless conversation, some fow jerking their tails on the edge of the cliffs, while the greater number pursued their course among the bushes, scarching for food as they descended our side of the valley and climbed the opposite face. Their belaviour, but for their noisy tongues, was very like that of a wcll-ordered flock of Rooks, with their sentries on their feeding-ground. When they had reached the north ridge of the valley they secmed to take stock of the situation, and very soon rose in the air, perhaps stimulated by our ineffective shots, and pursued their course till out of sight."

The Great Spotted Cuckoo is a somewhat shy bird, and lives in welltimbered districts. It may sometimes be seen on the ground, where its long tail makes it conspicuous; but it is perhaps most frequently observed among the branches. Its flight is moderately rapid and undulating, something like that of the Aagpie, and when alarmed it gencrally contrives to slip out of that part of the tree furthest away from the observer. If followed, it will fly from tree to tree or grove to grove, and is too wary to allow the observer to approach it very close. The usual call-note of this bird is described as somewhat resembling that of the Common Cuckoo, and may be expressed by the worls kee-ou, kee-ou. Its alarm-note is said by Tristram to be intermediate between that of the Jay and the Roller, and to resemble the word cark; it also possesses a third note of wurree, wurree, from which it has doubtless derived its Arab name. The food of the Great Spotted Cuckoo is composed of insects, especially caterpillars, and this fare may be varicd by an occasional cgg stolen from the nests of its dupes. It often sits on some favourite stump, whence it sallies forth to catch a passing fly or to pounce down on a locust.

Like the Common Cuckoo, the present bird is a parasite, and deposits its eggs in the nests of other birds, and leaves its young to be hatched and reared by other species. This interesting fact was not known with absolute certainty until 1850, when Brehm observed it in Egypt. In the 'Ibis' for 1866 (p. 281) Tristram gives many details concerning its habits during the breeding-season. The nests selected by this bird for its purpose are the species of Crows; and Tristram thinks sometimes the Southern Little Owl. A Magpie's nest, either the common species or the Azure-winged Magpie, is gencrally sclected in Spain and Algeria; but in Egypt that of the Hooded Crow is preferred, and in some parts of Palestine that of the Black-headed Jay is probably chosen. This Cuckoo sometimes lays as many as four of her own eggs in the selected nest, but usually not more than two. Opinion is still divided upon the point; but it is thought by some naturalists that the bird conveys its egg in its beak, and deposits it in the nest without sitting on the nest to lay it. There is 
no evidence to show that the young Cuckoos when hatched attempt to eject the other nestlings, and they have been several times observed living in apparent peace with their distant relations.

The eggs of the Great Spotted Cuckoo are very pale bluish green in ground-colour, spotted and blotched with light brown and with numerous underlying markings of violet-grey. On some specimens these underlying spots are more numerous than the surface ones; and the markings are generally pretty evenly distributed over the whole surface, but most numerous at the larger end of the egg. I have a very fine specimen in my collection which, though otherwise rather sparingly marked, has a ring of streaks and scratches and spots of rather rich brown and one or two underlying streaks of lilac round the large end. They vary from 1.35 to 1.2 inch in length, and from 1.05 to .92 inch in breadth. Although the eggs of this bird bear considerable superficial resemblance to those of the Common Magpie, they may be distinguished from them by the recldish instead of olive-brown colour of the surface-markings, and by the numerous grey underlying markings. They are also on an average smaller and rounder.

Small birds apparently are as suspicious of this Cuckoo as they are of the common one, and never let slip an opportunity of mobbing it, and with a chorus of cries endeavour to drive it away from their vicinity, probably mistaking it for a bird of prey, although they have no need to dread its visits.

The adult male Great Spotted Cuckoo is adorned with a handsome crest, which, with the rest of the head and the ear-coverts, is slate-grey. The rest of the upper parts are brown, suffused with slate-grey on the rump, and the feathers conspicuously tipped with white on the scapulars, wing-coverts, wings, and tail, but almost obsolete on the primaries and two centre tail-feathers. The colour of the underparts is nearly white, the feathers of the throat and breast having black shafts. Bill black, palcr at the base of the lower mandible; legs, feet, and claws slate-grey; irides brown. The female differs from the male in having a somewhat smaller crest, and in having the ground-colour of the primaries chestnut. The male of the year resembles the female, but has the head and nape dark brown, the crest only slightly developer, and the throat, breast, and under tail-coverts suffused with chestnut. Birds in first plumage scarcely differ from birds of the year, but are somewhat darker on the underparts.

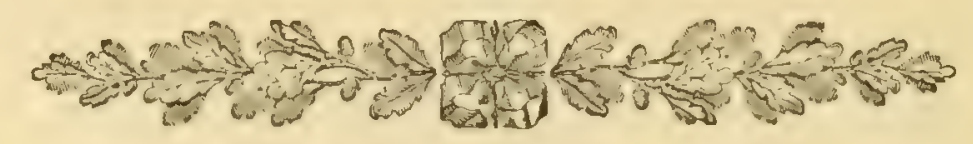




\section{Genus COCCYZUS.}

The American Cuckoos were included by Linnacus in his genus Cuculus; but in 1816 Vieillot, in his 'Analyse d'une nouvelle Ornithologie Elémentaire' (p. 28), removed them into a separate genus under the name of Coccyzus, designating the Yellow-billed Cuckoo as the type.

The American Cuckoos are distinguished by their rounded wings and by having only ten feathers in the tail.

There are between twenty and thirty species in this genus, confined to the southern portions of the Nearctic and the northern portions of the Neotropical Region. Two species are accidental visitor's to Europe, both of which are said to have visited our islands.

The Cuckoos comprised in this genus frequent well-wooded districts, especially orchards and groves, preference being shown for low ground and swampy places. Their fight is moderately quick and powerful, and their notes are loud and guttural. Their food consists almost exclusively of insects and larvæ. Unlike the birds in the preceding genus, these Cuckoos build a nest and hatch and rear their own young. The nests are placed in trees and large bushes, and made of twigs, roots, strips of bark, moss, grass, \&c., and the eggrs are unspotted green of different shades. Sometimes they will deposit an egg in the nest of another species. They are very much attached to their off'spring, and become very noisy when their nests are menaced. 


\section{COCCYZUS AMERICANUS.}

\section{YELLOW-BILLED CUCKO0.}

(Plate 68.)

Cuculus dominicensis, Briss. Orn. iv. p. 110, pl. ix. fig. 2 (1760).

Cuculus carolinensis, Briss. Om. iv. p. 112 (1760).

Cuculus americanus, Linn. Syst. Nat. i. p. 170 (1766); et auctorum plurimorum -(Wilson), (Audubon), (Baird), (Sclater), (Dresser), (Newoton), \&c.

Cuculus dominicus, Limn. Syst. Nat. i. p. 170 (1766).

Coccyzus pyropterus, Vieill. N. Dict. d' Hist. Nat. viii. p. 270 (1817).

Coccyzus americanus (Linn.), Bonap. Obs. Wilson's Orn. no. 47 (1825).

Cureus americanus (Limn.), Boie, Isis, 1831, p. 541.

Cuculus cinerosus, Temm. Man. d'Om. iii. p. 277 (1835).

Erythrophrys carolinensis (Briss.), Swains. Classif. B. ii. p. 322 (1837).

Erythrophrys americanus (Linn.), Bonap. Comp. List B. Eur. \& N. Amer.p. 40 (1838).

Coccystes americanus (Limn.), Keys. u. Blas. Wirb. Eur. p. 34 (1840).

Coccyzus dominicus (Linn.), Baird, Proc. Ac. Phil. 1863, p. 64.

Coccyzus bairdi, Sclater, Proc. Zool. Soc. 1864, p. 120.

Coccygus julieni, Lawr. Ann. Lyc. N. Y. viii. p. 42 (1864).

The claim of the Yellow-billed Cuckoo to be included in this volume is supported by the record of half a dozen British-lilled examples. All of these liave occurred near the coast in the west of our islands, and all, so far as is known, at the season of autumnal migration. These facts, confirmed by the occasional appearance of the birds on the Bermudas, are very strong evidence that the Yellow-billed Cuckoo has occasionally succeeded in crossing the Atlantic from America. The first specimen was shot at Youghal, co. Cork, in the autumu of 18.25, and a second at Old Comnaught, near Bray, co. Dublin; both of these specimens were recorded by Mr. R. Ball, of Dublin ('Field Naturalist's Magazine,' 1832, p. 6). The third specimen was shot near Stackpole Court, in Pembrokeshire, in the autumn of 1832 (Tracy, 'Zoologist,' 1851, p. 30-16). The occurrence of a fourth specimen in Cornwall was communicated by Yarrell to Temminck, but the date of its capture appears to be unknown (Temminck, Man. d'Orn. iii. p. 279; and Jenyns, Man. Brit. Vert. An. p. 155). A fifth specimen was found dead in a wood at Wallog, near Aberystwith, on the 26th of October, 1870 (Dresser, Proc. Zool. Soc. 1871, p. 299; and Newton, ed. Yarr. Brit. B. ii. p. 415$)$; whilst a sixth is said to have been picked up dead near the lighthouse on Lundy Island in October 187 $\$$ (Newton, ed. Yarr. Brit. B. ii. p. 115$)$. Two other examples have occurred in Europe, one in Belgium on the 22nd of October, 1874 (Dubois, Bull. Ac. Roy. 
Belg. xxxix. p. 9), and the other near Turin in October 1883 (E. Cavendish Taylor, 'Ibis,' 1884, p. 115).

The Yellow-billed Cuckoo has a very extensive range on the American continent, breeding as far north as New Bruuswick and Minnesota, and as far south as the West Indies. Its lateral range is equally extensive, reaching from the Atlantic to the Pacific. In winter it is found in Central America and the northern portions of South America, probably as far south as Buenos Ayres. An example was shot in Greenland in 187 t.

The Yellow-billed Cuckoo is as well known in North Amcrica as the Common Cuckoo is in England, and its appearance in spring is looked forward to and welcomed in a similar manner. It frequents orchards, woods and groves, and dense timbered swamps, where it seeks the most secluded places amongst the foliage; for, like our Cuckoo, it is a somewhat shy and solitary bird, though I have seen it in the Central Park in New York. It arrives in the Northern States about the third week in April, but in the Southern States it already has eggs at that datc. It leaves Peunsylvania about the middle of September for its winter-quarters. The males are said to arrive first, as is the case with many other migratory birds, and are followed by the females a little later. Writing of the note of this species, Wilson remarks:- "A stranger who visits the United States for the purpose of examining their natural productions, and passes through our woods in the month of May or June, will sometimes hear, as he traverses the borders of deep, retired, high-timbered hollows, an uncouth guttural sound or note, resembling the syllables kowe, kowe, kowe, kowe, lowe! beginning slowly, but ending so rapidly, that the notes scem to rum into each other, and vice versâ ; he will hear this frequently without being able to discover the bird or animal from which it procceds, as it is both shy and solitary, secking always the thickest foliage for concealment. This is the Yellow-billed Cuckoo, the subject of the present account. From the imitative sound of its note it is known in many parts by the name of the Cow-bird; it is also called in Virginia the Rain-Crow, being observed to be most clamorous immediately before rain."

Nuttall says that the Yellow-billed Cuckoo often calls during the night; and in the daytime his voice is incessantly heard near his nest, where, as a sentinel, he watches over the sacred spot and guards it from all intruders. Dr. Coues writes:- " It is a rather shy and unfamiliar species, inhabiting high, open woods, as well as the large shade-trees of parks and cities, and gencrally remains high among the branches. When dashing about in active pursuit of the various large-winged insects that form its chicf food, they are conspicuous objects, the metallic olive-grey flashing in the sum, and the snowy underparts contrasting with verdure. But ordinarily they are hidden birds, oftener heard than seen; they pass from one tree to another stealthily, with a rapid, gliding, noiseless flight, and often rest 
motionless as statues for a long time, especially when crying out, or when they have detected a suspicious object. They court the seclusion of the thickest foliage. Their curiosity is not small, and they may be observed to frequently peer down with inquisitive looks through the dense foliage, trying to make out some unusual object."

The food of the Yellow-billed Cuckoo is composed largely of caterpillars, and on these its young are chiefly fed. It also eats other insects, small shells, soft fruits, and various kinds of berries.

Unlike our Cuckoo, the Yellow-billed Cuckoo both builds a nest and hatches and rears its own young. The nest is generally placed in trees and large bushes, often in a fruit-tree, or in a cedar, a crab, or a thorn. It is very carclessly put together, and composed of small sticks loosely mixed with grass, and is almost as slight and flat as the nest of a Pigeon. The eggs are from three to five in number, of a uniform pea-green, and measure from $1 \cdot 4$ to $1 \cdot 1$ inch in length, and from 98 to $\cdot 83$ inch in breadth. The shell is somewhat rough in texture, and possesses little or no gloss. A curious fact in the nesting-economy of the Yellow-billed Cuckoo is that the eggs are frequently laid at such intervals that young birds and freshly deposited eggs may be seen in the nest at the same time, the warmth from the young birds assisting in incubating them. Although this species of Cuckoo is not a parasite like so many others of this group of remarkable birds, there seems to be considerable evidence that it occasionally drops an egg into the nests of other birds (Allen, Bull. Nutt. Orn. Club, 1877, p. 110); whilst Ridgway states that its eggs have been found in the nest of the Black-billed Cuckoo. It is acknowledged, however, that few birds are so anxious for the safety of their eggs and young as the Yellow-billed Cuckoo. Like the watchful wary Stormeock of our own woods and groves, the male Yellow-billed Cuckoo is ever on the alert to drive away any prowling bird or beast from the vicinity of its nest, and will even flutter along the ground in a secmingly helpless manner to allure the intruder from the presence of its eggs or young. The old birds also seem much attached to each other, and should one be wounded its mate will often show much affection and anxiety for its fate.

This species often migrates southwards in immense flocks, and has been noticed on the Bermudas in thousands, passing on to its winter-quarters in Central and South America.

The general colour of the upper parts, including the two centre tailfeathers, is uniform buffish brown, with a greenish metallic gloss; the remaining feathers of the tail, which is much graduated, are nearly black, with broad white tips, and the primaries are suffused with buffish chestnut, especially on the inner webs. The underparts are nearly pure white. The upper mandible is nearly black, yellow at the base, and the under mandible is yellow, nearly black at the tip; legs, feet, and claws slate- 
grey; irides dark brown, orbits greyish white. There is no external difference between the sexes; but young birds are said to be without the chestnut on the primaries, as in the Black-billed Cuckoo, from which they may always be distinguished by the yellow on the bill.

An example of the Black-billed Cuckoo (Coccyzus erythrophthalmus) was shot by Dr. Rea at Killead, ten miles from Belfast, near the end of September 1871. It was erroneously recoriled ('Zoologist,' 1872, p. 2943) as a Yellow-billed Cuckoo ; but Lord Clermont subsequently identified it as the black-billed species ('Zoologist,' 1872, p. 3022). The only other example obtained in Europe occurred in Italy near Lucca in 1858 (Bolle, Journ. Orn. 1858, p. 457). Newton, in his edition of Yarrell's 'British Birds,' does not devote an article to this species, though in the 'Ibis List' it is mentioned without brackets. It is very difficult to detcrmine whether an American bird, which has only appeared once or twice in Europe, should be included in the British list or not; but much may be said in favour of excluding American birds that have only once been obtained in our islands. Many species of American birds occasionally wander far from home, and some habitually visit the Bermuda Islands. MIost of these birds which visit this country are inhabitants of the north-west of America, many of them eren breeding on the Sibcrian coast; and there can be little doubt that they travel across Asia, appearing on our islands in the great stream of migration which reaches us in autumn from the east. It seems probable, however, that others cross or attempt to cross the Atlantic-birds that have lost their way in migrating southwards from Labrador, or have been driven out to sea by heavy gales. Probably the greater number of these birds perish ; but some succeed in reaching Europe with or without the help of an occasional rest on the rigging of some of the numerous ships crossing the ocean.

The Black-billed Cuckoo inhabits the eastern half of the North-American continent, breeding as far north as Labrador, and as far south as Georgia and Texas. In winter it is found in Mexico, Central America, some of the West Indies, and the northern portions of South America. The habits of this bird differ little from those of the Yellow-billed Cuckoo. Its egg is figured on Plate 68. They vary in length from $1 \cdot 15$ to $1 \cdot 05$ inch and in breadth from 99 to $\cdot 8$ inch. The eggs of the Black-billed Cuckoo are on an average considerably smaller than those of the Yellow-billed Cuckoo; but small eggs of the latter are indistinguishable from large eggs of the former.

The Black-billed Cuckoo may be distinguished from its near ally by being slightly smaller, by having very little chestnut on the primaries, both mandibles of the bill nearly black, the orbits dull scarlet, and the white tips to the tail-feathers much less conspicuous. The sexes do not differ in colour. 


\section{Family COLUMBID $\mathrm{E}$, or PIGEONS.}

The Pigeons are a large and well-defined group of birds which are somewhat isolated. Sclater and Gadow regard them as allied to the Gallinaceous birds through the Sand-Grouse; but Forbes traced their relationship through the Sand-Grouse and Pratincoles to the Plovers. The sternum of the Pigeons resembles in many respects that of the Game Birds. There are two notches on each side of the posterior margin of the sternum; but the internal pair are small and generally closed at the entrance (the gulf thus becoming a lake), and the external pair are very deep and wide. The cranial bones of the Pigeons present a modification different from that to be found in any family of which we have hitherto treated. The Pigeons are said by IIuxley to be schizognathous, like the Game Birds, Sandpipers, Gulls, Auks, \&c. (Gadow, however, assures me that many species of Birds of Prey and Owls are also schizognathous). In their pterylosis the Pigeous partake of the characters of both the Sandpipers and some of the Game Birds, which latter family they also somewhat resemble in their digestive organs, and still more closely in their myology.

In spite of what has been written by Naumamn, Meves, and others on this subject, there can be no doulbt that, in a wild state, Pigcons moult twice in the year, in spring and autumn, as carefully dated specimens in my own collection abundantly prove. Young Pigeons are covered with yellow down when they are first hatched, but are born blind.

The most striking external character of the Pigeons is the bill, which is thinnest in the middle, expanding towards the point, as in the Plovers; the basal portion is covered by a soft skin, in which the nostrils are situated. The hind toe and claw are small, as in Picarian birds. The Pigeons are divided into several subfamilies, which show considerable modification both of the wings and tail. The number of primaries in the former is ten, but the feathers in the latter vary considerably in this respect.

The number of species of Pigeons probably exceeds 350, which are distributed all over the world, except in the Arctic regions. They are rarest in the Palrearctic and Nearctic Regions, and most abundant in Australia. 


\section{Genus COLUMBA.}

The genus Columba was included by Linnæus in the 12 th cdition of his 'Systema Nature' published in 1766 (i. p. 282). It is impossible to guess which species Linnaus considered typical. The first species mentioned by him, the Rock-Dove (his Cohumba cenas), has been generally admitted to be the type.

Ornithologists have not yet succeeded in discovering any structural characters by which the Pigeons may be grouped into natural genera. The species in the genus Columba are distinguished by their moderately short and nearly square tails, consisting of twelve feathers, moderately stout bills, and by the prevailing slate-grey colour of the plumage, which is glossed with metallic tints. The wings are moderately long and pointed. The tarsus is very short and stout, scutellated in front, fincly reticulated behind, and the upper portion is feathered.

There are about fifty species in this genus. Twenty of these are found on the American continent, and are somewhat aberrant in their coloration, and may possibly be generically distinct. Of the species found in the Old World, half belong only to the Ethiopian Region, and the remaining half are distributed in the Palæarctic and Oriental Regions. Three only are found in Europe, all of which are residents in the British Islands.

The birds in this genus breed both in rocks and forests, but they are in the habit of wandering sometimes for a considerable distance into the open country to feed. Their flight is straight and powerful, and on the ground they walk or run with ease. Their notes are very monotonous. Their food consists principally of grain, tender shoots, \&c. They build slight flat nests, and lay two white eggi. 


\title{
COLUMBA PALUMBUS.
}

\section{RING-DOVE。}

\author{
(Plate 17.)
}

Columba palumbus, Briss. Orn. i. p. 89 (1760); Limn. Syst. Áat. i. p. 282 (1706); et auctorum plurimorum-Latham, Temminck, Naumann, Dresser, Saunders, \&c.

Columba torquata, Leach, Syst. Cat. Mamm. \& c. Brit. Mus. p. 26 (1816).

Palumbus pnlumbus (Limn.), Kaup, Nat. Syst. p. 107 (1829).

Columba pinetorum, Brehm, Vög. Deutschl. p. 488 (1831).

Palumbus torquatus (Leach), Bonap. Cat. Par $\approx$ ud. p. 9 (1856).

Palumbus excelsus, Bonap. Compt. Rend. xliii. p. 836 (1850).

The Ring-Dove is a common resident in the wooded districts of England and Wales, Scotland, and Ireland. In the lattcr country it is said to decrease or increase in numbers as plantations are cut down or new ones made; but in Scotland, where the number of plantations has greatly increased and the preservation of game has been carried to a much greater degree, it has, as might naturally be expected, become much more abundant, especially in winter, when the flocks of resident birds are increased by risitors from the continent, some of which pass the Orkney and Shetland Islands on migration. It brecds sparingly on the Channel Islands and on the Inner Hebrides; but on the Outer Hebrides it is only known as an accidental straggler in spring and autumn.

The Ring-Dore is confined to the Western Paliearetic Region, where it is a residcnt, except in the most northern portions of its range. In Scandinavia and West Russia it is a common summer visitor up to lat. $64^{\circ}$, and occasionally strays as far north as the Arctic circle and as far west as the Faroes. In the Ural Mountains it does not appear to breed north of lat. $60^{\circ}$, but occasionally wanders eastwards into the valley of the Tobol. It is an accidental visitor to the Azeres, but has not been recorded from the other Atlantic islands. It brects sparingly throughout the basin of the Ifediterranean, but is principally lnown in that district as a winter visitor. It is doubtful whether it breeds in Palestine, and there is no satisfactory evidence of its erer haring oceurred in Egypt at any scason of the year. It is a resident below the pine-region of the Caucasus; but in Persia, Afghanistan, and Turlicstan, as far cast as Gilgit, it is represcuted by Columba casiotis, which differs in haring the neck-patch buff instead of pure white.

The Ring-Dore, Wook-Pigcon, or Cushat is not only the largest but is 
certainly the best-known of its kind in the British Islands. In our mild climate it remains throughout the year; but in North Germany, in consequence of the severity of the winter, it is only known as an carly spring migrant, arriving in March and leaving in October. It haunts all wooded districts, from the rich low-lying forests and game-coverts on the lowlands and near the coast to the larch-and fir-plantations on the mountains and the moors. It is very partial to a wooded park, and often frequents shrubberies which are mixed with deciduous trees, as well as the open fields, in the hedges of which there are plenty of trees, and now and then a little copse in the out-of-the-way corners. At all seasons of the year it may be seen, either on the open fields or in the shady woods, according to time and season; and though a proverbially wary bird, it may often be seen quietly feeding in the fields within a few yards of a passing train. The flight of this handsome bird is straightforward, very powerful, and rapid. As it flies, the white parts in the wings and the white collar show very conspicuously, the latter often shining with great brilliancy in the sunlight.

The love-song or screnade of the Ring-Dove is one of the most characteristic sounds of the spring, and in districts where they are abundant the entire woods seem filled with their gentle murmurs; it sounds particularly soothing and pleasant in early April, when every thing seems waking into life after the long winter sleep. The note is a soft full c00-00-00, c00-r00-00, and is most vigorously repeated when the male is paying court to his mate.

In no place is the Ring-Dove tamer than in the Jardin des Plantes, in Paris. They may be seen walking about on the grass in the enclosures where the deer and other animals are kept, and secm to take no notice whatever of the visitors strolling in the grounds. They will allow them to approach within a few paces, as they sit perched upon the railings or in the low branches of the trces, or, in the company of Sparrows, steal the food which is wasted by the animals. They may constantly be secn flying over Paris in the direction of these gardens, and they may be often observed slightly ascending, with motionless wings, describing a curve in the air before they descend on a branch near the top of a tree. They are equally tame in the park outside the gates of Berlin; and Dixon has remarked the same in the grounds of the mausoleum near Grimsby, in Lincolnshire. They even allowed him to pass within a few yards of their nests without leaving their eggs.

The Ring-Dove is an early breeder, and often commences its nest late in March or early in April. It chooses a varicty of situations. A favourite site is in a plantation of firs; it also selects almost every forest-tree for its purpose, sometimes making its nest in a tall hedge, a holly, or a yew tree, and has been known to build in the branches of a whin bush. In forest- 
trees a flat broad branch, usually near the trunk, is the site selected; but in evergreens it is often placed near the end of the branches. The RingDove will often rear its young close to houses, sometimes in the ivy growing over them or in a shrub in the garden. A pair used to breed every year in the tall elms in the playground of the Boys' School at Bootham, just outside the walls of the city of York. Once, however, its young are safely reared, it quits the nesting-place, its disposition seems to change, and it does not reappear until the following breeding-season. In this respect it resembles the Missel-Thrush. The nest is rudely made, almost flat, and is merely composed of a few dead sticks so lightly interwoven that the eggs can often be seen through it from below. Sometimes a squirrel's drey forms a good foundation; and Dixon has known it lay on old SparrowHawks' nests and in those of the Magpic, without making any further provision. Dixon says that a favourite place for the nest is in the thick masses of branches which are so often an abnormal growth on wild cherrytrees; and he has seen its old nest in a large clump of mistletoe on a poplar tree. The birds often return yearly to the same tree, and if the old nest be still there often build on the top of it, or more frequently on a branch close by. The eggs are almost iuvariably two in number, never more; but in some cases the bird will sit on a single egg. They are rather small for the size of the bird, elongated and oval in shape, and pure white. They are very smooth and more polished than the eggs of the Owls, but less so than those of the Woodpeckers. They vary in length from $1 \cdot 7$ to 1.55 inch, and in breadth from 1.35 to 1.15 inch. As a rule, they are larger than those of the Rock-Dove and may be distinguished from those of the Stock-Dove by being much whiter. Both birds assist in incubating the eggs.

Dixon writes:- "When the two young are hatched, the efforts of the old birds are taxed to the utmost to supply them with food; for, judging from the number of times the parents visit the nest, they are voracious feeders, which may account for the small number of eggs laid. Almost as regularly as the Rooks, the old Ring-Doves may be scen flying to and from their nest. They do not feed their young like most other birds, but eject semi-digested food from the crop, the young eating from the open mouth of the parent. The young birds advance to maturity somewhat slowly; but when they can fly they are abandoned by their parents, who often rear a second or even a third brood in the season, building a new nest for each brood. As an instance of the late breeding of this bird, I may mention that I have shot young birds in the middle of November that had certainly not left the nest more than a fortnight or ten days, for small particles of down were still adhering to many of the feathers. Before leaving the nesting-cconomy of this species, it is well to draw attention to the following facts:-The excrements of birds of the Pigeon tribe are of a peculiar nature and withont 
smell; and these excrements are never removed from the nest (as is the case with the Starling, for instance), but are suffered to remain. They soon harden on being exposed to the air, and, combined with the platform of sticks, form a structure, strong and durable, for the young birds to inhabit until they are able to fly."

The food of the Ring-Dove is varied, but confined chiefly to vegetable substances. In the summer they subsist on tender shoots of clover, green corn, peas, beans, and even fruit; and I have taken from the crops of nestling birds ears of corn, small pieces of flinty stone, and numbers of small land and freshwater shells. In autumn, when the birds to a great extent become gregarious and assemble in large and small flocks, often of a thousand birds or more, the Ring-Dove's dict is changed; then it eats all kinds of ripe grain, the seeds of vetches and other plants, many of which are very troublesome to the agriculturist. At this season they search under the oak trees for acorns and under the beech trees for mast, sometimes feeding in the branches. They also frequent the stubbles, especially those sown with clover. It also eats many kinds of fruits and berries, such as hips and haws, blackberries, holly-and yew-berries. It has also been known to eat hazel-nuts, which it swallows whole; and in winter, when hard-pressed for food, it will consume the slender shoots of sprouting turnips and has even been found with its crop distended with large pieces of the turnip itself, which had probably been nibbled by sheep. It is an extremely voracious feeder, and consequently, where the bird is numerous, it is a great pest to the farmer. Great flights of Ring-Dores come to this country in autumn, which chiefly frequent the open ficlds in the daytime, but at dusk retire to the neighbouring plantations and woods to roost. The Ring-Dove at this season is silent, its well-known call being peculiar to the breeding-season. This bird drinks very frequently, and is also fond of bathing and sanding itself. Like other Pigcons, it is very fond of salt and has been observed to eat seaweed left bare on the rocks at low water. As some sort of recompense for the great damage it does to the crops, it must be remembered that the flesh of this bird is very palatable, and enormous numbers find their way into the markets. The Ring-Dove is easily kept in confinement when taken yonng, and there are several instances on record where it has even bred in captivity.

The general colour of the upper parts of the Ring-Dore are pale slategrey or lavender-colour, suffused with a metallic gloss on the nape and sides of the neck, which is emerald-green in some lights and pinkish purple in others. On each side of the neck is a large patch of white; the mantle, scapulars, and innermost secondaries are greyish brown, shading into lavender on the wing-coverts, but suddenly changing to white on the outside web of the outermost wing-coverts. The primary-coverts are dark brown; the wings are dark brown, each feather margined with white on 
the outside web; the tail-feathers are dark brown, with a broad subterminal band of lavender. The breast is lavender-pink, shading into lavender on the upper throat and chin, flanks, and under tail-corerts. Bill scarlet at the base, shading into yellow at the tip; legs and fect dull scarlet; claws brown; irides pale yellow. The female differs from the male in having the white patch on the sides of the neck smaller, the metallic colours less brilliant, and the lavender of the breast less pink. Males of the year scarcely differ from adult females; but in the young in first plumage of both sexes the white patches on the neck are absent and the whole plumage is much duller and browaer in colour.

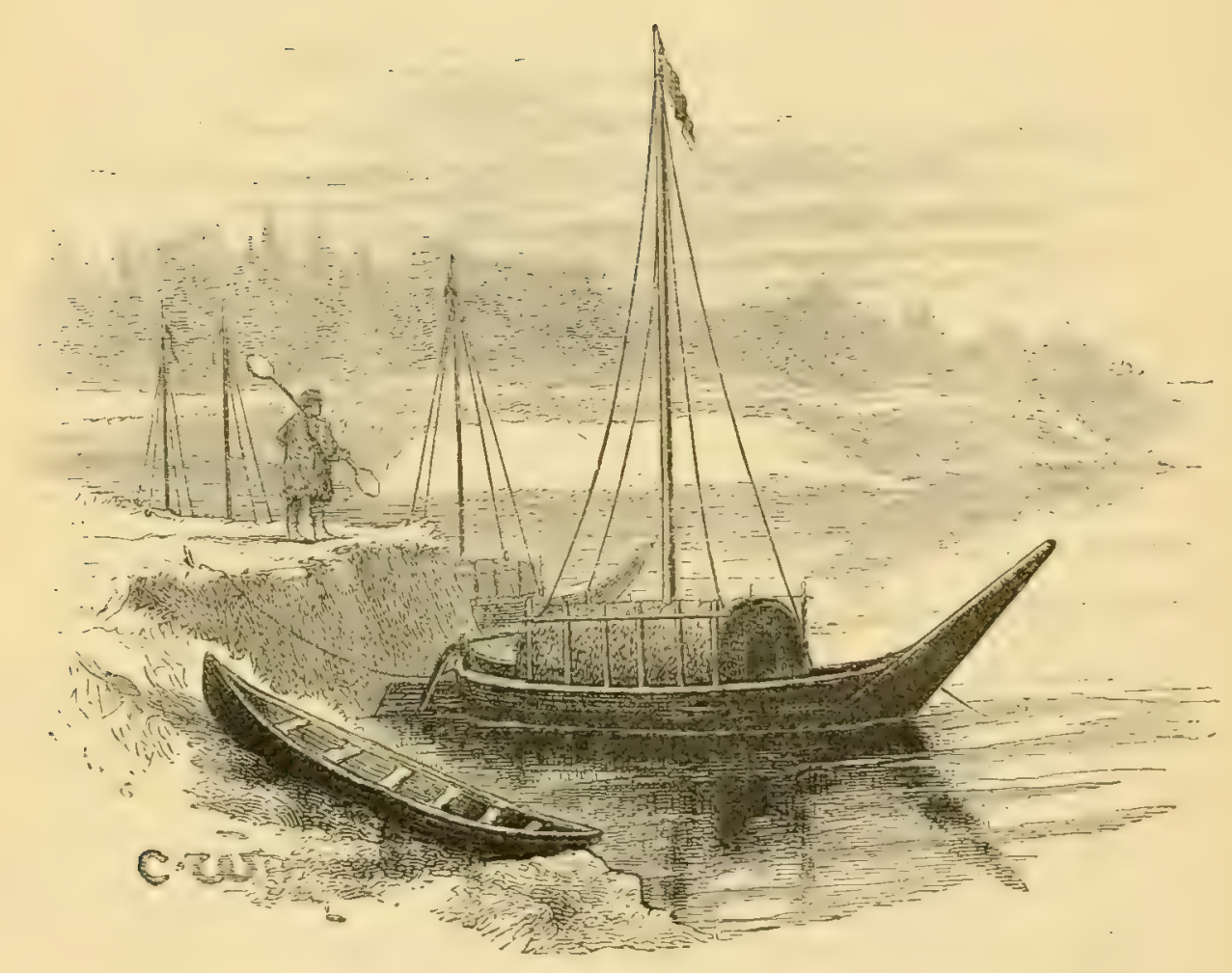




\title{
COLUMBA CENAS.
}

\section{STOCK-DOVE.}

\author{
(Plate 17.)
}

Columba œnas, Briss. Orn. i. p. E(i (1760); Gmel. Syst. Nat. i. p. 769; et auctorum plurimorum-Latham, Temminck, Naumann, Bonaparte, Dresser, Saunders, \&c. Columba vinago, Briss. Orn. i. p. 86 (1760).

Palumbona œnas (Briss.), Bonap. Compt. Rend. xxxix. p. 1107 (1854).

Palumbœna columbella, Bonap. Compt. Rend. xliii. p. 838 (1856).

The Stock-Dove is generally, though locally, distributed throughout the whole of England and Wales. It is a resident bird, and its numbers are said to be steadily on the increase. It is only knomn with certainty to have occurred three times in Scotland, on each occasion in the central districts, once in Stirlingshire and twice in Perthshire (Dalglish, 'Ibis,' 1878, p. 38.2); and it has once becn observed on migration in the Orkney Islands (Gray, 'Birds of the W' unknown except in the north-cast, where, however, it is said to be very rare (Lord Clermout, 'Zoologist,' 187\%, p. 383). Its occurrence in the Channel Islands appears to be doubtful.

The Stock-Dove is a resident in the extreme west of the Palæarctic Region, but to the colder portions of its range it is only a summer visitor. In Scandinavia it breeds up to lat. $62^{\circ}$; in West Russia it is very rarely found north of St. Petersburg, and in the Ural Mountains it is not known to breed north of lat. $5 \tilde{7}^{\circ}$. The only proof of its occurrence in Siberia is the doubtful evidence of an example in the Omsk Muscum said to have been killed in the neighbourhnod. It has not been recorded from any of the Atlantic islands, where it is replaced by screral nearly allied but quite distinct forms, but it is a common resident throughout Central and Southern Europe and North-west Africa. Its occurrence in Egypt is doubtful, and in Palestine it is said to be rery rare; but in Asia Minor and the Caucasus it is a common resident. Serertzow says that it breeds in West Turkestan; but its occurrence in I'ersia is not satisfactorily proved. In Central Asia it is represcuted by C.eversmanni, which may be distinguished by its pale rump, vinous crown, black base of the bill, and slightly smaller size. This specics winter's in North India and Scind. The Stock-Dove has no other very near ally, and may always be distinguished from the dark-rumped * forms of the Rock-Dore by the welldeveloped black bars across the wing-coverts of the latter.

* It is a somewhat singular fact that the colour of the rump in this group of birds is always correlated with that of the axillaries.

VOL. II. 
The Stock-Dove can scarcely be regarded as a forcst bird, though it is especially partial to well-timbered parks. It spends nearly all day in the open country, but frequents the skirts of the forests in order to find a brecding-place in the hollows of the old trees. It frequents the flat open country of the lowlands, where the pollard willows provide it with a suitable nesting-site, and makes its home both on the stupendous sea-girt cliffs and the limestone crags or quarries of the moors. In some of its habits the Stock-Dove very closely resembles the Ring-Dove, whilst in other respects it shows nearer affinity to the Rock-Dove. The portion of Sherwood Forest known as Birklands is a paradise for the Stock-Dove, abounding as it does in hollow old oaks. It frequents this district throughout the year, and may be repeatedly secn flying to and from the woodlands to the neighbouring fields. Its flight is light, buoyant, and swift, performed by an incessant and rapid beating of the wings, and it will sometimes glide down into the cover with amazing speed. In the woods it flies through the trees, threading its way amongst the matted branches, twisting and darting from side to side with such speed as to make it a very difficult bird to shoot. It may often be seen feeding on ncwly sown fields, picking up scattered grains of corn which the harrow has not covered, and mingling with the farmer's dove-cot Pigeons quite socially. It is a shy and wary bird, and upon the least alarm hurries impetuously off to the adjoining woods. It perches in trees with the greatest ease, and may often be seen running along some broad branch, and, if it be in the pairing-scason, spreading out its tail like a fan. Upon the ground it runs and walks with the peculiar bobbing gait of all Pigeons. It often comes to water to drink, and occasionally bathes.

In spring the gentle disposition of the Stock-Dove is to a great extent changed; and under the influence of sexual rivalry two males often eugage in combat for the possession of a female. This bird is a rather early breeder, and from the great diversity of its nesting-habits is one of the most interesting of its family. Its nesting-site varies considerably according to the mature of the district. By the end of March the birds are in pairs, and the eggs are laid during the last half of April. In places where there are no hollow trees the Stock-Dove often rears its young in the old nest of a Magpie or a Crow ; or in the dense ivy growing over trees or buildings. Wherever the timber is full of holes and hollows, either in decayed forest-trees or pollard willows rotted with the rain, it lays its eggs in these, only making a most rudimentary nest, and in some cases the decaying wood is their only bed. Numbers of Stock-Doves breed together with Jackdaws in Sherwood Forest, and sometimes one tree will contain several of their nests. In treeless districts the Stock-Dove makes its nest in a crevice of the rocks or in a hole in the soft earth at the summit of the cliffs; whilst on sandy plains it nests regularly in the 
rabbit-warrens, laying its eggs in their holes several feet from the entrance, often upon the bare sand or on a scanty nest of a few twigs. Other and more curious sites have been recorded. It has been known to lay its eggs on a cross-beam in the spire of a church, and repeatedly on the ground under a dense furze bush. It sometimes makes its scanty nest in a woodstack in the forest; and its eggrs have been found laid on a very thick and dense Scoteh fir-branch, with no other nest whatever. The nest of this bird, when it does make one, is usually composed of a few twigs, dry roots, heather-stalks, \&c. The eggs of the Stock-Dove are never more than two in number, and are pale creamy white in colour-a characteristic which always distinguishes them from those of the Ring-Dove or the RockDove. They vary in length from 1.5 to $1 \cdot 4$ inch, and in breadth from $1 \cdot 2$ to $1 \cdot 13$ inch. Both birds assist in the task of incubation, but the female sits the most. The young are hatched in about eighteen days, and, as is usual in this group of birds, they remain in the nest for a considerable time, never quitting it until well able to fly. Afterwards they generally betake themselves to the neighbouring pastures, and the old birds rear a second or even a third brood. Fresh eggs of this species have been found as late as the beginning of October.

The note of the Stock-Dove is not quite so melodious as that of the Ring-Dove, nor is it so distinct or prolonged. In autumn great numbers of Stock-Doves often congregate with Ring-Doves, and frequent the stubbles and newly sown lands. Dixon writes:- "In some parts of Lincolnshire the Stock-Dove is almost better known than the WoodPigeon, and occurs in even greater numbers than that well-known bird. I have often seen the large fields contain several flocks of this Dove, and mingled with them a small number of domestic Pigeons and a few RingDoves, easily distinguished by the white in the wings and their conspicuous collars. These broad farmlands are the Doves' favourite pastures from the time the corn and beans are cut till the following spring. In such districts are numerous fir-plantations, and these are the nightly retreats of both species. I have sometimes watched them return from the fields just before dusk, and noticed how silertly they dashed into the cover, the rattling of their wings amongst the branches being the only sound they made, for at this season they scldom or never coo. In autumn the StockDoves frequent the bean- and pea-fields, where they do considerable damage; but this they partly compensate for by consuming millions of tiny sceds of most noxious weeds, such as charlock. The bird often perches on the bean-stacks ; and in severe weather it will do so in the farmyards."

The food of the Stock-Dove consists chiefly of grain and seeds, but it does not appear to consume so many shoots of clover and grain as the Ring-Dove. It is also said to eat acorns and beach-mast, and sometimes berries. Stock-Doves are voracious feeders, and though they consume a 
good deal of grain, and are thus rather troublesome to the farmer, they also keep the weeds in check. The flesh of this bird is prized as an article of food; and in some districts it is regularly caught for the table. Professor Newton states that in the warren districts the keepers add considerably to their incomes by catching the Doves which breed in the rabbit-holes, and that they keep a dog trained to discover the holes in which they breed. In winter the Stock-Dove wander's about in search of food, but there is no evidence to show that it ever leaves this country.

The Stock-Dove appears to have derived its name from its habit of nesting on the stocks of trees, and not, as some of the earlicr ornithologists imagined, from its being considered the stock or origin from which our domestic Pigeons have descended.

The Stock-Dove bears a general resemblance to the Ring-Dove, but is somewhat smaller, and has no white on the sides of the neck or on the wing-coverts and odges of the primaries; the lavender-pink of the underparts is also confined to the upper breast. The pale subterminal band across the tail is narrower, and is ill-defined from the lavender base of the tail by an obscure dark bar. The most important feature to distinguish it from the Rock-Dove is the dark brown patches on some of the wingcoverts and innermost sceondaries, which form a rudimentary wing-bar in strong contrast to the well-defined wing-bar of the Rock-Dove. The bill and feet do not differ from those of the Ring-Dove, but the irides are red. Adult females and males of the year differ in having less metallic gloss on the neck and less pink on the breast. Young in first plumage have no metallic colour's on the neck or pink on the breast, the rudimentary wing-bars are almost abserit, and the general colour of their plumage is browner.

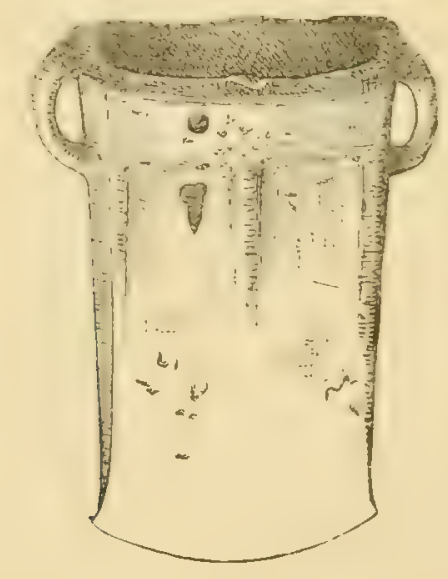




\title{
COLUMBA LIVIA.
}

\section{ROCK-DOVE.}

\author{
(Plate 17.)
}

Columba livia, Briss. Orn. i. p. 82 (1760); Bonnat. Tabl. Encycl. et Méthod.i. p. 227 (1790); et auctorum plurimorum - Temminck, Naumann, Bonaparte, Dresser, Saunder's, \&c.

Columba oenas *, Linn. Syst. Nat. j. p. 279 (1766).

Columba domestica, $\beta$. livia, Gmel. Syst. Nat. i. p. 769 (1788).

The Rock-Dove breeds on the coasts of Great Britain, Ireland, and all the adjacent islands, even including the distant St. Kilda, wherever the rocks are precipitous enough to give it protection and provide suitable breeding-places for it in their recesses. In a few similar localities inland, in Derbyshire, Yorkshire, Somersetshire, and other counties, white-rumped Pigeons are found breeding in an apparently wild state; but they are generally found mixed with birds with grey rumps, and are probably, in all these cases, the descendants of escaped birds.

The range of the Rock-Dove is much wider than that of any other British Dove, extending from the Atlantic to the Pacific; and its exact limits are very difficult to determine, in consequence of the impossibility of discriminating between wild birds and those whieh have becn or are in a semi-domesticated state. To the former belong most of the colonies of this bird on the coast, whilst those breeding inland in most cases probably belong to the latter. It is a common resident on the Faroes. The only colony known in Scandinavia is in the Stavanger Fjord, in lat. $59^{\circ}$. In France it is only known to occur in the Pyrenees, but is very common on the coasts of South Portugal and South Spain and in the mountains of the Sicrra Nevada. It is found on all the Atlantic islands, including even St. Helena. It breeds on all the rocky coasts and islands of the Mediter-

* Dresser and Saunders both violate the rules of the British Association in adopting the name of Columba cnas for the Stock-Dove. This bird may be the $C$. œnas of the 10th edition of the 'Systema Nature'; but it is absolutely certain that the Rock-Dove is the $C$. cenas of the 12th edition, the words "dorso postico albo" having been inserted in the middle of the diagnosis in the later work. If names which are not clearly defined are to be rejected, no insertion of the word 'partim' or ' in part' after them is the slightest excuse for their retention; in fact Saunders (Proc. Zool. Soc. 1876, pp. 649-650) inserts precisely the same expression in brackets as a reason for rejecting the name of Sternu hirundo of Linneus that he adopts (Yarr. Brit. B. iii. p. 8) without brackets as his reason for admitting the name of Columba conas of Linnæus. It is not easy to see on what grounds the presence or absence of brackets should reverse the rule. 
ranean and Black Seas, and on most of the adjacent mountain-ranges, as, for instance, in the Atlas, the Apennines, and in the Parnassus. It is found wherever there are rocks on the shores of the Red Sea, and, more or less mixed with tame birds, runs wild throughout Egypt, Nubia, and Abyssinia, Asia Minor, Persia, Baluchistan, Afghanistan, Turkestan, Gilgit, the Altai Mountains, South Siberia, North China, and Japan. In India and Ceylon a form occurs which has been inappropriately named Columba intermedia, under the impression that it was an intermediate form between the Rock-Dove and the Stock-Dove, having the dark rump* of the latter, but the well-developed wing-bars of the former. This species is the common domestic Pigeon of India, and appears to have been exported thence to most places where domestic Pigeons are kept. The scmidomesticated Pigeons which are found breeding on many of the inland cliffs, and on the churches and other buildings of Europe and Asia, from Archangel to Constantinople, and from Moscow to Irkutsk, consist of both these varietics and intermediate forms. These intermediate forms occur in a purely wild state in Gilgit, where the range of the two species coalesce, and have also been recorded from Palestine, Nubia, and Abyssinia. A third variety of Rock-Dove (C. mupestris) is apparently more distinct, and has the wing-bars somewhat less developed; it has the white rump of our Rock-Dove, but may at once be distinguished from it, and also from $C$. intermedia, by having a broad subterminal white band across the tail. The range of this form in the Eastern Palsarctic Region is almost the same as that of our Rock-Dove, comprising Turkestan, the Himalayas, the Altai Mountains, South-east Siberia, Mongolia, North China, and Tibet. An example of this bird in my collection from Lake Baikal, and another from Darjecling, in both of which the white subterminal band is nearly obsolete on the two centre tail-feathers, lead to the conclusion that this variety also interbreeds with the Rock-Dove.

The true home of the Rock-Dove is on the rocky coasts-bold headlands and beetling cliffs which are tumnelled by ocean-caves. Cliffs where there are few caves are not so much frequented by the Rock-Dove; thus at Flamborough, although it is far from uncommon, it is not nearly so numerous as on the wild rugged western shores of Scotland where so many caves are found. The haunt of the Rock-Dove is wild and romantic, and to make the bird's acquaintance it is necessary to visit some of the finest scenery our islands can boast. The Rock-Dove often sits on the ledges of the cliffs, and may be seen to dash rapidly out of the caves to fly upwards, turn, and pass inland to the distant pastures. It is most commonly seen

* As in the Stock-Dove and its allies, the colour of the rump appears to be always correlated with that of the axillaries; whilst the well-defined wing-bars are always correlated with a nearly black bill. Saunders appears to have copied Dresser's error in describing the bill of the Rock-Dove as reddish brown. 
on the fields near the sea; but often traverses enormous distances to its feeding-grounds. The Rock-Doves on St. Kilda are said to visit the Hebrides daily in search of food, a distance of about seventy miles. Upon the ground it runs and walks in true Pigeon style, bobbing the head backwards and forwards at each step. Its flight is very rapid and powerful. The Rock-Dove is not so shy as the Ring-Dove; but it is nevertheless a very wary bird, and generally examines the ground closely before it alights, and eren when settled on a ficld it usually looks warily from side to side before it begins to feed. The note of this bird does not differ perceptibly from that of the Ring-Dove, and is soft and full-coo, coo, roo-coo. It is particularly noisy in the carly spring, and the cliffs often resound with its cries in those districts where these birds are at all numerous. At this season of the year the male may often be seen performing various antics, and caressing his mate on the rocks, in a precisely similar manner to that of the Domestic Pigeon. He swells out his throat, droops his wings, and spreads out his tail like a fan, all the time screnading her with lis soft winning notes; and should she take wing, he flies impetuously after her, to repeat his courtship. The Rock-Dove rarely, if ever, perches on a tree, and thus differs very widely from all the other British species of Pigcons. It never alights except upon rocks or on the bare ground.

The Rock-Dove is more or less gregarious at all seasons of the year, and the colony is rarely entirely descrted. Birds are continually flying to and from the feeding-grounds, and when the young are being reared it is a pretty sight to see these birds leaving and entering their sea-girt homes. In stormy weather they often keep close to their cave. The food of the Rock-Dove resembles that of its congeners to a great extent. Like the Ring-Dove, it eats an enormous amount of grain; but it also cats many seeds which are troublesome to the farmer. Its fare of grain and tender shoots is varied in the summer by several kinds of land-shclls; and Sarby states that during ten months of the year it chicfly subsists upon the roots of the couch-grass and the seeds of various kinds of weeds. The RockDove drinks very often; and it has been known to settle on the water for this purpose, where the banks of the river were too steep to allow it to alight.

The Rock-Dove is a very carly breeder, its egges being often laid by the middle of March; and as it rears two, if not three or four, broods in a scason, fresh eggs may be obtained from that month till August or September. April and May is the great breeding-time. It is very probably a life-paired bird, and will nest year after year in one particular spot if not molested. A few Rock-Doves build their nests in the crevices of the cliffs; but the great majority resort to eares for breeding-purposes. These caves are sometimes dry, sometimes the floor is dry at low water; but in many cascs the sea is ever rolling inwards, dashing the spray far up the 
sides, and in "fresh" weather filling the interior with a noise like thunder. Far in these gloomy caves, hidden away from enemies, even where the light of day cannot penetrate, the gentle Dove rears its young in peace. It seems not to mind the angry strife of waters, and the booming of the billows never frightens it from its charge. The hirds build their scanty nests on the ledges, sometimes far up in the inaccessible roof of the cavern, and very rarely within reach of the hand without climbing. The moment a boat approaches, the birds begin to leare their dark retreat, and beiore it has time to reach the land they dash ont in twos and threes. The RockDove makes a very slight nest of dry grass or seawced, a dead stick or two, sometimes branches of heather, and Saxby states that gyrecin grass is oceasionally used. The nest is very flat, and little or no skill is displayed in its construction. Sometimes one or two nests are built quite close together; and as the bird's breeding-season is so irregular, the same care will often contain fresh eggs, eggs partly incubated, and young birds in all stages of growth. The eggs of the Rock-Dove are only two in number, pure white in colour, oval and rather elongated in form; they vary from 1.5 to 1.38 inch in length, and from 1.2 to 1.1 inch in breadth. As a rule, the eggs of this bird are rather more rotund than those of the RingDove, and they are always smaller than normal eggs of that bird. Both birds assist in incubating them; but the female performs the greater share of the task, and she is assiduously fed and tended by her mate. The young are reared in a similar manuer to those of the Ring-Dove, and do not generally quit the nest until well able to fly. The breeding-season of the Rock-Dove is sometimes prolonged into the autumn; for Saxby has seen fresh eggs on the 11th of October, and it occasionally begins very early, as he once saw in the ovary "an egg, which would certainly have been perfect in a couple of days," on the 21st of January.

In hard wcather the Rock-Dove may be seen on the beach searching for the seeds of various plints growing above high-water mark; but at that season it prefers to frequent the stubbles, if free from snow, and often congregates with Thrushes and Finches on the weedy pastures. It is also very fond of associating with tame Pigcons - with its lindred in fact; for there is no doubt that it is from the present species or its close allies that all the varieties of domestic Pigeons have sprung.

There is no evidence to show that the Rock-Dove is a migratory bird; but in winter it will sometimes wander far from its accustomed haunts, occasionally in enormous flocks. Hard weather sometimes causes it to leave a district almost entirely, as Dixon found to be the case in several parts of Skye.

The Rock-Dove differs from both the Ring-Dove and the Stock-Dove in having no brown tinge on the back, wing-coverts, or innermost secondaries, which are a paler lavender than the head and upper tail-coverts; it agrees 
with the Stock-Dove in having no white patches on the sides of the neck, and scarcely differs from it in the colour of the tail. There is very little difference in the colour of the underparts of the Rock-Dove and the StockDove, except that the latter has slightly less pink on the breast. The chief specific characters betwecn the two birds are the white lower back and upper rump of the Rock-Dove, and the two conspicuous black bands across its wing-coverts and innermost secondaries, which are only rudimentary in the Stock-Dore. Bill brownish black; legs, fect, and claws as in the other species; irides orange-red. The female chiefly differ's from the male in having less metallic lustre on the neck, less pink on the breast, and the plumage generally duller in colour. Nales of the year scarcely differ from adult females, but have the black wing-bars less clearly definerl. Young in first plumage are suffused with brown above and below, except the primaries, the rump, upper tail-coverts, and tail, which are the same as in the adult.

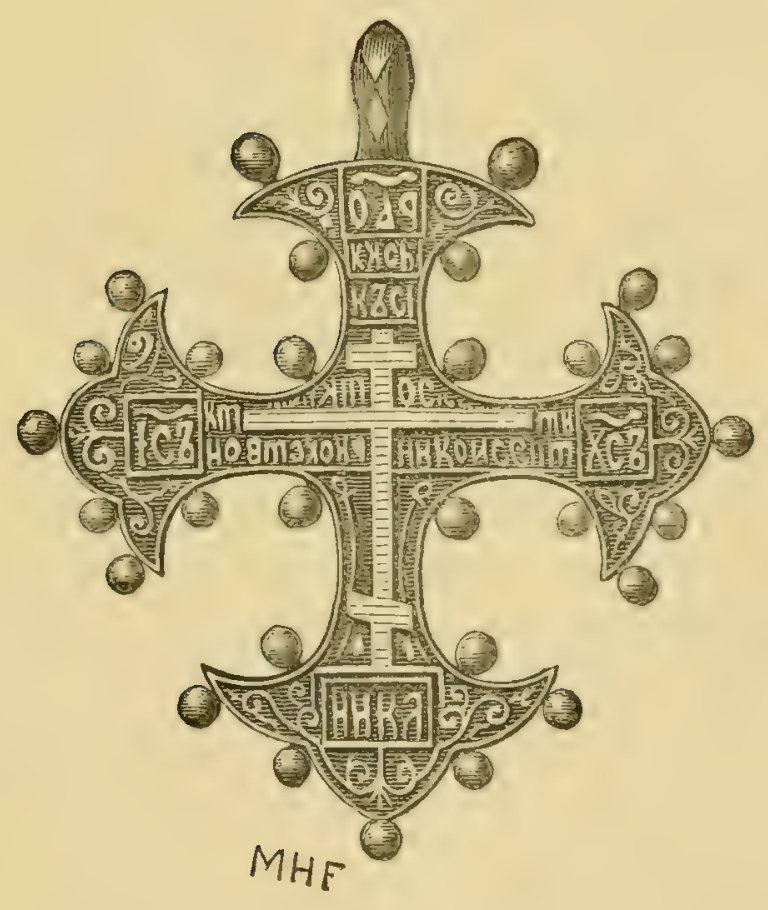




\section{Genus TURTUR.}

The Turtle-Doves were associated with the l'igeons by Linnæus. Boie included them in the genus Peristera, in which Swainson had, in 1827, placed the American Ground-Doves; but in 1835 Selby established the genus Turtur for their reception, in his ' Natural History of the Pigeons' (p. 169), which forms the fifth volume devoted to Ornithology of Jardine's Naturalist's Library. The Common Turtle-Dove, being the Columba turlur of Linnæus, becomes of necessity the type of the genus.

The Turtle-Dores may be distinguished by having the prevailing colour of the plumage brown, by their more or less defined black collar on the neck, and the total absence of any metallic shades in their plumage, and by their more or less rounded tails, which are shorter than the wings. They are birds of small size and slender form; the wings are long and pointed; the bill is very slender, and the tarsus is short and scutellated in front.

There are about twenty-four species of Turtle-Doves, all of which are confined to the Old World. They are distributed over the Southern portions of the Palæarctic, the Ethiopian, and the Oriental Regions, and the Austro-Malayan portion of the Australian Region. One species is a common summer visitor to Europe, including the British Islands; two others are rare stragglers into Europe, and one inhabits the extreme southeast of the continent.

The Turtle-Dores do not differ much in their habits from the Pigeons, but are more closely confined to well-rooded districts. Their flight is straightforward and powerful, and on the ground they run and walk. Their food is very similar to that of the Pigeons, and they also feed their young from the crop. They pair for life, building a slight flat nest in a tree or large bush; and their eggs, two in number, are white. 


\section{TURTUR AURITUS.}

\section{TURTLE-DOVE.}

(Plate 17.)

Columba turtur, Briss. Orn. i. p. 92 (1760); Linn. Syst. Nat. i. p. 284 (1766).

Columba turtur lusitanus, Briss. Orn. i. p. 98 (1760).

Peristera turtur (Briss.), Boie, Isis, 1828, p. 327.

Peristera tenera, Brehm, Vög. Deutschl.p. 494 (1831).

Turtur communis, Selby, Nat. Libr. Orn. v. pp. 153, 171_(1835)**

Turtur vulgaris, Eyton, Cat. Brit. B. p. 32 (1836).

Turtur auritus, Gray, Gen. B. ii. p. 472 (1844); et auctorum plurimorumTemminck, Bonaparte, Degland \& Gerbe, Cabanis, Salvadori, Riippell, Heuglin, Hartlaub, Gould, Shelley, Salvin, Tristram, Gurney, \&c.

Turtur migratorius, Selby, fide Sclater, Jardine's Contr. Orn. ii. p. 126 (1852).

Unlike the true Pigeons the Turtle-Dove leaves our islands on the approach of winter; but during the breeding-season it is generally distributed throughout England and Wales, becoming rarer in Cornwall, in the wilder Welsh counties, and north of South Yorkshire. In Scotland it is only known as an accidental straggler on migration; but in Ireland it is said to breed sparingly. It has occurred once in Orkney, and passes the Shetland Islands regularly in spring and autumn; but has not been recorded from the Outer Hebrides.

The Turtle-Dove is a summer visitor to the Western Palæarctic Region. On the Faroes its appearance is only accidental; but in Denmark and Scandinavia it appears to be irregularly distributed throughout the forest country. In Russia it has not been known to occur north of lat. $60^{\circ}$. East of the Urals it is a summer visitor to Turkestan (as far east as the Altai Mountains, Yarkand, and Gilgit), Afghanistan, Persia, and Asia Minor. It is a summer visitor to Central and Southern Europe, and in Palestine and North Africa as far south as Abyssinia it is principally

* The nomenclature of this bird exhibits perhaps more strongly than any other the evils of the Stricklandian Code. For many years the Turtle-Dove enjoyed undisturbed the name of Turtur auritus. Dresser, in his 'Birds of Europe,' however, adopts the name of Turtur vulgaris, ignoring the prior name of Brehm's, and placing a query in front of it in order to satisfy his conscience and justify his adoption of the later name. This is a case of "voluntary inaccuracy" for which the Stricklandian Code must be held responsible. Saunders, in his continuation of Newton's 'Yarrell,' rakes up another name, and calls the Turtle-Dove Turtur communis. Let us hope that his ignorance of German induced him blindly to follow Dresser in ignoring Brehm's earlier name. According to the rules of the British Association the name of the Turtle-Dove is Turtur tenera (Brehm). 
known as passing through on migration; but a considerable number remain to breed, especially in Algeria. It is extremely common in summer in the Canaries, but is only occasionally found in Madeira. The winterquarters of the Turtle-Dove are absolutely unknown; but as it passes through North Africa, and has not been found in South Africa, they must be in some unknown region in the centre of that continent.

A desert form of the Turtle-Dove, Turtur isabellinus, is a summer visitor to North-east Africa, and differs from our bird in having the wings only six instead of seven inches long, and the head buffish brown instead of bluish grey. In South-west Siberia the Turtle-Dove is replacerl by a very nearly allied species, $T$. ferrago, which occurs together with our bird in Turkestan, and with another allied species, T'. orientalis, in India, the latter being its representative in South-east Siberia, China, and Japan. $T$. ferrago differs from our bird in being larger, in having the tips of the feathers on the sides of the neck slaty blue instead of nearly white, and the colour of the breast much less vinaceous. In T. orientalis the colour of the breast more closely resembles that of our bird, but the under tail-coverts and the pale tips of the tail-feathers are pale slate-grey instead of white. The East-Sibcrian bird appears to be only subspecifically distinct from the West-Siberian bird, as intermediate forms occur in India, where the range of these two forms overlap. In Turkestan, where the range of the West-Siberian bird overlaps that of the European bird, it is not known that any intermediate forms occur between them.

The Turtle-Dove is one of the latest summer visitors to this country, sometimes arriving during the last days of April, but more frequently not until the first week of May. At Gibraltar its migration lasts from the milddle of April to the middle of May, the great body crossing the Straits during the first weck of the latter month. In Greece and Asia Minor the period of the spring migration is the same. Its departure from the British IsTands usually takes place in September; but individuals are occasionally met with much later.

The Turtle-Dove is very careful to conceal its nest, and breeds only in districts that afford it plenty of cover. It is very partial to dense game-coverts and plantations, and loves the more open districts if the hedges are tall and thick. It also frequents parks and pleasure-grounds, and is commonly met with in close shrubberics. Soon after their arrival the woods and groves are full of their soft note, which is a rich low coov $r^{r}-r^{r}-\operatorname{coor}^{2}-r^{r}-r^{2}$, prolonged for some time and of ten modulated in different ways. In cultivated districts it is a very timid bird, and at the least alarm seeks safety amongst the trees, where, when perched, it is ever looking anxiously from side to side as if fearful of an enemy's approach; but it is a very casy bird to shoot when feeding in open country where it is not molested. 
The. Turtle-Dove has not arrived many days ere it seeks out a site for its nest, and the eggs are usually laid in the latter half of May or early in June. The nest is sometimes built in a tall dense hedge, sometimes in an evergreen bush or in the branches of a pinc-tree; as a rule, however, it is generally much nearer to the ground than that of the Ring-Dove, sometimes within easy reach of the hand. It is usually a slight flat structure made of slender twigs, but I have occasionally found it to be more substantially made. The eggs are two in number, creamy white in colour, like those of the Stock-Dove, and oval in form, both ends being almost equally pointed; they vary in length from 1.25 to $1 \cdot 1$ inch, and in breadth from 94 to 86 inch. The small size of the eggs of the TurtleDove prevents them being confused with those of any other British species of Pigeon. Both birds assist in the task of incubation, and in many cases two broods are reared in the year.

The food of the 'Turtle-Dove is chicfly composed of grain and small seeds, but, doubtless, like its near allies the Pigeons, it varies this diet with land-shells and fruit. Like the rest of the Pigeons, the Turtle-Dove drinks frequently and regularly. It is said by some writers that it only takes fresh water; but Stevenson, in his 'Birds of Norfolk,' notices its partiality for salt, and thinks that this is the reason why it occurs so abundantly near the coast. Other Pigeons are knowu to prefer brackish water to fresh.

Like its cousins the Pigcons, the Turtle-Dove often flies far to fecd, and small parties of these birds, as well as of Stock-Doves, may be constantly seen in spring on the Wallachian steppes ten miles or more from a tree or even a bush. I have shot them on these prairies as late as the 2Sth of May. The tlight of this bird is very powerful, and often accompanied with loud clashing together of the wings. On the ground it runs among the earth clods with great ease, continually depressing its head and contracting its neck.

Dixon, when in Algeria, made the following notes on this bird:- "The Turtle-Dove is very common in the oases, and by no means uncommon on the wooded sides of the Aurès, two or three thousand fect above scalevel, in the evergrecn-oak scrub. Although May had far advanced, I am inclined to think that many of the birds we saw in the extreme south were migrants, on their way northwards to Europe. The birds were gregarious in the oases, and were often in company with the Egyptian Turtle-Dove. Almost every date-palm contained one or two of thesc beautiful birds, and they seemed very fond of hiding themselves among: the thick foliage, rarely perching on the outside of the tree. They were not at all shy, and seldom left their retreat before the report of a gun drove them out. Numbers of these birds visited the almost dricd-up rirer to drink, usually in the early morning. 'They roosted in the date-palms, 
and many of the birds sat close together in pairs as if they had already mated."

In the early autumn, just previous to its departure, the Turtle-Dove often congregates in large or small flocks, which haunt the stubbles and "seed"-fields, where they subsist on the scattered grain and probably the tender shoots of clover. At this season they may often be flushed in numbers from the turnips. The Turtle-Dove is often kept in confinement, and has been induced to breed with its ally T. risoria when in captivity.

The Turtle-Dove may at once be distinguished from all the other British Pigeons by its very much smaller size. Like the Ring-Dove it has a conspicuous patch on each side of the neck; but in that bird the brown bases to the feathers are concealed, whilst in the Turtle-Dove they are very conspicuous, nearly black, with pale lavender tips. The hearl and hind neck are lavender, shading into chestuut-brown on the upper back, into lavender suffused with chestnut-brown on the lower back and rump, and into brown on the upper tail-coverts; the scapulars, innermost secondaries, and the adjoining wing-coverts are chestnut-buff with dark centres; the outermost wing-coverts are lavender, the secondaries are brown suffused with lavender; but the primaries and their coverts are brown; the two centre tail-feathers are brown, the others very dark slategrey, broadly tipped with pure white, the outside pair being also white on the outer web. The breast is pinkish lavender, paler on the chin, and shading into pure white on the belly and under tail-coverts, and into lavender on the flanks and axillaries. Bill brown; legs and feet crimson, claws brown; irides reddish brown. Adult females and males of the year are somewhat duller in colour. In the young in first plumage most of the feathers have brownish margins, and the black and white neck-patches are entirely absent.

The Passenger Pigeon (Ectopistes migratorius) forms the sulject of an article in Saunders's continuation of Newton's edition of Yarrell's 'British Birds,' and the Committee of the British Ornithologists' Union, in their List of British Birds, say that it is a rare straggler from the Nearctic Region. Examples have been shot in Fifeshire in December, Berwickshire and Yorkshire in October, near Royston in Cambridgeshire in July, and Kerry in Ireland. Great numbers of Passenger Pigeons have at various times been imported into this country; and in the case of the example shot in Berwickshire, it is known that a gentleman had turned out several of these birds shortly before the specimen in question was shot. The Passenger Pigeon is not known to have occurred in any part of Europe, not even in Heligoland. There is no reason why this bird should not cross the Atlantic if it felt so disposed; but there is not the slightest evidence that it has ever done so. The Passenger Pigeon breeds in 
the Northern States of $A$ merica and Canada, as far north as lat. $65^{\circ}$. In the Southern States it is comparatively a rare bird, and is only known occasionally to reach the Pacific. Wilson's account of the enormous numbers in which they collect to roost and to breed, and the immense flocks in which they wander in search of food, will be well known to most of our readers. It may at once be distinguished from any of the European Pigeons by its long wedge-shaped tail.

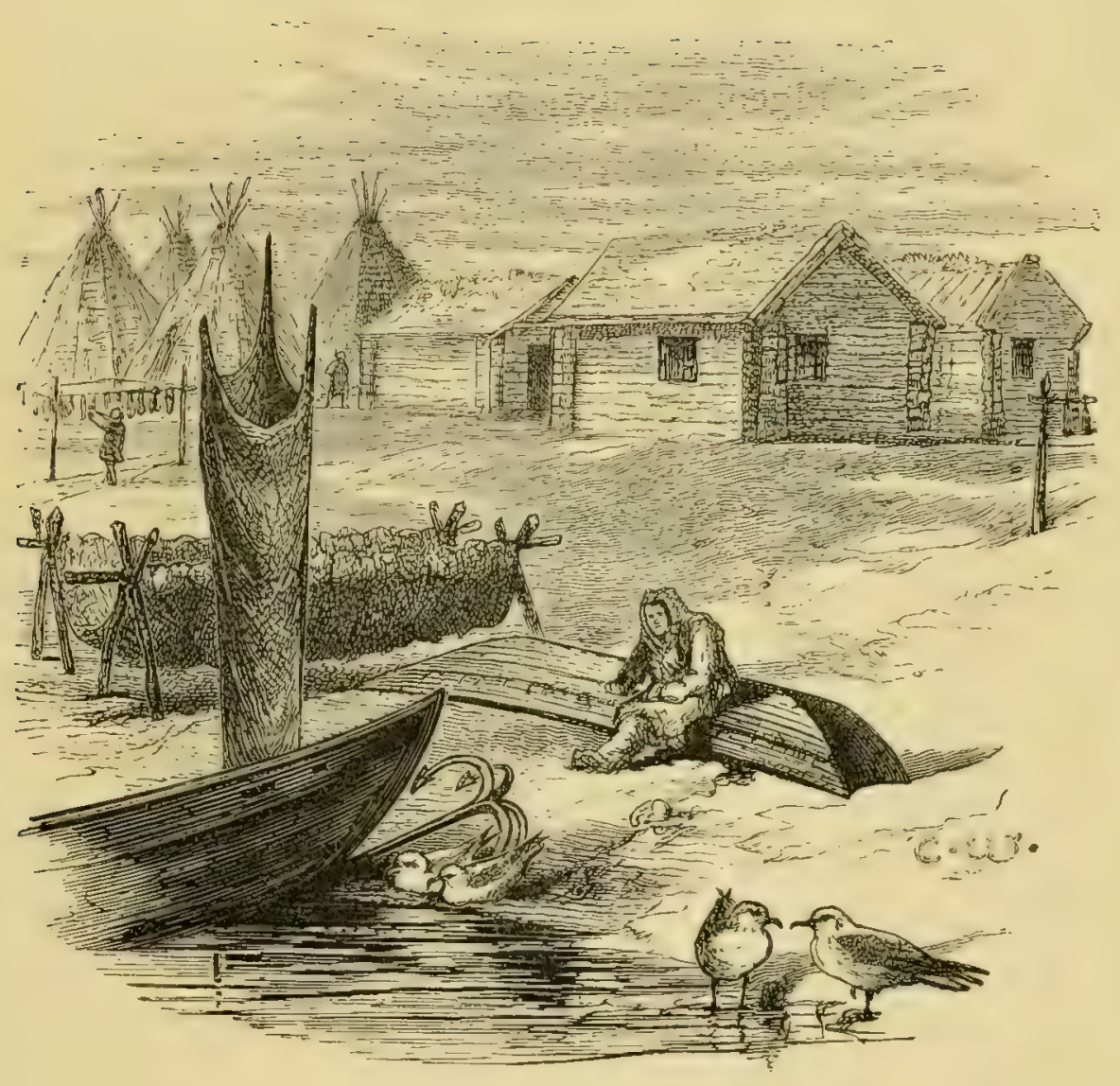




\section{Family PHASIANIDA, or GAME BIRDS.}

The Game Birds form a large and somewhat ill-defined group. Sclater places them between the Pigcons and the Rails. Forbes associated the Sand-Grouse and the Hemipodes with the Pigeons, the Plovers, the Gulls, and allied birds; whilst he placed the true Game Birds with the Cuckoos, the Bustards, aud the Rails. In the Game Birds the two notches on each side of the sternum are so deep that the exterior portion appears to have lost its character, the broad sternum appearing rery narrow and flanked by two lateral processes resembling abnormally developed ribs; but the sternum of the Sand-Grouse is exceptional in this respect, and somewhat rescmbles that of the Pigeons. The morlification of the cranial bones resembles that of the Pigeons, Sandpipers; Gulls, Auks, \&c. The pterylosis of the Game Birds is very specialized; but that of the Guinea-fowls and Grouse leads on through the Sand-Grouse to the Pigeons. Their myology, on the other hand, is very generalized, but shows affinities with the more highly developed muscular systems of the Sandpipers and other familics of Wader's. According to Gadow, their digestive organs are nearest allied to those of the Rails.

There is no family of birds in which there is more variation in the changes of plumage than in the Game Birds. The young are able to fly very soon after they are hatehed; and during the period of growth some of the quills are always being replaced by new feathers slightly larger than the old ones, so that, before the young bird has arrived at its full size, all the quill-feather's have been changed one after another three or four times orce, the last change taking place about the time when the autumnal moult of the parent birds occurs. In all Game Birds this antumnal moult is the only complete one that takes place, and it is not known that the Pheasant has any other. In the Partridges and Quails a partial spring moult, apparently confined to the feathers of the head and neck, takes place. According to Meves, the Black Grouse has a similar partial spring moult. It is not known that the Red Grouse has a spring moult; but its rery near ally, the Willow-Grouse, changes the colour of most of its small feather's in spring and moults them in autumu. Macgillivray says that the Ptarmigan has four nearly complete new sets of small feathers every year, the winter plumage being retained for nearly six months, the spring plumage being assumed in May. Incubation takes place in Jume; and from July to November a slow but continuous moult of the small feathers occurs, 
the summer, autumn, and winter plumages being successively assumed without any apparent interval between them.

The external characters of the Game Birds are very varied. Among the species in this family may be found birds of the most brilliant colours, and their heads are often adorned with caruncles, wattles, combs, and warty excrescences of the brightest tints. The hind toe is often small, sometimes absent, and when present always elevated above the plane of the others, whilst the toes are connected at the base by a membrane. The wings are generally very rounded and composed of ten primaries; but the tail is very variable in form, length, and number of feathers. The bill is short, curved, and wide at the base. The true Game Birds may be divided into several groups, respecting the importance of which authorities differ in opinion. Some of these have been raised by various ornithologists to the rank of orders ; others are constituted as families and subfamilies; whilst ornithologists who take a broad view of the subject treat them as genera. Of these, the Peacocks are only known in the British Islands in a domesticated state; the Pheasants are represented by at least one species, whose importation into this country dates so far back that it is now regarded as an indigenous bird; the Guinea-forls and Turkeys are only represented in our farmyards; the Partridges are indigenous to our islands, as are also the Grouse; but the Sand-Grouse can only claim to be British in consequence of the accidental appearance of numerous examples of one species which have visited our islands.

The young of Game Birds differ from the young of all the other birds hitherto mentioned in this volume in being born covered with down, able to see, and in a few hours to run and search for their own food.

There are about 270 species of Game Birds, which are distributed over the whole world with the exception of the Australian Region and South America, where they are represented by a somewhat nearly allied family, which differs in having the hind toe on the same plane as the others. Eighteen species are European, and three other's occasionally occur in Europe; of these, nine species are British, and one has visited our Islands.

\section{Genus SYRRHAPTES.}

The Sand-Grouse were included by Limmeus in his genus Tetrao; but in 1811 the genus Syrrhuptes was established for their reception by Illiger, in his 'Prodromus Systematis Mammalium et Avium' (p. 243). Pallas's Sand-Grouse being the only species mentioned by him, becomes of necessity the type.

VOL. II. 
The Sand-Grouse form a connecting-link between the Game Birds and the Pigeons*, but resemble the former in the important fact that the young are born covered with down and are able to run about and take care of themselves. In the shape of the bill, which is short and curves from the base to the point, they resemble the Game Birds; but their long pointed wings are similar to those of the Pigeons, as is also the sternum, the interior pair of notches on the posterior margin being very small. The tail is pointed, and frequently the two central feathers are very long; the tarsus is very short and is covered with feathers; the toes are also frequently covered with feathers, and the hind toe is always small and sometimes absent. The nostrils are almost entirely hidden by feathers.

There are about fifteen species in this genus, distributed over the southern portion of the Palrarctic Region and in the Ethiopian and Oriental Regions. Two species are found in South-west Europe, and a third occasionally migrates thither in winter and has wandered as fur as the British Islands.

The Sand-Grouse are essentially birds of the steppes, and prefer saltplains and sandy wastes. Their flight is straight and powerful, and they run on the ground with ease. They make no nest, but lay their eggs (which are usually three in number, and pale brown blotched with darker brown) in a slight depression in the sand.

* They are also a connecting-link between the Game Birds and the Plovers; but with our present ignorance of the relative value of structural characters in regard to classification, it is impossible to say to which of the three families they are most nearly allied. Dresser's statement, apparently prompted by his anxiety to show their relationship to the Pigeons, that the young of the Pintailed Sand-Grouse "are helpless, or, at least, unable to run," which he makes on the authority of Loche, is unsupported by evidence, and is evidently founded on a mistranslation.

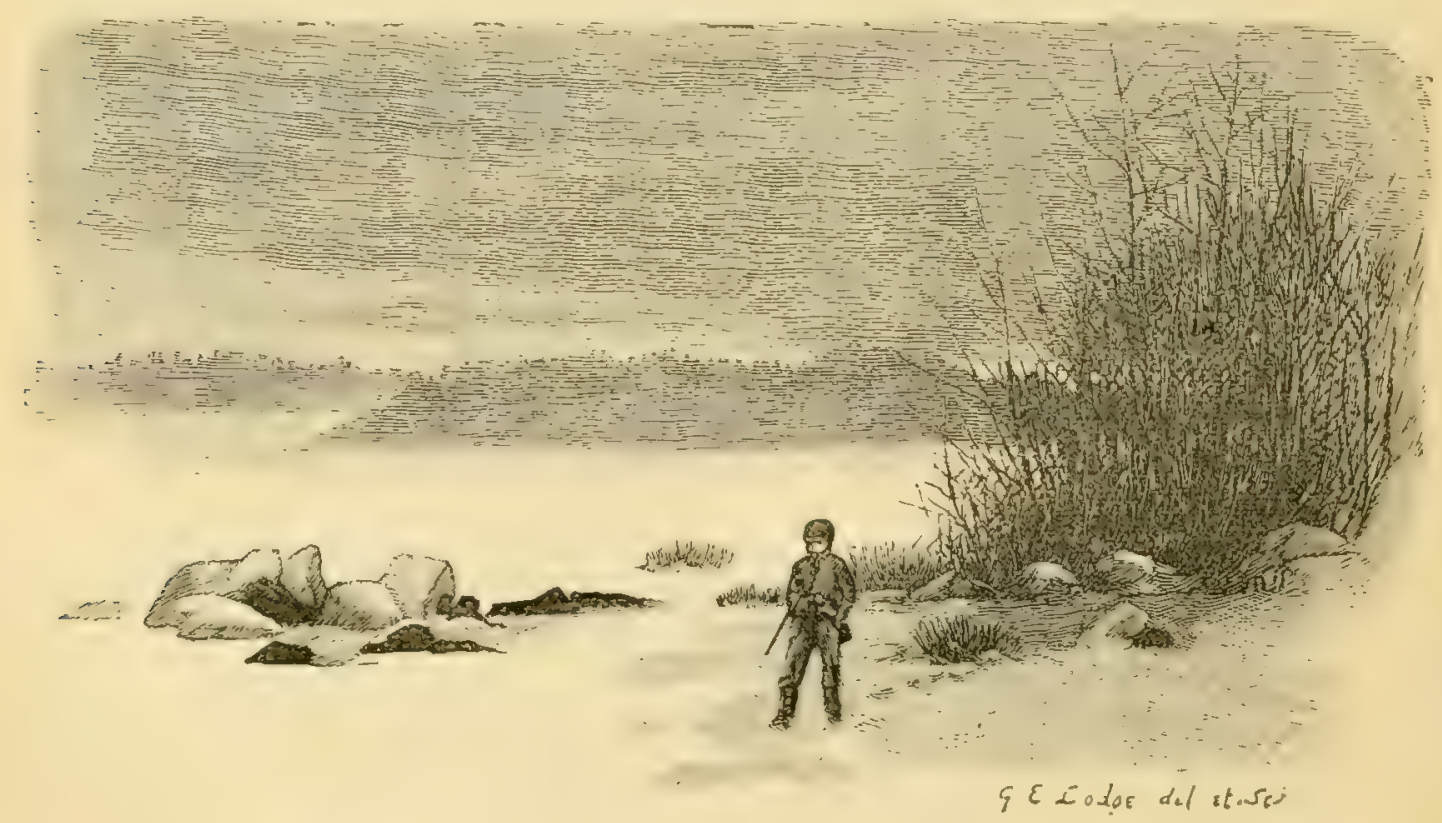




\title{
SYRRHAPTES PARADOXUS.
}

\section{PALLAS'S SAND-GROUSE.}

\author{
(Plate 20.)
}

Tetrao paradoxa, Pall. Reise Russ. Reichs. ii. App. p. 712, tab. F (1773); et auctorum plurimorum-Gmelin, (Radde), (Temminck), (Dresser), (Saunders), \&c. Syrrhaptes paradoxus (Pall.), Illiger, Prodr. p. 243 (1811). Syrrhaptes pallasii, Temm. Pig. et Gallin. iii. p. 28: (1815).

Heteroclitus tartaricus, Vieill. Nouv. Dict. d'Hist. Nat. xiv. p. 453 (1817). Syrrhaptes heteroclita, Vieill. Gal. des Ois. pt. iii.p. 64 (1834).

The first authentic occurrence of this A siatic bird in Europe was recorded by Moeschler in 1853 (Naumannia, iii. p. 305), who describes it as very rare in the neighbourhood of Sarepta, the well-known Mloravian settlement on the Volga, between the Kirghiz and Kalmuck steppes. In 1859 examples occurred at Wilna in Poland, near Hobro in Jutland, near Zandvoort in Holland, at Walpole St. Peters in Norfolk, New Romney in Kent, and near Tremadoc in North Wales (Newton, Ibis, 1864, p. 186). It is not known that this bird again visited Europe until 1863, when many hundreds, if not thousands, appeared. They seem to have wintered, as they often do, in the Kirghiz steppes; and from some cause or other they travelled due west, instead of east, and, passing through North Italy, the valley of the Danube, and Poland, found their way to the Pyrenees, various parts of France and Germany, Belgium, Holland, Denmark, South Sweden and Norway, and even Archangel. A large number passed Heligoland and arrived on almost every part of the eastern coasts of the British Islands, whence they spread inland to almost every county of Great Britain, a few reaching the Scilly Islands, North-west Ireland, the Shetlands, and the Faroes. They attempted to breed in many places, and several clutches of their cggs were obtained, especially on the sandy coasts of Denmark and Hollaud; but, as might be expected, they were soon exterminated by sportsmen, gamekcepers, and collectors of rare birds. Since that date the recorded occurrences of this bird have been few and far between. In 1872 a flock was observed in Northumberland early in June, and late in that month it is said that four birds were scen in the south of Scotland; but the only important occurrence in Europe was that observed by Henke (Ibis, 1882, p. 220). In 1876 great numbers bred on the Kirghiz steppes; and on the 4th of May in the same year an example was obtained at Modena, in J.taly (Giglioli, Ibis, 1881, p. 206).

The true home of Pallas's Sand-Grouse is in the centre of Asia. It breeds on the steppes of North-east Turkestan, Mongolia, and Dauria. In Mongolia it is a partial resident; but the birds breeding in North-east 
Turkestan migrate to West Turkestan in winter, occasionally straying as far as the Kirghiz steppes, between the Volga and the Ural rivers. In mild seasons the birds breeding in Dauria winter in the northern borders of the descrt of Gobi, in Mongolia, where a few remain to breed, but in severe seasons migrate south of this desert and sometimes reach North China.

The interest attaching to Pallas's Sand-Grouse in the eyes of the British ornithologist rivals that with which the Bohemian Waxwing is regarded. Both species have visited our islands in great numbers; but the Waxwing always appears in autumn, whereas the Sand-Grouse chooses spring for its visits. The Waxwings are driven from their usual winter-quarters by exceptionally heavy falls of snow, which bury their food-supply; whilst we may imagine that the Sand-Grouse, impelled to migrate by their hereditary instincts to the summer home of their youth, are sometimes forced in late and stormy springs either to breed in their winter-quarters or to seek new breeding-grounds in milder climates. It is possible, howerer, that the remarkable visits of the Sand-Grouse to Western Europe may have been only the result of blunders in the dircetion of migration; but the dates of their visits suggest the idea that they had visited or attempted to visit their usual breeding-grounds, and, finding thcir progress castwards barred by cold or snow, had changed their course. Most of the recorded visits of these birds to Europe are in May, and the great invasion in 1863 reached our shores during the last half of May; but Rarde says that they usually arrive at their brecding-grounds at Tarei-Nor*, in the extreme south of Siberia, before the end of March. On the day that the first flock arrived he states that the thermometer only reached $37^{\circ}$ at midday, and went down to $22^{10}$ (nearly $30^{\circ}$ below freezing-point!) at night. He found eggs in the middle of April, and saw young birds in the middle of May. They make no nest, but merely scratch a shallow hollow, about 5 inches across, in the salt-impreguated soil, though in some cases a little grass or a few sprigs of a saline plant are placed round the margin. Three is the usual number of eggs, though it is said that four are occasionally found. They are rcmarkably elongated in shape and are scarcely at all pyriform, in this respect resembling the eggs of the Pigeons. In their colour, which is strictly protective, they resemble much more the eggs of the Plovers, especially the Ring-Plovers. The ground-colour varies from olive-buff to brownish buff, the latter being the most commou. They are generally pretty evenly, but not very profusely, spotted with overlying markings of clark brown, and with paler and greyer underlying markings; these spots

* Tarei-Nor, or the lake of Tarei, is situated in the middle of the steppe of Kerbon, which lies due south of Nertchinsk, a town famous (or, rather, infamous) as the centre of the gold-and silver-mines in which the poor Russian exiles are condemmed to work. 
are irregular, sometimes almost fantastic in shape, and vary in size from that of a small pea to a mere speck. The eggs vary in length from $1 \cdot 8$ to $1 \cdot 6$ inch, and in breadth from $1 \cdot 2$ to $1 \cdot 1$ inch*.

These birds breed in small colonies scattered over the salt-plains; and on their arrival in spring they are generally seen flying in small strings or skeins. After the breeding-season has begun, as soon as the sun has risen high enough to make it safe to leave their cggss, they may be seen flying in pairs to drink on the margin of a lake, where considerable numbers often accumulate, but afterwards disperse to feed before returning to their nests. Tro broods are usually reared during the season; and the young are able to run and take care of themselves as soon as they are hatched. The female does not appear to be a very close sitter, but leaves her eggs on the approach of danger, as Plovers do, trusting to their protective colour for their security.

In the middle of the hot summer they may often be secn basking in the sun about noon, in small partics consisting of one or more pairs. They scratch a hole in the salty sand and lic slightly on one side, with puffed-out plumage, as is the custom of many other Game Birds. If disturbed, they utter a cry as they rise and fly away with great rapidity, thcir wings making a peculiar noise. The swiftness of their flight is said almost to surpass that of the Falcous. On the ground their short legs cause them to rum somewhat clumsily, with short steps, and with the body swaying from side to side as they feed.

The food of Pallas's Sand-Grouse consists principally of the sceds and young shoots of the peculiar plants that grow on the salt-plains. It is a very shy and timid bird and difficult of approach.

Prjevalsky writes:--" After their morning feed the flocks betake themselves to some well or salt-lake to drink, apparently preferring the fresh to the salt water. At the drinling-place, as well as at the feeding-places, these birds never settle on the ground without first describing a circle, in order to assure themselves that there is no danger. On alighting, they hastily drink and rise again; and, in cases where the flocks are large, the birds in front get up before those at the back have time to alight. They know their drinking-places very well, and very often go to them from

* It would be as absurd to base a classification of birds on their eggs alone, as it would be to do so on any other singlo character. The oology and myology, the nervous system and digestive organs, the pterylosis, the form of the stermum, and the modifications of the cranial bones may all be very important characters, but we are absolutely ignorant of their relative importance. No classification based upon one only of these characters can be of any value; but the fnct that the eggs of the Sand-Grouse and the Hemipodes differ from those of Game Birds in haring two sets of spots (underlying as well as surfice), but agree with the Plovers in this respect, is an argument, as far as it goes, for regarding the Saud-Grouse and Hemipodes as moro nearly allied to the Plorer's than to the Game Birds. 
distances of tens of miles, especially in the mornings between 9 and 10 o'clock; but after 12 at noon they seldom visit these spots."

In autumn they collect into large flocks, which, if the winter be mild, remain at no great distance from their breeding-grounds; but a heavy fall of snow will often compel them to migrate to greater distances. Swinhoe says that in North China they are sometimes caught in great numbers by the natives, who clear the snow from a patch of ground, into which they tempt the Sand-Grouse with small green beans, occasionally capturing a whole flock in their clap-nets. The note of this bird is described as a rather melodious chuckle, which is uttered both on the wing and on the ground.

The general colour of the upper parts of the adult male of Pallas's SandGrouse is sandy buff or isabelline; the back, scapulars, innermost secondaries, rump, and upper tail-coverts, the two centre tail-feathers, and the inner webs of the remainder are transversely barred with very dark brown. The primaries are lavender, with black shafts, and the secondaries are dark brown on the outside webs and pale buff on the inside webs, as are also the primary-corcrts; the outer webs of the tail-feathers, except the two centre ones, are narrowly edged and broadly tipped with buff. An obscure ring round the neck and the ear-coverts are yellowish orange. The general colour of the underparts is sandy buff, paler on the chin, thighs, and under tail-coverts. The feathers of the upper breast have narrow dark-brown tips; the lower breast and belly is dark brown; the axillaries are buffish white, tipped with brown. Bill and claws brown; irides dark brown. The female differs from the male in having the barring on the back more obscure and extending onto the hind neck and crown; the yellowish orange on the head and neck is paler, and bounded on the throat with a black margin; the dark band across the breast is entirely absent; and the outside primaries and centre tail-feathers are not so elongated. The young male has the barring on the back intermediate between that on the adult male and female; but in other respects it resembles the female.

Pallas's Sand-Grouse is a very highly specialized bird. The first primary in each wing and the two centre tail-feathers are prolonged into a very fine point in an extraordinary manner. The toes, which are feathered on the upper surface as well as the tarsus, are united together into a broad pad, ornamented with three claws and granulated underneath.

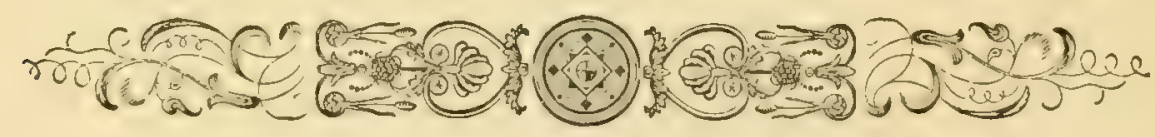




\section{Genus TETRAO *:}

The genus Tetrao was included by Linnæus in 1766 in the twelfth edition of his 'Systema Nature' (i. p. 273). The Capercaillic has by common consent been regarded as the type.

The Grouse may be distinguished by their feathered tarsi and the absence of spurs. The wings are short, rounded, and very convex, and the nostrils are covered with short feathers.

This genus contains about twenty species, which are confined to the Palæaretic and Nearctic Regions. Six species are European, of which four are British.

The birds in this genus frequent mountains, moors, and forests. They are more or less gregarious in autumn and winter. They run and walk on the ground, and several of the species perch freely in trees; their flight is swift, and performed with rapid beatings of the wings, and when they rise they make a whirring sound. Their notes are harsh. Their food consists of insects, fruits, berries, sceds, grain, tender shoots, and buds. Some of the species are monogamous, others polygamous. Their nests are slight, placed under the shelter of small bushes or amongst heath, and their eggs are numerous.

* Brisson in 1760 divided the genus Tetrao of the first edition of the 'Systema Naturæ' of Linnæus into two genera, Lagopus and Perdix; but in 1766 Linnæus reunited them in his twelfth edition under the old name. The genus Layopus, of which the Willow-Grouse is the type, can only be considered additional to that of Linnæus by maling some other bird the type of the Linnæan genus. The first ornithologist who subdivided the Linnæan genus Tetrao was probably Latham, who in 1787 (Gen. Syn. Suppl. i. p. 290) adopted Brisson's genus Perdix for the Partridges. The Ptarmigan appear to have been first elevated to the rank of a genus by Leach in 1816 (Syst. Cat. Mamm. \&c. Brit. Mus. p. 27), who adopted Brisson's genus Lagopus for them. As the Black Grouse is the only Tetrao mentioned by Leach, it might be argued that he assigned this bird as the type; but as there seems to be some doubt on the question, I prefer to regard the Wood-Grouse as such, because it has been so considered by the majority of writers. Under these circumstances the genus Lagopus of Brisson becomes additional to the genus Tetrao of Linnæus; and the Willow-Grouse, his Lagopus lagopus, must be regarded as the type if this genus be recognized. 


\section{TETRAO MUTUS.}

\section{COMIMON PTARMIGAN.}

(Plate 20.)

Tetrao mutus, Montin, Physiogr. Sällsk. Handl. Lund, i. p. 155 (1776-86); et auctorum plurimorum-(Gould), (Degland \&. Gerbe), (Dresser), (Saunder's), \&c.

Tetrao lagopus, Linn. apud Lath。Gen. Syn. Suppl. i. p. 290 (1787).

Lagopus mutus (Montin), Leach, Syst. Cat. Mamm. \&c. Brit. MIus. p. 27 (1816).

Tetrao alpinus, Nils. Orn. Succ. i. p. 311 (1817).

Lagopus vulgaris, Vieill. N. Dict. d' Hist. Nat. xvii. p. 199 (1817).

Tetrao montanus, Brehm, Lehrb. eur. Vög. i. p. 448 (1823).

Attagen montanus (Brehm), Kaup, Syst. Nat.pp. 170-177 (1829).

Lagopus montanus (Brehm), Brehm, Vög. Deutschl. p. 516 (1831).

Lagopus alpina (Nils.), Nits. Skand. Faun. ii. p. 98 (1835).

Tetrao rupestris, Gmel. apud Jenyns, Man. Brit. Vert. Anim. p. 171 (1835).

Lagopus cinereus, Macgill. Hist. Brit. B. i. p. 187 (1837).

The Common Ptarmigan is a bird of the tundra; and in the British Islands is confined to those moors in Scotland which lie above the limit of forest-growth. These localities are principally in the Highlands, and extend to the Outer Helrides; but the Ptarmigan breeds ou the mountaintops as far south as the island of Arran. Its reputed occurrences in Cumberland and Wales appear to be myths. It does not occur on the Orliney or Shetland Islands.

The Ptarmigan is a circumpolar bird, breeding on the tundras of Europe, Asia, and America, above the limit of forest-growth as far north as land extends, and in a similar climate at high elevations further south. In Europe, south of the Arctic circle, it breeds above the willow-and birchregions in the Dovre fjeld, on the outskirts of perpetual snow in the Pyrenees, in the rhododendron region of the Alps, and on the Ural Mountains wherever they rise too high for the growth of the millow and the birch. In Asia, besides frequenting the shores of the Aretic Ocean, it probably occurs on all the high mountain-ranges of Southern Siberia. Finsch obtained it in the Chinese Altai range at an elevation of 6000 feet; Dyborsky and Radde found it on nearly all the mountain-ranges round Lake Baikal at an elevation of about 9000 feet; Captain Blakiston has sent me an example from the main island of Japan, obtained about 9.250 feet above the level of the sea; and Mr. Snow found it breeding on one of the northernmost of the Kurile Islands. In America it is found from Alaska to Greenland above the limit of forest-growth, and in the northern portion of the Rocky-Mountain chain as far south as lat. $55^{\circ}$. It is also found on Iceland, Spitzbergen, and Nova Zembla. 
On the Rocky Mountains south of lat. $63^{\circ}$ it is found, together with a nearly allied and probably distinct species, Lagopus leucurus, distinguished by having the tail white at all seasons of the year. The range of this specics extends southwards throughout the Rocky Mountains, and on their western spurs in British Columbia and the Washington Territory. Intermediate forms, however, with more or less white at the base of the tail, occur on the Pyrenees, and were shot by Captain Feilden about lat. $82 \frac{1}{2}^{\circ}$ in Grinnell Land, and are said to be the only variety on Spitzbergen. The latter might fairly claim to be regarded as a subspecies, under the name of $L$. mutus var. hemileucurus, on the ground of their larger size. Examples from Spitzbergen vary in length of wing from 8.9 to 8.6 inch, whilst the typical form only measures from $7 \cdot 9$ to $7 \cdot 2$ inch. European examples, which must be regarded as the typieal form, are apparently in the adult male much darker-coloured, especially on the breast, in spring plumage than those from other localities; but no difference can be discovered in the autumn plumage or in that of the female. Scotch cxamples are said to be intermediate in this respect. None of the examples that I have secn in spring plumage, obtaince in Iceland or within the Arctic circle in either the Old World or the New, have the dark breast; they may be distinguished as L. mutus var. rupestris. Of the South-Sibcrian and Japanese birds I have not been able to see males in spriug plumage, and am therefore unable to say to which form they belong.

The haunts of the Ptarmigan in our sonthern latitudes are on or near the summits of the highest mountains, in a region where solitude and rocks are the predominant features of the scene. MIany of these summits are somewhat barren plateaux strewed with stones, and studded here and there with large boulders, but abounding with ground-fruits of various kinds, though in some places large patehes of suow are always to be found in the hollows. The plumage of the Ptarmigan in summer so closely resembles surrounding objects that the traveller may often wander through a flock of them without knowing it; whilst in winter, when the mountaintops are deep in snow, the white plumage which it assumes at that scason is its principal shield from its numerous encmies. Many of the habits of the Ptarmigan closely resemble those of the Red Grouse. Like that bird it is fond of perching on the large boulders. Its mode of progression, its food, and its monogamous habits are also very much the same. The Ptarmigan only uses its wings when absolutely compelled, and always strives to elude pursuit by running or crouching low and motionless amongst the rough broken ground. Its flight is so rapid that even the Peregriue or the Arctic Falcons are often hard pushed to fly it down. The note of the Ptarmigan is not so loud and clear as that of the Red Grouse, and is said to rescmble the croaking of a frog uttered in a low tone. 
The food of the Ptarmigan is almost exclusively composed of vegetable substances, such as the seeds, buds, and tender shoots of mountain-plants, especially the heath and ling. This fare is varied in autumn with berries of various kinds and ground-fruit. Macgillivray says that the Ptarmigan picks up a quantity of quartz to aid in the digestion of its food, and that it breaks off the twigs or picks the buds and shoots until it has accumulated a large quantity, just like a grazing animal, and then goes off to a suitable spot to rest and slowly digest the food it has gathered.

Ptarmigan pair very early in the spring, and each couple retire to seek a nesting-place. The nest is very slight, and consists of a little hollow, either scratched out by the bird, or a ready-formed depression in the soil, which is lined with a few twigs, a little withered grass, and sometimes a few feathers that probably drop from the parent's plumage. In this scanty nest the female deposits from eight to ten or even twelve eggs, which are usually laid early in May, but sometimes not until the end of that month if the season be backward. They vary in ground-colour from dirty white to rich brownish buff, and are spotted, speckled, and blotched with rich chocolate-brown. All the markings are on the surface, no grey underlying ones being traceable; the spots and blotches only vary in intensity of colour, the largest being generally the darkest. They vary in length from 1.8 to 1.65 inch, and in breadth from 1.26 to 1.15 inch. The eggs of the Ptarmigan may generally be distingujshed from those of the Red Grouse by their much buffer ground-colour, which is all the more conspicuous from the eggs being less profusely spotted. The female Ptarmigan does not sit very closely, as if well aware that her eggs will reccive protection from their colour in her absence. The young birds are able to run about and follow their parents as soon as they leave the shell, and even at such an early period of their lives are well able to escape from enemics. When menaced by danger the old birds will often flutter along the ground in an cxcited way, and the brood scatters, each little chick making off to some convenient place, where it remains, motionless as the stones amongst which it is crouched, until the cause of alarm has gone.

Ptarmigan gather into flocks much earlier than Red Grouse, often as soon as the end of July. During the greater part of the year these flocks reside on the highest parts of the mountains; but in winter, especially in very stormy weather, they come lower down the hill-sides. Although these flocks are very wary, they often allow the sportsman or the shepherd to come close to them ere they take wing. When alarmed they often fly from the particular haunt from which they were disturbed, aud cross the intervening valley to another mountain-top, perhaps more than a mile away. They fly in a scattered manner, and do not rise en masse, but one or two at a time, to the no small astonishment of the observer, who canuot detect a single bird until they rise almost at his feet, 
or here and there in the immediate vicinity of where he is standing. Ptarmigan appear to be subject to the same disease as Red Grouse; but it is not nearly so widely spread nor so disastrous in its results, probably because the Ptarmigan is not so highly protected or its natural enemies destroyed to such a great extent.

The Ptarmigan in winter plumage is pure white, with the exception of the tail-feathers, which are black with narrow white tips. The male has also the lores and a stripe behind the eye black. Bill and claws blackish brown; irides hazel; above the eye there is a dull scarlet wattle, which increases in size and brilliancy during spring. The white plumage of the wings, outer wing-coverts, lower breast, belly, and the under tail-coverts is for the most part retained until it is renewed in autumn, though many of the white feathers of the underparts are often replaced in summer by coloured feathers. The rest of the plumage appears to be gradually moulted twice before the final autumn moult, the spring feathers being gencrally nearly black, with buffish-brown vermiculations, and those of autumn pale grey with black vermiculations. The change of feathers proceeds so slowly that the summer moult begins before the spring moult is complete, so that it is impossible to obtain a bird in full spring or summer plumage. The female retains the white on the quills and outermost wing-coverts only, the ground-colour of all the rest of the feathers, except that of the tail, being buff, transversely barred with semi-confluent black bands, and tipped with nearly white, a plumage which appears to be retaincd until the autumn moult. In birds of the year, after their first spring moult *, the small feathers are very much vermiculated with buffish brown; but the black becomes more and more predominant cvery year, until in very old birds the buffish brown almost disappears from the back and breast. In winter the toes are protected with thick feathers reaching halfway down the claws; but in summer the fore half of the toes is almost bare. Young in down are very similar to those of the Red Grouse.

* It is not certain that the spring plumage is obtained by a moult. It is possible that the white feathers gradually change colour in spring, only those being moulted which, by accident during winter, have been so injured that they have lost the power of changing colour. Willow-Grouse kept in confinement are said to change from the white winter dress into the brown summer dress without moulting more than ten per cent. of their feathers; and early spring examples of this species show white feathers with brown bases, and brown feathers with white tips, apparently proving that the change of colour begins at the base of the feather.

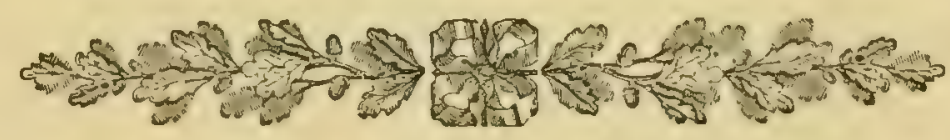




\section{TETRAO SCOTICUS.}

\section{RED GROUSE.}

(Plate 20.)

Lagopus bonasa scotica, Briss. Om. i. p. 199 (1760).

Tetrao scoticus, Lath. Gen. Sym. Suppl. i. p. 290 (1787); et auctorum plurimorum -Temminck, (Vieillot), (Degland \& Gerbe), (Dresser), (Saunders), \&c.

Tetrao lagopus, var. $\gamma$, Gmel, Syst. Nat. ii. p. 750 (1788).

Lagopus scoticus (Briss.), Leach, Syst. Cat. Mamm. \&c. Brit. Mus, p. 27 (1816),

Oreias scoticus (Briss.), Kaup, Natïrl. Syst. p. 177 (1829).

Tetrao saliceti scoticus (Briss.), Schlegel, Rev. Crit. pp. lxxvi, 89 (1844).

The Red Grouse, or, as it is locally called, the Moor-fowl, Brown Ptarmigan, or Gor-cock, is, par excellence, the national bird of Great Britain, being the only species which is only found in the British Islands. It is a resident bird, and is found on all extensive moorlands throughout Great Britain aud Ireland, except in those counties of England which lie south or east of a line drawn from Bristol to Hull. It is found throughout the Hebrides and the Orkneys, but does not occur on Shetland. On the continent the Red Grouse is represented by the Willow-Grouse (Tetrao allus), which differs from its British ally in assuming, like the Ptarmigan, a white winter plumage, which is retained on the primary and sccondary wing-feathers at all seasons of the year. The Willow-Grouse is a circumpolar bird, inhabiting the arctic tundras of Europe, Asia, and America above the pine-regions*; but, unlike its British representative, it is very fond of perching in trees, especially preferring to roost in them, and is only found where birch or willows occur.

The Red Grouse is confined to the moors, which are hilly tracts of country, for the most part peat and rock, the former profusely covered with ling. They abound in springs, which form mountain-streams in the lower gorges, or produce bogs in the wider valleys and plateaux, where the ling is often overpowered with a rank growth of rushes, carices, and coarse grasscs. The rocks are often millstone grit, and sometimes are huge isolated masses, but in Yorkshire generally appear as a range of perpendicular cliffs locally called "edges." The peaks and ridges above these

* Howard Saunders has an example of this bird from the Caucasus. The evidence in favour of its having been shot in the district, and not been imported in a frozen state from the north, appears to be incontestable, were it not for the fact that the alleged date can scarcely be true. It is labelled May; but as many of the white feathers are in the pen, it must have been killed in late autumn. 
cliffs sometimes rise to an elevation of two thousand feet above the level of the sea. The moors are interspersed in many parts with narrow winding valleys, locally called "groughs," where you may often get a chance shot at a Grouse when you have learnt where to look for him. Nothing is more delightful than to stroll up these "groughs" in spring, on the edges of the streams which generally run down them. The sloping banks are a favourite breeding-place of the Ring-Ouzel; sometimes a chance Black Grouse nests in a quict corner; the Twite is generally to be seen, and, strange to say, the Grasshopper Warbler may often be heard. In the lower ground you may often flush a Snipe; and as you emerge from the "grough" on the higher plateaux you are not unlikely to come upou a Curlew or a party of Golden Plovers, and if you are lucky you may drop upon their nests. In early spring you may chance ou a small flock of Dotterel resting on the hills during their migrations, but the Red Grouse remains always the bird par excellence of the moors.

Of course these moors are very strictly preserved; and the only way to ornithologize upon them with any comfort is to make friends with the gamekeeper. These men are generally very zealous in looking after their employer's' interests, and are indefatigable in pursuing trespasser's and hunting down all sorts of vermin. Weasels, Stoats, Magpies, and Jays are trapped and ignominiously nailed to the rail or fastened to the wall which forms the gamekeeper's museum of trophics. They undoubtedly deserve their fate, if the sucking of the eggs or the devouring of the young of the sacred Grouse constitutes a capital crime. The Carrion-Crow and the Rook are perhaps greater criminals; but their extra cunning enables them to escape their due share of punishment. When the young Grouse begin to run, the Sparrow-Hawk, the Merlin, and occasionally a Harrier are special objects of the gamekeeper's care. The greater number of these Hawks are shot off every year, generally when they have young of their own and can be more easily approached within gunshot; but every spring brings a fresh supply. The gamekceper's museum would, however, be but thinly stocked with Hawks, did he not eke out their number with a goodly row of Kestrels, and with such birds as Cuckoos and Nightjar's. It is melancholy to contemplate the wholesale slaughter of these innocent and charming birds.

The Red Grouse is an early breeder and is strictly monogamous, each male pairing with a female and assisting her to l'ear the young. In the sheltered lower grounds eggs are occasionally seen before the end of March; but on the high grounds I have frequently seen eggs unhatched in June. In some seasons a sudden fall of snow has been known to cover the ground to such a depth that the poor Grouse have been unable to find their nests; and after such storms the gamekcepers pick up cggss here and there, which, as they express it, have been "laid wide." The situation of 
the nest varies. It is always placed on the ground, usually in the long heather, often near a clump of very tall ling or near a protruding rock. The edge of a patch of moor where the heath has been burnt off a year or two previously is a favourite place, and an oasis of heather which has escaped the general conflagration is a still more likely locality to find the nest of a Grouse. The motives which guide them in their choice of a site for their nest seem to be merely the selection of a place where the bird and egrgs will be concealed and sheltered by the long heather, and one that can easily be recognized by themselves. The Red Grouse can scarcely be said to make a nest; it merely scratches a slight hollow in the ground, and such materials, twigs of heather, dry moss, or grass, leaves, \&c., as happen to be on the spot are allowed to tumble in as lining. The Red Grouse has never been known to cover its eggs before leaving the nest, as the Pheasant and Partridge are in the habit of doing.

The number of eggs laid by the Red Grouse secms to vary with the propitiousness or otherwise of the season. In very wet and cold springs the smallest clutches contain four or five, and the largest eight or nine, whilst in very favourable seasons the small clutches are six or seven, and the larger ones from ten to twelve, or even fifteen and seventeen; but in the latter cases it is probable that the eggs may not all be the produce of one bird. In an average year most nests will contain seven or eight eggs. Birds which breed late on the high grounds do not seem to lay fewer eggs than those which breed early in the more sheltered situations. The sitting bird does not easily forsake her eggs. You may watch her daily as she sits upon them; you may even catch her eye without frightening her away. You may send her off cok-cok-cokling in alarm, by accidentally almost stumbling over the nest; and you may handle the eggs without much danger of causing her to "forsake." Gamekeepers are always very anxious to impress upon trespassers the fact that it is of the utmost importance not to disturb the birds during the breedingseason. The real truth is, that if strangers were allowed on the moors at this season of the year, the danger would be, not that the birds would forsake the eggs, but that the eggs would forsake the birds.

The eggs are not subject to much variation; they are usually 1.75 inch in length and 1.32 inch in breadth, and of an almost uniform oval shape, the smaller end being scarcely more pointed than the larger. Exceptions to this rule are, however, occasionally met with. Towards the end of May 1864 or 1865 (I remember it was Derby-day) I found a nest of Grouse during a heavy snowstorm, containing five eggs, which would probably have hatched the following day; they measured 1.82 inch in length by 1.22 inch in breadth, and, as might be expected in eggs that were longer and narrower than usual, were much more pointed at the small end than is usually the case. The ground-colour of the egg is 
usually a pale olive, spotted and blotched all over with dark red-brown. The spots are frequently so confluent as almost entirely to conceal the ground-colour. In fresh-laid eggs the brown is often very red, in some instances almost approaching crimson; it appears to darken as it thoroughly dries, and sometimes almost approaches black. When fresh laid the colour is not very great; and before the eggs are hatched the beauty of the original colouring is generally very much lessened by large spots coming off altogether, no doubt from the friction of the feathers or feet of the bird when sitting. If the weather is wet when the bird begins to sit, this is much more the case. When the colour has once become thoroughly dry, it will bear washing in water without injury. The colour of the eggs is admirably adapted for the purpose of concealment from the prying: eyes of Rooks, Crows, and Birds of Prey, being very much like the mixture of moss, lichens, and peat where they are laid. It is impossible to distinguish the eggs of the Red Grouse from those of the Willow-Grouse; but those of the Ptarmigan are more sparsely marked and much buffer in general appearance. Most of the eggs laid come to maturity. I' once asked a gamekeeper to watch half a dozen nests which were near his house. He told me that out of forty-nine cggs he counted forty-seven chicken Grouse.

As soon as the young are hatched, especially in dry seasons, the hen takes her brood down to the more swampy parts of the moor. The Red Grouse remains paired all the year round; and whilst the hen is sitting her mate is generally not far off, to give the alarm by flying away at the approach of supposed danger, uttering his loud kok, kok, kok, to which the female replies with a low hoarse croak.

The note of the male is heard to the greatest advantage in early morning in spring; it is then modulated in various ways, each note sometimes being long drawn out and frequently very rapidly repeated. The cock may usually be discerned through the early morning mist perched upon some conspicuous hillock, from which he will spring up into the air and descend again to the same spot. His note will be answered by many females, and his actions generally are somewhat similar to those of the polygamous species of Grouse, though it is not known that he pairs with more than one hen. It appears that the cock does not take his turn at the duties of incubation; but when the young are hatched both parents wait upon them.

The food of the Grouse is chicfly the flowers and young shoots of the ling; but the capsules of carices are also found in their crop. Were it not for the sportsman the Grouse would live a very quiet life on his native heath, as much so as the poultry on the farms in the valley. He does not migrate in spring or autumn, and his wanderings are confined to an occasional raid into the nearest farms when food is scarce, where he will 
subsist un grain, especially oats. In the autumn Grouse feed largely on the berries and fruits found on the moors. In very severe and long-continued frost and snow I have known isolated instances of Grouse being caught in the streets of Sheffield. The Red Grouse is not generally a conspicuous birl ou the moors. You may often drive for miles without sceing more than one or two. During the evening three or four may often be scen sitting on a stone wall, and sometimes much greater numbers; but for the most part they live upon the ground, though they are oceasionally seen perehed in the stunted birches and hawthorns on the edge of the moors. When fecding, they are very wary birds; and if alarmed they will stretch out their necks, their heads appearing like so many suakes above the heather. They are very fond of perching on large boulders, and frequently dust themselves, delighting to bask in the sun.

Grouse-shooting begins on the 12th of August. In average seasons there are at that date no "cheepers" (birds whose parents have been disturbed in their first nests and have bred again); and few of the young birds are so strong on the wing as to prevent the second-rate shots from making a bag. For the first few days Grouse are shot over dogs-pointers or setter's. A good shot on a good moor will bag his twenty-five to thirtyfive brace the first day; but enormous quantitics are sometimes shot $*$ In a short time the birds become very wild, generally rising beyond range; they also "pack" on the high grounds, especially before stormy weather. 'The Grouse-shooters then resort to driving. 'The gumners are partially concealed in erections made of turf, and the birds in the next valley are driven by the gamekecper's and their assistants over the brow of the intervening hill; in the thick of the drive the shooting is fast and furious, and large bags are sometimes made. Grouse-driving is excellent sport for the mere marksman, requiring a very quick hand and a very accurate eye; the birds fly towards the butts like arrows from a bow, and are out of shot almost before the echoes of the keeper's m-ull-a-rk have died away. The flight of the Grouse is generally near the surface of the ground, and it often glides or skims for a considerable distance with motionless wings. If much persecuted, large flocks of Grouse may sometimes be seen high in the air crossing over deep valleys from one moor to another.

Grouse are subject to an epidemic disease, which generally appears in spring, when the birds are sitting; they become thin and out of condition

* Of late years the noble sport of Grouse-shooting has degenerated, in too many instances, into wholesale slaughter. Instead of shooting a ferw brace for themselves or their friends, as sportsmen used to do in the good old days, too many owner's or renters of moors degrade themselves to the level of bird-butchers. 'Their only object seems to be to obtain as big a bag as possible, for the unsportsman-lize object of turning it into money, or the vulgar pleasure of seeing their names at the head of a long figure in the newspaper's. 
and are frequently picked up dead. The cause of this discase has given rise to much controversy. The birds which have died of it are frequently found, when dissected, to be infested with a small parasitic worm in the intestines. Some sportsmen maintain that these parasites are the cause of the weakness and subsequent death of the Grouse; others, on the other hand, assert that the abundance of parasitic worms is only a symptom of, and caused by, the diseased state of the bird. Grouse, in common with other animals, are subject to the attacks of two parasitic worms. The long species of worm does not appear to be particularly injurious: so far as I have been able to learn, it attacks principally the young birds. It is not an uncommon thing on the Sheffield moors to shoot fine plump young Grouse with four or five inches of tapeworm hanging from them. The cause of the prevalence of these most injurious parasites is probably insufficient or improper food. In early spring (i.e. during the breedingseason) Grouse seem to require the young shoots of the heather to keep them in a healthy condition. It sometimes happens that these young shoots or buds are nipped by a late frost, which turns them brown; it has been frequently observed that upon moors where such has been the case Grouse-disease has soon made its appearance. Upon some moors this disease has doubtless been caused by the young shoots of the heather having been eaten off by sheep, so that there has not been sufficient left for the Grouse. On other moors the same result has happened from an overstocking of the birds themselves. It is obviously of great importance to the health of the birds that the moors should neither be overstocked with Grouse nor sheep. The preserving of Grouse is a more artificial arrangement than it at first sight appears. It is true that we thin them pretty effectually during some months of the year after the 12th of August, when the chance of scarcity of food is over. Nature's Grouse-shooting, on the other hand, begins some months earlicr. Before the spring food has scarcely made its appearance, she sends her migratory Hawks to the moors. Should any disease show itself because the Grouse were too numerous for their supply of food, the birds of prey would doubtless soon stamp it out, removing at once cause and effect by destroying the sickly birds, which would naturally be the easier prey. Some gamekeepers assert that Grouse-disease is an affection of the liver, caused by long-continued cold and rainy weather in spring; but the probability is that the seat of the disease, where such exists, is rather in the lungs. The year 1873 was a bad one for Grouse on the Shefficld moors. Towards the end of May a great many dead birds were picked up in an emaciated condition. Some of these were carefully dissected by Mr. B. Cartledge, a well-known veterinary surgeon in the town, who pronounced the cause of death to be in all cases chronic inflammation of the lungs. Many of them had the

VOL. II. 
long taperrorm in the intestines; but he did not detect the smaller parasitic worm.

The Red Grouse has often been kept in confinement, and has even been known to breed under such conditions. Hybrids between the present species and other game birds are extremely rare. It has been known to interbreed with the Black Grouse, and possibly with the Ptarmigan.

The general colour of the adult male Red Grouse in spring plumage is chestnut-brown, most of the feathers being barred, vermiculated, and speckled with black. There are obscure indications of a moustachial stripe; the axillaries and under wing-coverts are nearly white; and the feathers on the belly, legs, and feet are grcyish white. Bill and claws brownish black; irides hazel; over cach eye is a brilliant scarlet wattle. In the female the chestnut-brown is replaced by buffish brown, and the wattles over the eye are much smaller and duller in colour. The autumn plumage scarcely differs from that of summer; but birds of the year may be distinguished by the pale tips to most of the feathers, causing them to appear much more distinctly spotted. Young in down are buffish yellow mottled with chestnut-brown.

There is considerable individual variation in the colour of the plumage in this species; and many writers have endeavoured to show that this variation is local; but the balance of evidence in this, as in many other similar cases, is in favour of the supposition that we are dealing with climatic and not geographical races.

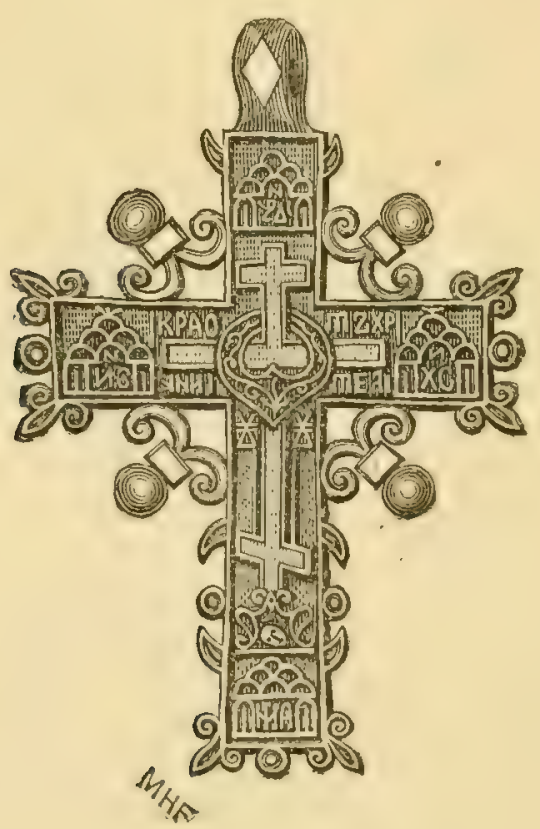


BLACK GROUSE.

\section{TETRAO TETRIX.}

\section{BLACK GROUSE.}

(Plate 20.)

Lagopus urogallus minor, Briss. Orn. i. p. 186 (1760).

Tetrao tetrix, Linn. Syst. Nat. i. p. 274 (1766); et auctorum plurimorumLatham, Temminck, Naumann, Dresser, Saunders, \&c.

Urogallus tetrix (Linn.), Kaup, Nat. Syst. p. 180 (1829).

Lyrurus tetrix (Linn.), Swains. Faun. Bor.-Amer. p. 497 (1831).

Tetrao juniperorum, Brehm, Vög. Deutschl. p. 509 (1831).

Lyrurus derbianus, Gould, Proc. Zool. Soc. 1837, p. 132.

Tetrao derbianus (Gould), Gray, Gen. B. iii. p. 516 (1845).

The Black Grouse formerly inhabited the whole of Great Britain wherever suitable localities were to be found; but in many of these, especially in the south and east of England, it has been exterminated, though in some it has been successfully re-introduced. It is not found on the Orkneys or the Shetland Islands; nor, strange to say, in any part of Ireland, though attempts have been made to introduce it into all these localities. There is no record of its occurrence on any of the Outer Hebrides or the Channel Islands.

The Black Grouse inhabits the pine- and birch-forests of Europe and Siberia. There is no record of its occurrence on the Faroes or Iceland. In Scandinavia its range extends as far north as lat. $69 \frac{1}{2}^{\circ}$; but in Russia and West Siberia, as far east as the Yenesay, it scarcely reaches lat. $68^{\circ}$; and in the valley of the Lena it does not exceed lat. $63^{\circ}$. The occurrence of this bird in North Siberia cast of the latter valley is very doubtful. Throughout Central Europe and Southern Sibcria it is found in suitable localities as far south as the Alps and the northern Apennines. Its occurrence in the Pyrenees appears to be doubtful. In the valley of the Danube it is almost exterminated, and appears to be absent altogether from the extreme south of Russia, being replaced in the Caucasus by an allied but perfectly distinct species. It is found at an clevation of from 6000 to 10,000 feet in North-eastern Turkestan, and is very common in South Siberia, extending eastwards in the valley of the Amoor as far as the river Ussuri, and southwards up the tributaries of the Amoor into Mantchooria *, thus nearly, but not quite, reaching the shores of the Pacific.

* Dresser, in his 'Birds of Europe,' says that Swinhoe says that Père Darid says that the Blick Grouse occurs in North China. Saunders, in his continuation of Nerton's 'Yarrell,' also says that it occurs in North China, without quoting any authority. David 
The Black Grouse of the Caucasus (T.mlokosiewiczi), already mentioned, differ's in being somewhat smaller, in having a different-shaped tail, and being without white in the plumage. The female is much greyer, and the markings on the feathers are finer.

The true home of the Black Grouse, although very near the moors, is lower down the hill-sides, where the pine-woods, fir-plantations, and birchcopses afford it the seclusion it loves. It frequents the borders of the moors where the clumps of pines, birches, and alders form the boundaryline between the cultivated districts and the wild. It is fond of those sheltered hollows, just below the tableland of moor studded with spruceand fir-groves, where the ground is covered with heath and bracken, and strewed with boulders of rock over which the bilberry and the cranberry grow so luxuriantly, whilst here and there the recd-patches and alderclumps mark out the marshy swamps. It loves the half-cultivated "roughs" and steep ravines near the margins of the brooks, and the commons covered with bushes and tall, rank vegetation, with here and there a silver birch. Although it likes to frequent the open, it must be in the immediate vicinity of cover of some kind, whither it can retire when alarmed or disturbed.

Like the Capercaillie the Blackcock is polygamous, and certain localities are selected by the males as pairing-grounds. These "laking"-places*, as they are locally termed, are frequented by a great number of males, who fight for the possession of the females, who are enticed to the place by their peculiar love-notes, or "spel," as it is called in Sweden. Mr. Lloyd ('Game Birds and Wild Fowl of Sweden and Norway,' p. 79) says that the spel of the Blackcock consists of two notes, or rather succession of notes, the first being a kind of loud cooing, and the latter a hissing noise, which in clear and calm weather are audible more than a mile off. The hens, as they gradually approach, run to and fro with drooping wings, uttering a plaintive response.

Dixon writes :- " The Blackcock lives in peace throughout the greater part of the year, but early in April commences a fierce and incessant warfare until all the females are won. Some particular spot is chosen in their haunts, where they congregate or 'lek,' as it is sometimes called; and a visit to such a place will well repay the ornithologist. Repair to the birds' mecting-place a little before dawn, and, carefully concealing yoursclf amongst the surrounding vegetation, watch their actions with case. It

and Oustalet do not include the Black Grouse amongst the birds of China, and imply that Swinhoe's statement was based upon a female of Tetrao urogalloides, which Père David probably erroneously identified as a Black Grouse.

* "To lake" is a common word in Yorkshire signifying "to play." A workman who is out of work or has taken a holiday is said to be "laking." 
is just before daybreak. A warm glow lights up the eastern heavens, and the light breezes of early morning rustle through the pine-branches; surrounding objects are becoming more distinct every moment; and the few early notes of the Stormcock from the neighbouring copse, and the cry of a noisy Blackbird fresh from its roosting-place in the hollies, tell you that morning is at hand. Sce, the Curlews are astir, and the Lapwings are just waking up from the rough fallows. But your musings are broken by the flapping noise of pinions and the approach of a dark heavy bird. It is a Blackcock coming to the pairing-station, ready to fight for and win his brides. A handsome fellow he is, and his rich glossy plumage shines with a healthy lustre in the dim morning light. He looks round a moment, as if half-conscious of your presence, and then busies himself with his own affairs. Drawing himself up to his full height he struts proudly about, now trailing his wings, and ever and anon erecting and spreading his broad fanlike tail, all the time incessantly uttering his peculiar love-song. Now he springs into the air, turning halfway round as he descends, then crouches to the ground, swells out his throat, and in a dozen different ways strives to display his charms or give challenge to a rival. But your attention is soon called away from him, for shortly another cock bird makes his appearance. Another and another speedily arrive, and all are soon engaged in the same strange antics; and, see, there are scveral females, too, much less conspicuous in their brown plumage. Now two males will meet in this strange arena and a combat occurs, the birds fighting with as much zest as a couple of Bantam cocks, and in much the same manner, the feathers falling quickly as the battle gains in fierceness. The females are getting more interested every moment, ready to bestow their affections on the victorious males, and run to and fro with drooping wings, occasionally uttering their call-note. And so these combats proceed until all the brides are won, when the strife ceases, and the birds retire to seek their morning meal, but again assemble in the evening, and not unfrequently in the middle of the day as well. Throughout the laying-season the Blackcock is a noisy and pugnacious creature; and once the full complement of eggs is deposited by the female, he quits her society probably for ever, leaving her to hatch and rear her brood unaided."

Eggs of the Blackcock are rarely found before the beginning of May. The site of the nest is varied, but generally well and artfully concealed. It may be where a pine tree or a larch has been snapped off by a winter storm, and its branches covered with a luxuriant growth of bracken and brambles, or it may be under a dense briar or bramble, or not unfrequently under a thick mass of heather and fern. Very little nest is made-a hollow is scratched out and lined with a few bits of herbage, fern-fronds, scraps of heath, or bracken-stems. In this rudely formed nest the Greynen (a name by which the female is technically known) deposits from six to ter 
eggs. They are yellowish white or buff in ground-colour, spotted with rich brown. These spots vary in size from minute pale specks to rich irregular blotches occasionally as large as a pea. The small spots are generally very numerous, but the larger blotches are few in number and often entirely absent. The shell is minutely pitted and possesses some gloss. The eggs vary in length from $2 \cdot 1$ to 1.9 inch, and in breadth from 1.45 to 1.38 inch. Their much larger size, comparatively fewer markings, and buff instead of purplish appearance effectually prevent them being confused with those of the Red Grouse. They more resemble the eggs of the Capercaillie, but are much smaller. Many eggs of the Black Grouse are destroyed in wet seasons by the nest being placed in low-lying situations or too near water. One brood only is reared in the year. The old female will often reel and tumble as if wounded should her brood be menaced by danger. In some cases the nests are said to contain as many as sixteen eggs, most probably the produce of two hens-a theory which is supported by the fact that sometimes a large brood is seen tended by two females.

The Black Grouse is an extremely wary bird, skulking amongst the vegetation, and, especially in autumn, lying close until almost trodden upon before rising. Its flight is swift, more so, perhaps, than that of the Red Grouse, but somewhat laboured. When disturbed this bird generally flies for a considerable distance, and often at a great height. Another peculiarity is its partiality for perching in trees. It may continually be seen in the branches; and in most districts almost its only roosting-place is in pine, fir, and holly trees. The Black Grouse is quite as much a bird of the forest as of the moor, and it feeds much on the buds and flowers of trees. In autumn it is very fond of frequenting bracken, and may sometimes be seen on the stubbles, whilst in spring it often perches on low walls, peat-banks, or rocks. It sometimes leaves its cover for some considerable distance; for Dixon has noticed the male birds in considerable numbers feeding on the bare hill-side, who when alarmed, instead of flying off to the distant woods, invariably ran off to the tufts of rushes and hid themselves in them. At this season the male birds feed peacefully close to each other.

The food of the Black Grouse is almost entirely of a vegetable nature, varied according to the season of the year. In summer it feeds upon various seeds and the tender shoots of heath, leaves, and also insects of different kinds, including ants and their eggs, on which latter food the young are almost exclusively fed. In autumn its food is still more varied; the various wild fruits of the moor and mountain-side are eaten in immense quantities-bilberries, cranberrics, juniper-berrics, together with the berries of the guelder-rose and mountain-ash. It fecds largely on grain, and searches the stubbles near its haunts for barley, oats, and wheat. 
In winter, when the bleak mountain-sides seem unable to support a bird of any kind, the Black Grouse lives on the willow-, fir-, and alderbuds, birch-catkins, sprouts of turnips, seeds, and the never-failing heather, and has been known to feed upon the leaves of the common polypody fern. During heavy snow-storms or in very severe weather in the high north of Europe, the Black Grouse sometimes burrows into the snow for shelter, only leaving its refuge to fecd or when the storm has abated.

The general colour of the adult male Black Grouse is black, shading into brownish black on the wing-coverts and wings, with purple reflections most brilliant on the back, neck, and breast; the axillaries, under wingcoverts, under tail-coverts, and a bar across the wings (formed by the greater wing-coverts being white at the base) are white. The thighs and the feathers round the vent are mottled with white. The outermost feathers of the tail curve outwards, somewhat in the shape of a lyre. Bill, feet, and claws brownish black; irides hazel. Above the eye is an erectile scarlet wattle. The female has the general colour of the plumage chestnut, shading into grey on the wing-coverts, breast, and under tailcoverts, and barred and vermiculated with black. There appears to be little difference between summer and winter plumage, but spring birds have all the appearance of being newly moulted. Males of the year show traces of the coloration of the female on the head, neck, innermost secondaries, wing-coverts, and upper tail-coverts, and the outermost tail-feathers show little or no sign of being curved outwards. Young in first plumage of both sexes closely resemble females; but the male assumes his semi-adult plumage of the bird of the year in the first autumn.

The Blackcock not unfrequently pairs with the female Capercaillie, and the produce is a very liandsome bird, having a nearly square tail, intermediate in shape betwcen the forked tail of the Black Grouse and the rounded tail of the Capercaillic. It is a somewhat curious fact, though probably conformable to a definite law, that the male hybrids, though intermediate in colour between the male Black Grouse and the male Capercaillie, approach nearest the latter, whilst the female hybrid approaches nearest to the female Black Grouse. The influence of the male parent is apparently greatest upon the female hybrid, and that of the female parent upon the male hybrid, the former transmitting the influence of his mother and the latter that of her father.

Hybrids between the Blackcock and the female Red Grouse sometimes occur; and the Blackcock has also been known to interbrecd with domestic fowls, the Pheasant, and the Willow-Grouse. Barren females not unfrequently more or less assume the plumage of the male, showing much purplish black on the back and breast, and having the tail shaped as in the male. 


\section{TETRAO UROGALLUS.}

\section{CAPERCAILLIE.}

(Plate 21.)

Lagopus urogallus major, Briss. Orn. i. p. 182 (1760).

Tetrao uregallus, Linn. Syst. Nat. i. p. 273 (1766); et auctorum plurimorumLatham, Temminck, Naumann, Dresser, Saunders, \&c.

Tetrao major, Brehm, Vög. Deutschl. p. 503 (1831).

In the British Islands the Capercaillic, Capercailzie, or Wood-Grouse, as it is variously called, appears to be confined to the counties of Perth and Forfar, in Scotland, and a few adjoining districts. These birds were introduced into this locality in the year 1837 by Sir Thomas Fowell Buxton. They appear to have been previously exterminated, both in Scotland and Ireland, towards the end of the last century. The only evidence of their ever having inhabited England is to be found in the occurrence of the bones of this species in the caves of Teesdale and amongst the Roman remains at Settle in North Yorkshire. The latest record of the occurrence of this bird in Ireland is that of Pennant, who states that about the ycar 1760 it was to be found in Tipperary. In Scotland the same author mentions an example obtained north of Inverness.

The range of the Capercaillie is very similar to that of the Black Grouse. In Scandinavia it extends as far north as lat. $70^{\circ}$; and in Russia and Sibcria as far east as the valley of the Yenesay up to about lat. $67^{\circ}$. Where it has not been exterminated the bird is an inhabitant of the pineregions of Europe, and is still found as far south as the Spanish slopes of the Pyrenees and throughout the Cantabrian chain. In the Alps it is still found on the eastern Italian slope; but its occurrence in Greece appears to be doubtful, as it has not been obtained by recent travellers; nor has its occurrence in the Balkans been accurately determined. It is found in the high forests of the Carpathians; but appears to be absent from South Russia. In South Siberia it is a resident in the Altai Mountains, its range extending into North-eastern Turkestan, where it breeds at an elevation of from 8000 to 10,000 feet above the level of the sea. It is found as far east as Lake Baikal; but east of the valley of the Yenesay, ranging beyond East Siberia through Mantchooria into North China, it is represented by a perfectly distinct species, Tetrao urogalloides, a bird with a longer and more graduated tail, with a glossy purple and green head and neck, and with much more white on the wing-coverts and the upper tailcoverts, but with no white on the tail. Taczanowsky has described a third 
species from Kamtschatka under the name of T. kamtschaticus, which is somewhat intermediate both in comparative measurements and colour.

The Capercaillie is almost exclusively a bird of the pine-forests; but it is sometimes found at a distance from its favourite haunts, occasionally feeding amongst oaks or birches, especially where ground-fruits of various linds are luxuriant. It prefers those forests where swampy places abound, and is seldom seen during the breeding-season far from water. It is a very conspicuous bird, and may often be observed from a great distance perched upon the extreme summit of a pine tree. It is very wary, and in Siberia the hunter's are obliged to have dogs trained to bark at the foot of the tree in order to attract its attention and allow them to creep up within shot. They are not quite so timid when perched on the lower branches, and I have sometimes passed very near them when sledging through the forests over the snow. The female is much less wary than the male, apparently trusting in some measure for protection to the unobtrusive colour of her plumage.

During the long Siberian winters, when the ground is covered for seven months or more with six feet of suow, the Capercaillie feeds almost entirely on the spines of the Scotch fir and the Siberian cedar. As soon as the summer comes the berries of the cranberry, whortleberry, crowberry, and bilberry, that have been preserved during the winter under the frozen snow, afford it abundant food until insects and their larva abound, which, with the tender shoots and buds of various trees, are its principal food until the strawberries and the cloudberries are ripe enough to tempt it to change its diet again. It also feeds upon buckwheat, corn, and acorms. The hen Capercaillic is so much superior to the cock when brought to table that there can be little doubt that she eats very few of the pine-needles which give to the cock bird a strong flavour of turpentine. She probably obtains most of her food on the ground, whilst the cock, living so much in the trees, is often tempted to feed there even in summer.

The Capercaillic is a bird of powerful flight, though it is seldom scen on the wing for long together, except on the rare occasions when it crosses a deep valley from one hill-side to another. The motion of its wings is rapid, steady, and not particularly noisy, except when it gets up suddenly: on such occasions there is noise enough, and the contemplative traveller who flushes a Capercaillie unexpectedly at his feet as he strolls on mountain or moor may be excused if some seconds elapse before he has re-collected his scattered senses and realized the fact that the world has not come to an end.

The breeding-habits of this bird are very interesting. Although the males are said to exceed the females in number, the Capercaillie is a polygamous bird, and for two months in the year, April and May, the males devote themsclves almost entirely to love and to war. The scene of opera- 
tions is usually a farourite pine tree, conspicuous from its position on an eninence or in an open part of the forest, but it is said that a flat-topped rock in the forest is sometimes chosen as the lek-ställe or "laking-place." Just before sunrise and immediately after sunset are the times chosen by the male to repair to the "laking-place" which he has frequented for ycars. Perched on a conspicuous branch he stretches out his neck, ruffles his feathers, and with drooping wings and crected tail, which is spread out like a fan, he begins his "spel" or love-song. Mr. Lloyd ("Game Birds and Wild Fowl of Sweden and Norway,' p. 21) describes it as consisting of three notes: pellep, several times repeated, resembling the sound of two dry sticks struck together; klickop, also repeated, like smacking the tongue against the palate; and hede, several times repeated, said to resemble the sound made by sucking in the breath noisily, or by the grinding a knife on a whetstone. The performance lasts two or three minutes, and is often immediately repeated. The bird works himself into such a state of eestasy that during the last part of the "spel" he is oblivious of surrounding objects, and is often shot by the natives, who take advantage of these periods to advance by hurried stages within range. The females reply with a harsh croak, and gather round him trying to attract his attention, and finally he descends from his perch and pairs with each in succession. The "laking-places" are usually near each other, and are often frequented by numerous cocks; but only the strongest birds are allowed to "spel," the younger and weaker ones being obliged to stand aside until they have fought their way into the privileged circle.

The Capercaillie does not make any nest, but merely scrapes a hollow in the ground among the heather or bilberries in the forest, collecting no lining, but merely arranging the bits of dry grass that happen accidentally to be on the spot. Naumann, who no doubt obtained his information from the German foresters, says that young hens seldom lay less than five, or more than eight eggs, but that older birds lay as many as eight to twelre, and in rare instances fourteen or even sixteen. The ground-colour is pale brownish buff spotted with reddish brown; these spots are generally profuscly distributed, and in size vary from that of a pin's head to a mere speck. In exceptionally handsome eggs many of the spots approach the size of a pea, and some of them are fantastically shaped, whilst clutches are occasionally found in which the spots are principally very small and so evenly distributed over the entire surface of the egg as to conceal the ground-colour. The eggs vary in length from 2.35 to 2.0 inch, and in breadth from $1 \cdot 7$ to 1.5 inch, and resemble very closely those of the Black Grouse, but may be distinguished by their larger size.

The Capercaillie generally roosts in trees, but in severe seasons it will seek shelter from the cold by burrowing into the snow.

The general colour of the adult male Capcreaillie is dark slate-grey, 
shading into chestnut-bromn on the scapulars, ming-corerts, and quills, erery small feather being rery finely rermiculated with white; the feathers of the beliy, fianks, and upper and under tail-corerts are broadly tipped with white; the breast is metallic green. Bill and fect pale greyish brown; claws nearly black; irides hazel. The female rery closely resembles the Greyhen, but is a larger bird; all the feathers, except the quills, are chestnut, barred and vermiculated with black, and more or less tipperl with white. After the antumn moult the white tips of the feathers of the underparts are rery conspicuous, and considerably alter the general appearance of the bird. In spring they disappear to a considerable extent, possibly by abrasion, but more probably by a moult; for examples obtained in spring appear to be in absolutely perfect plumage, not only the small feathers but also the wings and tail. Naales of the rear retain the female plumage principally on the mantle, upper tail-corerts, breast, and flanks. Young in first plumage of both sexes are rery similin in colour to the adult female.

As is the case with most polygamous birds, occasional hybrids are produced betreen the Capercaillie and other species; but the only hrbrid known to oceur in a wild state is that betreen the male Black Grouse and the female Capercaillie. Barren females occasionally assume more or less the plumage of the male, and various intermediate stages are found between her plumage and that of the adult male. The latter may be distinguished by their smaller size.

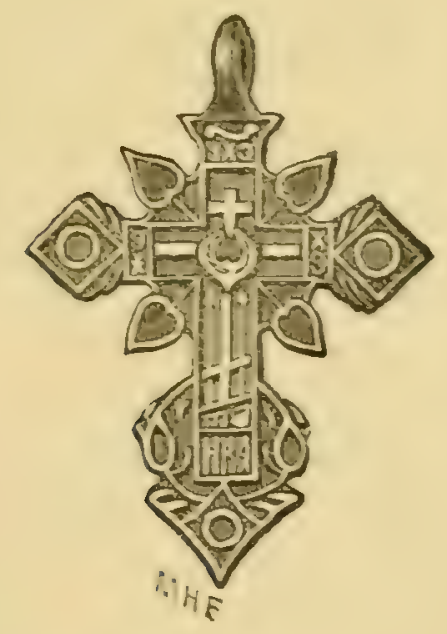




\section{Genus PHASIANUS.}

The genus Phasianus was included by Linnæus in 1766 in the twelfth edition of his 'Systema Naturæ' (i. p. 270). The Common Pheasant (the Phasianus phasianus of Brisson) must be accepted as the type of the genus.

The Pheasants may be distinguished from all the other Game Birds by the absence of an occipital crest and their long pointed tail. The tarsus is long, and in the male armed with one small spur. The nostrils are partially concealed with a membrane.

There are about a dozen species of Pheasants, entirely confined to the south-eastern portions of the Palearctic Region and the northern portions of the Oriental Region. One species only is European, which is a common resident in the British Islands.

The Pheasants are shy and retiring, and only frequent places in which plenty of cover is to be found-large woods and plantations in which there is plenty of undergrowth surrounded by open country, which they visit to feed. They fly heavily but quickly, making a whirring sound when they rise; and on the ground they walk and run about much like domestic poultry. They are both granivorous and insectivorous. Their notes are harsh and discordant. The females make a slight nest on the ground, merely a hollow in which are scraped a few dead leaves, withered grass, \&c. Their eggs are numcrous, and, so far as is known, plain unspotted brown or olive-green in colour. 


\section{PHASIANUS COLCHICUS.}

\section{PHEASANT.}

\section{(Plate 21.)}

Phasianus phasianus, Briss. Orn. i. p. 262 (1760).

Phasianus colchicus, Linn. Syst. Nat. i. p. 271 (1766); et auctorum plurimorumLatham, Temminck, Naumann, Dresser, Saunders, \&c.

Phasianus marginatus, Wolf, Taschenb. i. p. 291 (1810).

The Pheasant never was a really wild bird in the British Islands, although to all appearances it is so at the present time; but it is an abuse of terms to call any bird wild whose existence is entirely dependent on the protection of keepers. The date of its introduction to this country is unknown. Pheasants appear in the bills of fare as far back as these have been handed down to us, even in the times of the Saxon lings before the Norman conquest, from which circumstance it has been inferred that they were introduced by the Romans; but this hypothesis is of course purely guess-work. Little or no interest attaches to the distribution of the Pheasant in the British Islands, as there appears to be no part of the United Kingdom, even to the Outer Hebrides, where they have not been introduced, and: where they are not found in a more or less semi-domesticated state. The protection of sufficiently extensive cover, together with more or less regular artificial feeding in frosty weather, seems to be all that is required.

The Common Pheasant has been acclimatized in most parts of Europe; but its true home appears to be in the extreme west of Asia, in the western portions of the basin of the Caspian Sea, and the southern and eastern portions of the basin of the Black Sea. In a wild state it is a common resident in the valleys of the Caucasus up to an elevation of 3000 feet; along the shores of the Caspian from the delta of the Volga in the north to as far east as Asterabad on the southern shores; in the northern parts of Asia Minor as far south as Ephesus; and, curiously enough, on the island of Corsica. It has been introduced and now lives in a wild or semi-domesticated state in every country in Europe, with the exception of Spain and Portugal and the northern parts of Scandinavia and Russia.

The Pheasant has several very near allies, the geographical distribution of which has puzzled many ornithologists from the anomalies which it appears at first sight to present. These difficulties, however, may be disposed of in two ways. We may either assume that the white neckcollar in all the examples west of China is the result of the migration or importation of East-Chinese birds, which have interbred with the resident 
spccies, or we may come to the conclusion that the presence or absence of a white collar is not an important character. There appears to be only five species in the subgeneric group to which the Common Pheasant belongs. P. versicolor is confined to the central and southern islands of Japan, and may at once be distinguished by its unspotted metallic green underparts; it is somewhat closcly allied to $P$. elegans from the provinces of Setchuen and Yunnan, in South-mest China, which principally differs in having the flanks golden brown, barred with black like the other Pheasants. It is not known that either of these species ever has a white ring round the neck; but the Japan bird readily interbreeds with $P$. torquatus, which scems to be its most nearly allied species. The latter inhabits China, South Siberia, Mongolia, and Thibet east of the meridian of Calcutta. Like the Japancse and the other Chinese species, the prevailing colour of the rump and upper tail-coverts is green, and that of the wing-coverts bluish grey, but the breast is copper-coloured as well as the flanks, dividing the green of the throat from that of the belly. This species may be divided into several races, of which the typical one with the white eye-stripe and the white ring round the neck inhabits South-east Siberia, East Mongolia, and East China. In South-cast Thibet and West China P. torquatus var. decollatus occurs, which is distinguished by the absence both of the white eye-stripe and the white ring round the neck. In North-east Thibet $P$. torqualus var. vlangatii occurs, differing from its allicd races in having the ccntre of the back and shoulders unspotted, and in possessing traces of a white collar at the back of the neck. T'ine Formosan Pheasant has also been dignified with a name, $P$. torquatus var. formosanus; but it only differs from the typical form in having a palcr ground-colour to the upper back and flanks, which are pale buffish white instead of brownish buff. Examples from Hankow and the Corea are intermediate. In Mongolia, west of the meridian of Calcutta, and in Turkestan P. mongolicus occurs, which may always be known by its nearly white wing-coverts, and which, like all the Pheasants west of the meridian of Calcutta, has the prevailing colour of the rump and upper tail-coverts red instead of green. The typical form is found in North-west Mongolia and the castern portion of Russian Turkestan, and is distinguished by having a broad white ring ncarly round the neck, but interrupted in front. The north-east portion of its range probably impinges upon the north-west portion of the range of $P$. torquatus. South of the Thian-Shan Mountains, in Chinese Turkestan, P. mongolicus var. shawi occurs, which differs from the typical form in having no white ring on the neck, and no green reflections on the upper tail-coverts (character's which the typical form may owe to interbrecding with $P$. torquatus); but west of this stupendous chain it meets the typical $P$. mongolicus in South Russian Turkestan. IIcre the two races have apparently interbred and produced an intermediate form, P. mongolicus var. insignis (P.chry- 
solaus of Severtzow), having scarcely perceptible green reflections on the upper tail-coverts, and a very narrow white ring, but with the green tips to the feathers of the underparts very large. West of Turkestan $P$. colchicus occurs, ranging into Lurope. The western species is best distinguished by its reddish-brown wing-coverts. It is supposed that the Pheasant was introduced into Europe from the Caucasus, and. that the Ring Pheasants now found in many parts are the results of the interbreeding of native or Caucasian birds with examples of $P$. torquatus imported from China; but Latham says that the ringed variety occurs in South-cast Russia, a statement which Pallas appears to confirm. It is possible that there may be a ringed form of $P$. colchicus, or we may suppose that Ringed Pheasants were brought into Russia by the caravans from the east.

The Pheasant is a very timid bird, and seldom strays far from cover. It is most successfully reared in plantations where there is plenty of underwood to conceal it during the day, and cultivated land close by on which it can stroll out to feed in early morning or late evening, ready at the slightest alarm to run back into cover. Large parks sprinkled over with snug little copses are its favourite haunts, and it may often be seen on the broad green drives in the forest. But though the Pheasant is never seen far from trees, and roosts in a tree, or will take refuge in the branches if it be disturbed by a fox or persecuted by the sportsman, it is essentially a ground-bird, and trusts more to its fect than to its wings for safety. It runs with great speed, and does not take wing except in extreme need. In the quiet of an early misty morning or in the calm of a summer evening the Pheasant quits the corer and repairs to the neighbouring fields in scarch. of food; but where the herbage is tall and dense it will remain amongst it throughout the day, only quitting it at nightfall for the nest or the roosting-place. It feeds on grain, insects, worms, tender shoots of many kinds, and various small seeds and berries, especially those of the elder and the blackberry. It consumes enormous quantities of wire-worms, and in autumn it frequents the open glades, feeding upon the acorns and beech-mast. To this fare is usually added much artificial food spread by the gamekcepers on the "drives" and platforms of branches erected in the woods, the birds being often so tame as to come and pick up this food at the keeper's feet. Small patches of beans are often planted near the woods for this bird to feed upon in autumn. When surprised in an open spot the male invariably runs off at the approach of a stranger; but the female often crouches close to the earth and remains motionless, her colours so blending with the withered leaves that she is comparatively safe. If she perceives that she is detected, she starts suddenly up, and running rapidily through the intricacies of the underwood is soon lost to view.

In the semi-domesticated state in which this bird is found in England it 
is undoubtedly polygamous. It can scarcely be said to have a "lakingplace" like the Capercaillie or the Black Grouse; but during the pairingscason the crow of the Pheasant may be heard continually in the morning as he calls his hens around him. This cry is a long drawn-out kor-ork, and is followed by a clapping of the wings; it is continually heard as the birds are retiring to roost at night, or if they are disturbed during their slumbers. There seems to be some reason to believe that in his native wilds the Pheasant pairs like most other birds, and that his polygamous habits have been acquired, like those of the domestic Mallard, since his acclimatization in our parks and plantations. During the shooting-season probably far more cocks are shot than hens, and the inequality of numbers of the sexes thus produced may have something to do with their habits in this respect. In the wild state what little information there is to be found on the subject points to the conclusion that the Pheasant is monogamous. Prjevalski says that in Mongolia whenever he saw a family either of the Ring-necked Pheasant or the ringless variety of the same species both parents were always present, and the cock bird seemed to look as anxiously after the young as the hen. It is said that even in this country the cock bird is sometimes found upon the nest, and occasionally takes part in the care of the young. The flight of the Pheasant is very quick, and performed by rapid and incessant beats of its rounded wings. Its whirr as it rises is particularly loud and startling as the bird tops the bushes, and threading its way through the network of branches, hurries off to a place of safety.

In the hot months of the year the Pheasant often seeks some bare sandy spot where it dusts itself like a Lark; and it also frequently drinks, the presence of water being an important item in a good preserve.

The inherent timidity which characterizes the Pheasant naturally causes it to brecd in localities where its privacy is not disturbed. Its favourite breeding-grounds are in the deepest woods, plantations, and copses, in the dense hedgerows, or even amongst the growing crops. In this country the male birds separate late in March or very early in April, and crow, flap their wings, and otherwise display their attractions; but upon their pugnacity depends the annual possession of the females. Armed with powerful weapons of offence, feiw birds fight so fiercely, the strongest and most vigorous males often having six or eight females in their harem, each of which is probably the trophy of a well-fought conflict. After pairing-duties are over, the male bird kceps in company with his mates until the eggs are deposited in April and May, when he usually quits them for ever, and leaves them to bring up their families alone. Each female makes her own nest, though it is not improbable, where the eggs are large in number, that two birds lay in the same nest. It is usually placed amongst fern, under brushwood and brambles, and amongst the herbage in the fields and hedges. Sometimes the nest 
has been found at a considerable height from the ground, in an old squirrel's drey or on the top of a wood- or hay-stack. It is a very simple structure, a slight hollow lined with a few leaves and bits of herbage. In this the female lays from eight to twelve eggrs, though in some cases as many as sixteen or twenty are found; and Dixon has known a single bird hatch safely twenty-six eggrs. They are generally brown or olive..brown, but many examples are bluish green, and one in my collection, taken in Northumberland from a clutch of the usual colour, is a delicate greenish blue, almost the colour of a Starling's egg; they are always unspotted; the shell is smooth and rather polished, but full of minute pits. They vary in length from 1.9 to 1.75 inch, and in breadth from 1.45 to 1.35 inch. They usually resemble the eggs of the Partridge in colour, but are readily distinguished by their larger size. Bittern's eggs are the same colour as typical eggs of the Pheasant, but they are much larger.

Only one brood is reared in the season, but birds have been found sitting as late as the beginning of September. When the old bird leaves her eggs to search for food, which she does invariably in early morning and late in the evening, she covers them earefully with leaves. When leaving her nest she is very wary and cunning, always flying from it and returning in the same manner, leaving no track that might be followed up by an enemy. When the young are hatched the hen leads them and shelters them in the same manner that a domestic fowl tends her brood. The young birds advance to maturity rather slowly, and are seldom well able to fly before the end of July, sometimes much later, according to the time they were hatched. The female and her brood often kecp together in a family party until the following spring.

The Pheasant will sometimes pair with other species of game birds, and hybrids are occasionally produced between it and the Domestic Fowl, the Black Grouse, and the Guinea-fowl; but all or most of these are said to be barren. With many of the allied species the Common Pheasant produces fertile crosses.

The brilliant cock Pheasant (with his conspicuous ear-tufts and scarlet wattles, the metallic green and purple of his head and neck, and the mixture of gold or copper with black or buff of a considerable part of the rest of his plumage) and the comparatively sombre-coloured hen (with her alternations of buff, dull chestnut, and black) are too well known to need detailed description. Young cocks resemble hens in colour, but attain an almost adult plumage at their first autumn moult.

The hen Pheasant sometimes assumes the plumage of the cock, probably old birds, or birds that are barren through defects in their organs of reproduction. The Pheasant is subject to considerable variation in plumage, every variety being known from pure white to the normal colour.

Most of the Pheasants now found in our islands are crosses between the VOL. II. 
Common and the Ring-necked species, the latter strain showing itself not only in the more or less perfect ring of white round the neck, but also in the greater or less predominance of green instead of red on the rump. The great fertility of these crosses apparently proves that the Common Pheasant and the Ring-necked Pheasaut, and probably scveral others of the nearly allied Pheasants, are only subspecifically distinct.

In a polygamous bird like the Pheasant, pairing takes place every spring, in April and May. When the pairing-season is over and the female begins to sit, the male begins his moult, which lasts during June and July. The moult of the female is delayed until incubation is finished, and takes place in July and August. The magnificent plumage of the male bird is generally attributed to sexual selection; but if it be true that pairing takes place just before the annual moult, when the plumage of the male is rendered comparatively shabby by the abrasion of ten months' wear, the theory can scarcely be maintained. Possibly the plumage of the cock may become more brilliant in carly spring by an accession of colour at that season without a change of feather.

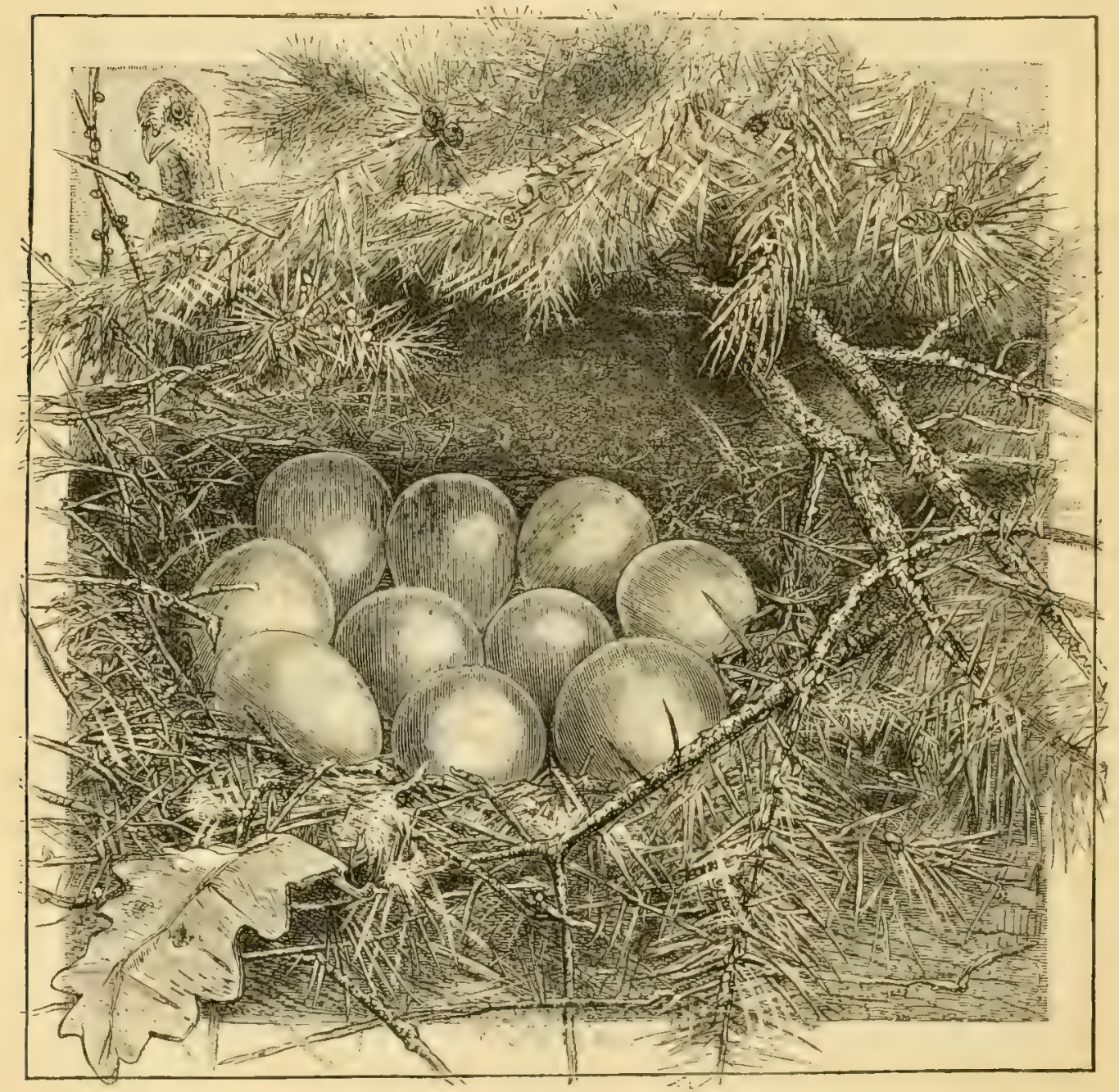

NEST OF PIIEASANT. 


\section{Genus PERDIX.}

The genus Perdix was established by Brisson in 1760 in his 'Ornithologia' (i. p. 219), and is one of the genera which are additional to those of Linnæus. The Common Partridge (the Tetrao perdix of Linnæus) is of necessity the type.

The Partridges are distinguished from the Pheasants by their short tails, from the Grouse by their bare tarsi, and from the Quails by their larger size and shorter first primary. The males of many of them are distinguished by having a spur on the tarsus*; but in some species this is only represented by a blunt tubercle, and in others it is absent altogether. The number of tail-feathers varies from twelve to eighteen. The nostrils are bare of feathers, protected by a hard scale, and the tarsus is scutellated in front, but reticulated behind.

This group of birds contains from a hundred to a hundred and fifty species, distributed throughout the world, except in the Arctic Region, the southern portion of the Nearctic Region, and the Australian Region. There are about fifty species in the New World, which have been placed in a separate subfamily, Ortyginæ, the birds in which are characterized by the bidentation of both sides of the lower mandible. About forty species belong to the Ethiopian Region, and about thirty to the Oriental Region. These tropical Partridges have been subdivided into a great number of small genera, founded upon very trivial characters; but it is not known that they differ in any important respect from the Partridges found in the Palæarctic Region. About half a dozen species are found in the Palæarctic Region; but one or two others occasionally stray within its limits from the Oriental Region. Three or four are European, two of which are residents in our islands; but one of them is known to have been introduced.

The birds in the prescnt genus principally frequent open country, cultivated fields, jungles, grassy hill-sides, and the open ground in wooded districts. They are ground-birds, walking and running with great ease. Their notes are harsh, and their flight is rapid. Their food consists of grain, fruit, insects, \&c. They rarely perch in trees. They make a very slight nest on the ground, often under a bush; and their eggs are numerous, white or buff in colour, sometimes spotted with brown.

* Naumann, Gray, and Macgillivray agree in describing the rudiments of a spur on the tarsus of the male Red-legred Partridge, but state that the Common Partridge is without this appendage. Dresser, on the other hand, says that the male Common Partridge has usually a nob behind, and that the Red-legred Partridge is without any spur on the tarsus. It is needless to say which is correct. 


\title{
PERDIX CINEREA.
}

\section{COMIMON PARTRIDGE.}

\author{
(Plate 21.)
}

Perdix cinerea, Briss, Orn. i. p. 219 (1760); Lath. Gen. Syn. Suppl. i. p. 290 (1787)

et auctorum plurimorum-Temminck, Naumann, Dresser, Sanmder's, \&c.

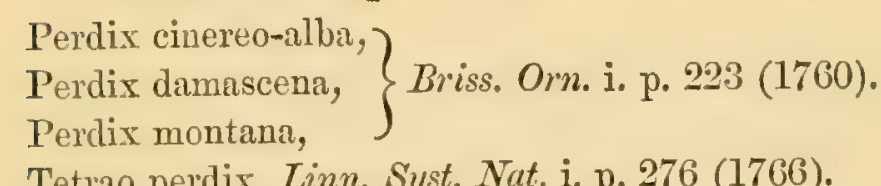

Tetrao perdix, Linn. Syst. Nat. i. p. 276 (1766).

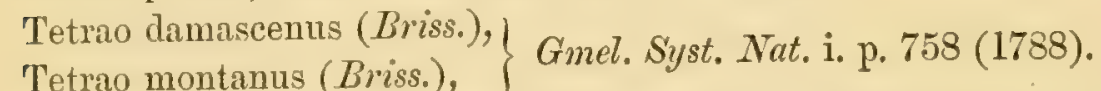

Perdix vulgaris, Leach, Syst. Cat. Mamm. \&c. Brit. Mus. p. 27 (1815).

Perdix cineracea, Brehm, Vög. Deutschl. p. 525 (1831).

Starna cinerea (Briss.), Bonap. Comp. List B. Eur. \& N. Amer. p. 43 (1838).

Starna perdix (Linn.), Bonap. Cat. Parzud. p. 13 (1856).

The Partridge is a resident in all the cultivated districts of the British Islands where game is preserved. It is not found in the Outer Hebrides, but it has been successfully introduced into the Orkncys. In the eastern counties of England it has been partially exterminated by the Red-legged Partridge, but still occurs locally in these counties.

The range of the Common Partridge begins where that of the Red-legged Partridge and its allies ceases. West of a line from Brussels to Venice the Common Partridge is rare or local, and apparently in the process of being exterminated by the stronger species. It is still found in some parts of North Spain and North France and in the plains of Italy ; but it does not extend to Sicily nor to any of the Mediterranean islands. It is found throughout Germany, the Netherlands, Denmark, and in the plains of Austria and North Turkey in the valley of the Danube. In Scandinavia it almost reaches the Arctic circle, but is very local, being continually partially exterminated by scvere winters. In West Russia it occurs as far north as lat. $60^{\circ}$, but in East Russia only to lat. $58^{\circ}$, and as far south as the Caucasus; east of these mountains it ranges into Central Asia and North Persia. In West Siberia it is found as far north as lat. 5\% , where it appears to be migratory, wintering in North Turkestan. Its range in South-west Siberia is not very accurately determined; but Middendorff met with it in the Barabinska Steppe. Finsch did not notice that the Partridge of that district differed from the European bird; but in the Altai Mountains Perdix cinerea var. robusta occurs, a larger and greyer form. In East Russian Turkestan and South-east Siberia, East Mongolia, North-cast Thibet, and North China, P. barbata occurs-a smaller species, with the breast-mark black instead of dark chestuut, and with the feathers on the 
throat elongated into hackles. In East Thibet a third species ( $P$. hodgsonia) also occurs, which is somewhat more distantly allied to our bird, and has most of the feathers of the underparts tipped with a black crescent.

The presence of the Partridge depends to a great extent on the co-existence of high farming with strict preserving. The bird is most fastidious in the choice of a haunt. The ground may be too wet and cold; it may be too wooded; or the hedgerows may not afford sufficient cover in the nesting-season; or the fields may be too large and open : all these conditions are unfavourable to the increase and successful breeding of the Partridge. The places best adapted to it are rich well-cultivated districts, where the soil is light and sandy, and where the fields are comparatively small and bounded by thick low hedges. Sometimes the Partridge frequents sheltered places near the moors, and even wanders to them from the adjoining fields, but never in great numbers. It is, however, very fond of straying to waste grounds and commons; but it rarely enters woods.

The Partridge is a thorough ground-bird and rarely perches on treesso rarely, in fact, that only one or two isolated instances have been recorded, and these have been when the ground was covered with snow or when the bird was pursued by dogs. Like the Pheasant the Partridge runs with great specd, and when not alarmed will walk about and feed after the manner of domestic poultry. It always prefers to escape from its enemies by running, and will often thread its way up a tangled hedge-bottom with great celerity, only taking wing when absolutely compelled. It often squats close to the earth when menaced by danger, trusting for safety to the similarity between the colour of its plumage and the surroundings. Nevertheless the flight of the Partridge is remarkably swift, and is usually performed by rapid beats of its short rounded wings, which make the rellknown whirring sound characteristic of most game birds: rery often, however, especially when just about to alight, the wings are held out, and the bird glides or seems to float through the air, skimming over the hedges and dropping into the cover. The Partridge has learnt to know that a railway-train is not a source of danger; and often enough do we get a sight of a pair or a covey, if it be autumn, quietly feeding in the fields below the embankment, or even on the bank itself. During the heat of the day the Partridge keeps very close, and is especially fond of frequenting some open spot, where it loves to dust its plumage in the sandy soil, doubtless for the purpose of freeing itself from parasites.

Morning and afternoon are the times of the Partridge's greatest activity; at other times it may often be flushed from the hedge-bottoms or places overgrown with shrub and fern, whilst fields of turnips or "seeds" are also favourite places of resort during the middle of the day. The food of the Partridge in spring is chicfly composed of tender shoots of herbage and the grain which it picks up on the ncwly-sown fields. Later in the season 
this fare is varied by insects, beetles, and grubs, on which it chiefly lives in the summer, and when the young are hatched the parent birds lead them to the ant-hills to feed on the larvæ. In autumn the stubbles are visited for the sake of grain of all kinds, from wheat to beans; and the tender shoots of the clover, blackberries growing in the hedges, and small seeds of all kinds are greedily devoured. The Partridge usually retires to rest at dusk, generally choosing some bare place in the open fields, where, after the young can fly, the whole party arrange themselves in a small circle, with their heads outwards. Should danger then approach, no matter from what direction, it is detected, the alarm-note sounds, and the birds either crouch low and motionless, or separate and fly quickly off, not to unite again until daylight. In spite of all this vigilance, however, the rat and the weasel often thin its ranks.

The Partridge pairs early in the year ; late in February or early in March the coveys break up; the old cock quietly leaves the flock with his mate, to whom he remains faithful as long as the lives of both are spared by the sportsman; and the birds of the year pair, not without an occasional fight, for the males are said to exceed the females in number.

The note of the Partridge is a very peculiar one; clear, loud, and pitched very high, it can be heard at a great distance, and it is constautly uttered, principally in the morning and evening, and most persistently during the pairing-season. It resembles the word kir-r-rik, the latter syllable sometimes repeated many times rapidly, especially if the bird be flying away alarmed. This note is common to both sexes.

The Partridge appears to be strictly monogamous; but though the coveys break up early, it is by no means an early breeder. The poor bird has so many enemies, that it seldom happens that a pair enjoy each other's society for many scasons in succession, and April is generally over before the successful males are in secure and undisputed possession of the females. It is not often that egrgs are found even in the south of England before May; and in Scotland, Macgillivray says that they are seldom found before June. In England most eggs are laid during May, and the great hatching-time is the latter half of June. The Partridge seeks a site for her nest in some dense hedge-bottom, in the ditches where the tangled vegetation is the densest, or amongst the growing corn or clover or under a gorse bush, and not unfrequently in the most exposed situations on the roadside or near a path, where, curiously enough, it very often escapes discovery. The Partridge nests on the ground; but Dixon has known it to bring off its young in safety from a hole in the thatch of a bean-stack twelve feet from the ground, and other instances quite as eccentric are on record. The nest is a very slight structure, and consists of a few dry grasses and dead leaves, or other vegetable substances, scratched together in a slovenly manner. The eggs of the Partridge are usually from ten to fifteen 
or twenty in number, but sometimes many more are discovered; as many as thirty-three have been known, but it is very probable that these large clutches are the produce of more than one female. The eggs are pale olive-brown without mirkings, and resemble very closely those of the Pheasant, but are much smaller; they vary in length from 1.5 to 1.32 inch, and in breadth from 1.15 to 1.05 inch. White and pale bluishgreen varieties are sometimes found. The shell is smooth and possesses considerable gloss. The female Partridge is a very close sitter and is most devotedly attached to her eggs, occasionally allowing herself to be stroked by the hand on the nest; and she has even been known to remove her eggs to safer quarters when they have been menaced by danger. The male bird is very attentive to his mate, and keeps guard in the vicinity of the nest, driving off all intruders of his own species from his particular domain. As soon as the young are hatched they are tended by both parents, who not only practise many alluring arts for the safety of their brood, but even attack large predatory birds who menace them. It is very doubtful whether the Partridge will lay a second time if her first clutch be destroyed. A brood of young Partridge chicks and their parents are always interesting to watch: the old birds lead them about and find food for them, and the little creatures keep uttering their whistling notes; the female often gathers them under her wings like a domestic hen does her brood.

In the autumn the Partridge becomes a very social bird: covey joins covey, and if not molested these packs keep in company, feeding and roosting together. At this season the Partridge delights to "jug" in the grass-fields, repairing to the turnips and the stubbles to feed.

The Partridge is not a migratory bird, and though some ornithologists have suspected that its numbers have been increased on several occasions by immigrations on the east of England, there is no reason to believe that the bird ever comes over from the continent. Partridges have often been known to fly for some considerable distance out to sea, especially if shot at near the coast, returning to land in an exhausted condition. In winter, when the weather is severe and the snow is deep, the Partridge often visits the stackyards to pick up a meal, or frequents the banks of running streams to feed upon the tender grass-shoots, and readily takes any grain that may be scattered by the gamekeeper to tide it over an unusual spell of severe weather.

The Partridge is easily kept in confinement, but very seldom breeds in captivity; numbers of young birds are, however, reared under hens every year and turned out like Pheasants. Hybrids between the Common Partridge and the Red-legged Partridge are sometimes met with.

The male Partridge has the forehead, the sides of the head, the chin, upper throat, and the tail-feathers, except the two centre ones, chestnut. The crown and nape are brown, streaked with buff; the general colour of 
the rest of the plumage is pale slate-grey, finely vermiculated with black and transversely barred with buff and chestnut, palest on the flanks, darker on the back, rump, and upper tail-coverts and two centre tail-feathers, and darkest of all on the scapulars and wing-coverts. Wherever these buff and chestnut bars occur the feathers have also buff shaft-lines. The groundcolour of the belly is very pale, and is marked with two large chocolate marks, which are confluent on the upper half. Bill pale slate-grey; legs, feet, and claws dull slate-grey; irides hazel. Behind the eye is a bare scarlet patch. The female very closely resembles the male in colour, but is somewhat duller, and has only traces of the dark patches on the belly. Males of the year resemble females. Young in first plumage have no chestnut on the head and neck, the general colour of the plumage is buffish brown instead of pale slate-grey, and the chocolate patches on the belly are entirely absent, as are also the transverse chestnut bars on both the upper and under parts. 


\section{PERDIX RUFA.}

\section{RED-LEGGED PARTRIDGE。}

(Plate 20.)

Perdix rubra, Briss. Orn. i. p. 236 (1760).

Tetrao rufus, Limn. Syst. Nat. i. p. $276(1766)$; et auctorum plurimorum-Latham Gmelin, (Dresser), (Saunders), \&c.

Perdix rufa (Linn.), Lath. Gen. Syn. Sutppl. i. p. 290 (1787).

Perdix rufipes, Forst. Syn. Cat. Br. B. p. 55 (1817).

Caccabis rufa (Limn.), Kaup, Nat. Syst. p. 183 (1829).

Perdix rufidorsalis, Brehm, Vogelfang, p. 266 (1855).

The Red-legged Partridge is principally confined to the eastern counties of England, where it has more or less succeeded in driving out the resident species. It was introduced into this country about a ccntury ago, a large number of eggs having been imported from the continent about 1770 by the Marquis of IIertford and Lord Rendlesham, the chickens having been turned loose in Suffolk. It does not seem to have obtained much footing in other parts of England, though examples are occasionally met with. The attempts to introduce it into Ireland and Scotland appear hitherto to have failed, the climate of those countries probably being scarcely dry enough.

The range of the Red-legged Partridge is very restricted, and is confined to the extreme south-western portions of Europe. The bird is absent from Scandinavia, Russia, Germany, Holland, and all the countries east of a line drawn from Brussels to Venice. It is of very accidental occurrence in Belgium, local and rare in the north of France; but in South and Central France is abundant and generally distributed. It is a common bird in Spain and Portugal; and although it has not been known to visit Gibraltar or any part of North Africa, it is found in Madcira and the Azores, but has been probably introduced into those islands. It is somewhat common in Savoy, and ranges into Switzerland and southwards into the northern and central portions of Italy, and is found in Elba, Corsica, and the Balearic Islands.

The Red-legged Partridge has several very near allies. It is intermediate between the Barbary Partridge ( $P$. petrosa) and the RockPartridge ( $P$. saxatilis), possessing both the black gorget of the former and the spotted gorget below it of the latter. The Barbary Partridge has quite as restricted a range as its British ally, being confined to North-west Africa, the island of Sardinia, the Canary Islands, and the rock of Gibraltar. The Rock-Partridge has a very extensive range, and is consequently subject to much local variation. The typical form with the throat within the gorget white inhabits the Alps, the Eastern Pyrences, the Carpathians, and 
the Apennincs, ranging also to Dalmatia and Sicily. In Greece*, Asia Minor, the islands of the Levant, Palestine, Persia, the Caucasus, Turkestan, Afghanistan, Scind, the Western Himalayas, the mountain-ranges dividing Siberia from Mongolia, Eastern Mongolia, and North China the Chukar Partridge (P. saxatilis var. chukar) occurs. This form is distinguished by having the throat buff instead of white (but examples from Cyprus are intermediate in this respect) and the lores buff instead of black. In North-east Tibet $P$. saxatilis var. magna occurs, a larger and paler race with a double neck-band, having the lores of the typical form, but the general coloration of the throat and upper parts of the Chukar Partridge. Other paler races from various localities in Palestine, Russia, Turkestan, Cashmere, and Chinese Turkestan, otherwise having the characteristics of the Chukar Partridge, have been called P. saxatilis vars. sinaica, pallescens, and pallidus, but are scarcely worthy of even subspecific rank.

The Red-legged Partridge frequents very similar districts to those chosen by the Common Partridge, but is more often seen on heaths and commons than that species. It seems to have no preference for any kind of soil, and is found on both heavy and light lands. The bird is easily recognized, even at a distance, by its larger size and much darker colour, and the whirring sound made by the wings in flight is different to that made by the Common Partridge. It is a somewhat shy bird, and appears always to prefer running along the ground to taking wing: this peculiarity is especially manifest directly after a heavy fall of snow; the birds are unable to run over the soft and yielding surface, and seek shelter in the dense hedgerows or under whin bushes. When flushed the Red-legged Partridge often perches in the nearest trees, a practice in which the Common Partridge never indulges. It may sometimes be seen perched on the short thick hedges. Stevenson states that he has known a covey of these birds to be flushed from an oak tree, and that when chased in snowy weather they frequently settle on the tops of the pollard oaks. They may also be seen sitting in rows on the tops of walls as Red Grouse often do, or perched on the ridge of a barn-roof or on a park-fencing. Stevenson (B. of Norfolk, i. p. 412) also states that "when alarmed they carry their heads erect, turning them in all directions to catch the sound of any approaching danger, and continue this even when running at their greatest speed. If undisturbed, however, and feeding leisurely, their appearance (as seen through a glass) is very different, and with feathers puffed out

* Dresser, in his 'Birds of Europe,' includes the mainland of Greece in the range of $P$. saxatilis, on the faith of a skin in the collection of Canon Tristram, said to have been obtained in that country; but as Kriiper does not distinguish between the Partridges of the mainland and those of the Grecian Archipelago, and as eggs which I obtained near Athens and in the Parnassus are evidently those of the Chulkar Partridge, it seems to me that Dresser must be mistaken. 
and rounded backs, whilst slowly searching the ground for grain and insects, they look almost as large as Pheasants. They are partial to the shelter of thick hedgerows and plantations, but, unless driven into such cover, are seldom found far from the outer fence, through which they can run on the slightest alarm; and in walking quictly up a woodside, where these birds are plentiful, it is very usual to see one or more Red-legs issuing from the hedge-bottom and hurrying along under the bank. They are fond also of basking in thick rushy carrs; and in low meadows will hide in the sedgy margins of the watercourses, where I have shot them late in the season when looking for Snipe."

In the pairing-season the Red-legged Partridge is a rather pugnacious bird, and not only fights with its own kind, but also with the Common Partridge. The latter bird is gencrally worsted in the conflict, consequently in many districts the Red-legged Partridge is persecuted as vigilantly as Hawks and Magpies. It is even said that it will drive the Common Partridge from its nest and appropriate it to its own use; but such a charge is not yet clearly proved, besides the Red-legged Partridge is said to lay much earlier. The nest of this bird is made upon the ground amongst the tall grass in a hedge-bottom or in the growing crops, and is merely a few bits of dry grass and withered leaves arranged in a little hollow. Mr. J. Cullingford informs me that it often makes its nest amongst the thatch of stacks or on the ground by the roadside. The eggs vary from ten to eighteen in number, and are deposited by the latter end of April or early in May. They are pale buff or stone-colour, speckled, spotted, and blotched with yellowish or light chocolate-brown, and some eggs are much more thickly spotted than others. The shell is thick and strong, finely pitted, and shows considcrable gloss. They vary in length from 1.6 to 1.5 inch, and in breadth from 1.25 to 1.15 inch. The eggs of the Red-legged Partridge very closely resemble those of the Barbary Partridge, but those of the latter are usually redder. The Red-legged Partridge is said to lay its eggs at long intervals; and though it may commence laying before the Common Partridge, it is, through its irregular habits, the last to hatch its brood. The eggs of the Common Partridge and the Pheasant are sometimes found with those of this species; and it has been suggested that these birds had been driven from their nests, but the evidence is in favour of the theory that they had laid in the nest of the Red-legged Partridge-a habit which is common to many species of game birds.

The food of the Red-legged Partridge consists in summer largely of insects, but in autumn and winter grain and seeds are its main support. The cry of this bird resembles both that of the Quail and that of the Common Partridge, being a threefold note like the former, though almost as harsh in tone as the latter. When the young are hatched they are 
ready almost at once to follow their parents in search of food; and in the autumn these broods often join into coveys for the winter. They are not favourites of the sportsman, and the most practicable way of shooting them is by driving. When followed by the guns the birds run quickly off, seldom rising until out of shot, and always preferring to escape from danger without using their wings. Instead of kecping together, the covey scatter in all directions, disturbing the Common Partridge, which would otherwise lie close for a short time, run with incredible speed towards the hedges, to fly over them, and again alight to run quicker than before.

The general colour of the upper parts, including the wings, of the Redlegged Partridge is brown, shading into pale slate-grey on the crown and forehead; a broad stripe over the eye, the chin, and the upper throat are nearly white; the lores are black, and the white on the throat is margined with black on the lower throat, the feathers of the upper breast being brown with black centres; the lower breast is pale slate-grey, and the belly and under tail-coverts are dull chestnut. Each feather on the flanks is pale slate-grey, broadly barred with white, black, and light and dark chestnut, the latter colour forming the terminal margin. The six outermost tail-feathers on each side are bright chestnut, and the remainder are coloured like the back*. Bill, legs, toes, and a bare space round the eye scarlet; claws brown; irides hazel. The female scarcely differs from the male in colour, except that she is slightly duller and is without the rudiments of a spur on the tarsus. Young in first plumage have the slate-grey replaced by buffish brown, and the black on the lower throat is not contimuous. Birds of the year are intermediate between these two plumages.

Although the Barbary Partridge has been included as a British bird by many writers, and is even inserted without question in the 'Ibis' list $\dagger$, it has not the slightest claim to be regarded as such. A specimen of this bird was picked up dead near Melton Mowbray in April 1812 (Yarrell, Hist. Brit. B. ii. p. 400); several other examples have been obtained in Suffolk, one in Yorkshire, and one in Cornwall. The range of this bird and the points in which it differs from the Red-legged Partridge have already been noticed above. The examples obtained in this country leave little room for doubt that they have escaped from confinement.

* Ornithologists differ as to the number of the latter, the upper tail-coverts being difficult to distinguish from them. Naumann and Macgillivray consider four of these feathers to belong to the tail, making the total number sixteen; and in my opinion they are correct, though Saunders states that this bird has only fourteen.

$\dagger$ The inconceivable slovenliness of this publication is pointedly shown in its geographical distribution of these birds. The Red-legged Partridge being confined to Western Europe, is said to be "found in Eastern and Southern Europe;" and the Barbary Partridge being exclusively confined to the western portion of North Africa, the island of Sardinia, and the rock of Gibraltar, is said to "inhabit Southern Europe and Northern Africa." 


\section{Genus COTURNIX.}

The Quails were included by Linnæus in his genus Tetrao, but in 1790 Bonnaterre established the genus Coturnix for their reception in the 'Tableau Encyclopédique et Méthodique des trois Règnes de la Nature' (i. p. 217). The Common Quail (the Tetrao coturnix of Linnæus) must of necessity be the type.

The Quails may be distinguished by their long pointed wings and very short tail. They are birds of small size. The tarsus is scutellated in front, reticulated behind, and is generally without a spur. The nostrils are bare of feathers.

There are about twenty species of Quails, which are distributed throughout the Old World, with the exception of the Arctic Region. One species only is European, which is a regular summer visitor to the British Islands.

The Quails rescmble the Partridges in their habits. They are groundbirds, fond of skulking amongst the herbage, and are more or less gregarious. Many of the species are migratory, and journey to and from their breeding-grounds in immense flocks. Upon the ground they walk and often run with great speced: their flight is very quick and whirring, but is seldom prolonged. Their notes are shrill and monotonous. Their food consists principally of small seeds and insects. They are both polygamous and monogamous. Their nests are mere depressions in the ground, in which are scraped a few bits of grass, leaves, \&c.; and thcir eggs are numerous, olive-green or yellow, sometimes spotted and blotched with brown. 


\section{COTURNIX COMMUNIS.}

\section{COMMON QUAIL.}

(Plate 20.)

Perdix coturnix, Briss. Orn. i. p. 247 (1760).

Perdix coturnix major, Briss. Orn. i. p. 251 (1760).

Tetrao coturnix, Limn. Syst. Nat. i. p. 278 (1766).

Coturnix communis, Bonnat. Tabl. Encycl. et Méthod. i. p. 217 (1790); et a uctorum plurimorum-Bonaparte, Degland \& Gerbe, Dresser, Saunders, \&c.

Coturnix dactylisonans, Meyer, Vög. Liv- und Esthl. p. 167 (1815).

Coturnix vulgaris, Flem. Brit. Anim. p. 45 (1828).

Coturnix europeus, Swains. Classif. B. ii. p. 344 (1837).

Ortygion coturnix (Briss.), Keys. u. Blas. Wirb. Eur. p. lxvi (1840).

Coturnix indicus, Hodgs. Gray's Zool. Miscel. p. 85 (1844).

Coturnix vulgaris japonica, Temm. \& Schlegel, Fauna Japon. p. 103, pl. lxi. (1847).

Coturnix baldami, Brehm, Vogelfang, p. 274 (1855).

Coturnix leucogenys, Brehm, Naumannia, p. 288 (1855).

Coturnix capensis, Licht. fide Gray, Hand-l. B. ii. p. 268 (1870).

There are few birds whose history has been more intimately associated with migration than the Quail, the numbers which cross the Mediterranean on their way to their winter-quarters in Africa being counted by millions instead of by thousands. Nevertheless in the south of England and in Ireland * the Quail is a partial resident, though the greater number are probably only summer visitors. It breeds throughout the British Islands, including the Outer Hebrides, the Orkneys, and Shetland, but is nowhere common.

The Quail is an occasional summer visitor to the Faroes. In Scandinavia and Russia it occur's up to about lat. $64^{\circ}$; there is an example in the Muscum at Omsk; and in the valley of the Yenesay it has been found as far north as lat. $61^{\circ}$. Eastwards it is found throughout Dauria, the valley of the Amoor, in East Mongolia, China, and Japan. It is a resident in the Azores and the Canaries, but is a summer visitor to Central Europe. It is found throughout North Africa, Palestine, and Asia Minor; but in the basin of the Mediterranean and on the Mediterranean islands it is principally known as passing through on migration to its chief winterquarters in South Africa, where it is found in Damara Land, the Cape Colony, Natal, and the Transvaal. A few remain to breed and a few remain to winter in the basin of the Mediterranean. It is a common summer visitor to Persia, Afghanistan, and Turkestan, and winters throughout India. It has not occurred in Ceylon, but is a rare winter visitor to Burma. Most of the birds breeding in Siberia and the north island of Japan are

* Mr. Lloyd Patterson informs me that the Quail is gradually becoming extinct in Ireland. 
migratory, and winter in Turkestan and China as far south as Formosa, but a few remain during the winter.

The greater number of Quails obtained east of Irkutsk are slightly smaller than European examples, but this small race is also found on the Azores. The alleged differences of colour appear to be only stages of plumage.

The Quails that visit this country every year seldom make their appearance until May among the last of our summer visitors. In the south of Europe these birds pass in enormous numbers during March and April, during which months a vast stream of these birds is constantly flowing from Africa, the great winter home of this species. The return migration takes place in September and October. It has been observed that on Malta the Quail arrives during the night in spring, but migrates during the daytime in autumn. Vast numbers of these little travellers are netted during their amnual journeys to and from the north, for their flesh is a highly and justly esteemed article of food.

The Quail is a much rarer bird in this country than the Partridge, and from its skulking habits it is very liable to be overlooked by those ornithologists who do not pay special attention to the notes of birds. The sandy plains of Central Germany, wherever they are highly farmed, or the dry steppes of Southern Europe, especially in the cultivated parts, are its favourite haunts. In many parts of this country, especially on heavy land, it prefers dry patches of unreclaimed ground; but in countries like Algeria, where every drop of moisture and every blade of grass is soon dried up by the burning sun, it not unfrequently selects the vicinity of marshes where such are to be found.

The familiar call of the Quail, which is said to be confined to the male only, is a clear flute-like note, or succession of three notes, which, though not very loud, can nevertheless be heard at a considerable distance. This note may be best represented by the syllables clik-lik-lik, the accent sometimes being on the first and sometimes on the second syllable. The female replies by a double note, low and unmusical, which appears to be common to both sexes. The alarm-note, when the bird is suddenly surprised, is very similar to that of the Partridge.

Like the Land-Rail it scarcely ever takes wing unless compelled to do so by dogs ; but although it so rarely gives the ornithologist an opportunity of seeing it, its presence is instantly detected by the peculiarity of its note, which, especially during the breeding-season, is almost constantly repeated, and is as familiar to every ploughboy, in localities where it is found, as the crake of the Land-Rail. The note is generally heard in corn-fields and in meadows. The Quail is very susceptible to cold and damp, and consequently does not thrive on clay soils.

The Quail is par excellence a ground-bird, and never perches in trees. 
Its flight is quick and performed by rapid beats of its rounded wings, but it sometimes skims for some distance with outspread wings like a Partridge or Grouse. It seldom flies at any great height, usually a yard or so from the ground; nor does it fly further than it can possibly help, always taking the first opportunity to drop down into cover.

Like the Partridge, the Quail is very fond of taking a dust-bath; and during the heat of the day usually lies very close, being most active in the early morning and late afternoon and evening.

The fond of the Quail is largely composed of seeds of different kinds, chiefly of grasses and weeds, but it will also eat grain. To this fare must be added many kinds of insects and slugs, for which it often searches amongst the turnips and other root-crops. It sometimes picks an insect from the leaves, and occasionally snaps at one as it flics by. The gizzards of these birds contain a little sand or quartz, as is usual with game birds, to assist in the digestion of their food.

The Quail is partly polygamous and partly monogamous; as a rule, the male pairs with only one female, but probably in localities vhere there is an excess of females he pairs with several. Few birds are so pugnacious as the Quail. Each male is very jealous of its particular haunt, from which it strives to beat off all intruders. It is a late breeder, and its eggs are not laid before June. The nest is generally in the open fields amongst the growing herbage, not under the shelter of the hedges, but often in the centre of the ficld, in a similar situation to that generally selected by the Sky-Lark : sometimes a grass-field is chosen, but more frequently a cornfield, or even the rough herbage of the open common. The nest scarcely merits the name, for it is only a slight hollow scratehed in the ground, in which are gathered a few withered bits of herbage or a dead leaf or two. It is no uncommon thing to find two nests quite close to each other, doubtless belonging to two females mated to one male. Some nests contain as many as twenty eggs, others only sixtecn, and frequently only eight or twelve are found.

The eggs of the Quail are very handsome, varying in ground-colour from creamy white or buff to yellowish olive, boldly blotched and spotted with olive-brown and rich blackish brown. Some eggs are far more thickly blotched than others, many of the markings being confluent, others are sparingly marked with large spots and numcrous paler and smaller blotches; less frequently they are minutely and evenly speckled over the entire surface with spots of very dark brown, here and there large round portions of the ground-colour appearing as if the colour had been accidentally rubbed off. They vary in length from 1.2 to 1.1 inch, and in breadth from $\cdot 92$ to 82 inch. The female alone performs the duties of incubation, which lasts about three weeks; and when the eggs are hatched both parents are often found in company with the brood. The young are 
able to run and follow their parents almost as soon as they are hatched, and they quickly learn to pick up and search for their own food. Only one brood is reared in the year. As soon as the young are capable of taking care of themselves the family party appears to be broken up, and the birds are solitary in their habits until the time of migration arrives. The resident birds in this country are never found in coveys like Partridges, and are usually flushed singly from the cover. The Quail seems very much attached to its haunts, appearing in them regularly; and Dixon has known an instance of several pairs of these birds having becn turned out, and though always absent in winter, their well-known call unfailingly proclaiming their presence in the district the following summer.

The Quail may almost be regarded as a miniature Partridge; and the two species resemble each other so closely in the pattern of their coloration that it is difficult to believe that they can be generically distinct. The general colour of the adult male Quail in spring plumage is buff. The cheeks are chestnut, and the chin and throat are nearly black. The crown, back, rump, and upper tail-coverts are barred with dark and light brown, and behind each eye is a buff streak. Pale shaft-lines form a mesial line on the crown, and are conspicuous on the back, scapulars, innermost secondaries, the sides of the rump, and flanks. Bill, legs, feet, and claws brown. Irides hazel. The female differs from the male in having the chin and throat pale buff, and the breast and flanks profusely spotted with very dark brown. After the autumn moult the colour is retained on the chin and upper throat, but the chestnut on the cheeks and the dark brown of the lower throat is moulted into buff. Males of the year resemble females, but have very few spots on the breast. In what appear to be males in first spring plumage the chin and throat, as well as the cheeks and ear-coverts, are chestnut. In examples which are probably males in their secund spring plumage, the dark brown on the chin and throat is confined to the centre. The fully adult plumage does not appear to be attainer until the third spring. Immature males have the flanks richly spotted as in the female.

Several attempts have been made to naturalize the Virginian Colin (Ortyx virginianus) both in England and in Scotland, but none of them have proved successful. Some ornithologists have introduced this bird into the British list on the strength of examples thus imported, which have been shot in various parts of the country. It is a resident in the Eastern States of North America, extending northwards into South Canada and westwards into Texas, being subject to some local variation in colour, which has given rise to its being divided into several subspecies. In its general appearance this bird is intermediate between a Quail and a Partridge, but is very different from either, and in America it is called by both these names.

vol. II. 


\section{Family PELARGID $A$, or HERONS.}

The Herons and their allies form a small and isolated family, which Sclater elevates to the rank of an order under the name of Herodiones (the Pelargomorphre of Huxley). Forbes agreed with this classification, except that he removed the Ibises and the Spoonbills, which he placed in juxtaposition with the Curlews and the Crancs. In the Herons, Storks, and at least one of the Spoonbills, there is only one deep cleft on each side of the posterior margin of the sternum; but in the majority of the Spoonbills, and in the Ibises, there are two notches on each side. The modification of the cranial bones in this family, like that of the Birds of Prey and the Owls, is somewhat variable, the typical desmognathism being occasionally incomplete. In their myology, and in the character of their digestive organs, they agree fairly well together; but in their pterylosis the Hcrons are somewhat peculiar, the presence of what are called "powderdown patches" isolating them from all other birds, except some species of Birds of Prey, Parrots, and one or two other genera.

It has generally been supposed that most of the birds belonging to this family have only one complete moult during the year, which takes place in autumn. All ornithologists admit that the Ibises moult their small feathers a sccond time in spring; and there can be little doubt that the special nuptial feathers, such as the elongated scapulars of the Egrets and the crests of the Spoonbills, appear in spring and are lost in the autumn moult. In the birds of all these genera the quill-feathers are moulted very slowly, and apparently in pairs, only as they are required, and probably at any season of the year except when the birds are engaged in breeding, in this respect resembling the Swifts and the Birds of Prey.

Their principal external characters are their long legs, and long and powerful bill. The young birds are covered with down, and are able to sce as soon as they are hatched, but are comparatively helpless, and are fed by their parents for a considerable time before they are able to leave the nest. The wings are usually long and broad and contain ten primaries, and the tail is short and nearly even.

This family includes about a hundred and twenty species, and is almost cosmopolitan, except that it is not represented in the Arctic Regions. 'I'hirteen species are European, three of which breed in the British Islands, and the rest are accidental stragglers to them, as is also one American species. 


\section{Genus ARDEA.}

The genus Ardea was included by Linnæus in 1766 in the twelfth edition of his 'Systema Naturæ' (i. p. 233), and contained the Herons, Storks, Cranes, and Bitterns. The Common Heron (the Ardea ardea of Brisson) is the type.

The true Herons may be distinguished from the Spoonbills and the Ibises by their long straight bills, from the Storks by having only one of the intervals between the toes webbed, from the Bitterns by having twelve tail-feathers, and from the Night-Herons in having the front of the tarsus covered with broad plates. The bill is very long and nearly straight, and the feathers of the crest and scapulars are very often abnormally developed. The middle claw on each foot is serrated at the side, like that of the Nightjar.

The genus Ardea contains about forty species, and is almost cosmopolitan, the Aretic Regions being the only portion of the world which they do not visit. Six species breed in Europe, one of which is a common resident in, and the others accidental visitors to, the British Islands.

The Herons frequent swamps, the banks of rivers and lakes, and lowlying coasts. They walk with great ease, and often wade into the water to catch their food. Their flight is moderately slow but powerful, and often prolonged for great distances. Their notes are loud aud harsh. Their food consists principally of fish, small reptiles, and mammals. They generally breed in colonies, placing their nests on trees and bushes, or amongst rank aquatic vegetation, or on cliffs. Their nests are made of sticks, grass, moss, \&c., and their eggs are pale bluish green. 


\title{
ARDEA CINEREA.
}

\section{COMMON HERON.}

\author{
(Plate 38.)
}

Ardea ardea, Briss. Orn. v. p. 392, pl. xxxiv. (1760).

Ardea cristata, Briss. Orn. v. p. 396, pl. xxxv. (1760).

Ardea cinerea, Briss. Orn. v. p. 403 (1760); Linn. Syst. Nat. i. p. 236 (1766); et auctorum plurimorum-Latham, Temminck, Naumann, Bonaparte, Dresser, \&c.

Ardea nævia, Briss. Orn. v. p. 410 (1760).

Ardea major, Linn. Syst. Nat. i. p. 236 (1766).

Ardea rhenana, Sander, Naturforscher, xiii. p. 195 (1779).

Ardea johannæ, Gmel. Syst. Nat. i. p. 629 (1788).

Ardea cineracea, Brehm, Vög. Deutschl. p. 580 (1831).

Ardea brag, St.-Hilaire, Jacquem. Voy. dans l'Inde, iv. p. 85 (1844).

Ardea leucophæa, Gould, Proc. Zool. Soc. 1848, p. 58.

The Common Heron is a somewhat local resident throughout the British Islands, but it does not appear to breed in the Outer Hebrides, and rarely does so in the Orkney and Shetland Islands.

The Common Heron has a very extensive range, breeding in most parts of Europe, Asia, and Africa, and probably in Australia. It is an occasional visitor to the Faroes, a rare straggler to Iceland, and has occurred once or twice in Greenland. In Scandinavia it breeds up to lat. $65^{\circ}$, and occasionally wanders as far north as lat. $68^{\circ}$. In Russia it is not known to breed further north than lat. $57^{\circ}$, but sometimes occurs in West Russia up to lat. $60^{\circ}$. In West Siberia it is occasionally seen in lat. $55^{\circ}$, and breeds near Lake Baikal and throughout the valley of the Amoor. Southwards it is said to breed in most parts of Africa. It is a resident on the Azores, and is occasionally seen on the other Atlantic islands. South of the limits already given it breeds in most parts of Europe and Asia as far east as China and Japan, and has occurred in Java and Australia. On the American continent it is represented by Ardea herodias, distinguished by its black underparts, and $A$. wiirdemannii, distinguished by its white crest.

Although the Heron is a resident bird in the British Islands, in other parts of Northern and Eastern Europe it is principally known as a summer visitor. Considerable numbers cross the Straits of Gibraltar during February and March, and arrive in Germany late in March or early in April; they leave again for the south in September and October, arriving 
in North Africa during November and December. In Eastern Europe, in consequence of the severcr winters, they arrive somewhat later and depart somewhat earlier, passing through Greece in March and again in August.

The Heron is found wherever there is water, and may be seen standing in it, not only on the sea-shore and the banks of rivers and lakes, but also in small brooks, ponds, marshes, and flooded fields. It has been so much persecuted in the British Islands that heronries have become comparatively rare, but it is still occasionally seen even at a long distance from its breedingcolonies. It is specially partial to swamps, but is rarely seen on the high lands. So conspicuous a bird has naturally become very wary, and soon takes flight on the approach of danger. If not molested it may often be seen standing in the water at some distance from the shore, remaining almost motionless watching for its food, its neck bent, and its head almost between its shoulders, ready at a moment's notice to dart its bill like an arrow into the water to secure a fish or a frog. Occasionally it may be seen walking with stately step on the mud, or resting with one leg drawn up to its body. Not unfrequently it may be observed standing on the flat branch of a pine tree, where it looks very singular and out of its element, but not perhaps so much so as on the slender branches of a pollard willow in the neighbourhood of its nest. The flight of the Heron is slow and steady, with deliberate and regular beats of the long wings, and in the evening several birds may sometimes be seen flying home to roost, steadily and at a considerable height, like Rooks. Although the flight appears to be so laboured, it is really very rapid, and the bird frequently wanders great distances to feed. When flying, its long legs are carried straight out behind, and serve to balance and guide it in its course, whilst the head is drawn almost up to the shoulders.

The Heron can scarcely be regarded as a gregarious bird, although it breeds in colonies. Except at the nests it is seldom that more than four or five are seen together, and in winter solitary Herons, mostly immature birds, wander far from their birthplace, and take up their residence on the banks of a suitable stream or creek. The Heron prefers running streams to still water, and on the sea-coast frequents for the most part the mouths of rivers. It is seldom or never seen to swim, except when winged; but Waterton records that at Walton Hall the Herons occasionally alighted on the deep water in hot weather, and swam just like Waterhens; he also observed them hovering above shoals of fish like a Tern. The Heron is most active late in the evening and early in the morning. It may be seen standing for some time in a large field a long way from water, and is often disturbed from the horse-pond in a secluded corner; it is frequently seen walking about amongst feeding cattle, but it never relaxes its great wariness. 
The note of the Heron is harsh, rather like the sound of a trumpet, but more guttural and very short, and is generally uttered when the bird is flying. When the bird is alarmed this note is modulated into a sort of croak. The Heron is, however, generally a very silent bird.

In the south of England the Heron is one of the earliest birds to breed, and eggs may be obtained in the first week of March, but in Scotland they are seldom laid before the end of that month. In Germany they are not laid until the latter half of April, in Norway not until May, and in the valley of the Lower Danube not until the first week of June. The late breeding of this species in the valley of the Danube is a remarkable instance of the special adaptation of the habits of a bird to the peculiar circumstances by which it is surrounded: neither a warm climate nor abundance of food tempt it to begin operations until the sun has begun to melt the snow on the Carpathians and the Alps, causing this great river to rise and to overflow the lowlands that extend for miles between its main branches, and make the willow-forests inaccessible, except with a boat. In these solitudes it breeds in immense colonies, together with Ibises, Night-Herons, Squacco Herons, Little Egrets, and Pigmy Cormorants, building a large nest in the middle of a pollard willow, a few feet above the level of the flood, with perhaps a score nests of its smaller companions in the same tree. The favourite breeding-place of the IIeron is, however, lofty trees, the flat branch of a larch or the extreme summit of an elm, a Scotch fir, an oak, or a sycamore. These heronries are generally to be found near water, but sometimes at a considerable distance from it. In localities where there are no trees, it builds its nest on ledges of rocks or ruins, and even on the heathery slope of a mountain-side. The nest is a large structure, composed of sticks and lined with fine twigs; it is very flat, and sometimes contains turf and moss. The old nest is usually repaired year after year, and by the time the young are able to fly, it is whitewashed with the droppings of the birds. Several nests are generally built in one tree.

The Heron lays from three to five eggs, but the full number seems rarely to come to maturity. On the ground under the nests numerous dead young birds of various ages are usually to be seen amongst the broken egg-shells that the Herons have cast out of the nest and the twigs which they have dropped in the process of building. When the young are able to fly, frequently not more than one or two are seen in each nest, and these if pursued will climb on the branches or up to the neighbouring nests, using their bills, as well as their feet, almost like a parrot.

The eggs of the Heron are greenish blue in colour, dull, and chalky in texture. The shell is often full of minute pits, or covered with small white excrescences. Some eggs are a much bluer green than others. They vary in length from $2 \cdot 65$ to $2 \cdot 3$ inch, and in breadth from $1 \cdot 79$ to 
1.5 inch. It is absolutely impossible to distinguish the eggs of this species from those of the Purple Heron and the Great White Egret. Should the nests be approached, the old birds make little noise, but rise into the air and fly anxiously above the trees. Only one brood is reared in the year.

The Heron obtains much of its food at night, especially when the moon is at the full. It feeds largely on fish, frogs, lizards, insects, small mammals, and occasionally a young bird. Dixon found the skeleton of a small wader in a nest of a Heron in Skye, and it is said to feed habitually on young Waterhens and Coots. It is a voracious feeder, and very rapidly digests the food it takes. Sometimes it may be seen wandering about on the beach at low water, scarching amongst the stones and rocks for small crabs and shrimps. Its partiality for fish renders it objectionable to the river-kecpers, by whom it is often shot; and in the breedingseason, when the hungry voracious young are ever clamouring for food, it levies no small tribute on the fish-ponds and streams. The Heron often has to fly for a considerable distance to obtain food for its young, and may then be seen passing through the air almost as regularly as the Rook. The smell in a Heronry arising from the decayed fish, especially on a warm close day in late spring, is very objectionable.

The colour of the plumage of the adult male Heron is a mixture of black, white, and slate-grey. The black is distributed in the following manner :-On each side of the head a broad streak extends to the nape, where it is prolonged into a crest, ornamented with two or more long narrow feathers; a row of spots extends down the fore neck, leading to a broad stripe on each side of the breast and belly; the primaries, primarycoverts, and secondaries are dark slate-grey, approaching black; the rest of the wing-coverts, axillaries, flanks, rump, upper tail-coverts, tail, scapulars, and mantle are pale slate-grey. The feathers of the lower back are also slate-grey, shading into white at the tip, which is prolonged into a narrow plume, as are also the feathers on the lower neck. The rest of the plumage is white. Bill, a bare space before the eye, and irides ycllow; legs and feet reddish brown, suffused with reddish yellow on the tibia; claws black. The female resembles the male in colour, but is slightly smaller, and the crest is not quite so long. In the young in first plumage the forchead and crown are grey instead of white; the crest is very short and dark slate-grey; the slate-grey of the back is more or less suffused with brown, the elongated feathers of the back and neck are absent, and the black on the breast and belly is only represented by greyish-brown stripes. The upper mandible is more or less brown, and the legs and feet are dark grey, suffused with yellowish green, especially on the tibia. After the first moult, which is completed by the time the bird is a year old, the 
plumage of birds of the ycar is assumed, which is intermediate between that of young in first plumage and that of the adult, which is completed by the sccond spring - that is to say, when the bird is nearly two years old *.

* Dresser's description of the changes of plumage of this bird is extremely misleading, owing to a mistranslation of Naumann's remarks on this subject. After having described the young in first plumage, Dresser proceeds to describe the bird of the year, prefacing his remarks by saying that "after the first moult (that is, when the bird is two years old)." This ought, no doubt to read, when the bird is scarcely one year old. Naumann distinctly states that the young commence their first moult early in November, and have scarcely finished it by spring.

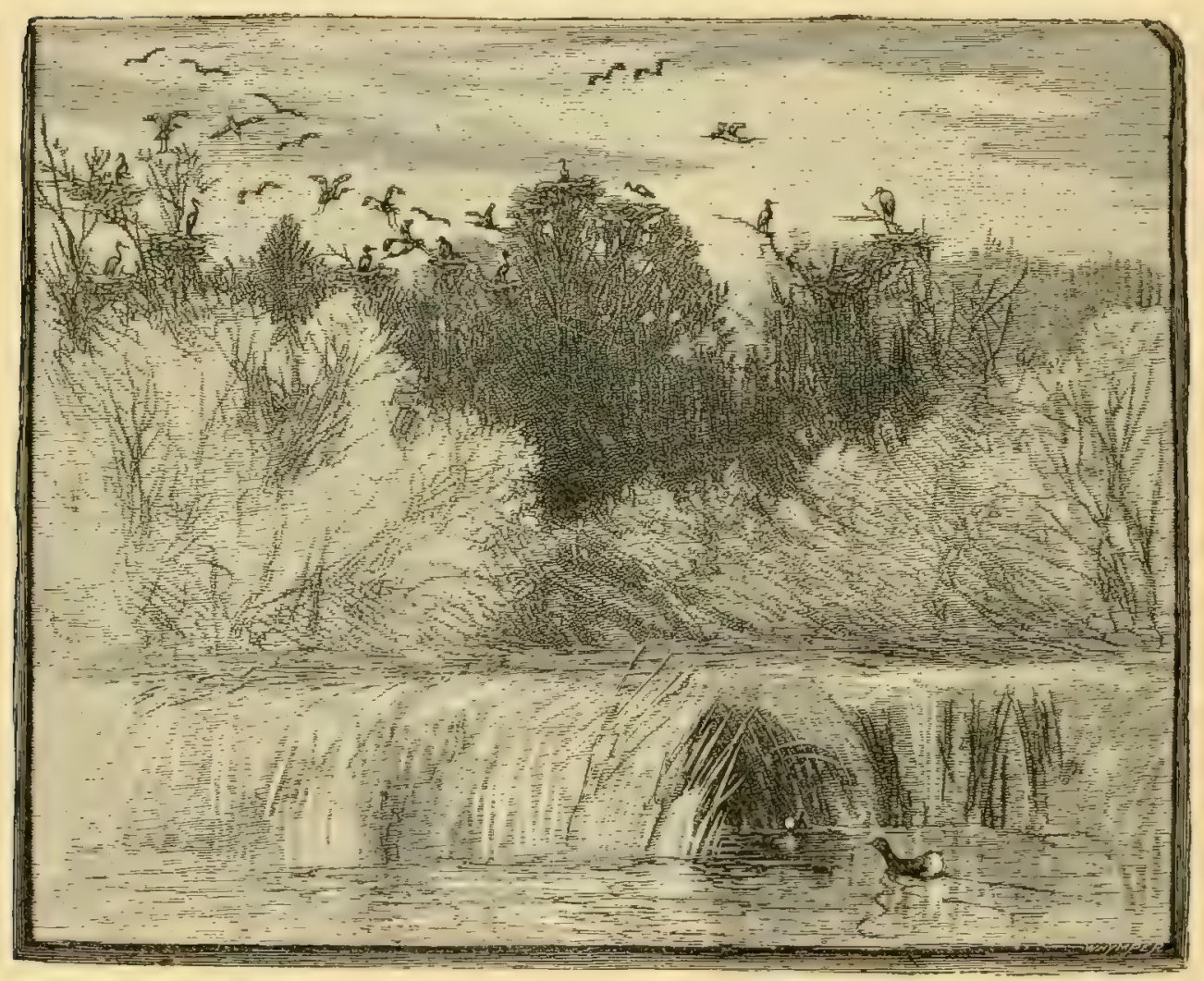

HERONRY NEAR EPPING FOREST, 


\title{
ARDEA PURPUREA.
}

\section{PURPLE HERON.}

\author{
(Plate 38.)
}

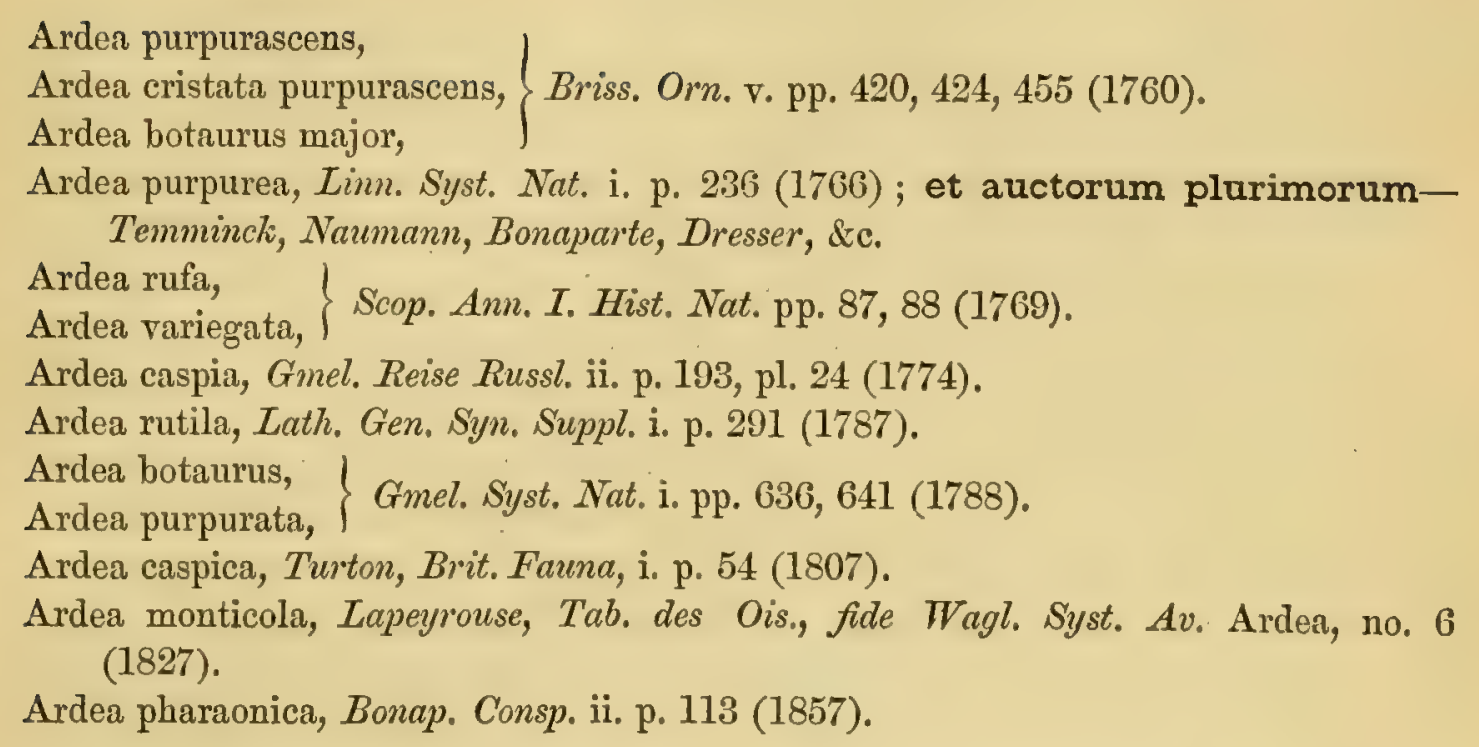

There is no reliable evidence that the Purple Heron has ever bred in this country, and it must be regarded as a somewhat rare straggler, principally to the eastern and southern counties of England, though it has been obtained twice in Scotland and once in Ireland. Of the Scotch specimens one was killed in Caithness, and the other in Aberdeenshire in March, whilst the Irish example was taken near Carrickmacross in Monagan.

The range of the Purple Heron is almost as great as that of the Common Heron, except that it does not extend so far north. The bird is a summer visitor to the Spanish peninsula, the south of France, Italy, Central and Southern Germany, the valley of the Danube, the extreme south of Russia, Greece, and Asia Minor, and occasionally wanders into North France, Holland, Belgium, and North Germany, but has only once been found in Scandinavia. It is said to be a resident in Sicily and Palestine and in most parts of Africa, including Madagascar, its numbers in those countries being increased during winter. It is said to be found in Damara Land at all seasons of the year, and is very common at the Cape, although it has not actually been found breeding there, but its eggs have been taken in the Transvaal. Eastwards it breeds in Persia, Turkestan, India, Ceylon, and Burma. It also occurs, and may probably breed, in Sumatra, Java, Borneo, Celebes, and the Philippine Islands. It has been met with, though very rarely, in various parts of China; and Finsch and 
Hartlaub iecord it from Japan; but it is not known to breed in either of these countries, and its occurrence in the latter is doubtful. Pallas says that it has occurred in Siberia south of lat. $55^{\circ}$; but it is possible that he was in error, as no subsequent travellers have met with it. The Purple Heron has no near ally.

The Purple Heron is only known in Europe as a migratory bird. It does not occur every year in this country, and usually makes its appearance in autumn. Most of the specimens obtained were in immature plumage. It arrives in the sonth of Europe about the end of March or the beginning of April, and leaves for its winter-quarters in Scptember.

The Purple Ileron is a more skulking bird than the Common Heron, and is less frequently seen, even in districts where it is by no means uncommon. It very seldom frequents open water or the banks of rivers ; but it loves marshy districts, where the reeds and rushes are sufficiently dense to afford it a safe retreat, and it often takes up its summer-quarters in wooded country that is flooded, especially willow-thickets. It is a shy and wary bird, and only takes wing when absolutely compelled, always preferring to skulk amongst the reeds and aquatic vegetation in the hope of escaping detection. Like that of the other Herons, its flight is deliberate and powerful, the legs being stretched straight ont bchind, and the head drawn in between the shoulders. The Purple Heron is less gregarious and more of a ground-bird than the Common Heron. It seldom alights in trees, and on the rare occasions that it does so it conceals itself amongst the branches, and is never seen perched on the topmost twigs, as is so often the case with the common species; it rarely ventures into open places, and searches for its food amongst the reeds. Upon the ground it walks to and fro with a sedate and slow gait. Its note resembles that of the Common Hcron, but is not so loud, and is likened by Naumann to the quack of the Wild Duck.

The Purple IIeron is most active at dusk, when the various creatures that compose its food are astir. It dozes away the hot portions of the day, and, it is said, is very fond of sitting in a peculiar position on its tarsi with its neck stretched out at an angle. It is said to be much attached to certain haunts, and a pair of birds return year after year to a favourite breeding-place. It is very fond of running or walking over the large masses of floating aquatic vegetation, or pushing its way through the dense reed and rush thickets, often wading in the water to do so. When flushed it looks very much like a Bittern, as it rises over the tall reeds, and flaps slowly away to more secluded quarters. Jerdon says that in India it may often be observed with its long neek and head above the grass, all the rest of its body being hid from view, and making it appear like the head of a snake. He also says that when flushed it utters its loud harsh note, which it repeats as it flies away. 
The food of the Purple Heron is composed largely of fish ; but this fare is varied with watcr-insects and their larvæe, mice, rats, and frogs. This prey it captures by silently waiting and watching for it in some secluded part of its haunt; darting now at a little fish swimming past, or a frog that has unwittingly approached too near. It is not improbable that this bird occasionally leaves the cover at night and repairs to the drier and open land near its haunt, to hunt for the small mammals that are known to form part of its fare. It obtains much of its food during the night, especially if there is a moon, when it may sometimes be noticed stalking solemnly along the gloomy margins of pools. It is said often to roost on small islands, and occasionally to resort to a low tree or tall shrub.

The valley of the Danube is the most northern locality where the Purple Heron breeds regularly, and even there it is generally found in isolated pairs, fresh eggs being obtained during June. In South-west Russia Göbel found it breeding in small colonics at about the same date. It is a much more tropical bird than the Common Heron, and is much less gregarious in its habits during the breeding-season. Mr. Ayres found it breeding in the Transvaal, and remarks that frequently five or six pairs breed in company, placing their nests within five or six yards of each other. Hume remarks that in India fresh eggs have been met with as early as April and as late as August. Irby obtained eggs at Gibraltar during the latter half of April. In all these cases the nests were large structures, built of dead reeds, and resting upon bent-down reeds. Göbel, however, states that the foundations of the nests that he found were placed upon low willow bushes, from one to two fect above the level of the ground, and under the shclter of reeds. Oates found large colonies of these birds breeding in Burma in July and August, the nests being made of sticks, and placed on matted reeds near the surface of the water. On the other hand, Major Legge says that its breeding-habits in Ceylon are somewhat different. He states that it breeds in trees, in colonies, together with the Great White Egret. He obtained nearly fresh eggs in the north of Ceylon in December, and in the south of that island newly hatched young have been obtained in March.

The nest of the Purple Heron is a large structure, two feet or more in diameter, and is very flat. The eggrs are from three to five in number, and vary considerably both in size and shape, some being much more rounded than others. They vary in length from $2 \cdot 4.5$ to 1.95 inch, and in breadth from 1.75 to 1.45 inch. They are greenish blue, and do not differ in colour or texture from those of the Common Heron, from which it is impossible to distinguish them, though on an average they are slightiy smaller. The Purple Heron only rears one brood during the season. When the colony is disturbed the birds fly round, uttering loud cries.

The Purple Heron is slightly smaller than the Common Heron, but 
being more essentially a marsh-bird, its toes and claws are much longer than those of its ally, approaching the Rails in this respect. In its general style of coloration it resembles the Common Heron; but differs from it in having the forehead and crown black instead of white; the dorsal plumes, which are white in the Common Heron, are chestnut; on each side of the neck and halfway down its back, connected by a band across the earcoverts, are black longitudinal stripes; and the ground-colour of the sides of the neck and underparts below the throat are pale chestnut. Many of the under wing-coverts are chestnut, the sides of the breast are reddish chestnut, and the white of the belly and thighs is represented by chestnut, and that of the under tail-coverts by black and white. Bill, legs, feet, claws, and irides the same as in the Common Heron. The female resembles the male, except that all the colours are duller, and the crest-feathers and dorsal plumes are much less developed. In the young in first plumage the crest-feathers and the elongated feathers of the neck and back are absent. The black stripes on the neck, breast, and belly are only represented by obscure dark centres to the feathers, and all the small feathers of the upper parts have broad chestnut margins. After the first moult, which is completed when the bird is scarcely a year old, the intermediate plumage of birds of the year is assumed *.

* There can be little doubt that Dresser has mistranslated Naumann when he states that the full plumage of the Purple Heron is not assumed until the bird is three years old. The progress of these birds towards maturity appears to be as follows:-1880-birds (for example) are born in July; at the end of the same year they begin their first moult, which is completed in March 1881; during the following antumn they moult into nearly adult plumage, which they complete in March 1882 - that is to say, in the third year during which they have lived, though they are only twenty months old, and not three years, as erroneously stated by Dresser.

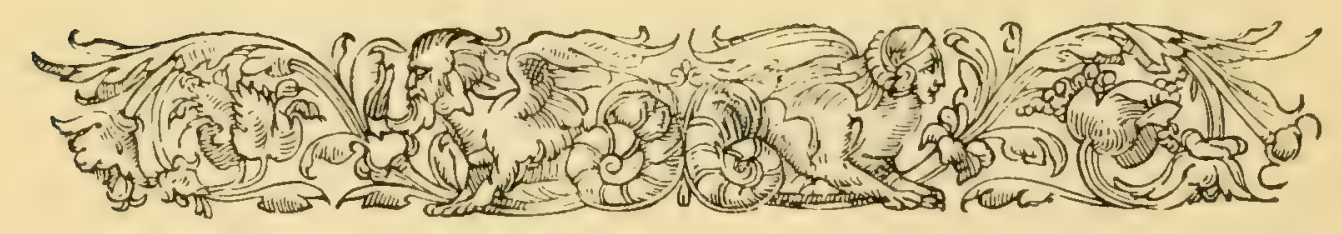


ARDEA ALBA.

\section{GREAT WHITE EGRET.}

(Plate 38.)

Ardea candida, Briss. Orn. v. p. 428 (1760).

Ardea alba, Linn. Syst. Nat. i. p. 239 (1766); et auctorum plurimorum-Gmelin, Scopoli, Latham, (Bonaparte), (Salvadori), (Degland \& Gerbe), (Dresser), \&c.

Ardea egrettoides, Gmel. Reise Russl. ii.p. 193, pl. 25 (1774).

Egretta melanorhyncha, Wagler, Isis, 1829, p. 659.

Herodias candida (Briss.), Brehm, Vög. Deutschl.p. 584 (1831).

Egretta alba (Linn.), Bonap. Comp. List B. Eur. \& N. Amer. p. 47 (1838).

Erodius vietoriæ, Macgill. Man. Brit. B. ii. p. 131 (1842).

Erodius albus (Linn.), Macgill. Man. Brit. B. ii. p. 134 (1842).

Egretta nigrirostris (Gray), apud Macgill. Hist. Brit. B. iv. p. 460 (1852).

As long ago as 1676 the occurrence of the Great White Egret in this country was known to Willughby and Ray, who were indebted for the information to their correspondent, Mr. Ralph Johnson, a Yorkshireman "of singular skill in zoology, especially the history of birds." This species is only an accidental straggler to the British Islands; but about twenty instances of its occurrence have been recorded, principally in the eastern counties of England and Scotland. It is not known to have occurred in Ireland or Wales ; but has been met with on the west coast of England, in Cornwall, Devonshire, and Cumberland. The latest record is that of an example which was said to have been seen near Penzance on the 4th of February, 1866. Very little reliance can be placed upon the accuracy of the identification, and the date is strong evidence against it. There does not appear to be any reliable instance on record of the occurrence of this species in our islands during the last thirty or forty years.

The Great White Egret is not known to breed regularly in any part of Europe except in South Russia and the valley of the Lower Danube. Homeyer found a single pair breeding with a colony of Common Herons in Silesia, and similar instances doubtless occasionally occur elsewhere. As an accidental straggler it has occurred in every country in Europe, most frequently, of course, in the south. It is not known to have occurred on Iceland or the Faroes; but it occasionally visits the Azores. It is found in suitable localities throughout Africa, and is said to breed there; but in South Africa it may have been confused with Ardea intermedia. Eastwards, it is a summer visitor to Asia Minor and Palestine, and breeds throughout Turkestan, South-west Siberia, as far north as lat. $47^{\circ}$, Persia, the valley of the Amoor, South-east Mongolia, and Japan. It is a resi- 
dent in India, Ceylon, Burma, and China. Examples from Europe and North Africa vary in length of wing from 16 to 18 inches, and in length of tarsus from 7 to 8 inches. Examples from Asia are on an average smaller, varying in length of wing from $13 \frac{1}{2}$ to 16 inches, and in length of tarsus from $5 \frac{1}{4}$ to $6 \frac{3}{4}$ inches. The latter, if subspecifically distinct, may be distinguished as Ardea alba var. modesta* .

In addition to the two forms of uncrested White Egrets whose range is given above, there are two nearly allied species with which they have often been confounded. Both of these may be distinguished in summer by the colour of the bill, which is yellow at all seasons of the ycar. Ardea egretta does not differ in measurements from its black-billed ally; but its variations in size do not appear to be geographical. It breeds throughout the Southern States of America, from the Atlantic to the Pacific, in New Zealand, and Australia, and occasionally wanders as far as Japan. Ardea intermedia is a much smaller bird, almost as small as its crested European ally $(A$.garzetta); it breeds in South Africa, India, Burma, China, and Japan. It is not known that the Great White Egret has any nearer allies than these and the Crested White Egrets mentioned in the article on the Little Egret. There is some difficulty about the determination of the White Egrets in winter plumage; but it scems probable that $A$. candidissimia and A. eulophotes do not lose their crests in winter. A. garzetta loses his crest, but retains his black bill, which is a sufficient distinction. The bill of $A$. alba becomes yellow in winter, at which season this bird is indistinguishable from $A$. egretta, or from small examples of $A$. occidentalis after they have lost the crest-feathers.

The Great White Heron is only a summer visitor to Europe, arriving in April and leaving in September. It appears to be nowhere a very common bird, and to have become rarer of late years.

The habits of this graceful bird resemble those of the Common Heron in many respects. It delights to frequent the outskirts of extensive swamps, the margins of rivers, and shallow weed-grown lakes, together with willow-thickets and other wooded country when it is flooded. It may frequently be seen in small parties of perhaps half a dozen individuals walking sedately about mud-flats and low islands, or standing preening its brilliantly white plumage. It is a very conspicuous bird, and may be obscrved for half a mile or more; consequently it is very wary, and seldom allows the observer to come near. It looks remarkably graceful as it walks

* The synonymy of the enstern form is as follows:-

Ardea flavirostris, Temm. fide Wagl. Syst. Av. Ardea, sp. 9 (1827).

Ardea modesta, Gray, Ill. Ind. Zool. ii. pl. 49 (1834).

Egretta modesta (Gray), Bonap. Consp. ii. p. 117 (1857). 
slowly up and down the marshy banks of a stream, or stands motionless, sometimes on one leg, in the water patiently watching for food. It is very rarely that this bird allows the observer to approach it sufficiently near to get a good view of it, and generally it takes wing the moment it is alarmed. Its flight is moderately slow, performed by a series of regular flappings of the wings. It seems more buoyant in the air than the Common Heron, and looks more graceful. Its flight is often prolonged for a considerable distance, and the bird is very conspicuous as it flaps slowly over the dense waving reeds. The Great White Egret may be seen in little parties all through the breeding-season, and in winter congregates into much larger flocks. It also mingles freely with other species of Herons; but its large size is always enough to distinguish it from its congeners. It does not appear to frequent the most secluded and inaccessible parts of the marshes and reed-beds so much as their borders. It seldom, if ever, pushes its way through the dense and almost impenetrable reeds like the Bittern, but haunts the little open spaces and the borders of the swamps, and is very fond of the tangled herbage on the bank of a stream. It often wades for some distance in the water, and seems as partial to running streams as to still lakes and ponds.

The food of the Great White Egret is principally composed of small fish, but great quantities of water-insects and their larvæ, frogs, and small mammals are captured. The bird appears to obtain the greater part, if not all, its food in the daytime; but it may seek for it at night when the moon is at or near the full. The note of the Great White Egret is a harsh and deep bark; but it is only occasionally heard. The note of the young birds is described by Homeyer as kek, rapidly repeated.

In Europe the breeding-season of the Great White Egret takes place in May, and eggs may be obtained from the middle of that month till the middle of June. Its nesting-places are selected on some low swampy island, or in a large dense thicket of reeds. In India the eastern form of the Great White Egret is said invariably to make its nest in trees. Both forms appear often to take up their residence with other species, and generally make their nest in the same tree as Ibises, Pigmy Cormorants, Night-Herons, and Little Egrets. The nest is a moderately large structure, almost exclusively made of sticks, the larger and coarser ones forming the outside and the finer twigs the lining; but when it is placed in swamps it is made of dead reeds and portions of aquatic regetation suitable for the purpose. The nest is broad and quite flat, and by the time the young are able to fly is so trodden about as only to rescmble a mere heap of sticks. It appears that the old nests are repaired and enlarged in many cases, in a similar mamner to those of the Rook. The eggs are generally three or four in numbcr, sometimes five; they are greenish blue, rough in texture, and possess no gloss. They vary from $2 \cdot 7$ to $2 \cdot 35$ 
inch in length, and from 1.77 to 1.7 inch in breadth. They vary somewhat in shape, some specimens being much more pointed than others. It is impossible to distinguish the eggs of this species from those of the Common Heron or the Purple Heron. When the young are nearly fledged they often leave the nest and perch on the adjoining branches to wait for their parents' arrival with food. It is a very pleasing scene, when the young are being reared, to watch the old birds pass to and fro with food, or fly hither and thither with legs thrown out behind and head drawn in between the shoulders, anxious for the safety of their broods. The Great White Egret only rears one brood in the season.

The spring plumage of the Great White Egret is as white as snow; there is a very slight crest on the head, and the feathers of the lower neck are prolonged into narrow plumes; and from the lower back extend two tufts of long plumes which reach beyond the tail. Bill black; bare space round the eye greenish yellow; legs and feet reddish brown; claws black; irides yellow. The female resembles the male in colour, but the plumes on the head, neck, and back are shorter. In the course of the summer the dorsal plumes are gradually lost, and are not renewed until the spring moult. The winter plumage does not otherwise differ from that of summer; but about the time of the autumn moult the black bill becomes yellow, changing to black again at the spring moult. Young in first plumage only differ from adults in having no long plumes, and in having a yellow instead of a black bill. Birds of the year only differ from adults in having the plumes shorter; the bill in summer is yellow at the base and the legs are paler.

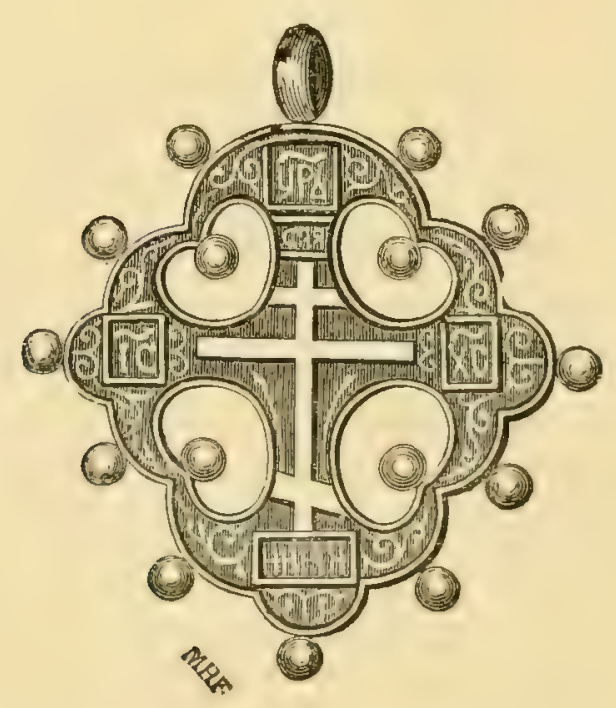




\section{ARDEA GARZETTA.}

\section{LITTLE EGRET.}

\section{(Plate 38.)}

Ardea egretta, Briss. Orn. v. p. 431 (1760).

Ardea garzetta, Linn. Syst. Nat. i. p. 237 (1766); et auctorum plurimorumLatham, Temminck, Naumann, Schlegel, Dresser, \&c.

Ardea niuea, Gmel. Reise Russl. i. p. 164 (1770).

Ardea santodactylos, Gmel. Reise Russl. iii. p. 253 (1774).

Ardea nivea, Gmel. Syst. Nat. i. p. 640 (1788).

Ardea æequinoctialis, Linn. apud Leach, Syst. Cat. Mamm. \&c. Brit. Mus. p. 33 (1816).

Herodias garzetta (Linn.), Boie, Isis, 1822, p. 559.

Ardea melanopus, Wagler, Isis, 1829, p. 660.

Herodias jubata, Brehm, Vög. Deutschl. p. 586 (1831).

Ardea nigrirostris,

Ardea orientalis, f Gray, Zool. Miscell. pp. 19, 20 (1831).

Egretta nigrirostris (Gray),

Egretta orientalis ( $G r(1 y)$,

Egretta garzetta (Linn.),

Bonap. Comp. List B. Eur. \&. N. Amer. p. 47 (1838).

Ardea nigripes, Temm. Man. d'Oin. iv. p. 377 (1810).

Erodius garzetta (Linn.), Macgill. Man. Brit. B. ii. p. 135 (1842).

Herodias immaculata, Gould, B. of Austr. vi. pl. 59 (1848).

Garzetta immaculata (Gould), Bonap. Compt. Rend. xl. p. 722 (1855).

Garzetta egretta (Briss.),

Garzetta orientalis (Gray), Bonap. Consp. ii. pp. 118, 119 (1857).

Garzettr nigripes (Temm.),

Herodirs melanopus ( $W a g l_{\text {.) }}$, Gould, Handb. B. Austr. ii. p. 304 (1865).

Garzetta niven (Gmel.), Tacs. Bull. Soc. Zool. France, 1877, p. 159.

The Little Egret is a very rare accidental visitor to the British Islands. The last known occurrence of this bird is that of an example which was shot on the 4th of January, 1881, a few miles north of Scarborough (Harper, 'Zoologist,' 1881, p. 213). Ten years previously an example was killed on the 3rd of June, 1870, near Exeter (Gatcombe, 'Zoologist,' 1870, p. 2308). During the previous thirty-five ycars no reliable instance of the appearance of this bird in our islands is recorded, the alleged occurrences in Morayshire (Gordon, 'Zoologist,' 1841, p. 513) and in Warwickshire (Christic, 'Mag. Nat. Hist.' 1836, p. 647) being very doubtful. About 1834 an example was obtained near Norwich, and another near Yarmouth about the same date. Two examples are said to have been obtained in Cornwall about 1825, one in Hampshixe in July 1822, and one in Devonshire in 1816. The alleged occurrences of this bird in Ireland and in Wales at the close of the last century cannot be relied on.

The range of the Little Egret is not such a northern one as that of the VOL. II. 
Great White Egret, nor is the bird as local. It is resident and breeds in most suitable localities throughout the whole of Africa and the Cape-Verd Islands, occasionally visiting the Canaries and the Azores. To Europe it is only a summer migrant, breeding in Spain, the delta of the Rhone, Sardinia, Sicily, the valley of the Danubc, and South Russia; but a few remain during winter in the extreme east of the Mediterranean. To the rest of Europe it is an accidental straggler, or occurs on migration in cvery country south of the Baltic. It occurs in Palestine, Asia Minor, and Persia, and is a resident in India, Ceylon, Burma, and the main island of Japan. It is a summer visitor to North China; but is a resident in South China, and occurs probably in winter in Java, Sumatra, the Philippines, Celebes, and Australia.

The nearest ally to the Little Egret is Ardea occidentalis. The crest of this bird resembles that of the Little Egret, but its bill is yellow at all seasons of the year, and the bird itself is very large, frequently exceeding the Great White Egret in size. It is found in South Florida and Cuba. Two other White Egrets are very nearly allied to the Little Egret; but may easily be distinguished from it by the much greater number of plumes in the occipital crest. A. candidissima inhabits the Southern United States, from the Atlantic to the Pacific, and does not differ from the Little Egret in size or in colour of bill. A. eulophotes, from South China and Formosa, is a slightly smaller bird than the Little Egret, but has a yellow bill all the year round.

The Little Egret is a summer visitor to Europe, arriving in Southern Spain early in April, and in Greece towards the end of March, but not reaching its breeding-grounds in the valley of the Danube until early in May. The nests are completed about the end of May, and eggs are laid during the first half of June. It is constantly seen on the wing during the breeding-season. Although it breeds principally in the densest willow-thickets, it frequents open marshes, sand-banks, and shallows in the river, and the margins of the streams, where its snow-white plumage makes it an extremely conspicuous bird. In its flight it resembles the other species of Herons, procceding with steady flaps of its broad wings. having the head drawn up between the shoulders, and the legs extended so as to make a straight line with the beak. It is not quite so gregarious as the Squacco Heron, being seldom seen in large parties except at the nests. Upon the ground it walks about with the sedate and easy action of the other Herons. It can scarcely be called a shy bird; but is nevertheless very difficult to shoot except at its breeding-colony. It may often be seen standing in the water, but does not show any partiality for perehing in trees except in the vicinity of its nest.

The food of the Little Egret consists principally of fish and waterplants, but it also eats aquatic insects, frogs, and worms. 
The breeding-colonies of these birds on the Danube are very difficult to find, and can only be approached by a boat. The nests are generally placed in forests of pollard willows, but those only appear to be selected that are under water at the time of the rising of the river, which fixes the date for the commencement of their breeding-operations. When I was in the valley of the Danube last spring we sailed down the river from Giurgivo for three days without discovering a heronry; but on the evening of the third day, the number of Little Egrets and Night-Herons which we observed feeding on the marshes, near the little river which lcads from the main stream to the town of Kalarash, was so great that we suspected the existence of a heronry in the neighbourhood. After watching for some time we discovered that many of the birds disappeared into a dense forest of pollard willows which was situated at the west angle of the junction of the two rivers. On the following morning, the 27 th of May, we reached it, shooting a Night-Heron on the way. As we approached the forest we occasionally saw a Little Egret flying over; but there was nothing to denote that we were near a large colony of birds. The banks of the river were flooded in many directions, and we at length succeeded in reaching the forest, though we sometimes rowed over the tops of willow trees where the water was deep, and occasionally had to get out and push the boat over the shallows. In the forest the water was about four feet deep; but on its outskirts it rose as high as the tops of the trunks of the pollard willows, which presented a dense mass of boughs, through which it was impossible to force the boat. We succeeded, however, in entering from behind, and by dint of pushing and squeezing, and a liberal use of the axe, we reached the outskirts of the colony, and having put on our wading-trousers proceeded to investigate it. The water was so deep that it was impossible for us to stoop, and it was with great difficulty that we selected places where the branches allowed us to squeeze through them. Before we reached the nests we conld hoar birds getting up with great flutter of wings, and our invasion of the colony was heralded by incessant cries. We walked or rather squeezed in for about fifty yards, threading our way through the labyrinth of boughs, and found ourselves in an intensely interesting position. The trces were full of nests, some of them so near the surface of the water that we could sce the eggs without climbing. Few nests were more than from ten to twelve feet above the surface of the water, and some trees contained as many as ten nests with eggs belonging to three species, the Night-Heron, the Little Egret, and the Squacco Heron, those of the Little Egret being the most numerous. The nests of these birds were generally placed in a fork of a side branch of the pollard willows, and were made on quite a different model to that adopted by most birds: they were entirely composed of slender twigs, on some of which the leaves were still remaining; but the 
peculiarity of their structure was that nearly all the twigs radiated from the centre. The nests were rather deep, but the sides were so thin that the eggs could be scen from the level. It is difficult to give exact measurements of nests formed on this plan, but the thick part of the nest was about ten inches across.

The Little Egrets were very noisy, and their notes of alarm or defiance resembled the syllables $a k$, ark, and ork. It was a most wonderful sight, the varied cries of the birds, the incessant flapping of wings, the continual flight of birds overhead, the unusual spectacle of long-legged waders perched on the slender branches of willow trees, the smell (which reminded me of that of a colony of Cormorants), the dense tangle of branches overhead, and the novel sensation of bird's-nesting in three feet or more of water, which made it impossible to stoop, and the enormous numbers of nests, all combined to form a scene of intense interest. We found hundreds if not thousands of eggs in the nests, and after we had taken as many as we wanted, we lunched on the spot, and then turned out of the boat in the water to stroll once more through the novel scene, to smoke a cigar amongst the flapping of Herons' wings, and to shoot an example of each of the species, which we had not the slightest difficulty in doing, for the complete identification of the eggs.

The eggs of the Little Egret are from three to six in number, and uniform bluish green in colour. They vary in length from 1.9 to 1.65 inch, and in breadth from 1.4 to 1.25 inch. On an average they are smaller than eggs of the Night-Heron; but small eggs of the latter species are indistinguishable from large eggs of the Little Egret. The eggs of the Squacco Heron are much smaller. Only one brood is reared in the season.

A fortnight later we visited a second colony of Little Egrets, breeding in company not only with the Night-Heron and the Squacco Heron, but also with the Common Heron and the Pigmy Cormorant; and we were informed that they sometimes make their nests on the bent-down reeds, in company with the Ibis and the Great White Egret. As soon as the young are fledged they leave the nests to perch on the neighbouring branches, where they are fed by their parents. In Ceylon and Southern India this bird begins to breed in December; but in Northern India it lays its eggs in July.

The Little Egret is an exact miniature of the Great White Egret, but it has two long narrow white feathers in the crest. Wher fresh killed the Little Egret is one of the most beautiful birds to be found; the snowy whiteness of the plumage contrasts with the black bill, and the lores and the space round the eye are bare of feathers, the flesh being a beautiful lavender colour. Irides pale lavender; legs bluc-black, feet suffused with yellow, claws black. The female resembles the male in colour, but 


\section{LITTLE EGRET.}

the dorsal plumes and crest-feathers are shorter. After the autumn moult the elongated crest-feathers and the dorsal plumes are not renewed, and only appear in the following spring. Young in first plumage scarcely differ from adults in winter plumage, whilst birds of the year are somewhat intermediate between them, but have the base of the under mandible yellow.

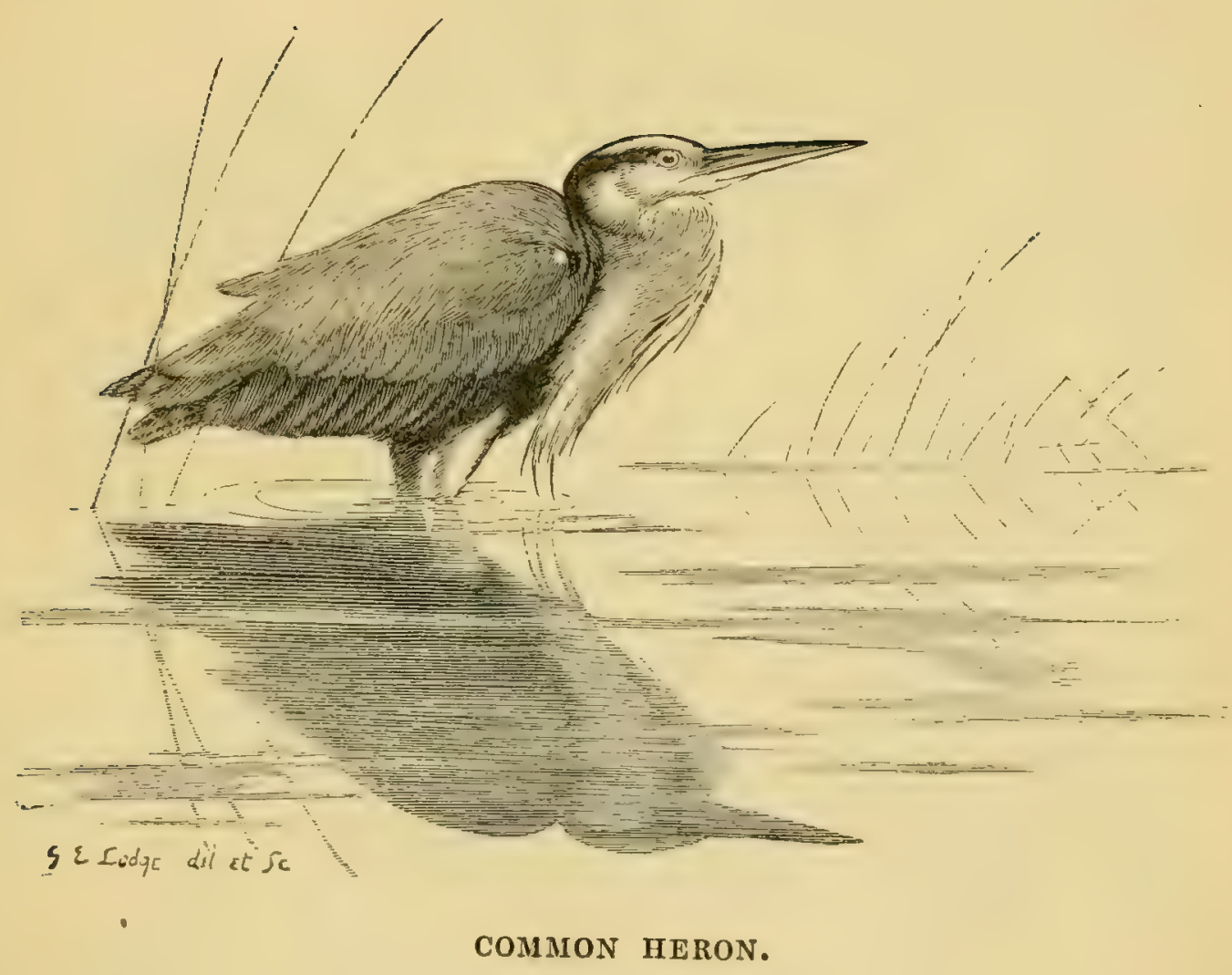




\title{
ARDEA COMATA.
}

\section{SQUACCO HERON.}

\author{
(Plate 38.)
}

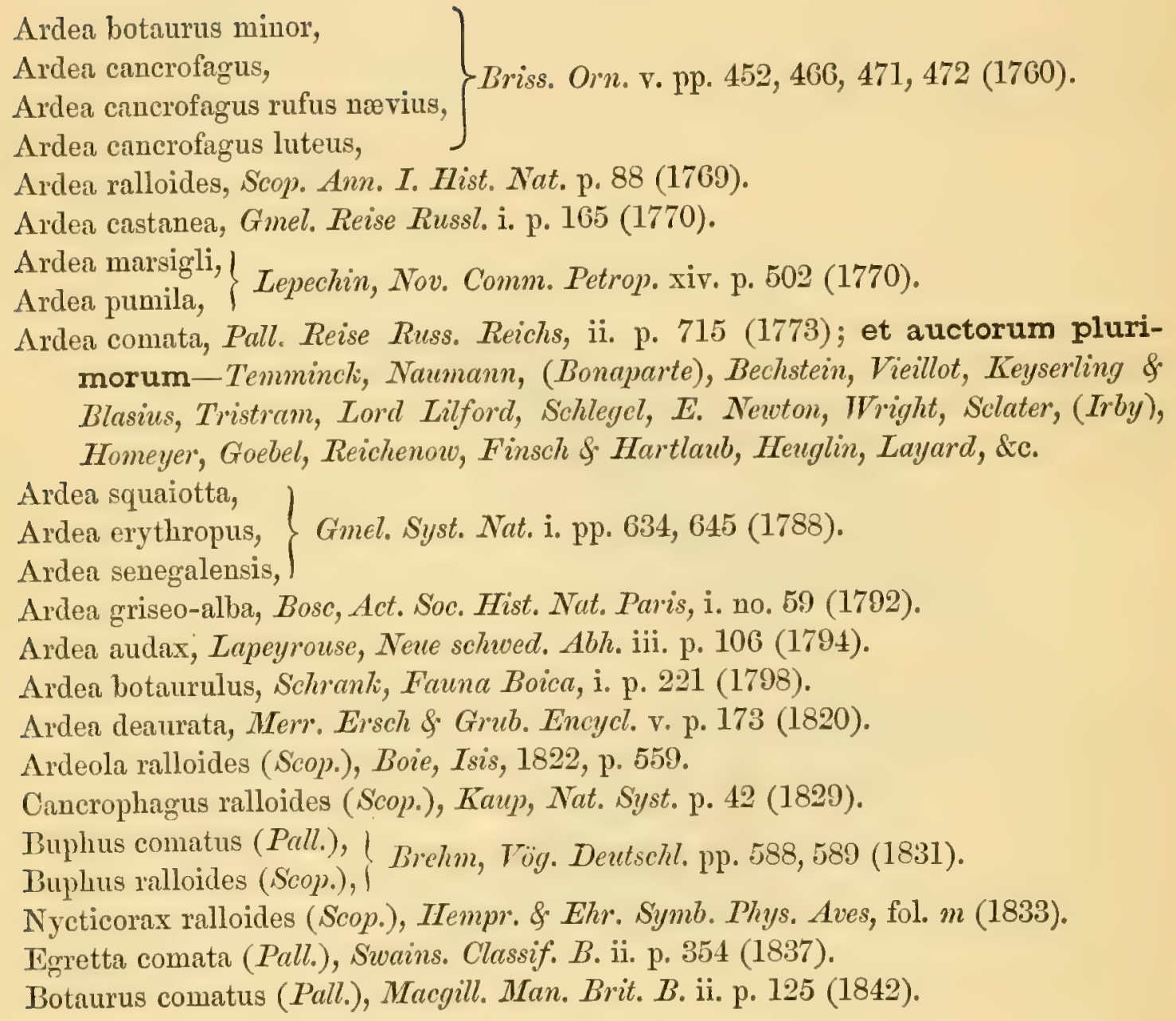

The Squacco Heron must be regarded as a very rare straggler to the British Islands, principally on spring migration. It was first recorded as a British bird by Latham, who mentions one example obtained at Boynton, in Wiltshire, in 1775 (Gen. Syn. Suppl. ii. p. 302), and a second at Ormsby Broad, in Norfolk, in 1820 or 1822 (Gen. Hist. B. ix. p. 110). It does not appear to have been noticed again until 1831, from which date until 1867 twenty-two examples occurred, most of which were obtained in the counties on the south coast of England and in Norfolk and Suffolk; one example, however, was obtained in Nottinghamshire, one in Durham, one in Cumberland, and one in Ireland. During the last seventeen years there does not appear to have been any record of its occurrence in England, 
but three examples have occurred in Ireland*. Most of these birds were obtained in May, which is about the date at which they arrive at their breeding-quarters in Southern Europe. There is no record of its occurrence in Scotland.

The Squacco Heron is confined to Africa and the basin of the Mediterranean and Black Seas. It is an accidental straggler to the Canary Islands, but is a resident in all suitable localities in Africa, breeding in Algeria, Egypt, Damara Land, the Transvaal, \&c. In the Spanish peninsula it is only known as a summer visitor, and to the east it breeds in the valley of the Danube, South Russia, the basin of the Caspian, and Palestine. In the rest of Europe it is an accidental straggler to most countries south of the Baltic. The Squacco Heron has no ally with which it can be confused; it belongs to a small group of Herons which are distinguished by their short tarsus, which is not as long as the beak or as the middle toe and claw.

The Squacco Heron is only known in Europe as a migratory bird, arriving in Southern Spain and Greece early in April, but not reaching its breeding-grounds on the Danube until early in May. It differs little in its habits from the Little Egret and the Night-Heron, but is not quite so shy as these birds and is somewhat more gregarious. Although it was not so numerous at either of the great breeding-colonies which we visited last year, it was more often seen in sailing down the Danube than they were. It chiefly frequented the green grassy banks of the river, sometimes singly, but generally in small parties consisting of eight or ten individuals. It was not nearly so active as the other Herons, and was frequently observed standing for a long time in the same position, when alarmed flying on a few steps only. It is a remarkably silent bird, and we never heard it utter a note, even at the nest; but Naumann says that it utters a low hoarse sound somewhat resembling the syllable karr. In its flight the neck and legs look very short and the wings very broad, but, like its near allies, it flies in a direct steady manner, the bill, which is drawn up close to the body, and the legs, which are stretched out, being in one line. Like the Night-Heron it is somewhat less of a fish-eater than the Little Egret, the stomachs of those we shot containing only beetles and vegetable matter. It also eats crabs; and Naumann says that he has found very small fish, frogs, small shells, and water-insects in its stomach. He also remarks the partiality of this bird for the company of pigs. It is probable that it is in the habit of feeding after these animals as they turn up the ground with their noses, in the same way that Rooks follow the plough.

* An example was shot near Killarney in 1875, a second in King's Co. in 1877, and Mr. R. Lloyd Patterson informs me that a third was shot near Londonderry by $\mathrm{Mr}_{\mathrm{r}}$. Bond on the 23rd of November, 1881. 
It is a somewhat later breeder than the Night-Heron and the Egrets, in

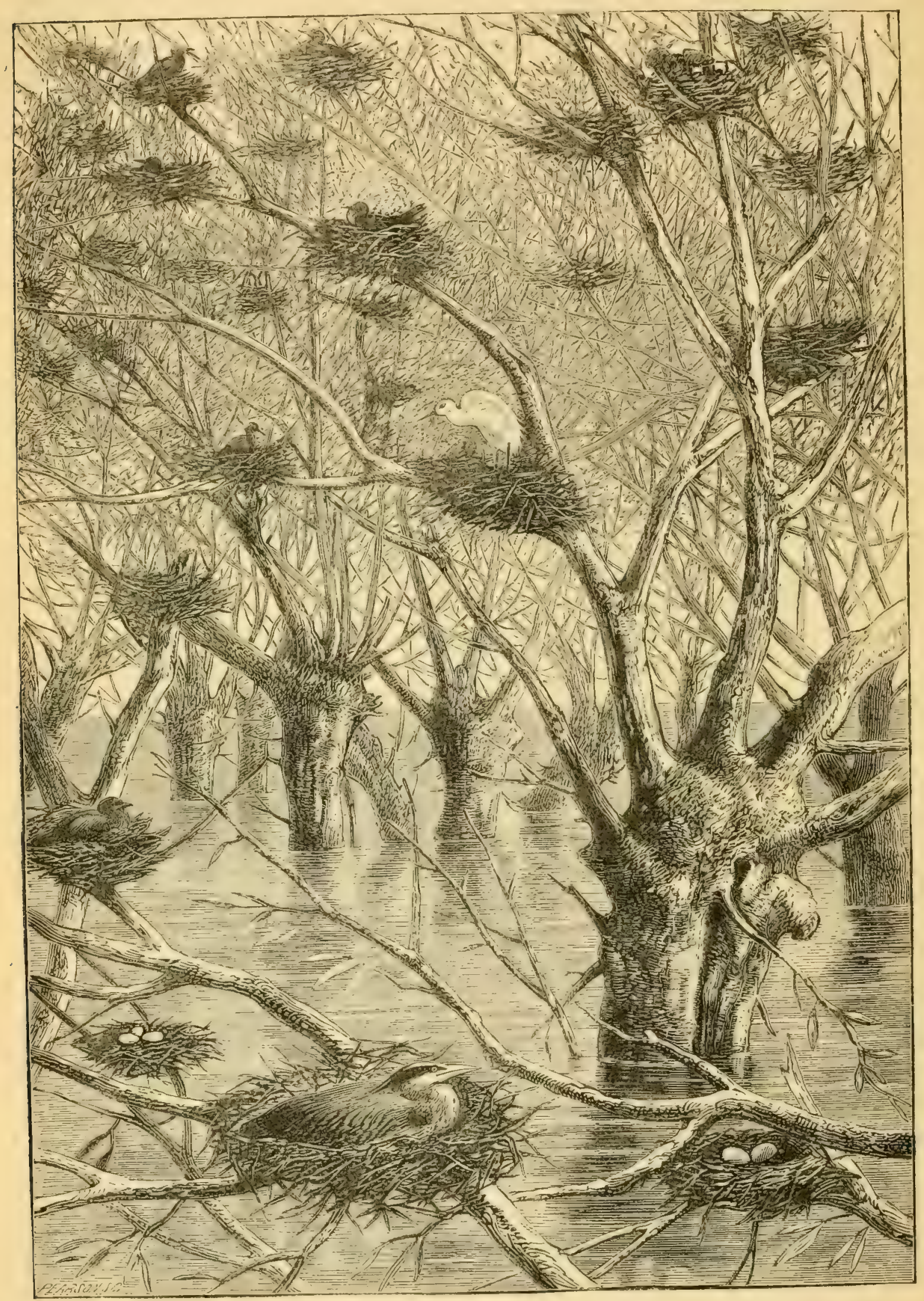

whose company it builds its nest. The largest Heron-colony which we visited in the Lower Dauube was not far from the town of Hirsova. It 
would have been impossible for us to have discovered this colony without a guide. It took us four hours' rowing across country to reach it. As far as we could see, from the bluffs which form the western boundary of the steppes of the Dobrudscha, the country beyond was under water. After crossing the main stream we entered a bed of rushes, and passing by a colony of Black Terns, we rowed down a long wide lane with walls of reeds on each side, and sprinkled all over with water-lilies in full bloom, the stalk of one we pulled up measuring eight feet. Then we crossed meadows gay with the yellow flowers of the spurge, having occasionally to get out of the boat to push it over a mud-bank. Crossing a large lake where Swans floated amongst scattered reeds, and a pair of Grey-lag Geese were flying round as if we were near their nest, we entered a labyrinth of willows and meadows, sometimes gliding with the current between rows of willows, where the stream was too narrow to admit of the use of oars, and where we had frequently to lie down in the boat to squeeze under the branches of the trees. After crossing another main arm of the river our guide pointed out to us a large forest of pollard willows about half a mile square, in the centre of which he told us we should find the great Heroncolony. We approached it across a lake thinly sprinkled over with reeds; now and then we could see a Little Egret; and small parties of Cormorants and Ibises occasionally flew over the forest, but there were no signs of our being near any great breeding-place. No one would ever have suspected that the forest contained the treasures it did, nor would any one who did not know every inch of the ground have been able to find a way to it in a boat across country. The water was from five to seven feet deep, so that wading was cntirely out of the question. Fortunately the trees were not very crowded, being planted, for the most part, in groups, leaving paths wide enough for the boat in every direction. The part occupied by the colony was near the centre of the forest, and consisted of four or five hundred pollard willows, each of which contained from five to twenty-five nests, belonging to five species of birds. The place of honour in each tree was generally occupied by the large nest of a Common Heron, whilst almost every available fork contained smaller nests of the Little Egret and Night-Heron and, smallest of all, the nests of the Pigmy Cormorant and the Squacco Heron. Before we penetrated the centre of this great breeding-colony, which must have consisted of at least five thousand nests, we found ourselves in the midst of a perfect babel of birds. We had disturbed many hundred Herons from their nests, some of which were flying round us in every direction, whilst others were perched in the slender branches of the willows, the snowy white Little Egrets contrasting with the almost black Pigmy Cormorants. It was difficult to say which looked most out of place as the branches bent beneath their weight. Most of the birds, probably the males, flew round and round far above 
our heads, but we had no difficulty in shooting a Squacco Heron and a Pigmy Cormorant, and might have obtained any number had we required them. Although it was the 12th of June, all the eggs of the Common Heron, nearly all those of the Squaceo Heron, and many of those of the Pigmy Cormorant were quite fresh. The Night-Heron was the closest sitter (but the reason may have been that its eggs were the most incubated), and of the five species this was the only one which had any young. The nests of the Squacco Heron were built on the same model as those of the Little Egret and Night-Heron, the twigs of which they were composed being arranged from the centre, thus forming radii, whilst those of the Common Heron and the Pigmy Cormorant were arranged, as usual, round the centre, forming arcs. The Squacco Heron builds a very slight nest, somewhat deep, though the sides permit the eggs to be seen through the sticks, the more solid part of the nest not exceeding six inches across. It is impossible to describe the interest of such a scene. In these flooded forests there is scarcely any current, and the water was quite warm and discoloured by the droppings of the birds, whilst the smell was similir to that of a guano warehouse. The sun was burning hot, and not a breath of air penetrated the thicket. By the time we had explored the colony many thousand birds must have been upon the wing, flying wildly round and round and backwards and forwards, in the greatest excitement, every now and then perching on the willow trees, and incessantly uttering their loud discordant cries. We had some little difficulty in identifying the eggs of the Night-Heron and the Little Egret. Concerning those of the Common Heron, the Squacco Heron, and the Pigmy Cormorant, there can be no manner of doubt; but after watching a Night-Heron rise from its nest we often found on reaching the spot that two or three other nests were so close to it that it was impossible to say which was the one that belonged to the bird we had watched. The excitement of the birds lasted long after we had left their colony, and had not subsided when we lost sight of it.

In North Africa the Squacco Heron is said always to nest on the ground amongst the sedges, probably in consequence of the absence of trees; but in the valley of the Danube it is not known to breed anywhere except in trees. The eggs of the Squacco Heron are from four to six in number, and are greenish blue in colour; they vary in length from 1.6 to 1.5 inch, and in breadth from 1.2 to 1.06 inch. They cannot be confused with the eggs of any of the other European Herons. Only one brood is reared in the year.

The Squacco Heron is, if possible, even a more beautiful bird than the Little Egret. It is pure white, with the exception of the feathers of the back, neck, and upper breast, which are buff, suffused with pale russetbrown on the back, each feather of the forehead, crown, and nape margined 
with black, and six long narrow white feathers margined with black extend beyond the crest: the feathers on the lower back and breast are spread out into plumes. The soft parts of the head of this Heron are very beautiful. When newly killed it has the tip of the bill black, the remainder cobalt-blue, and the bare skin round the eye emerald-green; the legs and fect are flesh-colour, yellow on the soles and round the knces, claws black; irides pale yellow. The female resembles the male in colour, but the plumes are shorter. After the autumn moult all the feathers of the neck, except the chin, throat, and a narrow line down the fore neck, have dark brown margins, like the feathers on the crown in summer plumage; the black and white feathers of the crest, and nearly all the nuptial plumes on the back, are absent, and the feathers of the upper back, the scapulars, and imnermost sccondaries are earthy brown. Young in first plumage have the upper parts more or less streaked, but otherwise very closely resemble the aclults in winter plumage, birds of the year being slightly intermediate.

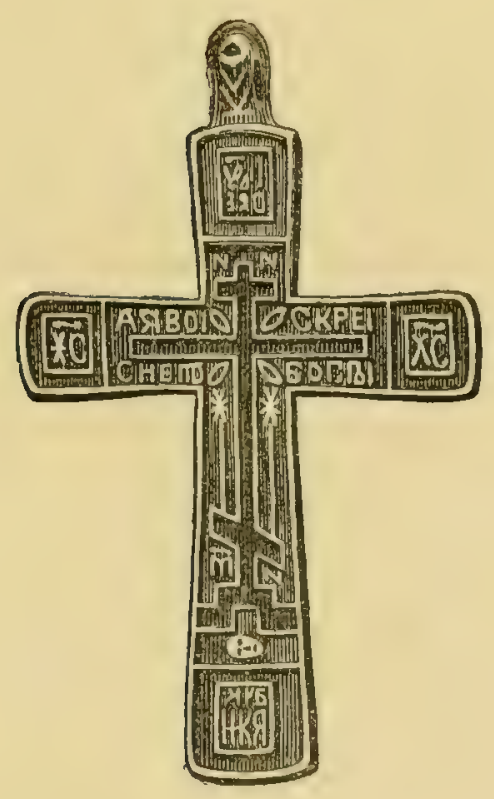




\section{ARDEA BUBULCUS.}

\section{BUFF-BACKED HERON.}

(Plate 38.)

Ardea candida minor, Briss. Orn. v. p. 438 (1760).

Ardea lucida, Rafinesque-Schmaltw, Caratteri nuovi gen. e sp. Sicilia, p. 5 (1810).

Ardea æquinoctialis, Linn. apud Mont. Orn. Dict. Suppl. sheet M (1813).

Ardea bubuleus, Audouin, Expl. somm. Pl. Ois. de l'Egypte, i. p. 298, pl. viii. fig. 1

(18.5); et auctorum plurimorum-Lesson, Mïller, Heine, Schlegel, Henglin,

Gray, Hartlaub, Brehm, Salvadori, Taczanowshi, Finsch, Gurney, Sclater,

Dresser, \&c.

Ardea russata, Wagl. Syst. Av. Ardea, no. 12 (1827).

Ardea verany, Roux, Orn. Prov. pl. 316 (1829).

Egretta russata (Wagl.), Swains. Classif. B. ii. p. 354 (1837).

Erodius russatus (Wagl.), Macgill. Man. Brit. B. ii. p. 135 (1842).

Buphus russatus (Wagl.), Hengl. Syst. Uebers. p. 59 (1856).

Ardea ruficristata, Verr. fide Bonap. Consp. ii. p. 125 (1857).

Bubulcus ruficristata (Verr.), Bonap. Consp. ii. p. 125 (1857).

Herodias russata (Wagl.), Salvin, Ibis, 1859, p. 357.

Herodias bubulcus (Aud.), Taylor, Ibis, 1860, p. 313.

The Buff-backed Heron has scarcely any claim to be regarded as a British bird, having only been obtained in this country three times. Montagu (Trans. Linn. Soc. ix. p. 197) records a female shot near Kingsbridge, in Devonshire, in October 1805. Stevenson ('Birds of Norfolk,'ii. p. 151) mentions a young bird shot at Martham, near Yarmouth, in 1827; and Mr. Cleveland ('Zoologist,' 1851, p. 3116) states that an example was obtained in South Devonshire in April 1851.

The Buff-backed Heron is an African bird, and is resident throughout that country, brecding in all suitable localities, from Algeria and Egypt in the north to the Cape Colony and Madagascar in the south. It is an accidental visitor to Madeira and to various parts of South Europe. In the Spanish peninsula it is partly a resident and partly a spring migrant. It is not known to breed in any other part of Europe; but in the east its breeding-range extends into Palestine. It is an accidental straggler to the south of France, Italy, Sicily, Greece, and South Russia, but is not known to have occurred in North Europe*.

* Nordmann's statement that this species is abundant on the Danube is erroneous, as is also the statement of De Filippi that it is abundant on the shores of the Caspian. In both these localities it is almost as rare as it is in the British Islands, and I have only been able to find one authentic instance of its occurrence in each of them. The Squacco Heron is, no doubt, the bird alluded to in both cases. 
The Buff-backed Heron is represented in the east by Ardea coromanda, which is a resident in India, Ceylon, the Burmese peninsula, South China, South Japan, and the islands of the Malay archipelago. It differs from its western ally in being slightly larger in size and richer in colour. The range of the two species does not quite coalesce, that of the African bird only extending as far east as the valley of the Jordan, and that of the Asiatic bird only as far west as the valley of the Indus. They have no very near ally.

The Buff-backed Heron differs in its habits in many respects from its allies. Its favourite haunts are pastures where cattle are feeding, and it is generally seen in small parties on the most friendly terms with the cows or buffaloes, from whom it picks the parasites which infest them, or catches the flies which tease them. So familiar is it with its friends that it may often be seen resting on the back of an ox or an elephant, who seem to appreciate its services. It also frequents arable land, where it is in the habit of following the plough, as Rooks and Gulls often do, to pick up the insects from the newly turned-up ground. Heuglin says that in Egypt it also frequents marshes in search of frogs, and visits the African steppes in thousands to feed upon the locusts which abound there, and is sometimes seen in the deserts, visiting the halting-places of the caravans.

Like the Squacco Heron this species feeds more upon insects than on fish or frogs; indeed it seems probable that the Buff-backed Heron is almost exclusively an insectivorous bird, though it is difficult to believe that it docs not also feed upon the tender shoots of various water-plants.

They are comparatively silent birds, except at their breeding-places, where, especially after the young are hatched, they are noisy enough. Heuglin says that the note resembles the syllable grah, and other travellers have likened it to the bleating of sheep.

The Buff-backed Heron breeds in colonies, making its nest in trees, sometimes in swamps, but often in dry forests, and even, according to Heuglin, in gardens. Where there are no trees it breeds in reeds. Like its congeners it is a somewhat late breeder, waiting in Egypt until the Nile has overflown its banks, in May and June. The nest is composed of sticks, and probably does not differ much from that of the Squacco Heron; but we have no reliable information on the subject. The number of eggs varies from three to five. They are almost white in colour, but are slightly shaded with bluish green, and after they are blown the dark green of the inner shell is visible through the hole when held up to the light. They vary in length from 1.9 to 1.7 inch, and in breadth from 1.32 to 1.28 inch. The eggs are indistinguishable from those of Montagu's Harrier, but are so much paler in colour than those of any other European Heron that they are not likely to be confused with eggs of the Little Egret or Night-Heron. Only one brood is reared in the year, 
The general colour of the plumage of the Buff-backed Heron is snowy white. In spring plumage the feathers of the head, neck, upper breast, and upper back are buff and are filamented. Two tufts of similar hairlike feathers, mixed buff and white in colour, spring from the upper back and extend beyond the tail. Bill, legs, and feet yellow; irides yellow; bare space in front of the eye greenish yellow. The female differs from the male in having the nuptial plumes less developed. In winter plumage all the nuptial plumes have disappeared and the bird is snowy white; the legs also become dark brown. Young in first plumage resemble adults in winter plumage, except that the back and crown are more or less suffused with buff. In birds of the year the buff is confined to the crown.

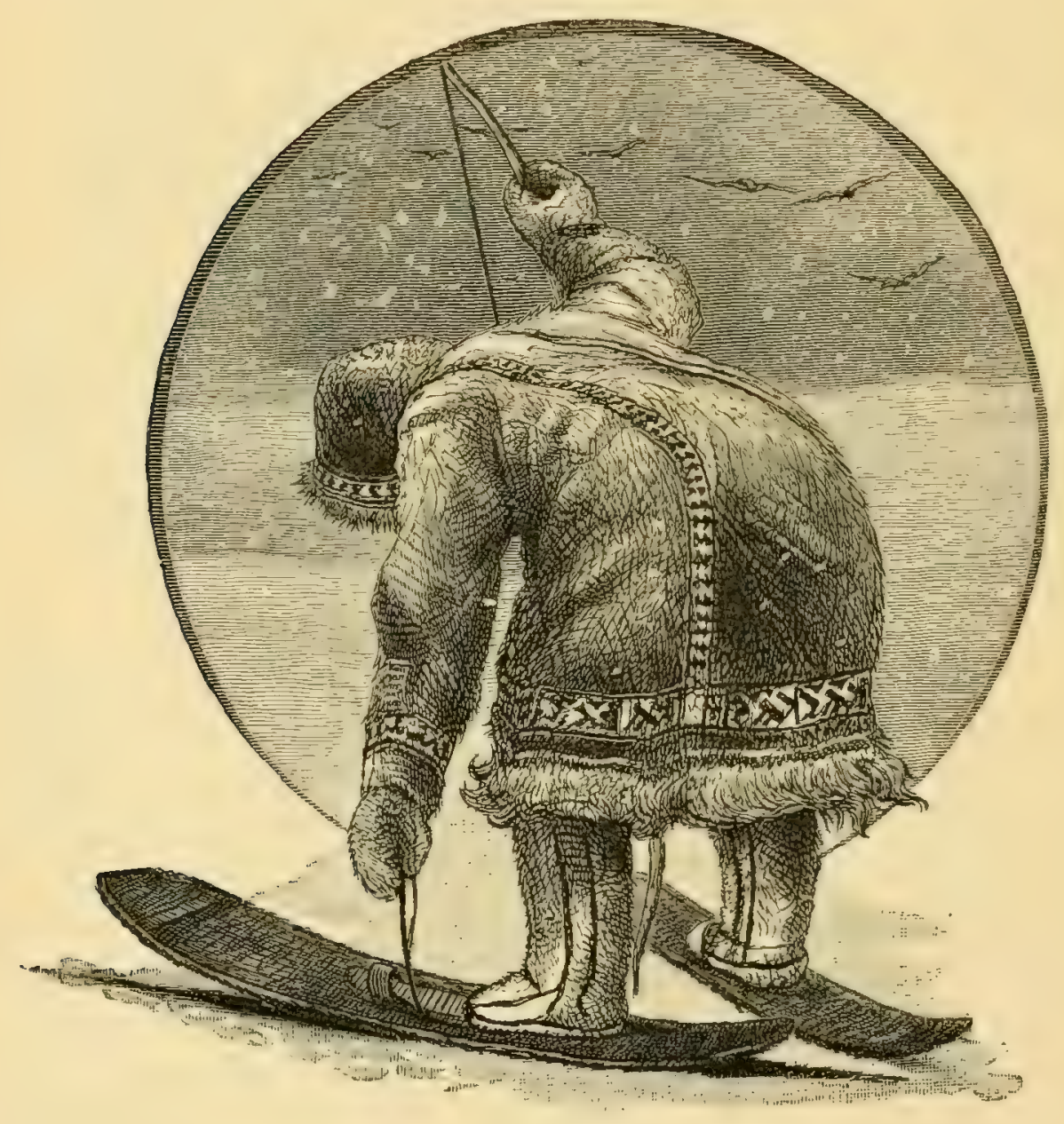




\section{Genus NYCTICORAX.}

The Night-Herons were included by Linnæus with the typical Herons in his genus Ardea, but were separated by Stephens in 1819 (Shaw's Gen. Zool. xi. pt. 2, p. 608), who established the genus Nycticorax for their reception. The European Night-Heron (the Ardea nycticorax of Linnæus) became of necessity the type.

The Night-Herons may be distinguished from the Spoonbills and the Ibises by their long straight bills, and from the Storks by having only one of the intervals between the tocs webbed. Like the typical Herons they always have twelve tail-feathers, a character which distinguishes them from the Bitterns. From the typical Herons they may be distinguished by having the tarsus reticulated in front as well as at the back, the bill scarcely longer than the head, and the occiput ornamented with long cylindrical feathers.

There are about ten species of Night-Herons, five of which belong to the Neotropical Region, the remainder being distributed throughout the rest of the world, with the exception of the Arctic Region. Only one species is found on the continent of Europe, which occasionally strays as far as the British Islands.

The Night-Herons do not differ much in their habits from the other Herons. They frequent extensive morasses and wooded swamps, and their food consists chiefly of fish, small reptiles, and insects. They perch freely on trees, walk about the ground slowly and sedately, and their flight is powerful but not very quick. Their mode of nidification and the colour of their eggs do not differ from those of the true Herons. 


\title{
NYCTICORAX NYCTICORAX. NIGHT-HERON.
}

\author{
(Plate 38.)
}

Ardea grisea,

$\left.\begin{array}{l}\text { Ardea mexicana cristata, } \\ \text { Ardea botaurus nævius, }\end{array}\right\}$ Briss. Orn. v. pp. 411, 412, 462 (1760).

Ardea nycticorax, Briss. Orn. v. p. 493, pl. xxxix. (1760); Limn. Syst. Nat. i. p. 235 (1766); et auctorum plurimorum-Scopoli, Latham, Gmelin, (Bonaparte), Jenyns, Vieillot, Wagler, Boie, Temminck \& Schlegel, Degland \& Gerbe, Lichtenstein, Finsch, Heuglin, David \& Oustalet, \&c.

Ardea kwakwa, $\{$ Gmel. Nov. Comm. Petrop. xv. pp. 452, 456 (1771).

Ardea cyanocephala, Molina, Sagg. Stor. Natural. Chili, p. 344 (1782).

Ardea nævia (Briss.), Bodd. Tabl. Pl. Enl. p. 56. no. 939 (1783).

Ardea jamaicensis,

Ardea hoactli,

$\left.\begin{array}{l}\text { Ardea hoactli, } \\ \text { Ardea maculata, }\end{array}\right\}$ Gmel. Syst. Nat. i. pp. 625, 630, 645 (1788).

Nycticorax infaustus, Forst. Syn. Cat. Br. B. p. 59 (1817).

Nycticorax europæus, Steph. Shaw's Gen. Zool. xi. p. 609 (1819).

$\left.\begin{array}{l}\text { Ardea sexsetacea, } \\ \text { Ardea tayazaguira, }\end{array}\right\}$ Vieill. Tabl. Encycl. Méthod. iii. pp. 1130, 1131 (1823).

Nycticorax gardenii (Gmel.), Jardine, Wils, Am. Orn. iii. p. 5 (1832).

$\left.\begin{array}{l}\text { Nycticorax vulgaris, } \\ \text { Nycticorax brevipes, }\end{array}\right\}$ Hempm. \&. Ehr. Symb. Phys. Aves, fol. m (1833).

Ardea discors, Nutt. Man. Orn. U. S. ii. p. 54 (1834).

Nyctiarden europæa (Steph.), Swains. Classif. B. ii. p. 355 (1837).

Nycticorax americanus, Bonap. Comp. List B. Eur. \&. N. Amer. p. 48 (1838).

Ardea (Scotaeus) nycticorax (Briss.), Keys. u. Blas. Wirb. Eur. p. Ixxx (1840).

Nycticorax ardeola, Temm. Man. d'Orn. iv. p. 384 (1840).

Nycterodius nycticorax (Briss.), Macgill. Man. Brit. B. ii. p. 127 (1842).

$\left.\begin{array}{l}\text { Nycticorax griseus (Briss.), } \\ \text { Nycticorax nævius (Briss.), }\end{array}\right\}$ Gray, Gen. B. iii. p. 558 (1847).

Scotaeus nycticorax (Briss.),
Scotaeus guttatus, Heugl. Syst. Uebers. p. 59 (1856).

Nyctiardea gardeni (Gmel.), Baird, B. N. Am. p. 678 (1858).

Nycticorax ægyptius (Hasselq.), Gurney, Anderss. B. of Damara Ld. p. 293 (1872).

Nyctiardea nycticorax (Briss.), Swinhoe, Proc. Zool. Soc. 1871, p. 413.

The Night-Heron was first recorded as a British bird by Latham (Gen. Syn. iii.p. 53), who mentions a male in the Leverian Museum, which was shot not many miles from London in May 1782. Since then it has been obtained in our islands at least fifty times. Most of these occurrences were in the southern and eastern counties; but it has 
been found in most parts of England, three or four times in Scotland, and as many times in Ireland. These occurrences have been chiefly in spring, but there does not scem to be any evidence that this bird has ever bred in our islands.

The Night-Heron, subject to some slight variation in size, is found both in Europe, Asia, Africa, and America. To the countries north of the Baltic it is a very rare straggler, having occurred once on the Faroe Islands and once in Sweden. At the present time it can only be regarded as a straggler to Holland and North Germany, its old breeding-colonics in both these countries having becn destroyed. It is still a regular summer visitor to the Spanish peninsula, the south of France, North Italy, the valley of the Danube, Transylvania, South Russia, and the Caucasus. It breeds in all suitable localities throughout Africa down to the Cape Colony, in Palestine, Asia Minor, Persia, West Turkestan, throughout India and Ceylon, the Burma peninsula, China, and South Japan, and has been found in many of the islands of the Malay Archipelago. On the continent of America it is found throughout the United States, extending northwards as far as New Bruuswick, and southwards into Mexico, Central America, and Brazil.

The Night-Heron has several near allies. In the southern portion of South America it is represented by $N$. obscurus, in which the grey portion of the plumage is darker and browner. Other more distantly allied species (N. caledonius, trom Australia, and N. manillensis, from the Malay Archipelago) are distinguished by their chestnut-brown backs.

The Night-Heron is not found in Europe during winter; it arrives in Spain and Greece during April, but does not reach its breeding-grounds in the valley of the Danube until May. It is said to be more nocturnal in its habits than its allies, but I did not find it so during the breedingseason. On the marshes near the great colonies, where it nests with the Little Egret and Squacco Heron, all three species were scen feeding at all hours of the day; but most writers on the subject agree that when the breeding-season is over, the Night-IIeron is less active during the day, and feeds principally in early morning and late evening. From the nature of its food it is essentially a swamp-bird, and is found most commonly in marshes surrounded with trees, in which it roosts at night or perches during the daytime.

During flight the broad wings and comparatively short legs of the Night-Heron cause it to resemble more the Squacco Iferon than the Little Egret; but like both these birds it flies with a steady flapping of the wings, its head almost between its shoulders, and its legs stretched out in the same line as the beak. Its flight is very noiseless, but well sustained. It seems to be quite at home on the thick branches of a tree, and even clings with ease to the almost perpendicular, slender twigs of the pollard willows.

VOL. II. 
Away from its nest the Night-Heron is a very silent bird; but if the colony in which it breeds be invaded, its cries are louder than those of any of its companions. As you approach the nests a lazy quak is heard, when you are in sight of the bird you hear a more anxious $c a-w a k$, and when really alarmed the notes that rapidly follow each other might be compared to the sound that a giant would make if he gargled.

The Night-Heron is almost exclusively a swamp-feeding bird, and the stomachs of those I have examined contained freshwater crustacea and the tender shoots of water-plants. It also feeds on small fish, small frogs and tadpoles, water-beetles, the larve of dragonflies and other insects, worms and snails.

In the valley of the Danube this species is the earliest Heron to breed. Both the colonies which I visited were in flooded forests of pollard willows. On the 12th of June some of the eggs of the Night-Heron were hatched, whilst many of those of the Little Egret and Squaceo Heron were highly incubated; but nearly all the eggs of the Common Heron were fresh. In Ceylon Capt. Legge found eggs of the Night-Heron in March; in Cashmere Brooks found it breeding in April and May; but in the plains of North-west India Hume obtained eggs as late as the 21st of August. In India and Ceylon, as well as in China, it breeds in trees; but it is said sometimes to make its nest ou the bent-down reeds in treeless marshes, though the evidence of this is not very reliable*. A visit to one of the great breeding-places of the Herons is an event in the life of an ornithologist. I have already described the colonies on the Danube, where I found the Night-Heron breeding in company with the Little Egret and Squaceo Heron, and extract the following narrative of a visit to a similar colony, somewhat later in the year, from Barkley's 'Bulgaria before the War':-

"For a long time it had been a puzzle to me where the various waders \&c. built their nests; for though the birds were to be seen at every few yards along the muddy banks of the river, or slowly flying over the marshy islands, I had as yet never discovered their nesting-ground. It last, one fine afternoon in the early summer, I accompanied a friend in a small boat on an excursion a few miles down the river below Rustchuk. On approaching a small island which was corered with water about a foot deep, we heard, amidst the dense willow-thicket which orerspread it, a noise as if the inhabitants of Purgatory had made their home there, and were having an unusually bad time of it. Pushing our small boat into a

* My friend Mr. Sennett informs me that he found the Night-Heron breeding on broken-down rushes in a great heronry in the salt-marshes in Texas. The American bird is, however, on an average larger than ours, and is regarded by American ornithologists as subspecifically distiuct, under the name of Nycticorax grisea rar. ncevia. It generally breeds in trees. 
narrow creek, we took off our boots and stockings, and, turning up our trousers, picked our way through the tangled boughs in the direction of the sound, which evidently proceeded from the centre of the island; and I shall not easily forget the sight we beheld when we reached it.

"There, on the pressed-down boughs of the willows, only a few feet above the water, were hundreds of great flat nests of the various kinds of herons, spoonbills, egrets, bitterns, \&c., all huddled together in one confused mass, and the entire colony reeking with the most indescribably filthy smell.

"It was rather late for eggs, as most of them were hatched off; but it was just the time to observe the doings of the children of these sedate, quiet, peaceful-looking birds; and I must say that I never yet beheld such a collection of little fiends, inor a more hideous set. Their bodies were of the smallest proportions, while every other part of them-their wings, legs, necks, and beaks-were of the longest; most of them liad no feathers, and all seemed possessed with one idea, and that was either to limb a small brother or swallow him whole, and all kept up either a shriek of fear or pain or a yell of rage. Floating on the top of the putrid water were masses of dead birds, some with legs torn off, others without heads or wings. Most of them were dead; but others were dragging their maimed carcasses about in a ghastly manner. So intent were they on their fiendish pastime that they took little notice of us, and dragged and clawed themselves about after their weaker brethren at our very feet, whilst the old parent birds sat looking on from the topmost twigs, as if fratricide were the proper moral pastime of the young. A big spoonbill would chase a small egret from bough to bough, till at last he tired it out, and then seizing it with one claw, would take hold of its leg or wing and tear it from the poor victim, or clsc getting its head in its mouth, would try to swallow it whole, and gulp and gulp till so much of the little one was down its throat that it was itself choked, and would turn over on its back kicking and struggling, to be in turn seized by a brother, and torn limb from limb.

"All kept up some hideous scream, and all kept clambering and dragging themselves about from bough to bough, all either hunting or being hunted; and from what we saw I am sure nine-tenths of all hatched in that colony came to an untimely end before they could fly. We did not stay long to watch them, but quickly securing some eggs from the few nests that were not hatched off', we beat a retreat, with our opinions of the beautiful, gentle-looking birds greatly changed."

Swinhoe * describes a colony of these birds in China as follows:-"This is the sacred bird of the great Honam Temple, Canton. The court-yard in front of this temple contains some venerable banyans, as well as a few towering cotton-trees (Bombar malabaricum). On the higher branches of

$$
\text { * 'Ibis,' 1861, p. } 53 .
$$


the former the small flat wicker-nests of the Night-Heron may be seen in all directions, some only a foot or so from others; and the croaking and flapping and fighting that goes on overhead bear's some distant resemblance to the crowded deck of an emigrant steamer on first encountering a turbid sea. The granite slabs that form the pavement beneath these trees are so bedaubed with the droppings of old and young, that permission to scrape them clean daily might prove a fine speculation for the guanocollectur. The birds, from the protection afforded them, were remarkably tame, and we could stand beneath the trees and watch them without their evincing the slightest fear. This was in April. Some might be seen sitting on their nests, with their loug legs bent under them, the weight of their hodies resting for the most part on the tarsal joint; others standing; on single leg close by, with shortened neck, the beak and head occasionally moving partially round as on a pivot; others flapped to and fro, ruffling up their head-gear, and occasionally sparring together. In their various movements, the dark-green-black of the head and back, with the thin suow-white occipital streamers flowing and quivering over the latter, gave a quaint, though not ungainly, look to the birds. From some of the nests we heard a subdued chattering like the cry of young, and it was to feed these hungry mouths that the parents were coustantly leaving the trees to seek for food at all times of the day, while others were returning with supplies. As the sun set, however, they became more active. While I sat watching them from a neighbouring roof-top in the evening, numbers of them emerged from the leafy darkmess, and one by one settled on the stark bare outstanding arms of the cotton-tree. After resting for a little time like gaunt spectres on the tree-top, off they went, one after the other, with a kwa-seldom more than two in the same direction. As darkness set in, many returned, and the noise and hubbub from the trees rose to a fearful pitch. Until night hid them from my view, I could see the old birds going and coming, and hear the clamour of the young. What kind of nocturnal slumbers the priests enjoyed in the temple below, I never took the trouble to inquire, though I have little doubt that from constant use the noise of these croakers has hecome quite cssential to their good night's rest. Though these birds moved about very much during the day, yet it strikes me that twilight is the most active time with them, and that in most instances the departures during the day were to seek food for the newly-hatched young, which would require fecling oftener at first, and perhaps with more choice food. I sent my man up one of the trees, whence he brought down three nests, two of which contained eggs, and the third two young birds and one egg. Judging from their size, one of these little birds must have been born at least three days before the other ; and on opening the egg I found a live chick inside, which wonld have required at least two days before it could have ventured out. The varying stages 
of the embryos in the other six eggs confirmed this idea. I should say the differences between them could not have been more than six days, and certainly not less than three; so that the Night-Heron must commence sitting on the first egg laid, and while engaged in its incubation, keep on laying, at fixed intervals, the other two, which form the complement. . . . Besides the colony of Night-Herons at Honam, there is another at the Old Man's Home, where a large pond is enclosed by a hedge of tall bushes and shrubs, and beyond this is a high wall all round. Among these bushes the Night-Herons muster in countless numbers, placing their nests on every suitable branch, though often only a few feet from the ground. They are held sacred by the pricsts in the adjoining temple, and no one is allowed to kill or disturb them."

The eggs of the Night-Heron, from three to five in number, are bluish green in colour. They vary in length from 2.18 to 1.8 inch, and in breadth from 1.5 to 1.3 inch. Some specimens are slightly paler than others. It is impossible to distinguish small eggs of this species from large examples of those of the Little Egret; but on an average the eggs of the Night-Heron are larger. The eggs of the Buff-backed Heron, although similar in size, are distinguished by their much paler colour. The Night-Heron only rear's one brood in the year; but if its first eggs are destroyed others are deposited, and the same nesting-place is used year after year.

The general colour of the plumage of the adult Night-Heron is lavendergrey; the crown and nape, upper back, and scapulars are dark brown glossed with metallic green ; several long, white, cylindrical feathers form a crest on the nape; the forehead, eye-stripe, and the whole of the underparts are pure white. Bill black; legs and feet yellow, suffused with orange on the back of the tibial joint; claws black; irides Indian red; lores and a bare space round the eye dark slate-grey. The female scarcely differs in colour from the male, and the winter plumage does not differ from that of summer. Young in first plumage have the general colour of the upper parts brown, shading into lavender-grey on the wings and tail; the feathers of the head have nearly white shaft-lines, which broaden into white tips on the back; and all the wing and tail-feathers have white tips. All the feathers on the underparts, except the under tail-coverts, are brown, with broad white shaft-lines. In birds of the year the white shaft-lines and tips have disappeared from the upper parts except on the wing-coverts and primaries, and the underparts are white, more or less suffused with brown on the flanks and the sides of the neck.

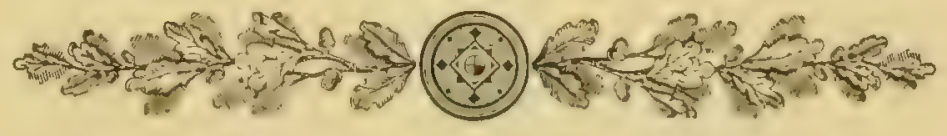




\section{Genus BOTAURUS.}

The genus Botaurus was established in 1819 by Stephens, in the eleventh rolume of Shaw's 'General Zoology' (p. 592), the Common Bittern (the Ardea botaurus of Brisson) being the type.

The Bitterns may be distinguished from the typical IIerons by having only ten tail-feathers instead of twelve. The bill is long, slender, and nearly straight, like that of the Herons; but the ridge of the upper maudible, like that of the Night-Heron, is more curved. Like that of the Herons, the tarsus is covered in front with broad scales, a character which distinguishes them from the Night-Hcrous and Storks. The plumage is generally mottled with shades of brown, finely vermiculated. The back of the neck is generally bare of feathers and only covered with down; but this peculiarity is found in the genus Butorides, which otherwise differs in having the reticulated tarsus and tivelve tail-feathers.

There are about five and twenty species of Bitterns, which are distributed throughout the world, execpt in the extreme north. Two species are European, both of which are very rare residents in the British Islands, and a third has repeatedly visited our islands from the American contincnt.

The Bittcrus frequent the decpest and most sccluded swamps and morasses, amongst the shelter of luxuriant aquatic regetation. They are shy and retiring in their habits, resting for the most part during the day, becoming rery active and fecding at night. Their flight is slow but powerful and is seldom prolonged. Their notes are loud and very peculiar. Their food consists of fish, reptiles, aquatic insects, \&c. They build their nests in large marshes, making them of aquatic plants, and their eggs are unspotted olive-brown or white. 


\section{BOTAURUS STELLARIS.}

\section{BITTERN.}

(Plate 39.)

Ardea botaurus, Briss. Orn. v. p. 444, pl. xxxvii. fig. 1 (1760).

Ardea stellaris, Lim. Syst. Nat. i. p. 2.39 (1766); et auctorum plurimorumLatham, Temminck, Naumann, (Bonaparte), (Dresser), \&c.

Botaurus stellaris (Linn.), Steph. Shaw's Gen. Zool. xi. p. 593 (1819).

$\left.\begin{array}{l}\text { Botaurus lacustris, } \\ \text { Botaurus arundinaceus, }\end{array}\right\}$ Brehm, Vög. Deutschl. p. 596 (1831).

Nycticorax stellaris (Linn.), Itemp). ct Ehr. Symb. Phys. Aves, fol. m (1832 .

Butor stellaris (Limn.), Swains. Classif. B. ii. p. 354 (1837).

Ardea stellaris capensis, Schlegel, Mus. Pays-Bas, Ardece, p. 48 (1863).

The Bittern is occasionally found in all parts of the British Islands, and may probably still breed in some of our largest marshes, especially in Ireland and Scotland, but can scarcely be regarded as more than an accidental straggler on migration. It was probably at one time a common resident in this country.

The Bittern breeds from the Atlantic to the Pacific; but its range does not extend very far north. It has not occurred in Norway; but in South Sweden it is found up to lat. $59^{\circ}$, and has been shot there as late as November. In West Russia it is a summer visitor as far north as lat. $62^{\circ}$; but in East Russia and the valley of the Obb it has not been found north of lat. $57^{\circ}$. In the valley of the Yenesay I obtained a skin in lat. $61^{\circ}$, said to have been shot in that district. It is a summer visitor to Lake Baikal, throughout the valley of the Amoor, and East Mongolia. It is found throughout China and Japan. It is a resident in the Azores, and occurs accidentally on the Canaries and Madeira. It is a resident throughout Africa in all suitable localities, as far south as the Cape Colony. It is a summer visitor to Europe south of the Baltic; but on the northern shores of the Mediterranean it is principally known as passing through on migration, though a few remain to breed and a few are seen cluring the winter. It is a resident in Palestine and Asia Minor, breeds in South Russia, Persia, and Turkestan, Northern and Central India, and has occurred in Burma.

Of the habits of the Bittern a great deal has been written, but rery little has been observed. The mystery which attaches to a bird so skulking in its nature that comparatively few ornithologists have ever seen it alive, but which makes its presence known by its extraordinary note, causes it to be regarded with peculiar interest. In this country it has become very rare. 
It is exclusively a bird of the marshes, and as these have been drained it has been compelled to vanish. No reeds no Bitterns is the rule almost without exception. On rare occasions it may be seen crossing a broad from one reed-bed to another, but unless suddenly disturbed it is never seen on the wing except for a second or two. Its long feet, like those of the Rails, are made to traverse the swamps; and when it is accidentally put up it seeks the first opportunity to drop into the shclter of its favourite reeds as soon as possible. Its flight is slow, steady, and silent, and, like its allies the Herons, its legs stretch out behind in a line with the beak, the head being drawn up between the shoulders, whilst flying. It is far more nocturnal in its habits than any of the Herons, and the "boom" or love-song of the male is lieard at all hours of the night during the brecding-season, and never in the day. It is a weird, unearthly noise, not to be dignified with the name of a note, and may be heard at a considerable distance. The hird is so shy that the noise is instantly stopped on the slightest alarm. Some writers have likened it to the bellowing of a bull, others think it rescmbles the neighing of a horse, whilst more imaginative ornithologists trace in it a resemblance to their ideal conception of demoniac laughter. It consists of two parts, one supposed to be produced as the bird inhales and the other as it exhales its breadth. Naumann attempts to express it on paper by the syllables ii-prumb, repeated slowly several times. The call-note, which is common to both sexes, is a hoarse croak like the ca-wak of a Night-Heron or the ery of a Raven, and is sometimes heard when the birds are on migration; but the "boom" is only heard from the reeds, and as it is uttered the bird is said to stand with its neck stretched out and its beak pointing upwards. The Bittern rarely perches in a tree, but on its first arrival at its brceding-grounds it is said to roost on a sheltered branch until the reeds have grown high enough to conceal it.

The Bittern is a voracious eater; fish six inches long, eels twice that length, and even a water-rat have been found in its stomach; but its principal food consists of small fishes, frogs, and water-insects of all kinds, occasionally varied with the tender shoots of water-plants.

The Bittern is a somewhat early breeder, and eggs may be obtained during May. The nest is very difficult to find. The marshes where it breeds are almost impenetrable; the reeds are too thick to admit of a hoat being pushed through them, and the water and the mud make wading almost impossible in the dark and sultry recesses of the reed-forest. The nest is built on the mud, and is composed of dead reeds and flags carelessly placed together so as to form a platform with a slight depression in the centre. The number of eggs varies from three to five. They are uniform buffish grey in colour, the shell is smooth and not very glossy, but does not partake of the chalky character of that of the true Herons. They vary in length from 2.15 to 1.97 inch, and in breadth from 1.55 to 1.45 
inch. It is almost impossible to distinguish the cggs of the Common Bittern from those of the Amcrican Bittern. The only eggs of a British bird with which they can be confused are those of the Pheasant; but the latter are more olive in colour and are much smaller. The eggs of the Bittern, when held up to the light, are not green inside, like those of the Herons, but yellowish brown. The eggs of the Common Bittern vary somewhat in shape, some specimens being pointed almost as much at each end, like those of a Grebe.

Except perhaps at the season of migration, the Bittern is a solitary bird, and has never been known to breed in company with others of its own or different species. It has the reputation of being one of the least sociable of birds; and Naumann asserts that to avoid detection it sometimes remains perfectly motionless in a very peculiar position, imitating the appearance of a bunch of dead reeds, to deceive the passer-by : seated on its tarsi, its tail on the ground, the body is held erect, the neck is extenderl, and it points its beak upwards.

Almost every feather in the plumage of the Bittern is buff, irregularly vermiculated with obscure cross bars and shaft-lines of brownish black, most conspicuous on the back and scapulars. The forehead, crown, and nape are almost uniform dark brown, and the feathers on each side of the breast are uniform dark brown margined with buff, but the latter are almost concealed by the elongated feathers of the lower neck. Bill greenish yellow; legs and feet yellowish green ; claws dark brown; irides ycllow ; bare space before the eye yellowish green. There are no important differences in the colour of the plumage attributable to age, sex, or season. The young birds are covered with rusty-yellow down.

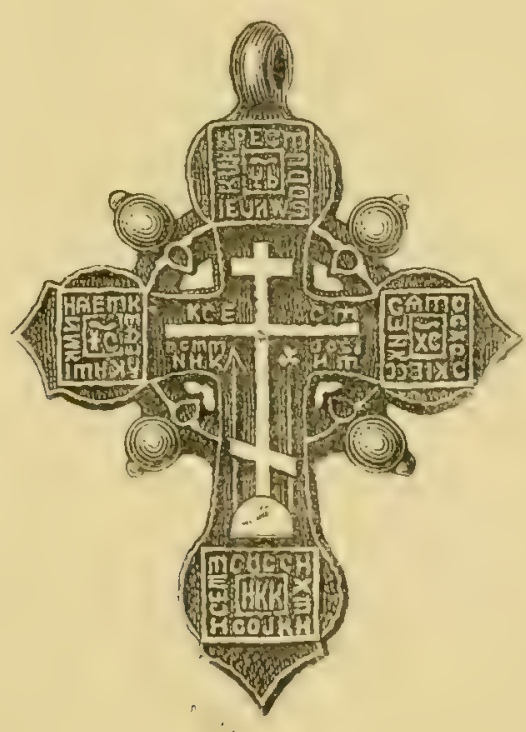




\title{
BOTAURUS LENTIGINOSUS.
}

\section{AMERICAN BITTERN.}

\author{
(Plate 39.)
}

\author{
Ardea botaurus freti hudsonis, Briss. Orn. v. p. 450 (1760). \\ Ardea stellaris, var., Forst. Phil. Trans. lxii. p. 410 (1772). \\ Ardea stellaris, $\beta$, Gmel. Syst. Nat. i. p. 636 (1788). \\ Ardea lentiginosa, Mont. Om. Dict. suppl. \& pl. (1813); et auctorum pluri- \\ morum-Temminck, Audubon, (Keyserling \& Blasius), (Coues), Diesser, \&c. \\ Ardea minor, Wils. Am. Orn. viii. p. 35, pl. 65. fig. 3 (1814). \\ Ardea mokoho, Tieill. N. Dict. d' Hist. Nat. xiv. p. 440 (1817). \\ Botaurus lentiginosus (Mont.), Steph. Shaw's Gen. Zool. xi. p. 596 (1819). \\ Ardea hudsonias, Mer\%. Ersch \& Grub. Encycl. v. p. 175 (1820). \\ Botrurus minor (Wils.), Boie, Isis, 1826, p. 979. \\ Butor americana, Swains. Classif. B. ii. p. 354 (1837). \\ Butor lentiginosus (Mont.), Jard. Brit. B. iii. p. 147 (1842). \\ Botaurus adspersus, Licht. Nomencl. Av. p. 89 (1854). \\ Ardea freti-hudsonis, Schl. Mus. Pays-Bas, Ardece, p. 49 (1863). \\ Botaurus mugitans, Cones, Proc. Ac. Nat. Sc. Phil. 1875, p. 353.
}

The type of Ardea lentiginosa, which is now in the British Museum, was shot by $M r$. Cunningham near Piddletown in Dorsetshire in the autumn of 1804 (Montagu, 'Orn. Dict.' suppl. \& pl., under the heading of "Freckled Heron"). Since that date sixteen examples were recorded between the years 1829 and 1875, of which six were obtained in Scotland, three in Ireland, two in Wales, four in England, and one in Guernsey. With the exception of one example which was obtained on the 25th of Narch, 1873, in Dumfriesshire (Gunny, 'Zoologist,' 1876, p. 4929), all these specimens were obtained in the months of October, November, and December. To this list an cightecnth example must be added, which was shot on the 1st of November, 1883, near.Ballynahinch, in co. Down. Mr. Lloyd Patterson informs me that he examined it in the flesh two days after it was shot, and ascertained it to be a male. The occurrence of the American Bittern in the British Islands is no doubt owing to the prevalence of westerly gales in autumn, which drive the birds out of their usual line of migration. One of the "fly-lines" of this species crosses the Bermuda Islands; and Captain Reid writes ('Zoologist,' 187\%, p. 473) that the American Bittern is a regular visitant there in autumn (no less than thirteen having been shot by one officer in the autumn of 1875), but that on spring migration it is only occasionally secn in March. These facts are remarkably coincident with the dates of its appearance in our islands. 
It is not known that the American Bittern has ever occurred on the continent of Europe. It is found throughout the continent of North America south of Alaska and Greenland, being a resident in the southern States, but further north it is only a summer visitor, and further south only a winter visitor.

The American Bittern closely resembles its larger European congener in its habits. Its haunts are in the wildest and most secluded bogs, in impenetrable swamps, and dismal morasses. Dr. Coucs * thus graphically depicts this singular and interesting bird:- "The Bittern, as has been said, is essentially 'wild, shy, and solitary.' We oftener start one from his lonely vigils in the bog than find several or even a pair together, excepting in the breeding-season. No doubt he enjoys life after his own fashion; but his notions of happiness are peculiar. He prefers solitude, and leads the eccentric life of a recluse, 'forgetting the world, and by the world forgot.' To see him at his ordinary occupation one might fancy him shouldering some heavy responsibility, oppressed with a secret, or labouring in the solution of a problem of vital consequence. He stands motionless, with his head drawn in upon his shoulders, and half-closed cyes, in profound meditation, or steps about in a devious way, with an absent-minded air; for greater seclusion he will even hide in a thick brush-clump for hours together. Startled in his retreat, whilst his thinking-cap is on, he seems dazed like one suddenly aroused from a deep sleep; but as soon as he collects his wits, remembering unpleasantly that the outside world exists, he shows common sense enough to beat a hasty retreat from a scene of altogether too much action for him. Some such traits have doubtless led to the belief that he is chiefly a nocturnal bird; but such is not the case. He may migrate by night; but so does the Killdecr, and the Bobolink, and many other birds not in the least nocturnal. Nor is the Bittern either lazy or stupid, as some may suppose. He is simply what we call a shady character-one of those non-committal creatures whom we may invest, if we please, with various attributes, and perhaps consider very deep, without sufficient reason, the fact being that we make the mystery about him. There is nothing remarkable in the fact that he prefers his own company, and dislikes to be bored. He lives in the bog, where he finds plenty to eat that he likes best, and is satisfied to be simply let alone.

"When the Bittern is disturbed at his meditation he gives a vigorous spring, croaks at the moment in a manner highly expressive of his disgust, and flies off as fast as he can, though in rather a loose, lumbering way. For some distance he flaps heavily with dangling legs and outstretched neck; but when settled on his course he proceeds more smoothly, with regular measured wing-beats, the head drawn in closely, and the legs stretched straight out behind together, like a rudder. He is very easily

\footnotetext{
* 'Birds of the North West,' p. 527.
} 
shot on the wing-casily hit, and dropping at a touch even of fine shot. When winged, he croaks painfully as he drops, and no sooner does he touch the ground than he gathers himself in defensive attitude to resent aggression as best he can.

"The food of this bird consists of various kinds of small aquatic animals. In its stomach may be found different molluses, crawfish, frogs, lizards, small snakes, and fishes, as well as insects. Such prey is captured with great address by spearing, as the bird walks or wades stealthily along. The thrust of the bill is marvellously quick and skilful-more action is displayed on such occasions than probably under any other circumstance."

Audubon writes * - " Although in a particular place, apparently favourable, some dozens of these birds may be found to-day, yet, perhaps, on visiting it to-morrow, you will not find one remaining; and districts resorted to one season or year, will be found deserted by them the next. That they migiate by night, I have always felt assured; but that they are altogether nocturnal is rather uncertain, for in more than half a dozen instances I have surprised them in the act of procuring food in the middle of the day, when the sum was shining brightly. That they are extremely timid I well know, for on several occasions, when I have suddenly come upon them, they have stood still from mere terror until I have knocked them down with an oar or a stick."

The notes of this Bittern must be very similar to those of the European species. Its love-note Nuttall compares to the syllables 'mump-aŭ-gah, whilst Dr. Cones adopts Mr. Samuels's rendering of chunk-a-lunk-chunk, quank-chunk-a-honk-chunk, as best expressing its singular cry. He also states that in addition to this note its ordinary cry is something like the syllable quark or hauk, uttered in a rough, guttural tone; this note is uttered when the bird is disturbed in its marshy haunts. The American Bittern is said to be a comparatively silent bird, and as it keeps very close, may often be passed by unnoticed. The first intimation of its presence is usually its startling cry, and the next moment the bird itself sails hurriedly above the reeds, to drop down again in a more secluded spot.

Although the American Bittern appears to be such a common bird, but little secms to be known of its nesting-habits, and considerable diversity of opinion is expressed concerning them. Some writers, as for instance $\mathrm{Mi}^{\mathrm{i}}$. Samuels, affirm that it breeds in colonies, a dozen pairs often nesting within a small area. The observations of other ornithologists show that this species is solitary, and that each pair resides in their own part of the swamp. Neither do ornithologists agree respecting the position and materials of the nest. Some observers say it is built in trees and low bushes, and made of coarse grasses, twigs, and leaves ; whilst others assert * Orn._Biogr. iv, p. 296. 
that the eggs are laid on the bare ground, on a tuft of grass, or at the foot of a bush. The eggs of this bird are similar in colour to those of the Common Bittern, being greyish buff, sometimes with an olive or a brownish tinge. They are from three to five in number, and vary from $2 \cdot 1$ to 1.9 inch in length, and from 1.65 to 1.4 inch in breadth. It is impossible to distinguish with ecrtainty between the eggs of this bird and those of the European Bittern; the latter may on an atverage be a little paler and a trifle larger ; but of course the locality, if it can be relied upon, is quite sufficient for identification. It is difficult to believe that the habits of the two species are not equally similar. It is in the highest degree improbable that the American Bittern is a gregarious bird, except during the period of its migrations; nor is it likely that it ever breeds in colonies or makes its nest in trees, or lays its eggs upon the ground without making any nest.

The American Bittcrn bears considerable superficial resemblance to the Common Bittern, but differs from it in being a much smaller bird, with a longer and more slender bill; the vermiculations on the plumage are much finer, the quills are uniform instead of barred, and the top of the head is brown instead of black; the gorget also is not so large. The female resembles the male very closely in colour, but is somewhat smaller:

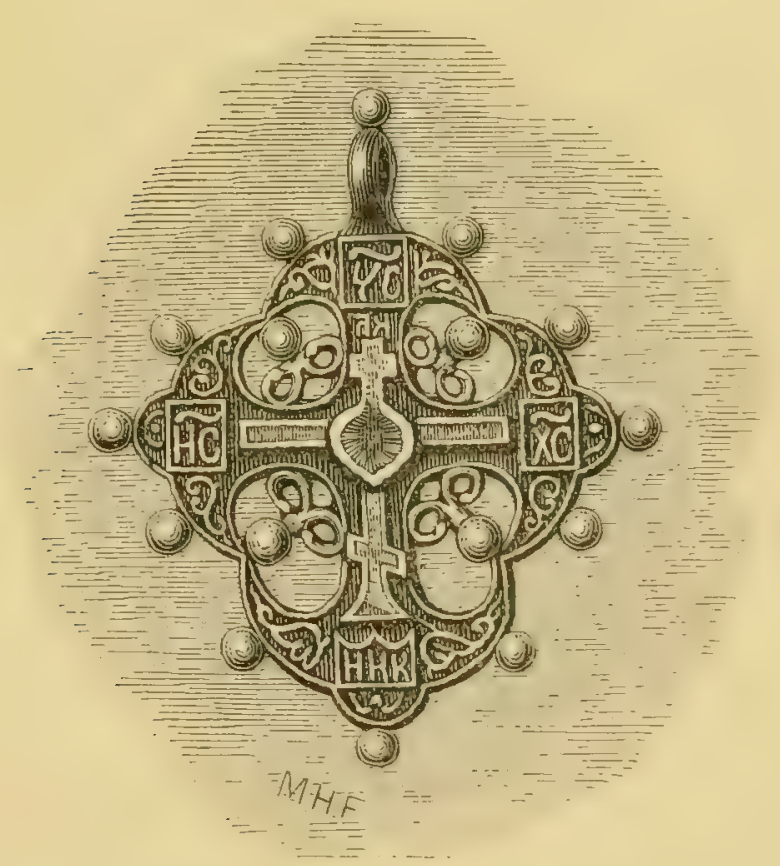




\title{
BOTAURUS MINUTUS.
}

\section{LITTLE BITTERN.}

\author{
(Plate 38.)
}

Ardea ardeola, Briss. Orn. v. p. 497, pl. xl. fig. 1 (1760).

Ardea ardeola nevia, Briss. Orn. v. p. 500, pl. xl. fig. 2 (1760).

Ardea minuta, Linn. Syst. Nat. i. p. 240 (1766); et auctorum plurimorum-

Latham, Temminck, Nauman, (Bonaparte), (Dresser), \&c.

Botaurus minutus (Linn.), Boie, Isis, 1822, p. 559.

Cancrophagus minutus (Linn.), Kaup, Nat. Syst. p. 42 (1829).

Botaurus pusillus, Brehm, Vög. Deutschl. p. 598 (1831).

Butor minutus (Linn.), Swains, Classif. B. ii. p. 354 (1837).

Ardeola minuta (Limu.), Bonap. Comp. List B. Eur. \& N. Amer.p. 48 (1838).

Ardetta minuta (Limn.), Gray, List Gen. B. Append. p. 13 (1842).

The Little Bittern is another of those birds which were first recorded as British by Pennant, who states that a male was shot whilst perched on one of the trees of the public wallss in Shrewsbury (Brit. Zool. ii. p. 537); and Latham records a second example killed in 1773, near Christchurch, in Hampshire (Gen. Syn. iii. p. 66). It is a very rare summer visitor to this country, but there is no reliable instance of its eggs cver having been obtained in our islands. It has occurred most frequently on the marshes of the Norfolk broads, but has also been obtained in most counties on the south and east coasts of England. In Scotland and in Ireland it is much rarer; but it has occurred botl in the Shetland and Orkney Islands, and also in Aberdecnshire and East Lothian, and at least half a dozen times in Ireland. The Little Bittern has been obtained most fiequently in our islands in spring and summer, but several cxamples have been shot in winter.

The Little Bittern is a summer migrant to Europe south of the Baltic, and has occurred as an accidental straggler in Iceland, the Faroes, and the Scandinavian peninsula. It is a resident in the Azores, Madcira, Algeria, and to a limited extent in Egypt, and winters in various parts of South Africa as far south as the Transvaal. It is a summer visitor to Palestine, Asia Minor, Persia, Baluchistan, Cashmere, Nortli-west Turkestan, and the Western Himalayas.

The Little Bittern has several very near allies. To the east, ranging through India, China, Japan, the Philippines, and Celebes, it is represented by Ardea sinensis, a very distinct species, which may at once be distinyuished by having the back brown instead of black. But there are three hlack-backed species which appear to be very elosely allied to our bird; all of these may be distinguished from it by having the neck rich dark 
chestnut instead of pale buff. The nearest of these to our bird is $A$. podiceps, from South Africa. In Australia A. pusilla is found, which further differs in having the greater wing-coverts chestnut instead of nearly black; and this difference is still further emphasized in a North-American species, A. exilis, which has the outside webs of the imermost secondaries also rufous.

The Little Bittern arrives in South Spain late in April, but in Greece at the end of March or beginming of April. In the northern portions of its range it does not arrive until May, this being also the time of its appearance in England, where, however, it may sometimes remain during the winter. It leaves Holland and other northern countries in September; and Irby says that it has left Gibraltar by October. It leaves Greece at the end of September.

The Little Bittern is very skulking in its habits, and frequents large marshes, swamps, clumps of bulrushes, and large expanses of reeds and rushes. Although it loves to frequent the solitudes of reeds it may sometimes be observed in the trees on the borders of the swamps, sitting quite still on the branches, with its neck stretched out and its beak pointing upwards. It is very unwilling to take wing, and sometimes skulks so closely as to allow itself to be caught by a dog, or even taken in the hand. It keeps very close and quiet during the day, coming out at night to feed. When pursued it often perches on the thick stems of the reeds or bulrushes, hopping from one to the other with as much ease as a Reed-Warbler. It is equally agile amongst the branches of trees, and perches in them freely, being more often scen in them than any other Heron. It runs with great quickness amongst the reeds, and threads its way through the dense aquatic vegetation. When flushed it mounts up into the air, and flies rapidly away orer the reeds and water with quick and powerful beatings of its broad wings. When standing by the side of the water it draws its head close in between its shoulders and holds its body erect. Sometimes it stands on one leg, and frequently wades in the water in quest of its food.

The food of the Little Bittern, which is almost entirely obtained at night, is composed of small fish, frogs, and other reptiles, worms, small shells, and aquatic insects with their larva. The note of this bird bears some resemblance to that of the Common Bittern, but is not so lond or harsh. Naumann says that it resembles the syllable pumm several times repeated, then a long pause, and again uttered, and that the cry of the female sounds like the word gate or get rapidly repeated.

The nest of the Little Bittern is gencrally placed amongst the dense vegetation of its marshy haunts. Sometimes it is built amongst reeds a few inches above the water, and is often at a considerable distance from the shore. It is even said to sometimes take possession of a deserted 
Magpie's nest in a trce close to its haunt. The nest is very large for the size of the bird, loosely put together, and made of pieces of aquatic vegetation, sometimes a few twigs, and lined with finer material, such as grass or dead leaves of the reed.

The eggs of the Little Bittern are from five to nine in number and pure white in colour*. They soon become stained by contact with the hird's feet and the damp materials of the nest. 'Their small size and colour' is a suflicient distinction from the eggs of all the other Herons. They vary in leugth from 1.15 to 1.29 inch, and in breadth from 1.05 to .98 inch. They are oval in shape; the shell is fine, but closely pitted with small pores. Only one brood appears to be reared in the year.

IIume writes in his 'Nests and Eggs of Indian Birds' :- "It lays in June. Four is the usual, and five the maximum, number of eggs. It appears always to build in amongst rushes or wild rice, and to place its nest sometimes on the ground, but more generally on a little platform a foot or so above the water's level, formed by beuding down the rushes or reed in situ. The nest itself is slight and flat, composed of recl and rush loosely put together, 6 or 7 inches in diameter, and from an inch to 2 inches in thickness. This, however, I state mainly on the evidence of the native collector I sent to Cashmere, as I have ouly myself seen one single nest."

The general colour of the plumage of the adult male Little Bittern is bulfi and dark brown glossed with green, the latter colour being confined to the forehead, crown, and nape, the back, rump, upper tail-coverts and tail, scapulars, innermost secondaries, secondaries, and primaries. A ruff of reddish-brown feathers margined with buff' is displayed on each side of the breast. All the rest of the plumage is buff, shading into grey on the sides and back of the neck and the tips of the greater wing-coverts. The f'cmale principally differ's from the male in being smaller, in having the back of the neck and the sides of the head chestnut, and the feathers on the chin, throat, and fore neck have dark shaft-lines; the ruff on each side of the breast is smaller in extent; and the feathers of the back, the inmermost secondaries, and scapulars are dark chestnut-brown, narrowly margined with pale buff. Young in first plumage rery closely resemble the adult female, but the chestnut on the back of the neck is duller and the feathers have pale tips, the back is darker and duller, the wing-coverts have dark centres, the sides of the head, the chin, throat, and fore neck are buff, each feather with a broad dark brown centre. Birds of the year are intermediate in plumage. The young are first corered with chestnut-buff down, and the bill is not so pointed and much shorter than in adults.

* The light green egg figured by Hewitson may be a faded example of the egg of the Squacco Heron. The eggs of the Little Bittern are as white as those of a Turtle-Dove, even when held up to the light, but are larger and less glossy. 


\section{Genus PLATALEA.}

The Genus Platalea was included by Linnæus in 1766 in the twelfth edition of his 'Systema Naturæ' (i. p. 231), and the Common Spoonbill (the Platea platea of Brisson) is unquestionably the type.

The birds in this genus are easily distinguished by the form of the bill, which is very broad, long, thin, and dilated at the extremity, like a spoon or spatule. Their tarsus is covered with fine reticulations all round; the face and throat are sometimes bare of feathers; the legs are long and rather slender; the nostrils are subbasal and placed in a groove partly closed by a membrane; the tail is short and even, and consists of twelve feathers.

This genus contains only four or five species, which are distributed throughout the temperate and tropical portions of both hemispheres, with the exception of the smaller islands. One species is European, which is an accidental straggler to the British Islands.

The Spoonbills frequent marshy coasts, large swamps, and the borders of lakes and streams, where they wade or walk about in search of the frogs, aquatic insects, worms, \&c. on which they feed. They are said to even dive or swim in search of food. They have no note, but make a snapping sound with their bill. Their flight is graceful and buoyant. They are shy and wary birds, and are ever on the look out for danger. They breed either on the ground or in trees in their marshy haunts, making a large nest of sticks and coarse aquatic vegetation; and their eggs are dull white, sparingly spotted and blotched with reddish brown. 


\title{
PLATALEA LEUCORODIA.
}

\section{SP00NBILL.}

(Plate 37.)

\author{
Platea platea, Briss. Orn. v. p. 352 (1760). \\ Platalea leucorodia, Linn. Syst. Nat. i. p. 231 (1766) ; et auctorum plurimorum- \\ Latham, Temminck, Naumann, Bonaparte, Degland \&. Gerbe, Dresser, \&c. \\ Platea leucopodius, Gmel. Reise Russl. p. 163 (1770). \\ Platea leucorodia (Limn.), Leach, Syst. Cat. Mamm. \&.c. Brit. Mus. p. 33 (1816). \\ Platalea nivea, Cuv. Règne An. i. p. 482 (1817). \\ Platalea pyrrhops, Hodgs. Gray's Zool. Miscell. p. 86 (1844). \\ Platalea major, Temm. \& Schl. Faun. Japon. p. 119, pl. Ixxv. (1847).
}

The Spoonbill was formerly a regular summer visitor to this country, and bred in the marshes of Norfolk and Suffolk. They were exterminated at the close of the 17th century. The last record of their breeding in England is to be found in Sir Thomas Browne's 'Notes on the Birds of Norfolk,' who describes them as breeding about 1670 in Trimley in Suffolk, and as formerly having bred at Claxton near Norwich and Reedham near Yarmouth in Norfolk (Stevenson, 'Birds of Norfolk,' ii. p. 184). In spite of the persecution which caused them to cease to breed in this country two hundred years ago, the hereditary instinct which leads these birds to migrate to our country in spring does not appear to have entirely died out, and scarcely a year passes without a few birds being seen, most of which, the Birds' Protection Act notwithstanding, fall victims to the insatiable desire to acquire specimens of rare British birds. In other parts of the British Islands the Spoonbill is principally known as an occasional straggler in autumn, sometimes appearing in small flocks. We may therefore regard the Spoonbill as an occasional straggler on migration to the whole of the British Islands, including the Channel Islands, the Hebrides, the Orkneys, and Shetland.

The Spoonbill, like most of its Herodian allies, has a most extensive range, reaching from the Atlantic to the Pacific; but owing to the rapid increase of population its breeding-colonies are few and far between. It breeds in Spain, Holland, the valley of the Danube, the delta of the Volga, and in the country north of the Aral Sea. It passes through France and Germany on migration, and is a rare straggler to the south of the Scandinavian peninsula. It is occasionally found in the Baltic Provinces; and Hencke records a flock of eight Spoonbills appearing in December near Archangel. Finsch did not observe it in West Siberia 
north of lat. $48^{\circ}$; but it is a regular summer visitor to the southern portions of Dauria and the valley of the Amoor, breeding also in Southeast Mongolia, and occasionally occurring in various parts of China and Japan*. It is an accidental visitor to the Azores, Madeira, and the Canaries, and is a resident throughout North Africa as far south as the Soudan. In Grece, Asia Minor, and Palestine it is principally known as passing through on migration. It is a rare bird in Persia; but breeds throughout India and Ceylon. The Spoonbill has several near allies in South Africa, Australia, and America, all of which may be distinguished by having the face bare of feathers.

The migration of the Spoonbill into Europe from Africa commences at Tangiers in March; it arrives in South Spain in the middle of April, but does not reach its breeding-grounds in Holland and the valley of the Danube till early in May. Its arrival in the east of Europe is at about the same date as in the west. It leaves its breeding-grounds in Holland in September, and has been observed at Gibraltar as late as November.

The Spoonbill frequents open swamps and low-lying ground near the sea, rather than the centre of dense reed-beds and rush-covered marshes. It may sometimes be seen in swampy meadows, in similar localities to those the White Stork loves to frequent. It walks about slowly and sedately, and when alarmed often flies to a tall trec, where, perched perhaps on the topmost bough, it is a very conspicuous object for a great distance. It is very fond of frequenting mud-flats, searching them with its peculiar bill for food. It is rather shy, and seldom allows the observer to approach it very closely. The food of the Spoonbill is very largely composed of crustaceans, mollusks, and small insects, which it catches in its broad bill, using it in the same manner that a Duck does. To this fare is added small fish, frogs, and quantities of vegetable matter, such as the buds and leaves of water-plants and probably grass. The Spoonbill does not appear to ever utter any note, beyond making a sharp snapping sound with its bill. It does not possess any true muscles

* Temminck and Schlegel described two supposed new species of Spooubill from Japan. An adult male collected by Captain Blakiston at Hakodadi in A pril belongs to the European species, of which Platalea major of Temminck is undoubtedly a young bird, the primaries not having yet been moulted. In a paper on the ornithology of Japan ('Ibis,' 1882, p. 370), I made the mistake of identifying Swinhoe's examples from Formosa with this species; they belong undoubtedly to $P$. minor of Temminck, which species is founded on immature examples of the previously described $P$. regia from Australia. This species differs from our bird in being slightly smaller, in having the bare space on the forehead and sides of the head extending to the eye, and in having the gular pouch fenthered to the base of the lower mandible, beyond which the chin is black. The signs of immaturity are the same as in the Common Spoonbill. By an maccountable oversight, Dresser, in his 'Birds of Europe,' has omitted any mention of the immature stage of plumage, though it is described and figured by Naumann. 
of the organs of voice; and Dresser is in error in ascribing to Naumann the statement that its note "is deep and Heron-like."

The most accessible breeding-colony of the Spoonbill is situated on the banks of the Horster Meer, a lake situated between Amsterdam and Utrecht. I paid a visit to this colony late in May 1880, in the company of Captain Elwes. The country is vcry flat, and bears a striking resemblauce to the broads of Norfolk. Stretching away on each side of the road, almost as far as the eye could reach, nothing was to be seen but lakes, swamps, marshes, and willow-beds, intersected by a river, and in a few places, where the ground was firm enough for pasture, with dykes. We soon found the lessee of the meer, who informed us that he paid a rent of about $\& 420$ a year for the right of fishing, shooting in winter, collecting eggs in summer, and gathering an annual crop of willow-twigs for basket-making. We rowed for a short distance between willow-beds until the dyke became too narrow for oars, when our guide jumped on to the bank and towed us along for some distance. Occasionally we saw a Black T'ern or a Cormorant, and at length had the pleasure of secing two pairs of Spoonbills. On landing we found ourselves on marshy ground thickly overgrown with reeds and sedges, amongst which were growing two rare species of British ferns, Lastrea thelipteris in great abundance and Lastrea cristata somewhat sparingly. The ground was also considerably diversified by a display of wild fiowers, such as marsh-mallow, ragged robin, \&c. To our right alder and willow bushes appeared to extend indefinitely; but to the left open ground led to the meer, on the bauks of which a large colony of Cormorants, consisting of at least five hundred birds, were breeding. Turning our backs on this interesting colony for the present, we entered the alder-and-willow thicket, and after some time suddenly came upon the object of our search. A flock of at least two or three hundred Spoonbills rose from behind the alder bushes, their white wings glittering in the sun in strong contrast to their black legs stretched out behind, and their long necks and dark bills projecting so conspicuously in front. For some time they flew about like Gannets at the Bass Rock; but we never heard them utter a cry. We made for the direction in which they rose, and after wandering backwards and forwards for some time at length came upon three nests containing eggs, and we were not long in finding the main colony, which consisted of perhaps fifty nests, all contained within a radius of about twenty yards. The nests are robbed every Saturday and the eggs sold; and few of them contained more than one egg. Most of the nests were built on grassy tussocks, but a few of them were in the alder trees three or four feet above the ground; and the efflurium from the droppings of the birds was very strong, and would have been disagreeable had not a strong gale been blowing all the day. Upon our invasion of their nesting-grounds, most 
of the birds flew right away, but small parties of five or six were always on the wing near us. Their powerful Heron-like wings enabled them to sail along for considerable distances without much exertion; and I noticed that they had a habit of dropping their legs occasionally, probably to assist them in keeping their balance in the high wind. Most of the nests were built upon a foundation of a few sticks, the principal structure being of dead reeds lined with dry grass.

In the valley of the Danube the Spoonbill breeds in low willow trees in colonies adjoining to, but not intermixed with, those of the Herons, Ibis, and Cormorant. In India its habits are very similar. Hume writes that he is acquainted with at least fifty of its breeding-places. In most cases these are placed close to, though not on, the same trees as those occupied by the Heron colonies. The Indian colonies of the Spoonbill are always found on trees, on the banks of a lake, or in a swamp, and generally near a village, sometimes absolutely in its midst. When built on trees, the nests appear to be larger than those constructed on the ground. Hume describes them as varying from two to three feet in diameter, and as being sometimes nearly a foot in thickness. They breed year after year in the same trees, and if the old nests are not blown down, they simply repair them. Hume found both eggs and young in August; but in the south of Ceylon Legge obtained highly incubated eggs at the end of March.

The eggs of the Spoonbill are four or five in number, and vary much in size, shape, and colour: some are long and narrow, with the small end almost as blunt as the large end, and scarcely vary in shape from typical eggs of the Cormorant, whilst others are so round that they might easily be passed off by unprincipled dealers as eggs of the Kite. They are dull chalky white in ground-colour, sparingly spotted and blotched with small spots or short streaks, and occasionally large smudged blotches, principally at the large end, of reddish brown. Occasionally a ferr grey underlying spots are observable; and sometimes the surface-markings form a zone round the large end of the egg. They vary in length from 2.9 to $2 \cdot 2$ inch, and in breadth from 1.9 to 1.7 inch. Only one brood is reared in the year.

The adult male Spoonbill in spring plumage is pure white, suffused with rusty yellow on the lower neck and crest, the latter consisting of a bunch of narrow feathers about six inches long. Bill black at the base and much corrugated, shading into yellow at the tip, which is smooth; legs, feet, and claws black; irides brick-red; bare skin in front of the eye pale yellow; chin extending to the upper throat bare of feathers and reddish yellow. The female resembles the male in colour, but the crest is shorter. The winter plumage is similar to that of summer, but the crest is very small, and the yellow on the lower neck is probably absent. Young in first 
plumage differ from adults in having the primaries more or less tipped with black, with black shafts to these feathers and the secondaries, in only having the rudiments of a crest, and in having the bill dusky yellow and without corrugations. Birds of the year have the bill somewhat intermediate, the primaries are pure white, but the crest is not fully developed, and both it and the neck are pure white. The nestling is covered with white down, and even at this carly age has the bill widened and flattened at the tip.
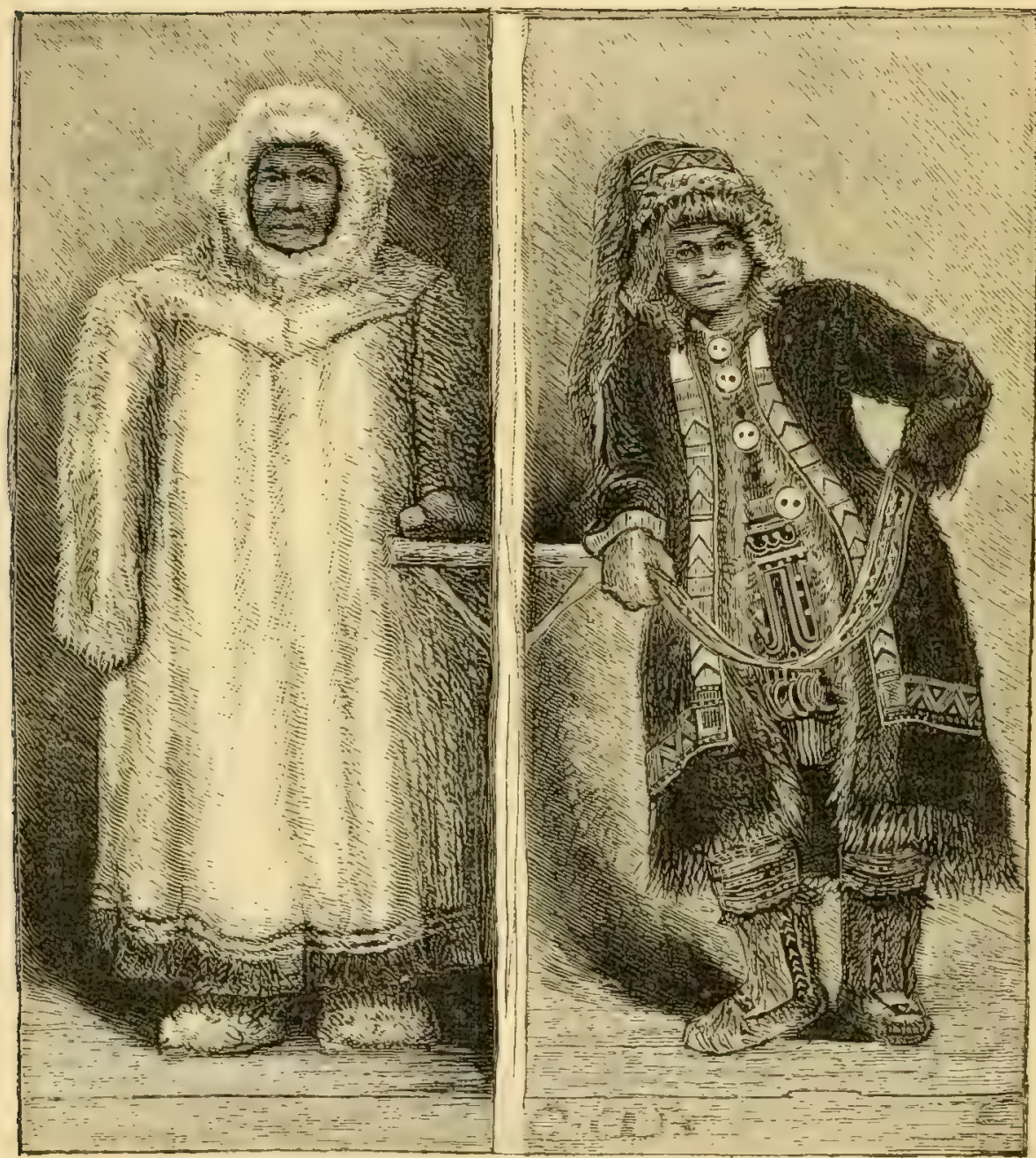


\section{Genus IBIS.}

The Ibises were included by Linnæus in the genus Tantalus, of whick Tantalus loculator, the "Tantalus" of Klein, is generally accepted as the type. This species, having only one notch on each side of the posterior margin of the sternum, has been removed into the subfamily of the Storks, and a new genus has been made for the true Ibises. The genus Ibis was established by Lacépède in 1801, in the third volume of the Mém. de l'Inst. Sc. Math. et Phys. p. 518, the Sacred Ibis (the Tantalus ibis of Linnæus) being the type.

The Ibises are distinguished by the form of their bill, which is long, narrow, and curved downward, like that of a Curlew. The tarsus is covered with small reticulations before and behind in the larger species; but scutellated in front in the smalier species. The head and part of the neck are sometimes bare of feathers. The wings are moderately long, and the tail is rather short, consisting of twelve broad feathers. The plumage is often adorned with metallic tints, and several species are very brilliant in colour.

This genus contains about a score species, which are distributed throughout the temperate and tropical portions of both hemispheres, with the exception of the smaller islands. Only one species is European, which is a rare straggler to the British Islands.

The birds in this genus frequent swamps, the reed-and marsh-covered shores of lagoons and lakes, and flat coasts. They are wary and gregarious in their habits. They walk about very sedately, and their flight is powerful but somewhat laboured. Their notes are harsh. Their food consists of aquatic insects, small reptiles, fish, \&c. They breed in large swamps, making their nests of sticks and aquatic herbage; and their eggs are green or white spotted with reddish brown. 


\section{IBIS FALCINELLUS.}

\section{GLOSSY IBIS.}

(Plate 38.)

Numenius viridis,

$\left.\begin{array}{l}\begin{array}{l}\text { Numenius castaneus, } \\ \text { Numenius mexicanus varius, } \\ \text { Numenius ibis, }\end{array}\end{array}\right\}$ Briss。Orn. v. pp. 326, 329, 383, 347 (1760).

Tantalus falcinellus, Lim. Syst. Nat. i. p. 241 (1766); et auctorum plurimorum -(Temminck), (Naumann), (Salradori), (Sari), (Dresser), \&c.

Ardea rufa, Scop. Ann. I. Hist. Nat.p. 87 (1769).

Numenius igneus, Gmel. Reise Russl. i. p. 166 (1770).

Tantalus castaneus (Briss.), Müll. Natursyst. Suppl. p. 112 (1776).

Tantalus igneus (Gmel.), Lath. Gen. Syn. Srppl. i. p. 291 (1787).

Tantalus viridis (Briss.),

$\left.\begin{array}{l}\text { Tantalus niger, } \\ \text { Tantalus mexicanus, }\end{array}\right\}$ Gmel. Syst. Nat. i. pp. 648, 650, 652 (1788).

Ibis sacrn, Temm. Man. d'Orn. p. 385 (1815).

This ignea (Gmel.), Leach, Syst. Cat. Mamm. \&c. Brit. Mus. p. 33 (1816).

Ibis falcinellus (Linn.), Vieill. N. Dict. d'Hist. Nat. xvi. p. 23 (1817).

Plegadis falcinellus (Linn.), Koup, Nat. Syst. p. 82 (1829).

Numenius falcinellus (Linn.), Pall. Zoogr. Rosso-Asiat. ii. p. 165 (1831).

Ibis castaneus (Briss.), Brehm, Vög. Deutschl. p. 606 (1831).

Tantalides falcinellus (Linn.), Wagl. Isis, 1832, p. 1231.

Ibis erythrorhyncha, Gould, Proc. Zool. Soc. 1837, p. 127.

Ibis ordi, Bonap. Comp. List B. Eur. \& N. Amer. p. 49 (1838).

Falcinellus igneus (Gmel.), Gray, List Gen. B. p. 87 (1841).

Plegadornis falcinella (Linn), Brehm, Naumannia, 1855, p. 290.

Falcinellus bengalensis,

$\left.\begin{array}{l}\text { Falcinellus peregrina, Miill. fide } \\ \text { Falcinellus mexicanus (Gmel.), } \\ \text { Falcinellus erythrorhyncha (Gould), }\end{array}\right\}$ Bonap. Consp. ii. pp. 158, 159 (1857).

Falcinellus ordii (Bonap.), Coues, Proc. Ac. Nat. Sc. Phil. 1866, p. 96.

Ibis falcinellus (Linn.), var. ordii, Cones, B. of N.W. Amer. p. 517 (1874).

Eudocimus falcinellus (Limn.), Bocage, Journ. Orn. 1876, p. 300.

Falcinellus rufus (Scop.), Reich. Journ. Orn. 1877, p. 146.

Plegadis falcinellus (Limn.), Salvin, Ibis, 1878, p. 112.

The Glossy Ibis was first recorded as a British bird in 1787 by Latham, on the authority of an example then in the Leverian Museum, which had been shot in Cornwall (Gen. Syn. Suppl. i. p. 291). It is an accidental visitor, principally on autumn migration, to our islands, especially to the south and east counties of England. In Scotland it has occurred in the Shetland and Orkney Islands, and in the counties of Kincardine, Fife, and Ayr; and in Ireland in Belfast, Cork, Longford, Waterford, Wexford, Dublin, and King's County. 
The geographical distribution of the Glossy Ibis is very similar to that of the Spoonbill, but its breeding-colonies are more isolated. It is said to breed in Morocco, and certainly does so in Spain and in the delta of the Rhone. Its other breeding-colonies are confincd to the valley of the Danube, the Lower Volga as far north as lat. $18^{\circ}$, and the plains of the Caucasus, whence it straggles into North Persia. It is a rare straggler to the rest of Europe, having occurred several times in Scandinavia north of the Arctic circle, at least once on the Faroes, and five times in Iccland. It breeds in suitable localities throughout Turkestan, and was found by Finsch in South-west Siberia as far north as lat. $48^{\circ}$. It passes through Afghanistan on migration and winters in India. It also breeds in Scind and Ceylon, and is said to be a rare winter visitor to Burma. Its occurrence in China is doubtful ; but it has occurred, probably during its winter wanderings, in Java, Borneo, Celebes, New Guinea, and various localities in Australia. It has occurred in most parts of Africa, but it is doubtful whether it breeds anywhere except in the north-west. It occurs irregularly in all the countries bordering the basin of the Mediterranean. Examples of an Ibis, which is said to be undistinguishable from the European species, have occurred in various parts of the eastern United States of America; but as there are two other nearly allied species found on the American continent, and as the breeding-place of the Glossy Ibis in the New World remains undiscovered, its occurrence there must for the present be considered accidental. Of these American species $P$. ridguayi is said to inhabit Peru, and $P$. guarauna is supposed to inhabit the whole of the Neotropical Region, extending northwards as far as Texas and California. Both these species may be distinguished by having the head brownish chestnut without any metallic green gloss.

The Ibis is only found in Europe during summer. Kriper says that it begins to arrive in Greece at the end of March; but Irby did not observe it at Gibraltar before late in April. The Ibis is a thorough Heron in its habits and frequents the same districts, but like the Night-Heron it prefers the swamps and marshes to the rivers and streams. Its flight resembles that of a Heron, or perhaps more that of a Stork, for the legs droop at a slight angle from the body and complete the curved line of the beak and extended neck. The flight is more rapid than that of cither of these birds, and is performed by quicker beats of the wings, and every now and then it skims along with outspread pinions. The Ibis is very gregarious, solitary birds or even pairs are seldom seen; half a dozen or more birds fly in company and keep together in a wedge or string, like Cranes or Geese. On the ground the Ibis walks sedately like a Heron. It is a very silent bird, but when alarmed it is said to utter a harsh croak like that of a Heron.

Its food consists principally of worms, crustacea, small shells, aquatic 
insects and frogs, for which it may often be seen searching on the lowlying coasts and on the shores of lakes and rivers, walking about something like a Curlew.

The most celebrated breeding-place of the Ibis in Europe is the district in the valley of the Danube near Belgrade, extending northwards into the valley of the Theiss, and southwards into that of the Save. This district, extending for a hundred miles from the Weisse Morast to the Obedska Bara, is the Eldorado of Herons, Ibises, Spoonbills, Cormorants, Terns, Gulls, Sandpipers, Ducks, Geese, and Pelicans. It looks like an endless plain, a boundless forest of reeds, a paradise of fish and fish-eating birds, full of rivers and lakes, ponds and canals, marshes and swamps, flooded meadows, half-drowned forests of pollard willows and alders, every possible combination to make bird-life easy and bird-nesting difficult. The Danube and its tributaries rise in summer like the Nile. Hundreds of square miles are under water; but in most places the reeds and rushes, the sedge and rank vegetation of all kinds are so thick that it is seldom possible to squeeze a boat through them. Many of the colonies are absolutely inaccessible, and those that can be reached require the assistance of a guide who is acquainted with the intricate labyrinths of the channels which lead to them. When once they are reached the sight is one that remains photographed for ever on the eyes of the ornithologist. I have twice been in this district, but not in the breeding-season, and must refer my readers to the glowing description of the Weisse Morast to be found in 'Naumannia,' i. pt. 2, p. 73, written more than thirty years ago by Baldamus, and the briefer account of the Obedska Bara, communicated to the 'Ibis' for 1884, p. 125, by my friend Mr. W. Eagle Clarke.

The Ibis builds in willows which are half under water, and makes its nest at various heights from the surface in the same trees as Common Herons, Night-Herons, Squacco Herons, Little Egrets, and Pigmy Cormorants. Sometimes one tree will contain nests of all the six species. The Great Cormorant and the Spoonbill are not so sociable; they each occupy a part of the forest reserved for themselves, but in the immediate neighbourhood, sometimes surrounded by the nests of the other speciesa colony within a colony. The nests arc made of sticks and reeds; but whether they are built on the radius model of the Egret or on the are model of the Cormorant it is impossible to say. The eggs are said to be three, and occasionally four, in number. They arc dark greenish blue in colour, rather rough in texture, and the shell is finely pitted with small pores. They vary in length from $2 \cdot 2$ to $2 \cdot 0$ inch, and in breadth from 1.55 to 1.38 inch. The eggs of the Ibis cannot well be confused with those of any other European bird; they are readily distinguished from those of the Herons by their much darker colour and less chalky appearance. 
Writing of the labits of this bird in India, Mr. Doig remarks (Stray Feath. 1879, p. 377):-“ In May 1878 I observed these birds in pairs and sent men after them to try and find out their breeding-grounds, but in vain; and so being unable to go myself, in consequence of work, I was obliged to give up the search. This year, however, in June, I was able to search myself, and found them breeding in great numbers on trees along the banks of the large lakes inside the sand hills, along the banks of the 'Narra.' The nests were placed on the tops of kundy-trees, and were constructed of sticks, about the size of Plotus melanogaster; on the same trees I found Inocotis papillosus and Ibis melanocephala breeding, while close by were numbers of nests of Herons, Egrets, and Cormorants." Legge found this bird breeding in Ceylon, and writes:- "In March 1872 I found a small colony of these Ibises, numbering about eight pairs, nesting at Uduwila, near Tissa Maha Rama. The nests were placed on thorny trees growing in the half-dried bed of the small tank already referred to in former articles, and the trees chosen were those on which the Shell-Ibises were nesting. The nests were small and mostly made of twigs and grass-roots, almost flat in shape, and placed upon the horizontal forks of small branches high up in the trees. The young were fledged, but unable to fly, and when I approached the trees stood up in the nests, scrambling along the branches and climbing actively about them as I mounted to the nests; when seized they clung tightly with their feet, and were with difficulty removed. My efforts to keep them alive were not successful, for while several Pelicans and Pelican-Ibises thrived on fish and meat, the Glossy Ibises died, only living two days. When flying away from their nests the old birds made a whizzing sound with their wings." The Ibis only appears to rear one brood in the year.

The general colour of the Ibis in summer plumage is brownish chestnut, suffused on the forchead and crown with metallic green, on the back with purple, and on the wings, rump, upper tail-coverts, and tail with both purple and green; the under tail-coverts are nearly black. Bill greenish brown; legs and feet greenish grey, claws black; irides brown; facial skin slate-grey. The female resembles the male in colour. In winter the underparts are earthy brown, slightly suffused with reddish purple; the head and the upper half of the neck are earthy brown, each feather margined but not tipped with white. Young in first plumage and birds of the year differ very little from adults in winter plumage, but have much less metallic gloss on the feathers.

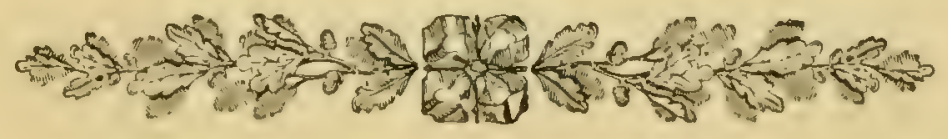




\section{Genus CICONIA.}

The genus Ciconia was established by Brisson in 1760, in his 'Ornithologia' (v. p. 361), for a group of birds which was composed of the Storks and tie Cranes. The latter birds were removed by Bechstein in 1793, leaving this genus restricted to the Storks. The White Stork (the Ardea ciconia of Linnæus) must of necessity be accepted as the type of the genus.

The Storks may be distinguished by their long straight bills, and by having the middle toe united by a web at the base to both the outer toes; they are connected with the Ibises by the genus Tantalus, in which the bill is curved downwards.

This genus contains about fifteen species, ten of which belong to the Oriental and Ethiopian Regions, two to the Palæarctic, one to the Australian, and two to the Neotropical Region. Two species breed in Europe, both of which are rare stragglers to the British Islands.

The Storks frequent marshy districts, fields, and plains, especially those near houses and towns. They search the banks of rivers and lakes for much of their food, which consists chiefly of small reptiles, fish, small mammals, and insects. They walk about very sedately, and have great command over themselves in the air, wheeling about very much like Vultures. They build a large nest of sticks, coarse grass, \&c., either on a tree, rock, or building, and their eggs are rough in texture and white. 


\section{CICONIA ALBA.}

\section{WHITE STORK.}

(Plate 37.)

Ciconia alba, Briss. Orn. v. p. 365 (1760); Bechst. Naturg.Deutschl. iii. p. 41 (1793); et auctorum plurimorum - Temminck, Degland \& Gerbe, Naumann, Dresser, \&c.

Ardea ciconia, Limn. Syst. Nat. i. p. 235 (1766).

Ciconia alba, var. major,

Ciconia azretti,

Ciconia alba asiatica,

Ciconia mycteriiarhyncha, Severtz. fide Dresser, Ibis, 1876, p. 324.

It is not known that the White Stork ever bred in the British Islands, but it occasionally visits them, either singly or in small partics, during the spring and autumn migration. It is most often seen in the eastern and southern counties. In Scotland it has occurred in the counties of Berwick and Forfar; but in Ireland there is only one record of its occurrence, in 1846, when three Storks were seen in the county of Cork, one of which was shot.

The range of the White Stork, like that of so many other birds, extends from the Atlantic to Central Asia. It is a summer visitor to the western Palæarctic Region, wintering in West Africa and throughout South Africa as far north as the Soudan. It does not breed in Norway, but occurs as an occasional straggler up to lat. $61^{\circ}$. It breeds in South Sweden, occasionally straying as far north as lat. $60^{\circ}$. In the Baltic Provinces it breeds up to lat. $58^{\circ}$; but it does not appear to be found in the valley of the Volga. It is a very common resident in the Caucasus; but is only a summer migrant to Turkestan as far east as Yarkand. It is a common summer visitor to the whole of Europe south of these limits; but in France it has been entirely exterminated during the breeding-season, aud in Italy nearly so, and is only known now in these two countries as passing through on migration. It occasionally visits the Canaries on migration; but is a regular summer migrant to Algeria. It passes in great numbers through Palestine and Egypt on migration, a few remaining to breed in the former country. It is a common summer visitor to Asia Minor and Persia, and winters in North India.

In the valley of the Lower Amoor, Manchooria, East Mongolia, North China, and Japan a nearly allied species occurs (Ciconia boyciana), 
differing principally in having the bill black, and the bare space in front and behind the eye vermilion $*$.

In South America a species of Stork is found ( $C$. maguari), which is said to have occurred in France. It differs from our species in having the bill greenish instead of red, and the upper tail-coverts black instead of white.

In England the Stork is only known by reputation; but on the continent it is in many places more familiarly known than any other bird. The arrival of the Stork is a landmark in the calendar. The date varies in different localities, and is dependent in some measure on the season. In Asia Minor it arrives carly in March; but in Poland it is seldom seen before the end of that month, and in South Sweden it only appears in April. Before the end of August the Stork takes its departure from North Europe, and by the end of September nearly all have disappeared, even from Southern Europe. They migrate in flocks during the day, generally at a great height, and roost on trees at night during their journey. The nature of their food causes them to be most abundant in marshy districts, and seldom to be seen except in the plains. In some districts they are extremely common. Almost every village in the valley of the Danube contains its half-dozen or more Storks' nests; and from the balcony of our quarters in the village of Nymphi in Asia Minor I counted fourteen nests all occupied. It can scarcely be called a gregarious bird, as isolated nests are quite as common as those built in what might be regarded as colonics; and a solitary Stork feeding in a swamp is a very familiar object, though I have often scen a score or more fishing together in a marsh.

There is something almost pompous in the dignified stride of the Stork, as he parades up and down the pasture, occasionally pausing leisurely to pick up a beetle from the ground, or standing still to precn his feathers in a nonchalant manner. He is, to all appearance, a very conten plative bird, and loves to stand in a very conspicuous position, on the edge of the nest, or ori the gable of a house, sometimes for hours together. At other times he sails round and round, with widespread motionless wings, high above the village, at which time he bears a striking resemblance to a Griffon Vulture. When flying across country the long broad wings are moved with slow deliberate beats, but they are powerful enough to carry the bird along at a considerable specd. The flight of the Stork differs somewhat from that of a Heron; the neck is stretched out instead of

* A White Stork with a red bill is said to have been seen in China (Swinhoe, Proc. Zool. Soc. 1873, p. 729); but as Taczanowsky received a pair of birds with three eggs, obtained by Dybowsky near the mouth of the Ussuri River in South-east Siberia, which he identified (Jouru. On. 1875, p. 256) with Swinhoe's description and plate, it is probable that Swinhoe's correspondent was in error. 
being folded up until the head comes between the shoulders, and though the legs are stretched out behind, and the neck and bill extended in front, they do not form a straight line as in the Heron, but both legs and neck are slightly drooped so as to form a distinct curve.

The Stork has no voice. If driven into a corner, it makes a sort of hiss; but its chief mode of expressing itself is by rapidly striking its mandibles together. The "klappering" of the Stork is a curious performance. Sometimes the beak is laid against the belly, and sometimes the neck is bent in the opposite direction, and the bill lies on the back, of course with the under mandible uppermost. The two mandibles are struck together so rapidly that a loud clear trill is produced, which is curiously modulated-now quick, now slow; now loud, now low.

The Stork procures most of its food from the water, into which, if necessary, it wades to some depth. Frogs and fish are its favourite diet; but no animal food comes amiss to it-rats, mice, lizards, snakes, young birds, shellfish, snails, and insects of all kinds are greedily devoured. It only varies this diet with vegetable food when hard pressed by hunger.

The Stork is not a very early breeder, even in South Europe and North Africa eggs are scldom found before the end of March, and in Central Germany they are usually laid late in April. In Denmark they are generally found during the second half of May. The Stork has attached itseif to human habitations almost as much as the House-Martin and the Sparrow. If possible it builds its nest on the roof of a house, and in civilized countries a platform of some kind, an old cart-wheel or similar structure, is provided for its accommodation. Occasionally several nests are built upon the same roof, and a house in the middle of a village is quite as eligible as one on the outskirts. The old nest is used year after year, a slight addition being made to it every season, so that after the lapse of years, if it happens to be in a situation protected from the wind, it sometimes attains a great height. Instances are on record of Storks' nests which have been inhabited every year for more than a century, and some have been known to reach a height of five or six feet. In the valley of the Lower Danube I have seen a Stork's nest in a willow tree. It occasionally breeds in trees in other localities; and Mr. Benson writes that in Seeland it may be found breeding in trees in small colonics. I have also seen its nest on the walls of old ruined houses in the steppes of the Dobrudscha; and Dixon observed small colonies breeding on the ledges of the cliffs in Algeria.

The nest is a very large structure, four or five feet in diameter, and is built of sticks, many of them of considerable thickness, mixed with lumps of earth and masses of decayed reeds; it is very shallow, and is lined with softer materials of all kinds-dry grass, moss, hair, feathers, rags, bits of paper, wool, or any thing it can pick up. Incubation lasts about a 
month; and when the young are hatched it is very interesting to watch them being fed by their parents, who disgorge half-digested food from their mouths to fill the hungry bills, which, even in the nest, have learnt to "klapper" with excitement.

The eggs of the Stork are from three to five in number, dull white in colour, rough in texture, and with little gloss. They vary from 3.0 to 2.72 inch in length, and from $2 \cdot 2$ to 2.05 inch in breadth. The eggs of this bird very closely resemble those of the Black Stork, but are on an average larger and, when held up to the light, are yellowish white inside, those of the Black Stork being green. I have an egg of this species, collected by Col. Irby in Spain, which is faintly blotched with pale reddish brown; but these markings may possibly be blood-stains. Only one brood appears to be reared in the year.

In most countries the Stork is protected and is regarded as a semisacred bird, bringing good luck upon the houses where it builds its nest. It is a prominent character in nursery tales of various kinds, and the same kind of stories are told of these birds as of Rooks ; but the "Storchgericht" is probably as legendar'y as the "Crows' Court."

The young in down of the Stork is of a nearly uniform greyish white, with yellowish-green bill and feet. Young in first plumage and birds of the ycar scarcely differ from adults, except that the colour of the bill, legs, and feet is paler and duller. Summer and winter plumage do not differ, nor is that of the female distinguishable from that of the male. Adult birds are pure white, except the primaries, the secondaries, the scapulars, and the larger wing-coverts, which are black. Bill, legs, and feet deep scarlet; claws dark brown; irides brown; bare space round the eye black.

Storks moult very slowly, and may be seen changing feathers at all times of the year, except during the breeding-season. The quill- and tail-feathers are ouly changed once in the year, a process which goes slowly forward in autumn and winter. Most of the small feathers are renewed in autumn, and very many in early spring.

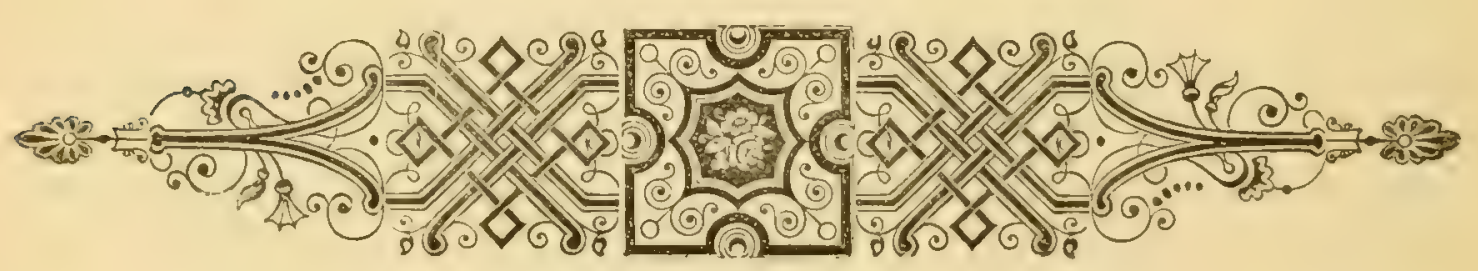




\title{
CICONIA NIGRA.
}

\section{BLACK STORK.}

\author{
(Plate 3\%.)
}

Ciconia fusca, Briss. Orn. v. p. 362 (1760).

Ardea nigra, Linn. Syst. Nat. i. p. 235 (1766); et auctorum plurimorum-(Temminck), (Degland \& Gerbe), (Naumann), (Dresser), \&c.

Ardea chrysopelargus, Licht. Cat. Rer. Nat. Rar. sp. 284 (1793).

Ciconia nigra (Linn.), Leach, Syst. Cat. Mamm. \&c. Brit. Mus. p. 33 (1816).

Melanopelargus niger (Linn.), Reichenb. fide Bonap. Consp. ii. p. 105 (1857).

The Black Stork is another of those birds for whose introduction into the British list we are indebted to the industry of Colonel Montagu, who described an example which was caught alive in May 1814 on West Sedge Moor in Somersetshire (Mont. Trans. Linn. Soc. xii. p. 19). After that date there is no record of the Black Stork having been obtained in this country until 1831, between which year and 1867 eleven examples are recorded. Of these one occurred in Devonshire, one in Somerset, two in Dorset, one in Oxfordshire, two in Kent, one in Suffolk, one in Norfolk, and two in Yorkshire. There is no reliable evidence of its ever having occurred in either Scotland or Ireland. Of the English occurrences two were obtained in May, two in August, one in October, and two in November, the dates of the others not being known. This bird must therefore be regarded as an accidental straggler to England during spring and autumn migration. It is probable that the less frequent occurrence of late years of this and other accidental visitors is owing to the rapid increase of population in Western Europe since the introduction of railways on the continent.

The Black Stork has a much wider range than the White Stork, being found from the Atlantic to the Pacific. It is a summer visitor to Europe, formerly breeding in the principal forest-districts south of lat. $55^{\circ}$. It has occurred twice in Norway, and still breeds in the extreme south of Swecien. It has been exterminated during the breeding-season in many parts of Europe, and is now only found on migration in France, Holland and Belgium, and the greater part of Germany; but it still breeds near Hanover, in Pomerania, in the valley of the Danube, and in Spain. In Italy and Greece it is only known as a spring and autumn migrant; but it breeds in South Russia, and is said to be a resident in the Caucasus. In the valleys of the Volga and the Obb it occurs as far north as lat. $55^{\circ}$; and is a regular summer migrant to the neighbourhood of Lake Baikal and throughout the valley of the Amoor. It is said to have occurred in VOL. II. 
Madeira, and is a regular winter visitor to most parts of Africa. It is said to breed in Palestine, but in Asia Minor is only known as passing through on migration. It is a summer visitor to various parts of Persia, and Turkestan as far east as Yarkand, and winters in North-west and Central India. It is said to pass through South-east Mongolia on migration, and winters in Central China, but may possibly breed in the north of that country. The Black Stork does not appear to have any nearer allies than Ciconia episcopus, which inhabits the Ethiopian and Oriental Regions, and C. microscelis, from Central Africa, both of which may easily be distinguished from it by their white necks.

The habits of the Black Stork differ in many important respects from those of its ally. Its range does not extend so far north during the breeding-season, and it never remains in Europe during the winter, as the White Stork occasionally does. It studiously avoids the presence of man, and seeks to hide its nest in the recesses of the virgin forest. It is not at all gregarious, except on migration, and is very silent, its "klapper" being rarely heard. From all these circumstances we may infer that the Black Stork is a much more cautious bird than the White Stork, though its extreme caution does not appear to have been of much advantage to it, as it is on the whole a much rarer bird than its bolder relative. It must be quite as hardy, since it arrives at its summer-quarters somewhat earlier, and leaves again for the south slightly later than the common species.

Neither in its walk, nor in its flight, nor in the nature of its food does it differ from the White Stork.

Five and twenty years ago the Black Stork bred regularly in many of the forests in the immediate neighbourhood of Brunswick; now it has become rare, and a visit to the "horst" of a pair of these interesting birds means a hard day's work, and only to be successfully accomplished after diligent inquiry. When I was in Eastern Germany in the spring of 1882 my friend Oberamtmann Nehrkorn was kind enough to conduct me to the nest of a pair of these fine birds in a forest about twelve miles from Riddagshausen, beyond the village of Glentorf. We picked up a guide on the way, and of course took with us our invincible "Kletterer" Gottlieb, armed with a rope-ladder. After a long cold drive in a bitter north-east wind (although it was the 19th of May) we reached Glentorf, and a couple of miles beyond the village brought us into the heart of the forest. We had not walked very far before we found ourselves in a virgin forest or "Urwald," with grand oaks probably five hundred years old, full of rotten branches, and occasionally with hollows in the stems. Intermingled with the oaks were fine lofty beeches, but there was very little underwood. The ground was very swampy, and underneath many of the oaks grew Arum, Oxalis, and other plants. 
We soon found a very large "horst" of a Goshawk. We tapped on the trunk of the oak in which it was, and shouted, but to no purpose. As the tree was easy to climb, Gottlieb got up to the nest, but found it empty. Before he had descended we found the nest of the Black Stork on a large oak not more than fifty yards from the other nest; but there was no sign of a bird. Our guide assured us that it was occupied, so we concluded that the noise we had made at the Goshawk's empty nest had frightened the bird away. The tree was an old oak at least five feet in diameter for some distance from the ground, and thirty feet without a branch. Gottlieb accordingly ascended a tree close by to reconnoitre; and just as he got up it to the level of the nest, to our great astonishment off flew a Black Stork and began to wheel round and round in the air above the tree. She was soon joined by another, so Gottlieb descended and at once began to make preparations for the ascent. We had some difficulty in throwing the line over the lowermost branch, which was dead but very thick; at last we succeeded, and having hauled up the rope-ladder, Gottlieb was soon on the branch. The distance to the next branch was too far to reach by sheer climbing, so the rope-ladder had to be got up another stage, and the nest was then soon reached. It was about fifty feet from the ground, on the fork of a large horizontal branch about halfway up the tree. It measured from five to six feet in diameter, and was in some places two feet high, and was composed of old dead twigs, bleached with many years' exposure. The top of the nest was almost flat, covered over with a thick layer of green moss, and in a slight depression in the middle lay three young birds not long hatched and one egg already chipped. Both parent birds remained within sight whilst we were at the nest.

Near the Lantow See in Pomerania I visited another nest of the Black Stork on the 30th of May in the same year, in the company of my friend Dr. Holland. It had not been occupied for the last year or two, and was built in a beech about thirty feet from the ground. It was very large and deep, but appeared flat at the top. The forester told us that for two successive years he had known of two nests of the Black Stork in one beech tree. In the afternoon we made a détour in the forest on our way to the station to visit another nest of this interesting bird. It was in a Scotch fir not more than forty feet from the ground, on the fork of a flat branch which grew out a few feet above the main fork of the tree. The oid bird was standing on the nest, almost as motionless as if she was asleep, contemplating her four "ugly ducklings," and she did not seem at all alarmed at our approach, and allowed us to examine her leisurely through our binoculars. The ground underneath the tree was covered with the droppings of the young. The nest was very large, at least four and a half fect across, and with scarcely any depression in the centre; the top was covered all over with green moss. As we stood looking at 
the nest the old bird slowly took wing and flew round whilst one of our party climbed up.

The Black Stork does not always breed in trees. Hudleston found it breeding in a cleft of the rocks in Bulgaria; and Elwes and Buckley observed a pair making their nest in a low rock on the edge of the forest in the north of the Dobrudscha. L'Abbé David also says that in China it breeds in perpendicular cliffs.

The eggs of the Black Stork are from three to five in number, and dull white in colour, coarse in texture, full of small pores, and with very little gloss. They vary in length from $2 \cdot 8$ to $2 \cdot 45$ inch, and in breadth from 2.05 to 1.85 inch. On an average the eggs of this bird are smaller than those of the White Stork, but large eggs of the former equal in size small eggs of the latter. They vary considerably in shape, some specimens being much rounder than others; they are, however, readily distinguished by the green colour of the inside of the shell when held up to the light.

The names applied to the two European Storks are unfortunate. The White Stork is not white, neither is the Black Stork black; but whereas in the former species the wings below the shoulders are the only parts which are black, in the latter the only white portions are the underparts below the long neck-feathers. The rest of the plumage is, however, by no means black; it is metallic blue, green, purple, violet, and almost red as the light falls upon it in different directions. The bill, legs, and feet are deep scarlet, as in the White Stork, but the bare space round the eye is deep scarlet instead of black. The Black Stork is slightly the smaller bird. Young in first plumage differ considerably from adults; the metallic gloss on the upper parts is much duller; the feathers of the sides of the head and of the neck, aud some of the wing-coverts, have rusty white tips, and the bill, legs, and feet are olive-brown. Birds of the year are intermediate in plumage.

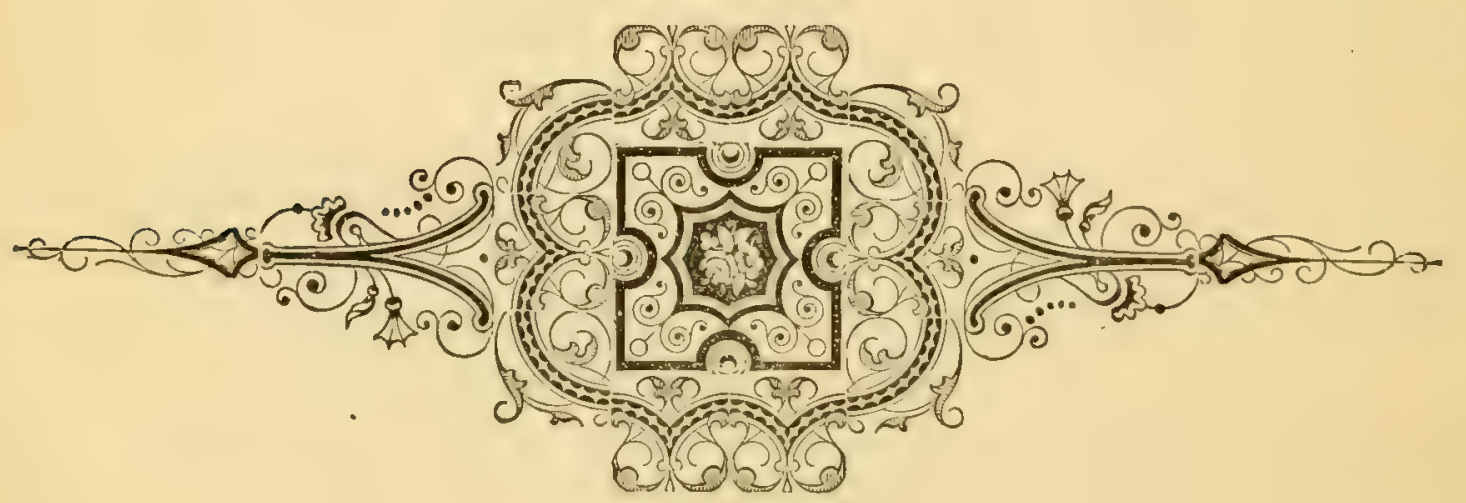




\section{Family RALLID E, or RAILS.}

The Rails are a fairly well-defined group of birds. Sclater places them in an Order by themselves between the Hemipodes and the Cranes and Bustards; but Forbes removed them from the vicinity of the Cranes, and associated them with the Bustards and the Stone-Curlews, in a group which comprised also the Game Birds and the Cuckoos; whilst Gadow places them near the Cranes.

The Rails resemble the IIerons and the Storks in having one deep notch on each side of the sternum, but in the modification of their cranial bones they do not belong to the same great group, being placed by Huxley near the Cranes, the Bustards, the Sandpipers, and other schizognathous birds. This position appears to be confirmed by their pterylosis, myology, and digestive organs, in all of which they show very close relationship to the Cranes and Bustards.

Amongst the Rails, as in the Game Birds, genera are to be found the birds of which only moult once in the year, whilst others have a spring as well as an autumn moult. To the former group, so far as is known, belong the true Rails, the Waterhens, and the Coots, that moult only in autumn, and attain their spring plumage by casting the ends of the feathers, which may also increase in brilliancy of colour without being moulted. To the latter group belong the Crakes, the Palæarctic species of which have a spring as well as an autumn moult.

The principal external characters of the Rails are their large feet (the hind toe being slightly elevated), comparatively short tarsus, short stout beak, and rounded wings and short tail (the former containing ten primaries and the latter composed of twelve feathers). The young of the Rails, like those of many other birds that breed on the ground, are covered with down when they are hatched, and are able to run almost immediately.

There are about 150 species of Rails, which are found throughout the world, except in the Arctic Region. Nine species breed in Europe, and two others are occasional stragglers to that continent; of these seven are British.

\section{Genus CREX.}

The Crakes were included by Linnæus in his genus Rallus, from which Bechstein in 1803, in his 'Ornithologisches Taschenbuch' (ii. p. 336), removed the Corn-Crake (the Rallus crex of Linnæus), making it the type of a new genus, Crex. 
The Crakes are distinguished from the Waterhens and the Coots by having the forehead covered with feathers to the base of the bill, and by having no lateral membranes to the toes. From the Rails, to which they are very nearly allied, they may be distinguished by the bill being shorter instead of longer than the head.

There are about twenty-five species of Crakes, which are distributed throughout the Old World with the exception of the Arctic Region. Four species are European, all of which are summer visitors to the British Islands, occasionally remaining during winter.

The Crakes do not differ in their habits, nidification, or in the colour of their eggs from the Rails.

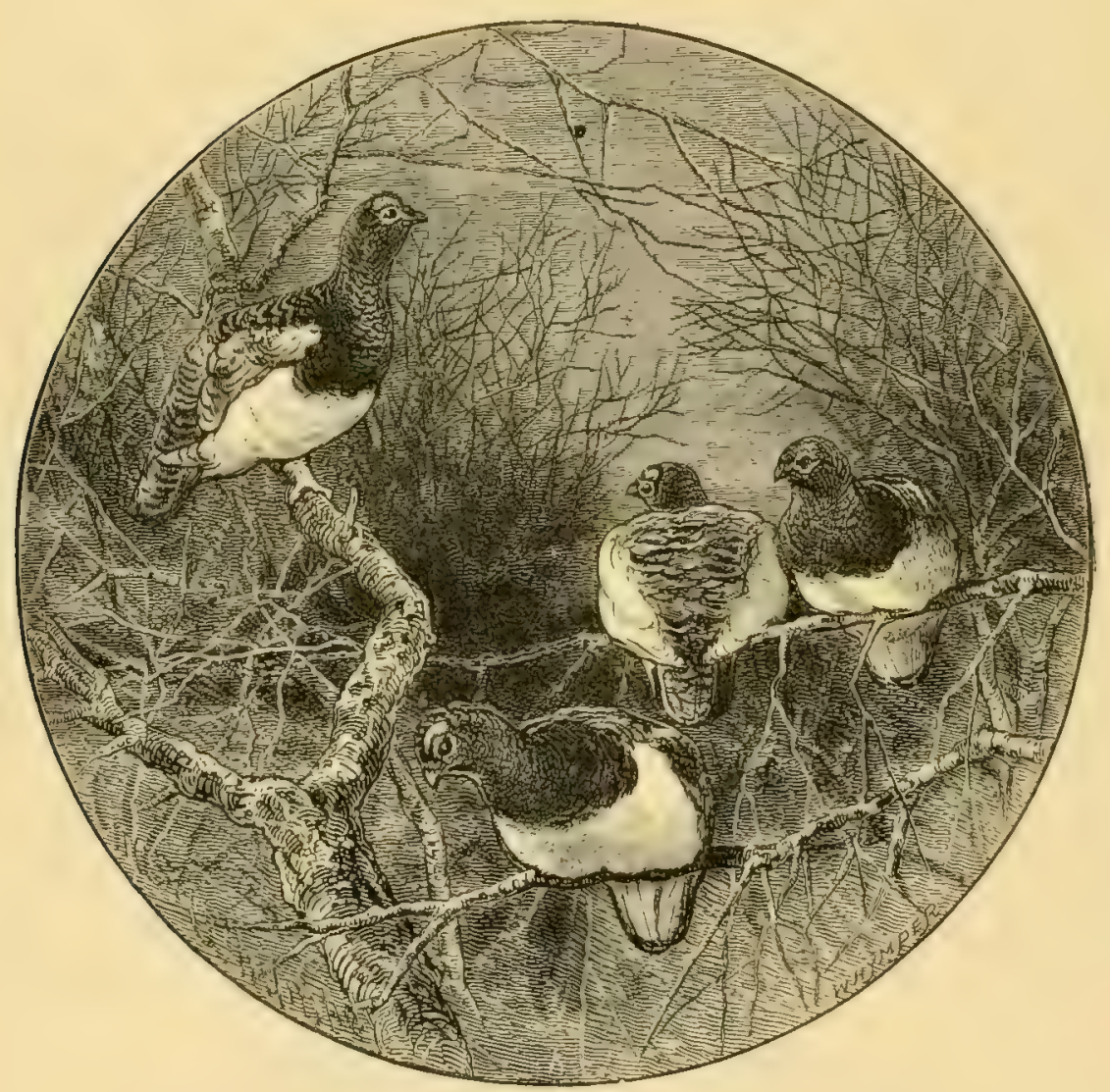

W ILLOW-GROUSE. 


\title{
CREX PRATENSIS.
}

\section{CORN-CRAKE.}

\author{
(Plate 23.)
}

\author{
$\left.\begin{array}{l}\text { Rallus gẹistarum, } \\ \text { Rallus ortygometra, }\end{array}\right\}$ Briss. Om. v. p. 159, pl. xiii. fig. 2 (1760). \\ Rallus crex, Linn. Syst. Nat. i. p. 261 (1766). \\ Gallinula crex (Linn.), Tunst. Orn. Brit. p. 3 (1771). \\ Crex pratensis, Bechst. Orn. Taschenb. ii. p. 336 (1803); et auctorum pluri- \\ morum-(Naumann), Loche, Degland \& Gerbe, Jerdon, Salvadori, Dresser, \\ Saunder's, \&c. \\ Ortygometra crex (Limn.), Leach, Syst. Cat. Mamm. \&c. Brit. MLus. p. 34 (1816). \\ $\left.\begin{array}{l}\text { Crex herbarum, } \\ \text { Crex alticeps, }\end{array}\right\}$ Brehm, Vög. Deutschl. p. 694 (1831).
}

The Corn-Crake or Land-Rail, as it is often called, is a common summer migrant to the British Islands, and is found in all suitable localities, including the Outer Hebrides, the Orkney and Shetland Islands, St. Kilda, and the Channel Islands. A few birds occasionally remain during the winter in this country.

The Corn-Crake breeds in the western Palæarctic Region as far east as the valley of the Yenesay, and winters in the Ethiopian Region. It is a summer visitor to the Faroes; but its occurrence in Iceland is doubtful. In Scandinavia it breeds as far north as the Aretic circle, and has been obtained in lat. $69 \frac{1}{2}^{\circ}$. It is a rare summer visitor to Archangel; but in the Ural Mountains is not known to occur north of lat. $60^{\circ}$. In Western Siberia it has only been recorded in the extreme south, where it is abundant in the Altai Mountains; but in the valley of the Yenesay it occurs as far north as lat. $59 \frac{1}{2}$. The Corn-Crake is a summer visitor to Central and Southern Europe, except that in the Spanish peninsula, Southern Italy, and Greece it is only known as passing through on migration. It is an accidental visitor to the Azores, and oceasionally occurs in the Canaries and Madeira. It is a resident in Algeria, but passes through Egypt on spring and autumn migration. In Palestine and Asia Minor it is said to be a resident. To the Caucasus and Russian Turkestan it is a common summer visitor. It appears to be only of very accidental occurrence in North-west India; but is said to be common in Afghanistan, and has occurred in North Persia. It is very common during our winter in Natal, and has been obtained in the Transvaal and the Cape Colony. Although it is so difficult to make the Corn-Crake take wing, it is nevertheless a bird of very powerful flight, and has been known to stray to Greenland, the Bermudas, 
the east coast of the United States, and, it is said, even to New Zealand. The Corn-Crake has no near allies.

The migration of the Corn-Crake into Europe begins in February and March and lasts until the end of May. Irby says that at Gibraltar it is most numerous in February; but he has seen it as late as the 2nd of May. It passes Heligoland every year in April and May, arrives in Holland about the middle of May, but does not reach South Sweden until the end of that month. It usually arrives in the south of England during the last week in April, but does not appear to reach the northern counties and Scotland until the beginning of May.

The haunts of the Corn-Crake are very different from those usually selected by the other species of this group of birds. It loves the dry meadows and corn-fields, especially those through which rivers flow. In many parts of the Highlands the Corn-Crake makes its appearance before the grass or clover in the meadows is tall enough to afford it shelter, and it retires to the tangled hedges and sunk fences, the dry ditches, and even to large gardens and orchards. It is a very skulking, retiring bird, and would be almost entirely overlooked were it not for its well-known and monotonous note. The Corn-Crake is much commoner in certain districts in some years than in others, and Dixon has observed that they are generally most abundant in a wet season. Shortly after its arrival in this country, and for some considerable time, it appears to be very restless, and wanders about from one meadow to another, as if undecided as to its choice of residence; it may be heard calling lustily in a certain field one day, and perhaps a week may elapse before it is again heard in the same field. If the peculiar song of this bird be confined to the males, the explanation probably is that they are seeking the females from field to field. These actions continue until a nesting-ground has been chosen, after which the bird keeps closely to the fields in the immediate neighbourhood of its nest. It is very difficult to study the habits of this skulking bird, which when it leaves the cover for a few moments is always on the alert, and at the least alarm hides itself and hurrics quickly off through the grass. If in its wanderings it should chance to come near a place where the herbage is not thick enough to hide it from view, it generally runs quickly over it to the nearest cover, where it can pursue its way more leisurely. The Corn-Crake is very fond of the hedges, especially those where the bottom is choked up with bramble and luxuriant herbage; and it is quite surprising with what speed the bird will thread its way through them, always trying to elude danger by running, and only taking wing when absolutely compelled. When surprised in a hedge it often crouches close to the ground, remains motionless, and almost allows itself to be touched by the hand ere it starts off again. It is very seldom that the Corn-Crake can be flushed, only when it is hard pressed by dogs or man; it then rises in a very slow 
laboured manner, and flutters along just above the ground with its long legs hanging down, and pitches into the first cover it can reach, where it is seldom flushed a second time. In spring it sometimes perches on the hedges, especially if lured by a "call," as if the bird were anxious to get at its rival at once. Sometimes, especially in early autumn, when the hay is cut and the second crops of clover are scarcely tall enough to afford it shelter, the Corn-Crake may be seen in the grass-ficlds. At this season, when all the green cover has been laid low by the scythe, it often repairs to the fields of standing corn, from which it comes to the adjoining meadows to feed. Its feeding-time is in the early morning and at dusk. It is very wary when on these open grasslands, and every now and then lifts its head and stretches out its neck on the look out for danger. It rarely ventures far from the hedges, and at the least alarm either crouches close to the ground, or runs rapidly off through the hedge into the adjoining corn. The Corn-Crake is very fond of turnip-fields, and is as difficult to flush in them as elsewhere, glimpses being occasionally obtained of it as it runs across the ridges or pauses a moment in the open spaces.

The note of the Corn-Crake is so well known and familiar that it scarcely needs description. It is a very loud and harsh crek or crake uttered twice, and then a brief pause before it is again repeated. It may be readily imitated by drawing a knife-blade smartly across a stout comb, little skill being required in the operation. By thus imitating its note, especially in spring, the bird may be brought almost to the feet of the performer, if he remains very quiet. This singular note is heard most commonly in early morning and evening; but the bird utters it at intervals throughout the day, and it may be heard at all hours of the night. The Corn-Crake sometimes calls as he flics, more frequently as he runs through the herbage, but generally when he is standing quite still. The bird's keen scnse of hearing, and the rapidity of his retreat from the approach of an observer, has given rise to the theory that he is a ventriloquist. But such is not the case. When a high wind is blowing, great difficulty is sometimes experienced in making out the direction whence the sound proceeds, as it sometimes sounds bigh and close at hand, and anon appears fuint and distant, as the breeze carries it away or brings it close. The Corn-Crake does not call so frequently in cold dull weather, and still less so during the period of incubation. The song, if such it can be termed, ceases in the late summer, and it is rarely heard again until the following spring.

The food of the Corn-Crake is largely composed of worms, slugs, and snails, together with many kinds of insects, especially beetles. The bird also eats the tender shoots of herbage and the seeds of various grasses.

The Corn-Crake pairs annually, shortly after its arrival on our shores, but the eggs are not generally laid until the end of May or early in June. The nest is usually built amongst the meadow-grass or clover, 
and far less frequently in grain-fields. It is a much better structure than is generally supposed, and to call it a mere hollow lined with a few straws is certainly a libel on the poor Corn-Crake. The materials used are coarse dry grasses and other herbage, and very often a few withered leares; whilst the inside is lined with fine grass, very similar to that used by the Missel-Thrush. It is very carefully made, the materials being well interwoven, and is quite as elaborate a structure as the nest of a Pipit or a Sky-Lark. It is generally built in a little hollow in the ground, either a natural one or one made by the old birds. Dixon has known two nests of this bird only a few yards apart; and in many cases several nests are built in one large ficld. The eggs of the Corn-Crake are from eight to twelve in number, nine being an average clutch. They vary from pale buff to creamy white or bluish white in ground-colour, spotted and blotched with surface-spots of reddish brown, and underlying ones of pale lilac. The markings are seldom so numerous as to. cover much of the ground-colour, and are generally distributed over most of the surface. Sometimes one egg in a clutch is much paler than the rest and the markings much smaller. They vary in length from 1.5 to 1.36 inch, and in brealth from 1.1 to 1.02 inch. The eggs of the CornCrake very closely resemble those of the Water-Rail, but they are on an average much more thickly spotted. The Corn-Crake often sits upon her eggs as soon as they are laid. Dixon has known this species remove its eggs from a nest which had been exposed by the mowers. It sits very close when the eggs are nearly hatched, and often pays for its devotion with its life, from an unlucky stroke of the scythe or the knives of the modern mowing-machine.

The young are soon able to follow their parents through the herbage in scarch of food, and should any danger threaten they will scatter in all directions, and by crouching close to the ground endcavour to cscape detection. When about half-grown, they will scratch and bite with great vigour the liands of their captor. Sometimes, when caught, the Corn-Crake will feign death. Dixon has known a bird of this species, when caught, to feign death so closely as to be laid on the grass by its captors and left for dead; but the moment it thought it was unobserved it set off ruuning as if nothing were the matter. Jesse records a similar instance. It is very difficult to say when the Corn-Crake leaves this country in autumn, but numbers probably migrate south in September. The date of its departure is undoubtedly influenced by the decay or cutting of the herbage which forms its only shelter. It passes Heligoland in August and September, and is most numerous at Gibraltar in October.

The general colour of the upper parts of the adult Corn-Crake is brownish buff, each feather having a nearly black centre; the primaries and secondaries are chestmut-brown, and the wing-coverts chestnut. A 
stripe over the eye, the cheeks, throat, and breast are dull slate-grey, much paler on the chin, and shading into buffish white on the centre of the belly and the under tail-coverts. The under wing-coverts and axillaries are chestnut, and the flanks are chestnut-brown barred with white. Bill, legs, feet, and claws pale brown; irides hazel. The female scarcely differs from the male in colour. After the autumn moult the slate-grey on the underparts is replaced with pale russet-brown, but it is retained on the eye-stripe. Young in first plumage differ from adults in winter plumage in having the eye-stripe pale russet-brown like the breast; this plumage is retained until the first spring moult, when the plumage of birds of the year is assumed, which scarcely differs from that of adults in winter plumage. Young in down are almost uniform deep black.

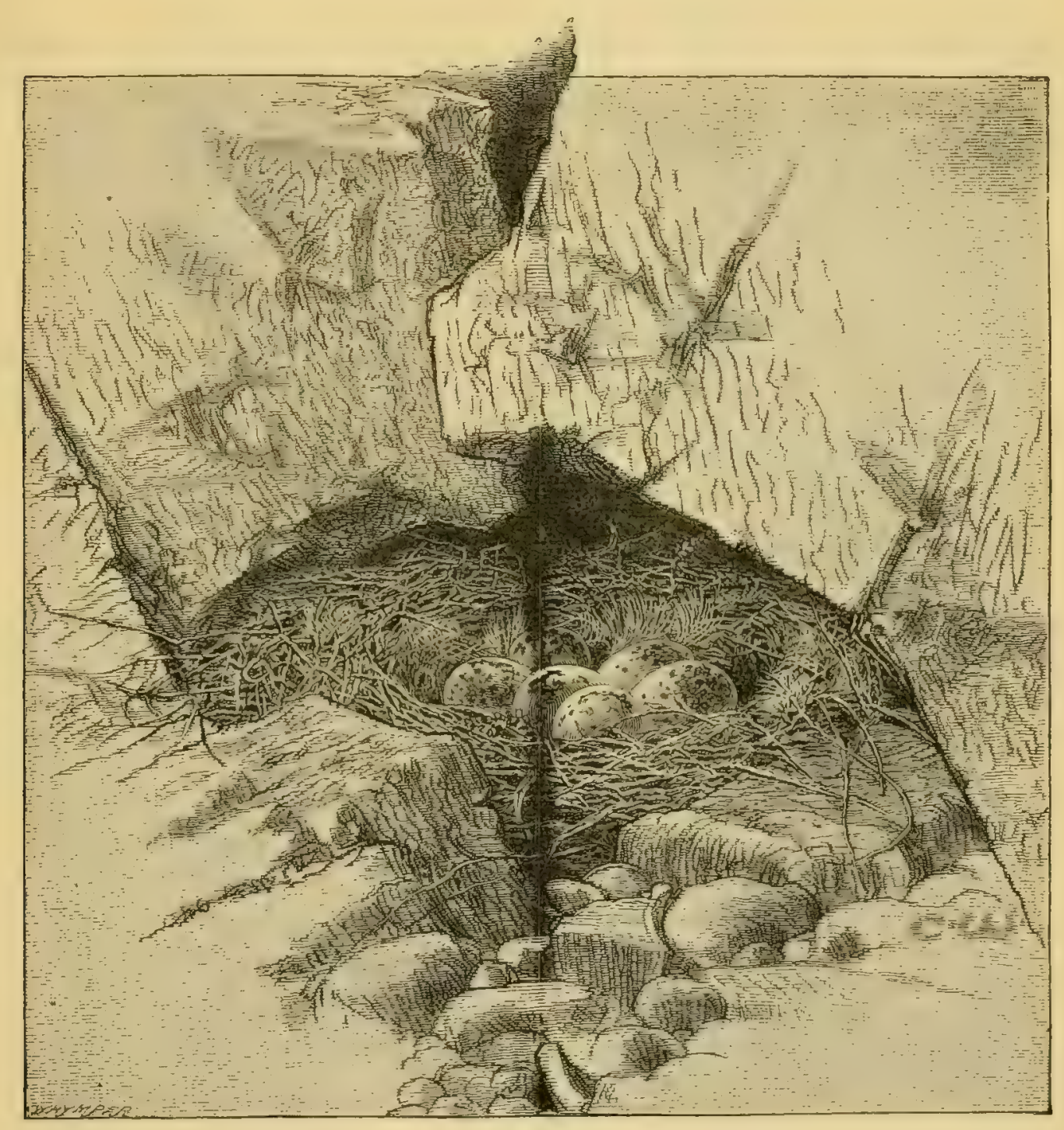

NEST OF SNOW-BUNTING. 


\section{CREX PORZANA.}

\section{SPOTTED CRAKE.}

(Plate 23.)

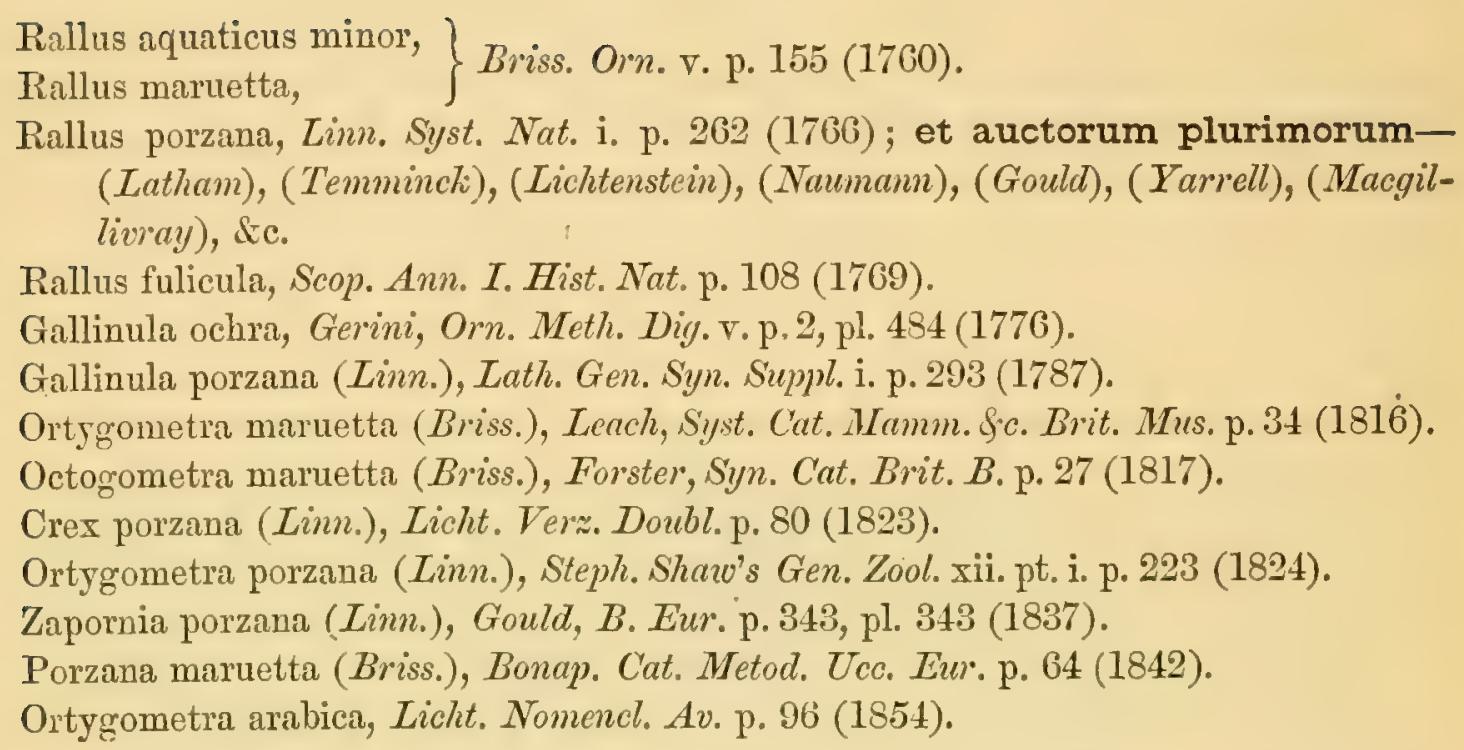

The Spotted Crake is generally distributed throughout the British Islands wherever swamps and marshes are to be found, but it is much more local than the Water-Rail and nowhere so abundant. It is found on both the Orkney and the Shetland Islands, but has not been recorded from the Outer Hebrides. It is principally known as a summer migrant, but has been met with in most districts during the winter months.

The geographical distribution of the Spotted Crake is very similar to that of the western form of the Watcr-Rail. It has been twice obtained in Greenland, but is not known to have occurred either in Iceland or the Faroes. It is a summer visitor to Scandinavia up to lat. $65^{\circ}$, and in West Russia up to lat. $64^{\circ}$. In the Ural Mountains it is not known to have occurred further north than lat. $58^{\circ}$, or in West Siberia than lat. $55^{\circ}$. It is a summer visitor to Turkestan, at least as far east as Yarkand. Pallas records it from Eastern Siberia, but no recent traveller has met with it in that country. It has been recorded from the Canaries. It is a resident in the basin of the Mediterranean; but is only a summer visitor to Northern and Central Europe; and it is doubtful whether it breeds in Egypt. To South Russia and the Caucasus it is a spring migrant, but it appears to be a partial resident in Persia. A few pairs breed at Gilgit, where it is principally known as passing through on migration to winter throughout India, and it has been known to occur at that season in Burma.

The Spotted Crake has probably no nearer ally than the Carolina Crake 
(Crex carolina), which may easily be distinguished by having the forehead, lores, chin, and upper throat black. An example of this species was shot in October 1864 by Mr. H. S. Eyre on the Kennet river, near Newbury, in Berkshire (Newton, Proc. Zool. Soc. 1865, p. 196). This species breeds in the Northern United States and in Canada up to about lat. $62^{\circ}$, wintering in the Southern States, Mexico, Central America, and the West-Indian Islands. It has once been obtained in Greenland. It is impossible to say whether the specimeu obtained in England had escaped from confinement.

The habits of the Spotted Crake are precisely the same as those of the Water-Rail, to which bird it otherwise bears so close a resemblance that it is difficult to believe that they ought to be placed in different genera. The two birds are equally shy and skulking; they frequent the same fenny and marshy districts; one is as unsociable as the other and as unwilling to take wing; their flight is the same, heavy, laboured, straight progress through the air, with rapid beats of the broad, rounded wings; the note during the breeding-season is the same liquid whit, though that of the smaller bird is not so loud; and the position of the nest and the materials of which it is composed are so similar that a description of the one reads like a copy of that of the other. Naumann says that the call-note of the Spotted Crake is between a squeak and a whistle, which cannot be expressed on paper.

The best locality in which to study the habits of the Spotted Crake is the village of Valconswaard in Holland, on the borders of Belgium and Germany. The country is almost a dead level, with here and there a small range, not of mountains, but of mounds, which are apparently heaps of sand or gravel. In the area of, say, a hundred square miles, of which Valconswaard in the centre, fifty miles are open heath-covered moor, where Peewits, Curlews, and Black Terns breed. About five and twenty miles are forests of Scotch fir, inhabited by Tits, Crows, and Hawks. Perhaps fifteen miles are arable land, wheat and other corn-crops, varied with beans, potatoes, and rape; whilst the remaining ten square miles are river, lake, and marsh, abounding with Ducks and Sandpipers of various species, and the favourite breeding-grounds of the Spotted Crake. The nests are very difficult to find; but Wharton and I succeeded in finding two nests during our first day's search, but one was empty and the other contained only one egg. The following day we were not so successful, but meeting a peasant early in the day who had found a nest with six eggs, we rashly commissioned him to obtain us some more at the price of three pence each. In the evening he turned up at our little inn, and we had to pay him for forty-eight eggs! He told us that he had a couple of dogs which he had trained to go bird-nesting with him. In spite of the abundanec of the bird we did not catch a sight of it more than half a dozen times during 
our visit to the district. The nests were large for the size of the bird, and were built in clumps of rushes or amongst reeds; they stood nearly a foot above the level of the water, and were composed of flat leaves of the reed, sedge, and other water-plants, and generaily, when built in the reeds, had a foundation of dead broken reed. The number of eggs varies from eight to twelve; they are usually laid in May or early in June. They vary in ground-colour from buff to very pale greenish white, boldly spotted and speckled with pale and dark brown, and with underlying markings of violet-grey; the spots vary in size from that of a small pea to a mere speck. Most eggs are finely dusted over the entire surface with these small specks, amongst which the larger markings are somewhat evenly dispersed. On some specimens most of the markings are at the large end, where they sometimes form broad irregular streaks joining the larger blotches together. On many eggs the underlying spots are as numerous as the surface ones, sometimes more so, sometimes less. The egrs vary in length from 1.4 to 1.2 inch, and in breadth from 1.0 to $0.9 \mathrm{inch}$. The eggs of the Spotted Crake are the most distinct and the easiest to determine of all the British species of this group of birds. Their bold, large, and distinct spots, and greenish tinge iuside when held up to the light, readily distinguish them from those of all European Crakes. The Spotted Crake probably only rears one brood in the year; but if the first eggs are destroyed others, in many cases, are laid.

The general colour of the upper parts of the adult Spotted Crake is olivebrown, sometimes approaching russet-brown, each feather having a nearly black centre, and most of them spotted on the margin with white. The primaries and secondaries are brown, but the outer web of the first primary is white. The lores are brown, the feathers above and below them being very dark brown, and the ear-coverts are brown; the forehead, a broad line over each cye, the chin, throat, and breast are slate-grey, shading into white on the centre of the belly, into brown on the flanks, and into buff on the under tail-coverts. The breast is slightly suffused with brown, and the cheeks and breast are spotted with white; the under wing-coverts, axillaries, and flanks are transversely barred with white, each spot and bar being slightly emphasized with a margin of nearly black. Bill yellow, shading into orange at the base ; legs, feet, and claws olive-green; irides hazel.

The female scarcely differs from the male in colour, and autumn plumage very slightly differ's from that of spring. Young in first plumage and birds of the year after their first spring moult have all the slate-grey parts more spotted with white, especially on the chin and upper throat; and young in first plumage have the dark centres of the feathers of the upper parts smaller and less clearly defined. Young in down are black. 


\title{
CREX BAILLONI.
}

\section{BAILLON'S CRAKE.}

\author{
(Plate 23.)
}

Rallus pusillus, Pall. Reis. Russ. Reichs, iii. App. p. 700 (1776).

Rallus bailloni, Vieill. $N$. Dict. d'Hist. Nat. xxviii. p. 548 (1819); et auctorum plurimorum - (Temminck), (Degland \& Gerbe), (Yarrell), (Diesser), (Saunders), \&c.

Gallinula baillonii (Vieill.), Temm. Man. d’O»n. ii. p. 692 (1820).

Gallinula stellaris, Temm. Man. d'Orn. ii. p. 693 (1820).

Crex baillonii (Vieill.), Licht. Verw. Doubl. p. 80 (1823).

Ortygometra baillonii (Vieill.), Steph. Shaw's Gen. Zool. xii. p. 228 (1824).

Gallinula pygman, Naum., fide Brehm, Lehrb. Naturg. eur. Vög. ii. p. 64l (1824).

Rallus minutus, Pall. Zoogr. Rosso-As. ii. p. 155 (1826).

Phalaridion pusilla (Pall.), Kaup, Nat. Syst. p. 173 (1829).

Crex foljambei, Montagu apud Eyton, Cat. Brit: B. p. 46 (1836).

Crex pygmæa (Naum.), Naum. Vög. Deutschl. ix. p. 567 (1838).

Ortygometra pygmæa (Naum.), Keys, u. Blas. Wirb. Eur. p. Ixviii (1840).

Porzana pygmæa (Naum.), Bonap. Cat. Metod. Ucc. Eur.p. 64 (1842).

Zaporina pygmæa (Naum.), Bonap. Cat. Paraud. p. 15 (1856).

Porzana baillonii (Vieill.), Degl. \& Gerbe, Orn. Eur. ii. p. 258 (1867).

Baillon's Crake appears to be a very rare resident in the United Kingdom. It has only been known to breed in the fens of Cambridge and the Norfolk broads, but has occurred in Yorkshire, Derbyshire, Somersetshire, and Cornwall. In Scotland it has only occurred twice, at Caithness in the extreme north, and in Dumfriesshire in the extreme south. It has also occurred in the Isle of Man, and three times in the extreme south of Ireland. A bird so skulking in its habits and breeding in almost inaccessible swamps may easily have been overlooked in other localities.

The geographical distribution of Baillon's Crake is either imperfectly known or is a very singular one. This bird appears to be a local resident throughout the whole of Africa, including Madagascar, on the northern shores of the Mediterranean, India, Burma, China, and Japan, its numbers being increased in winter by migrants from the north. To Central Europe it is a summer migraut, but its range does not extend north of the Baltic. Its occurrence in the Baltic Provinces appears to be doubtful, but in East Russia it breeds as far north as lat $56^{\circ}$. It has hitherto escaped detection in Asia Minor, Persia, and South-west Siberia; but it is a regular summer visitor to South-east Siberia, and in winter visits the Philippine Islands, Borneo, and the Andaman Islands. 
The habits of this interesting little Crake do not differ much from those of its allies. It frequents small pools and marshes which are surrounded with rank vegetation, and appears to prefer retirement amongst reeds and rushes to open water. It is very skulking in its habits, and conceals itself as much as possible amongst the rank vegetation of its haunts. It swims very gracefully, and dives with the greatest ease. Upon the land it both walks and runs, and frequently passes over the broad leares of watcr-lilies or other aquatic plants in its scarch for food. When suddenly alarmed it rises quickly, but in a somewhat laboured manner, and flies a little way, then drops down into the reeds again. It hides itself amongst the reeds if closely pursued, and conceals itself in a similar manner to the Coot or the Waterhen. Its flight is performed by a scries of rapid beats of its short wings, and the legs are allowed to hang down as if broken; it is seldom prolonged far, but often at night the bird remains in the air for some time flying in wide circles above its reedy haunts. It keeps close during the day, but appears to become more active at dusk, and often plays about in the open water, every now and then uttering a piping cry. The call-note of Baillon's Crake very closely resembles that of the Little Crake, a kind of kik several times repeated.

The food of Baillon's Crake is largely composed of insects, especially gnats. This fare is varied by small worms and shells, and more rarely by vegetable substances. The bird often snaps at flies as it is swimming on the water, or catches them when they alight on the stems and leaves of aquatic plants.

It is not improbable that Baillon's Crake breeds in our islands every year. It is such a skulking species and so small that it is very easily overlooked; and the discovery of its nest and eggs some years ago was due almost entirely to accident. The first recorded instance of Baillon's Crake nesting in this country is that of Mr. A. F. Sealy ('Zoologist,' 1859, p. 6329), who described two nests that were found in the fens of Cambridgeshire. One of these was discovered on the 6th of June of that year, containing six eggs; the other, on which the female was captured, was found in the first week in August, and containcd seven eggs considerably incubated.

Of the nests that were discovered in Norfolk, Stevenson ('Birds of Norfolk,' ii. p. 403) gives the following particulars:-“It appears that the four eggs mentioned by Mr. Overend* as purchased on the 9th of June were taken on that day at Potter-Heigham, or rather on Heigham Sounds, near Hickling, by a labouring man, who sold them to a lad named John Smith, at Yarmouth, who had been in the habit of collecting eggs for $\mathrm{Mr}$. Crowfoot. The former was of course ignorant as to what 
they were; but as soon as their rarity was known, it was elicited from the man who took them that he had seen the parent birds near the nest, which was placed in a parcel of reeds growing in water about a foot in depth. It was very small and loosely made, composed of dry rushes. A few days later Smith paid a visit to the spot with the hope of securing the nest, but found that the reeds had been cut and the nest spoiled; and no doubt the man who discorered it was employed in recd-cutting at the time. The five eggs procured on the 7 th of July were also taken in the same locality; but of these, unfortunately, three were broken. What became of the last nest I cannot say; but the two were most likely constructed by the same pair of birds."

In Europe the breeding-season of Baillon's Crake commences late in May or early in June. I have eggs taken in the former month at Valconswaard; but in India it is much later. Writing of its breeding-habits in that country Hume remarks ('Nests and Eggs of Indian Birds,' p. 601):- "This species lays in July and August in the plains of Upper India, and in June and July in Cashmere and the valleys in the lower ranges of the Himalayas, containing suitable rice-swamps or marshy pools. It is pretty common near Syree, below Simla. The full number of eggs is, I believe, eight, as we found the fragments of this number of shells round a nest that had hatched off. Six is the greatest number of eggs that I have yet obtained, but then I have only seen two nests with eggs. The nest is made of rush and weed, completely concealed in water-grass, wild rush, and the like, and is apparently usually placed very little above the water-level." Other nests that he describes were inade of similar materials, one being placed amongst grass and wild rice very little above the surface of the water, and another amougst dense rushes and sedges on the margin of a little pool encircled by rice-ficlds. In Europe the nest is gencrally placed amongst the aquatic vegetation on the banks of a pool or stream, and is made of sedge, dry leaves, and grasses; it is rather large, loosely put together, but not badly marle.

The eggs of Baillon's Crake are from five to eight in number, six being an average clutch. They are oval in form, and rather glossy; in groundcolour they vary from pale olive to rich buff, profuscly but indistinctly spotted, blotched, freckled, and mottled with olive-brown and dull violetgrey. On some eggs the markings are more confluent than on other's, and most are to be seen on the large end. They vary from $1 \cdot 2$ to $1 \cdot 1$ inch in length, and from $\cdot 9$ to $\cdot 8$ inch in breadth. It is almost impossible to distinguish with certainty the eggs of this species from those of the Little Crake, but as a rule they are slightly smaller. The female sits very closely, and should she be disturbed slips quietly off' into the water and hides her'self amongst the vegetation at once. It is possible that two broods are reared in the year, and if the first eggrs are destroyed another clutch is laid.

VOL. II. 
The general colour of the upper parts of the adult male Baillon's Crake is pale chocolate-brown, most of the feathers having a nearly black centre with a broken white streak along it. The primaries and secondaries are brown, but the outer web of the first primary is white; the forehead, eye-stripe, and the whole of the underparts are slate-grey, shading into black, transversely barred with white on the flanks, belly, and under tailcoverts. Bill green, darker at the tip; legs, feet, and claws olive; irides crimson. The female differs from the male in having the lores and the earcoverts brown instead of slate-grey, in having the general colour of the upper parts buffish brown, and in liaving the underparts paler and suffused with brown on the sides of the neck and breast. The winter plumage of the male is intermediate betreen the summer plumage of the male and that of the female. Young in first plumage very closely resemble females, but the slate-grey of the underparts is replaced by greyish white, and the breast is mottled with brown. After the first spring moult young males resemble adult females, and young females are intermediate between them and young in first plumage. Young in down are black.

Baillon's Crake is very nearly allied to the Spotted Crake; in both species the outer wcb of the first primary is white; but Baillon's Crake is much the smaller bird, has no spots on the sides of the throat or breast, and the under tail-coverts are black barred with white, instead of uniform buff. The Little Crake is a much more distantly allied bird; it is somewhat intermediate in size between the two species, but the white spots on the upper parts are confined to the centre of the back, the white margin to the outcrmost primary is entirely absent, and the flanks are slate-grey instead of black barred with white, the under tail-coverts only being black tipped with white.

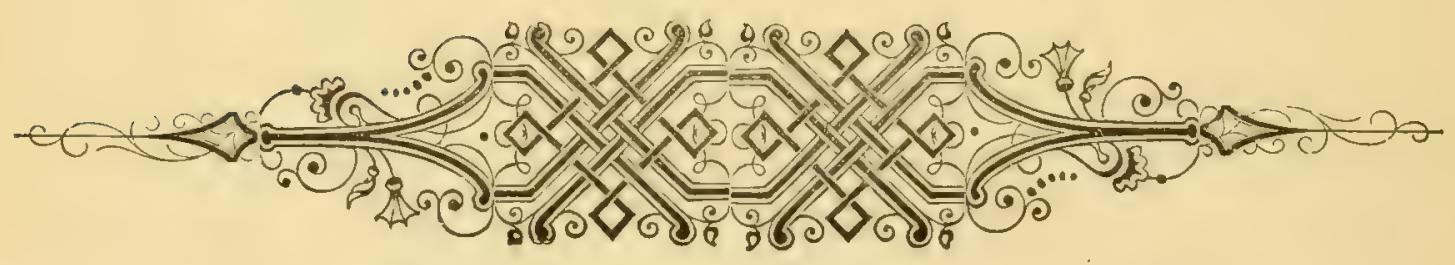




\section{CREX PARVA.}

\section{LITTLE CRAKE.}

(Plate 23.)

Rallus parvus, Scop). Ann. I. IIist. N'ut. p. 108 (17(;9); et a uctorum plurimorum --(Hume \& MLarshall), (Biddulph), (Scully), (Dresser), (Saunders), \&c.

Rallus mixtus, Lapeyr. Mamm. ct Ois. de la Ilante-Garonne, p. 38 (1799).

Gallinula pusillus, Bechst. Orn. Taschenb. ii. p. 340 (1803, nec Pall. 1826).

Gallinula minuta, Mont. Orn. Dict. Suppl. G 2, fol. 9 (1813, nec Pall. 1826).

Gallinula foljambei, Mont. Om. Dict. Append. fol. B $b$ (1813).

Zapornia minuta (Mont.), Leach, Syst. Cat. Mamm., \&o. Brit. Mus, p. 34 (1816).

Rallus peyrousei, Vieill. N. Dict. d'Hist. Nat, xxriii. p. 562 (1819).

Ortygometra olivacea, Steph. Shaw's Gen. Zool. xii.pt. i. p. 226 (1824).

Rallus minutus, Pall. apud Bunaparte, Keyserling s' Blasus, Degland s. Gerbe, Blan- ford, \&c.

Rallus pusillus, Pall. apued Lichtenstein, Stephens, Bonapurte, Meves, Temminck, \&c.

The Little Crake is a rare visitor to our islands on spring and autumn migration; it is not impossible that some may remain to breed, and others occasionally remain during the winter. It has occurred in England between thirty and forty times, but is not recorded from Wales, only once from Scotland, and twice from Ireland.

The range of the Little Crake is much more restricted than that of Baillon's Crake, and coincides very closely with that of the western form of the Water-Rail. It has not occurred on the Faroes, and can scarcely be regarded as more than an accidental visitor tu South Sweden. In Denmark it is more numerous, and in Russia it is a summer visitor in the west as far north as Riga, and in the cast as far north as Astrakhan, whence its range extends in Asia throughout Russian Turkestan except in the north-east. It passes through Gilgit on migration, and winters in Western Scind. It breeds in Afghanistan, but does not appear to have been discovered in Persia, Asia Iİnor, Palestine, or North-cast Africa, although it is very common in the Cancasus. In Central and Southern Europe it is somowhat locally distributed, and is a resident in Algeria. It passes through Spain and Greece on migration, and probably breeds and winters in both countries.

The Little Crake, from its shy and retiring habits and small size, is very apt to be overlooked, and consequently very little has been recorded of its labits. The haunts it frequents are marshes, the reeds and other coarse vegetation growing on the banks of large pools and sluggish streams, and dense reed-beds. It is very fond of swimming on open water, aud may often be seen running on dry land; but when alarmed it always takes 
shelter amongst the rank vegetation, only using its wings when absolutely compelled. Hume, who found this species very common in the broads or "dhunds" in Scind, writes (Game Birds of India, ii. p. 209) :- "I never flushed these birds out of sedge or reed, but found them everywhere running about over the lotus and water-lily leaves, or swimming about from leaf to leaf, and exhibiting far less timidity than Baillon's Crake. Like this latter they look, when in the water, exactly like tiny Waterhens, jerking their tails and nodding their heads precisely like them. But one thing I noticed in this species which I never observed in either of the others-I saw one bird voluntarily diving several times, apparently in search of food. The others will dive when a shot is suddenly fired near them or when wounded; but this bird was deliberately diving for its own amusement. When pressed they rose more readily and flew more strongly than Baillon's Crake, taking refuge in the thickets of tamarisk that fringed the broads and were studded about most of them as islands ..... The food of this species seems to consist far more exclusively of insects than that of Baillon's Crake. In more than a dozen specimens that I examined, the stomachs contained water-bugs and beetles, small insects of all kinds, and larvæ of various, to me quite unknown, species, with only here and there a few small black seeds and a trace of vegetable matter; of course, as is the case with Baillon's Crake, there were a good many minute pebbles or fragments of quartz, coarse sand in fact, mixed with the food, in the trituration of which it no doubt plays an important part."

Dixon writes:- "I met with this little bird in the oasis of Biskra, It was frequenting the short reeds round the margin of a small pool near the southern extremity of this beautiful oasis. I saw the female, a diminutive bird, floating amongst the short reeds a few yards from shore; but as 1 approached, it hid amongst the water-plants. It floated very buoyantly, and every now and then seemed to pick what I suspected was an insect from the reed-stems, and often buried its head amongst the grass-like weed which covered the surface. Upon my nearer approach, and when I was walking round the slimy edge of the pool, the cock bird rose from the reeds in a slow fluttering manner, with his legs drooping downwards, and was off to the other side of the pool, had I not stopped him with a successful shot in mid-course. When it rose it uttered a few clicking notes, something like the sound made by a small ratehet-drill. When I dissected my specimen, which an Arab, up to his breast in mud and water, had fetched from the pool, I found its stomach contained the wing-cases of several bectles and a few bits of gravel. I have no doubt that this pair of birds would have bred here, but I was obviously too early for eggs."

The call-note of the Little Crake is described by Naumann as kik-kik-kik, frequently uttered.

The breeding-season of the Little Crake is in May, and its eggs are 
generally laid towards the end of that month, but sometimes in the beginning. Its nest is generally very carefully concealed amongst the reeds and rushes that grow in the bird's swampy haunt. Sometimes it is built on a large mass of decaying reeds which have been laid by the wind, and is placed from a few inches to a foot or more above the surface of the water. It is rather large for the size of the bird, very flat, and somewhat loosely put together. It is generally made of bits of flags, leaves of the common reed, coarse grass, and scraps of other aquatic vegetation.

My friend Mr. Eagle Clarke has sent me the following note on this bird:- "During a recent ornithological trip in South-cast Sclavonia I was fortunate enough to find the nest, eggs, and young in down of this species. The nest (discovered on the 2th of May) was in an extensive and particularly secluded shallow marsh near the village of Obrez. The surface of this marsh was clothed with sallow brakes, reed-beds, and areas covered with tussocks of selge. The nest, containing seven eggs, was placed on the side, not in the centre, of one of these tussocks of medium size. It was merely a depression, amply lined with short broad pieces of withered reed-blades, and was about six inches above the surface of the water, which was here about eighteen inches deep. The young in down was captured alive on the large swamp known as the Obedska-bara, three days later. Attention was drawn to it by the loud clear note of the parent bird as our party was proceeding in a boat through a bed of sedge. The little creature was found after a few moments' search; it was newly hatched, and was covered with down of a glossy black, with a beautiful dark green cast ; the legs were bluish grey."

The eggs of the Little Crake are seven or eight in number, pale yellowish brown in ground-colour, indistinctly but evenly marbled and blotched over the entire surface with darker brown, and occasionally a few small very dark brown specks. Some specimens have the markings more numerous at the large end, where they form an ill-defined mass. They vary from 1.3 to $1 \cdot 2$ inch in length, and from $\cdot 9$ to 85 inch in breadth. Eggs of this species very closely resemble those of Baillon's Crake, but are larger; the character of the markings is also very similar. It is not known that more than one brood is reared in the season.

The Little Crake, when disturbed from the nest, generally prefers to slip quietly off into the water or surrounding reeds, and soon conceals itself, to await until the cause of its alarm has passed. It is very rarely seen at the nest, and in this respect does not differ from its congeners. The nest is very difficult to find, hid as it is so cleverly in the dense luxuriant vegetation of the swamps and marshes, and is usually discovered purely by accident, the sitting bird rarely, if ever, aiding the observer in his search.

The general colour of the upper parts of the adult male Little Crake in 
spring plumage is buffish brown, most of the feathers, except those of the head, nape, and the wing-coverts, having obscurely defined dark centres. The primaries and secondaries are brown; the forehead, a line over the eye, the sides of the head and neck, and the rest of the underparts are slategrey; the shortest under tail-coverts are brown tipped with white, and the longest black tipped with white. Bill green, tinged with red at the base; legs and fect green; irides deep carmine. The female difier's from the male in having the slate-grey confined to the forehead and eye-stripe, the general colour of the underparts being buff, shading into nearly white on the chin and throat, and into brown on the flanks, which are transversely barred with white. The winter plumage of both sexes scarcely differs from the summer plumage of the adult female. Young in first plumage are somewhat more spotted on the upper parts, and have the eyc-stripe and the whole of the underparts buffish white, obscurely barred with brown at the sides. Birds of the year are intermediate between young in first plumage and females in winter plumage. Young in down are black.

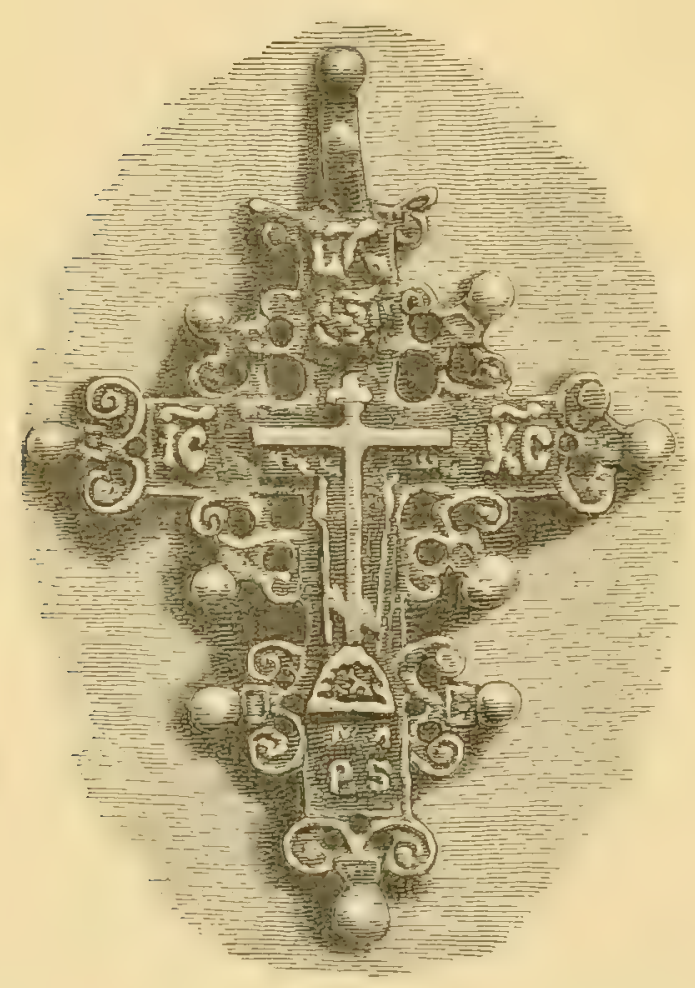




\section{Genus RALLUS.}

The genus Rallus was included by Linnæus in 1766 in the 12th edition of his 'Systema Naturæ' (i. p. 261). The Water-Rail has been generally accepted as the type, as being the Rail par excellence.

The species in this genus are distinguished from the Waterhens and Coots by having the forehead covered with feathers to the base of the bill, and by having no lateral membranes to the toes, and from the Crakes, to which they are very nearly allied, by having the bill longer than the head.

There are about fifteen species of Rails, which are found in most parts of the world, except in Australia and the Arctic Region. Only one species is European, which is a partial resident in the British Islands.

The birds in this genus chiefly frequent the dense vegetation on the banks of slow-flowing rivers and lakes. They are shy, and conceal themselves amongst the luxuriant vegetation at the least alarm. Most of them swim and dive with ease, and walk about the dry land equally well. Their flight is heavy but quick, and is seldom prolonged. 'Their call-notes are clcar and harsh. Their food consists of aquatic insects, seeds, shoots of plants, \&c. They build large slovenly nests made of reeds, rushes, flags, dry grass, \&c.; and their eggs are numerous, reddish buff in ground-colour, spotted and speckled with reddish brown and grey. 


\title{
RALLUS AQUATICUS.
}

\section{WATER-RAIL。}

\author{
(Plate 23.)
}

Rallus aquaticus, Briss. Orn. v. p. 151; pl. xii. fig. 2 (1760); Limn. Syst. Nat. i. p. 262 (1766); et auctorum plurimorum-Latham, Temminck, Naumann, Dresser, Saunders, \&c.

Scolopax obscura, Gmel. Reise Russl. iii. p. 90, pl. xvii. (1774).

Rallus sericeus, Leach; Syst. Cat. Mamm. \&c. Brit. Mus. p. 33 (1816).

Rallus germanicus, Brehm, Vög. Deutschl. p. 690 (1831).

Aramus aquaticus (Briss.), Gray, Hand-l. B. iii. p. 59 (1871).

The Water-Rail is found on all the marshes that are big enough to afford it sufficient shelter throughout the British Islands, iucluding the Orkneys, Shetlands, and Outer Hebrides, but is nowhere very abundant, though its skulking habits make it appear rarer than it really is. It is a partial migrant, in some districts being most common in summer, in other's in winter.

The geographical distribution of the Water-Rail is a somewhat peculiar one. It is said to be a resident in Iccland, and is probably so in the Faroes. To Scandinavia it is a summer visitor as far north as lat. $63^{\circ}$, and is occasionally found during winter in the extreme south of Sweden. In West Russia it breeds as far morth as Riga, and is said to occur accidentally near St. Petersburg. In East Russia its range is said to be about the same. It has not occurred in West Siberia, but breeds in Russian aud Chinese Turkestan, at least as far cast as Yarkand, and passes Gilgit on migration to winter in North-west India. In Central and Southern Europe it is a resident, but is more abundant in summer in the north and west, and is principally known as a winter visitor in the south and east. The same remarks apply to North Africa; in Algeria, for example, it is a resident whose numbers are largely increased during winter, whilst in Egypt, as in Grecce, Palestine, Asia Minor, Persia, and Afghanistan, it is known as a winter visitor, occasionally remaining to breed.

In Eastern Siberia, in the neighbourhood of Lake Baikal, and in the valley of the Amoor, in both islands of Japan and in North China, a WaterRail breeds, so mearly allied to the western species that many writers regard it as the same, though others distinguish it as Rallus indicus*. It

* The synonymy of the Eastern form is as follows:Rallus indicus, Blyth, Journ. As. Soc. Beng. xvii. p. 820 (1849). Rallus japonicus, Schlegel, fide Goebel, Thes, Orn. iii. p. 406 (1877). 
winters in South China, Burma, Eastern and Southern India, and Ceylon. This eastern form is on an average slightly larger than the western race; the slate-grey on the underparts is always more or less suffused with brown, the dark brown lores extend below and behind the eye, and the under tail-coverts are more barred with black; but it must be admitted that no one of these characters is always constant.

The Water-Rail is almost as exclusively a reed-bird as the Bittern or the Great Reed-Warbler. The one great object of its life appears to be to conceal itself. It threads its way through reed and sedge, only occasionally venturing to swim across a narrow picce of open water, and never exposing itself on the muddy margin of the marsh, or venturing out to feed on the grass of the neighbouring meadows, until its movements are concealed by the shadows of evening. When alarmed, it is very reluctant to seek safety in flight; but runs through the grass with the celerity of a mouse, twisting and twining amongst the tufts of herbage like a Grasshopper Warbler. It is as unsociable as it is timid; two pairs are seldom seen near each other, and eren the male and female are rarely observed together. It is said that even on migration it does not fly in flocks as most birds do. It is difficult to account for the extreme shymess of this species and its congeners, so different from the comparative tameness of the Waterhen or the Coot. Possibly the Rails have acquired their timidity and caution in consequence of having endured many generations of persecution from Hawks and Harriers, as the Egyptians have acquired their cowardice from generations of oppression at the hands of the brutal Turkish officials; whilst the Waterhens and the Coots, like the Arabs, have pluckily fought their way to the respect of their more powerful adversarics. In spite of its caution the Water-Rail seems to be decreasing in numbers. The drainage of the fens where it lives is no doubt one of the chief causes; but another may be found in the difficulties which it has to encounter in winter. The birds which do not migrate no doubt suffer much in severe seasons, and many perish both from hard frosts and the guns of sportsmen; whilst the perils of a long journey to a distant clime are unusually great to a bird of such timid and solitary habits.

Naumann states that the Water-Rail has been known to perch for a moment or two in a thick willow tree. He describes its note, which is only heard as the bird is flying round in the evening preparing to migrate, as a clear, shrill, but melodious kreek. In the pairing-season the call-note is a liquid whit, not unlike that of the Nuthatch, but is only heard after dusk.

The Water-Rail feeds upon all kinds of insects, worms, small shell-fish, and gnats that are found in the swamps, and occasionally varies its diet with the tender shoots of aquatic plants or the seeds of reeds and sedge.

The Water-Rail is a somewhat early breeder, and eggs have been found 
in the first week of April. It is probable that two broods may occasionally be reared, as eggs have been taken as late as July.

In the fen-countries it is still a common bird. In the middle of May three years ago I spent a day or two in the Norfolk broads with my friends Mr. Howard Saunders and Mr. Arthur H. Evans. We placed ourselves under the guidance of a well-known marshman of the name of Joshua. Leaving Hickling Broad we punted down the stream across Higham Sounds, and landed on the bank of the river further on, where Joshua had marked for us the nest of a Water-Rail. We found ourselves in the middle of an ocean of reeds, most of them in a dense mass, just covered at the roots with water, but some more thinly sprinkled over rougher ground, and almost choked with sedges, rushes, and coarse rank vegetation of other kinds. The nest was admirably concealed, and with all our care we only caught a momentary glimpse of the bird as she disappeared. Such a nest can ouly be found by accident. The perfect silence of the bird, the quiet way in which she slips off the nest and threads her way amongst the sedge and reeds, and the absolute concealment of the nest itself, which eannot be seen until the vegetation which hangs over it is pulled aside, make it an almost hopeless task to try and find a nest in such extensive reed-beds. The nest was about a foot from the ground, but had a solid foundation under it, formed by the roots of the clump of rushes in the midst of which it was built. It was carefully made of flat sedge and the flat leaves of the reed, lined with dry brokeu pieces of round slender reeds, and contained five eggs. In spite of the difficulty of finding the nests of this bird, the indefatigable Joshua had a second nest marked for us not very far off, but on the other side of the river. This nest was more favourably situated for obtaining a sight of the bird, as the clump of tangled reeds and rushes in which it was concealed only covered five or six square yards and was surrounded by almost bare swamp. To secure a sight of the bird we each approached the nest from different sides; but, as before, we only caught a momentary glimpse of her as she slunk from the nest. We remained standing round the clump for some time, during which she was skulking in the herbage. At last we succeeded in driving her out, when she attempted to make a run across the naked part of the swamp. Saunders was standing a few yards further off than we were, and by chance she ran into his arms, or rather into his legs, whereupon she instantly took wing and flew right away, with legs hanging down as if anxious to alight at the first possible opportunity. Her flight was not very quick lut very straight; in fact she would have been an easy shot. She dropped into the recds at about sixty yards distance, not having uttered a note during the whole time. The nest was quite as perfectly concealed as the former one, and did not differ from it in construction; it also contained five eggs. 
The Watcr-Rail has been known to lay as many as nine or eleven eggrs, but from five to seven appears to be the usual number. They are pale buff or buffish white in ground-colour, sparingly spotted and speckled with reddish-brown surface-markings and violet-grey underlying ones. The spots are seldom larger than No. 6 shot, and are most abundant on the large end of the egg. The underlying spots are as numerous as the surface ones, and on some eggs predominate. Sometimes the markings are congregated in a semi-confluent mass on the large end of the egg. On some exceptional specimens a few of the spots are as large as peas. They are very smooth; but do not exhibit much gloss. They vary in length from 1.5 to 1.28 inch, and in breadth from 1.09 to .98 inch. The eggs of the Water-Rail are somewhat similar to those of the Corn-Crake, but are rarely so thickly spotted; those of the Spotted Crake can never be confused with them, the spots are always larger, besides being more numerous and distinct.

The general colour of the upper parts of the adult Water-Rail is buffish brown, each feather having a nearly black centre; the primaries and secondaries are brown; the lores are brown; the rest of the sides of the head and neck and the underparts are slate-grey, slightly paler on the chin, and the feathers are tipped with buff on the belly and vent; the flanks, axillaries, under wing-coverts, and shortest under tail-coverts are black, transversely barred with white, and the longest under tail-coverts are white. Bill dark brown, the edges of the upper and three fourths of the lower mandible dark orange; legs, feet, and claws brown; irides orangered. Winter plumage scarcely differs from that of summer, and the female is only slightly duller in colour than the male. Young in first plumage have the chin, the middle of the throat, breast, and belly nearly white, the grey feathers of the underparts much suffused with brown, and barred on the sides of the breast with blackish brown. This plumage is moulted in the first autumn into that of birds of the year, which only cliffers from the adult in having the slate-grey of the underparts slightly suffused with brown, and the brown tips to the feathers of the lower flanks longer. Young in down are nearly black. This species varies considerably in size, especially in length of bill, legs, and feet.

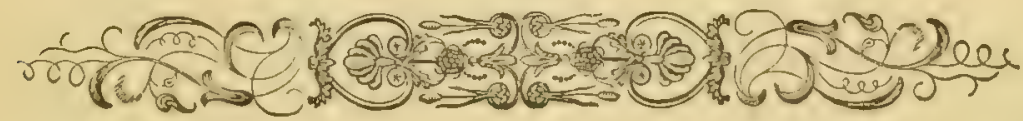




\section{Genus GALLINULA.}

The genus Gallinula was established by Brisson in 1760 in his 'Ornithologia' (vi. p. 3), and is one of those gencra which are additional to those of Limnæus, who associated the Waterhens with the Coots in his genus Fulica. The Waterhen (the Gallimula gallinula of Brisson) is the type.

The Waterhens may be distinguished from the Coots by the absence of the broar scolloped membrane on the toes, and the much smaller frontal shield or bare space on the forehead at the base of the bill. The tail is very short and rounded, and consists of twelve feathers.

This genus contains about sixteen species, which are distributed throughout the world, with the exception of the Arctic Region. Only one species is found in Europe, which is a common resident in the British Islands.

The Waterhens frequent the borders of lakes, ponds, swamps, and sluggish rivers, haunting the dense growth of flags, reeds, and other vegetation. They are skulking birds, and when alarmed often conceal themselves by diving; they swim well, progressing in a jerky manner; they walk about the land gracefully, and they perch in trees and bushes with ease. They are slow fliers, and when walking about have the habit of jerking their short tails. Their food consists of slugs, worms, insects, the seeds of water-plants, herbage, grain, and berries. Their call-note is loud and harsh. They make bulky nests of aquatic regetation, placing them amongst reeds, flags, \&c., or even in the branches of trees; and their eggs are numerous, of a buffish ground-colour, spotted and blotched with brown and grey. 


\section{GALLINULA CHLOROPUS.}

\section{WATERHEN.}

\section{(Plate 23.)}

Gallinula gallinula, Briss. Orn. vi. p. 3, pl. i. (1760).

Fulica fusca, Limn. Syst. Nat. i. p. 257 (1766).

Fulica chloropus, Limn. Syst. Nat. i. p. 2058 (17ti6); et a uctorum plurimorum(Temminck), (Naumann), (Degland \& Gerbe), (Jerdon), (Dresser), (Saunders), itc.

Gallinula chloropus (Linn.), Tunst. Orn. Brit. p. 3 (1771).

Gallinula fusca (Linn.), Lath. Ind. Orn. p. 771 (1790).

Rallus chloropus (Limn.), Savi, Om. Tosc. ii. p. 382 (1829).

$\left.\begin{array}{l}\text { Stagnicola septentrionalis, } \\ \text { Stagnicola chloropus (Linn.), }\end{array}\right\}$ Brehm, Vög. Deutschl. pp. 704, 706 (1831).

The Waterhen or Moorhen is a very common resident on the banks of most lakes, ponds, rivers, and canals throughout the British Islands, including the Outer Hebrides and the Orkneys; but it is only known as a straggler to the Shetlands. It is an accidental visitor to the Channel Islands on migration, and probably sometimes remains to breed.

The Waterhen may almost be regarded as a cosmopolitan bird. It is an accidental visitor to the Faroes. In Scandinavia it breeds up to lat. $63^{\circ}$, in West Russia to lat. $58^{\circ}$, and in East Russia to lat. $56^{\circ}$. It has not been recorded from West Siberia, but breeds in Turkestan and the country round Lake Baikal. It is a summer visitor to North China and the north island of Japan; but is a resident in the main island of Japan and South China. It is a resident throughout India, and has occurred in Ceylon; it is also a resident in the Burma peninsula, the Philippine Islands, Celebes, Borneo, Jara, and Sumatra. To the west it is found in South-west Asia, the whole of Africa (including Madagascar), Central and Southern Europe, and the Atlautic islands, including the Azores. In America it breeds from the Southern States down to Southern Brazil, and is said to have occurred in British North America. In Australia a form occurs (G. tenebrosu) which appears to be specifically distinct, being: on an average somewhat larger, and having no white stripes on the flanlis. In the typical form of the Waterhen, which appears to be confined to the western Palæarctic Region, the length of wing varies from 7 to $6 \frac{1}{2}$ inches, and the frontal plate scarcely reaches as far back as the eye. All the other forms have on an arerage a larger frontal plite, which frequently extends beyond the eye. Examples from India and western South Africa are smaller than those from Europe, the length of wing varying from $6 \frac{1}{2}$ to 
$5 \frac{1}{2}$ inches; whilst those from America are on an average larger, the length of wing varying from $7 \frac{3}{4}$ to $6 \frac{1}{2}$ inches.

Few birds are better known than the Waterhen, Moorhen, or Gallinule, as it is called in different localities. It is a resident in our islands, and almost every pool where the banks are sufficiently covered with vegetation to afford it shelter is inhabited by its pair of birds. Where the conditions are farourable the Moorhen is very numerous, and a score or more of these birds may often be seen swimming together. It is most partial to large pouds, especially if they are full of weeds, and slow-running rivers the courses of which are overgrown with aquatic vegetation of different kinds. It does not occur very commonly on swift-flowing streams, but a few pairs may generally be observed on those portions where the water is still, especially if there be a few small islands covered with tall grass and weeds in which they can find shelter and suitable breeding-places. In many localitics the Waterhen lives in a semi-domesticated state. On many fish-ponds and ornamental waters it is so tame as to scarcely take any notice of man; but it never loses its habitual wariness altogether, for should any strange object appear, especially a dog, it will hurry off at once to the water or take refuge amongst the reeds. It soon becones accustomed to different sounds, and may be seen paddling about close to the mill-wheel, or sitting quictly on the water within a few yards of the passing railway-train .

The Waterhen is as graceful in its movements on the land as it is in the water, and it is a pretty sight to watch several birds early in the morning or a little before dusk walking gracefully about the meadows or the smooth turf-covered banks of the water. They invariably make their appearance on land after a shower of rain, to search the grass for food in company with Blackbirds, Starlings, and Thrushes. It walks about slowly and sedately, sometimes ruming forward a few steps to catch an insect, and its short tail is jerked up and down cvery few moments. The Waterhen is by far the most frequently seen in the water, where it swims with the greatest ease, notwithstanding the fact that its feet are not webbed. It progresses in a peculiar manner, bobbing its head backwards and forwards, and every now and then diving in search of food or at the approach of danger. It may often be seen running nimbly over the floating masses of reeds and decaying regetation, its long toes supporting it on the treacherous surface. The Waterhen is often seen to chase its mate through the water or splash about for amusement. It often floats quite motionless for sereral minutes in succession, as if intently listening for the approach of an enemy. When its alarm subsides it may be watehed swimming about, every now and then picking an insect from the surface or snapping at one as it passes by in the air. If alarmed when swimming the bird usually dives under the surface at once, so quickly as often to 
escape the shot that was aimed at it, and progressing with great speed under water, it will make for the reeds or the aquatic vegetation, where it conceals itself. Occasionally it will remain for some considerable time with its body submerged and only the point of its bill out of the water, maintaining its position by clinging to the stems of the water-plants with its long toes. If suddenly alarmed on the land, the Moorhen usually takes wing at once, and hurries off to the nearest cover with its legs hanging down as if broken. Its flight is not very powerful, and the wings do not seem strong enough to support the body; but once the bird gets well into the air its flight is rapid and well sustained. The Moorhen often flies at a considerable height, generally at night, and in some districts it appears to take these nocturnal wanderings merely for amusement, or perhaps for the purpose of catching certain species of insects. Dixon has often known this bird to fly round and round in the air for an hour or more at night, every now and then uttering its singular cry. Sometimes when the Waterhen is feeding in the meadows near its favourite water it will, when alarmed, stretch out its neck to its full length for a moment as if watching or listening, and then run off at full speed to the nearest cover. It is very remarkable how this bird will conceal itself even in places where there is little cover, and where all means of escape secm impossible.

The Waterhen is rather pugnacious, and is very jealous of its own particular haunt. A pair of birds will take up their quarters on some small pond, or if a large shect of water, some particular part of it, from which they drive off' all intruders, and will even attack much larger birds than themselves, such as Geese and Ducks, if they happen to invade the sacred haunt.

The food of the Waterhen is varied. It feeds largely on the different species of aquatic insects, worms, and the larve of dragonflies; and on the land it searches for slugs and worrns amongst the grass. To this fare is added much of a vegetable nature, such as the buds, shoots, and seeds of water-plants and grass. In winter, especially during a long-continued frost, the bird may often be seen in the hawthorn trees eating the haws or scrambling amongst the brambles to pick off the hips of the wild rose. In districts where the haunt of this bird is exposed and bleak it will often, in winter, seek shelter amougst the tangled undergrowth of the neighbouring woods; whilst if evergreens be near, nothing suits it so well as to wander under the low drooping branches or even roost amongst them.

The Waterhen has been known to display carnivorous propeusities, killing and cating young Pheasants and destroying Ducklings. In many places it is so tame as to come outo the lawn to be fed, or mingle with Pheasants and poultry to pick up the food that has been scattered for them. The note of the Waterhen is a loud, shrill kek-ek-ek, modulated in various ways into kik-ik-ik or kerk-erk-erk. 
The Waterhen is an early breeder, especially after a mild open winter, its young in some instances having been known to be hatched in the beginning of April. The nest is commenced usually by the beginning of April, and the eggs are laid by the second week, or in backward seasons not until the end of the month or early in May. The nest is often placed amongst the reeds and aquatic vegetation on the banks of the water, but not unfrequently it is floating in the centre of the pool amongst the horsetail, reeds, or yellow iris. Sometimes it is placed amongst gnarled roots or tall grass, and often on a low flat branch of a tree. In some cases it habitually builds in fir trees, and has been known to hatch its young in a tree twenty feet from the ground. This peculiar choice of a site is probably to save its eggs from the sudden rising of the water. The nest is in many cases a large mass of reeds, sometimes intermixed with flags and coarse grass; it is very loosely put together, but the materials being moist soon settle down into a tolerably firm mass. The middle of the nest is rather more carefully finished than the other parts, and the matcrials are finer, sometimes dry leaves being used. Some nests are much larger than others, and some are much more finished in appearance. Stevenson says that some ncsts are "ingeniously arched over with the young reeds, as if to conceal the eggs."

The eggs of the Waterhen are from four to ten in number, seven or eight being an average clutch. They are buffish white or pale reddish buff in ground-colour, spotted and speckled with reddish brown and dark grey. 'The markings are never so numerous as to hide much of the ground-colour, and generally they vary in size from that of No. 6 shot to a speck, but sometimes many of them are as large as a pea. Some eggs are very sparingly marked with very fine specks, other's only have a few large blutches, whilst many are evenly sprinkled with small markings over the entire surface. 'The most richly marked clutch of Waterhen's eggs that I have ever seen is one containing five eggs, which I took on the 13th of May this spring on a pond on Lord Walsingham's estate at Merton in Norfolk. Some of the blotches are nearly an inch long, those eggs which are the most blotched being also the most highly incubated; and one egg, the least incubated in the clutch, has very few and small surface-spots. This seems to show that the bird commences to sit before the full number of eggs is laid, and that the colouring-mattcr is frequently cxhausted before the clutch is completed. They vary in length from 1.9 to 1.55 inch, and in breadth from 1.3 to $1 \cdot 15$ inch *. The eggs of the Waterhen very closely rescmble those of the Corn-Crake and the Rails, but their much larger size prevents their ever being confused with them. The Waterhen often rears as many as three broods in the year. Its young in down lave been found as early as

* An abnormally large egg in my collection measures $2 \cdot 19$ inch in length and 1.45 incls in breadth. 
the beginning of April, and Stevenson records them as late as the 29th of August; it is also said that in some cases the young birds, when able to fly, assist in rearing the later broods, and even help the old birds to make new nests! The Waterhen generally covers her eggs, when she leaves the nest, with pieces of surrounding vegetation. Several instances are on record where this bird has been known to add materials to its nest to make it higher from the surface of the water ; and in one case at least it would appear that the old birds removed their eggs while this was being done and then replaced them (Selby, Proc. Berwickshire Naturalists' Club). Mr. Maurice C. H. Bird writes to inform me that he knew of an egg of this bird which was found in an unfinished Blackbird's nest. When suddenly alarmed, the sitting bird generally flies from its nest; but if possible it always prefers to slip quietly off into the water or reeds, in order not to betray the whereabouts of its treasure. When the nest is built in an elevated situation, the young birds are conveyed to the ground in the long claws of their parents. Both birds assist in incubating the eggs. The young birds take to the water shortly after they are hatched, and may sometimes be seen running over the masses of fallen reeds or over the large leaves of the water-lily. If running water be near, the old birds often take their broods to it; and when alarmed the little creatures will scurry off and take refuge in the nearest holes, or amongst the vegetation, where they lie motionless until the danger is passed.

In winter, when the still waters are frozen over, these birds often repair to the running streams, and will take up their quarters in woods, plantations, and shrubberies. At this season they will even enter stackyards; but, unlike the Coots, they seldom or never retire to the coast. In hard weather they often congregate into small flocks; but this is probably because their feeding-grounds are much more restricted, and not from any gregarious impulse. If the weather still keeps severe the Waterhens have a bad time of it, and numbers are often picked up in an emaciated starved condition. The flesh of this bird, especially of the young, is, when properly dressed, said to be of good flavour.

The general colour of the adult Waterhen in spring plumage is dark olive-brown, shading into dark slate-grey on the head and neck, and into brown on the quills and primary-coverts; the outside web of the first primary is margined with white; the whole of the underparts are slate-grey, shading into brown on the flanks, which are broadly striped with white, the feathers of the belly having obscure white tips, which become more prominent on the vent; the short under tail-coverts are black, and the long ones are white. The frontal plate and bill are scarlet, shading into yellow at the tip of the latter; legs and feet green; irides hazel. The female scarcely differs from the male in colous. After the autumn moult the white tips to the feathers of the belly and vent are more conspicuous,

VóL. II. 
and the general colour of the upper parts is a brighter olive-brown. Young in first plumage have the mantle and innermost secondaries russetbrown, the slate-grey on the head and neck replaced by oljve-brown, the chin and throat nearly white, and the slate-grey of the rest of the underparts replaced by brown, with the pale tips to the feathers very much developed. In their first autumn they moult into the plumage of birds of the year, which is intermediate. Young in down are black.

Several species belonging to the allied genus Porphyrio have occurred at various times in the British Islands; but as they are often kept in aviaries and on ormamental waters, it is probable that they have never occurred in this country in a wild state. Of these, the Purple Gallinule (P. ceruleus) is a resident in Algeria, Spain, and Italy*. This is a large species, about the size of a Coot, with an enormously thick red bill and red legs, the general colour of the plumage being a deep rich blue. One specimen of this bird was caught at Boldon Flats in August 1863, and another near Ponteland in the same month of 1873 (Hancock, 'Birds of Northumberland and Durham,' p. 126). A third example was shot near Campbeltowu, in Argyleshire, in the first week of December 1863 (Gray, 'Birds of West of Scotland,' p. 337). Several other examples have been met with. In its habits this bird resembles the Watcrhen, but it is more retiring and shy. The egg is similar to that of the Waterhen, but larger.

The second species, which has the back dark green instead of bluc, the Green-backed Gallinule (P. smaragnotus), is even still less likely to have occurred in this country in a wild state. It is only known north of the Mediterraneau as a very rare straggler, and inhabits the whole of Africa with the exception of the north-west, where it is replaced by its blue-backed ally. Three examples of this bird have been obtained in Norfolk, and many other's in various parts of the country; but as they have all doubtless escaped from confinement, no interest can attach to the special locality.

The third species, the Martinique Gallinule ( $P$. martinicus), inhabit the tropical portions of the American continent. One specimen has occurred in Ireland (Thompson, Ann. Nat. Hist. xviii. p. 311, 1846).

* The evidence of the occurrence of this species east of Italy is of the most unreliable character. It is not found in Egypt; its alleged occurrence in Palestine is founded upon a single example which cannot now be found. S. G. Gmelin stated that it was found abundantly on the Caspian; but I have lately had an opportunity of examining a series of skins from Lenkoran, which prove to be the Indian species $P$. poliocephalus, so that the name supposed to have been given to the western species by Gmelin falls to the ground. Its occurrence in South Russia, Asia Minor, Turkey, or Greece appears to be equally legendary, no modern collector having obtained it in auy of these countries. 


\section{Genus FULICA.}

The genus Fulica was included by Linnæus, in 1766 , in the twelfth edition of his 'Systema Naturæ' (i. p. 25\%). The Common Coot (the Fulica fulica of Brisson) is the type.

The birds in this genus are distinguished by having the tocs furnished with a broad scolloped membrane, and have a broad shield on the forehead at the base of the bill ; the tail is very short and rounded, and consists of twelve feathers.

This genus contains about a dozen species, which are distributed throughout the world, with the exception of the Aretic Region. Two species are found on the continent of Europe, one of which is a common resident in the British Islands.

The Coots very closely resemble the Waterhens in their habits and the places they frequent, but show more partiality for salt-water. They are most active during the dusk of evenimg aud early in the morning; they swim and dive with the greatest ease, and on the land walk and run with facility. They are more or less gregarious, especially in winter. Their call-notes are loud and harsh. Their food consists of aquatic insects, mollusks, worms, buds and shoots of water-plants, and seeds of various kinds. Their nests are large bulky structures, often built in the water, and made of fine and coarse pices of aquatic vegetation. Their eggs are numerous, buffish white in ground-colour, spotted and speckled pretty evenly with light and dark brown. 
FULICA ATRA.

COMIMON COOT.

(Plate 23.)

$\left.\begin{array}{l}\text { Fulica fulica, } \\ \text { Fulica major, }\end{array}\right\}$ Briss. Orn. vi. pp. 23, 28 (1760).

Fulica atra, Lim. Syst. Nat. i. p. 257 (1766) ; et auctorum plurimorum-Latham, Temminck, Naumann, Degland \&. Gerbe, Dresser, Saunders, \&c.

Fulica aterrima, Linn. Syst. Nat. i. p. 258 (1766).

$\left.\begin{array}{l}\text { Fulica fuliginosa, } \\ \text { Fulica albiventris, }\end{array}\right\}$ Scop. Ann. I. Hist. Nat.pp. 104, 105 (1769).

$\left.\begin{array}{l}\text { Fulica leucoryx, } \\ \text { Fulica æthiops, }\end{array}\right\}$ Sparrm. Mus. Carls. pls. 12, 13 (1786).

Fulica atrata, $\}$ Pall. Zoogr. Rosso-Asiat. ii. pp. 158, 159 (1826).

Fulica pullata,

Fulica lugubris, Sal. Niüll. Ver\%. Naturl. Gesch. Nederl. Bewitt. iii. p. 454 (1839-44).

Fulica australis, Gould, Proc. Zool. Soc. 1845, p. 2.

Fulica atra japonica, Temm. \& Schl. Faun. Japon. p. 120, pl. 1xxri. (1847).

Fulica cinereicollis, MacClell. fide Gieb. Thes. Om. ii. p. 211 (1875).

The Coot, although not quite so common as the Waterhen, and rather more local, is found in the neighbourhood of slow-running streams, lakes, and ponds throughout the British Islands. It is a resident on the Outer Hebrides and the Orkneys, but is only an accidental visitor to the Shetlands, as it also is to the Channel Islands. The Coot is a resident bird in this country, but in severe weather it often shifts its quarters from the inland waters to the coast.

The Coot is almost as cosmopolitan as the Waterhen, but the American and South-African forms appear to be specifically distinct. It passes the Faroe Islands regularly on migration, is an accidental visitor to Iceland, and has once been obtained in Greenland. In Scandinavia and West Russia it brecds up to lat. $60^{\circ}$, and occurs accidentally further north. In the Ural Mountains it is found in lat. $57^{\circ}$, and in West Siberia in lat. $55^{\circ}$. In East Siberia it is a summer visitor to Lake Baikal and the valley of the Amoor. It is a summer visitor to East Mongolia, North China, and the north island of Japan; but is a resident in the main island of Japan, South China, and Formosa. It is not known that the Coots inhabiting Australia and Java belong to a distinct species. It is a resident throughout Burma, India, and Persia, but is a summer visitor to Russian Turkestan, and passes through Afghanistan on migration. In Central Europe it is a resident, but in South Europe it is much more common in winter than in summer. It is a resident in Asia Minor, Palestine, North Africa, and the Azores. It passes the Canaries and 
Madeira on migration, and winters in great numbers in North Africa, ranging at that season as far south as Senegambia in the west, and the Blue Nile in the east. In Southern Spain and in Africa it meets with, and is partially replaced by, a nearly allied species, the Crested Coot (Fulica cristata), which differs in having no white on the wing, and in having the frontal shield terminating in two crimson appendages. The American Coot $(F$. americana) is very nearly allied to the Common Coot, but differs in having a considerable amount of white on the under tail-coverts.

The Common Coot is more frequently found on open water than the Moorhen, especially preferring broads, large lakes, fish-ponds, and quict slow-running rivers. It is also seen, but in smaller numbers, on the mountain-lochs and tarns; and is especially common in winter on lowlying coasts where there are extensive mud-flats and quiet creeks, which are almost without water at low tide. It is very partial to broad open ditches, especially if there are beds of reeds and flags in them. It does not scem to require or prefer such rank vegetation as the Waterhen, but the banks of the water on which it lires must be weed- and rush-grown, or covered with tall grass and brambles. On many shects of ornamental water the Coot lives in a semi-domesticated state, and will allow an observer to approach it quite closely; otherwise it is an exccedingly wary bird, ever on the alert for danger, and giving the alarm to the other Water-fowl with which it often congregates. As it feeds in the daytime, it too often prevents the gunner approaching the flocks of Geese and Ducks, that otherwise might allow him to come within range, by at once giving the alarm.

The Coot is most at home in the water. It swims and dives with the greatest ease, and may often be seen quietly sitting on the surface of a pool, remaining in one spot for a considerable time. It soon gets accustomed to noises, and frequently allows the passing train to go by without showing the least alarm. It approaches with the greatest unconcern the splashing water-wheels, secming to know that it is safe from harm. It swims with the same peculiar motion of the head and tail as the Waterhen, venturing sometimes far out from shore, but more frequently kecps close to the margin of the water. When alarmed it very often instantly dives, and will go for a long distance under water to a place of safety. It takes wing with the greatest reluctance, and usually flies in a very clumsy manner just above the water, its feet, which are hung downwards, every now and then touching the surface. It is, however, capable of performing extended flights, and when once well on the wing progresses - with great rapidity. It often flies about at night round and round above its watery haunts, every now and then uttering its peculiar note, like the Waterhen. Although the feet of the Coot seem so ill-adapted for progress on the land, it is by no means an ungraceful bird, as it walks leisurely about the lawn or on the bare bauks of the broads and lakes. It 
progresses in a similar manner to the Waterhen, and when alarmed will often ruu with great speed to the nearest cover. Sometimes it takes wing and alights on the water with a heavy plunge, diving at once, and progressing under water to the reeds, remaining in such a position for a considerable time, with only the point of its bill out of the water. It is a very sociable bird, and may be seen in parties at all times of the year, but it congregates in the largest numbers in winter. It is fond of the society of other water-birds, and by its presence and great wariness adds considerably to the safety of the whole flock. It may frequently be scen walking gracefully about the mud islands in tidal rivers, and when winged often runs with surprising quickness, concealing itself in an old wall or amongst the gnarled roots of trees. The Coot may occasionally be seen perched in trees, and it sometimes ascends them, leaping from branch to branch with as much ease as a gallinaceous bird. It sometimes roosts in trees, and has been known to repair to them to feed on berries. It generally sleeps on the water; but if this is not convenient it repairs to the land, choosing the highest portions, where it is better able to discern ny danger or become aware of its approach.

The food of the Coot is composed of very small fish, aquatic insects, and tender shoots, buds, and seeds of water-plants; and upon the land it eats great quantities of common meadlow-grass, small shells, slugs, and worms, which it finds amongst the aquatic vegetation and the grass near its haunt. It eats grain readily, but will seldom or never come near to farmhouses or enter stackyards to obtain it, but picks it up from the new-sown lands or stubbles. It obtains much of its food by diving. The cry of the Coot is loud and plaintive, sometimes a single note, but frequently repented several times. It is a clcar bell-like $k \ddot{o}$, not unlike the cry of the Golden Plover.

The Coot is a rather late breeder, and its eggs are seldom laid before the beginning of May, sometimes later, according to the state of the season. The nest is sometimes built on the dry land amongst tangled reeds and grass on the banks of the water; but more frequently it is placed in shallow water amongst flags and tall rushes, the foundation being commenced under the surface. It is often placed on the margin of the water on small islands. The nest is a large bulky structure, sometimes as much as two feet in height, this varying according to the depth of the water. In some cases it is a floating structure, anchored safely to the surrounding reeds, or built on a large mass of rushes that have been broken by the wind and lie on the surface of the water. The outside is generally made of coarse flags, rceds, dead leaves, and portions of aquatic plants ; and as it approaches completion finer materials are used, and the lining generally consists of dry recd-lcaves. The eggs are from six to twelve in number, seven or eight being an average clutch. They are buffish white or stone-colour, 
spotted and speckled evenly over the entire surface with blackish brown. The markings are seldom very large, generally varying from about the size of No. 10 shot to mere specks. On some eggs many of the spots are underlying and violet-grey. They are not subject to much variation in colour, but differ considerably in size. They vary in length from $2 \cdot 2$ to 2.08 inch, and in breadth from 1.55 to 1.05 inch. The eggs of the Coot cannot be confused with those of any other British bird, but are indistinguishable from those of the Crested Coot. Stevenson states that he has frequently known a Waterhen's egg laid in the nest of this species. The Coot does not cover her eggs when she leaves them, and when disturbed slips quietly off the nest, and often remains submerged in the water close by until the danger is passed. Both parents assist in incubation. The young are able to leave the nest soon after they are hatched, and are tended most assiduously by their parents; they adopt the same means for procuring their safety when menaced by danger as their parents, and dive or conceal themselves amongst the herbage with great quickness. Many, however, fall victims to rapacious pike, and the Heron often catches them.

In winter Coots collect into immense flocks in the low-lying counties, and frequent the fresh water as long as it remains unfrozen, only quitting it for the sea when absolutely compelled by long-continued frost. They appear to migrate to the coast under these circumstances in large flocks, quitting their freshwater haunts to a bird. Many Coots come to our eastern counties at this season and swell the ranks of the resicient birds; and it is said that these migrants arrive singly and afterwards congregate. When alarmed they generally scatter at once, which they do more or less when feeding. These winter visitors appear to take their departure in March, just about the time that the resident Coots are pairing for the coming breeding-season.

The general colour of the plumage of the adult Coot is dull slate-grey, shading into nearly black on the head, neck, and under tail-coverts. The quills are brown, shading into white on the tips of the secondaries, which form a white bar across the wing, most conspicuous during flight. Bill flesh-colour, shading into white at the tip and on the frontal plate; legs, feet, and claws olive, shading into orange above the tarsal joint; irides crimson. The female resembles the male in colour. Toung in first plumage liave the upper parts suffused with olive-brown, and the chin, throat, breast, and belly nearly white. In their first autumn they moult into the plumage of birds of the year, in which the white is nearly lost on the chin and throat, and partially so on the belly. Young in down are black, some of the filaments being tipped with white. 


\section{Family GRUID\&, or CRANES.}

The Cranes are a very small and well-defined family, but great difference of opinion exists as to their affinitics. Forbes supposed them to be nearest related to the Ibises and the Plovers, but Sclater places them in the same order as the Bustards. The Cranes have no notch in the posterior margin of the sternum. In the modification of their cranial bones, in their pterylosis, myology, and in their digestive organs they appear to be nearest allied to the Bustards and Rails.

There can be little doubt that the Cranes moult twice in the year, carly in autumn and in spring. Cranes shot on the autumn migration are said to be in perfect plumage; and Naumamn says that they sometimes arrive at their breeding-places before the spring moult is quite complete.

The Cranes somewhat resemble in their external cliaracters the IIerons and the Storks, but may be distinguished from both by their much shorter bill, which resembles in some respects that of the Plovers. The wings are long, and the innermost secondaries are lengthened and pendent. The tail is short and even, and composed of twelve feathers. The hind toe is small and somewhat elevated.

The young of the Cranes, like those of the Rails and the Bustards, are covered with down when they are hatched, and they are able to run shortly afterwards.

It is supposed that there are only 16 species of Cranes, which are distributed over all the large continents of the world, but are absent from the Arctic and Neotropical Regions and from all the smaller islands. Three species of Crane are Euronean, two of which are said occasionally to visit our islands.

\section{Genus GRUS.}

The Cranes were associated by Brisson with the Storks, and by Linnæus with the Herons; but in 1793 Bcchstein established the genus Grus for their reception in his 'Naturgeschichte Deutschlands' (iii. p. 60), and the Common Crane, being the Ardea yrus of Limnacus, became of necessity the type.

The true Cranes have been separated from the Crested Cranes in conscquence of the absence of the bristly occipital crest, aud on account of 
their long bills and their elongate instead of ovate nostrils ; but no purpose can be served in splitting up such a small genus, since we are absolutely ignorant of the taxonomic value of these characters.

The number of species, their characters and distribution, are consequently the same as those of the family.

The Cranes frequent open tracts of country, large plains, and extensive swamps. They are migratory (brecding in the north and wintering in the tropics), and perform their annual journeys at great elevations. Their notes are very loud and powerful. Their food consists principally of grain, small mammals and reptiles, and insects. Their nests are large, and composed of reeds, dry grass, sticks, \&c., and are built on the ground in a little-frequented part of a morass. Their eggs are very handsome, olive or greenish brown in ground-colour, spotted and blotched with various shades of brown.

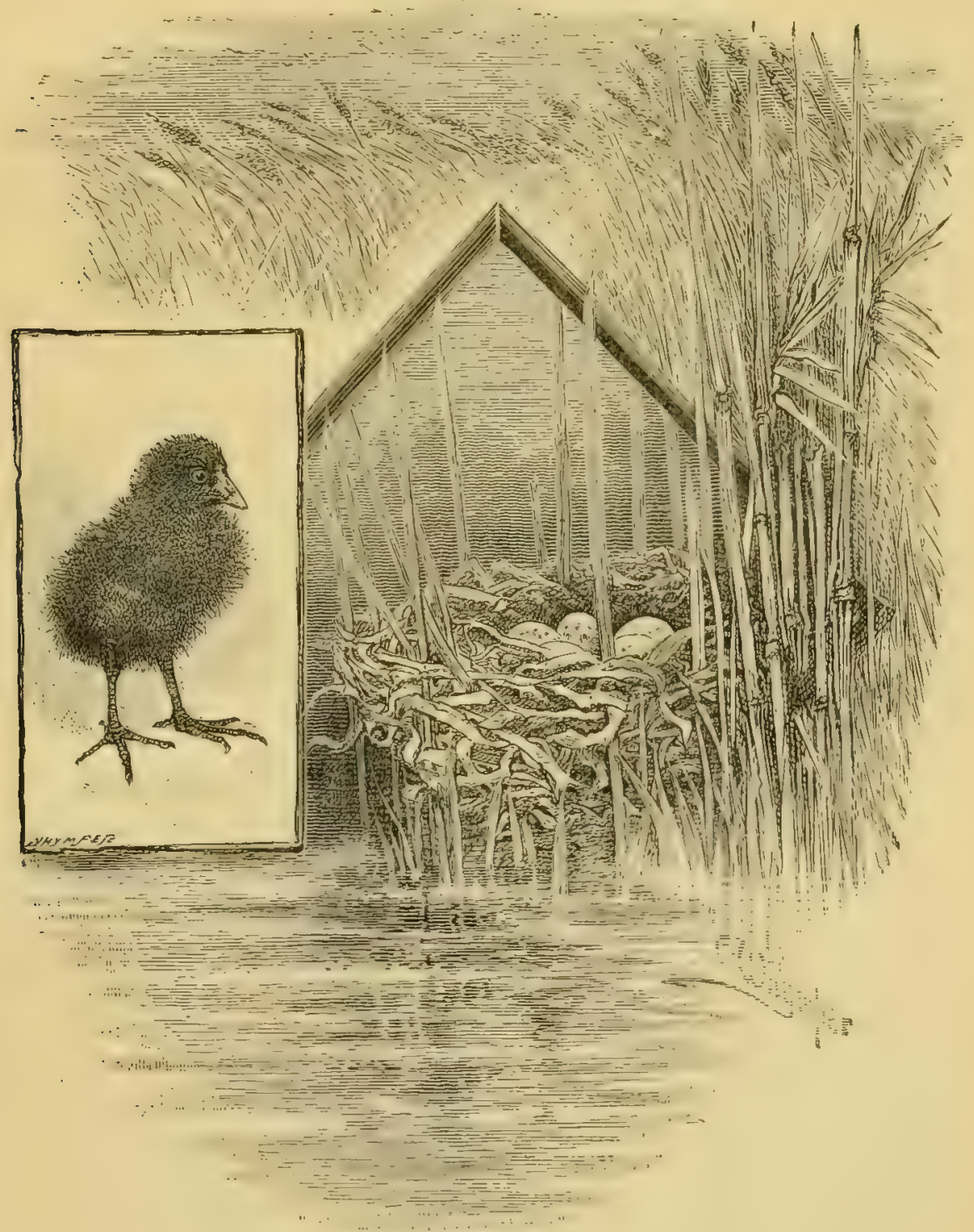

NLST OF WATERHEN, 


\section{GRUS CINEREA.}

\section{COMIMON CRANE.}

(Plate 36.)

Ciconia grus, Briss. Orn. v. p. 374, pl. xxxiii. (1760).

Ardea grus, Linn. Syst. Nat. i. p. 234 (1766).

Grus communis, Bechst. Natur\%. Deutschl. iii. p. 60 (1793).

Grus cinerea, Bechst. Naturg. Deutschl. iv. p. 103 (1809); et auctorum plurimorum-Temminck, Naumann, Bonaparte, Degland \& Gerbe, Tristram, Wolley, Salvadori, \&c.

Grus canorus, Forst. Syn. Cat. Br. B. p. 58 (1817).

Grus vulgaris, Pall. Zoogr. Rosso-Asiat. ii. p. 106 (1826).

Grus cinerea longirostris, Temm. \& Schl. Faun. Japon. p. 117 (1847).

Grus cineracea, Brehm, Naumannia, v.p. 289 (1855).

Grus communis, var, orientalis, Blyth, Nat. Hist. Cranes, p. 59 (1881).

Flocks of Common Cranes appear to have migrated to the British Islands to breed in the fens and marshes up to the close of the 16th century, and, if the ancient records are to be believed, remained to winter in considerable numbers. A century later Willughby and Ray were unable to ascertain whether they still continued to breed in this country. At the present time this bird can only be regarded as an accidental straggler on migration to our islands, principally to the southern and eastern counties. The spring of 1869 was remarkable for the numerous occurrences of this handsome bird in this country (Gurney, 'Zoologist,' 1869, p. 18њ1). It frequently passes the Orkneys and Slietlands on migration, and is occasionally seen on the mainland of Scotland. In Ireland Cranes are very rarely seen, but three were shot out of a party of four in November 1851, near Kinsale, in co. Cork; and Mr. Lloyd Patterson informs me that a fine male was shot near Killyleagh, co. Down, on the 10th of May, 1882. Two Cranes were seen near Lough Mask, co. Mayo, on the lst of January, 1884, one of which was shot (Ussher, 'Zoologist,' 1884, p. 72). They are recorded to have been extremely numerous, no doubt breeding on the extensive bogs in this country, in the 12th and 14th centuries.

The Crane breeds in suitable localities throughout Europe and North Asia, wintering in North Africa and South Asia. It occasionally passes the Faroe Islands on migration. In Scandinavia and in Russia it is a local summer visitor up to lat. $68^{\circ}$. In West Siberia it has not been found breeding north of the Arctic circle; in the valley of the Yenesay I did not observe it north of lat. $60^{\circ}$; Middendorff does not appear to have found it in East Siberia; but Pallas records it from Kamtschatka ; and it is a summer visitor to the neighbourhood of Lake Baikal and the valley of the 
Amoor. West of Russia and south of the Baltic it is a very local bird during the breeding-season. Beyond the Baltic Provinces and Poland its breeding-range extends through Pomerania to the Elbe, and in South Russia into the valley of the Lower Danube. Further west we have no reliable evidence of its breeding, except in the marshes of Andalusia, where Saunders and Irby obtained its eggs. In other parts of Europe it is only seen on migration to its winter-quarters in North Africa. It winters in Algeria, Egypt, Nubia, and Sennar, and occasionally in various parts of Southern Europe, Palestine, and Persia. Eastwards it breeds in Russian Turkestan; passes through Mongolia, North China, and Japan on migration; and winters in South China, India, and possibly Burma. The Crane has sevcral allies in Asia and America, but none with which it can easily be confounded. Blyth suspected that the Cranes in the cast differed slightly from those in the west, having less black on the plumes and less red on the crown, and the plumage being generally browner; but subsequent researches have not confirmed this view.

There are many interesting points in the history of the Crane. Its home is on the plains, in their wettest part. It is rarely found except in places which are half lake and half swamp. It never perches in a tree, and never builds its nest on a tree, but it does not object to the vicinity of trees. I have heard them calling to their young in the forests of Pomerania, and seen them flying over the trees in small flocks in June. In these forests are swampy places, where the trees are drowned out, and where rushes, coarse grass, and sedge grow in small hummocks, with clear water between; and on the outskirts of the forests are extensive moors, where similar swampy places, generally with a lake in the middle of them, are found. In both these localities the Crane breeds. I found it quite as abundant near the treeless steppes of the Danube, on the swampy margins of the lagoons which are so common on the western shores of the Black Sea, and doubtless are the remains of old mouths of the Danube. In both these localities the Crane was more or less gregarious, even in the middle of the breeding-season. Like most other large birds, it is very shy; and flocks of Cranes always, it is said, appoint one of their number to act as spy, and give the alarm to the rest on the approach of danger. They are diurnal birds, and may be scen feeding at all hours of the day, and they migrate during the day in flocks. It is a very interesting sight to watch them on their migrations. They fly very high and very quick, like Wild Geese or Swans, and, as these birds do, they keep in a line together like a regiment of soldiers, as if actuated by one mind. This line is generally $\mathbf{V}$-shaped, often it changes to $\mathbf{W}$-shaped; but in spite of the great speed, every movement is conducted with wonderful regularity. The mode of flight rescmbles that of a Stork, inasmuch as the neck is fully outstretched; but it approaches that of the Heron in the fact that the legs when extended form a perfectly straight 
line with the neck and bill, instead of a slight curve. It must not, however, be supposed that the Crane is a near relation of the Stork or the IIcron; on the contrary, it has scarcely a character in common with these birds except its long legs and large size. The Crane might be regarded as a gigantic long-legged Rail, as a Water-Bustard, or as a huge form of Stilt-Plover; but from the Herons and Storks it differs in almost every important respect-in the modification of the bones of its palate, in its richly spotted eggs, in the fact that the young can run as soon as hatched, and in various other characters.

Unlike the Herons and the Storks, the Crane has a loud and not unmusical voice, which can be heard at an immense distance. The keel of its sternum is hollow, and the windpipe is convoluted between the plates on each side; and from this long pipe, as from a trombone, proceed loud, clear, trumpet-like notes, so rapidly trilled as almost to split the ear with their vibrations. These notes can be variously modulated to express the different feelings of the bird.

The Crane feeds more on vegetable than on animal food. It eats all sorts of corn, secds, buckwheat, peas, the tender shoots of aquatic plants, and even grass; but it often devours worms, insects of various kinds, and even lizards and small frogs, but it is not known to eat fish.

Many Cranes winter in South Europe, but the migrating parties which cross the Mediterrancan are conspicuous enough. They cross the Straits of Gibraltar as early as February; but in the east they are somewhat later, arriving at Smyrna carly in March. They reach Central Germany late in March or early in April, according to the season, but they do not arrive in Lapland until May. The return migration takes place during October.

The Crane is an early breeder. In Spain the first eggs are laid about the last week of April, and in Bulgaria not more than a week later. In Germany its eggs are laid late in April or early in May, but in Lapland not until the end of the latter month. In Pomerania the nest of the Crane is generally built on one of the hummocks in the swamps. It is a very slight structure : the top of the hummock is trampled down, and the sedge, part of it fresh new foliage and part last year's dead leaves, is twisted round into an apology for a nest.

The earliest authentic information respecting the breeding of the Crane which reached Enghish ornithologists was the graphic account which Wolley published in the first volume of the 'Ibis' of his discovery of its nest and eggs in Lapland, thirty years ago. It is impossible to overestimate the interest of this narrative; but in justice to continental ornithologists it must be remembered that the Germaus had been familiar with all the details of the breeding of this interesting bird for many years before then, and thought no more of taking a Crane's nest than we do of finding 
the nest of a Curlew or of a Golden Plover on the Derbyshire moors. In Wolley's time Germany was a terra incognita to English ornithologists, and to a great extent remains so still. But the accurate account which Naumann wrote of the breeding of the Crane in 1838 does not in the least degree detract from the merit of Wolley's narrative in 1859. Wolley was one of the few ornithologists who possessed a kcen appreciation of the poetry of bird-nesting, and was able, to a limited extent, to transfer some of the poetic feeling to his readers. I say to a limited extent, because there has not yet appeared a writer on this subject whose best productions do not fall almost infinitely short of the reality. Wolley's account of the breeding of the Crane is very charming. In the Aretic Regions, long before the mysterious tundra is reached, foretastes of it can be enjoyed. North of the Aretic circle the trees soon become dwarfed, the larches grow weird and stunted, birch and willow thickets show the presence of stagnant water, and large swamps, too wet for the growth of trees, occur, and lie like lakes in the forest, or lead on to rising ground at the foot of the fells. These swamps have all the brilliant flora of the tundra-the ground-fruits of many kinds, the pink Andromeda like an exotic heath, and the white aromatic Ledum being the most conspicuous. These treacherous-looking bogs are safe enough in early spring; the mosquitoes are not yet born; a foot or so below the surface is a solid pavement of ice, which is also a preventative against the malaria which is so dangerous in the southern breedinggrounds of the Crane. Wolley was able to camp out under the shelter of the larches, and conceal himself behind the clumps of birch and willow to watch the birds. At the end of May in these regions midnight is not even twilight; it is day, with the sun obscured for a moment. Birds are constantly to be seen and heard. Fieldfares perched above his head, Ruffs were holding high carnival on the moors ; from far in the distance came the cries of the Black-throated Divers, like the screams of tortured children; he was able to recognize the birds which passed by the waft of their wings, and now and then he heard overhead the sweeping wave of great wings with which he was unfamiliar. The watching the female to the nest, her graceful walk, the dainty way in which she bent her breast to the eggs and subsided on the nest, the preening of her feathers, until at last she falls asleep, are all graphically described. Equally charming is his account of the taking of the eggs, the bird catching his eye and taking wing, and the behaviour of a pair of birds whose newly hatched young he discovered running amongst the sedgy grass. He found several nests, some empty and some with eggs; they were gencrally in wet places, and the wetter the place the larger was the nest, sometimes more than two fect across. Pieces of old egg-shells were found under the lining of one, showing that they sometimes breed in the same nest year after year.

Two is the usual number of eggs laid, but in very rare instances three 
have been found. They vary in ground-colour from brownish buff to greenish buff, spotted and blotched with rich brown, and with underlying markings of paler brown and greyish pink. Some specimens have most of the markings on the large end, where they form a scmi-confluent mass ; in some they form an irregular zone; whilst in others they are evenly distributed over the entire surface, many being indistinct and confluent. Some specimens have much of the brown surface-colour clouded over the shell, with one or two large spots and an indistinct mass of colour at the large end, intermingled with a few dark-brown spots. The shell is conspicuously pitted, almost like pig-skin, and shows little gloss. They vary in length from $4 \cdot 1$ to 3.5 inch, and in breadth from 2.5 to 2.3 inch. The eggs of the Common Crane may always be distinguished from those of the Demoiselle Crane by their larger size, but the variations in colour and shape are common to those of both species.

The Crane is one of the largest birds that visit our islands, and stands from three to four fect in height. The general colour of the plumage is pale slate-grey, shading into black on the quills and innermost secondaries, which are elongated and disintegrated into handsome plumes, which conceal the tail. The sides of the upper half of the neck are white up to the eye; but the nape, chin, and upper throat are very dark slate-grey; ou the crown is a scarlet warty patch devoid of feathers; the forehead and lores are covered with dark hairs. Bill greyish olive; legs, feet, and claws nearly black; irides deep crimson. The female differs very slightly from the male in colour. Young in first plumage have the parts of the head which are naked in the adult covered with feathers, and the black and white on the head and upper part of the neek are replaced by brown and grey; the plumes are much smaller and less curled. After the first spring moult it has assumed a nearly aduit plumage. There can be little doubt that the adult bird has also a spring moult, and that the winter plumage is browner than that of summer, the red erown much less vivid, and the nuptial plumes not so well developed. The young in down are chestnut-brown above, shading into paler brown below.

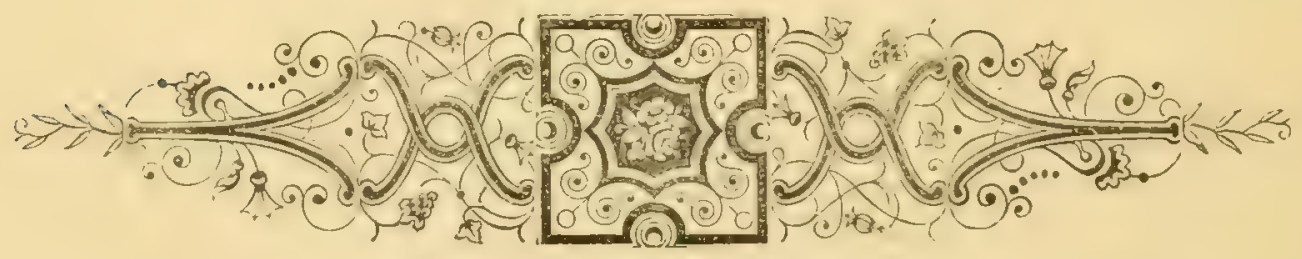




\title{
GRUS VIRGO.
}

\section{DEMOISELLE CRANE.}

\author{
(Plate 36.)
}

Ciconia grus numidica, Briss. Om. v. p. 388 (1760).

Ardea virgo, Linn. Syst. Nat. i. p. 234 (1766); et auctorum plurimorumLatham, (Temminck), (Naumann), (Benaparte), (Degland \& Gerbe), (Dresser), \&c.

Anthropoides virgo (Linn.), Vieill. N. Dict. d'Hist. Nat. ii. p. 163 (1816),

Grus virgo (Linn.), Pall. Zoogr. Rosso-Asiat. ii. p. 108 (1826).

Scops virgo (Linn.), Gray, List Gen. B. p. 86 (1841).

The Numidian or Demoiselle Crane must be regarded as a very rare accidental visitor to the British Islands, as a pair were seen on one of the Orkney Islands on the 14th of May, 1863, and one of them, which proved to be a male, was shot (Saxby, 'Zoologist,' 1863, p. 8692). The reported occurrence of this bird in Somersetshire in 1876 ('Science Gossip,' 1876, p. 66) rests upon very unsatisfactory evidence (Cecil Smith, 'Zoologist,' 1883, p. 333).

The summer range of the Demoiselle Crane is very extensive, but the bird is only locally distributed. It nests in the scattered marshes of Algeria, but does not appear to be met with in Europe during the breedingscason, except in Sonthern Spain, in the lagoons on the western shores of the Black Sea, and in the steppes of Southern Russia between lat. $50^{\circ}$ and the Caucasus. It breeds throughout Turkestan and in South-west Siberia, at least as far north as lat. $46^{\circ}$. In Central Siberia it breeds near Lake Baikal as far north as lat. $53^{\circ}$, and is common in summer in Dauria and in Eastern Mongolia, as far as the extreme north-west of China proper. The Asiatic birds appear to winter in the plains of India. On migration, or as an accidental straggler, it has been seen in various parts of Europein Scandinavia, Heligoland, Germany, Switzerland, Spain, Italy, Grecee, and Asia Minor. In autumn it passes up the valley of the Nile in enormous numbers, and winters in Sennar as far south as lat. $12^{\circ} *$.

* The evidence of the occurrence of this species in Africa south of the Equator is very doubtful. Dresser, in his 'Birds of Europe,' quotes Natal as a locality, on the authority of Messrs. Woodward ('Zoologist,' 1875, p. 4510). These gentlemen describe it as breeding in that country and as being the commonest Crane, known locally as the "Kafir Crane." There can be little doubt that the bird referred to is Grus regulorum, which Mr. Ayres found breeding in the "Transvaal, thungh the description does not quite agree. This species is doubtless the one which Livingstone met with on the Zambesi, also mentioned by Dresser as Grus virgo (Kirk, 'Ibis,' 1864, p. 331). 
The Demoisclle Crane is only a summer visitor to Europe, arriving at its breeding-grounds in South Russia and the Lower Danube in March and April. It departs again in September, and is said to pass through Northeast Africa in October, on its way to its winter-quarters. In Siberia, Radde states that it arrived at Tarei-nor about the Gth of May, and left from the middle to the end of August. Prjevalsky says that it arrived in Mongolia about the end of March, and left in September. It arrives at its winter-quarters in India in Oetober, where its appearance is hailed with delight, as a signal that the cold season has commenced. This graceful Crane migrates in large flocks like its congener the Common Crane, and often flies so high as to be out of sight, its presence only being made known by its note. When on migration these flocks generally fly in the form of the letter $\boldsymbol{V}$ or $\mathbf{W}$. The flight of this bird is very graceful, performed with slow and regular beats of the broad wings, with the neck and legs outstretched. Sometimes the flocks pass over during night, sometimes during day; and when arrived at the end of their journey they do not disperse for some little time. Heuglin says that when on migration the scattered flocks alight on the sand-banks and on the marshes; they also frequent grain-fields on the steppes, and if alarmed rise en masse with a loud babel of cries. The Demoiselle Crane appears sometimes to perform various grotesque movements, which hare not inaptly been termed dancing. These antics are probably connected in some way with pairing, and serve the same purpose as the "lek" of Game Birds. This bird loves to frequent sandy districts, steppes, and extensive sandy plains, even the deserts, where it is said to visit the wells to drink after the cattle have been watered.

I saw the Demoiselle Crane on the sandy shores of the inland lakes on the Lower Danube. It is a very elegant and slender-looking bird, well worthy of its namesakes before Mrs. Grundy had deformed them with dress-improvers. It was in small partics, which allowed us to approach within long gunshot, when they flew leisurely away, making a cry like $k r r$, very different to the loud trumpet-like note of the Common Crane.

Its food consists of grain, seeds, shoots of herbage, insects of various kinds, worms, and, it is said, lizards and snakes. They are said to drink very regularly; and in the evening leave the fields where they have spent the day, and retire to the nearest marshes to roost.

In the valley of the Lower Danube this Crane commences to make preparations for breeding about a fortnight after its arrival. The large flocks break up and scparate in pairs, but small flocks are constantly to be secn fecding together during the brecding-scason. The nest is always built on the ground, often amongst growing grain of some kind or amongst tall grass in the meadows. It is a very slight structure, the surrounding herbage being generally trodden down and a slight hollow formed, into which are scraped a few straws, and sometimes one or two small stones. 
The eggs of the Demoiselle Crane are two in number, placed side by side in the nest, with the small ends pointing in the same direction; they are sometimes laid about the end of April, but more frequently during the first half of May, or not until the end of that month if the season be backward. They are pale buff or olive in ground-colour, spotted and blotched with umber-brown and with numerous underlying markings of brownish pink. On some eggs most of the spots and blotches are underlying and ill-defined; others are only sparingly marked with one or two large irregular confluent blotches. The surface is rather smooth and is full of small pores, but does not show much gloss. The eggs vary in length from $3 \cdot 8$ to 3.1 inch, and in breadth from $2 \cdot 2$ to $2 \cdot 0$ inch; they very closely resemble those of the Common Crane, but are much smaller. Both birds assist in incubation; and when one is sitting, its partner is generally not far away, standing sentinel, ready to give the alarm the moment danger threatens. From the wary habits of this bird, its eggs are difficult to find; it leaves the nest in a very unconcerned manner, walking for some distance, and then taking wing, but always returning as soon as the intruder has disappeared. During the period of incubation the old birds are said to be very pugnacious, never failing to attack an Eagle, a Harrier, or even a dog that has inadvertently approached the sacred spot. The young are able to follow their parents very soon after they are hatched. Only one brood appears to be reared in the year.

The Demoiselle Crane is gregarious during winter, and sometimes assembles in enormous companies, several thousands not unfrequently congregating together. In its winter-quarters in India this Crame is said to prefer the shelving shores and sand-banks of rivers, but it also haunts the banks of lakes and ponds. Hume, in the 'Game Birds of India' (iii. p. 34), writes:- "They feed in fields in the early mornings, come down to the river or to large tanks about 9 o'clock, and spend a good part of the day there, though gencrally paying a second visit late in the afternoon to their feeding-grounds, and return to the water about sunset to pass the night upon some bare, low sand-bauk, whence their harsh cries ceaselessly resound till they again leave, about or just before dawn. I have not observed them so perpetually on the wing as Mr. Vidal, whose remarks I quote below, tells us it is their habit to be in the Deccan, nor have I found them one whit more wary or difficult to shoot than the Common Crane. More noisy they certainly are, and the uproar that rises when, after a successful drift, you have fired into one of the enormous flocks, such as I have already described, is alike indescribable and, to any one who has had no personal experience of it, incredible. Thousands of mighty pinions, almost convulsively beating the air at the same moment, and thousands of powerful windpipes, all simultmeously grating out the harsh kurr-kurr-kurr, \&e., some shriller, some baser, each single roice

VOL. II. 
amongst the multitude capable of making itself heard for two miles. Scream as you will, it will be a couple of minutes before you can make a man close beside you hear a syllable you say."

The Demoiselle Crane is said by Hume to run well, but not so quickly as the Common Crane. When wounded, it sometimes takes to the water or fights fiercely. In some countries this Crane is chased by Hawks. Throughout the wiuter the Demoiselle Crane is constantly shifting its quarters, and the large flocks are continually scparating into smaller parties and reuniting again. When the grain is cut they frequent the stubbles, where, if alarmed, they often rise for some distance in the air, and soar in wide circles for hours. They are at all times very wary and suspicious, and usually one or two birds are always on duty as sentincls to warn the flock of the approach of any danger.

The Demoiselle Crane is a smaller bird than the Common species, but is more elegant in shape. Its general colour is pale slate-grey. The sides of the head and neek and the entire chin and throat are black, the feathers of the latter elongated and pointed, concealing the upper breast. A tuft of long white feathers ormaments each side of the heal. The quills are black, as are also the ends of the innermost secondaries, which are long and pointed, concealing the tail, but not curled as in the Common Crane. Bill olive at the base, pale brown at the tip; legs, feet, and claws nearly black; irides deep scarlet. The female is slightly duller in colour than the male, and her nuptial plumes are somewhat smaller. Winter plumage scarcely differs from that of summer, except that the nuptial plumes are less developed. In young in first plumage the nuptial plumes on the sides of the head are very small and grey, the innermost secondaries and the feathers of the throat are not elongated, and the black on the head and neck is only represented by a brown patch in the middle of the latter. Birds of the year, after their first spring moult, are intermediate. They probably do not breed until the sceond year' and the sumall flocks that are seen during the brecting-season most likely consist of birds of the year.

An example of the Soudan Crane (Grus pavonia), often erroneousily called the Balearic Crane, was shot in Ayrshire on the 1\%th of September 1871 (Gray, Ibis, 1872, p. 201). There can be little doubt that it had escaped from confinement, as this species is only known to breed in West Africa and the Upper Valley of the Nile, where it is said to be a resident. The Soudan Crane may casily be recognized by its peculiar crown of feathers at the back of the head, by its white wing-coverts and chestnut secondaries. 


\section{Family OTIDIDAE, OR BUSTARDS.}

The Bustards are at somewhat ill-defined little family, apparently intermediate between the Plovers and the Game Birds. Forbes divided them into two families, the Bustards and the Stone-Curlews, which he regarded as very nearly allied to each other and to the Rails, and not very distantly related to the Game Birds and the Cuckoos. Sclater also recognizes the two families; but places the bustards in the same Order as the Cianes, and the Stone-Curlews in the same Order as that of the Plovers, in each case associating groups of birds which, in the opinion of liorbes, are very distantly related. 'The notches on each sicle of the posterior' mar'yin of the sternum in the Bustards are two in number, decper than in the Ibises and Spoonbills, but not so deep as in the Sandpipers. Huxley, in his clissification, founded upou the modification of the cranial boues, places them next to the Cranes and the Rails, and not far from the Sandpiper's, the Gulls, Game Birds, \&c. Nitzsch says that in the structure of the skcletou, particularly in the form of the sternum and furcula, the Bustards are very nearly allied to the Sandpipers, especially to the Curlews. In the structure of the skull they most closely approach the Stone-Curlews; but in some other respects they diverge very distinctly from the type of the Sandpipers. In their pterylosis, myology, and digestive organs they approach nearest to the Cranes and the Rails.

The Bustards have only one cornplete moult in the year, in autumn, but some of the feathers of the head and neck are changed in spring.

In their external character's the Bustards appear to be an intermediate link between the Game Bircls and the Plover's. The style of coloration and the shape of the bill generally very closely resemble those of some of the Grouse, but the wings are long and pointed, and the tail is short and rounded. The legs are rather loug, the toes very short, aud the hind toe is wanting. The young of the Bustards, like the young of the Game Birds and Plovers, are covered with down when they alle hatehed, and they are able to run before they are many hours old.

'This family contains about thirty-five species, and is almost cosmopolitan, beimg only absent from the Aretic and Nearetic Regions. Three species are European, and are, or were, British. Four other species occasionally wander into Europe, one of which is said to have visited our islands. 


\section{Genus O'TIS.}

The genus Otis was included by Linnæus, in 1766 , in the twelfth edition of his 'Systema Naturee' (i. p. 264), and the Great Bustard (the Otis otis of Brisson) is universally admitted to be the type.

The Bustards very closely resemble the Stone-Curlews; but have a slightly shorter bill, with the chin-angle less conspicuous; the wings are somewhat less pointed, and the style of coloration is more vermiculated, resembling that of the Grouse. The tarsus is reticulated before and behind.

The genus Otis contains about twenty-six species, which are found throughout the temperate and tropical portions of the Old World with the exception of Madagascar and the islands of the Malay Arehipelago. They are most numerous in the Ethiopian Region. Two species are resident on the continent of Europe, both of which are accidental visitor's to the British Islands, and two others are accidental stragglers, one of which occasionally visits us.

The Bustards are steppe-birds, only frequenting large tracts of open country. They are ground-birds, rumuing and walking with ease; but fly well and rapidly. Their food is principally composed of the leaves and buds of plants, grain, and insects. Their nests are very slight, being little more than depressions in the ground; and the eggs are olive-brown or green, spotted and blotched with dark brown. 


\section{OTIS TARDA.}

\section{GREAT BUSTARD.}

(Plate 22.)

Otis otis, Briss. Orn. v. p. 18 (1760).

Otis tarda, Linn. Syst. Nat. i. p. 264 (1766); et auctorum plurimorum-Latham, Temminck, Naumann, Dresser, Saunder's, \&c.

Otis major, Brehm, Vög. Deutschl. p. 531 (1831).

"Once upon a time," as the story-books say, the Great Bustard was a resident in the British Islands. It must always have been an extremely local bird in this country, as it is exclusively a bird of the steppes, seldom or never found near trees. In the days of long ago, before the forests were cut down, the steppe country of England was probably confined to four districts-the Merse of Berwickshire across the Scottish border; the Yorkshire and Lincolnshire wolds; the warrens or "brecks" of Norfolk, Suffolk, and Cambridgeshire; and the downs of Dorset, Wilts, Hampshire, and Sussex, including Salisbury Plain. The earliest account of the Great Bustard in the British Islands is to be found in 'A History of Scotland,' published in the year 1526 by Hector Boece or Boethius. He describes this bird, which he calls " the Gustard," as being as great as a Swan, but in colour of feathers and taste of flesh differing little from a Partridge; and breeding on the lowlands of the Merse in Berwickshire, a district a hundred thousand acres in extent, which may be regarded as the Salisbury Plain of Scotland. On the Yorkshire wolds the last specimen was supposed (Eagle Clarke, 'Handbook Vert. Fauna of Yorkshire,' p. 65) to have been killed about the year 1830; but on the neighbouring wolds of Lincolnshire it had probably become extinct about the commencement of the present century (Cordeaux, 'Birds of the Humber District,' p. 83). The heathy warrens of the eastern counties, with their adjoining wheat-lands, appear to have been the last breeding-place of this fine bird in the British Islands. It is believed that the last male was destroyed in 1838; but females lingered on until 1845 (Stevenson, 'Birds of Norfolk,' ii. p. 15). The latest reliable information of the existence of the Bustard on the Downs appears

* The word steppe is derived from some old English word signifying "wide-stretching." The Merse may possibly mean the "March" or boundary-line between England and Scotland. The word breck has the same origin as the German word "Brach," a fallow or" broken ground. A doun (the same as a dume or sand-hill) means a range of hills near the sea without trees upon it. A wold now has almost the same meaning, a range of naked hills, but is evidently derived from the same root as the German "Wald," a forest. 
to be that of Montagu (Orn. Dict. 2nd ed. p. 63), who was informed in 1813 by the shepherds of Salisbury Plain that these noble birds had not been seen for the last two or three years in their favourite haunts. Since 1845 the Great Bustard must be regarded as an accidental straggler in winter to our islands. For the first quarter of a century the occurrences of this bird did not average one every year, most of them being in the old hreeding-grounds, but others in less suitable localities, as Cornwall, Deronshire, and Northumberland. During the winter of 1870-71 more than a dozen Great Bustards occurred in this country: one was seen in September by Mr. Harting, near Wells; seven were seen in North Devon, three of which were obtained, in December; one was shot in Middlesex in January; and another, in the same month, on the coast of Northumberland; whilst three others were seen on Salisbury Plain, one of which was shot ('Zoologist,' 1871, p. 2472). During the next eight years three or four Bustards were seen in their old quarters, and one was shot as far north as the Orkney Islands; but in the winter of 1879-80 a sccond important migration of Bustards to this country took place. Examples are recorded from Jersey, Cornwall, Dorset, Cambridge, and Essex, and three from Kent. A similar migration of Great Bustards also occurred in France during the same year (Harting, 'Zoologist,' 1880, p. 252). During the last four years there is no record of the Great Bustarl having visited this country. There does not appear to be any authentic evidence that it has ever visited Ireland.

The Great Bustard, where it has not been exterminated, breeds on all the steppes and large open plains throughout the sonthern portion of the Palararctic Region, from the Atlantic to the Pacific. It is not quite extinct in Denmark ; but is no longer found in Scandinavia, though it was formerly a summer visitor in the extreme south of Sweden. In Russia its range does not extend further north than Moscow or Kazan; and in Siberia than Omsk and the valley of the Amoor. It breeds in Mantchooria; but is probably only a winter visitor to Japan and North China, where it occurs as far south as the valley of the Yangtsze. South of the limits already mentioned it is still found in suitable localities throughout Europe, being especially common in some parts of Spain. It is found on the plains of Northeru and Central Germany, Italy, the steppes of the Damube, South Russia, Turkey, and eastwards into Palestine and throughout 'Turkestan. It was formerly common in France, Greece, and North-west Africa, but is now very rare, and only known as an accidcntal visitor, principally in winter, to the latter country, as it also is to Asia Minor and North Persia, whilst it has even strayed as far as North-west India.

Lixamples from Eastern Siberia have been described as distinct under the name of $O$. dybowskii, the characters relied upon being the somewhat smaller size, slightly longer and more slender bill, paler head, and the fact 
that the lesser wing-coverts arc grey like the greater and median wingcoverts, instead of being mottled with brownish buff and black like the back. Dybowsky states that he has obtained both old and young from Dauria. If this species really be distinct, it is probably the form which also occurs in China and Japan. The only male example which I have seen from these localitics is one obtained by $\mathrm{Mr}$. Ringer at Nagasaki, which agrees with Taczanowsky's description. On the other hand, l'Abbé David states that the Bustard of China does not differ in any respect from European examples. Further research appears to be uccessary before we can state positively that the eastern form of the Great Bustard differs from the western form, and that the examples litherto obtained in the east are fully adult.

In the extreme northern portions of its range the Great Bustard is a migratory bird; but even in Germany it is a resident. These birds collect into large flocks during winter, which often wander a great distance from their breeding-grounds in search of food. In South Siberia it is only known in summer, although it is said to arrive at its breeding-quarters as early as March. In the Caucasus and Turkestan it might be described as a partial resident, breeding in the steppes from 5000 to 10,000 feet above the level of the sea, and descending in flocks to winter in the plains.

To study the habits of the Great Bustard it is now, unfortunately, necessary to visit the continent. This noble bird is par excellence the bird of the steppes. The continent of Asia, of which civilized Europe is only a peninsula, consists of a central group of mountains of enormous altitude, not inaptly called in many atlases " the roof of the world," flanked in various directions with outlying spurs, which stretch almost uninterruptedly from the Bay of Biseay to the Sea of Japan. These mountains are clothed almost up to the limit of perpetual snow with pinc- and birchforests, which extend northwards far beyoud the Arctic circle. Between many of these ranges lie extensive plains of fertile country, destitute of trees, where the dcep rich soil produces endless varieties of brilliant flowers and delicate grasses, where these have not been partially removed to make way for the cultivation of wheat, rye, and other crops. These plains, which in Ameriea are called prairies, in Asia are called steppes. The most important of these steppes extends from Bukharest to Tomsk, a distance of about three thousand miles. This is the great breeding-ground of the Great and Little Bustards, the home of the Wallack, the Kalmuck, and the Kirghiz, and the paradise of sheep, cows, and horses. Hay and corn are so cheap that, in travelling for a thousand miles over the snow across the Barabinski steppe, watered by the tributaries of the Obb, I only paid for the hire of my horses a halfpeuny a horse a mile. The steppes exactly suit the requirements of the Bustard-abundance of food and absence of cover. So large a bird, standing from three to almost four 
feet high, and weighing from 15 to $30 \mathrm{lb}$, is necessarily a very conspicuous object; consequently the Bustard chooses a locality where there is little or nothing to intercept the view. It is very suspicious of danger, and does not willingly place itself in a position where an enemy cannot be discerned a long way off. My first introduction to the Great Bustard was on the Wallachian steppes south of Bukharest. A day's sail down the Danube from Giurgivo will, if you choose the northern arm of that river, bring you to the little town of Kalarash. On the 28th of May last year, Mr. John Young and I started in two waggons from that town, accompanied by a German chasscur who "knew the ropes," and to whom we were indebted to the kindness of Mr. Green, of Buklarest. We were tired of blowing Heron's and Egret's eggs, and gladly hailed the chance of a raid amongst the Bustards. North of Kalarash the steppe extends with slight undulations as far as the eye can reach. Most of the land is cultivated with wheat, Indian corn, and other crops near the town, but after we had driven about eight miles we found herds of cattle feeding on the grass, horses, oxen, and buffaloes. The steppes abounded with birds. Flocks of Stock-Doves and Turtle-Doves from Bulgaria, and pairs of Sky-Larks, Calundra Larks, and Corn-Buntings were the commonest birds, and Quails were continually heard. Now and then a Steppe-Eagle or a Black Kite passed over; and once we saw a flock of eighteen Griffon Vultures sailing round and round. We spent an hour in the corn, hoping to put up a Bustard; but it yielded nothing but Quail and Montagu's Harriers, so we made for the open steppe. Although the Bustard is so wary, he often permits of the near approach of a waggon if the driver is concealed ; and we soon had the pleasure of seeing a female Great Bustard rise from the grass, and after a slight struggle take wing and fly slowly away. . We ran to the spot whence she rose, and were delighted to find two eggs on a piece of bare earth trodden down into the scmblance of a hollow. There was no nest and scarcely any cover' the grass was thin, and only here and there were weeds high enough to shield the sitting bird from view in certain directions. Whilst we were feasting our eyes on the eggs, she came round again, but after one turn flew right away, with slow heavy flap of wing not unlike a Heron. Soon afterwards we descried cight male birds on a slight incline nearly a mile away. At first we mistook them for sheep, but our binoculars soon convinced us that they were Great Bustards. In the course of the day we saw several parties of two or four birds, and once a Hock of eighteen, probably last year's birds not yet breeding. The female is very silent, but the male occasionally utters a note like the syllable mrunt, $^{2}$ and when alarmed both sexes make a sort of hiss.

The breeding of the Great Bustard may, however, be seen much nearer home than the valley of the Danube. On the 23rd of May, 1882, I took the nest of a Great Bustard in North Germany. The Brocken is the highest 
peak of the Hartz Mountains. To the north stretches a vast rolling prairie, bounded by low ranges of hills, for the most part covered with oak-and beech-forest. In the middle of this prairie lies the town of Halberstart, celebrated amongst ornithologists as the seat of Heine's great collection of birds. Oberamtmann Ferdinand Heine lives in an old mansion which was formerly (in the pre-Napoleonic days) the monastery of St. Burchard, now a Rittergut; and here he most hospitably entertained me and my son, who, with Dr. Blasius, were expressly invited to take the nest of a Great Bustard, and examine our host's magnificent collection of birds. A carriage and pair met us at the station to drive us up to the nest. We stopped halfway to lunch at another Rittergut, where one of Heine's sons occupies himself with farming on a great scalc-ligh farming, said to be carried to the greatest perfection of which it is capable. No hedges are to be seen, and, except on the roadsides and round the villages and baronial halls of the Oberamtmänner, no trees are visible. Ryc, wheat, barley, peas, potatoes, and especially beetroot for sugar, grow in fields which may almost be measured by square miles instead of acres. The nest had been discovered four days before, when the bird ran through the low wheat, which was not much more than a foot high, for about fifty yards and then took wing. It was scarcely to be expected that she would sit so close when her neighbourhood was invaded by such a formidable expedition as ours was, and we saw nothing of her, but we soon found the nest, containing three eggs. It was a slight hollow in the midst of the wheat, not more than an inch depressed even in the centre, and occupied a space about 18 by 13 inches. A handful of dry grass was all the lining below the eggs, which were warm and slightly incubated. A fer miles further on, the ground slightly rises, and trees and roads and villages are much thinner' on the ground. This is the best Bustard district, and here in winter flocks of thirty or forty birds are sometimes seen together. The Great Bustard is said to be polygamous, but there does not seem to be any satisfactory evidence of the fact. They do not migrate except in very hard winters.

The Great Bustard lives almost entirely on vegetable food, the leaves of various plants, the young corn, and seeds of different kinds. The young are said to feed almost exclusively upon insects. The old birds are said occasionally to eat insects and not to refuse a mouse, a hamster, or even a lizard or a frog. In winter the females flock apart from the males. Naumamn is of opinion that the Great Bustard is not polygamous, that it pairs early in spring, and that the flocks seen in summer are composed of birds of the year not yet old enough to breed. Although the Bustard has not yet learnt that a waggon may contain a dangerous chasseur, it has convinced itself that a railway-train is a harmless apparition. We passed within thirty yards of a hen Bustard on the line between Kustendji and 
Tchernavoda. As the train passed she strutted slowly along as if on tiptoe, with neck upstretched and head turning round, to follow the train, but she never took wing.

The eggs of the Great Bustard are generally only two in number, but sometimes three are laid. They vary from olive-green to pale buff and olive-brown in ground-colour, and are spotted and blotched with reddish brown, and with numerous underlying markings of greyish pink. The markings are generally obscurely defined, and somewhat evenly distributed orer the entire surface. On some eggs the blotches are very irregular, and are intermingled with small rich dark brown streaks and scratches. The surface is slightly rough, full of small pores, and possesses a little gloss, but some specimens are much smoother than others. They vary in length from $3 \cdot 2$ to $2 \cdot \%$ inch, and in breadth from $2 \cdot 4$ to $2 \cdot 15$ inch. They differ considerably in shape, some being elongated at both ends, whilst others are nearly round.

The male Great Bustard is a very handsome bird, as richly marked as a Ptarmigan and as large as a Turkey. The general colour of the upper parts is chestnut-buff, transversely barred with black. The quills and primary-coverts are nearly black, with white bases. The lesser wing-coverts and several of the centre tail-feathers are coloured like the back, but many of the outer tail-feathers are white, with a broad transverse subterminal black band. The larger wing-coverts, the upper neck, and the underparts helow the lower neck, which is chestnut-buff, are white. The head and a long moustachial tuft on each side are pale slate-grey. Bill slate-grey, darker at the tip; legs, feet, and claws brown; irides dark hazel. The female is a smaller bird, about half the weight of the male, from which it differs chiefly in having no moustachial plumes and no chestnut on the lower throat. Young in first plumage of both sexes resemble adult females, but have the white wing-coverts broadly barred with black, and three instead of one black band across all the outer tail-feathers; the white both of the upper and underparts is also suffused with chestnut and mottled with grey. Many of the primaries are mottled with white, and all are tipped with white, and some of the feathers of the crown are coloured like the back. It is supposed that this plumage is retained until the second autumn, when an intermediate plumage is acquired, the fully adult plumage not being assumed until the third autumm. It is probable that some of the feathers of the head and neek, especially the moustachial plunes, are moulted in the spring.

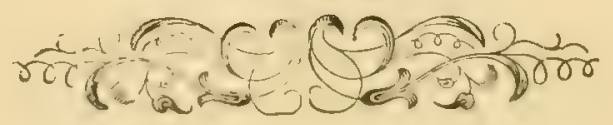




\section{OTIS TETRAX. \\ LITTLE BUSTARD.}

(Plate 22.)

Otis minor, Briss. Orn. v. p. 24 (1760).

Otis tetrax, Lim. Syst. Nut. i. p. $-64(1766)$ : et auctorum plurimorum-Latham, Temminck, Ncumann, Dresser, Saunders, \&c.

Tetrax campestris, Leach, Syst. Cat. Mamm. Se. Brit. Mus. p. 28 (1816).

Otis tetrno, Macgill. Man. Brit. B. ii. p. 40 (1846).

The Little Bustard was first described as a British bird from a female taken in the county of Cornwall, and exhibited at a meeting of the Royal Society of London in 1751; but as there did not happen to be a Fellow of the Society then present who was able to identify the bird, the Sccretary sent it to Edwards, who figured and described it in his 'Gleanings of Natural History,' p. 89, pl. 251. Edwards's plate is dated 1754, but his book was not published until 1758 , although a paper on the occurrence of this bird in England appeared in the 'Philosophical Transactions' for 1754. Since then it has occurred in our islands on an average every other year. As nearly all these examples were obtained during winter, and as there is no evidence that this bird ever bred in this comntry, it must be included amongst the list of accidental stragglers to our shores during that season. Most of these occurrences were in the eastern and southern counties. It appears to have occurred most frequently in the counties of York and Norfolk, but four examples are recorded from the east const of Scotland and two from Ireland. It was especially abundant in the winter of 187 1-75 ('Zoologist,' 1875, pp. 4839, 4369). The last recorded visit of this bird to our islands was in December 1880, when two examples were obtained in Devonshire (Mathew, ' Zoologist,' 1881, p. 58); but my good friend Gaetke writes to me that a male in the plumage of the sccond year was shot on Heligoland on the 27th of June, 1882.

The Little Bustard has a more restricted range than its larger congener. In Spain and Portugal it is more numerous, and has recently become so in Central France; but in Germany it is very rare, and can only be regarded as an accidental straggler north of the valley of the Damube, though it occasionally strays as far as Denmark and South Scandinavia. In Russia and West Siberia it is common on the steppes up to about lat. $55^{\circ}$, and ranges eastwards as far as lake Saisan. It breeds in the plains of North-west Africa, but is said to pass southwards in autumn to winter $\mathrm{n}$ some of the more remote oases of the Sahara. In the moun- 
tainous countries of Italy and Greece it is principally known as passing through on migration; but it is a resident in Sardinia and Sicily, and is extremely common on the steppes both north and south of the Danube. To Egypt it is principally known as a winter visitor, but in Palestine and Asia Minor the greater number pass southwards in autumn. It breeds in Nortl Persia and Russian Turkestan, and winters in the valley of the Indus.

Although the Little Bustard winters in considerable numbers in the basin of the Mediterranean, migratory flocks are constantly secn crossing the Straits of Gibraltar in the west, and the Ionian Islands in the east, during the month of April, returning again in October. In autumn the flocks are much greater than they are in spring, and these birds are described as sometimes crossing the steppes south of the Caucasus in millions. The Little Bustard is quite as much a steppe-bird as the Great Bustard, and is only found in extensive plains. It runs on the ground like a Partridge, and is never known to perch in trees. It is solitary during the breedingscason; but Hudleston, describing its habits in the Dobrudscha immediately after its arrival, says that "the male birds are particularly demonstrative at this time of the year, and being often occupied in parading their attractions in groups of ten or a dozen to the females, which are crouching somewhere in the grass, they are not so wide awake as at other scasons, and thus afford a better chance to the gun." It has been said to be polygamous, but there does not appear to be any evidence in support of this conclusion. When I visited the steppes of the Danube in May last ycar, although Great Bustards were constantly to be seen in flocks, I never saw two Little Bustards together, probably because the smaller species breeds in its first spring.

In several respects it presents in its habits points of contrast to its larger ally. It is a more southern bird, though in the Danulbian steppes it is much the commoner of the two. It is a partial migrant, arriving at its breeding-grounds in flocks early in April, which are dispersed in May. It is so much less than the Great Bustard, that by the middle of May the grass and the flowers hide it completely from view. The females sit very close and are difficult to find, but the males betray themselves by their curious note. As you drive slowly across the steppes your attention is arrested by a distant cry, resembling the sound of the syllable spurrtz. By following with the waggon in the direction whence it proceeds for a hundred yards or more, you may generally put up the bird, frequently within shot; but if followed on foot there is little or no chance of securing it. The flight is quite different to that of the Great Bustard, more resembling that of a Partridge than that of a Heron. The wings are moved with great rapidity, and the flight is very straight, though not very slow. The beats of the wing are so rapid that they make quite a loud whirring sound, and 
they show more white when flying than the Great Bustard does. In many respects their flight resembles that of a butterfly or of a Snow-Bunting. We never saw two males together during the breeding-season. The nest can only be found by accident. We were driving rather quickly across the steppe, anxious to reach Kalarash before dark, when suddenly a female Little Bustard rose within ten feet of the waggon, and was speedily dropped by our Jäger, who was sitting gun in hand by the driver. We jumped out of the carriage, and in a quarter of a minute found the nest, containing four eggs. The hollow was deeper than that of the nest of the Great Bustard, and there was a distinct nest of dry grass and weeds, though very slight; it was about seven inches across, and well concealed by tufts of a kind of lucerne.

The eggs of the Little Bustard are usually four in number, but three are often found, and it is said sometimes five. They vary in groundcolour from buffish brown to dark olive-brown and olive-green, indistinctly mottled and spotted with pale reddish brown. Most of the markings are congregated on the large end of the egg, sometimes on the small end, and form an indistinct confluent mass. The surface is very highly polished, rather smooth, and the pits or pores are not very conspicuous. They vary in length from $2 \cdot 15$ to $1.93 \mathrm{inch}$, and in breadth from 1.6 to 1.5 inch. The eggs of the Little Bustard cannot easily be confused with those of any other European bird.

The Little Bustard is said to be more insectivorous than the Great Bustard, though it also eats vegetables and seeds.

The Little Bustard is about the size of a Grouse, and differs little in colour from the Great Bustard, except that the ground-colour of the plumage is less chestnut and the black markings finer. The top of the head and all the tail-feather's are coloured like the back. The male has no moustachial plumes, but the nuptial plumage is very pronounced. The nape is ormamented with a black crest; the chin, ear-coverts, and upper throat are pale slate-grey, below which is a gorget of white, followed by a second gorget of black, a third of white, and a fourth of black. Bill brown; legs, feet, and claws brownish yellow; irides yellow. In the female the head and neck are coloured somewhat like the back, and similar markings are more or less conspicuous on the breast and flanks. The markings on the back are much coarser than in the male. After the autumn moult the male loses all the white and black gorgets on the throat, and nearly rescmbles the female; but it is not known whether they are assumed again in spring by a partial moult or by a change in the colour of the feather. Young in first plumage are said to resemble females; and males of the year probably retain the coarse markings on the back which are supposed to be characteristic of the adult female, though ornithologists do not agree on these points. Dresser says that "the young male has the 
back marked with the same fine striations as the adult male;" but Saunders appear's to assert that the adult female is also finely striated on the back, though he omits all mention of the young*.

* There can scarcely be any doubt that the male Little Bustard loses the black and white gorgets after the autumn moult. My Bukharest Jïger, a very intelligent man, assured me that the males assumed the plumage of the female before they left the Danubian steppes. Loche makes the same statement respecting the Algerian birds; and Hume says that in India they are never seen with the black and white gorgets, though it is difficult to believe that these are not assumed in spring before the birds migrate worthwards to breed. Heuglin, speaking of the Little Bustard in Egypt, states that the young males have the head and neck coloured as in the female, but that the back has the fine vermiculations of the adult male. A slin of a Little Bustard in the British Museum, and another in Dresser's collection, have the back coarsely vermiculated, though the nuptial gorgets show them to be males. The only conclusion I can draw is that Heuglin confounded the adult male in winter plumage with the young male in first plumage; that the latter resembles the female until the spring moult, when it assumes the gorgets of the adult, but does not moult the coarsely rermiculated plumage of its back until the autumn. It is remarkable how little is known of the changes of plumage of birds which do not breed in Germany, and have not had the advantage of having been studied by Naumann.

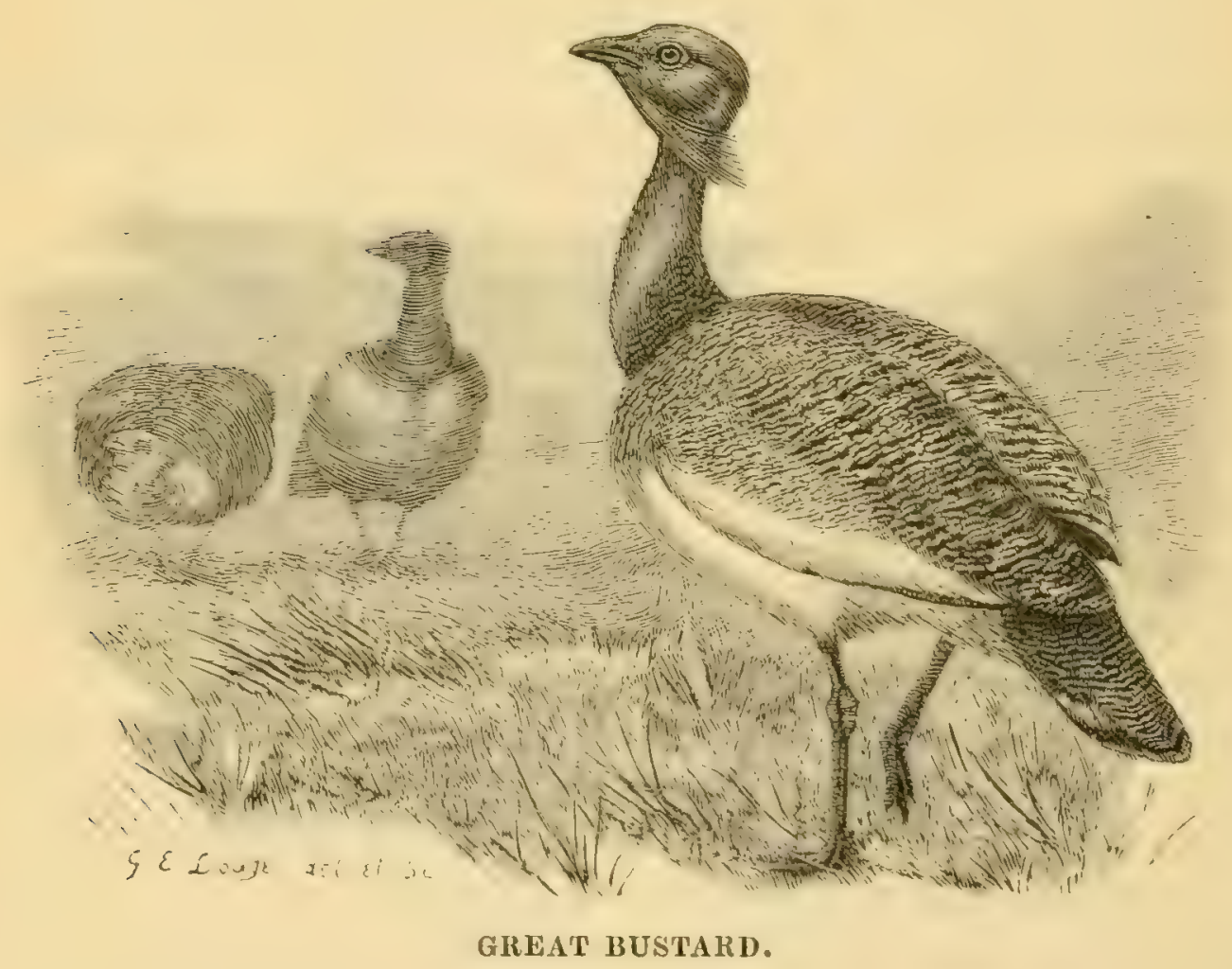




\section{OTIS MACQUEENI.}

\section{MACQUEEN'S BUSTARD.}

(Plate 21.)

()tis macqueenii, (ival, Ill. Ind. Zoel. ii.pl. 47 (1.3̈); et auctorum plurimorum-I)egland \&. Gerbe, (Jerdon), Blanfoid, Diesser, Saunders, \&c.

Houbara macqueeni (Gray), Gray, List B. Brit. Huss. pt. iii. p. 57 (1844).

Eupodotis macqueeni (Groy), Gray, Gen. B. iii. p. 533 (1845).

Otis houbara, Desf. apud Naumann, Temminck, Gould, \&c.

Macqueen's Bustard ranges sufficiently far north in Asia to place it under the influence of the great autunn stream of migration that proceeds from that region westwards into kurope, where it has frequently occurred. The claim of Macqueen's Bustard to be regarded as a British bird rests upon a single example which was shot by $M r^{2}$. G. Hunsley on the 7th of October, 1817, in a stubble-field on Kirton cliff at Kirtonin-Lindsey, in the county of Lincoln ('Zoologist,' 1818, pp. 1969, 2065, 2146). This specimen is now in the museum of the Philosophical Socicty at York.

The breeding-range of Macqueen's Bustard appears to be confined, so fir as is known, to Turkestan, from Yarkand to the eastern shores of the Caspian, extending northwards into the extreme south-west of Siberia, as far east as Lake Saisan, and southwards into Persia and Afghanistan. It winters in South Persia, Baluchistan, Scind, and the Punjaub. Further east, in Mongolia, a small Bustard occurs, but no specimen has yet been obtained. 'To the west, in Armenia, Palestine, and North Africa, a nearly allicd species occur's, O. houbara, from which Macquecu's Bustard differs in having the crest-feathers black on the terminal portion, instead of being pure white; the upper parts are lighter aud more finely vermiculated, and the elongated feathers on the lower throat are grey instead of white. Macqueen's Bustard only occurs accidentally in Lurope; but examples have been obtained in North Germany, Belgium, South Deumark, Poland, the Baltic Provinces, and even in Finland and Italy.

Macqueen's Bustard, or the Houbara as it is often erroncously called, like its congeners, is a bird of the open plaius-loroad stretches of undulating country corered with regetation, where the wary bird can always keep a good look out in every direction, aud where it is only approached with the greatest difficulty. Lxcept in the breeding-scason, it is a gregarious bird. During the heat of the day the flocks are said to lie very close, when they can be easily approached, as they are flushed with difficulty. In some parts of India this handsome bird is fond of frequenting fields 
of mustard and other crops which yield the oil-seeds of commerce; less frequently they are said to haunt fields of wheat, barley, and other grain, but ouly when the plants are small and tender. Its true home is the boundless steppes, where, for miles and miles, the rich vegetation affords it a congenial home, and effectually enables it to elude those enemies which its large size is constantly attracting.

Hume (Hume and Marshall, 'Game Birds of India') writes :- "By preference the [Indian] Houbara affects the nearly level, though slightly undulating, sandy semi-desert plains, which constitute so important a feature in the physical geography of Westcru India. Plains, semi-desert indecd, but yet affording in places thin patches, in places a continuous sea, of low scrubby cover, in which the dwarf Zizyphus (the Ber), the Lana (Anabasis multiflora), the Booce (Avrua bovii), various Salsolas, stunted Acacia-bushes, and odorous tufts of lemon-grass are conspicuous.

"Here the IIoubara trots about carly and late, squatting under the shade of some bush during the sumiest hour's of the day, fecding very largely on the small fruit of the Ber, or the berries of the Grewia, or the young shoots of the lemou-grass, and other herbs; now picking up an ant or two, now a grasshopper or beetle, and now a tiny land-shell or stone, but living chiefly as a vegetarian, and never with us, to judge from the hundreds I have examined, feeding on lizards, snakes, and the like, as the Great Bustard certainly does, and the African Houbara is said to do.

"The Houbara greatly prefers running to flying, and when the weather is not too hot will make its way through the labyrinth of little bushes which constitute its home at a really surprising pace. So long as the cover is low, its neck and body are held as low as possible; but as soon as it gets where it thiuks it cannot be seen, it pulis up, and raising its head as high as possible, takes a good look at its pursuers. Not unfrequently it then concludes to squat, and though you may have been, unobserved, watching it carefully, whilst it was only watching others of the party coming from an opposite direction, it becomes absolutely invisible the moment it settles down at the foot of a bush or stonc. Once it has thus settled, especially if it is hot and about noon, you may walk past it within ten yards without flushing it, if you walk carelessly and keep looking in another direction. But it is weary work trudging on foot, under an Indian sun, after birds that rum as these can and will, and in the districts where they are plentiful, people always either hawk them or shoot them from camels."

Macqueen's Bustard is often hawked by the natives, but it is said to afford little sport, because it so soon drops into cover and thus eludes the Falcon. The above-named writer thus describes the chase of the Houbara by the aid of the camel :- " Taling the camel at a long, easy, six miles an hour trot, across one of thuse rast wildernesses they affect, you will not 
be long before, raised high up as you are on camel-back, you catch sight of one or more Houbara feeding amongst the bushes. To them camcls have no evil import; everybody uses them; none but the veriest pauper walks, every one rides, and rides camels. The peasant going out to plough his field rides on one camel and puts his plough on the other, which, with its nose-string fastened to the tail of the one he rides, trots along complacently behind. When, thercfore, the Houbara see you coming along on a camel, they only move a little aside, so as to be out of your line of march, and you at once begin to describe a large spiral round them, so that, while appearing always to be passing away from them, you are really always closing in on them. Sometimes, if the time be early or late, or if the day be cold or cloudy, long before you are within shot, they start off running, and, if you press them further, ultimately take wing, flying heavily, and soon re-alighting and running on, never, so far as I have seen, taking the long flights that the Great Bustard does, and never fluttering and skylarking in the air as do the little ones. Generally, however, if the time be between 10 and 4 , and the day bright and warm, as your spiral diminishes, the birds disappear suddenly. They have squatted. Still you go on round and round, closing in in each lap, and straining your eyes, usually in vain, to discover their whereabouts; suddenly, perhaps from under the very feet of the camel, up flutters one of the birds, and, after a few strides, rises, to fall dead a few yards further on, as they are easy to hit and easy to kill. . . . . A the first shot all the Houbara that are at all close usually rise; but after shooting a brace right and left, and having them picked up and slung, I have known a third blunder up from within a few yards.

"Often, especially when you are out alone, and, after breaking up a large flock (which it is always best to do), are working a single bird, you close in and in until you reach the very bush by which you last saw it, and yet can find no trace of it. You pull up, as this generally starts the bird, but sometimes even then nothing is to be seen. The way they will squat at times on an absolutely bare patch of sand is astonishing, their plumage harmonizes perfectly with the soil, and you will have a bird rise suddenly, apparently out of the earth, within five yards of you, from a spot where there is not a blade of cover, and on which your eyes have perhaps been fixed for some secouds. This is especially the case about midday, when the sun is nearly vertical, and no shadow is thrown by the squatting bird. Sometimes they try another plan: they get behind a single bush, and as you circle round they do the same, always kecping the bush between themselves and the sportsman. Here, unless the sun is quite vertical, their shadow projected on the ground, apart from that of the bush, is sure, at certain positions in the circle, to betray them, and a shot through the bush brings them to bag." 
Macqueen's Bustard does not appear to be a polygamous bird, but lives in pairs during the breeding-season. Respecting its habits during this interesting period nothing has been definitely recorded: whether it builds a nest, or merely lays its eggs in a hollow on the bare plain, those naturalists who have been on its breeding-grounds omit to say. Doubtless in its nidification it resembles its close ally the African Bustard, whose nest is only a depression in the ground, with no lining. I have an egg of this hird in my collection which was obtained by Tancre's collectors on the Altai Mountains. It is buffish brown or rich stonecolour, sparingly blotched and spotted with surface-markings of dark brown, and with paler underlying blotches of the same colour and dull grey; the spots are evenly distributed over the entire surface, but none of them are very bold or decided. This specimen measures 2.55 inch in length and 1.85 inch in breadth. The eggs of the African species somewhat closely rescmble that of Macqueen's Bustard, but are a trifle less in bulk and paler in ground-colour, but the spots are quite as distinct. It will be noticed that the egg of the present species is a very distinct type from either of the other British Bustards, and more closely approaches that of the Plovers.

Macqueen's Bustard is a very silent bird. Hume writes:- " $\mathrm{I}$ have never heard this bird utter any sound, cither when feeding undisturbed, or when suddenly flushed, or when wounded or seized, or about to be seized, by man or dog. Possibly, during the breeding-season, the males have some call." It is only a winter visitor to India, where it usually makes its appearance early in September, and leaves again in March or early in April, according to the warmth of the weather.

Macqueen's Bustard is intermediate in size between the female Great Bustard and the Little Bustard. In the colour of its plumage it very closely rescmbles the male of the latter species, but the upper parts are still more fincly vermiculated with black, and the vermiculations cxtend to all the wing-coverts and to the head and throat. The plumes on the head and neck are quite difierent; those on the crown and nape are pale slategrey, tipped with black; and the upper neck is furnished with black plumes, and the lower neck with white plumes on either side. Bill dark brown, paler at the base of the under mandible; legs, feet, and claws dark yellow; irides yellow. The female is somewhat smaller than the male, but, unlike that of the Little Bustard, it does not otherwise differ from the male in its gencral appearance, except that the crest and neck-plumes are somewhat less developed. Nales in first plumage are said to resemble females, except in being larger. Winter plumage scarcely differs from that of summer. 


\section{Genus EDICNEMUS.}

Both Brisson and Linnæus associated the Stone-Curlews with the Plovers, whilst Latham included them amongst the Bustards. Temminck removed them from these birds, and in 1815 established the genus Edicnemus for their reception, in his 'Mannel d'Ornithologie' (p. 322). The Common Stone-Curlew (the Charadrius adicnemus of Linnæus) is of necessity the type.

The Stone-Curlews differ principally from the Bustards in having a rather longer bill, with the chin-an ole very conspicuons. The wings are rather more pointed. The tarsus is finely reticulated before and behind.

This genus contains about eleven species, which are distributed throughout the world, with the exception of North America. They are most numerous in the Ethiopian and Oriental Regions; two only are inhabitants of the Neotropical Region, and one belongs to the Australian Region. Only one species is European, which is a summer visitor to the British Islands.

The Stone-Curlews frequent nearly the same places as the Bustards, which birls they rescmble closely in their habits. They are partly nocturnal, and their food consists of worms, frogs, small mammals, insects, \&c. Their call-notes are loud and discordant. Their flight is rapid, but somewhat laboured. They make no nest, but choose a slight depression in the soil. Their eggs are two (rarely three) in number*, and are buffish brown in ground-colour, spotted, blotched, and streaked with light and dark brown.

* In the number of their eggrs, as well as in their habits, the Stone-Curlews appronch the Bustards rather than the Plovers; but there can be little doubt that they form a connecting link between these two families, almost sufficient to justify the union of the Bustards, the Stone-Curlews, the Plovers, and their allies in one great family. 


\title{
GETCNEMUS CREPITANS.
}

\section{STONE-CURLEW.}

\author{
(Plate 21.)
}

\author{
Pluvialis major, Briss. Orn. v. p. 76, pl. vii. fig. 1 (1760). \\ Charadrius oedicnemus, Linn. Syst. Nat. i. p. 255 (1766). \\ Charadrius scolopax, Gmel. Reise Russl. iii. p. 87, pl. 16 (1774) \\ Charadrius illyricus, Piller, It. Poseg. Sclav. p. 26 (1783). \\ Otis œdicnemus (Limn.), Lath。Gen. Syn. Suppl. i. p. 290 (1787). \\ Edicnemus crepitans, Temm. Man. d'Orn. p. 322 (1815); et auctorum pluri- \\ morum-Naumann, Degland \& Gerbe, Savi, Loche, Blanford, Jerdon, Gould, \\ Tristram, Cavendish Tgylor, Salvin, Salvadori, Lord Lilford, Irby, \&c. \\ Fedoa œdicnemus (Linn.), Leach, Syst. Cat. Mamm. \&.c. Bvit. Mus. p. 28 (1816). \\ Oedicnemus griseus, Koch, Syst. baier. Zool. i. p. 266 (1816). \\ Edicnemus europæus, Vieill. N. Dict. d'Hist. Nat. xxiii. p. 230 (1818). \\ Oidicnemus bellonii, Flem. Brit. Anim. p. 114 (1828). \\ $\left.\begin{array}{l}\text { Oedicnemus desertorum, } \\ \text { Oedicnemus arenarius, }\end{array}\right\}$ Brehm, Vög. Deutschl. p. 539 (1831). \\ Oedicnemus indicus, Salvad. Atti Soc. Ital. sc. nat. viii. fasc. 4, p. 375 (1865). \\ Edicnemus senegalensis, Swainson, Birds of W. Africa, ii. p. 228 (1837).
}

The distribution in England of the Stone-Curlew, or, as it is frequently called, the Thicknee, or Norfolk Plover, is very similar to the former distribution of the Great Bustard in our islands. Its headquarters are the warrens of the eastern counties, whence its breeding-range extends northwards to the wolds of Lincolnshire and Yorkshire, and southwards through the counties of Bedford, Hertford, Buckingham, Oxford, and Berks, to the downs of Wiltshire, Dorsetshire, Hampshire, Sussex, and Kent. To the rest of England and Scotland it is a more or less accidental straggler on migration, though a few appear to winter in the countics of Somerset, Devon, and Cornwall. It has occurred once in winter near South Shields, at the mouth of the Tyne, and once at the same season near. St. Andrews, in Fife. In Ireland it is said to have occurred about half a dozen times, principally in winter.

On the continent the Stone-Curlew does not breed north of the Baltic. It is a resident throughout the basin of the Mediterranean; but to France, Holland, Belgium, Germany, and South Russia it is a summer migrant. It has only occurred twice in Denmark, and is not found in the Baltic provinces. Its northern range in South Russia has not been accurately determined; but it is common at Sarepta, and may range up to lat. $50^{\circ}$. It is a resident in the Canary Islands, and an occasional straggler to Madeira. It is a resident throughout North Africa, as far south as 
Abyssinia; but its numbers are largely increased during winter. It is also a resident in Palestine, Asia Minor, Persia, Baluchistan, India, Ceylon, and Burma. It is a summer visitor to Russian Turkestan, and probably also to West Siberia south of lat. $48^{\circ}$, as Finsch records it from the steppes north of Lake Saisan*.

Indian examples of the Stone-Curlew have been described as a distinct species on account of their alleged smaller size; but this statement does not appear to be supported by facts. Of the allied species which inhabit Africa, South America, and Australia, none can be confused with our bird, except $E$ dicnemus inornatus, inhabiting South Nubia and Abyssinia, which is doubtfully distinct from it. It is said to differ in not having the upper bar across the wing; but this bar is not shown in the figure of the Stone-Curlew in Dresser's 'Birds of Europe.'

The haunts of the Stone-Curlew are the lowland heaths, commons, large tracts of unenclosed country, sheep-walks, rabbit-warrens, and wolds. In this respect it very closely resembles the Bustards. It is fond of the bare districts where it can keep a good look-out, and thus be able to detect any danger, no matter from what point of the compass it may come. It loves the sandy wastes, and never frequents wooded districts. The Stone-Curlew is principally known as a summer visitor to this country, and arrives at its old haunts about the middle of April, leaving them again for the south in October, but, should the season be an open one, many linger still later.

In spite of high farming and the enclosure of commons, the habits of the Stone-Curlew may still be studied during a day's excursion from London in many localities. On Saturday morning the 21st of May, 1881, I left London for Ipswich, and, having met my friend Mr. Bidwell at the station, we walked out beyond the race-course to a lake or pond called Bixley decoy, a distance of perhaps four miles. Our first care was to make for the cottage of the decoy keeper, so that under his auspices we might be free from the molestations of gamekeepers, and also to post ourselves up in the latest intelligence concerning the movements of the Stone-Curlews, whose breeding-habits it was the special object of our journey to investigate.

We learned that these birds were by no means exterminated, and that, although the great heath where they had bred from time immemorial had been enormously encroached upon by recent enclosures, the StoneCurlews still frequented what was left of it. During the last quarter of a century reclamation has advanced with rapid strides. There used to be

* Neither Captain Legge, in his 'Birds of Ceylon,' nor Oates, in his 'Birds of Burmah,' nor Saunders, in his continuation of Newton's edition of 'Yarrell's British Birds,' mention the occurrence of this bird in Siberia, which is scarcely doing justice to Finsch, who states that he identified the species with absolute certainty, although he failed to obtain a specimen. 
only a patch of cultivated land here and there, which the farmer looked upon as oases in the great desert of heath. Now, only a few of the wildest and roughest parts of the heath remain here and there between the farmspatches of hilly and broken ground, covered over with heath with occasional clumps of furze bushes, places which we ornithologists look upon as oases in a desert of miserable fields and commonplace acres of corn, green crops, and such-like rubbish! We spent some time in examining the decoy, with all its complicated arrangement of "pipes," and walls, and cuttings, for luring the Wild Ducks to their fate in winter, and then started for Black Heath, where our decoy-man told us he had taken two Stone-Curlew's eggs a fortnight before. He showed us the place, a large. square bare piece of the heath, where he had some years ago cut away the turf for fucl, and which was now only sprinkled here and there with young leath springing up from the old roots. There was not the slightest apology for a nest; a mere hollow was scratcher in the bare peat without any lining whatever.

We walked on until we came to the brow of the hill, where we saw a Stone-Curlew rise from the ground about seventy yards ahead of us. We marked the spot; but before we had quite reached it, we found the two eggs on a place where the heath was short. As before, it was a mere hollow scratched in the bare black peat; not even a bit of grass had drifted in to serve as an apology for a lining. The two eggs were very different, both in size, shape, and markings, and no one would have suspected them to form a clutch; they were on the point of hatching, both cggs were chipped, and we could hear the young chirping inside. But for all that, the female flew right away, without any attempt to lure us from the spot, and though we stayed near the nest some time, we saw no more of her.

A little further on we noticed a Stone-Curlew on the heath, about a hundred yards or more ahead of us. She was sometimes running with head depressed, and sometimes standing still with head erect, looking eagerly around. As we approached she took wing and flew right away. We were unsuccessful in our search for her nest, though we spent some time in tramping the heather. The Stone-Curlew is a very conspicuous bird on the wing, the light and dark markings on the secondaries being specially conspicuous during flight. It is also easily seen on the heath, cven at a great distance, being so much paler and yellower than the prevailing colours of the grass, heath, and peat; as the season advances these naturally become burnt up or parched, and then the Stone-Curlew is much less conspicuous.

A little further on a third bird rose from the ground, and was shortly joined by her mate; both flew right away. We had no difficulty in finding the eggs. The bird runs about fifteen to twenty yards and then 
takes wing. These two eggs were similar in size and shape, but very different in style of coloration. As before, there was nothing but a slight hollow scratehed in the black peat. Although the eggs are very conspicuous, and there is obviously no attempt at concealment, their very conspicuousness assists in their concealment. In the localities chosen for depositing its eggs, the Stone-Curlew selects a place where the heath is short. Where we found them brown stones and white flints were lying: in all directions, and were far more conspicuous than the eggs; it was only when we began to look out for double stones that we found how casy it was to discover the eggs. The sitting bird seems to rely upon its powers of observation to escape enemies, and chooses a situation where it can see all round, regardless of whether it can be seen or not. We did not hear the birds uttcr any note, except a distant plaintive cry, like the wail of the Golden Plover. The actions of the birds at the nest are, however, most un-plover-like, and in its habits this species certainly resembles the Bustards.

The eggs of the Stone-Curlew (two in number*) vary from pale buffish or creamy white to rich clay-buff in ground-colour, spotted, blotched, and streaked with light and dark brown, and with underlying markings of lilac or grey. Some specimens are very boldly spotted and blotched, chiefly at the large end; others are evenly marked with spots and blotches, many of the latter being connected by streaky lines of paler brown. Two very handsome eggs in my collection have the large brown blotches very irregular, and all more or less streaky in appearance. Some specimens have the markings very small and distributed over the entire surface; and less frequently a nearly plain type occurs, with only a few blotches here and there, or the large end of the egg is very finely scratched and streaked, with one or two large grey spots. On some eggs most of the markings are underlying oncs; on others very few of these are to be seen: the intensity of the brown also varies considerably, some of it being alnost black. The eggs vary in length from $2 \cdot 2$ to $2 \cdot 0$ inch, and in breadth from $1 \cdot 6$ to 1.49 inch. The only eggs with which they are at all likely to be confused are those of the Oyster-catcher, but the eggs of the latter bird are larger and the markings are darker and much bolder and more decided. Both birds assist in the duties of incubation. Only one brood is reared in the year; but if the first eggs are destroyed others will be laid, and fresh eggs have been obtained as late as September. The young are clothed in down and are able to run almost as soon as they are hatched; they are very pretty little creatures, and possess the habit, in common with

* Hume says that two is the ordinary number in India, but that he has frequently taken three-the proportion of the latter to the former being about one nest in ten. $\mathrm{He}$ also says that the nest is sumetimes lined with a few blades of grass. The places it selects in India for nidification are also different in many respects from those in this country. 
so many other young birds, of squatting close to the ground when menaced by danger, where their protective tints shield them most effectually.

The Stone-Curlew is most active at nightfall, and searches for its food during dusk and even at night. Its loud plaintive cry may often be heard in its haunts at midnight, as the bird wings its way across the star- or moonlit sky. Its food consists chiefly of snails, slugs, worms, and beetles. It feeds frequently on earwigs, and also captures frogs and lizards and small mammals, such as field-mice. When the young can fly the StoneCurlew often visits the turnip-fields near its haunts, such situations usually abounding with its favourite food. Towards autumn they become more or less gregarious: the broods and their parents unite into bands, sometimes forming a flock of a hundred or more. These parties are probably formed for the purpose of migrating. The Stone-Curlew is rather a silent bird during the day; but at sunset it becomes very clamorous, especially so on moonlight nights, as if rejoicing at the favourable conditions for finding its food.

Almost every feather of the upper parts of the Stone-Curlew is greyish brown, with a dark-brown shaft-streak and a buff margin; but on the underparts, the ground-colour of which is nearly white (except the under tail-coverts, which are buft'), the streaks are confined to a moustachial band and to the breast and flanks. Two obscure white bands across the wings are formed by white centres to the wing-coverts, emphasized by their dark tips. There is much white on the quills and outer tailfeathers, which is conspicuous during flight. Bill yellowish green from the base to the nostrils, remainder black; legs and toes yellow, claws brown; irides yellow. The female does not differ from the male in colour. Young in first plumage verr: closely resemble their parents, but are duller in colour. When hatched the young are covered with pale buffish down, mottled and striped on the upper parts with rich brown. After the autumu moult the plumage of the Stone-Curlew is the brightest and most clearly defined, but by the following breeding-season much of its beauty is lost by abrasion.

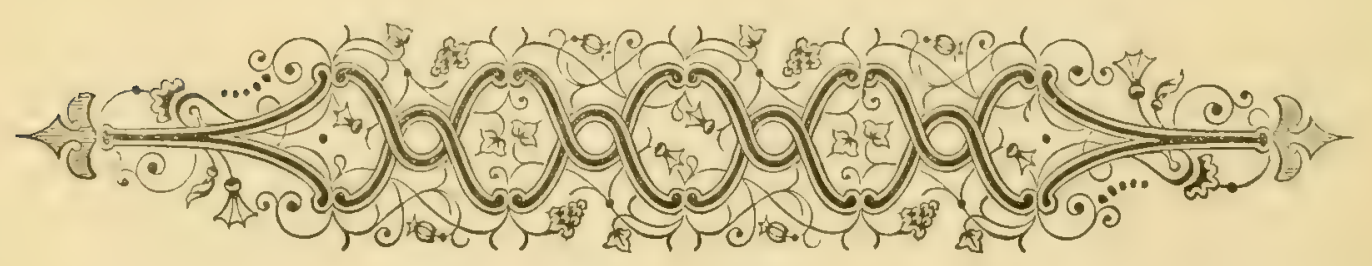







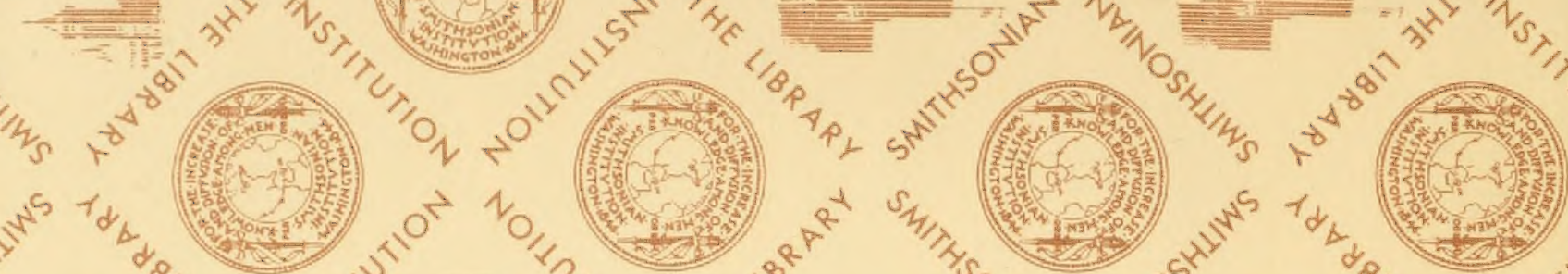

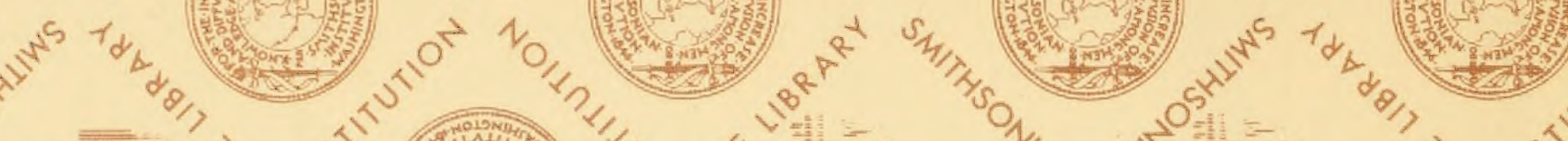

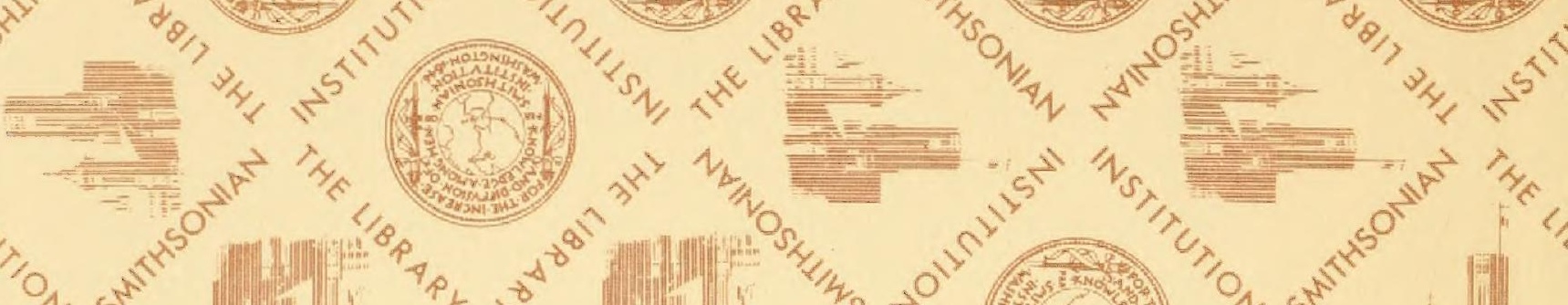

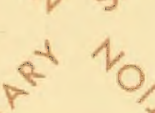

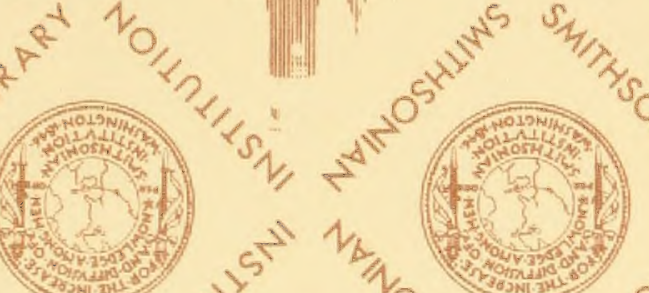

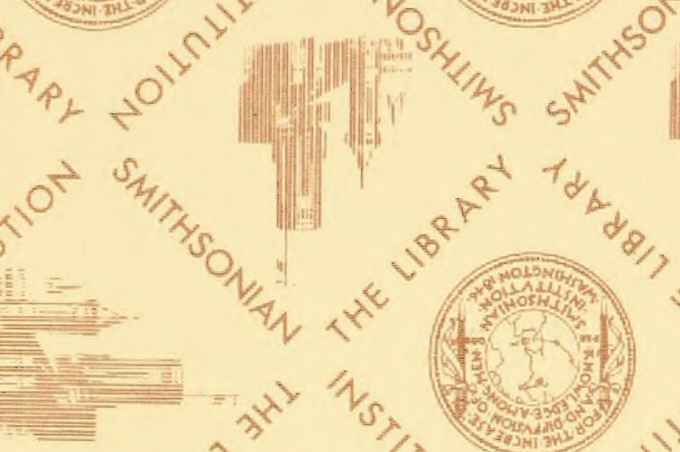

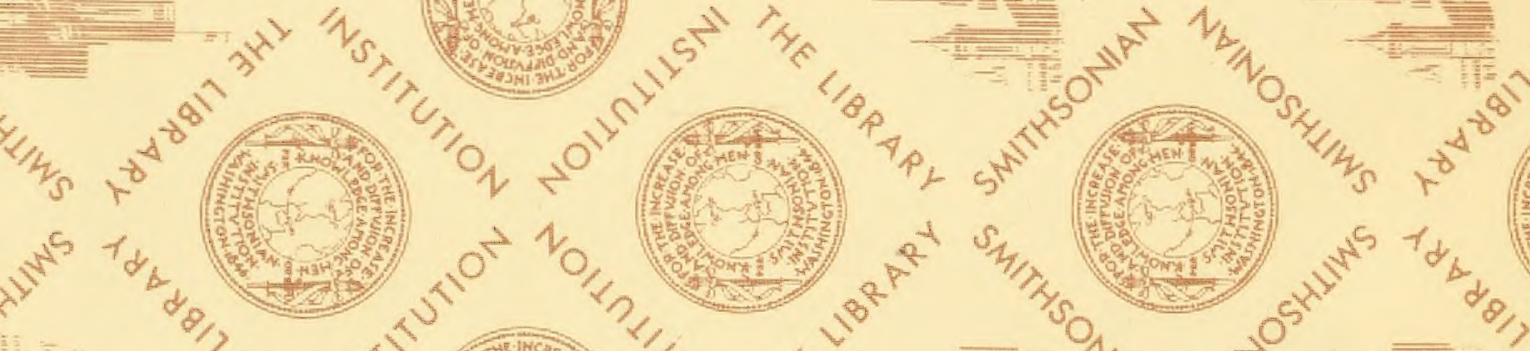

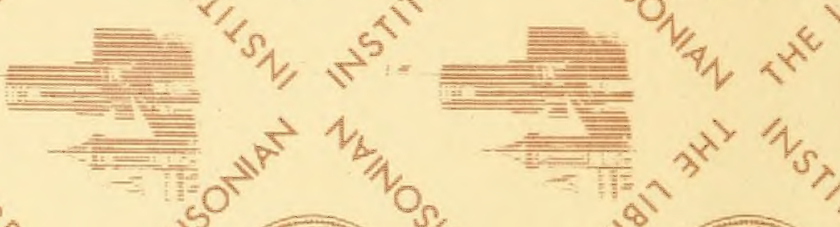

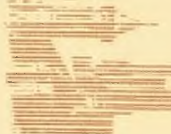

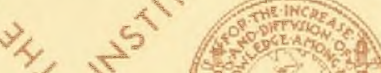

(1)

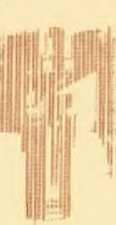

$4 x^{0^{2}}$<smiles>c1ccc2ccccc2c1</smiles>

\section{$p^{2}+1 / 2$}

i.
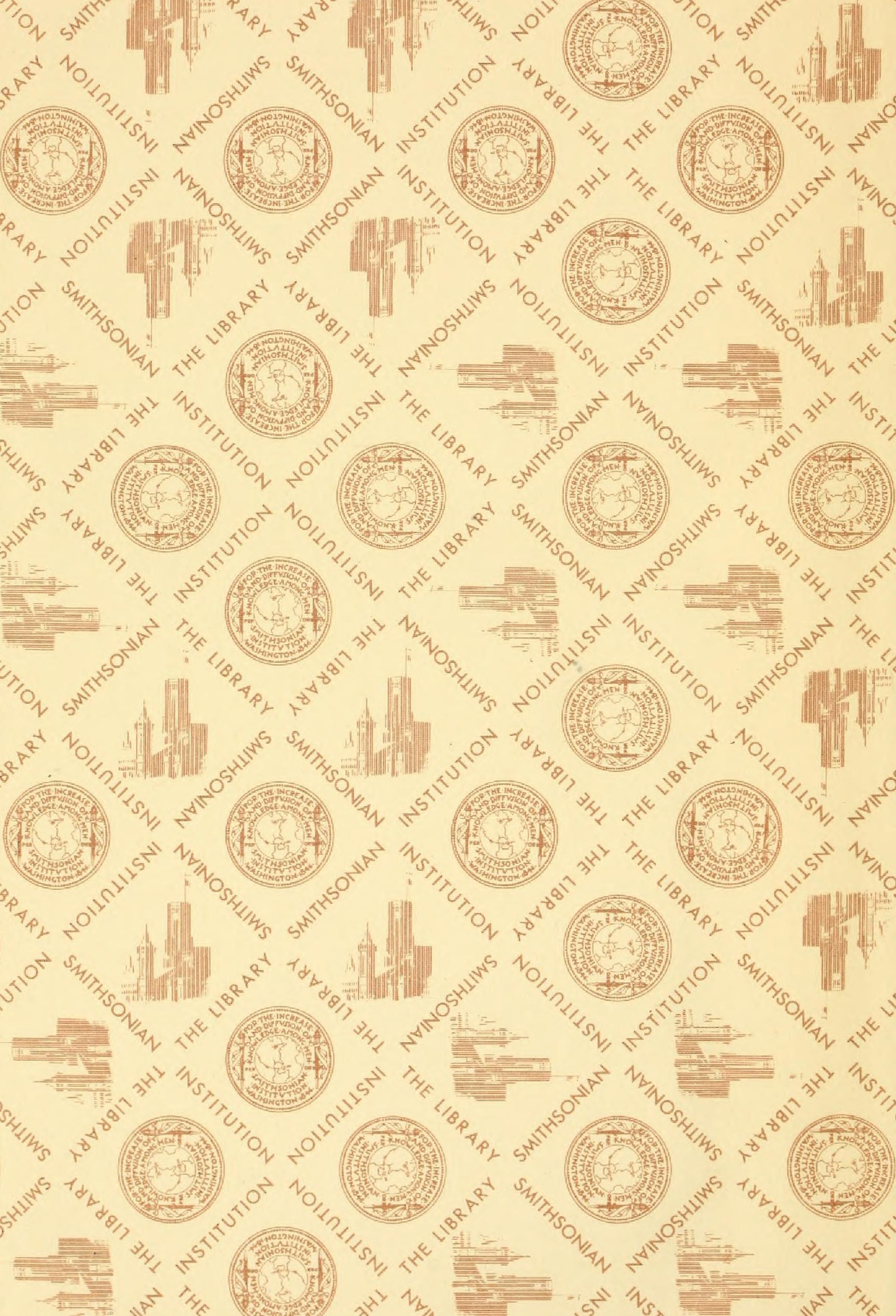


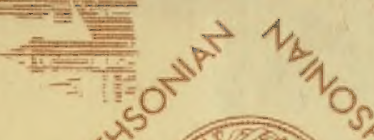

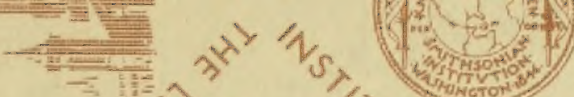

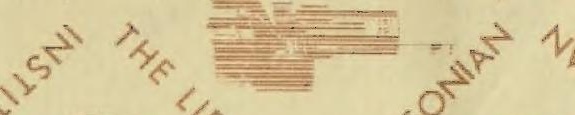

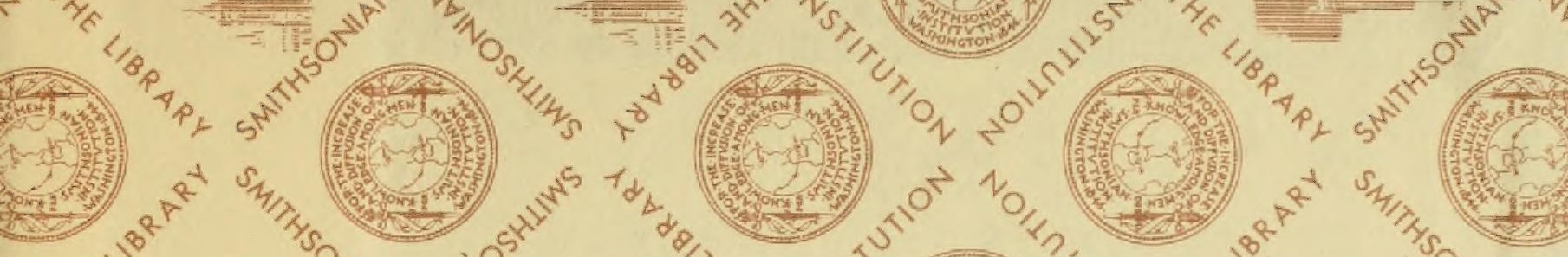

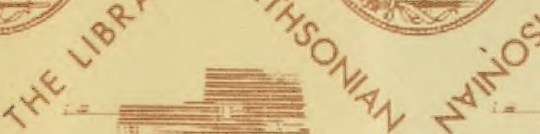

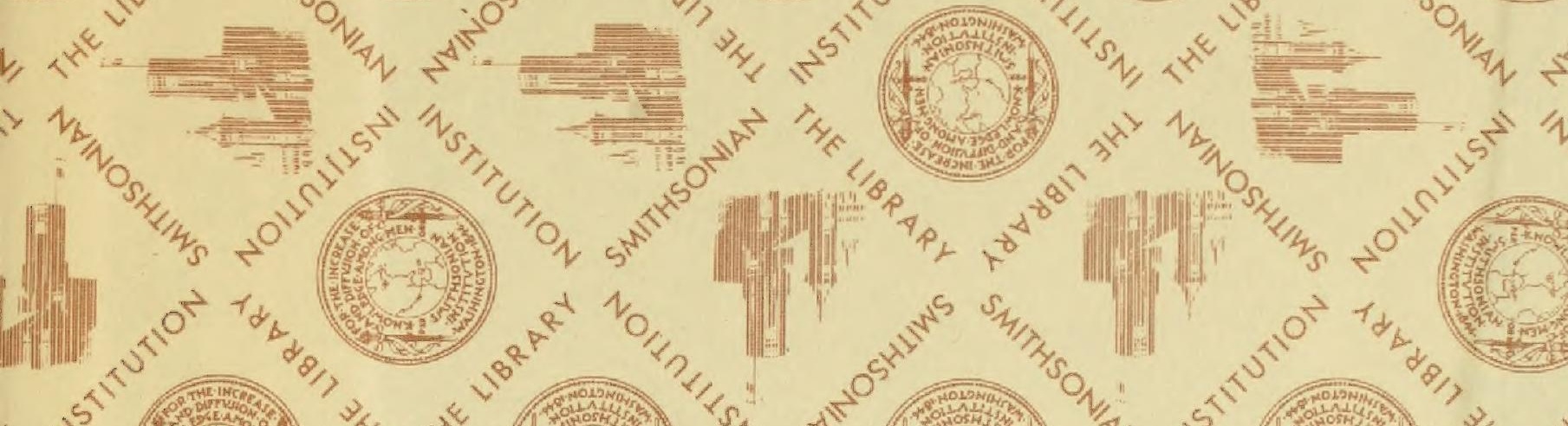

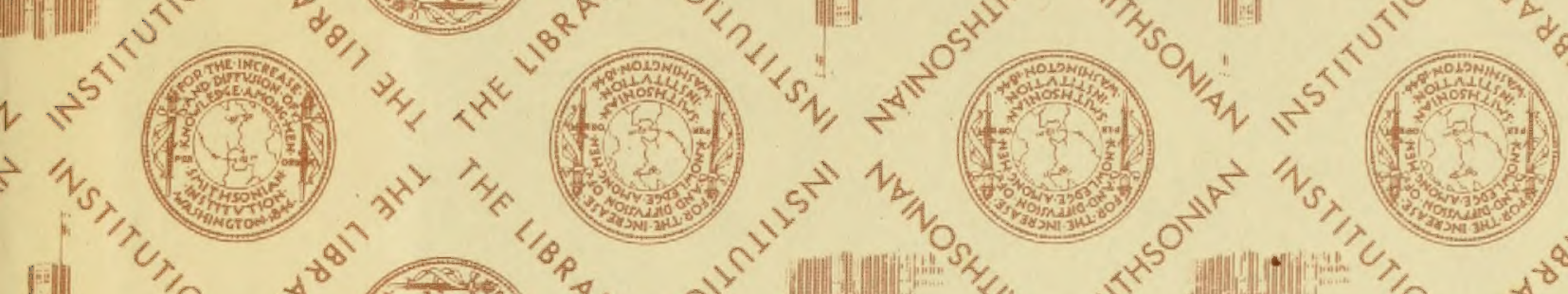

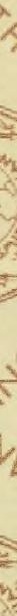

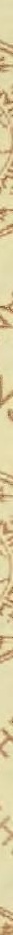

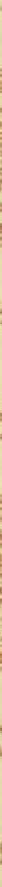


SMITHSONIAN INSTITUTION LIBRARIES 